UNIVERSIDADE DE BRASÍLIA

FACULDADE DE ARQUITEURA E URBANISMO

DEPARTAMENTO DE ARQUITETURA

PROGRAMA DE PÓS GRADUAÇÃO EM ARQUITETURA E

URBANISMO

\title{
Matriz Semântica para Projetos Aeroportuários no Brasil
}

\author{
JULIO TOLLENDAL GOMES RIBEIRO
}

Tese apresentada ao Programa de Pós-graduação em Arquitetura e Urbanismo da Universidade de Brasília (UnB), como requisito parcial para a obtenção do título de Doutor em Arquitetura e Urbanismo.

Tese elaborada com apoio do Conselho Nacional de Desenvolvimento Cientifico e Tecnológico - CNPQ (Doutorado sanduiche na "Pennsylvania State University")

Brasília, DF, 08 de julho de 2015 
UNIVERSIDADE DE BRASÍLIA

FACULDADE DE ARQUITEURA E URBANISMO

DEPARTAMENTO DE ARQUITETURA

PROGRAMA DE PÓS GRADUAÇÃO EM ARQUITETURA E

URBANISMO

\title{
Matriz Semântica para Projetos Aeroportuários no Brasil
}

\author{
JULIO TOLLENDAL GOMES RIBEIRO
}

Tese apresentada ao Programa de Pós-graduação em Arquitetura e Urbanismo da Universidade de Brasília (UnB), como requisito parcial para a obtenção do título de Doutor em Arquitetura e Urbanismo.

ORIENTADOR: NEANDER FURTADO SILVA

Brasília, DF, 08 de julho de 2015 
JULIO TOLLENDAL GOMES RIBEIRO

MATRIZ SEMÂNTICA PARA PROJETOS AEROPORTUÁRIOS NO BRASIL

Tese aprovada junto ao Programa de Pós-graduação em Arquitetura e Urbanismo da Universidade de Brasília como requisito parcial para a obtenção do título de Doutor em Arquitetura e Urbanismo.

\section{Banca examinadora:}

DR. NEANDER FURTADO SILVA

Orientador -PPG/ FAU/ UnB

DR. LOUKAS NICKOULAS KALISPERIS

Membro Titular - Pennsylvania State University

DR. DAVID RODNEY LIONEL PENNINGTON

Membro Titular - FAC/ UnB

DR. FRANCISCO LEITE AVIANI

Membro Titular - Design/ IDA/ UnB

DR. MÁRCIO AUGUSTO ROMA BUZAR

Membro Titular - PPG/ FAU/ UnB

DR. DANIEL RICHARD SANT'ANA

Suplente-PPG/FAU/ UnB

Brasília, 08 de julho de 2015 


\section{SUMÁRIO}

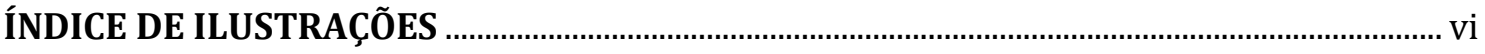

RESUMO / ABSTRACT ....................................................................................................

SÍMBOLOS, ABREVIATURAS, SIGLAS E CONVENÇÕES …….................................................

1-INTRODUÇÃO

1.1-DA LAPISEIRA E PAPEL AOS MODELOS COMPUTACIONAIS DE INFORMAÇÃO DA

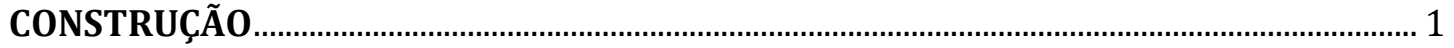

1.2-........ MATRIZ SEMÂNTICA COMO SUPORTE À MODELAGEM DA INFORMAÇÃO DA

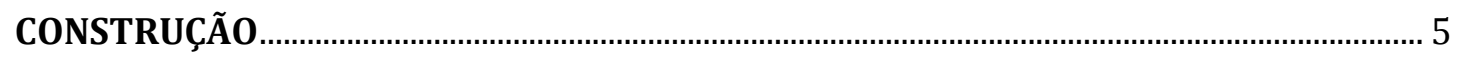

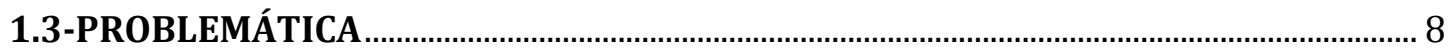

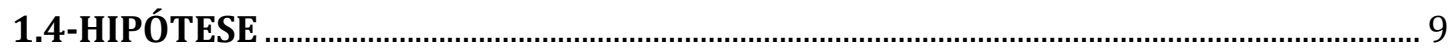

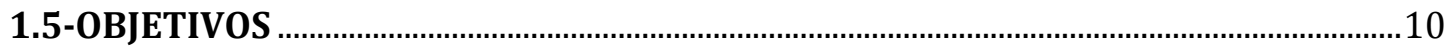

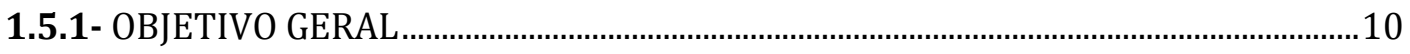

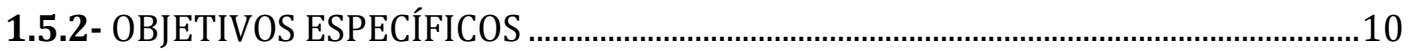

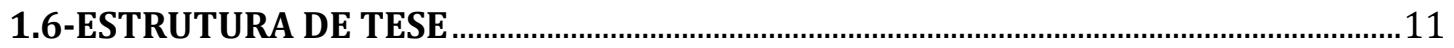

1.6.1- ESTA TESE FOI ESTRUTURADA EM CINCO CAPÍTULOS...........................................11

2-REVISÃO BIBLIOGRÁFICA

2.1- HISTÓRICO DOS SISTEMAS COMPUTACIONAIS E PROCESSO DE PROJETO

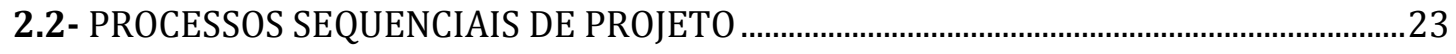

2.3- PROCESSOS DE PROJETO SIMULTÂNEOS..........................................................................25

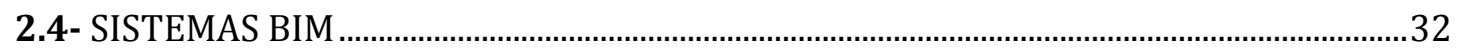

2.5- NÍVEIS DE AMADURECIMENTO NOS SISTEMAS BIM ………...........................................4

2.6- SISTEMAS BIM NO SETOR PÚBLICO BRASILEIRO ………………………........................46

2.6.1- REINO UNIDO: AEROPORTOS DE GATWICK ……..................................................4

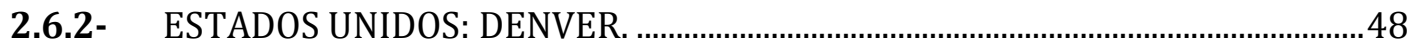

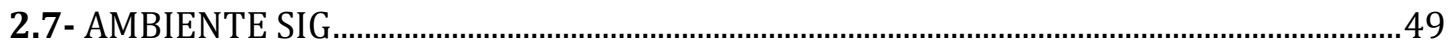

2.8- O CONCEITO DE LOD, “LEVEL OF DETAIL” E “LEVEL OF DEVELOPMENT” .................51

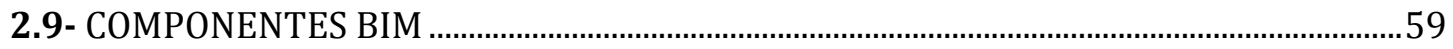


2.10- ASSOCIAÇÃO DOS SISTEMAS BIM E SIG .62

2.11- APLICAÇÃO DOS SISTEMAS BIM - PRECEDENTES IMPORTANTES .............................71

2.11.1- “GARDERMOEN AIRPORT”, OSLO, NORUEGA. ......................................................... 71

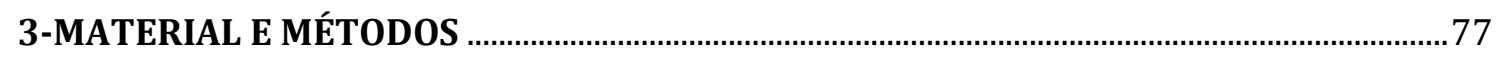

3.1- MATRIZ SEMÂNTICA DE REGRAS DE ABSTRACAO DA INFORMAÇÃO ..........................77

3.1.1- ESTRUTURA DA MATRIZ SEMÂNTICA - EXEMPLO DE CONSULTA........................88

3.1.2- RELACAO ENTRE OS COMPONENTES PARAMÉTRICOS E A MATRIZ ...................99

3.2- FORMACAO DE COMPONENTES PARAMÉTRICOS AEROPORTUÁRIOS ............... 100

3.2.1- A SELEÇÃO DOS COMPONENTES ACIMA OBEDECEU AOS CRITÉRIOS LISTADOS

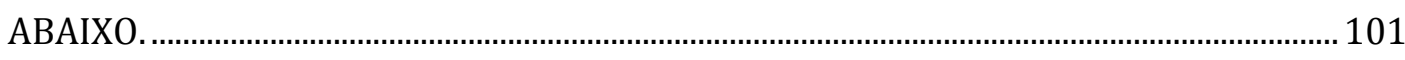

3.2.1- ELABORAÇÃO DE COMPONENTES NOS SISTEMAS BIM …….................................... 102

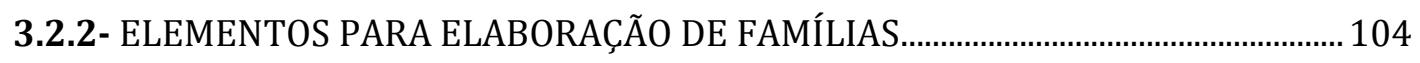

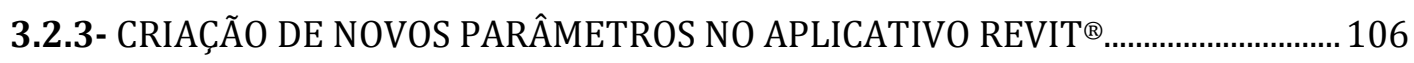

3.3- MODELAGEM DO TERMINAL DE PASSAGEIROS REGIONAL DA INFRAERO NOS SISTEMAS BIM E TESTE DO USO DA BIBLIOTECA DE COMPONENTES EM SEUS

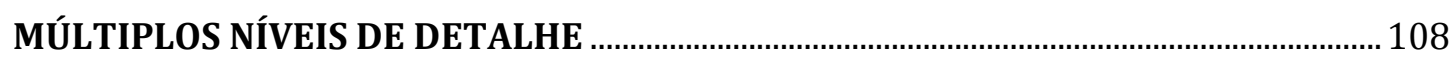

3.3.1- UTILIZAÇÃO DE COMPONENTES NATIVOS NO REVIT ${ }^{\circledR}$ ENVOLVEM:................. 110

3.3.2- DOCUMENTAÇÃO TRIDIMENSIONAL................................................................... 115

3.4- SIMULAÇÃO DE ALTERAÇÕES DE PROJETO NO DESENVOLVIMENTO DE ALTERNATIVAS PARA A CRIAÇÃO DE TORRE DE CONTROLE (TWR) NO TERMINAL DE

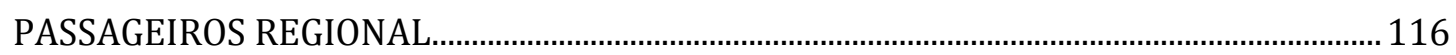

3.4.1- MODELAGEM DE EXPANSÃO DO TERMINAL REGIONAL....................................... 122

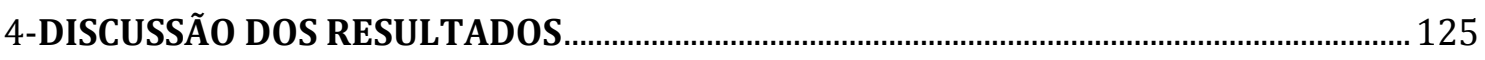

4.1- RELAÇõES DA MATRIZ SEMÂNTICA COM O PROCESSO DE PROJETO RESULTADOS DO DETALHAMENTO DO “CHECK-IN”.................................................... 125

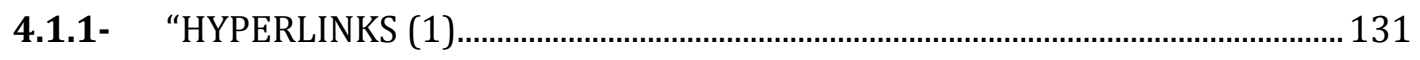

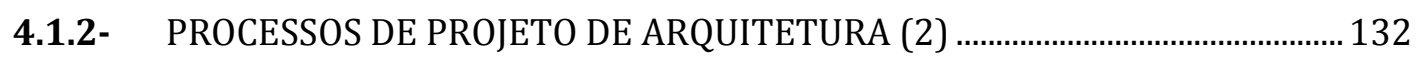

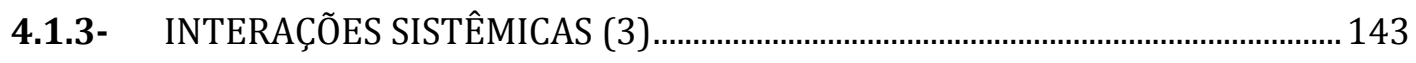

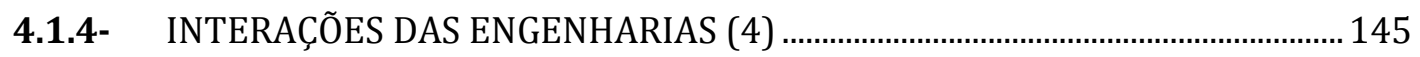


4.2- RESULTADOS DA ELABORAÇÃO DE NOVOS COMPONENTES NOS SISTEMAS BIM

4.2.1- ILUSTRACAO E DISCUSSÃO DOS PASSOS REALIZADOS PARA CRIAÇÃO DE NOVOS COMPONENTES PARAMÉTRICOS 160

4.2.2- TESTE DE VARIAÇÃO DE LOD NOS SISTEMAS BIM - REVIT 171

4.2.3- IMPORTAÇÃO DE COMPONENTES NOS SIG. 175

4.3- MODELAGEM DO TERMINAL DE PASSAGEIROS REGIONAL NOS SISTEMAS BIM E TESTE DE EMPREGO DE COMPONENTES EM SEUS MÚLTIPLOS NÍVEIS DE DETALHE 182

4.3.1- CONSTRUÇÃO DO MODELO BIM E PROCESSO DE ANÁLISE 183

4.3.2- MODELO BIM (REPRODUÇÃO POR MEIO DE MODELAGEM DO TERMINAL DE PASSAGEIROS REGIONAL - ARQUIVOS 2D CEDIDOS PELA INFRAERO) ........................ 184

4.3.3- RESULTADOS GRAFICOS DA MODELAGEM (SISTEMAS BIM - REVIT ${ }^{\circledR}$ )............. 200 4.3.4- TESTE DE MODELAGEM DO TERRENO PARA PROCESSOS DE ANÁLISE NOS ESTÁGIOS INICIAIS NO AUTODESK INFRAWORKS (SIG). 205

\section{4- SIMULAÇÃO DE EXPANSÃO DO TERMINAL EXISTENTE POR MEIO DE TRES} ALTERNATIVAS DE EXPANSAO DO TERMINAL EXISTENTE - PROJETO (TWR) ....... 213

4.4.1- RELACOES DA MATRIZ SEMANTICA E AS TORRES DE CONTROLE. 215

4.4.2- DEMONSTRACAO DOS PASSOS PARA EXPANSAO DE UMA DAS TORRES 223

4.4.3- IMAGENS PERSPECTIVAS DAS ALTERNATIVAS DE PROJETO - TORRE DE CONTROLE (TWR) 228

4.4.4- INFLUENCIA DOS SISTEMAS SIG NOS PROCESSO DE ANALISE E DE TOMADA DE DECISAO NOS ESTAGIOS INICIAIS DE PROJETO 231

4.4.5- PERSPECTIVAS DO TERMINAL DE PASSAGEIROS REGIONAL DO BRASIL ... AS FIGURAS 184 A 191 APRESENTAM PERSPECTIVAS DO TERMINAL REGIONAL MODELADO.

FIGURA 184 - PÁTIO DE AERONAVES E PONTES DE EMBARQUE. 237

5-CONCLUSÕES. 241

REFERÊNCIAS BIBLIOGRÁFICAS 245 


\section{ÍNDICE DE ILUSTRAÇõES}

Figura 1- Modelo digital do Boeing 777 , sendo esta a primeira aeronave projetada $100 \%$ digitalmente. Fonte: KOLAREVIC, B. 2003).

Figura 2- Desenho feito por Sansedoni no período Gótico]. Fonte: ROBBINS, Edward, 1944, p.14.

Figura 3- Processo de Concepção de Projeto. Fonte: (adaptado de LANG, 1974). 18

Figura 4- Base de conhecimento. Fonte: adaptado de Bittencourt (2001).

Figura 5- Comparação do desenvolvimento de produto em engenharia sequencial e em engenharia simultânea. Fonte: Adaptado de KRUGLIANSKAS,1995, apud FABRíCIO, 2002....... 25

Figura 6 - "Workflow" do Projeto Convencional. Fonte: SANTOS, 2008, apud ANDRADE, e AMORIM, 2011, p. 795-796. .28

Figura 7- "Workflow" do Projeto com BIM. Fonte: SANTOS, 2008, apud ANDRADE, e AMORIM, 2011, p. 795-796).

Figura 8- Representação da simultaneidade entre as equipes de projeto com a utilização do sistema BIM. Fonte: SANTOS, 2008, apud ANDRADE, e AMORIM, 2011, p. 796. 30

Figura 9 - Cenário A: a ferramenta de compartilhamento funciona apenas como repositório de modelos. Fonte: QUEIROZ, 2012, p. 6 36

Figura 10- Cenário B: a função do repositório de modelos incorpora funções de integração entre modelos. Fonte: QUEIROZ, S. 2012, p. 6.

Figura 11- Níveis de amadurecimento nos sistemas BIM. Fonte: OLIVEIRA, L. apud CLAYTON et al., 2008 , p. $46-48$

Figura 12- Detalhe do Aeroporto de Gatwick nos sistemas BIM. Fonte: (RICHARDSON, $S$ et al 2015).

Figura 13- Expansão do Aeroporto de Denver. Fonte: DIA \& GENSLER apud BALL, M. .48

Figura 14 - Diferentes Níveis de Desenvolvimento. Fonte: Adaptado de MCPHEE, 2013, p.1.. 52

Figura 15- Diferentes Níveis de Detalhamento. Fonte: Adaptado de MCPHEE, 2013, p.1. 53 
Figura 16 - Múltiplos níveis - detalhamento Geométrico SIG. Fonte: LÖWNER, et al, 2013, p. 4.

Figura 17 - Os cinco níveis de detalhe definidos (Lod) pelo CiyGML. Fonte: GRÖGER, G; KOLBE,

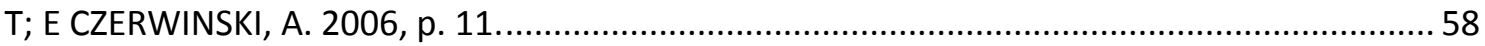

Figura 18 - "One Island East Tower", Swire, Properties Ltd. Fonte: OPUS Hong Kong. .............. 59

Figura 19- Gardermoen Airport Oslo. Fonte: (RENGIFO et al, 2008, p. 6)................................ 71

Figura 20- Vista do Terminal 2. Fonte: RENGIFO et al, 2008, p. 6......................................... 72

Figura 21- Arquivo de Modelo após dividir áreas. Fonte: Estudo de Caso AutoDesk: Gardermoen Airport, Oslo, Noruega. Fonte: RENGIFO et al, 2008, p. 6. 74

Figura 22 - Detalhamento e repetição de elementos construtivos. Fonte: RENGIFO et al, , p. 6).

Figura 23- Família 1 - Componentes adaptativos. Fonte: RENGIFO et al, 2008, p. 6. .75

Figura 24- Família 2 - Coluna e viga da estrutura. Fonte: RENGIFO et al, 2008, p. 6. .76

Figura 25- Família 3 - Estrutura do Telhado. Fonte: RENGIFO et al, 2008, p. 6. 76

Figura 26- llustração de tela de acesso da versão digital da Matriz Semântica onde pode ser vista a organização das Zonas, Áreas e Partes de um aeroporto. .78

Figura 27 - Tela de acesso aos módulos funcionais da matriz Semântica. 88

Figura 28 - Tela do módulo funcional "Esteira de Bagagem", com acesso aos campos de processos de aprovação, tarefas de projeto e requerimentos de projeto.

Figura 29 - Informações referentes ao Módulo funcional de Esteiras de Bagagem de um terminal de passageiros de pequeno porte. 90

Figura 30 - Estruturação lógica de informação na Matriz Semântica - Processos de Projeto. . 92

Figura 31- Tela de acesso na versao digital da Matriz Semântica para as Tarefas de Projeto Esteira de Bagagem. .93

Figura 32 - Tarefas de Projeto para uma Esteira de Bagagem na Matriz Semântica. 94

Figura 33 - Requisitos de Estudo Conceitual de Arquitetura na Matriz Semântica. 95 
Figura 34- Exemplo de tela de acesso na versao digital da Matriz Semantica para os Requerimentos de uma Esteira de Bagagem .96

Figura 35 - Tela de acesso aos requerimentos para uma Esteira de Bagagem na Matriz Semântica.

Figura 36 - Documento acessado via "hyperlink" (requerimento) na Matriz Semântica. .98

Figura 37 - Ilustração dos componentes paramétricos modelados nesta pesquisa. 100

Figura 38 - Exemplos de famílias do sistema no Revit ${ }^{\oplus}$. Fonte: AutoDesk 102

Figura 39 - Exemplos de famílias carregáveis do Revit ${ }^{\circledast}$. Fonte: AutoDesk. 103

Figura 40 - “Templates "para uma nova família no Revit ${ }^{\oplus}$ Fonte: AutoDesk 103

Figura 41 - Exemplo de extrusores no Revit ${ }^{\circledR}$. Fonte: AutoDesk ${ }^{\circledR}$ 104

Figura 42 - Tela de acesso às propriedades na criação de novos parâmetros no Revit ${ }^{\circledR}$. Fonte: AutoDesk. 105

Figura 43- Exemplo de modelagem do Terminal Regional no Revit ${ }^{\oplus}$ 108

Figura 44 - Programa de Necessidades do Terminal Regional. Fonte: INFRAERO 109

Figura 45- llustração da modelagem do terreno do Terminal Regional da INFRAERO, no Revit ${ }^{\circledR}$.

Figura 46- Ilustração da modelagem dos pilares e vigas do Terminal Regional da INFRAERO, no Revit $^{\oplus}$

Figura 47- Ilustração da modelagem das paredes do Terminal Regional da INFRAERO, no Revit .

Figura 48- Ilustração da modelagem das esquadrias do Terminal Regional da INFRAERO, no Revit $^{\oplus}$.

Figura 49- Ilustração da modelagem das coberturas (lajes) do Terminal Regional da INFRAERO, no Revit

Figura 50- llustração da adição de componentes (objetos) do Terminal Regional da INFRAERO, no Revit 
Figura 51- Representação bidimensional (automática) do Terminal Regional da INFRAERO no Revit ${ }^{\circ}$

Figura 52- Representação bidimensional (automática) do Terminal Regional da INFRAERO no Revit ${ }^{\circ}$

Figura 53- Representação bidimensional (automática) do Terminal Regional da INFRAERO no Revit $^{\oplus}$.

Figura 54- Representação bidimensional (automática) do Terminal Regional da INFRAERO no Revit $^{\oplus}$. 114

Figura 55- Representação bidimensional (automática) do Terminal Regional da INFRAERO no Revit ${ }^{\circ}$

Figura 56- Representação tridimensional (automática) do Terminal Regional da INFRAERO no Revit $^{\circ}$

Figura 57- Representação parcial da estrutura do Terminal Regional da INFRAERO no Revit . 115

Figura 58 - Ilustração do Terminal Regional da INFRAERO, antes do acréscimo das alternativas de projeto de Torre de Controle, no Revit ${ }^{\circ}$....

Figura 59- Diferentes alternativas para uma Torre de Controle (simulação de alteração projeto).

Figura 60 - Exemplo de inserção de componentes da biblioteca nativa para compor a escala humana na modelagem das Torres de Controle.

Figura 61 - Metodologia de projeto - múltiplas alternativas. 118

Figura 62- Documento de Requisitos de Navegação Aérea acessado via "hyperlink" na Matriz Semântica 119

Figura 63 - Documento de especificações técnicas para uma Torre de Controle acessado via "hyperlink" na Matriz Semântica. 120

Figura 64- Documento de Memorial Descritivo para uma Torre de Controle acessado via hyperlink na Matriz Semântica.

Figura 65- Exemplo do aeroporto modelado antes da criação das Torres de Controle. 123 
Figura 66- Vista do Terminal de Passageiros Regional modificado - TWR1.

Figura 67- Vista do Terminal de Passageiros Regional modificado - TWR2.

Figura 68- Vista do Terminal de Passageiros Regional modificado - TWR3.

Figura 69- Ilustracao parcial da tela de acesso principal da Matriz Semântica, destacando o Modulo de "check-in". 129

Figura 70 - Tela de acesso ao Detalhamento do "check-in" na Matriz Semântica. 130

Figura 71- Memorial Ostensivo número 06 - Fonte: DOPL/ INFRAERO.

Figura 72- Campo de acesso aos Processos de Projeto de Arquitetura na Matriz Semântica. 132

Figura 73- Exemplo de estruturação lógica dos dados na Matriz Semântica referente aos Processos de Aprovação de Projetos.

Figura 74- Caracterização e classificação das Tarefas de Aprovação de Projeto para a INFRAERO 134

Figura 75 - Tela de acesso aos Processos de Aprovação de Projetos da INFRAERO. 135

Figura 76- Processos de Aprovação de Projetos para um modulo de "check-in" na Matriz Semântica. 136

Figura 77- Partes do Aeroporto para um Módulo de “check-in” na Matriz Semântica.... 136

Figura 78- Sistemas do Aeroporto para um Módulo de “check-in” na Matriz Semântica

Figura 79 - Processos de Aprovação de Projetos para um modulo de "check-in" na Matriz Semântica 137

Figura 80- Classificação das Tarefas de Projeto para a INFRAERO 138

Figura 81- Tela de acesso as Tarefas de Projeto da INFRAERO. 140

Figura 82- Tarefas de Projeto para um Módulo de “check-in” na Matriz Semântica. 141

Figura 83- Exemplo de partes para Saguão "Lado Terra” de um Aeroporto. 141

Figura 84- Partes do Aeroporto para um Módulo de "check-in” na Matriz Semântica.

Figura 85- Sistemas do Aeroporto para um Modulo de "check-in" na Matriz Semântica 142 
Figura 86- Disciplinas da INFRAERO para um Módulo de "check-in" na Matriz Semântica..... 142

Figura 87- Interações de Projeto para um Módulo de "check-in" na Matriz Semântica.... 143

Figura 88- Interações Sistêmicas para o Saguão "lado terra" de um Aeroporto. 144

Figura 89- Tela de acesso às Dimensões das Engenharias na Matriz Semântica. 145

Figura 90- Tela de acesso aos processos de aprovação de sistemas eletrônicos.

Figura 91- Processos de Aprovação de Projetos para um Módulo de "check-in" na Matriz Semântica. 148

Figura 92- Partes do Aeroporto para o Módulo de "check-in" na Matriz Semântica. 148

Figura 93- Sistemas do Aeroporto para um Módulo de "check-in" na Matriz Semântica. 149

Figura 94- Tela de acesso às Tarefas de Projeto de Sistemas Eletrônicos da INFRAERO. 150

Figura 95- Tarefas de Projeto (Engenharias) para um Módulo de "check-in" na Matriz Semântica.

Figura 96- Partes do Aeroporto (Engenharias) para um Módulo de "check-in" na Matriz Semântica 151

Figura 97- Sistemas do Aeroporto (Engenharias) para um Módulo de "check-in" na Matriz Semântica. 151

Figura 98- Planta utilizada como referência de modelagem originalmente no AutoCAD AutoDesk. Fonte: INFRAERO. 154

Figura 99- Plantas de referência para modelagem proveniente do AutoCAD inserida no sistema BIM - Revit'. Fonte: INFRAERO. 155

Figura 100- Balcão de "check-in" de aeroporto modelado no Revit" 157

Figura 101- Esteira de Bagagem Desembarcada de aeroporto modelado no Revit ${ }^{\circ}$. 157

Figura 102- Raio-X de Bagagem de Passageiros de aeroporto modelado no Revit ${ }^{\circ}$. 158

Figura 103- Ponte de Embarque de aeroporto modelado no Revit ${ }^{\circ}$ 158

Figura 104- Esteira de Bagagem Geral de aeroporto modelado no Revit ${ }^{\circ}$. 159 
Figura 106- Seleção do modelo de família no Revit ${ }^{\circledR}$

Figura 107- Criação de planos e linhas de referência no Revit ${ }^{\circ}$.

Figura 108- Inserção e edição de arquivo ". DWG" no Revit

Figura 109 - Exemplo de extrusão simples no Revit ${ }^{\circ}$

Figura 110- Exemplo de configuração do plano de trabalho no Revit . 164

Figura 111 - Exemplo de extrusão no Revit ${ }^{\oplus}$ controlada para direção no eixo de altura. 165

Figura 112- Exemplo de inserção de cotas no Revit ${ }^{\circ}$ 166

Figura 113 - Exemplo de utilização de linhas como guias de modelagem para uma Ponte de Embarque no Revit ${ }^{\circ}$. 167

Figura 114- Ponte de embarque modelada no Revit ${ }^{\circ}$ segundo as especificacoes tecnicas colhidas na INFRAERO. 168

Figura 115 - Exemplo de acesso as configurações de visibilidade no Revit. 169

Figura 116 - Configuração das características correspondente ao LOD300. 169

Figura 117- Visualização do resultado da configuração de LOD no Revit ${ }^{\circledR}$. 170

Figura 118- Diferentes representações gráficas um mesmo objeto nos sistemas BIM.

Figura 119- Demonstração da criação do parâmetro SINAPI para uma Esteira de Bagagem. . 173

Figura 120- Configuração de novo parâmetro (SICAERO) no Revit ${ }^{\circ}$. 174

Figura 121- Exportação para arquivo do tipo "IFC" a partir do Revit ${ }^{\circ}$ 176

Figura 122- demonstração de componente BIM importado no ambiente SIG - InfraWorks ${ }^{\circledR}$. 177

Figura 123- Ilustração de componente BIM importado no ambiente SIG - InfraWorks ${ }^{\circ}$ 178

Figura 124- Exemplo de nível de detalhamento em LOD100 no InfraWorks ${ }^{\circledR}$. 179

Figura 125- Exemplo de variação de nível de detalhamento em LOD300 no InfraWorks ${ }^{\bullet}$....... 180

Figura 126- Exemplo de variação de nível de detalhamento em LOD100 no InfraWorks. 181 
Figura 128- Exemplo de inserção de planta bidimensional CAD como guia de modelagem no Revit ${ }^{\circ}$.

Figura 129- Ilustração de importação de planta baixa CAD-2D do Terminal Regional no Revit .

Figura 130- Ilustração do resultado gráfico da modelagem de pátio, calçadas e vias de acesso ao aeroporto regional no Revit ${ }^{\circ}$ 186

Figura 131- Ilustração da criação de diferentes níveis para a modelagem do Terminal Regional no Revit ${ }^{\circ}$

Figura 132- Ilustração de modelagem dos pilares no Terminal Regional no Revit ${ }^{\circ}$. 188

Figura 133- Ilustração de modelagem das paredes do Terminal Regional no Revit ${ }^{\circledR}$ 189

Figura 134- Ilustração de modelagem das esquadrias do Terminal Regional no Revit ${ }^{\circ}$. 190

Figura 135- llustração de modelagem das coberturas no Terminal Regional no Revit ${ }^{\circ}$. 191

Figura 136- Ilustração de inserção de componentes no Terminal Regional no Revit ${ }^{\circ}$ 192

Figura 137- Ilustração da inserção de componentes complementares ao Terminal Regional no Revit ${ }^{\circ}$.

Figura 138- Ilustração da ligação paramétrica de relacionamento entre as paredes e lajes do Terminal Regional no Revit ${ }^{\circ}$. 195

Figura 139- Configuração das dimensões da base em um pilar no Terminal Regional. 196

Figura 140- Ilustração da criação de um pilar do Terminal Regional com família nativa do sistema no Revit ${ }^{\circ}$ 197

Figura 141- Corte do Terminal Regional obtido de forma automática no Revit ${ }^{\circ}$. 198

Figura 142- Fachada do Terminal Regional obtida de forma automática no Revit ${ }^{\circ}$. 198

Figura 143- Planta baixa do Terminal Regional obtida de forma automática no Revit ${ }^{\circ}$ 199

Figura 144- Ilustração gráfica da projetação do Terminal Regional no REVIT 2014 200

Figura 145- Ilustração gráfica da projetação do Terminal Regional no REVIT 2014. 201 
Figura 146- Componentes paramétricos BIM modelados durante a pesquisa.

Figura 147- Componentes paramétricos BIM modelados durante a pesquisa. 204

Figura 148- Seleção da área de influência para obtenção de dados de satélite. Fonte: http://viewer.nationalmap.gov/viewer/. 206

Figura 149- Opção de "download" de dados de satélite para o terreno selecionado. Fonte: http://viewer.nationalmap.gov/viewer/. 206

Figura 150- Seleção de camadas de informação para obtenção de dados de satélite do terreno selecionado. Fonte: http://viewer.nationalmap.gov/viewer/. 207

Figura 151- Demonstração de acesso a criação de um novo modelo na tela do aplicativo InfraWorks ${ }^{\oplus}$ 208

Figura 152- Ilustração de adição de dados do tipo "raster" na tela do aplicativo InfraWorks". 208

Figura 153- Ilustração de formação do terreno com os dados "raster" importados, na tela do aplicativo InfraWorks ${ }^{\oplus}$ 209

Figura 154 - Ilustração de área de influência na tela do aplicativo InfraWorks ${ }^{\circledR}$ para o terreno importado

Figura 155 - Demonstração de inserção de um modelo BIM no relevo do SIG.

Figura 156 - Terminal Regional sem a presença de Torre de Controle. Fonte: INFRAERO.

Figura 157 - Exemplificação das alternativas de Torre de Controle para o Terminal Regional no Revit $^{\oplus}$. 214

Figura 158 - Ilustração da tela de acesso as informações sobre a Torre de Controle na Matriz Semântica. 215

Figura 159 - Ilustração da tela de acesso aos campos de Aprovação, Tarefas de Projeto e Requerimentos para uma Torre de Controle na Matriz Semântica. 216

Figura 160- Ilustração da tela de acesso as informações sobre os Processos de Aprovação de Projetos para uma Torre de Controle na Matriz Semântica. 217 
Figura 161- Ilustração da tela de acesso para as Tarefas de Projeto para uma Torre de Controle na Matriz Semântica.

Figura 162 - Ilustração da tela da Matriz Semântica com as informações sobre o estudo conceitual de Telemática na Matriz Semântica.

Figura 163 - llustração da tela de acesso aos Requerimentos de Projeto para uma Torre de Controle na Matriz Semântica.

Figura 164 - Ilustração de Requerimento da INFRAERO para projeto de uma Torre de Controle na Matriz Semântica.. Fonte: INFRAERO. 222

Figura 165 - Ilustração de requerimento da INFRAERO para projeto de uma Torre de Controle na Matriz Semântica.. Fonte: INFRAERO

Figura 166- Detalhamento de elemento a ser retirado na modelagem de uma das alternativas de Torre de Controle no Revit ${ }^{\circ}$.

Figura 167- Detalhamento dos pisos de uma das alternativas de Torre de Controle no Revit ${ }^{\circ}$.

Figura 168- Detalhamento do pilar na modelagem de alternativa de Torre de Controle no Revit ${ }^{\circledR}$.

Figura 169 - Detalhamento da viga na modelagem de uma das alternativas de Torre de Controle no Revit

Figura 170 - Detalhamento das paredes na modelagem de uma das alternativas de Torre de Controle no Revit ${ }^{\circ}$. 225

Figura 171 - Detalhamento dos elementos do fechamento na modelagem de uma das alternativas de Torre de Controle no Revit ${ }^{\circ}$. 225

Figura 172 - Detalhamento de elementos acessórios na modelagem de uma das alternativas de Torre de Controle no Revit . 226

Figura 173 - Detalhamento da cobertura na modelagem de uma das alternativas de Torre de Controle no Revit ${ }^{\circ}$. 226

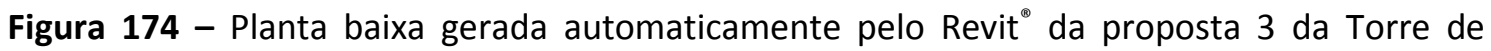
Controle. 
Figura 175 - Corte gerado automaticamente pelo Revit ${ }^{\circledR}$ da proposta 3 da Torre de Controle.

Figura 176 - Fachada gerada automaticamente pelo Revit ${ }^{\circ}$ da proposta 3 da Torre de Controle.

Figura 177 - Alternativa 1 de Projeto (TWR- Torre de Controle).

Figura 178 - Alternativa 2 de Projeto (TWR - Torre de Controle).

Figura 179 - Alternativa 3 de Projeto (TWR - Torre de Controle).

Figura 180 - Ilustração de teste de variabilidade no nível de detalhamento geométrico de um componente modelado nos sistemas BIM - Revit ${ }^{\circ}$ e importado no SIG - InfraWorks ${ }^{\circ}$.

Figura 181- Ilustração de um componente modelado no sistema BIM - Revit e importado no SIG - InfraWorks sem alteração na variação de seu nível de desenvolvimento. 232

Figura 182 - Aeroporto configurado no InfraWorks em LOD 100 para "abstração" das esquadrias, que não aparecem no projeto.

Figura 183 - Ilustração da inserção do Terminal Regional em sua integra no SIG - InfraWorks.

Figura 184 - Terminal Regional da INFRAERO (adaptado). Vista do Pátio de Aeronaves e Pontes de Embarque.

Figura 185 - Terminal Regional da INFRAERO (adaptado). Vista lateral do Terminal de Passageiros.

Figura 186 - Terminal Regional da INFRAERO (adaptado). Vista perspectiva da entrada do Terminal de Passageiros. 237

Figura 187 - Vista do Conector (“Concourse") de Transbordo de Passageiros. 238

Figura 188 - Vista lateral do Terminal de Passageiros 238

Figura 189 - Terminal Regional da INFRAERO (adaptado). Vista perspectiva superior do Terminal de Passageiros. 238

Figura 190- Imagem perspectiva do Terminal Regional. 239

Figura 191- Imagem perspectiva do Terminal Regional. 240 


\section{AGRADECIMENTOS}

Agradeço às famílias Tollendal, Prudente \& Roitman, minha filha Sofia, ao meu pai, Edson, irmã, Luísa, mãe, Vera, irmão, Sidarta \& Ernesto, para meus segundos pais Isaac \& Celina, à Elizangela irmãos Joana, Frederico, Adriano e sobrinha Bebel; Agradeço imensamente a Iris Roitman pelo suporte sem o qual esta pesquisa não seria possível, além de nortear o pensamento do autor quanto aos temas propostos e oferecer apoio incondicional sempre que preciso e aos meus padrinhos, Mario Theodoro e Luciana Jaccoud;

Agradeço especialmente ao Enio Ferreira da Rocha, pelo apoio incondicional, orientação de vida e aprendizado de tantos anos, ao Jonas Maurício Lopes, por acreditar e apoiar as mudanças que somente as pessoas de vanguarda o fazem e ao amigo João Eduardo Bandeira de Melo Araújo, pelo apoio em todas as horas... Ao amigo e mestre Marcos Furiati pela oportunidade de descobrir a engenharia e a vida e pela amizade construída ao longo do tempo; ao professor orientador Dr. Neander Furtado Silva e família pela dedicação, paciência e pela orientação ao meu desenvolvimento ao longo dos anos e ao Diretor de Engenharia da INFRAERO, Adilson Teixeira Lima, pela visão de futuro e o apoio na implantação dos sistemas BIM e aos colegas de trabalho;

Agradeço à INFRAERO e à ANAC, pelas oportunidades ofertadas ao meu crescimento como profissional e especialmente a: Adyr da Silva, Alexandre Henrique Radis, André Luiz de Lima, Antonio Milanez Ramos, Carlos André Lascano Pinto, Carlos Vinicius Meirelles, Cleuber Guedes, Alex Totem, Eduardo Ballarin, Francisco Erivan, Edmundo Farias Brito, Glauber Carvalho Cruz, ao grande amigo Luiz Fernando Machado Borges (pela motivação e fé inabalável no bem!), Laura Andrade, Jander Pedrosa do Nascimento, Marcelo Guaranys, Diretor - Presidente da ANAC, Nelson Mattei, pela amizade, Paulo Sérgio Ramos Pinto, Ricardo Alexandre Góis Ferreira, Saulo Luís de Aquino, Valnízia Marinho, Viviane Tavares Sobral, e ao Walter Américo, Zapata e Elton da Operações, pelo apoio incondicional; Agradeço ainda pela etapa e "Split-PhD." Em State College - PA, ao grande amigo Emile Tilghman Osborne, Oscar de La Reina, Marco De Giorgi, Pierre Troillard, Steven, Laura Collado, e família, Karen e Angelina Grieb, Tom e Emilia, Mike, Dylan, além de meu orientador nos Estados Unidos, Prof. Dr. Loukas Kalisperis e Kendra Rakovan, pela Penn State University. Agradeço à Beth Mori e ao Maestro Marden Maluf pelo exemplo; Agradeço a Deus e à vida por me permitirem chegar até aqui... E finalmente, à Universidade de Brasília - UnB, que cumpre seu papel de transformar em cidadãos do mundo os jovens de Brasília e do Brasil!

\section{DEDICATÓRIA}

Dedico esta pesquisa a minha mãe, Vera, ao meu pai, Edson, a Beth Mori, especialmente ao meu tio Fernando Tollendal, a minha filha, Sofia e ao meu irmão Sidarta Ribeiro, meu exemplo e guia nos caminhos tortuosos da investigação cientifica e a todos aqueles que se esforçam sinceramente no caminho do conhecimento, que incontestavelmente nos dirige, a todos, em direção à luz e a verdade! Dedico ainda esta pesquisa ao meu pai biológico falecido prematuramente aos 28 anos de idade, Sergio Barreira Gomes Ribeiro e seu irmão, Eduardo Ribeiro.

Dedico, ainda, esta pesquisa a Sergio Alves Gomes Ribeiro, Luís Pedro Basílio Neri, sua mãe Amparo \& família e ao primo Thales Tollendal Alvarenga, verdadeiros irmãos, que se foram prematuramente e que deixaram a certeza de ter sido um grande privilegio o convívio e o aprendizado ao seu lado...

Dedico finalmente, essa pesquisa à INFRAERO e seu corpo técnico. 


\section{RESUMO}

A concepção, desenvolvimento e execução de projetos de grande porte, como os do setor aeroportuário, são complexos. A otimização da gestão da informação é essencial para aumentar eficiência e transparência. Atualmente, existem diversas ferramentas computacionais capazes de auxiliar na integração e manipulação de dados, como o sistema de informação geográfica (SIG) e a modelagem da informação da construção (BIM). Contudo, tais ferramentas ainda não são utilizadas nos processos de projeto e aprovação (PPA's) de aeroportos no Brasil, nem tampouco existem estudos voltados para a sua aplicabilidade neste setor. Esta é a situação, por exemplo, da Empresa Brasileira de Infraestrutura Aeroportuária (INFRAERO). Os PPA's são caracterizados por elevada linearidade, que resulta em excesso de revisões de projeto e dificulta a integração das soluções de diferentes equipes e setores. O presente estudo investigou as potencialidades e limitações de tais ferramentas, por meio de um projeto piloto aplicado ao terminal de passageiros regional (TPR) da INFRAERO. Os objetivos específicos consistiram em desenvolver um processo de projetação e aprovação de projeto (matriz semântica de regras de abstração) para a sistematização dos PPA's. Além disto, teve-se como objetivo avaliar a aplicabilidade dos sistemas BIM associada ao SIG, por meio da criação de objetos paramétricos, modelagem do TPR e simulação de três alternativas de projeto para uma torre de controle. A matriz semântica foi construída no $\mathrm{XMind}^{\circledR}$ com base em documentos oficiais e manuais operacionais da INFRAERO. Na matriz foram sistematizadas informações relevantes ao processo de projeto de arquitetura de um TPR, incluindo todos os módulos funcionais e com maior detalhamento do módulo "check in". Para a modelagem nos ambientes BIM e SIG foram utilizados os softwares AutoDesk Revit ${ }^{\circledR}$ e AutoDesk InfraWorks ${ }^{\circledR}$, respectivamente. Foram modelados oito componentes aeroportuários de acordo com padrões e normas nacionais, customizados com diferentes parâmetros e níveis de detalhe. Os componentes foram exportados para o ambiente SIG, analisados sob diferentes níveis de detalhe semântico e geométrico e utilizados na etapa posterior de reprodução do TPR. A modelagem do TPR foi baseada em seu memorial descritivo, plantas baixas, cortes e fachadas e em um modelo tridimensional no formato do tipo ". SKP" (do SketchUp ${ }^{\circledR}$ ), todos eles fornecidos pela INFRAERO. Os resultados indicam que a associação do sistema BIM ao SIG pode aprimorar a gestão de PPA's na INFRAERO e em outras instituições que lidem com processos semelhantes, porque permite a integração de diferentes níveis e tipos informação em relação à estrutura (geometria, especificações técnicas, propriedades físicas e estruturais, custo, etc.), e aos processos de desenvolvimento e execução de projetos (procedimentos internos, requerimentos legais, termos de referência, pareceres, memorandos, etc.). Permite ainda a integração e sinergia entre as diferentes equipes e usuários. Para sua implantação será preciso construir uma ampla biblioteca de componentes paramétricos, como aqueles desenvolvidos no presente estudo, com campos específicos de informação para sua própria estrutura organizacional. O processo de modelagem, incluindo a sistematização da matriz, permitiu identificar alterações necessárias no desenho dos processos de aprovação da INFRAERO, expressas em um fluxograma que reflete a gestão integrada de informações inerente aos sistemas BIM e SIG.

PALAVRAS CHAVE: aeroporto; gestão da informação; infraestrutura aeroportuária; matriz semântica; modelagem da informação da construção; sistemas de informação geográfica. 


\begin{abstract}
The development and implementation of large-scale architectural projects, such as the ones in airport sector are highly complex. Optimizing information management is essential to increase their efficiency and transparency. Currently, there are several computer based tools that can assist in data processing and integration, such as geographic information systems (GIS) and building information modelling (BIM). However, such tools haven't been used yet in the design and approval processes (DAP's) of the Brazilian Airport Infrastructure Company (INFRAERO). Moreover, no studies have been made to investigate their applicability in company. The DAP's at INFRAERO are highly linear, which leads to excessive revision of project designs and hinders the integration of solutions from different teams and sectors. The present study investigated the potential and limitations of the above tools, based on a pilot project for INFRAERO's regional passenger terminal (RPT). The specific objectives were to develop a systemized database (semantic matrix of abstraction rules) of DAP's; and to evaluate the applicability of BIM associated with GIS at INFRAERO, by creating parametric objects, modelling the RPT, and simulating three design alternatives for a control tower. The semantic matrix was constructed in XMind ${ }^{\circledR}$ and based on INFRAERO official documents and operational manuals. The matrix systematized information relevant to the architectural design process of a RPT, including all functional modules and the "check in" module at a higher level of detail. The BIM and GIS software's used in this study were Autodesk Revit ${ }^{\circledR}$ and AutoDesk InfraWorks ${ }^{\circledR}$, respectively. Eight airport components were modelled according to national standards and regulation, and customized with different parameters and levels of detail. The components were exported to GIS, analyzed under different levels of semantic and geometric detail and used in reproduction of the RPT design. The RPT modelling was based on its descriptive memorial, floor plans, sections and facades, and a tridimensional model in .skp format (SketchUp ${ }^{\circledR}$ ), all of them provided by INFRAERO. Results indicate that incorporating BIM associated with GIS at INFRAERO can enhance the management of DAP's because it allows the integration of different data types and levels of information related to the structure (geometry, technical, structural and physical properties, cost, etc.) and processes of project development and implementation (internal procedures, legal requirements, reference terms, memoranda, etc.), as well as the integration and synergy between different teams and users. Implementing those tools requires building a large library of parametric components, such as those developed in this study, with specific fields of information associated to the company's organizational structure. The modeling process, including the systematization of data in the matrix, revealed the need to make structural changes in the INFRAERO's approval processes. Those changes were described in flow chart that reflects the integrated management of information inherent to BIM and GIS systems.
\end{abstract}

KEYWORDS: airports; airport infrastructure; building information modelling; geographic information systems; information management; semantic matrix. 


\section{SÍMBOLOS, ABREVIATURAS, SIGLAS E CONVENÇõES}
ANAC
Agência Nacional da Aviação Civil
SAC
Secretaria de Aviação Civil
TCU
Tribunal de Contas da União
BNDES
Banco Nacional de Desenvolvimento Econômico e Social
CAB
Civil Aeronautics Board
TWR
Torre de Controle do aeroporto
CBA
Código Brasileiro de Aeronáutica
PPA
Processos de Projeto e Aprovação
CNS/ATM Communication, Navigation, Security/Air Traffic Management
COMCLAR Comissão de Coordenação de Linhas Aéreas Regulares
CONAC
Conferências Nacionais de Aviação Comercial
BIM
"Building Information Modeling"
CAD Computer-aided design
SIG
Sistemas de Informações Geográficas
GOL
Gol Transportes Aéreos S.A.
IATA
International Air Transport Association
ICC
Interstate Commerce Comission
IPEA
Instituto de pesquisa Econômica e Aplicada
MF
Ministério da Fazenda
OACl Organização de Aviação Civil Internacional
OECD
Organization for Economic Co-Operation and Development
TPR
Terminal de Passageiros Regional do Brasil
SIG
Sistema de Informações Geográfica
SBDC
Sistema Brasileiro de Defesa da Concorrência
SITAR
Sistemas Integrados de Transporte Aéreo Regional
SNEA
Sindicato Nacional das Empresas Aeroviárias
CAM
Computer-aided manufacturing
TAM
TAM Linhas Aéreas S.A.
LOD-S
"Level of Development" - Nível de Desenvolvimento (Semântico)
LOD-G
"Level of Detail" - Nível de Detalhamento (Geométrico)
INFRAERO Empresa Brasileira de Infraestrutura Aeroportuária 


\section{1- INTRODUÇÃo}

\section{1- DA LAPISEIRA E PAPEL AOS MODELOS COMPUTACIONAIS DE INFORMAÇÃO DA CONSTRUÇÃO}

O processo de criação e execução de projetos de grande porte, como aeroportos, é extremamente complexo. O desenvolvimento tecnológico trouxe importantes ferramentas que facilitam o trabalho e a integração de arquitetos, engenheiros, gestores e clientes. Até meados da década de 1960, não existiam sistemas gráficos computacionais disponíveis no mercado.

Os profissionais dispunham basicamente de métodos bidimensionais e baseados em papel, com informação fragmentada e de difícil documentação. A necessidade de criação de sistemas computacionais para melhorar a produtividade dos engenheiros e arquitetos foi lentamente reconhecida por grandes corporações, ao contrário daquelas do setor automotivo, aeroespacial e naval que apresentaram adoção precoce de sistemas computacionais para auxiliar o projeto. Estas empresas impulsionaram o desenvolvimento dos sistemas de desenho assistido por computador, "Computer Aided Design"(CAD).

Para KOLAREVIC (2003), uma nova arquitetura surge da revolução digital, expressa em formas de alta complexidade: a arquitetura computacional, criada em espaço geométrico não Euclidiano, com sistemas cinéticos, dinâmicos e algoritmos gerativos de formas, auxiliada pela incorporação dos avanços já ocorridos na indústria automobilística, aeroespacial e naval (Figura 1).

A transferência de informações entre os meios de representação e de produção na arquitetura digital são confirmadas na era digital. Esta facilita o envolvimento dos arquitetos nos processos de fabricação, o que demonstra que a fabricação digital pode oferecer novas oportunidades de projeto, de soluções e de fabricação de maquetes e elementos construtivos (KOLAREVIC, 2003, p.1-6).

KOLAREVIC (2003) cita MITCHELL, ao observar que nos tempos sem tecnologia apropriada, "os arquitetos desenhavam o que podiam construir e construíam o que podiam desenhar". A integração dos sistemas CAD e CAM, para projeto e manufatura, permitiu a produção e construção de formas altamente complexas, anteriormente inviáveis, por fatores como custo e produção (Mitchell apud KOLAREVIC,2003, p. 32). 


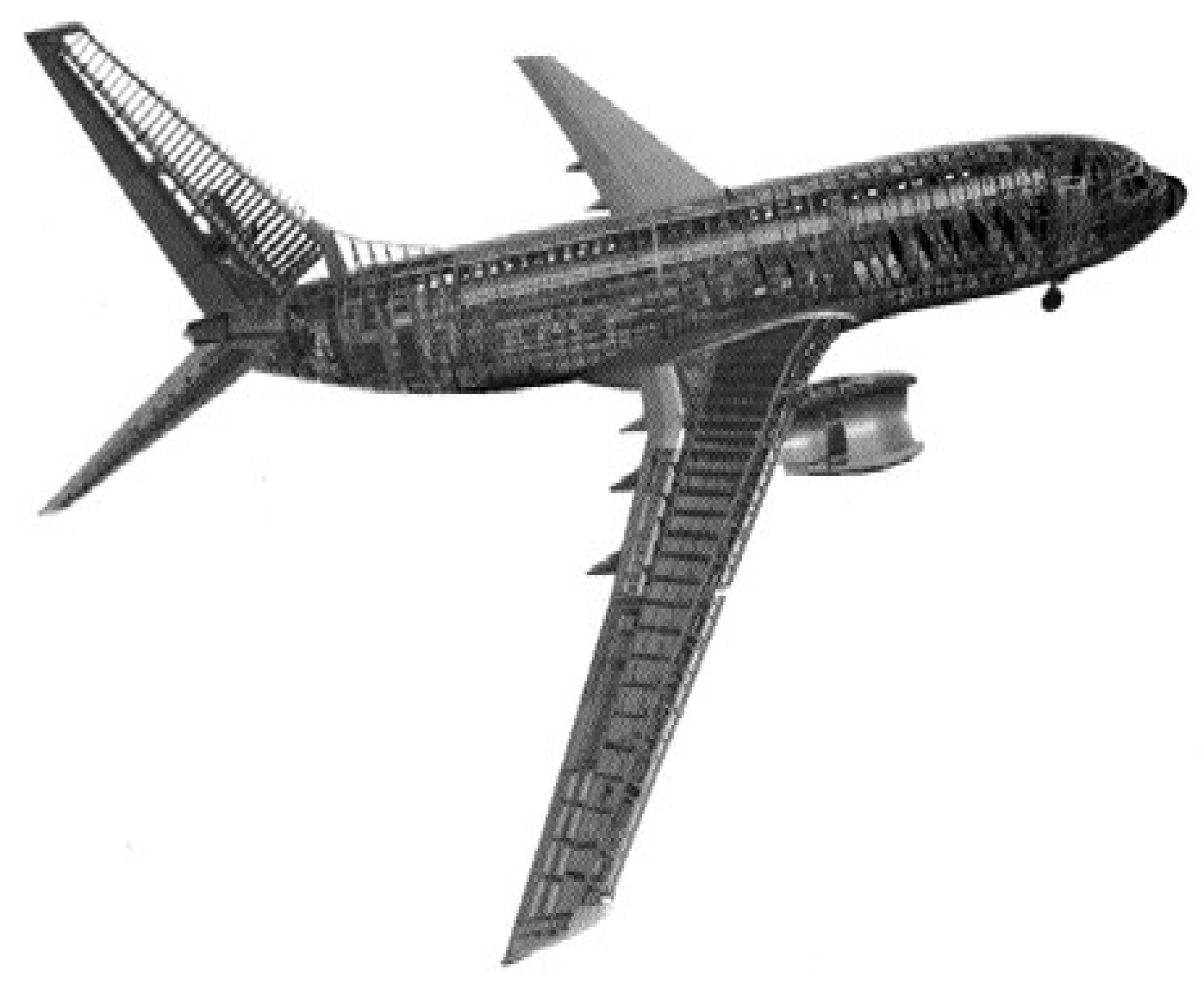

Figura 1- Modelo digital do Boeing 777 , sendo esta a primeira aeronave projetada $100 \%$ digitalmente. Fonte: KOLAREVIC, B. 2003).

Esses sistemas disponibilizam recursos para representação gráfica com elevada precisão e recursos visuais estáticos e dinâmicos, que possibilitam o controle do processo de desenvolvimento (SOUZA et al 2005).

Durante a década de 1990, a indústria CAD foi incorporada aos setores de Engenharia, Arquitetura e de desenvolvimento de infraestrutura (WEISBERG, D., 2008, p. 2-8 a 2-10).

Desde a criação dos sistemas CAD, outras ferramentas inovadoras tiveram papel importante no desenvolvimento desses setores, como os sistemas de informação geográfica (SIG) e os sistemas de modelagem de informação da construção, "Building Information Modelling" (BIM), também conhecidos como modelo paramétrico da construção virtual (TSE \& WONG, 2005, p.86). 
FITZ (2008) conceitua os SIG como sistemas constituídos por conjunto de programas computacionais com objetivo de coletar, armazenar, recuperar, manipular, visualizar e analisar dados espacialmente referenciados a sistema de coordenadas conhecido.

As geotecnologias podem ser entendidas como as novas tecnologias ligadas às geociências e correlatas, as quais trazem avanços significativos no desenvolvimento de pesquisas, em ações de planejamento, em processos de gestão, manejo e outros aspectos relacionados à estrutura do espaço geográfico. Exige interatividade para que se possa trabalhar o ambiente de forma interdisciplinar (FITZ, 2008 p. 19-30).

O conceito de parametrização é importante para compreender os sistemas BIM:

\begin{abstract}
"Pela primeira vez na história, arquitetos estão projetando não a forma específica do edifício, mas conjuntos de princípios codificados como sequência de equações paramétricas pelas qual instâncias específicas do projeto podem ser geradas e variadas no tempo que for necessário. O desenho paramétrico apela à rejeição das soluções fixas e pela exploração das potencialidades infinitamente variáveis" (KOLAREVIC, 2005, pp.18)
\end{abstract}

Em outras palavras, os processos de descrição e construção de projeto podem ser extraídos, transferidos, e utilizados com facilidade e maior velocidade. Enfim, com o uso das tecnologias digitais, a informação do projeto é a informação da construção (KOLAREVIC, 2003, p.07).

Os sistemas BIM possibilitam o gerenciamento de informações, desde a fase inicial de projeto, criando modelo digital que abrange todo o ciclo de vida da edificação e ainda disposição final da mesma. Representam outros tipos de informação além da geometria dos objetos.

Estes permitem definir uma série de parâmetros qualitativos e quantitativos como propriedades dos materiais, função estrutural dos componentes construtivos, as interrelações entre os mesmos, custos e etc. Integra diferentes especificidades de informação e processos em modelo ou arquivo único.

Isso facilita não só a modelagem, mas também a gestão dos processos de projeto. Os sistemas BIM podem ser definidos como a modelagem tridimensional associada a informação e aos diversos processos de concepção, análise, documentação e comunicação referentes ao edifício. 


\section{Na definição de EASTMAN et. al (2008), em The BIM Handbook":}

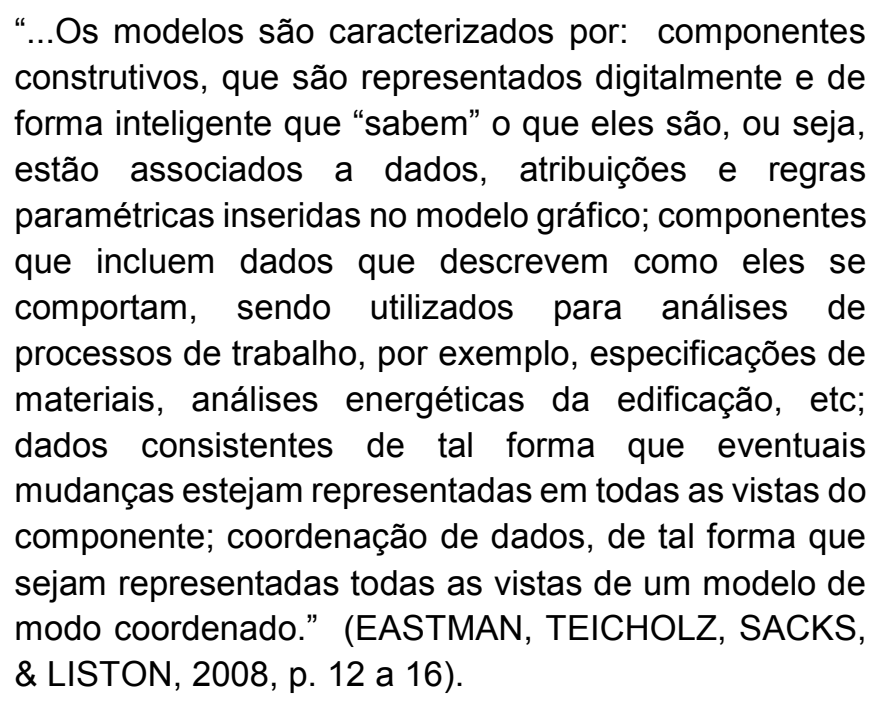

Nos sistemas BIM existe base de dados vinculada, o que implica em que cada vez que algum usuário pratica mudanças, ocorre a atualização em toda base de dados e seus respectivos documentos, sem que haja perda ou informação repetida, como ocorre nos processos baseados nos sistemas CAD bidimensionais. A colaboração entre os membros das equipes de projeto passa a girar em torno de um modelo mestre, baseado nas informações necessárias para o planejamento e construção de um edifício. Os SIG, por sua vez, tem sido utilizados como uma ferramenta essencial para o manejo e tratamento dos dados geográficos em múltiplas aplicações e problemas práticos: gestão de grandes infraestruturas físicas, realização e exploração de grandes bases de dados cadastrais, planificação urbana, ordenamento territorial, manejo de problemas do transporte, sistemas de ajuda a navegação em automóveis (BUZAI \& BAZENDALE, 2006, apud ARNDT, L; SCHEER, S; PHILIPS, J., 2012, p. 2).

Segundo PINA e SANTOS (2010) os SIG são: sistemas computacionais usados para o entendimento dos fatos e fenômenos que ocorrem no espaço geográfico. A sua capacidade de reunir grande quantidade de dados convencionais de expressão espacial, estruturando-os e integrando-os, torna-os ferramentas essenciais para a manipulação das informações geográficas (BONGIOLO, R; 2010, p.186).

Por outro lado, PARKER (1991) define SIG como "tecnologia da informação que armazena, analisa e exibe tanto dados espaciais como não-espaciais" (PARKER apud MAGUIRE, 1991, p.11).

BURROUGH (1986) define SIG como sendo "conjunto de ferramentas para coletar, armazenar, recuperar, transformar e exibir dados espaciais do mundo real" (BURROUGH, 1986, p.299). 


\section{2- MATRIZ SEMÂNTICA COMO SUPORTE À MODELAGEM DA INFORMAÇÃO DA CONSTRUÇÃO}

A customização de sistemas BIM voltados para os processos de projeto na INFRAERO exige que o projetista obtenha perspectiva sistêmica de procedimentos, competências e conhecimento dos setores envolvidos. A sistematização de informações para dar suporte às decisões de projeto demanda a criação de uma matriz semântica de regras de abstração e dicionário correlato a estas informações (ontologia dos problemas e variáveis abrangendo a todos os aspectos envolvidos neste processo). Isto permite recuperar as informações relevantes e identificar sua complexidade. As ontologias podem ajudar a integrar vários modelos de dados com diferentes níveis de detalhe. Possibilitam compreensão comum e compartilhada de domínio do conhecimento em que deve haver comunicação entre pessoas e sistemas (ALMEIDA, 2002, p. 42).

As ontologias têm papel importante no intercâmbio de informações, pois proporcionam estrutura semântica às fontes de dados. Nesse sentido, o desenvolvimento de modelo ontológico da estrutura organizacional da INFRAERO e dos processos internos referentes às áreas de Arquitetura, Engenharia e Construção Civil (AEC) constitui-se em um bom veículo de experimentação a ser utilizado para demonstrar a comprovação da hipótese desta Tese.

Comumente as ontologias são conceituadas como a seguir: "classes" (aspectos gerais) em muitos domínios de interesse; "relações" que podem existir entre coisas; "propriedades" (ou atributos) que essas coisas podem ter. A palavra semântica, segundo GUIRALD (1980), é originada do grego "sêmainô" (significar), derivado de sema (sinal), que corresponde a sentido. Para o autor, é semântica tudo o que se refere ao sentido de um sinal de comunicação e tudo o que se refere às palavras (GUIRALD, 1980, apud PICKLER, M., 2007, p.2).

A definição dos componentes paramétricos que possuam tais características (semânticas) pode facilitar o surgimento de protocolo de comunicação compartilhado de projeto de aeroportos no Brasil. BORST (1997) conceitua "ontologia" como "...especificação formal e explícita de conceitualização compartilhada", onde "formal" significa ser legível para computadores; "especificação explícita" diz respeito a conceitos, propriedades, relações, funções, restrições, axiomas explicitamente definidos; "compartilhado" quer dizer conhecimento consensual e "conceitualização" diz respeito a um modelo abstrato de fenômeno do mundo real (ALMEIDA, 2003, apud BORST, 1997, p.12). 
As regras de abstração fornecidas por uma matriz semântica permitem estabelecer ontologias bem como consultar a relação entre os módulos funcionais de um aeroporto e sua relação com os processos de aprovação e de projeto na INFRAERO, além de interligar a participação dos profissionais das diferentes especialidades. Por se tratar de problema complexo, que não permite a formulação definitiva de perguntas e respostas, propusemos um sistema aberto de apoio ao processo de projeto (matriz semântica) que pode ser utilizada na simulação do mesmo nesta pesquisa. Essa matriz pode ser configurada e acessada por profissionais das mais diversas especialidades, com objetivo de auxiliar na consulta sobre diversas dimensões de uma organização como a INFRAERO. A geração de modelos semânticos BIM, que possam ser topologicamente representados nos SIG, exige a definição de "templates" (SEBASTIAN e BÖHMS, 2013, p. 256). A caracterização dos componentes construtivos em níveis de detalhe (LOD), que se ajustam conforme as fases do processo de projeto, além de um melhor entendimento semântico sobre o aeroporto e suas partes, permite embasar a prática projetual com uso dos sistemas BIM. Desta forma estabelece repertório conceitual, que pode se adaptar à variação de informação pertinente a cada fase do projeto.

A "Web" atual é denominada por BREITMAN (2005) de "Web Sintática", na qual os computadores fazem apenas a apresentação da informação, enquanto o processo de interpretação fica a cargo dos seres humanos, já que isso exige grande esforço para avaliar, classificar e selecionar informações e conhecimentos de interesse. A formação de ambiente estruturado nos moldes de uma "WEB semântica" possibilitaria aos profissionais da empresa, em rede nacional, tanto através do extranet como da intranet da INFRAERO, realizarem consultas, transferência e edição de informação amparados por linguagem comum. A "Web semântica", através da qual buscam-se mecanismos que capturem o significado das buscas do usuário, interligando significados de palavras e, neste âmbito, tem como finalidade conseguir atribuir significado (sentido) aos conteúdos publicados na Internet de modo que seja perceptível tanto pelo humano como pelo computador. Isto cria um ambiente no qual os computadores possam processar e relacionar conteúdos provenientes de várias fontes. No sentido de que isso se torne possível, é necessário incorporar a semântica na estrutura dos documentos disponíveis na "Web" (BREITMAN, 2005, p. 5). A elaboração da matriz semântica teve como objetivo mitigar as limitações apresentadas pelos sistemas BIM nos estágios iniciais de projeto e ainda contribuir para a definição dos componentes a serem utilizados na INFRAERO. Uma das características principais dos sistemas BIM é a capacidade de integração de informações geométricas, características, comportamentos e interrelações em um mesmo modelo. 
Este conceito pode ser implementado por meio do uso de arquivos "IFC, Industry Foundation Classes", projetados para fornecer uma base para intercâmbio de dados complexos da construção civil. Além da provisão de uma grande variedade de tipos de dados para representar os parâmetros dos elementos de construção e de espaços, o IFC também permite definir as relações entre os mesmos (CORREA, F. R. e SANTOS, E. T., 2014, p. 7-22).

O padrão "IFC" é baseado em distinção entre a representação semântica e a geométrica. Na parte semântica, o edifício é representado como um aglomerado de entidades com propriedades e relações específicas entre si. Em cada uma das entidades semânticas, uma ou mais representações geométricas podem ser associadas. Esta é uma abordagem adequada para suportar as diferentes exigências referentes à representação da geometria por diferentes usuários ou aplicativos. No entanto, devido a essa distinção, existe o risco de que ocorram inconsistências entre as representações semântica e geométrica (CHENG, J; DENG, Y; e DU, Q. 2013, p. 502503).

Em sua plataforma "BIM Server", VAN BERLO e LAAT (2012) apresentaram estudo da associação do "IFC" e "CityGML", em que procuram descrever e avaliar a integração da geometria de modelos BIM com SIG por meio de modelos "CityGML". Concluíram que modelos BIM são muito mais detalhados do que modelos SIG tradicionais. Por exemplo, conforme VAN BERLO e LAAT (2012), alguns componentes de construção desaparecem após exportação para o modelo SIG. Além disso, o mapeamento de informação semântica do sistema BIM para o SIG ainda está incompleto. As informações semânticas encontradas em arquivos IFC, relacionadas ao proprietário, o custo e o tempo de construção não encontram correspondência em arquivos "CityGML" (VAN BERLO, L.; BEETZ, J; BOS, P; HENDRIKS, VAN TONGEREN, H., 2012, p. 4-7).

Uma solução seria utilizar ferramentas de definição semântica como a matriz produzida nesta pesquisa (descrita no capítulo sobre Material e Métodos na p. 77 e no capitulo de Resultados na p. 125) para alimentar o desenvolvimento do padrão "CityGML". A proposta de realização da matriz semântica teve por objetivo reunir informações sobre como a estrutura organizacional da INFRAERO interage com as atividades de projeto.

A estrutura dos dados perfaz uma base ontológica de como o processo de projeto acontece na empresa, enquanto os significados semânticos procuram abranger informações comuns a todos os participantes das equipes de projeto. 


\section{3- PROBLEMÁTICA}

O problema essencial de pesquisa desta tese é a inexistência de descrição estruturada e lógica do conhecimento da projetação aeroportuária no Brasil. Sua descrição precisa pode permitir a construção de sistema computacional que pudesse efetivamente auxiliar nos processos de projeto específicos desta área.

Pode-se definir os sistemas BIM como um processo para elaborar edificações por meio da integração dos trabalhos de diversos profissionais de diferentes especialidades de projeto e das informações decorrentes em uma base de dados integrada. A exigência de inserção de componentes paramétricos já com especificações definidas no início do processo de projetação, representa uma rigidez dos atuais sistemas BIM, uma vez que não permitem abstração dos componentes construtivos. Isso pode limitar o processo de criação, especialmente nas etapas iniciais do projeto, nas quais muitos dos componentes ainda não foram especificados e, portanto, precisam ser representados de forma ambígua permitindo múltiplas interpretações. Por exemplo, não é possível modelar as aberturas nas paredes, sem especificar o modelo e os detalhes da janela.

A associação entre os sistemas BIM e SIG pode responder positivamente na variação de informação e detalhe associada aos componentes construtivos. Ressaltase a dificuldade de se incorporar os sistemas BIM e SIG especificamente aos processos de projetos aeroportuários no Brasil. A impossibilidade de se representar diferentes níveis de detalhe nos sistemas BIM constitui fator agravante deste problema, apesar desta não ser específica da projetação aeroportuária, pois se aplica a qualquer tipo ou tema de projeto de arquitetura.

No entanto, isso não significa que o processo BIM represente os sistemas BIM. Uma série de diferentes "softwares", de projeto e análise podem ser integrados ao processo BIM, como, por exemplo, o Ecotect ${ }^{\circledR}$, específico para análises ambientais e desempenho energético da edificação, aplicativos para verificação e compatibilização de interferências, como o NavisWorks ${ }^{\circledR}$, da AutoDesk ${ }^{\circledR}$, entre outros. O processo BIM deve responder positivamente a todas as fases do processo de projeto de arquitetura e engenharia. Os sistemas BIM encontram limitações em relação aos estágios iniciais do processo de projeto, porque exigem especificação precisa dos componentes arquitetônicos desde o início. A obrigatoriedade de especificação impede o uso de informação dos componentes e a representação gráfica dos mesmos de forma abstrata. Essa variação de níveis de abstração possibilita ao arquiteto explorar inúmeras alternativas diferentes com níveis diversos de detalhe. 


\section{4- HIPÓTESE}

Acreditamos que uma descrição estruturada e lógica do conhecimento dos processos de projetação aeroportuária no Brasil pode ser elaborada por meio de uma matriz semântica. Acreditamos ainda que esta matriz pode resultar em um programa computacional de auxílio a estes processos de projetação. Acreditamos, por fim, que este programa pode facilitar a incorporação de recursos como os sistemas BIM e SIG na projetação de aeroportos no Brasil.

Os "softwares" SIG associados aos sistemas BIM reduzem consideravelmente a limitação descrita na problemática desta tese porque permitem a representação de elementos construtivos em diferentes níveis de detalhes geométricos e semânticos.

Por essa razão, a associação dos sistemas BIM e SIG é essencial para viabilizar a sua adequada incorporação aos processos de projetos de arquitetura e engenharia.

Nesse sentido, a associação dos sistemas BIM e SIG representa recurso valioso para gestão de projetos aeroportuários, particularmente na INFRAERO.

A comparação entre os sistemas CAD bidimensionais e BIM na concepção de projetos da INFRAERO já foi objeto de estudo de dissertação de mestrado (RIBEIRO, 2009).

Foram verificadas diversas vantagens na adoção dos sistemas BIM na projetação aeroportuária, mais especificamente na INFRAERO.

Contudo, ainda não foram realizados quaisquer estudos que simulassem de fato todo processo de modelagem da construção associado ao fluxo organizacional dos processos de projeto da empresa.

A associação no processo de projeto entre os sistemas BIM e os SIG pode responder positivamente às deficiências em relação aos estágios iniciais de projeto. Permite integrar a participação dos profissionais de projeto e reunir informação, tanto geométrica, comportamental e relacional, quanto dos processos de projeto na estrutura organizacional das empresas deste setor.

Acreditamos que a associação entre os sistemas BIM, que exigem a especificação precisa das características dos componentes, com o ambiente de informações dinâmicas dos SIG, resolve significativamente a questão da rigidez presente no estágio inicial da elaboração de projeto por meio dos sistemas BIM. 


\section{5- OBJETIVOS}

\subsection{1- OBJETIVO GERAL}

O OBJETIVO GERAL desta tese é associar, em um PROJETO-PILOTO, ferramentas de modelagem e processamento da informação, por meio de uma MATRIZ SEMÂNTICA que possa fornecer suporte à INTEGRAÇÃO dos sistemas BIM e SIG, utilizando a representação dos PROCESSOS DE ELABORAÇÃO E APROVAÇÃO DE PROJETOS aeroportuários da INFRAERO como veículo de experimentação, de forma a contribuir para o aprimoramento do mesmo.

\subsection{2- OBJETIVOS ESPECÍFICOS}

1- Elaborar um sistema de representação de informações aeroportuárias por meio de uma MATRIZ SEMÂNTICA DE REGRAS DE ABSTRAÇÃO que represente as estruturas e processos de projeto e aprovação da INFRAERO;

2- Modelar oito COMPONENTES PARAMÉTRICOS AEROPORTUÁRIOS de acordo os padrões e normas brasileiras;

3- Modelar o terminal de passageiros regional da INFRAERO (Projeto-piloto) em sistema BIM e testar o emprego da BIBLIOTECA DE COMPONENTES em seus múltiplos NÍVEIS DE DETALHES;

4- Avaliar a utilização dos sistemas BIM e SIG, por meio da SIMULAÇÃO DE ALTERAÇÕES de projeto no desenvolvimento de ALTERNATIVAS, para a criação de uma TORRE DE CONTROLE (TWR) no Terminal de Passageiros Regional. 


\section{6- ESTRUTURA DE TESE}

\subsection{1- ESTA TESE FOI ESTRUTURADA EM CINCO CAPÍTULOS.}

No CAPÍTULO 1 é apresentado contexto, no qual a pesquisa se insere, PROBLEMÁTICA e HIPÓTESE, seus OBJETIVOS, bem como a ESTRUTURA da TESE.

O CAPÍTULO 2 contém REVISÃO BIBLIOGRÁFICA sobre os temas abordados, apresentando HISTÓRICO DOS SISTEMAS COMPUTACIONAIS e do PROCESSO de ELABORAÇÃO de PROJETO. Mais especificamente apresenta os CONCEITOS de PROJETO, REPRESENTAÇÃO, MODELAGEM GENÉRICA, PARAMETRIZAÇÃO, ONTOLOGIA e SEMÂNTICA e o uso dos SISTEMAS BIM - SIG no Brasil e no exterior.

NO CAPÍTULO 3 são explicitados os MÉTODOS DE INVESTIGAÇÃO e procedimentos utilizados nas diferentes ETAPAS DE PESQUISA: construção da MATRIZ SEMÂNTICA, modelagem dos COMPONENTES PARAMÉTRICOS, modelagem do TERMINAL REGIONAL DE PASSAGEIROS e SIMULAÇÃO de ALTERNATIVAS de PROJETO para uma TORRE DE CONTROLE.

NO CAPÍTULO 4 são apresentados os RESULTADOS obtidos durante a pesquisa bem como a discussão da APLICABILIDADE DOS MÉTODOS em eventual adoção dos sistemas BIM na INFRAERO.

NO CAPÍTULO 5 são apresentadas as CONCLUSÕES desta pesquisa, onde abordamos a ABRANGÊNCIA, RELEVÂNCIA e IMPACTO dos resultados obtidos e das potencialidades dos sistemas BIM e SIG, bem como em relação a PESQUISAS FUTURAS. 


\section{2- REVISÃO BIBLIOGRÁFICA}

O início do processo de projeto de arquitetura envolve alto grau de abstração. Este muitas vezes acontece por meio de esboços abstratos feitos pelo arquiteto ao concatenar ideias, relacionamentos e possíveis soluções de projeto, permitindo explorar melhor diversas alternativas.

Estes procedimentos abstratos não são possíveis nos sistemas BIM porque requerem definição antecipada de considerável quantidade de informação sobre os elementos construtivos. As informações relativas aos elementos construtivos podem ser definidas como parâmetros nos sistemas computacionais como explica BRIDGES em "The Challenge of Constraints".

Segundo esse autor, paralelamente à representação geométrica de um objeto, é possível controlar sua forma e seu relacionamento ou adjacência com outros objetos. Isto é feito por meio de coordenadas definidas como valores não constantes, em função de uma ou mais variáveis dos vetores da composição gráfica ou ainda em relação à proximidade e interdependência entre sua posição espacial e a dos outros componentes construtivos.

BRIDGES (2006) ainda estabelece diferenciação entre os objetos que perfazem a construção (componentes) e os espaços construídos (cômodos da edificação). Isto influencia na classificação e organização das informações e coordenadas geográficas dos objetos que compõem uma edificação e das funções que definem seus espaços. (BRIDGES, 2006, p.6-8)

Ainda que sistemas BIM, como o Revit $^{\circledR}$, ofereçam a possibilidade de trabalhar com objetos genéricos como os estudos de massa, isto não ocorre de forma integrada no ambiente de projeto e não possui a flexibilidade, nem oferece liberdade semântica e cognitiva necessárias a sistemas informatizados para este fim.

Esta pesquisa se fundamenta no pressuposto de que os sistemas BIM deveriam ser usados em todas as etapas de aprovação de projeto.

Portanto, torna-se importante entender que, nos diferentes estágios do processo de projeto, existem diferentes níveis de detalhes requeridos para cada componente construtivo. 
Podemos conceituar os sistemas BIM como tecnologia de modelagem tridimensional e paramétrica, que integra os componentes e informações sobre seus comportamentos, inter-relações, propriedades dos materiais, função estrutural, custos e etc. nos diversos processos de concepção, análise, documentação e comunicação referentes ao edifício.

Os sistemas BIM facilitam testes de soluções alternativas, alterações e atualizações em um modelo único, a partir do qual as informações necessárias nos vários momentos do projeto podem ser extraídas em suas várias formas relevantes: desenho técnico, modelo digital, tabelas de medições, mapas de vãos, etc. (CRESPO \& RUSCHEL, 2007, p. 4).

O "software" Revit ${ }^{\circledR}$ e outros sistemas BIM adotam métodos diferentes daqueles bidimensionais de projeto assistidos por computador, que se aproximam mais de uma extensão digital da prancheta e nesse sentido não passam de auxiliares de desenho. Um modelo baseado nos sistemas BIM é composto por "objetos" digitais que representam componentes construtivos, cujas propriedades são descritas como elementos físicos da construção.

A elaboração do modelo corresponde à construção real da edificação, parte por parte, transformando-se na representação virtual da mesma. Isto obriga o projetista a pensar, desde o início, em todo o processo construtivo, criando forte vínculo entre o projeto e a construção. Podemos observar o desenho como linguagem usada para a comunicação, durante a elaboração do projeto. Os desenhos representam a linguagem da arquitetura, através da expressão das ideias, da sua avaliação e do seu desenvolvimento, sendo fundamental na sua prática e representa a própria evolução do processo projetual, significando "o modo pelo qual o projeto é conduzido, testado, controlado, apresentado e, por último, realizado”. (ROBBINS, 1994, p. 315).

EDWARD ROBBINS (1994), relaciona a utilização dos desenhos com a transformação de sua prática ao longo da história. No mundo antigo, como nas culturas grega, romana e egípcia, foram encontradas evidências do emprego de desenhos na produção da arquitetura: plantas baseadas em malhas quadradas, imagens pictóricas dos edifícios e alguns croquis. Estes desenhos eram usados para dar instruções aos operários. Entretanto, fica claro que o "arquiteto" não tinha ferramentas que o permitissem se afastar do canteiro de obras ou que houvesse plano global onde a edificação como um todo já tivesse sido preconcebida. Essa evolução pode ser ilustrada por um desenho encontrado daquela época: a elevação feita por SANSEDONI e descoberta por FRANKLIN TOKER (ROBBINS, E. 1994 p.10 a 20). 


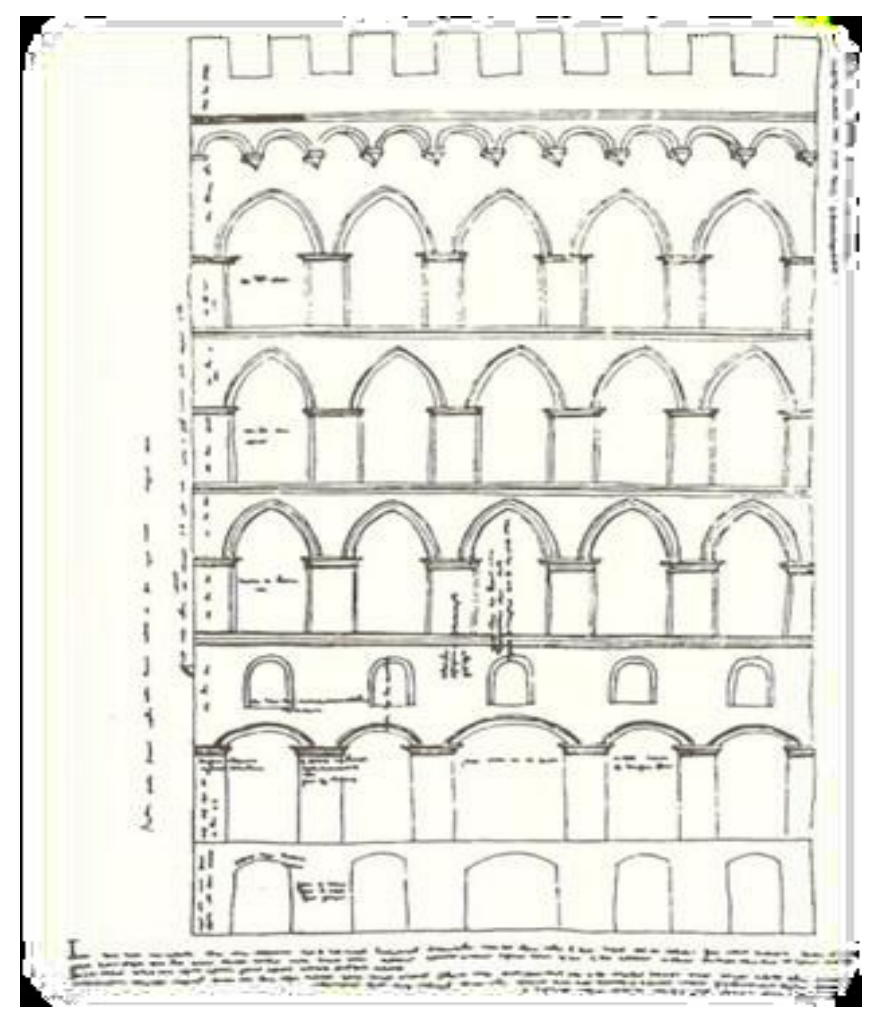

Figura 2- Desenho feito por SANSEDONI no período Gótico]. Fonte: ROBBINS, E, 1944, p.14.

Embora ainda incipiente quanto ao desenvolvimento da técnica de desenho, é muito significante, para um novo modo de se pensar a pratica profissional, até então conhecido como mestre construtor, e possibilitou o redirecionamento e remodelamento das profissões. Primeiro, porque se assemelha muito ao desenho a que estamos hoje habituados: um desenho ortogonal, feito em escala, acompanhado de anotações escritas para guiar a execução (ROBBINS, E. 1994 p.10 a 20).

\footnotetext{
"Reflete uma necessidade de mudança na maneira de pensar a prática profissional e anuncia, ainda que de modo muito elementar, uma introdução de novos valores na arquitetura como: a noção de autoria, a distinção entre o trabalho intelectual e o manual, e a função da representação como forma de simular o prédio antes de sua construção." (BATISTA, L. 2010, p.17).
}

ROBBINS (1997) destaca que o gradual desenvolvimento das representações bidimensionais tinha como objetivo possibilitar ao arquiteto progressivamente se distanciar do canteiro de obras a fim de desenvolver mais de um projeto simultaneamente (ROBBINS, 1997, p. 15). A arquitetura vive do espaço, porque o utiliza como material, e nos coloca no seu centro delimitando e destacando espaços para viver, percorrer e sentir (ZEVI apud STEELE 2001, p. 144). ZEVI (1996) apresenta um novo conceito de arquitetura: a arquitetura é a arte do espaço. Criou uma nova terminologia ou teoria arquitetônica centrada no espaço, a qual afirma que o valor original da arquitetura é o do espaço interior. 


\section{Conforme afirma ZEVI (1996):}

“... a mente humana descobriu que, além das três dimensões da perspectiva, existia uma quarta... O pintor parisiense de 1912 fez o seguinte raciocínio: eu vejo e represento um objeto, por exemplo... uma mesa; vejo-o de um ponto de vista e faço o seu retrato nas suas três dimensões a partir desse ponto de vista. Mas se... caminhar ao redor da mesa, a cada passo mudo o meu ponto de vista, e para representar o objeto desse ponto de vista devo fazer uma nova perspectiva. Consequentemente, a realidade do objeto não se esgota nas três dimensões da perspectiva; para possuíla integralmente eu deveria fazer um número infinito de perspectivas dos infinitos pontos de vista. Existe, pois, outro elemento além das três dimensões tradicionais, e é precisamente o deslocamento sucessivo do ângulo visual. Assim designou-se o tempo, 'quarta dimensão'." (ZEVI, 1996, p. 20-22).

A importância da quarta dimensão torna a representação do modelo fluida e amplifica o entendimento espacial. Nos sistemas computacionais modernos a simulação não apenas da geometria do modelo, mas ainda do contexto em que o mesmo deve ser inserido e dos processos de construção adicionam à compreensão espacial noções sobre as variáveis relevantes ao projeto de arquitetura. Os outros elementos funcionais, técnicos e artísticos podem ajudar a apreciar o edifício, em função da maneira como acompanham, acentuam ou obstam o seu valor espacial. Daqui resulta que a interpretação espacial da arquitetura não exclui as demais interpretações: a interpretação espacial constitui o atributo necessário de toda interpretação possível dotada de sentido concreto, profundo e compreensivo em matéria de obra arquitetônica.

ZEVI (1996) abordou a lacuna entre a representação do espaço arquitetônico e o entendimento real de como o espaço se distribui em uma edificação, uma vez que as plantas, fachadas e elevações de um edifício correspondem a projeções abstratas justificadas pela necessidade de medir as distâncias entre os diversos elementos da edificação, ou seja, larguras, alturas e comprimentos, permitindo que os operários executem a obra. Por outro lado, ZEVI (1996) defende que a arquitetura provém dos espaços encerrados, do vazio e do espaço interior em que os homens andam e vivem. Cita como exemplo a planimetria feita por MICHELANGELO BUONARROTI, da Basílica de São Pedro, em Roma. Olhando a planta, nenhuma pessoa de bom senso poderá dizer que esta é a melhor representação da concepção espacial de BUONARROTI para um jovem que se inicia no estudo da arquitetura. Na planta, existe uma ostentação de detalhes, que confunde neste primeiro momento crítico, em que todo o esforço é dedicado à ilustração da essência espacial da arquitetura. 


\section{1- HISTÓRICO DOS SISTEMAS COMPUTACIONAIS E PROCESSO DE PROJETO}

Nos últimos anos, o universo da arquitetura tem experimentado o impacto da informática nos seus métodos e procedimentos de projeto. CROSS (1994) considera que a origem dos novos métodos de projetação surgidos nos anos 50 e 60 se deve à aplicação de métodos científicos para a solução de problemas surgidos principalmente com a $2^{\text {a }}$ Guerra Mundial, decorrentes do desenvolvimento de técnicas mais criativas na década de 50. Pode-se também atribuir o desenvolvimento da projetação ao incremento e à complexidade dos produtos e dos processos de manufatura e de construção. $O$ próprio

CROSS (1984) acrescenta: "Deve-se fazer distinção crítica: método pode ser vital para ciência (onde ele valida os resultados), mas não no projeto (onde resultados não têm que ser repetidos)" (CROSS, 1984, apud OLIVEIRA, 2001, p.31-39). CROSS considera como importantes constituintes da ciência projetual: conhecimento aplicado das ciências naturais e humanas; teoria dos sistemas técnicos; teoria dos processos de projetação e metodologias de projetação (CROSS, 1984, apud OLIVEIRA, 2001, p.3139).

SIMON (1996) ainda registra a existência de um número de componentes de uma Teoria da Projetação e um corpo substancial de conhecimento teórico e empírico, que possibilitaria colocá-la ao lado das ciências naturais nos currículos dos cursos de Engenharia. O problema para os arquitetos é conceber e planejar o que não existe; como escreveu Simon: "a atividade de projeto está interessada em como as coisas poderiam ser", ao passo que as ciências naturais estão preocupadas em investigar como as coisas são.

Pesquisando a classe de tarefas de resolução de problemas mal estruturados, como os de processo de projeto de arquitetura. Todo o esforço de resolução de problemas deve começar com a criação de uma representação para o problema de um espaço do problema em que a busca para a solução pode ter lugar. Claro que, para a maioria dos problemas que encontramos na nossa vida pessoal diária ou profissional, tentamos recuperar, a partir da memória, uma representação que nós já temos armazenada e tenha sido utilizada em ocasiões anteriores, mesmo que se tenha que adaptar a representação para a nova situação, o que é geralmente uma questão simples. Um "software" de detecção precoce de soluções ou "padrões", desenvolvido em 1963, realizou a série de tarefas para uma sequência "ABMCDMEFM," devendo ser capaz de responder qual o grupo de letras deveria vir a seguir. A resposta correta é "GHMIJM", pois o padrão identificado significa que toda terceira letra é M. A primeira letra de cada tríade é a próxima no alfabeto para a segunda letra na tríade anterior, e a 
segunda letra na tríade é a próxima no alfabeto para a primeira. A resposta é uma extrapolação do padrão identificado. A ideia central de se utilizar um gerador de hipótese para procurar padrões em dados e sua utilização em indicadores de padrão, como exemplificado, para orientar a busca de forma heurística (SIMON, 1996, p.108 e 109).

O processo de concepção de projeto compreende atividades de análise, síntese, previsão, avaliação e decisão. O projeto arquitetônico faz parte da família de processos de decisão. O processo de decisão em projeto pode utilizar a descrição verbal, gráfica ou simbólica (isto é, vários mecanismos de informação) para antecipar analiticamente um modelo e seu comportamento (ROSSO, 1980 apud KOWALTOWSKI, D. C. C. K. et al. 2006, p.8).

Podem-se ainda considerar as principais fases do modelo geral da tomada de decisão de LANG (2006), que, traduzidas pela prática profissional dos projetistas, dividem-se em programa, projeto, avaliação e decisão, construção e avaliação pósocupação. Em cada fase, pode ser realizada uma série de atividades, conforme afirma LANG (Figura 3):

1- IDENTIFICAÇÃO DO PROBLEMA - Identificação do programa de necessidades;

2- IDEIAS PRELIMINARES - Após a natureza do problema ter sido identificada, a fase seguinte é a geração do maior número possível de ideias, por exemplo através de sessões "brainstorming";

3- REFINAMENTO DO PROCESSO - Algumas boas ideias são refinadas, utilizando desenhos em escala para determinar méritos, em termos de requisitos espaciais, medidas críticas, dimensões, etc. Uma especificação pormenorizada do produto a ser concebido. Inclui características físicas, funcionais, custos, qualidade e desempenho;

4- PROCESSO DE ANÁLISE - Avaliação dos melhores projetos, segundo os pontos de vista dos critérios, tais como custos e requisitos funcionais;

5- PROCESSO DE DECISÃO - Escolha do projeto que possui todas as características desejáveis (Figura 3 - Processo de Concepção de Projeto);

6- PROCESSO DE IMPLEMENTAÇÃO - Consiste essencialmente na fase de desenvolvimento detalhado de projeto. As especificações detalhadas de materiais, dimensões, tolerâncias e características da superfície devem ser fornecidas. A ideia é efetuar os desenhos a serem utilizados no desenvolvimento dos planos de processo, para que o produto possa ser fabricado. O uso do computador na projetação modificou a prática de arquitetos e engenheiros (LANG apud KOWALTOWSKI, 2006, p. 8). 


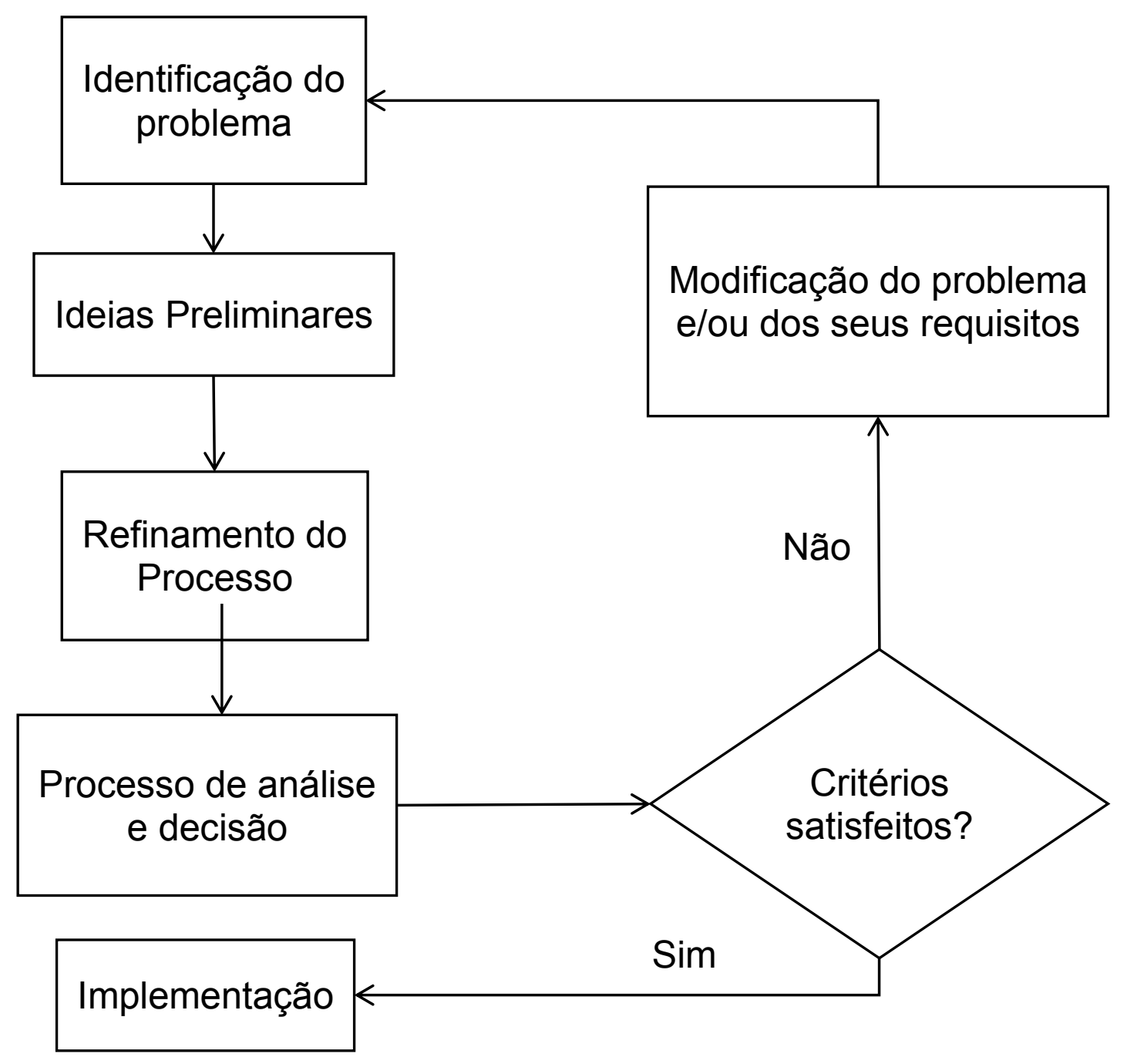

Figura 3- Processo de Concepção de Projeto. Fonte: (adaptado de LANG, 1974).

O uso do computador no processo de projeto foi gradualmente sendo adotado juntamente com a evolução tecnológica dos "softwares" e "hardwares". Inicialmente os computadores serviram para auxiliar e automatizar a representação gráfica e mais adiante contribuíram no próprio processo de projeto, por meio de ambientes virtuais de simulação e de análise de dados espaciais e contextuais, em relação ao entorno imediato.

O conceito de CAD nasce na década de 50: o Exército norte americano desenvolve os primeiros "Plotters", capazes de representar desenhos por intermédio de computador (ALMEIDA, G; 2012, p. 3).

O primeiro sistema de computação gráfica, denominado "Sketchpad", foi criado por IVAN SUTHERLAND, em 1963, no "Massachusets Institute of Technology". SUTHERLAND (2003), elaborou um "Sketchpad" computadorizado em sua tese de doutorado, no MIT. Ele criou um sistema CAD bidimensional com o intuito de substituir o desenho manual em prancheta. (SUTHERLAND, 2003, p.17-18). 
A introdução do computador no processo de projeto teve início por meio do estudo das interações funcionais entre espaços e atividades. Isto ocorreu no início dos anos 60, a partir das teorias desenvolvidas por diversos estudiosos de metodologia de projeto. ALEXANDER e JONES (1963) foram os que mais se notabilizaram. Foi JONES, em 1963, quem primeiro propôs a divisão do processo de projeto em três etapas distintas: 1- Análise - levantamento de dados para o programa; 2- Síntese - geração de soluções; e 3- Avaliação - escolha entre as alternativas geradas. JONES (1963) tinha dois principais objetivos, o de reduzir erros e modificações projetuais, e o de gerar projetos mais imaginativos (JONES apud MALARD, M; 2003, p. 4).

A teoria de JONES (1963) foi adotada por pesquisadores do campo da computação, que nela viram a oportunidade de construir sistemas computacionais com papel relevante no processo de projeto. Estes autores acreditavam que se o projeto podia ser pensado em três etapas separadas, então o computador seria uma ferramenta ideal. Os dados levantados na etapa de análise alimentariam o computador, que os processaria, gerando soluções alternativas (síntese).

O computador poderia, inclusive, prover informações sobre a eficiência do projeto em face do programa de necessidades (avaliação). Os projetos desenvolvidos por meio do sistema $C A D$, até o início dos anos 80, eram concebidos bidimensionalmente. A partir da segunda metade dos anos 80 , começam a surgir os primeiros modelos em matemática volumétrica tridimensional. A comercialização em larga escala de sistemas CAD teve início na década de 80 em decorrência do surgimento dos "PC's - Personal Computers", ou em português, "Computadores de Uso Pessoal" (JONES apud MALARD, M; 2003, p. 5).

Até o início dos anos 80, a computação gráfica era um campo pequeno e especializado, principalmente devido ao alto custo dos equipamentos e à escassez de programas gráficos fáceis de utilizar e com preços acessíveis. No início da utilização dos sistemas CAD, foi observado substancial avanço em termos de produtividade e de capacidade de edição. A representação digital de grande parte dos projetos forçou os desenhistas e projetistas a se adequarem a essa nova tecnologia, mas isto só ocorreu a partir de meados da década de 90. No entanto, os sistemas CAD da época não eram inovadores devido à grande similaridade com os procedimentos do processo manual. Em 1982, surgiu o AutoCAD ${ }^{\circledR}$, um sistema bidimensional, que trazia na sua concepção os princípios dos desenhos realizados em pranchetas. Apesar da popularidade que alcançou, este sistema apresentava limitações e não atendia convenientemente às necessidades dos projetistas (BOGADO, 2006, apud FOGGIATTO, J; VOLPATO, N; BONTORIN, A. p. 2). 
De acordo com GERO (2002) desde os anos 60, tem havido duas linhas principais de desenvolvimento do CAD: a primeira voltada apenas para a representação geométrica e topológica de objetos projetados e a segunda voltada para a representação e uso do conhecimento como forma de auxiliar a síntese do projeto. Enquanto a primeira é mais difundida e alcança o grande público, a segunda abordagem tem sido usualmente restrita a aplicações específicas e experimentais, o que inclui implementações de sistemas generativos e os chamados "knowledge-based systems" ou sistemas especialistas. Mais recentemente, contudo, tem havido convergência desses dois objetivos, e têm surgido alguns sistemas CAD, que além de permitirem a representação em todas as etapas do projeto, propõem-se também a colaborar no processo projetual (GERO, 1994, apud CELANI, 2002, p.30).

Ao falar sobre o uso CAD no processo de projeto em seu artigo "The theoretical foundation of computer-aided architectural design", MITCHELL discute como pode ser feita a divisão de tarefas entre o arquiteto e o computador, de acordo com um determinado grau de ambição do uso da máquina, e como esta distribuição pode contribuir para a automação do processo de projeto. Para ele o uso menos ambicioso do computador consiste em dar-lhe apenas funções de representação, deixando a responsabilidade pela geração e avaliação de soluções com o projetista (MITCHELL, 1975, p.134).

MITCHELL (1975) destaca que o computador pode receber a função de avaliar as soluções produzidas pelos projetistas, como atualmente acontece, por exemplo, nos sistemas de avaliação de conforto ambiental. A etapa seguinte consiste na geração de alternativas pelo computador e sua avaliação por projetistas humanos. O nível seguinte consistiria na geração e avaliação de alternativas pelo computador. No entanto, para que a avaliação e/ou a geração sejam feitas pelo computador, é preciso que o projetista estabeleça inicialmente critérios muito bem definidos para essas tarefas (MITCHELL, 1975, p.135). Segundo MITCHELL (1975), o uso mais ambicioso do computador consistiria na tentativa de utilizá-lo na solução inteligente de problemas não estruturados, possibilidade que dependeria de técnicas avançadas de inteligência artificial (MITCHELL, 1975, p.135). LAWSON (1997) ainda destaca o uso de sistemas especialistas (SE) como forma de ajudar os arquitetos na resolução de alguns dos problemas de projetos. $\mathrm{O}$ intuito principal desses sistemas consiste em reproduzir $\mathrm{O}$ comportamento de especialistas humanos na resolução de problemas em determinado domínio. Mas, como essa atividade geralmente envolve tarefas complexas de aprendizado e recuperação de dados, a estrutura básica de um SE é constituída por uma base de regras, memória de trabalho e motor de inferência (Figura 4) (LAWSON, 1997, apud CELANI, p.5). 


\section{Base de conhecimento}

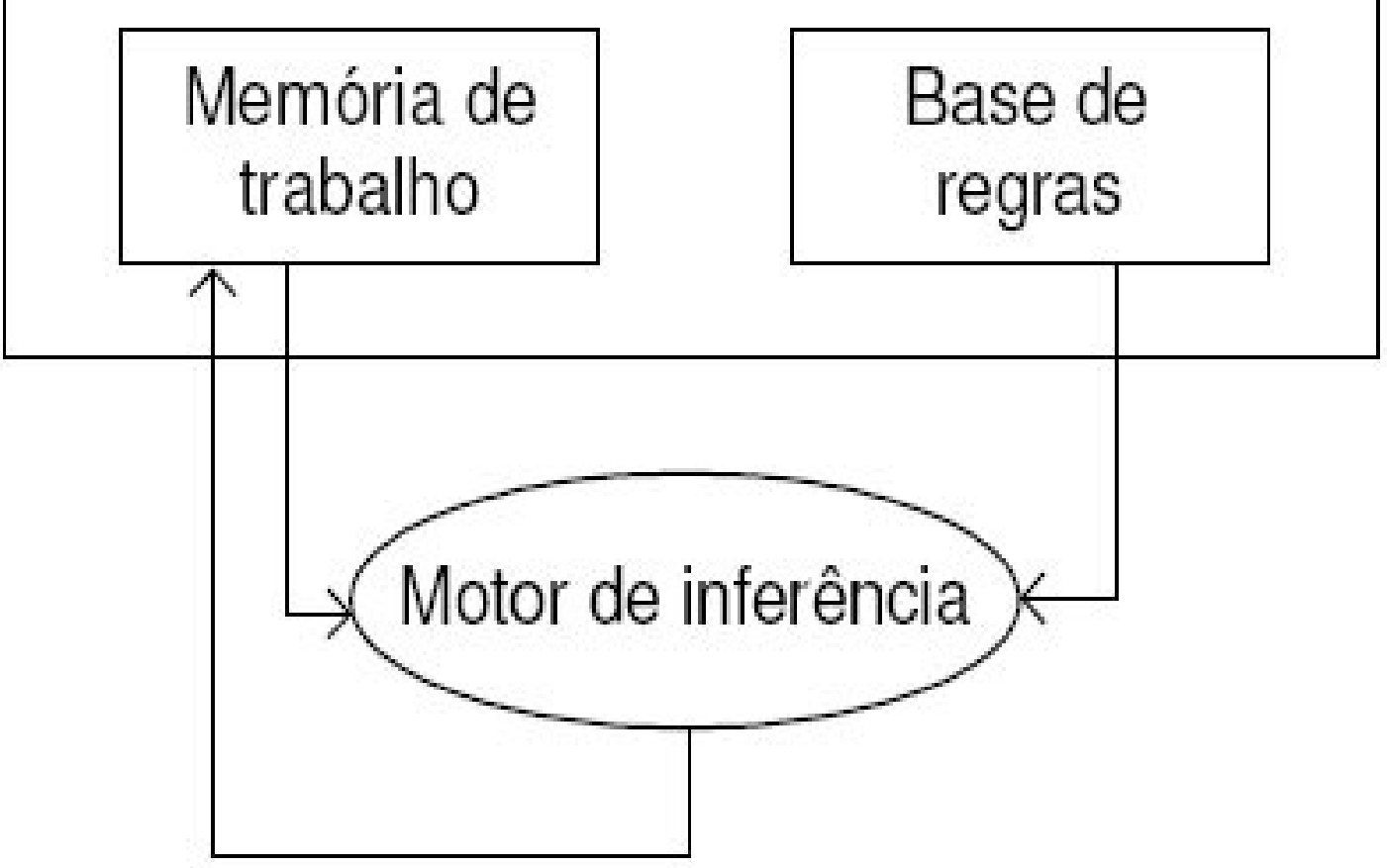

Figura 4- Base de conhecimento. Fonte: adaptado de BITTENCOURT (2001).

BITTENCOURT (2001) em seu livro "Inteligência Artificial", define a memória de trabalho e a base de regras como requisitos fundamentais para o funcionamento do SE. É na memória de trabalho que as informações sobre um determinado assunto são armazenadas, no momento de sua atividade. Através da base de regras existentes no sistema é que são realizados os questionamentos sobre a representação do conhecimento da memória de trabalho. O motor de inferência é o responsável por avaliar e aplicar as regras de acordo com as informações da memória de trabalho. Este novo paradigma computacional não é apenas uma possível tendência futura, mas realidade presente na maior parte das indústrias de engenharia e construção, além de escritórios de vários projetistas (Figura 4) (BITTENCOURT, 2001 apud CELANI, G., 2007, p. 5).

Os avanços no processo de projeto vão aos poucos incorporando a tecnologia computacional disponível e, em particular, a INFRAERO pode se beneficiar do uso dos sistemas BIM que representa ganhos na representação do conhecimento associado aos componentes paramétricos. Isto pode representar não apenas melhor uso da informação como também retenção desse conhecimento na empresa. Um outro fator reside na possibilidade de integração das informações em um processo em que os profissionais trabalhem de forma simultânea. Acreditamos que é necessário e possível substituir o processo de projeto manual e bidimensional, fragmentado, por um integrado, que trará benefícios substanciais à qualidade do mesmo e da edificação final. 
$\mathrm{Na}$ indústria da construção civil, como nas demais indústrias, o processo de desenvolvimento do produto (PDP) envolve o conjunto de atividades, com vistas à concepção, produção e comercialização. Especificamente no subsetor de edificações, no qual o produto é o edifício, seu desenvolvimento é um processo interdisciplinar, pois conta com a participação de vários agentes com diferentes formações técnicas. Nesse processo destacam-se, em especial, três funções: de marketing (interação entre empresa e clientes); de projeto (definição da forma física do produto) e de produção (gestão do processo de produção) (ULRICH; EPPINGER, 1995, apud JACQUES, 2001, p. 8 - 9).

Atualmente tornou-se inconcebível imaginar o projeto de edifícios sem o uso de computadores, que são utilizados a cada passo do processo de projeto de arquitetura, desde a etapa conceptual até os processos de construção civil. Modelagem tridimensional, visualização amplificada dos modelos, modulação de sistemas estruturais, gestão e coordenação de projeto são atualmente possíveis em razão do uso de práticas digitais.

A fabricação digital é com frequência um dos estágios finais do processo de projeto, utilizando dados digitais para o controle do processo de manufatura. Os sistemas CAD / CAM funcionam por meio de rotinas de computadores dirigindo máquina e ferramentas de corte de peças, tendo sido pioneiramente adotado pelos setores automotivo e aeroespacial a mais de meio século. Em período de tempo relativamente baixo, uma rede de atividades tem crescido em torno da digital fabricação a partir aplicações específicas de projeto e de construção civil (IWAMOTO, L., 2009, p. 5 e 6).

KALISPERIS (1996) faz referência à citação de MITCHELL, abaixo (PUPO, R., apud KALISPERIS, L; 2007, p. 3).

"A integração do computador no projeto de arquitetura e na fabricação e construção ... fundamentalmente redefine a relação entre projetar e produzir. Elimina muitas restrições geométricas impostas pelos métodos tradicionais de desenho e produção. Ela também elimina a lacuna que se abriu entre o desenho e a produção quando os arquitetos começaram a desenhar".

KALISPERIS (1996) afirma que o uso do computador nas atividades de projeto faz muito mais do que apenas otimizar tarefas repetitivas de representação gráfica, podendo auxiliar a encontrar soluções inovadoras através da exploração de um número maior de alternativas, em um processo de projeto holístico, ou seja, levando em consideração o todo, suas partes e inter-relações (KALISPERIS, 1996, p. 22). 


\section{2- PROCESSOS SEQUENCIAIS DE PROJETO}

O processo de projeto envolve todas as decisões, com o objetivo de subsidiar a criação e a produção de um ou mais edifícios, partindo de estudos do sítio, passando pela formulação do programa de necessidades, concepção e desenvolvimento do projeto até o planejamento da fabricação e construção, o projeto "as-built" e a avaliação da satisfação dos usuários (FABRÍCIO, 2002, apud SCHEER e AZUMA, 2009, p. 2-3), conforme abaixo:

1- CONCEPÇÃO DO PROJETO E DESENVOLVIMENTO DO PROGRAMA: abrange a tomada de decisão, seleção do terreno, recursos disponíveis e especificações desejadas;

2- PROJETOS: envolve desde a concepção e detalhamento, em particular, os projetos de arquitetura, estruturas, instalações elétricas e hidráulicas, etc.;

3- ORÇAMENTAÇÃO: estimativa de custos;

4- PROJETOS DE FABRICAÇÃO E CONSTRUÇÃO: seleção de tecnologia construtiva (considerando que diferentes partes podem requerer diferentes tecnologias), procedimentos de trabalho e recursos materiais necessários para a execução;

5- PLANEJAMENTO DE OBRA: acompanhamento do cronograma e do fluxo de caixa;

6- PROJETO “AS-BUILT”: acompanhamento da obra e atualização dos projetos;

7- SERVIÇOS ASSOCIADOS: acompanhamento de obra (projetistas), assistência técnica e análises pós-ocupação.

No processo de projeto manual, essas atividades acontecem de modo sequencial. No entanto, o processo de projeto manual e incremental é ineficiente. $O$ modo sequencial é problemático, pois acarreta perda e repetição da informação, além de um longo tempo de duração, uma vez que uma mudança no projeto precisa ser primeiro feita e depois transmitida para o próximo profissional para atualizações (MARSHALL- PONTING \& AOUAD, 2005, apud SCHEER, S. e AZUMA, F. 2009, p. 23).

O desenvolvimento sequencial do projeto se dá a partir da sucessão de diferentes etapas de projeto em níveis crescentes de detalhamento de forma, onde a liberdade de decisões entre as alternativas vai sendo substituída pelo amadurecimento e desenvolvimento das soluções adotadas. Portanto, o projeto caminha da concepção arquitetônica para o detalhamento dos projetos de especialidades. Assim, é comum, para ser iniciada uma etapa de projeto de determinada especialidade, que dependa do término de uma etapa de diferente especialidade, cujo grau de aprofundamento e amadurecimento das decisões é equivalente ao da etapa que se inicia (da outra especialidade). 
OS PROBLEMAS NO MODO SEQUENCIAL SÃO LISTADOS ABAIXO.

1- RELACIONAMENTO INEFICIENTE ENTRE CLIENTE E CONSUMIDOR ocorre devido à falta da participação de outros departamentos envolvidos (BRÖDNER, 1996 apud MARSHALL-PONTING \& AOUAD, 2005, apud SCHEER, e AZUMA, 2009, p. 2-3);

2- FALTA DE COMPETITIVIDADE EM RELAÇÃO AOS CUSTOS E QUALIDADE (WOMACK et al., 1990, apud SCHEER, e AZUMA, 2009, p. 2-3);

3- FALTA DE ATENDIMENTO A OUTROS FATORES ALÉM DAQUELES DA PRODUÇÃO, marketing e outros serviços que agregam valor à cadeia de desenvolvimento do produto (SYAN \& MENNON, 1994, apud SCHEER, e AZUMA, 2009, p .2-3);

4- TRABALHO REDUNDANTE E REPLICANTE NAS DIFERENTES INTERFACES ENTRE DEPARTAMENTOS (MULLER, 1987, apud SCHEER, e AZUMA, 2009, p. 2-3);

5- desenvolvimento lento do PROduto E dO PROCESSO DE IMPLANTAÇÃO (BUGGERT \& WEILPUETZ, 1995, apud SCHEER, e AZUMA, 2009, p. 2-3).

\section{VEERAMANI ET AL, ACRESCENTA OUTROS FATORES NESSE CENÁRIO:}

1- PROBLEMAS DE PROJETO DE INSTALAÇÕES conhecidos apenas na fase de construção, implicam em modificações durante a etapa de execução, afetam não apenas a produtividade bem como os custos e prazos do projeto (VEERAMANI et al., apud SCHEER, S. e AZUMA, F. 2009, p. 3);

2- MENOR FLEXIBILIDADE, resultando em possibilidades de mudanças abaixo do ideal para superar problemas de construção, por exemplo: uma edificação típica consiste em diferentes tipos de subsistemas (estrutural, elétrico, hidráulico, arcondicionado, etc.), que necessitam ser adaptados ao espaço disponível. Devido à complexidade de cada subsistema, o projeto é realizado por grupos separados de pessoas. No processo tradicional, podem ocorrer conflitos de espaço ou dificuldades de configuração. Devido ao fato de que atrasos no projeto de construção implicam em custos adicionais, na tentativa de evitá-los decide-se fazer modificações nos locais da obra. Essa solução pode resolver problemas imediatos de construção. No entanto, a longo prazo, podem ocorrer problemas de manutenção e acessibilidade (VEERAMANI et al., apud SCHEER, S. e AZUMA, F. 2009, p. 3). 


\section{3- PROCESSOS DE PROJETO SIMULTÂNEOS}

Engenharia simultânea pode ser definida como o processo no qual grupos interdepartamentais trabalham de modo interativo e formal no projeto do ciclo de vida completo do produto ou serviço, com o objetivo de encontrar e realizar a melhor combinação entre as metas de qualidade, custo e prazo (FABRÍCIO, 2002, apud SCHEER, S. e AZUMA, F. 2009, p. 3). Uma das principais vantagens da engenharia simultânea é uma maior redução das incertezas no processo de projeto (KOSKELA, 1994, HUOVILA, 1997, apud FABRÍCIO, 2002, p.143 60).

A superioridade dos resultados atingidos com o desenvolvimento de produtos por meio da engenharia simultânea, comparada com o processo sequencial, pode ser mostrada esquematicamente por meio da figura abaixo adaptada de KRUGLIANSKAS, no qual as curvas representam o tempo de desenvolvimento e as áreas sob as curvas representam o custo do projeto ao longo do tempo. (KRUGLIANSKAS, 1995, apud FABRÍCIO, 2002, p.167-168.) (Figura 5).

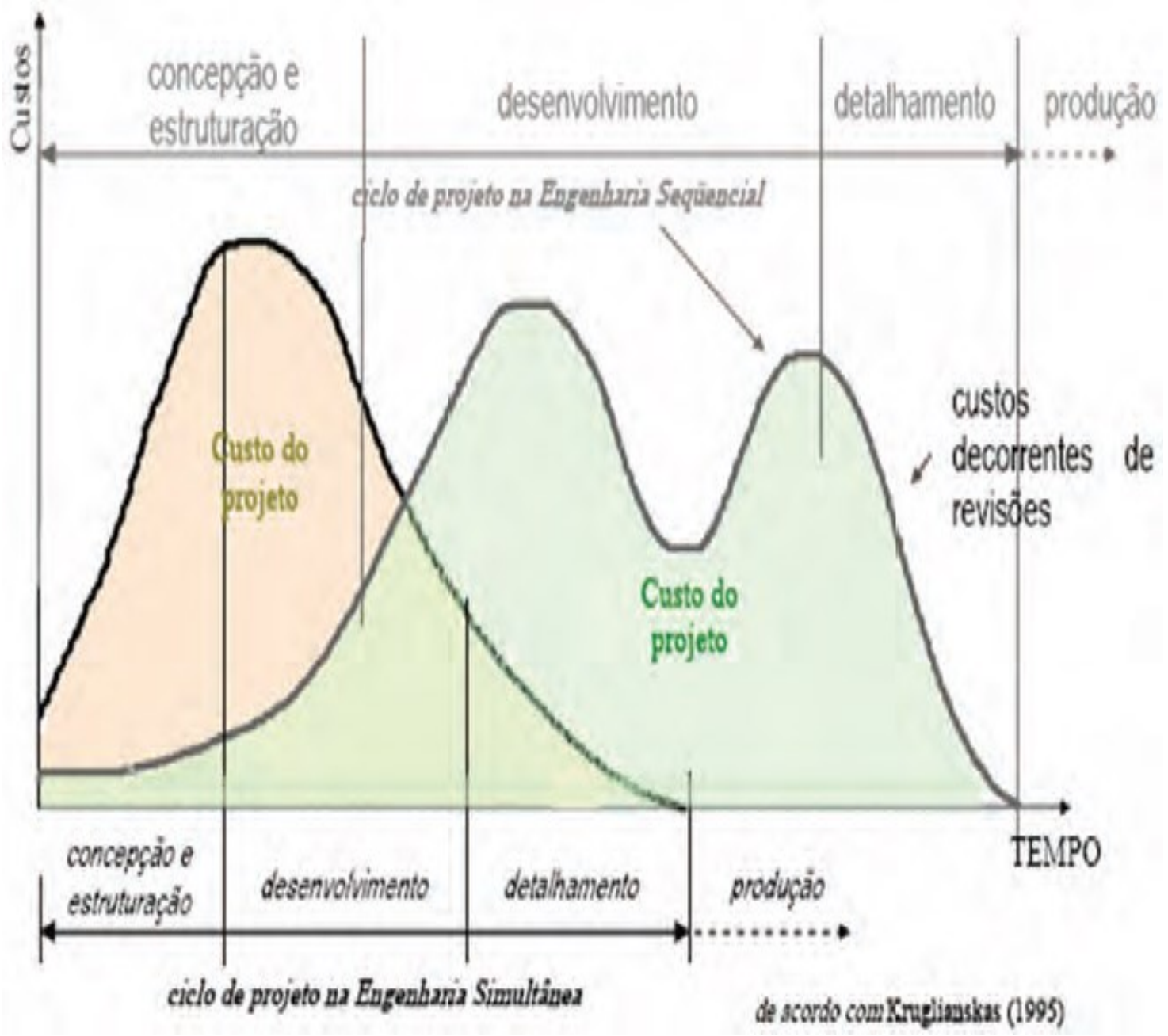

Figura 5- Comparação do desenvolvimento de produto em engenharia sequencial e em engenharia simultânea. Fonte: Adaptado de KRUGLIANSKAS,1995, apud FABRíCIO, 2002. 
Analisando a Figura 5, na página anterior, é possível verificar que a maior parte das decisões nos projetos feitos por meio da engenharia simultânea concentra-se nos primeiros meses. Em contrapartida, na engenharia sequencial, além das decisões, grande número de revisões e modificações na fase de detalhamento ocorre mais tarde, às vezes após o término da construção. Isso significa que alterações nas fases tardias do processo de projeto envolvem custos elevados e necessidade de revisões da documentação existente. Os resultados desta comparação reforçam a ideia de que as decisões de projeto e das diversas engenharias devem ser realizadas nas primeiras fases dos projetos conforme ocorre nos casos da engenharia simultânea (KRUGLIANSKAS, 1995, apud FABRÍCIO, 2002, p.167-168).

Por meio dos sistemas BIM torna-se possível, nos estágios iniciais, a gestão simultânea e pormenorizada da informação de projeto. Devido ao fato de que os sistemas BIM utilizam componentes (objetos) paramétricos, permitem a qualquer momento a extração automática da documentação gráfica e descritiva, orçamentação inteligente ao longo do processo de projeto e ainda a possibilidade de verificação de interferências e inconsistências entre os diversos projetos complementares, tais como Elétricos, Hidrossanitários, Eletromecânicos, etc.

Destaca-se ainda a representação efetiva do conhecimento específico de cada especialidade no processo conceptivo e de soluções técnicas de engenharia. Esta nova forma de trabalho pode permitir, com o amparo da tecnologia e de legislação específica, que engenheiros e arquitetos consigam efetivamente realizar trabalho colaborativo, na busca de soluções mais consistentes para o projeto em foco. Isto representa ganho de tempo, uma vez que no processo tradicional os projetos complementares ocorrem por meio de etapas isoladas subsequentes ao estudo conceptivo.

Por meio dos sistemas BIM as informações dos profissionais envolvidos podem ser confrontadas entre si permitindo ajustes ou mesmo novas soluções. O modelo de coordenação sofre modificações no processo de engenharia simultânea. As equipes que trabalham com partes diferentes e detalhamento do projeto, atualizam os arquivos com suas adições e alterações, os quais são atualizados na área determinada ("Workset"). O "Workset" ou plano de trabalho de cada profissional na referida equipe permite que cada um trabalhe com partes diferentes do projeto. "Worksets" são grupos do projeto criados e definidos como módulos independentes, que podem ser manipulados simultaneamente no projeto. Ao criar um "Workset", define-se a estrutura de trabalho da equipe de projeto e compara-se ao "layer" do sistema CAD. Por exemplo, existe um arquivo central, composto por todas as especificações de projeto, bem como com os projetos complementares. 
Porém, cada membro da equipe é responsável por partes específicas do projeto (estrutura, arquitetura, "tag's", cotas). Quem determina quais serão os planos de trabalho do projeto e qual membro da equipe trabalhará em cada um deles é o "Gerente BIM", responsável pela atualização do "Arquivo Central de Informação". Cada membro acessará seu "Workset" por meio de um usuário e uma senha, individual. Ao trabalhar e fazer as alterações e complementações, cada membro atualiza suas alterações no "Arquivo Central". Quando um membro da equipe alterar alguma característica de plano de trabalho não permitida, esta será arquivada. Porém, somente o "Gerente BIM" pode permitir ou não a atualização do "Arquivo Central". (ANDRADE e AMORIM, 2011, p. 794).

OS SEGUINTES PASSOS PODEM AJUDAR NA IMPLANTAÇÃO DOS SISTEMAS BIM:

1- COMPROMETIMENTO DA ALTA ADMINISTRAÇÃO da empresa com o projeto-piloto, entendendo seus benefícios e apoiando efetivamente o programa e a equipe responsável;

2- DEFINIÇÃO DAS EQUIPES E PARTES ENVOLVIDAS ("Stakeholders") e das suas respectivas responsabilidades;

3- ELABORAÇÃO DE PLANO DE AÇÃO para o foco desejado e estimativa de custos e recursos necessários para a efetivação do programa, ampliando a adoção dos sistemas BIM em outros empreendimentos visando consolidar a cultura BIM e promover melhoria contínua e validação;

4- SELEÇÃO DOS "SOFTWARES” e bibliotecas e hardwares (TI) a serem utilizados;

5- CAPACITAÇÃO E TREINAMENTO das equipes envolvidas;

6- IMPLANTAÇÃO DO PLANO DE AÇÃO e desenvolvimento dos projetos e modelagens;

7- MONITORAMENTO DOS RESULTADOS, identificação de desvios e implantação de ações corretivas e preventivas (ciclo PDCA);

8- AVALIAÇÃO DOS RESULTADOS via indicadores objetivos e mensuráveis;

9- APRESENTAÇÃO DOS RESULTADOS do projeto-piloto para a alta administração (TSE e WONG, 2005 p. 85-102). 
O papel do gerente de projeto (BIM) tende a se tornar mais significante na liderança de equipes de projeto, para colaborar e explorar o projeto integrado e as soluções construtivas. A utilização de "software" tipo BIM permite o gerenciamento de projeto a partir de "workflow", que permite diversas vantagens para o controle, tais como:

1- "Redução da necessidade da interação humana, o papel é substituído por formulários em meios digitais;

2- Aumento do controle sobre o processo de projeto, uma vez que é fácil observar qual personagem da equipe não cumpriu sua função no prazo estabelecido;

3- Diminuição no tempo de gerenciamento e de trabalho, uma vez que todas as atividades realizadas por meio digital são repassadas através do gerente de projetos para os demais membros da equipe por meio de arquivo central;

4- Individualização do tratamento das questões pertinentes ao projeto, uma vez que cada atividade é direcionada a um membro específico ('Workset')" (TSE e WONG, 2005, p. 85-102).

As Figuras 6 e 7 apresentadas por SANTOS (2008), no VIII Workshop Brasileiro do Processo de Projetos na Construção de Edifícios, diagramam de forma facilitada o processo de projeto nos dois tipos de "software":

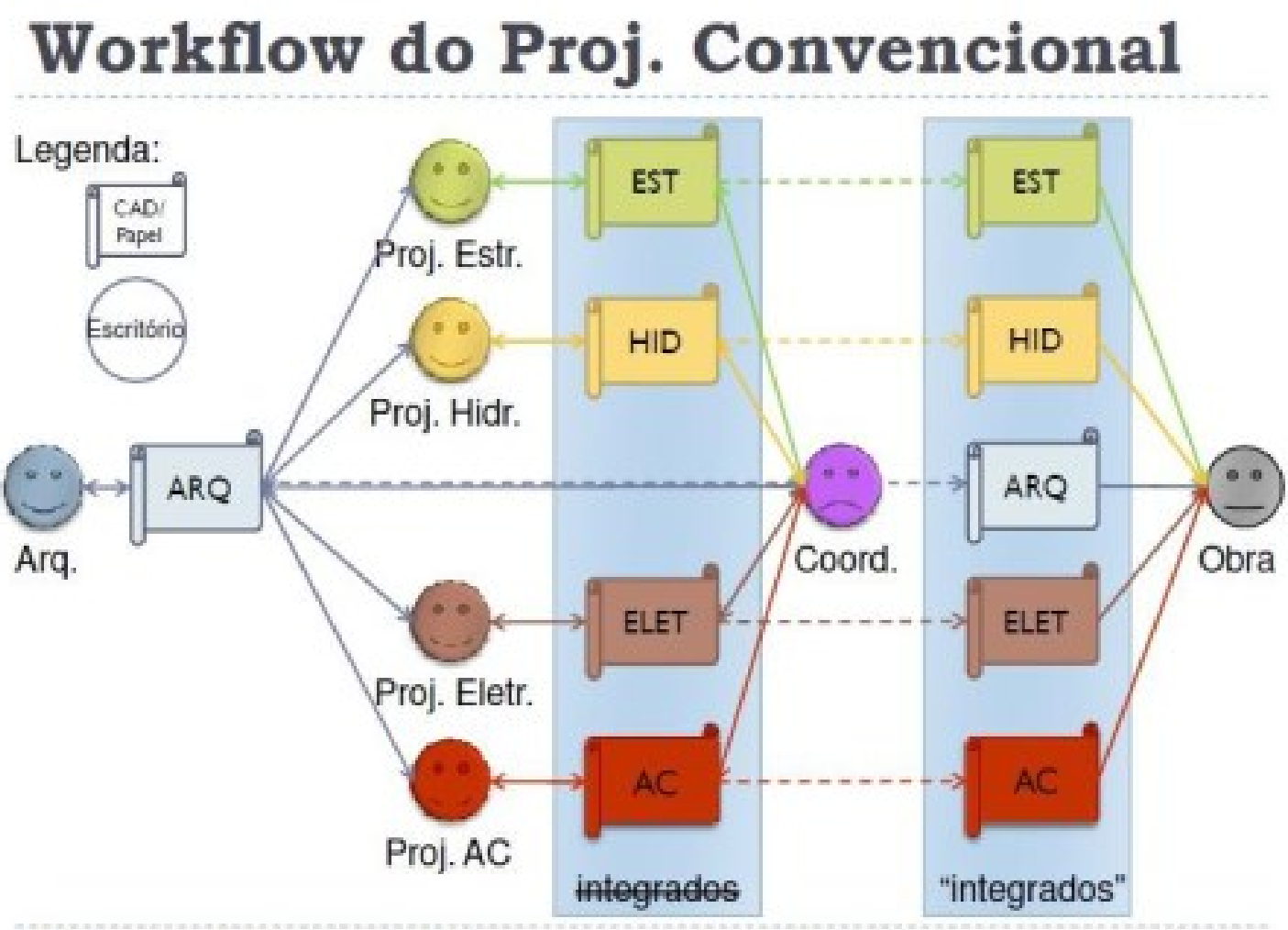

VIII Workshop Brasileiro Gestio do Processo de Projetos na Construção de Edificios

E. Toledo

Figura 6 - "Workflow" do Projeto Convencional. Fonte: SANTOS, 2008, apud ANDRADE, e AMORIM, 2011, p. 795-796. 


\section{Workflow do Projeto com BIM}

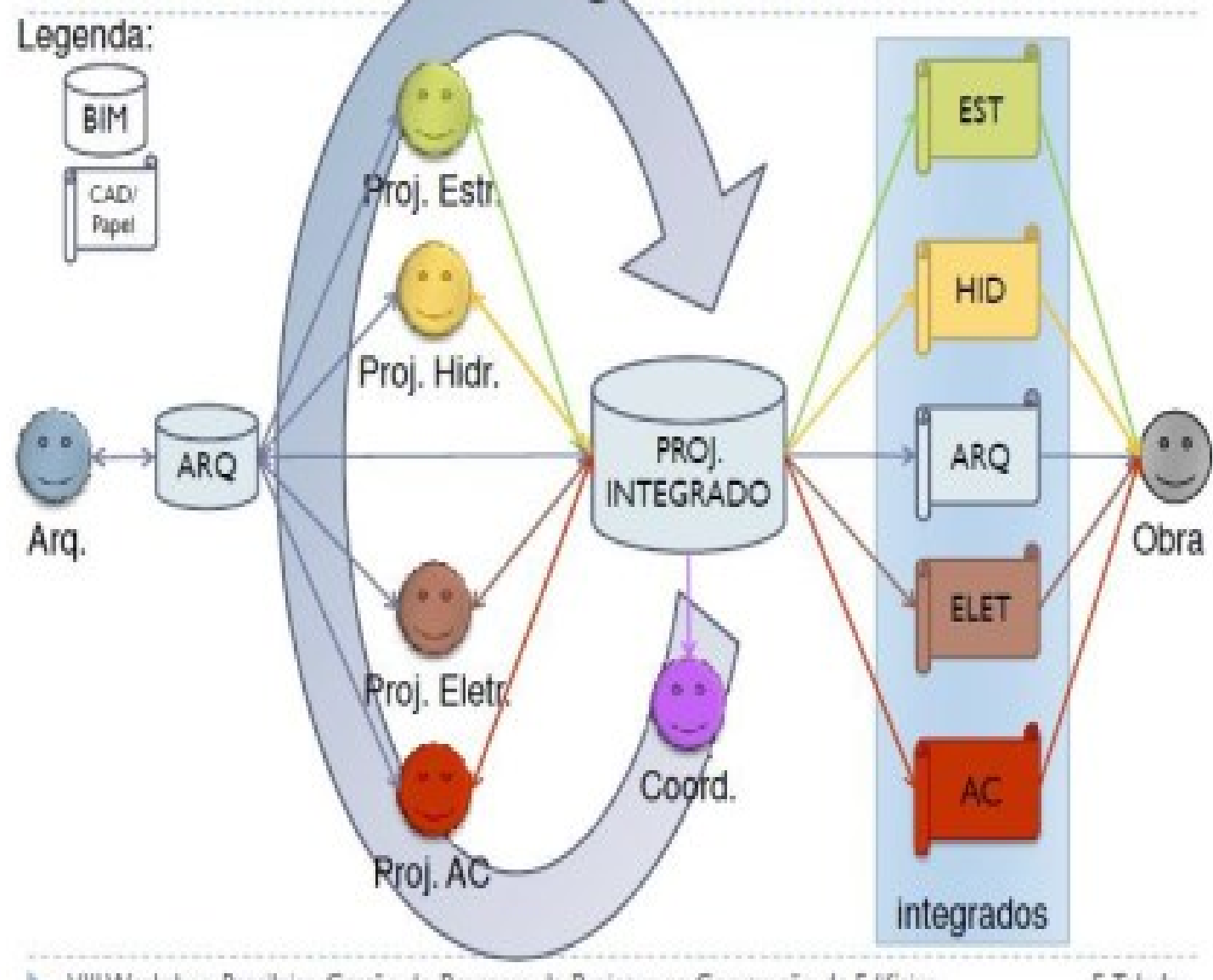

VIllWorkshop Brasileiro Gestio do Processo de Projetos na Construçio de Edficios

E. Toledo

Figura 7- "Workflow" do Projeto com BIM. Fonte: SANTOS, 2008, apud ANDRADE, e AMORIM, 2011, p. 795-796).

Segundo FERREIRA (2007), a dificuldade que se encontrava para a colaboração entre as equipes é que os conhecimentos envolvidos são bastante específicos e incorporados em diferentes tempos nas etapas de projeto. Devido a adoção dos sistemas BIM na confecção do projeto, incluindo as modificações já citadas, vindas da incorporação desse sistema, uma dificuldade no processo de colaboração ocorre no momento em que um membro da equipe de projeto atrasa a finalização de suas atualizações no arquivo central, podendo causar atraso no trabalho dos outros membros da equipe. (FERREIRA, 2007, apud ANDRADE, e AMORIM, S., 2011, p. 796).

O "software" permite que diversas pessoas trabalhem em áreas diferentes sobre o mesmo arquivo, permitindo o que chamamos de engenharia simultânea. Segundo GUIMARÃES e AMORIM (2006), a tarefa do gestor de projeto é "garantir a compatibilidade de informações e conteúdo dos projetos". (GUIMARÃES e AMORIM, 2006, apud ANDRADE e AMORIM, S., 2011, p. 796).

Ainda utilizando a apresentação feita por SANTOS (2008), e para facilitar o entendimento da simultaneidade de projeto, é importante observar a Figura 8 a seguir. 


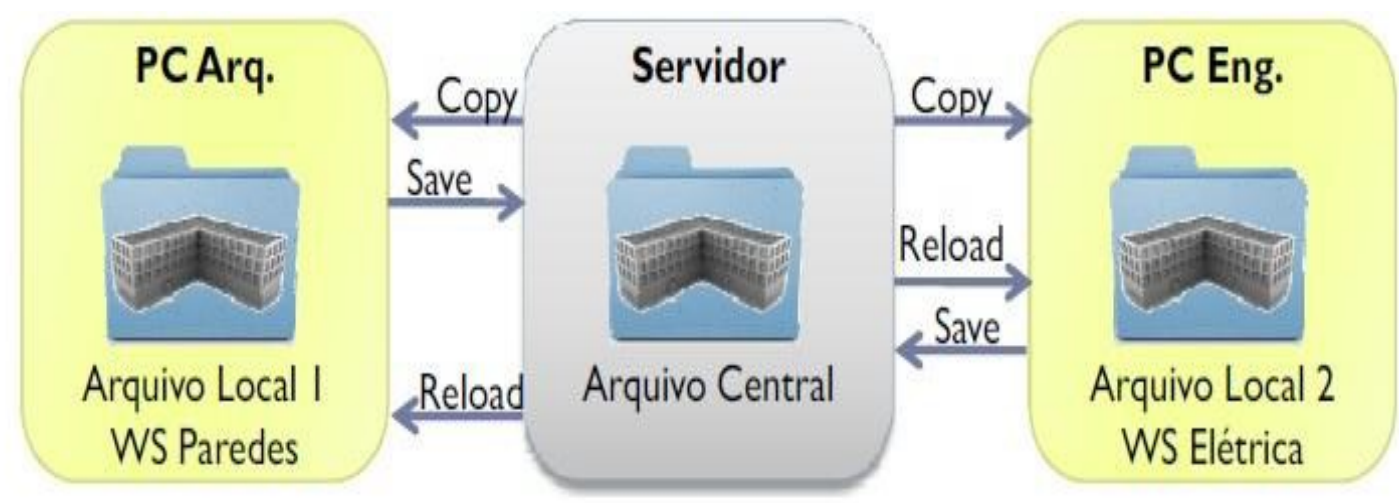

Figura 8- Representação da simultaneidade entre as equipes de projeto com a utilização do sistema BIM. Fonte: SANTOS, 2008, apud ANDRADE, e AMORIM, 2011, p. 796.

Para FERREIRA (2007), "o principal requisito para que a Engenharia Simultânea possa alcançar o resultado de encurtamento do tempo de produção é a colaboração constante e eficaz dos agentes intervenientes: indivíduos, equipes, empresas, etc.".

No período de concepção do projeto, o processo de tomadas de decisões é intenso. O projeto é iniciado com suposições e poucas informações. A partir do momento em que as equipes se reúnem e trocam informações, esta vai sendo moldada. As equipes de projeto passam então a trabalhar nos itens que foram definidos através do processo de colaboração. Esse tipo de troca de informações é importante, pois a participação de pessoas com diferentes tipos de conhecimento permite diversas possibilidades quanto à tomada de decisão (FERREIRA, 2007, apud ANDRADE, e AMORIM, 2011, p. 796).

Ferreira explicita isso na seguinte passagem:

“(...) o projeto é um processo de "afunilamento de informações”, ou seja, em um primeiro momento há muitos itens a serem manipulados (opções possiveis) com poucas informações de cada um. Na medida em que decisões vão sendo tomadas, algumas opções vão sendo descartadas e as opções escolhidas vão sendo cada vez melhor conhecidas e, consequentemente, especificadas". (FERREIRA, 2007, apud ANDRADE, e AMORIM, 2011, p. 796).

O trabalho de forma cooperativa facilita a tomada de decisões; permite que as incompatibilidades sejam vistas no início do processo de projeto e ocasiona também redução do tempo de projeto.

Quanto maior a interação entre os membros da equipe, mais facilmente serão resolvidos os problemas, para que o projeto seja entregue aos clientes com a menor quantidade de erros possível. 
Uma das vantagens da adoção dos sistemas BIM é a possibilidade de diversas equipes trabalharem com um mesmo arquivo, chamado "Arquivo Central", em "Worksets" pré-determinados, com redução de tempo de compatibilização de projeto, e também mais segurança no sentido de evitar erros de projetos, ou seja, a interferência entre o projeto arquitetônico e os projetos complementares.

\section{Segundo Andrade e Amorim:}

"O 'Workset' é o plano de trabalho de cada profissional na equipe, cada um trabalha com uma região diferente do projeto. 'Workset' são grupos do projeto criados e definidos como módulos independentes que podem ser manipulados simultaneamente no projeto. Ao criar um 'Workset', define-se a estrutura de trabalho da equipe de projeto, compara-se ao 'layer' do sistema CAD, como por exemplo: existe um arquivo central, composto por todas as especificações de projeto, bem como com os projetos complementares, porém, cada membro da equipe é responsável por trabalhar com uma parte específica do projeto (estrutura, arquitetura, 'tags', cotas)". (ANDRADE, e AMORIM, 2011, p.794-795).

Assim, são atualizados em todas as equipes, passando pelo gerente BIM, que verifica se cada equipe modificou somente o que continha em seu "Workset". Se, no caso, existirem modificações em outras áreas, este vai verificar se as mesmas são ou não necessárias, repassando as alterações para todas as equipes através do arquivo central (ANDRADE e AMORIM, 2011, p. 793-795). Um profissional qualificado como "gerente BIM" é responsável para organizar e comandar o "Workflow" e o "Workset" dentro da equipe de trabalho. O conceito de "Workflow" reside no comportamento que cada membro da equipe de trabalho deve assumir dentro do processo para que as atividades sejam cumpridas. Além disso, funciona com um conjunto de regras e rotas, ou seja, mostrando como a atividade deve ser feita (ANDRADE e AMORIM, 2011, p. 793-795).

O "Workflow" permite que o controle do projeto seja feito mediante atividade desenvolvida por parte de cada membro da equipe e não somente na totalidade. Dessa forma o gerenciamento é feito de forma individual: cada membro da equipe deve cumprir sua função seguindo prazos, regras e condições que favoreçam a obtenção do resultado esperado de forma mais controlada, sabendo os projetistas se cumpriram ou não o especificado. É uma maneira de integrar por meio de uma ferramenta a atuação de cada um no desenvolvimento do projeto. 


\section{4- SISTEMAS BIM}

Os sistemas BIM têm sido mencionados como forte fator de incremento da produtividade, pois possibilitam a redução de erros e prazos de projeto, além de trazer inúmeros benefícios para a gestão e posterior manutenção das edificações. Os "softwares" de código aberto criam linguagem universal dos sistemas BIM, a IFC, em contínuo desenvolvimento, permitindo que sistemas diversos leiam o mesmo modelo.

No Brasil, a situação se agrava pela falta de bibliotecas nacionais, que são coleções de famílias de objetos virtuais que representam os itens especificados em projeto, como, por exemplo, ferragens, portas e janelas, materiais de revestimento, tubos e conexões além de diversos equipamentos gerais e específicos para a área de construção civil. Esses objetos digitais são necessários para que arquitetos e engenheiros modelem com precisão as informações de projeto. De um lado, questões tecnológicas como a necessidade de integração de dados e de práticas profissionais em processos de projeto simultâneos, ou seja, com a participação efetiva e concomitante dos diversos profissionais (equipe de projeto), que representam as diferentes especialidades, de arquitetura, engenharia e construção. Isto coloca em xeque a interação de toda a cadeia produtiva.

Do outro, a criação de bibliotecas de componentes que aproximem o sistema virtual à realidade da obra e a qualificação de profissionais, tornam-se essenciais para o melhor aproveitamento do potencial da ferramenta. Devido a adoção dos sistemas BIM na construção civil, fornecedores de produtos e materiais ganham papel importante no processo de criação tanto de projetos de arquitetura, bem como de estrutura, instalações elétricas, hidráulicas etc. No sentido de que os modelos virtuais possam de fato representar a realidade de uma obra, a criação de bibliotecas de componentes paramétricos é imprescindível, assim como maior aproximação entre fornecedores, arquitetos e engenheiros.

Os componentes paramétricos permitem que se adicione e recupere informação constante no próprio modelo, estando essa informação associada não apenas a geometria, como aos atributos (características) e conexões e relacionamentos entre diferentes componentes construtivos. Isto difere das bibliotecas de componentes dos sistemas CAD, que são de natureza estática, não permitindo a conjunção entre a representação geométrica com os parâmetros relativos aos objetos. Além de informações detalhadas dos produtos (tais como dimensões e características físicas) também será necessária a divulgação dos dados relativos aos seus desempenhos, bem como às normas técnicas, à aplicabilidade e até a manutenção. 
Aos fornecedores apontam-se o desafio e a oportunidade de criação de diferencial competitivo: a criação de bibliotecas de componentes e produtos em modelagem tridimensional paramétrica. A ABNT (Associação Brasileira de Normas Técnicas) está desenvolvendo normas com vistas à padronização de um sistema de organização da informação da construção que guiará a classificação das famílias e facilitará a interoperabilidade e o uso destas no futuro. Não é apenas a implantação de um novo aplicativo, mas a estruturação de nova nomenclatura capaz de descrever cada ação, cada agente e cada componente de maneira que este possa ser reconhecido e reinterpretado pelos demais programas utilizados no processo de concepção e produção da indústria da construção civil e na manutenção dos elementos construídos. (NARDELLI, 2010, p. 404). Neste sentido, alguns passos já foram dados, como a elaboração da NBR 12006-2 (ABNT, 2010), normalizando os modelos de informação na construção civil brasileira a partir da norma ISO 12006-2. Esse trabalho foi realizado desde 2009 por grupo formado por meio de agentes dessa cadeia produtiva, sob a coordenação da ABNT - Associação Brasileira de Normas Técnicas e que prossegue buscando normalizar a classificação de componentes e materiais da construção, tendo como referência o padrão "OmniClass Construction Classification System" (OMNICLASS, 2006), além da própria ISO 12006-2 e normas brasileiras correlatas.

Faz-se aqui distinção entre a organização formal sobre como os componentes devem ser representados, como o faz a ABNT e a natureza dos componentes paramétricos no processo de projeto. Diversas aplicações específicas podem ser derivadas a partir de um mesmo tipo ou família de objeto na busca de diferentes soluções de projeto. A padronização acerca da representatividade e da organização semântica dos componentes BIM, através de protocolos como os desenvolvidos pela ABNT, significa apenas um requisito dentro do processo de projeto. Ressalte-se, no entanto, que vários dos obstáculos que ainda dificultam essa migração não estão especialmente restritos ao cenário brasileiro, uma vez que o próprio padrão de interoperabilidade ainda não foi estabelecido universalmente com eficácia. É o caso, por exemplo, do formato "IFC", desenvolvido e mantido pelo "BuildingSmart Alliance" como padrão para o intercâmbio de arquivos dos sistemas BIM, que ainda está longe do ideal, mesmo quando se exportam e importam arquivos entre este formato e um mesmo aplicativo (ANDRADE e RUSCHEL, 2009 apud NARDELLI, 2010, p. 404). É preciso, portanto, prosseguir nessa tarefa, alinhando ao mesmo tempo os padrões internacionais e a realidade brasileira, enquanto paralelamente se desenvolvem as bibliotecas de componentes e a metodologia capaz de orientar os novos processos resultantes da produção e gestão integradas ("IPD - Integrated Project Delivery") dos empreendimentos, inclusive na etapa de pós-ocupação (CARBASHO, apud NARDELLI, 2010, p. 404). 
Um dos principais efeitos práticos da utilização correta dos sistemas BIM será a antecipação das principais decisões, que interferem em custo e funcionalidade para as etapas iniciais do projeto (EASTMAN et al., 2008, p. 22), permitindo o aproveitamento desse ganho de produtividade no estudo de novas possibilidades, que poderão romper com os velhos paradigmas da construção.

THOMAS apud MACKEN e LEE (2008), analisou o uso de tecnologias da informação em desenvolvimento de projetos e a sua relação com o desempenho do projeto em obra. Os resultados desta pesquisa apontaram para benefícios que advirão do uso da tecnologia da informação ( $\mathrm{TI}$ ) em projeto, tanto para investidores quanto para construtores que obtiveram significativa redução de custos. As tecnologias de informação analisadas neste estudo foram: código de barras, bancos de dados integrados, sistemas de CAD tridimensional e EDI - "Exchange Data Information" (intercâmbio de dados eletrônicos). O desenvolvimento de bibliotecas de componentes tridimensionais paramétricos é uma tendência recente [THOMAS, MACKEN e LEE, apud FERREIRA, e SANTOS, 2008, p.3).

Nenhuma solução de "software" de computador consegue sozinha apoiar todas as tarefas associadas aos processos de projeto de arquitetura e de construção. A interoperabilidade constitui a necessidade de intercâmbio de dados entre aplicativos, permitindo a utilização de diferentes programas ("softwares") para contribuir para a realização do trabalho. A interoperabilidade, de forma geral, tem ocorrido através de intercâmbio de arquivos dos tipos DXF ("Drawing Exchange Format") e IGES ("Initial Graphics Exchange Specification") que consegue apenas lidar com geometria. (EASTMAN, TEICHOLZ, SACKS, \& LISTON, 2008, p. 65).

Em 1993, algumas das maiores empresas da indústria da construção dos Estados Unidos, iniciaram uma discussão para utilizarem mais efetivamente a tecnologia da informação neste setor. Estas se reuniram e formaram a IAI ("Industry Alliance for Interoperability"), que apresentou em 1995 no "AEC System Show" em Atlanta (EUA), uma proposta de sistemas CAD e softwares de simulação. Ainda naquele ano, com a agregação de outros interessados, se firmou como uma organização global chamandose "International Alliance for Interoperability" - IAI. Atualmente existem nove sedes mundiais servindo as necessidades de diversos países: Reino Unido, Estados Unidos, Países Nórdicos, Japão, Coreia, Austrália, Singapura, Alemanha, França. Essas sedes possuem membros em mais de 650 empresas distribuídos em cerca de 20 países. A IAI é um organismo sem fins lucrativos, de ação orientada. Sua missão é definir, publicar, promover especificações para classes de objetos da indústria da construção. 
O objetivo da IAI (http://www.bre.com.uk/iai) é disponibilizar e promover especificação para distribuição de dados, compatível com todos os processos e produtos.

A IAI buscou criar novo modelo de distribuição de dados, que trouxesse a informação a respeito dos objetos arquitetônicos, sendo eles reais (portas, paredes, aberturas, etc.) ou conceitos abstratos (espaço, organização, processos, etc.) que pudessem ser representados eletronicamente. Esta especificação representa suporte à estrutura de dados, em projetos eletrônicos através de modelo orientado a objetos. (JACOSKI, 2003, p. 9).

O modelo IAI representa uma coleção de classes designadas pelo termo "IFC" que representa uma estrutura de dados, cuja distribuição feita por meio de aplicativos usados pelos profissionais na indústria da construção e permite aos mesmos definir suas próprias caracterizações dos objetos. (EASTMAN, TEICHOLZ, SACKS, \& LISTON, 2008, p. 65 a 91).

Em decorrência dos trabalhos da IAI diversos softwares estão sendo desenvolvidos baseados na estrutura de especificação "IFC", para a criação de aplicações específicas na indústria da construção. Podemos citar, como exemplo, a criação de um objeto de determinada aplicação no projeto arquitetônico de forma a transferi-lo para ser utilizado por outro profissional em um projeto estrutural, permitindo assim uniformização da informação desde a concepção do mesmo até sua fabricação e montagem na obra.

O "IFC" define componentes construtivos como elementos de construção transferíveis entre aplicativos que operem com seus tipos de extensão. As extensões IFC são públicas e abertas para implementação e uso por qualquer membro. São definidas pela indústria, são extensíveis e são desenvolvidas a qualquer tempo, conforme a necessidade. Diversas indústrias de "software" utilizam extensões IFC devido ao fato de seu padrão ser aberto.

É possível que o mesmo se torne futuramente um padrão da indústria da construção. O "IFC" constitui-se em um modelo que define objetos, atributos e relacionamento entre as áreas, trazendo informação da geometria, unidades e utilidades comuns. O modelo de recursos da geometria tem múltiplas representações para o objeto: geometria referencial; espaço limitante; atributo-direção da representação geométrica; explícita representação geométrica. (EASTMAN, TEICHOLZ, SACKS, \& LISTON, 2008, p. 58 a 70). 
Ao contrário do método não-paramétrico, os sistemas BIM oferecem representação orientada ao objeto, de forma a espelhar as informações referentes ao mundo real, incorporando ao modelo objetos paramétricos que contenham especificações precisas sobre sua constituição, instalação, fabricante, preço e informação sobre qual fase da obra tal equipamento ou elemento construtivo deverá ser inserido no processo construtivo.

No entanto, a maioria das pesquisas concentra-se apenas em um tipo de "software" BIM, porque as informações paramétricas não podem ser trocadas entre diferentes sistemas BIM. Devido ao advento dos sistemas BIM, os objetos passam a possuir significado, em relação ao seu equivalente físico no mundo real, por meio de representação computacional abstrata do mundo físico que é muito mais conveniente para os arquitetos (RUPPEL, MEISSNER, e BERND M, 1993).

Dois cenários de colaboração entre os agentes do processo de projeto de AEC (Setores de Arquitetura, Engenharia e Construção) formarão o ambiente da pesquisa. Em ambos os cenários o modelo de informação não circula livremente entre agentes, mas são centralizados em servidor BIM.

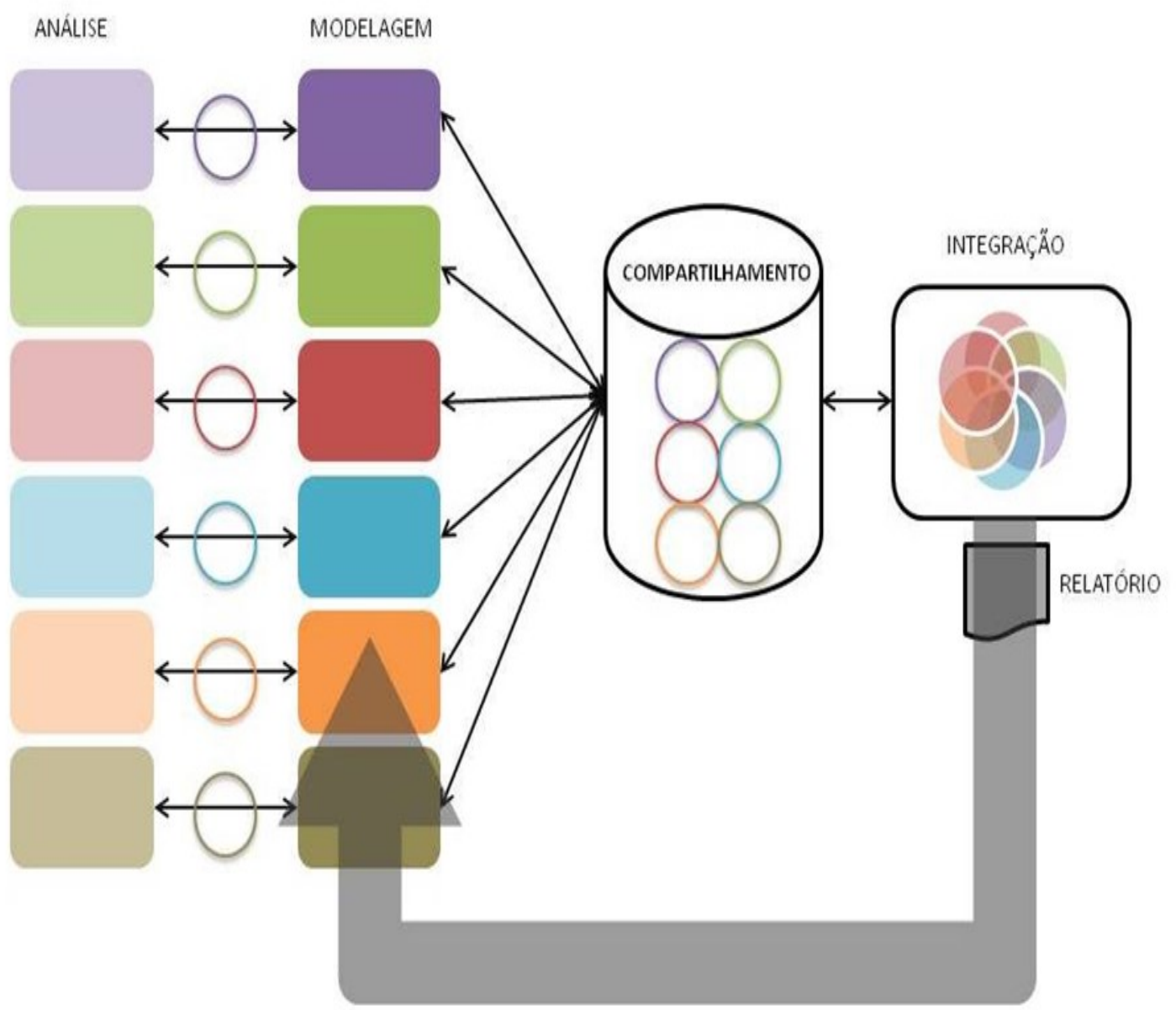

Figura 9 - Cenário A: a ferramenta de compartilhamento funciona apenas como repositório de modelos. Fonte: QUEIROZ, 2012, p. 6. 
Nas Figuras 9 e 10 é possível observar que o uso dos sistemas BIM permite às equipes manter visão digital atualizada e precisa do projeto, em todos os momentos. Os membros da equipe, em diferentes disciplinas e locais, utilizam informações consistentes e coordenadas, o que leva à colaboração efetiva da equipe. O modelo do edifício é um banco de dados. Toda informação necessária para a sua validação encontra-se automaticamente associada a cada um dos elementos. As informações estão integradas dentro de um único repositório central.

Segundo TSE e WONG (2005), existem pelo menos, três possíveis caminhos para melhor integração na implantação dos sistemas BIM:

1- IMPLANTAR MÓDULOS ADICIONAIS dos projetos complementares ao projeto arquitetônico na mesma plataforma (TSE e WONG, 2005, p. 85-102);

2- EXPORTAÇÃO DO MÓDULO ARQUITETÔNICO COMO ARQUIVO DE DADOS EM PADRÃO ABERTO, que pode ser importado pelos colaboradores do projeto e utilizado em suas aplicações específicas (TSE e WONG, 2005, p. 85-102);

3- DESENVOLVER APLICAÇÕES ESPECÍFICAS POR MEIO DE "APPLICATION PROGRAMMING INTERFACE" (API) que depende da permissão dada pelo representante BIM e da acessibilidade das propriedades dos objetos (TSE e WONG, 2005, p. 85-102).

ANÁLISE MODELAGEM

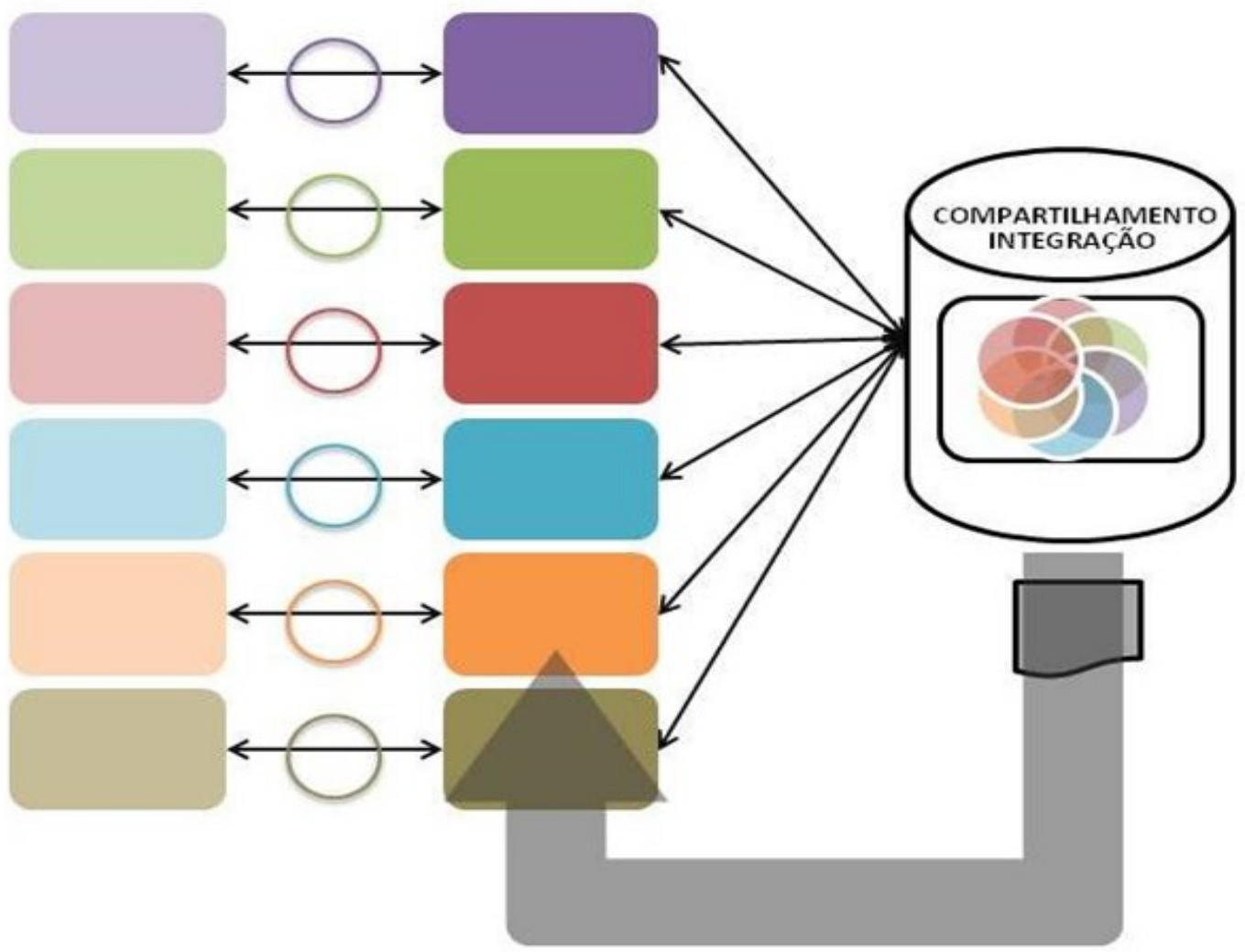

Figura 10- Cenário B: a função do repositório de modelos incorpora funções de integração entre modelos. Fonte: QUEIROZ, S. 2012, p. 6. 
No método que utiliza os sistemas BIM, é necessária a cooperação entre projetistas, consultores, empreendedores e construtores, com as devidas preocupações quanto à interoperabilidade dos dados, tendo em vista permitir o intercâmbio das informações entre os diversos participantes. Ao mesmo tempo, o processo de projeto possui diferentes participantes que influenciam no processo decisório, tais como usuários, projetistas e proprietários. O modelo é geralmente construído pelo arquiteto. $\mathrm{O}$ coordenador do projeto deve estabelecer um esqueleto. A partir desse esqueleto genérico, o engenheiro estrutural deverá dimensionar e projetar o seu sistema estrutural.

O domínio dessa tecnologia e a correta definição dos "templates" gráficos e das normas vigentes implica diretamente no grau de utilização e na utilidade prática das bibliotecas paramétricas. A composição de um arcabouço de projeto e o saber envolvido no seu emprego prático são temas centrais desta pesquisa (Figura 10).

Existem também dificuldades, uma vez que as equipes que trabalham com um mesmo projeto podem utilizar diferentes sistemas BIM. Segundo ANDRADE e RUSCHEL, entre os "softwares" BIM não existe um padrão para classificação das propriedades dos objetos. Isto dificulta a transferência de dados uma vez que muitos dados podem ser perdidos fazendo com que dados primários tenham que ser reinseridos no projeto.

Diferentes aplicativos apresentam grupos de propriedades diferentes, com unidades de medidas diferentes para os mesmos objetos. Isto também ocasiona perda de qualidade da transferência de dados dos diferentes aplicativos, mesmo com a utilização do padrão "IFC", que aparece no sentido de facilitar a interoperabilidade (ANDRADE E RUSCHEL, 2009, p.92).

Assim sendo, mais uma vez se reforça a importância do "Gerente BIM", devido à possibilidade de verificar se os dados necessários ao desenvolvimento do projeto foram incorporados, mesmo com programas com tipologia BIM diferentes.

Eastman et al apresenta a seguinte série de benefícios dos sistemas BIM:

"BENEFícIOS DE “PRÉ-CONSTRUÇÃO” PARA PROPRIETÁRIOS: antes que os proprietários contratem um arquiteto, é necessário determinar se um edifício de um certo tamanho, nível de qualidade e programa de necessidades desejado pode ser construído dentro de um determinado custo e tempo. Se respostas aproximadas a estas condicionantes puderem ser oferecidas, os proprietários saberão se suas metas são exequíveis dentro de um certo orçamento." (EASTMAN, TEICHOLZ, SACKS, \& LISTON, 2008, p. 16). 
Estas capacidades são de extrema relevância nos estágios iniciais de projeto, uma vez que possibilitam diminuir o grau de incerteza e ainda estabelecer uma margem de maior segurança no atendimento aos requisitos de projeto.

"Melhor desempenho e maior qualidade do edifício: o desenvolvimento de um modelo esquemático antes de gerar um modelo detalhado do edifício permite uma avaliação mais cuidadosa do esquema proposto para determinar se $o$ mesmo satisfaz às exigências funcionais e sustentáveis do edifício." (EASTMAN, TEICHOLZ, SACKS, \& LISTON, 2008, p. 16).

Por definição, os modelos gerados pelos sistemas BIM são necessariamente especificados em grande nível de detalhe, sem ambiguidades. A obrigação de especificar em detalhes os componentes BIM impossibilita a representação abstrata de objetos. Diferentes níveis de abstração e/ou especificação, por sua vez, encontram-se disponíveis em sistemas como os SIG, sendo esta uma limitação dos sistemas BIM para serem usados nos estágios iniciais de projeto, bem como os processos de tomada de decisão. A associação entre os sistemas BIM e SIG supre essa lacuna na capacidade de abstração para representação e manipulação da informação referente aos componentes construtivos. Os SIG permitem um ambiente exploratório acerca das diversas possibilidades e ainda de diferentes níveis de representação e detalhe dos componentes da construção e das condicionantes expostas aos mesmos em ambiente de projeto. Isto permite amparar o processo de tomada de decisão, e posterior formalização das informações, através da configuração dos parâmetros adequados nos componentes desenvolvidos nos sistemas BIM.

"BENEFícIOS DE PROJETO: o projeto é representado diretamente na forma tridimensional ao invés de ser o resultado da interpretação de representações bidimensionais feitas anteriormente." (EASTMAN, TEICHOLZ, SACKS, \& LISTON, 2008, p. 17).

Apesar de diferentes "softwares" atuais oferecerem a possibilidade de modelagem tridimensional, como o Sketchup ${ }^{\circledR}$, FormZ $^{\circledR}$ ou Rhinoceros ${ }^{\circledR}$, entre outros, isto não significa conseguir incorporar e manipular informação nos componentes modelados, carecendo de capacidades paramétricas que distinguem os sistemas BIM dos demais.

"CORREÇÕES AUTOMÁTICAS QUANDO SÃO FEITAS MUDANÇAS NO PROJETO: os objetos são controlados por regras paramétricas que asseguram que a construção do modelo tridimensional será viável. Isto reduz a necessidade de administrar inconsistências de projeto." (EASTMAN, TEICHOLZ, SACKS, \& LISTON, 2008, p. 17). 
As correções automáticas, presentes nos sistemas BIM, permitem que os componentes construtivos possam definir regras de relacionamento entre si, como por exemplo a conexão entre paredes e lajes, sendo a altura final da parede dependente do posicionamento da laje, Este conceito de dependência é empregado na modelagem computacional em programas como o $3 \mathrm{DMAX}{ }^{\circledR}$, Maya ${ }^{\circledR}$ ou Blender3D ${ }^{\circledR}$, podendo um objeto ser "filho" de outro, sendo que ao se mover o objeto "pai" o filho automaticamente se desloca seguindo o primeiro.

"DESENHOS BIDIMENSIONAIS PRECISOS E CONSISTENTES EM QUALQUER FASE DO PROJETO: O BIM proporciona desenhos precisos e consistentes para os objetos do projeto, o que reduz significativamente a quantidade de tempo e erros associados às tarefas de desenhos do edifício para todas as disciplinas de projeto. Quando uma mudança de projeto é efetuada, são gerados desenhos completamente consistentes que refletem essas modificações." (EASTMAN et al, , 2008, p. 17).

A extração de representações bidimensionais do modelo tridimensional e de sua consistência ser preservada após alterações não é exclusividade dos sistemas BIM. Alguns "softwares" atuais também oferecerem, como o Sketchup ${ }^{\circledR}$, FormZ $^{\circledR}$, Rhinoceros ${ }^{\circledR}$, entre outros. Porém, como a parametrização nestes programas não inclui informações sobre características construtivas, tais "softwares" não permitem extrair informações que extrapolam os aspectos geométricos. Os sistemas BIM possibilitam a composição de quantitativos e de cotação automática, se conectados a uma planilha de preços, ou ainda informações do fabricante, montagem e manutenção, por exemplo.

\footnotetext{
"COLABORAÇÃO MAIS CEDO DAS MÚLTIPLAS DISCIPLINAS DE PROJETO: a tecnologia dos sistemas BIM facilita o trabalho simultâneo das várias disciplinas de projeto. Encurta o tempo de projetação e reduz significativamente os erros de projeto e eventuais omissões. Também antecipa a visualização de problemas de projeto e apresenta oportunidades para um projeto ser melhorado continuamente." (EASTMAN et al, 2008, p. 17).
}

A colaboração já existia antes dos sistemas BIM, uma vez que a ideia de coordenação de projeto é análoga ao que hoje se intitula de colaboração ou de projeto simultâneo. Metodologias como o PMI/ PMBOK já ofereciam metodologias de gerenciamento de projetos muito antes dos sistemas BIM serem comercialmente conhecidos e disponibilizados enquanto "softwares". A concepção e desenvolvimento de projetos sob este princípio foi comum em países desenvolvidos. No Brasil as experiências neste sentido foram raras e mais comuns em projetos geridos por grandes empresas. Contudo, é preciso enfatizar que, embora possível, a colaboração mais cedo no processo de projetação é significativamente mais difícil e laboriosa através de desenhos bidimensionais. 
Os esforços envidados para a coordenação de projetos e participação simultânea entre diversas especialidades no processo dos mesmos são anteriores ao advento dos sistemas BIM, sendo as linhas gerais expressas pelos escopos e atribuições de projeto das diversas especialidades. Entretanto há facilidade significativamente maior nos sistemas BIM para gerenciar e manipular tais informações, por meio de modelo único digital, além da possibilidade efetiva de contribuição em um mesmo ambiente computacional de diferentes profissionais e equipes de projeto.

"VERIFICAÇÃO DAS INTENÇÕES DE PROJETO: os sistemas BIM proporcionam visualizações tridimensionais no início do processo de projetação e quantificam áreas de espaços e quantidades de materiais permitindo estimativas antecipadas de custo e com maior precisão. No tocante aos edifícios técnicos (laboratórios, hospitais, etc.), os objetivos de projeto estão frequentemente definidos de forma quantitativa, e isto permite usar um modelo de edifício para conferir estas exigências. No sentido de atender as exigências qualitativas (por exemplo, este espaço deve ser próximo a outro e etc.) o modelo tridimensional pode apoiar avaliações automáticas." (EASTMAN et al, 2008, p. 18).

Devido à complexidade envolvida no projeto de aeroportos e a multiplicidade de agentes intervenientes, requisitos e condicionantes, a possibilidade de simulação detalhada das variáveis envolvidas nas propostas de projeto ressaltam o papel dos sistemas BIM como ferramenta valiosa para redução da indefinição e do risco associado ao projeto. Permite ainda visualizar o impacto e as interferências, embasando assim o processo de tomada de decisão.

"ESTIMATIVAS DURANTE A FASE DE PROJETO: em qualquer fase do projeto, a tecnologia dos sistemas BIM permite extrair quantitativos e relatórios dos espaços projetados antes da construção, o que pode ser usado para estimativa de custos. Nos estágios iniciais da projetação, estimativas de custos são baseadas primariamente nos custos unitários por pés quadrados. À medida em que o projeto é desenvolvido, quantidades mais detalhadas podem ser disponibilizadas, podendo ser utilizadas para estimativas de custos mais precisas e detalhadas." (EASTMAN et al, 2008, p. 18).

Nas empresas de administração de aeroportos, em especial naquelas públicas ou de capital misto, como a INFRAERO, torna-se essencial obedecer às regras de licitação e especificação de materiais. A capacidade de extração automática de quantitativos e de cotação oferece não apenas a possibilidade de maior facilidade para o gerenciamento desses processos, como ainda maior transparência dos mesmos. 
"MELHOR EFICIÊNCIA ENERGÉTICA E SUSTENTABILIDADE: a integração do modelo do edifício a ferramentas de análise de energia permite avaliação energética do mesmo ainda nas fases iniciais de projeto. Isto não é possível por meio das ferramentas de representação bidimensionais. Estas exigem que uma análise de energia seja executada após o término do processo de projeto reduzindo, assim, o número de oportunidades para que modificações sejam implementadas de forma a melhorar o desempenho energético do edifício. A possibilidade de trabalhar conjuntamente o modelo de edifício com vários tipos de ferramentas de análise provê muitas oportunidades para melhorar a qualidade de edifício." (EASTMAN et al, 2008, p. 18).

Os aeroportos são por natureza construções que oferecem elevado impacto ao meio ambiente, devido às atividades da aviação civil, como, por exemplo, a poluição sonora, ambiental e o manejo de resíduos sólidos, além de apresentarem elevado consumo de recursos energéticos e materiais. A possibilidade de simulação de projeto para a melhoria do desempenho da edificação, através dos sistemas BIM representa característica relevante no projeto de aeroportos.

"SINCRONIZAÇÃO ENTRE O PROJETO E O PLANEJAMENTO DA CONSTRUÇÃO: o planejamento de construção utilizando CAD 4D requer a ligação de um plano de construção aos objetos tridimensionais em um projeto, de forma que seja possível simular o processo de construção e mostrar como o edifício e o sítio seriam em qualquer ponto no tempo. Esta simulação gráfica fornece grande clareza sobre como o edifício será construído dia a dia, revelando fontes de problemas potenciais e oportunidades para possíveis melhorias (local, pessoas e equipamentos, conflitos espaciais, problemas de segurança, etc.). Esse tipo de análise não está disponível nos documentos de propostas feitos em papel. A simulação gráfica, entretanto, fornece outros benefícios se o modelo inclui objetos temporários de construção tais como escoramentos, andaimes, guindastes e outros equipamentos de monta de tal forma que estes objetos possam ser ligados ao cronograma de atividades e refletidos no plano de construção desejado." (EASTMAN et al, 2008, p. 18-19).

Uma vez que os sistemas BIM representam processo colaborativo e de gestão de informação de projeto, sua adoção em organizações ou empresas prescinde do estabelecimento de protocolos e mudança de processos organizacionais para contemplar a participação simultânea das diversas especialidades de projeto e ainda gerir de forma adequada os dados em servidores que integram os modelos BIM e disponibilizam acesso aos agentes intervenientes. 
As informações de projeto dividem-se em diferentes tipos, em um modelo BIM, como as de natureza geométrica, aquelas associadas ao modelo geométrico, em campos paramétricos e ainda informações que são conectadas ao modelo por meio de "hyperlink". Tipos de informação que estão disponíveis em um modelo BIM.

1- "GEOMETRIA: obviamente este é o primeiro item necessário em um modelo tridimensional. Permite comunicar nossas ideias e intenção de projeto graficamente. Adicionalmente, a maioria das tecnologias de BIM hoje em dia nos permite gerar elevações e seções diretamente do modelo tridimensional e integrar as representações bidimensionais ao modelo. Quando uma mudança é feita no modelo virtual, podem ser atualizadas as vistas geradas sem necessidade de edição, evitando erros e retrabalho. Adicionalmente, a criação de um modelo tridimensional do edifício nos permite embasar a tomada de decisão de projetos muito mais cedo, antecipando problemas e suas possíveis soluções";

2- "INFORMAÇÃO PARAMÉTRICA: através do uso de tecnologia de informação orientada a objetos, definimos a função de cada objeto ou componente do projeto, sua estrutura e suas características. Assim, podemos adicionar todas as informações relativas ao processo construtivo e seus componentes, definir fases de projeto e de obra e gerar a documentação decorrente;

3- "GESTÃO DA INFORMAÇÃO: informações relacionadas ao modelo, mas não diretamente contidas no mesmo, podem ser conectadas por meio de "hyperlinks". Detalhamentos de componentes feitos por fabricantes, por exemplo, podem ser anexados via "link" ao modelo BIM do edifício". (DILLON, 2005, p. 1).

As ineficiências inerentes aos processos de concepção e de construção atuais residem, segundo o NIST ("National Institute of Standards and Technology" dos EUA) na interoperabilidade insuficiente entre o projeto assistido por computador e os softwares de engenharia e os sistemas utilizados pelo setor da construção civil nos EUA. Relatório do NIST publicado em agosto de 2004 e intitulado "Análise de custo inadequado em interoperabilidade nas "U.S. Capital Facilities Industry's", conclui que os problemas com a gestão de informação e da acessibilidade a essas informações não só prejudicam gravemente a gerência de projeto ou obra, mas representam a maior parte do custo inadequado. (EASTMAN et al, 2008, p. 11 e 12). O conceito de perdas na construção civil é, com frequência, associado unicamente aos desperdícios de materiais. No entanto, as perdas englobam tanto a ocorrência de desperdícios de materiais quanto a execução de tarefas desnecessárias que geram custos adicionais. A eliminação das perdas é hoje um grande elemento para a competitividade entre as empresas e para tanto é necessário mudar a maneira de abordá-las em todos os processos de um projeto. (FORMOSO et al, 1996, p. 1 e 2). 


\section{5- NÍVEIS DE AMADURECIMENTO NOS SISTEMAS BIM}

Abaixo estão apresentados os estágios de amadurecimento dos sistemas BIM e a gradual integração dos processos em um ambiente organizacional (OLIVEIRA, L. apud CLAYTON et al., 2008, p. 46 A 48):

1- BIM-A (“Accelerated”): métodos e tecnologias são usados internamente para acelerar a produção e as operações em uma dada empresa. O modelo é relativamente isolado e não há nenhuma versão comum a todos os membros da equipe. Devido a isso, o consumo de informação é limitado ao uso interno sem compartilhamento com outros profissionais. O estudo indicou que atualmente BIM-A oferece grandes vantagens sobre o CAD convencional ao comparar desempenho em termos de documentação projetual. Estudiosos do assunto relatam que usuários iniciantes desta estratégia em grandes empresas alcançaram economias de $30 \%$ ou mais em custos de produção, bem como aumentos na rentabilidade e vantagens em termos de documentação projetual em comparação ao CAD convencional. (OLIVEIRA, L. apud CLAYTON et al., 2008, p. 46-48.);

2- BIM-B ("Business"): consiste no uso dos sistemas BIM no estabelecimento de parcerias entre empresas que visam alcançar as vantagens das oportunidades de intercâmbio de dados e de informações para redução de custos de comunicação. Os autores ressaltam que o BIM-B vem sendo aplicado aos poucos, de forma experimental em alguns projetos-piloto. Nesta estratégia, os sistemas BIM requerem relações próximas e de longo prazo entre arquitetos, consultores e empreiteiros. Assim justificam-se também os esforços necessários à padronização de procedimentos de documentação e de representação. $O$ potencial deste nível reside no aumento do valor agregado na prestação de serviços no contexto da indústria AEC. (OLIVEIRA, L. apud CLAYTON et al., 2008, p. 46-48);

3- BIM-I ("Industry-wide”): é o terceiro e mais alto nível de adoção e é considerado o mais conceitual e distante da prática atual. Nesse nível é necessária a admissão de protocolos de intercâmbio de dados por meio de interfaces de aplicativos múltiplos. Segundo os autores, o BIM-I requer a ampla padronização dos referidos protocolos, além de acordos de compartilhamento de dados, requerendo tecnologias de informação proativas. (OLIVEIRA, L. apud CLAYTON et al., 2008, p. 46-48). 
A Figura 11, abaixo, posiciona as três estratégias acima em uma relação entre adoção cumulativa e tempo em termos de uso efetivo da tecnologia. $\mathrm{Na}$ lateral direita são posicionadas as categorias dos adotantes, caracterizados como inovadores, usuários iniciantes, maioria precoce e maioria tardia. Nesta escala os inovadores são caracterizados com o perfil de usuários que implantam os sistemas BIM assumindo os riscos da falta de informação e de maiores conhecimentos sobre o novo sistema. Por isso o tempo no início da curva ser maior quando comparado ao meio, característico da maioria recente, que ao adotar já detém um conhecimento maior que os inovadores quando da adoção (Figura 11).

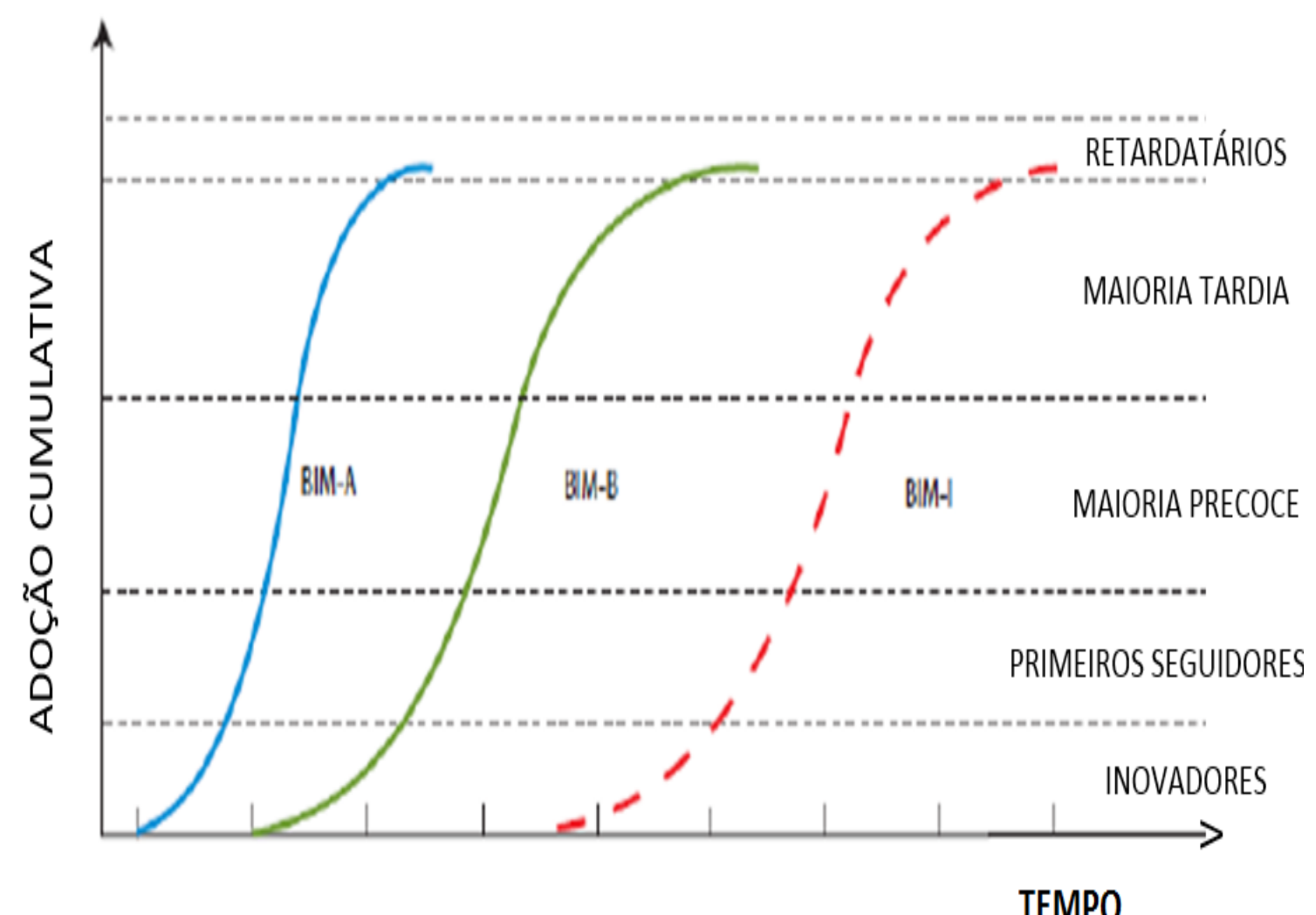

Figura 11- Níveis de amadurecimento nos sistemas BIM. Fonte: OLIVEIRA, L. apud CLAYTON et al., 2008, p. 46-48.

Os autores expõem ainda a percepção de que as três estratégias são sequenciais. Significa que uma empresa deve, primeiramente obter experiência com os sistemas BIM utilizando-se da estratégia BIM-A. Posteriormente, as características do BIM-B podem ser estendidas aos parceiros, explorando as técnicas de colaboração e de interoperabilidade. Também essa fase é preparatória para a evolução e o uso do BIM-I. Ainda segundo os autores, é duvidoso que uma empresa possa construir sua experiência interna nos sistemas BIM sem fazer uso de BIM-A. Semelhantemente, a adoção de BIM-B é uma excelente maneira de se preparar para BIM-I no exercício de uma empresa em novas relações contratuais e novos padrões de prática mercadológica (Figura 11). 


\title{
2.6- SISTEMAS BIM NO SETOR PÚBLICO BRASILEIRO
}

\section{Marcos Otávio Bezerra Prates, diretor do Departamento das Indústrias Intensivas em Mão de Obra e Recursos Naturais, do Ministério do Desenvolvimento, Indústria e Comércio Exterior (MDIC), ao analisar o mercado interno brasileiro pondera:}

\begin{abstract}
"O Brasil é um país que tem importantes lacunas de competitividade, cuja superação demanda a sistematização de esforços tanto do setor público como do setor privado. Tratando-se de um fator econômico básico, a sua insuficiência em termos quantitativos e qualitativos representa impacto negativo de competitividade para a economia brasileira, pois eleva os custos de forma difusa para todo o sistema produtivo e para a sociedade. Porém, a área habitacional não está acompanhando essa evolução, devido à falta de interoperabilidade técnica dos componentes e elementos da construção habitacional, fundamental para permitir que o processo de construção do edifício seja, tanto quanto possível, um sistema de montagem. Desta forma, se conseguiria reduzir o ciclo de produção do edifício, com redução de prazos, custos, desperdícios e aumento da produtividade".
\end{abstract}

NASCIMENTO e SANTOS (2003) e BAZJANAC (2004) afirmam que alguns fatores vêm dificultando a implantação efetiva da tecnologia BIM nos escritórios. Citam investimento alto em novos equipamentos, arquivos extras e necessidade de treinamentos dos profissionais, suporte técnico, falta de tempo, resistência à mudança, longo processo de aprendizagem, deficiência dos softwares e indisponibilidade de uma versão de software gratuita para teste. (NASCIMENTO e SANTOS, 2003 e BAZJANAC, 2004, apud MENEZES et al, 2011, p. 4). FARIA (2007) diz que, apesar das vantagens advindas do uso, os sistemas BIM entraram com força no mercado brasileiro apenas no segmento de projetos de arquitetura, na etapa inicial da modelagem da edificação (FARIA, 2007, apud MENEZES et al, 2011, p.4). Ressalta-se que o método bidimensional continua em voga em grande parte dos projetos nacionais, como por exemplo, o Estádio Nacional Mané Garrincha, em Brasília, DF, foi inteiramente elaborado por meio de sistemas CAD bidimensionais e desenhos impressos em papel. O processo de implantação dos sistemas BIM abrange, de um lado, questões tecnológicas e interesses comerciais e de outro, a criação de bibliotecas de componentes. Essas bibliotecas são essenciais porque são específicas do sistema de aeroportos brasileiros. Deve ser considerada também a necessidade de qualificação de profissionais para o uso adequado da ferramenta. Além disso, é necessário avançar no tocante a resolução de aspectos de interoperabilidade entre os diversos "softwares" utilizados no processo de projeto, como, Revit ${ }^{\circledR}$ Architecure, ArchiCAD ${ }^{\circledR}$, ou Bentley ${ }^{\circledR}$ 
para arquitetura, Revit ${ }^{\circledR}$ Structure, AutoCAD ${ }^{\circledR}$ Civil 3D e/ ou Ecotect ${ }^{\circledR}$, de análises de desempenho energético e ambiental, etc. O grupo interinstitucional sobre BIM, liderado pelo Sindicato da Indústria da Construção Civil do Estado de São Paulo (SindusConSP), com a participação da Associação Brasileira de Engenharia e Consultoria Estrutural (Abece), da Associação Brasileira dos Escritórios de Arquitetura (AsBEA) e da Associação Brasileira de Engenharia de Sistemas Prediais (Abrasip), propõe a criação de protocolo de comunicação comum compatível para os mais variados "softwares" de projeto e construção. A necessidade de adoção do "IFC" não é porém consenso. A implantação dos sistemas BIM, no entanto, não depende de resposta concreta para o desafio da interoperabilidade. Os sistemas BIM vêm sendo usados em processos de projetos aeroportuários, como alguns listados abaixo (Figuras 12 e 13):

\subsection{1- REINO UNIDO: AEROPORTOS DE GATWICK.}

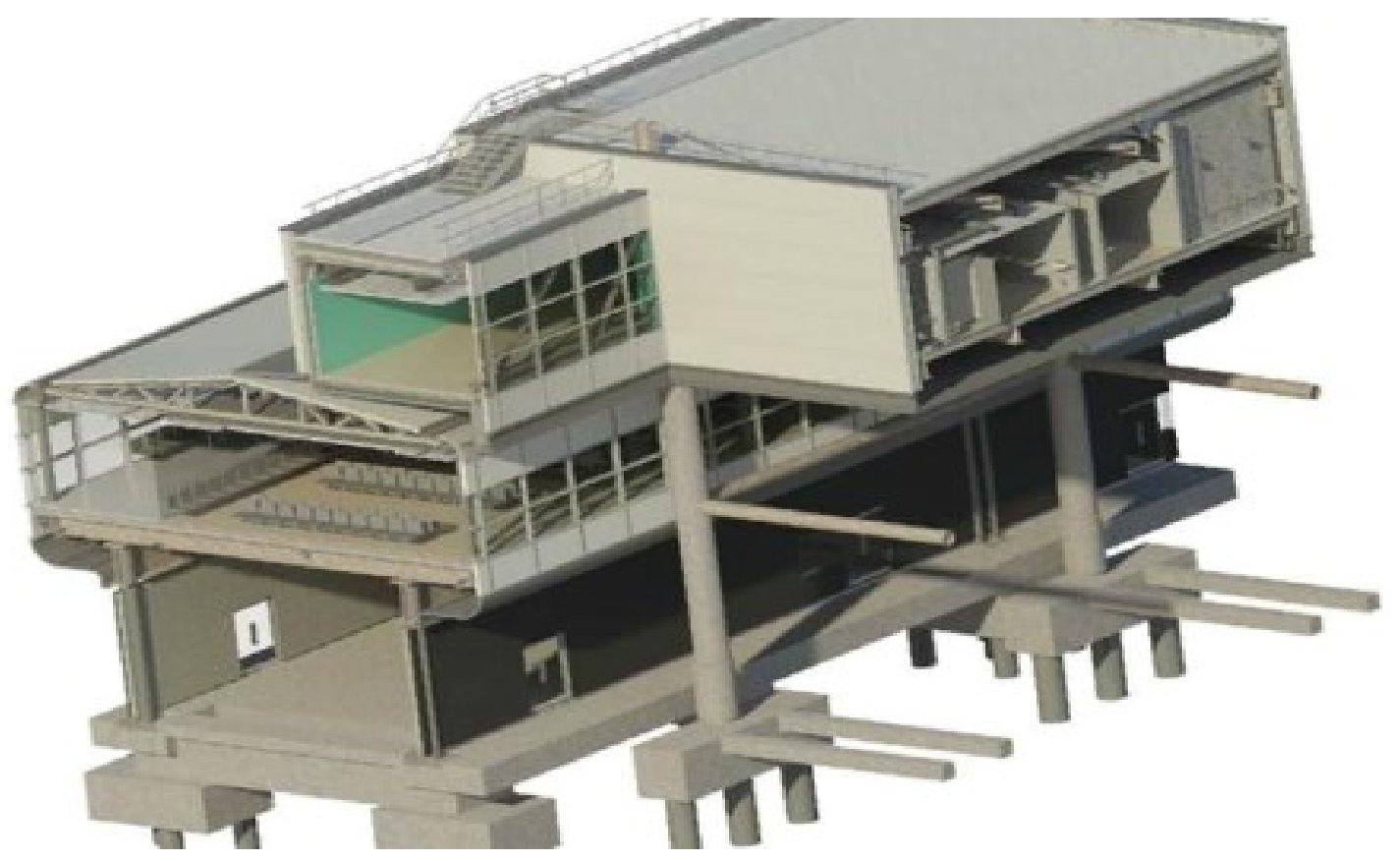

Figura 12- Detalhe do Aeroporto de GATWICK nos sistemas BIM. Fonte: (RICHARDSON, S et al 2015).

O Aeroporto de GATWICK (em detalhe na Figura 12) é o segundo maior aeroporto do Reino Unido e apresenta o maior movimento em uma única pista de pousos e decolagens no mundo. O aeroporto conecta cerca de 200 destinos em 90 países, apresentando movimento anual de cerca de 34 milhões de passageiros. O aeroporto pertence a um grupo de fundos de investimento internacional, dos quais a "GLOBAL INFRASTRUCTURE PARTNERS" (GIP) é o maior acionista. O aeroporto de GATWICK está passando pela maior transformação de sua história, com novos edifícios e outras instalações sendo projetadas em espaço muito curto de tempo. O Governo do Reino Unido exige processo colaborativo por meio dos sistemas BIM no mínimo até 2016, o que ocasiona redução de custos de $20 \%$ (RICHARDSON, S et al 2015). 


\subsection{2- ESTADOS UNIDOS: DENVER.}

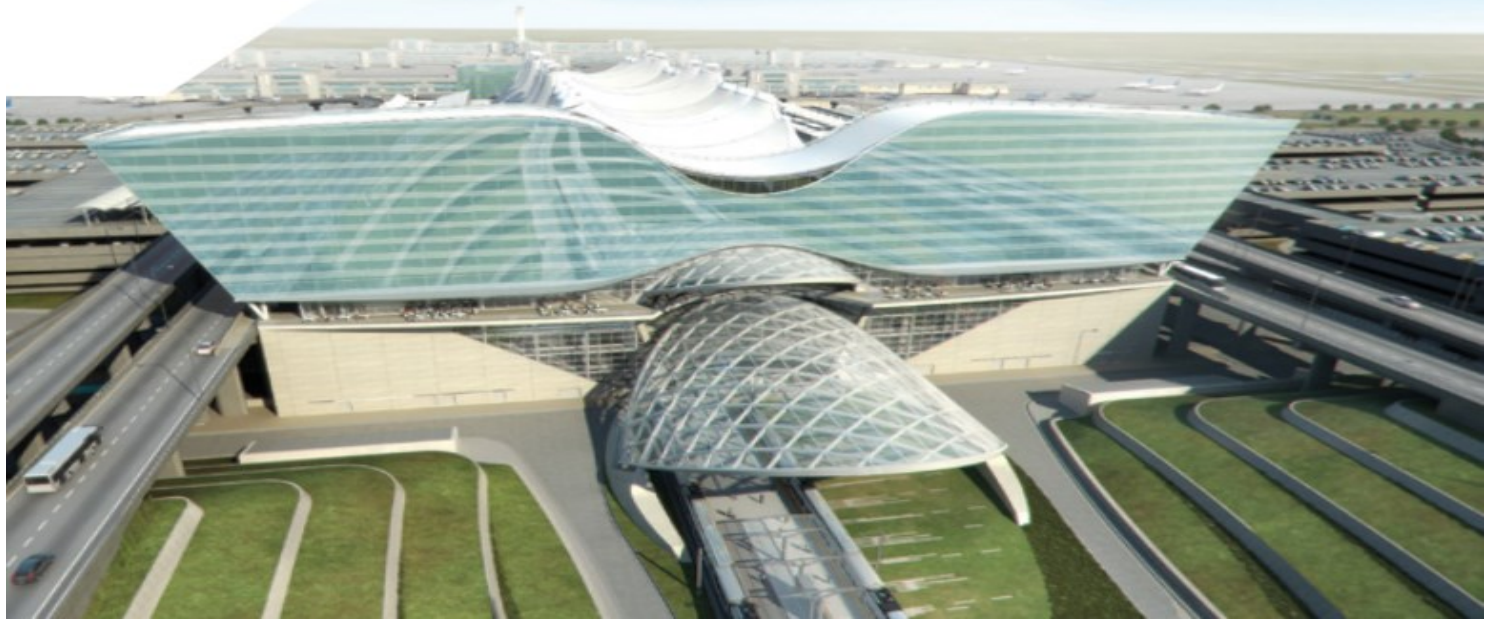

Figura 13- Expansão do Aeroporto de Denver. Fonte: DIA \& GENSLER apud BALL, M.

O projeto do aeroporto utilizou sistemas CAD, BIM e GIS em uma base regular no processo de projeto (Figura 13). O SIG foi utilizado para integrar informações de projeto com o contexto real do sitio existente. Os sistemas BIM foram a plataforma utilizada para integrar todas as informações de infraestrutura. Para manter a sincronização destes sistemas, atualizações bidirecionais foram realizadas de forma regular e programada. O BIM teve a vantagem de que os projetos foram criados pelos autores de cada especialidade, sendo que a informação do modelo corresponde à localização exata em uma base de dados no SIG. Os modelos foram detalhados com atributos e especificações que puderam ser compartilhados tanto nos sistemas BIM como SIG (BALL, M. - AutoDesk, 2010).

Nas empresas de administração de aeroportos brasileiras, a disponibilização de componentes paramétricos aeroportuários pode representar benefícios consideráveis para a utilização dos sistemas BIM. Por meio da análise de sua elaboração foram examinados os fatores endógenos (entraves e impactos como a criação de novos parâmetros e ainda a representação semântica dos mesmos no contexto do projeto), como por exemplo por meio da inserção dos novos componentes no terminal regional da INFRAERO, sendo possível observar seu relacionamento com a escala da edificação, tanto quanto os exógenos (pouco ou nenhum desenvolvimento nacional de metodologias BIM para o projeto de aeroportos) envolvidos no processo. Uma vez estabelecido o caminho a ser percorrido pela informação, torna-se imprescindível o domínio não só das ferramentas empregadas, mas da interface existente entre elas. As antigas práticas envolvidas no processo de projeto em vigor nas empresas brasileiras, como a INFRAERO representam não apenas atraso tecnológico, mas envolvem ainda outros aspectos como hierarquia e estrutura organizacional tradicional, acarretando dificuldade na gestão de práticas e processos na empresa. 


\section{7- AMBIENTE SIG}

A principal diferença de um SIG para um sistema de informações convencional é sua capacidade de armazenar tanto atributos descritivos como as geometrias dos diferentes tipos de dados geográficos (QUEIROZ, 2007, p. 5).

"Simultaneamente, o avanço dos ambientes computacionais tem permitido aperfeiçoar as representações gráficas do espaço urbano, indicando a possibilidade da prática da modelagem urbana retomar a trajetória de representação icônica de ambientes urbanos, sem que se percam as finalidades exploratórias e preditivas dos modelos. O paradigma atual da modelagem urbana passa por articular as possibilidades do CAD - Desenho Auxiliado pela Computação ao potencial exploratório dos SIG Sistemas de Informações Geográficas. O recente aporte dos SIG tridimensionais surge como um campo científico ainda a ser explorado neste sentido (BATTY et al, 2004; MARTÍNEZ, 2007, apud PERES, POLIDORI, 2009, p. 3).

Da modelagem tridimensional em sistema BIM associado ao SIG resultam modelos interativos ("smart models").

Tais modelos ao se associarem ao SIG (armazenamento, gestão, visualização e análise de informação) e aos sistemas BIM (geometria paramétrica e associativa), nos permitem dispor de uma base de trabalho que favorece a partilha de dados na escala da cidade.

Os SIG podem ser tidos como sistemas, ou conjunto de ferramentas, que são capazes de coletar, armazenar, analisar e exibir dados, espaciais ou não espaciais, representativos de algum aspecto, fato ou local do mundo real. A seguir é apresentado pequeno histórico da origem e desenvolvimento dos SIG:

A primeira fase é conhecida como "Fase Pioneira" ou "Fase de Pesquisa de Fronteiras". Nos Estados Unidos e no Reino Unido esta fase se estende mais ou menos do ano de 1950 até o ano de 1975 (COPPOCK, RHIND, 1991, apud BONGIOLO, 2008, p.186-188). A segunda fase, que transcorreu de 1972 até o início dos anos 80, é marcada pelos estudos formais e pelas pesquisas financiadas por agências governamentais. 
Nesta fase a influência individual perdeu espaço na escala global, a não ser no caso dos grandes nomes das agências do governo, mas continuava a ter muita influência em escalas locais, principalmente dentro dos centros de pesquisa e junto aos grupos de estudo. Esta fase ainda dependia muito de profissionais familiarizados e experientes com SIG, mas pode-se observar um maior contato e contribuição entre as diversas linhas de pesquisa. (COPPOCK; RHIND, 1991, apud BONGIOLO, 2008, p.186188).

\title{
A terceira fase tem início em 1982 e é conhecida como "Fase Comercial".
}

\author{
"Até então limitados pelo alto custo do hardware \\ [...], os SIG se beneficiaram grandemente da \\ massificação causada pelos avanços da \\ microinformática e do estabelecimento de centros de \\ estudos sobre o assunto." (CÂMARA, G. e DAVIS, C. \\ 2001, p.3).
}

Nessa fase, os SIG de uso comercial ganham espaço e diversas empresas com foco em SIG surgem ou se tornam mais abrangentes, o que acirrou a concorrência do mercado. É importante ressaltar a atuação de instituições e empresas como a 'Environmental Systems Research Institute' - ESRI, a Intergraph ${ }^{\circledR}$, a ComputerVision ${ }^{\circledR}$ e a Synercom ${ }^{\circledR}$, algumas das quais atuam até hoje no desenvolvimento dos SIG. Outra característica observada nesta fase é a centralização dos SIG.

Os sistemas que antes funcionavam individualmente dão lugar a sistemas interligados que podem utilizar diversas fontes de dados. Vale lembrar também que o uso dos SIG se tornou muito mais "rotineiro", diminuindo muito a dependência em profissionais conhecedores das tecnologias dos SIG, o que tornou possível maior disseminação desses sistemas (COPPOCK, RHIND, 1991, apud BONGIOLO, 2008, p.186-188).

O papel do usuário domina a quarta fase da história do SIG, pois os sistemas se tornam muito mais simples e disseminados. Eles também continuam a centralizar e interligar dados, e em diversas empresas funcionam em servidor central que provê a maioria dos dados necessários, que pode ser ligado a outros servidores SIG para obter mais dados e informações semânticas de que seus usuários necessitem (COPPOCK, RHIND, 1991, apud BONGIOLO, 2008, p.186-188).

Por exemplo, nos estágios iniciais de projeto podemos estar pensando na disposição das paredes e imaginando determinadas aberturas nas mesmas. Nesse estágio geométrico já é possível ter a descrição dos contornos das paredes e da disposição das aberturas. Ao atribuirmos algum nível semântico a essas aberturas, poderemos definir se serão portas ou janelas, sua função e significado 


\title{
2.8- O CONCEITO DE LOD, “LEVEL OF DETAIL” e “LEVEL OF DEVELOPMENT”
}

As representações ambíguas são importantes nos estágios iniciais da projetação.

Neste sentido, GOEL (1995) argumenta que são:

\begin{abstract}
"Sistemas de símbolos não notacionais, cujos limites de cada um são muito próximos uns dos outros e não são indesejáveis. Pelo contrário, eles desempenham funções cognitivas importantes, pois ... a ordenação densa de símbolos no sistema de esboços fornece aos mesmos um grau de continuidade... a redução da distância entre símbolos ajuda a garantir que possibilidades não sejam excluídas e ajuda a transformar um símbolo em outro, quando necessário. A ambiguidade do sistema de símbolos de esboços garante que o conteúdo dos mesmos durante as fases iniciais de projeto seja indeterminado. Ambiguidade é importante porque não é desejável que se cristalize as ideias muito cedo e se congele o desenvolvimento do projeto ... a reivindicação geral é que transformações entre símbolos contíguos precisam ocorrer durante a fase preliminar de resolução de problemas e que a densidade e ambiguidade do sistema de esboços facilitam essas operações cognitivas. Um sistema de símbolos notacionais, como o desenho técnico bidimensional, que difere dos esboços por ser não denso e não ambíguo, prejudicará as transformações laterais... além do mais, a ambiguidade facilitará as transformações laterais porque permite múltiplas interpretações e impede a cristalização das ideias muito cedo" (GOEL, 1995, p. 193-194).
\end{abstract}

A concepção de projetos requer a capacidade de abstração (acerca de uma demanda ou dados de programa de necessidades) e de antecipação (apresentação e representação de soluções plausíveis). Portanto, os processos de avaliação de possíveis respostas aos problemas de projeto precisam se valer de representação ambígua dos artefatos propostos, permitindo que diversas alternativas de especificação se mantenham em aberto e sejam avaliadas antes que se tomem decisões definitivas a favor de uma delas. A ambiguidade dos artefatos significa, em termos computacionais, que cada classe de equivalência dos componentes físicos denota o mesmo símbolo de representação. A diferenciação semântica pode ser vista como uma restrição, em sistemas BIM - Revit $^{\circledR}$, devido a limitação do sistema computacional representar o mesmo componente do mundo físico com diferentes representações de detalhamento geométrico e semântico, do ponto de vista da informação embutida no modelo. 
O conceito de LOD abrange significados distintos, porém relacionados, sendo descrito como nível de detalhe ("level of detail") pelo "American Institute of Architects" e Penn State University, "Building and Construction Authority" como também nível de desenvolvimento ("level of development") em "BIM Protocol Exhibit" (MCPHEE, 2013, p.1). Nesta pesquisa o conceito adotado representa a divisão dos níveis e LOD em dois tipos: LOD Semântico (Desenvolvimento) e LOD Geométrico (Detalhamento). As Figuras 14 e 15, no âmbito do conceito de LOD, ilustram o detalhamento de uma cadeira de escritório.

\section{LOD 100 LOD 200 LOD 300 LOD 400 LOD 500}
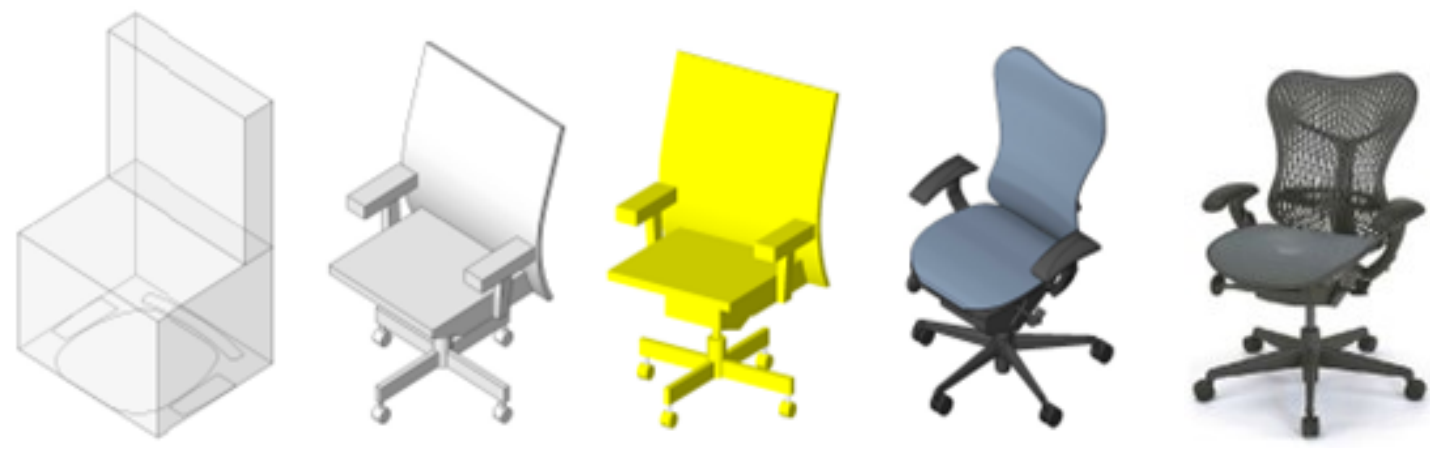

\begin{tabular}{|c|c|c|c|c|}
\hline ESTUDO CONCETUAL & PMOJETO BASICO & DOCUMENTACAO & CONSTRUCAO & GESTAO DE PATRIMON \\
\hline DESCRICAO & DESCRICAO & DESCRICAO & DESCRICAO & DESCRICAO; \\
\hline CADEIRA ESCRITORIO & CADEIRA ESCRITORIO & CADEIRA ESCRITORIO, & CADEIRA ESCRITORIO & CADEIRA ESCRITORIO, \\
\hline LARGURA: & $\begin{array}{l}\text { ROODAS } \\
\text { LARGURA: }\end{array}$ & $\begin{array}{l}\text { BOODS } \\
\text { LARGURA: }\end{array}$ & $\begin{array}{l}\text { RODAS, BRACOS } \\
\text { LARGURA: }\end{array}$ & $\begin{array}{l}\text { RODAS, BRACOS } \\
\text { LARGURA: }\end{array}$ \\
\hline & 700 & 700 & 685 & 605 \\
\hline PROFUNDIDADE: & PROFUNDIDADE: & PROFUNDIDADE: & PROFUNDIDADE: & PROFUNDIDADE: \\
\hline & & & & 430 \\
\hline ALTURA: & ALTURA: & ALTURA: & ALTURA: & ALTURA: \\
\hline ragnager & 1100 & 1100 & 1085 & 1005 \\
\hline FABRICANTE: & FABRICANTE: & FABRICANTE: & FABRICANTE: & FABRICANTE: \\
\hline Herman Miler, lnc. & Herman Miller, Inc. & Herman Ner, Inc. & Herman Miller, inc & Herman Miller, Inc \\
\hline MODELO: & MODELO: & MOOELE: & MOOELO: & MODELO: \\
\hline Mirra & Mirra & Mirta & Mirra & Mirra \\
\hline LOD: & LOO & LOD: & LOD: & DATA DECOMPRA: \\
\hline 100 & 200 & 300 & 400 & $01 / 02 / 2013$ \\
\hline
\end{tabular}

Figura 14 - Diferentes Níveis de Desenvolvimento. Fonte: Adaptado de MCPHEE, 2013, p.1.

A Figura 14 acima ilustra o acréscimo de informação (em vermelho) em um modelo de uma cadeira de escritório. Semelhantemente, o conceito de LOD acompanha as fases de desenvolvimento do processo de projeto, desde o estudo conceitual, projeto básico, documentação e projeto, etapas construtivas até a gestão e manutenção da edificação. 
Frequentemente o conceito de LOD encontra-se associado às informações geométricas, o que pode levar a entender os sistemas BIM apenas como sinônimo de representação tridimensional. Um elemento do modelo, por sua vez, é qualquer parte de um modelo BIM que represente componente, ou sistema de construção (AIA, G2022013, p. 2-5). Este último documento define cinco LOD's (100, 200, 300, 400 e 500), que são frequentemente associados às fases de projetos de construção.

A Figura 15 abaixo demonstra graficamente o ganho em complexidade na representação de uma cadeira de escritório. Aliada à variação geométrica do LOD, está a representação semântica, que influencia na quantidade e qualidade das informações associadas ao modelo, em razão crescente de complexidade, desde o LOD100 até o LOD 500.

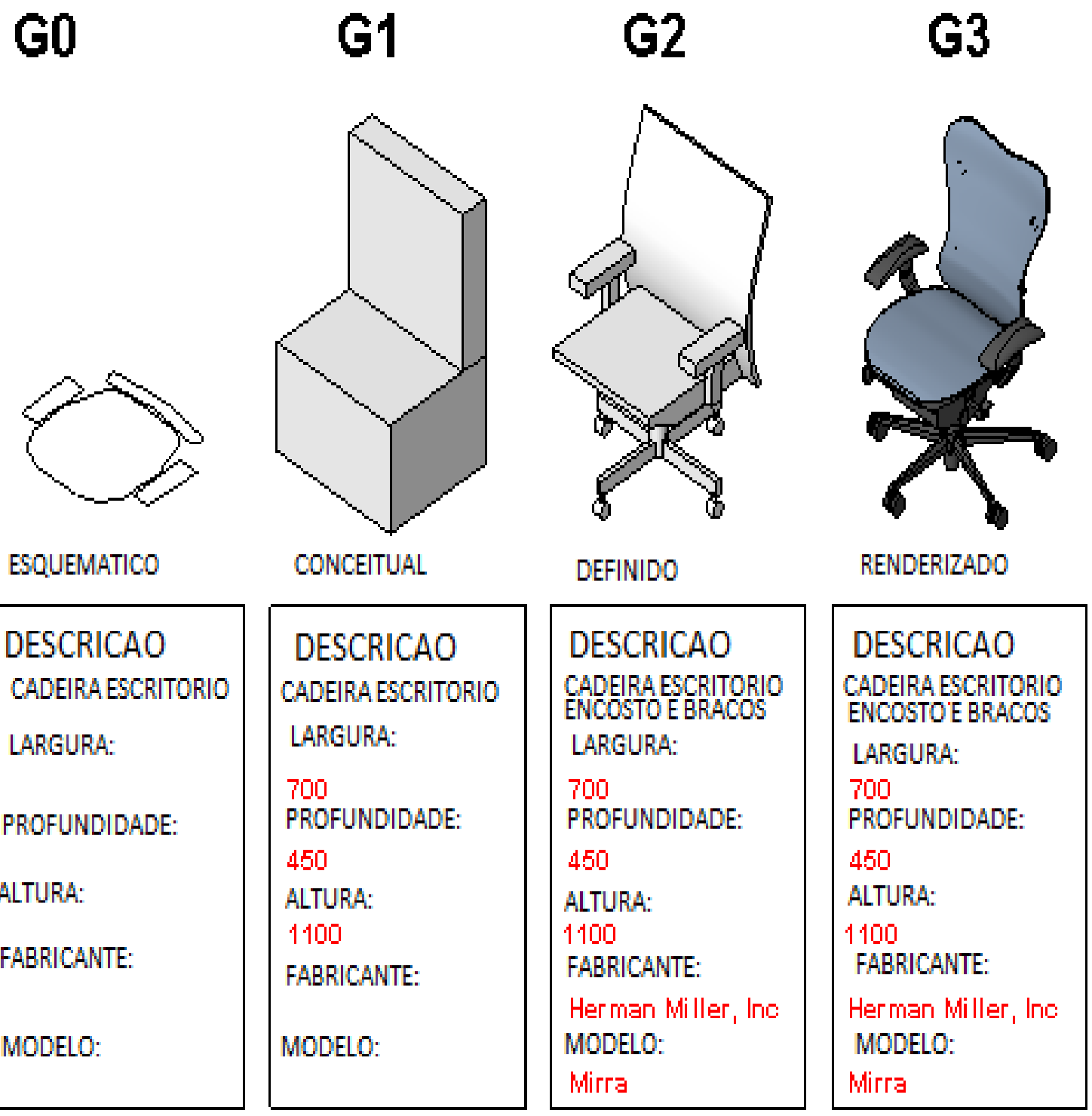

Figura 15- Diferentes Níveis de Detalhamento. Fonte: Adaptado de MCPHEE, 2013, p.1.

LOD na definição proposta pela AIA, estabelece três diferentes níveis de desenvolvimento para o processo de projeto: 
LOD-100 estabelece que o elemento pode ser representado graficamente no modelo por um símbolo ou outra representação genérica, mas não satisfaz os requisitos do LOD 200 (Figura 14 e 15) (MCPHEE, 2013, p.1). LOD-200 estabelece que o elemento é graficamente representado no modelo como um sistema genérico, objeto ou montagem com quantidades aproximadas, tamanho, forma, localização e orientação. Informações não gráficas também podem ser ligadas ao elemento de modelo (Figura 11 e 12) (MCPHEE, 2013, p.1). LOD-300 estabelece que o elemento é graficamente representado no modelo como um sistema específico, objeto ou montagem em termos de quantidade, tamanho, forma, localização e orientação. Informações não gráficas também podem ser ligadas ao elemento de modelo (Figuras 14 e 15) (MCPHEE, 2013, p.1).

Os LOD-400 e 500 pertencem aos processos de fabricação e de construção, razão pela qual não foram detalhados nesta pesquisa. Exemplo dos mesmos é a formação de vãos em conjunto com as esquadrias, sendo impossível para sistemas BIM como o Revit ${ }^{\circledR}$ representar apenas as aberturas. Esta limitação torna impossível abstrair a solução de fechamento de esquadrias e trabalhar apenas com os vãos desejados naquele momento do processo de projeto. A conceituação semântica de componentes aeroportuários (LOD Semântico), segundo cada fase de projeto, bem como das informações geométricas de componentes paramétricos (LOD Geométrico), pode servir para documentar aquilo que se encontra não definido e trazer benefícios para o processo de projeto de aeroportos no Brasil, mais especificamente na constituição de bases de conhecimento que definam com maior clareza os aspectos objetivos dos componentes BIM aeroportuários (LOD Geométrico) e dos aspectos subjetivos de sua natureza (LOD Semântico) (Figura 14 e 15) (MCPHEE, 2013, p.1).

A utilização do LOD-300 traz nível menor de abstração, uma vez que agora tornase necessária a especificação de materiais e o detalhamento dos sistemas construtivos, para que se possa determinar se o custo de manutenção e de operação são adequados a projetos de natureza pública, no caso da INFRAERO. Da mesma forma, o LOD-400 detalha ainda mais os componentes construtivos, para que seja possível manipular a informação em nível de complexidade suficiente para os Projetos Executivos. O LOD500 pertence a esfera de "as-built", devendo ser atualizado a partir do LOD-400 com informações pós-construção da edificação, de forma a atualizar a base de dados de projeto para operação e manutenção, ao longo do ciclo de vida. Apesar de ser uma vantagem em relação ao CAD tradicional, a presença de todos os elementos geométricos em um mesmo local não garante a estruturação e a possibilidade de manipulação de abstração das informações de projeto (Figura 14 e 15). 
O alto grau semântico e de detalhe dos sistemas BIM dificulta seu emprego nos estágios iniciais de projeto, quando necessitamos de variável nível de abstração e de detalhamento. Embora ainda sejam poucos os estudos quantificando as vantagens obtidas pelo uso dos sistemas BIM, as pesquisas na área de tecnologia de informação concordam em relação à sua influência positiva sobre o desempenho do processo de projeto e a respeito da irreversibilidade da transição do CAD geométrico para os sistemas BIM. A síntese para a utilização dos sistemas BIM na INFRAERO representa um ambiente semântico que oferece suporte à transferência coerente e interoperável de dados entre pessoas e sistemas inteligentes de informação. Estes trabalhariam em conjunto com um ambiente SIG que permitisse representar os modelos BIM em diferentes níveis de abstração, para diferentes contextos, conforme afirmado anteriormente. Na prática, o tipo de análises que se faz em um modelo SIG é diferente daquelas nos sistemas BIM. Nestes últimos pode-se produzir estimativas de custos, verificação de interferências nas diversas fases da obra em diferentes níveis semânticos, como descrito a seguir.

As limitações dos sistemas BIM para responder a variação de informação e detalhes (LOD Semântico e LOD Geométrico), oscilando entre múltiplas definições entre a forma e a função, ou em outras palavras, entre a imaginação e a solução, os torna inadequados para as fases iniciais de projeto. A seguir detalhamos a utilização dos SIG associados aos sistemas BIM e os impactos desta metodologia nos processos de projeto, tomada de decisão e análise, associados ao nível de detalhe (Figura 16) (LÖWNER, et al, 2013, p. 4).

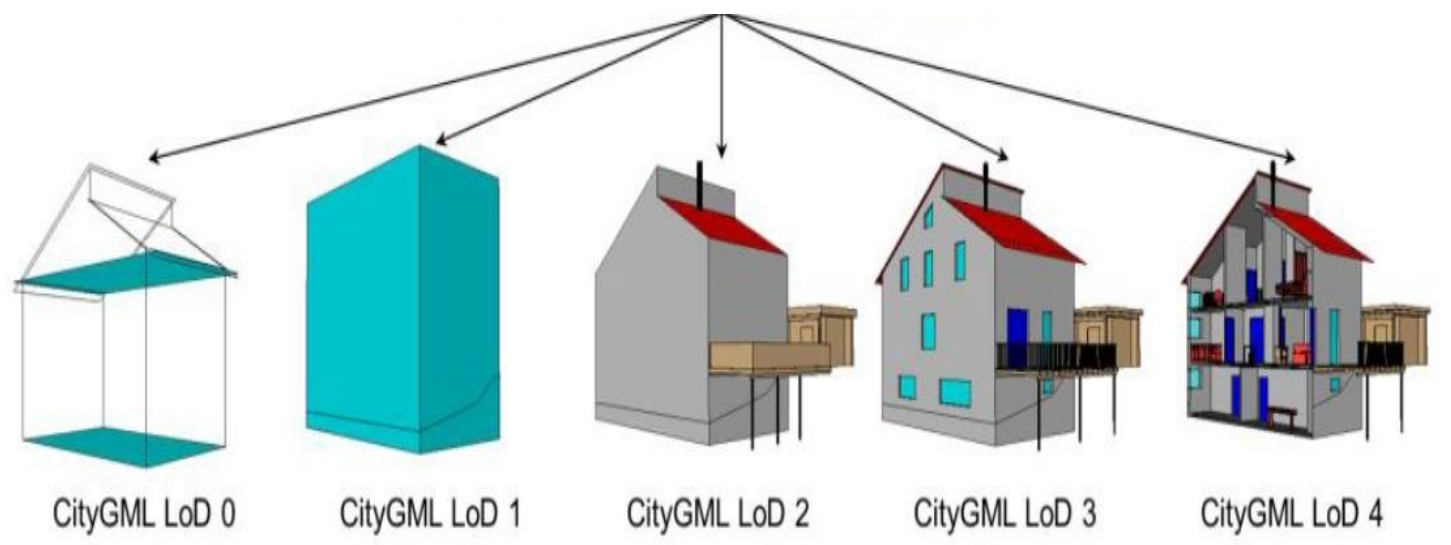

Figura 16 - Múltiplos níveis - detalhamento Geométrico SIG. Fonte: LÖWNER, et al, 2013, p. 4.

Se entendermos ontologias como uma forma de sistematização de informações do mundo real e as conexões semânticas como os significados, ou descrições da realidade, dentro do contexto cultural em que o projeto se encontra inserido podemos enxergar as atividades de projeto mais precisamente - formulação, síntese e análise como transposições entre os requisitos e condicionantes do mundo real e as alternativas e possíveis soluções, do mundo ideal (LÖWNER, et al, 2013, p. 4). 
Os LOD's são baseados nos componentes do modelo e não nos modelos como um todo, ou seja, não existem modelos BIM com determinados LOD's, que representem as fases do desenvolvimento de um projeto de construção, mas modelos BIM que possuem componentes com determinados LOD's consoante às especificidades $\mathrm{e}$ objetivos do projeto de construção; (AIA, G202-2013, p. 2-5). Esta observação define não só a escala em um processo de projeto (mas também a escala de análise e de condensação de informação dos modelos BIM, de forma geral.

A adoção das tecnologias BIM e SIG nos diferentes estágios de um processo de projeto contempla diferentes níveis de detalhe para cada um dos componentes construtivos. O detalhamento das informações referentes aos componentes construtivos ao longo das fases de um projeto envolve não apenas sua conceituação geométrica, mas ainda a necessária coordenação entre os processos que o perfazem.

Por esta razão adotamos nesta pesquisa a definição do nível de detalhe (LOD) proposta em "New Concepts for Structuring 3D City Models" - na "Extended Level of Detail Concept for CityGML Buildings" (LÖWNER, et al, 2013, p. 466-480).

Os autores diferenciam nível de detalhe geométrico (GLOD) e nível de detalhe semântico (SLOD). Estes dois conceitos de LOD são apresentados separadamente para as características do interior de um edifício e em relação à estrutura externa da edificação, respectivamente.

O "CityGML - Geography Markup Language" é um aplicativo independente e de código aberto ("open source"), que serve como modelo de informação para a representação, o armazenamento e a transferência de dados em ambientes tridimensionais. Abrange as representações geométricas de objetos tridimensionais, bem como sua semântica e a sua inter-relação com outros objetos.

No passado, modelos tridimensionais de áreas urbanas eram puramente visuais. No entanto atualmente são enriquecidos com componentes de diversas plataformas que possuem modelo de informação comum e aberto para permitir a representação de objetos urbanos tridimensionais.

Um deles é conhecido como "CityGML", aprovado pelo "Open Geospatial Consortium" (OGC) como padrão oficial desde 2008, disponível em: http://www.opengeospatial.org/standards/citygml. Este modelo define em detalhe as duas classes que irão participar de um modelo urbano e suas propriedades geométricas e topológicas, além de aspectos semânticos e geométricos. Além disso, caracteriza-se por níveis de detalhe que permitem recriar modelos de um ambiente básico bidimensional em um ambiente tridimensional, de grande complexidade. 
Nos estágios iniciais de projeto, em termos gerais, utilizamos o chamado LOD100, que representa informação conceitual, croquis, etc.

O LOD-200 corresponderia ao Estudo Preliminar em um processo de projeto, em termos gerais, acrescentando a terceira dimensão na análise de projeto No entanto, cabe ressaltar a importância não apenas da descrição semântica dos objetos, mas das interfaces ontológicas e da contextualização do modelo.

A Lei 8.666 prevê, como objetivo principal do Estudo Preliminar, a comprovação da viabilidade do empreendimento. Ao estabelecermos o LOD-200 como nível de abstração de trabalho, reduzimos a complexidade do detalhamento e as especificações de materiais de forma a ressaltar as soluções de projeto empregadas e sua viabilidade econômica, assim como o desempenho projetual em face dos requisitos e condicionantes do empreendimento.

Os sistemas BIM podem representar diferentes níveis de detalhes dos componentes construtivos, em sua representação geométrica, mas ainda assim exigem classificação e detalhamento prévios e o preenchimento de campos de informação referentes aos parâmetros que definem o modelo BIM.

O "CityGML" diferencia cinco níveis de detalhes consecutivos (LOD), onde os objetos se tornam paulatinamente mais detalhados. No "CityGML" o mesmo objeto pode ser representado em vários LOD's, permitindo a análise e a visualização do mesmo objeto em relação aos diferentes graus de resolução (abstração).

O nível mais simples é o LOD-0, em essência, um modelo digital do terreno. O LOD-1 é um modelo de blocos simples, sem quaisquer estruturas de telhado. Um edifício em LOD-2 caracteriza-se pelas estruturas de telhado, varandas e escadas.

LOD-3 indica modelos arquitetônicos com as estruturas de parede, telhado, portas e janelas. O LOD-4 complementa um LOD-3 adicionando ao modelo detalhes dos interiores como escadas e móveis, como pode ser visto na página seguinte. (Figura 17).

Um contexto urbano necessita ter diferentes níveis de detalhe (por exemplo em arquivos "CityGML", LOD-1, LOD-2, etc.) para representar quantidade maior ou menor de informação, como pode ser observado na figura abaixo. Uma alteração de escala equivale a uma mudança na forma de pensar determinado objeto (um prédio, bairro, cidade ou região). O problema de ter objetos em diferentes níveis de detalhe é a dificuldade de integrar todos eles em um único modelo (GRÖGER et al, 2006, p. 11) (Figura 17). 


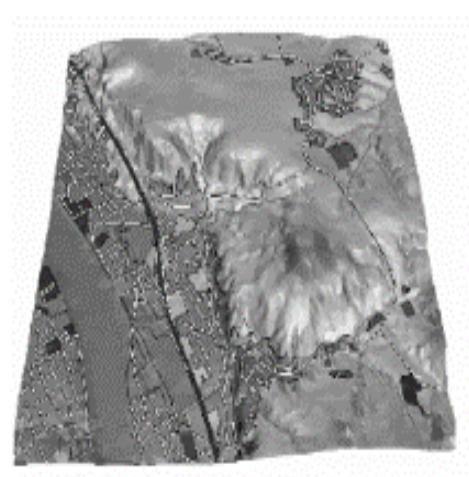

LoD0

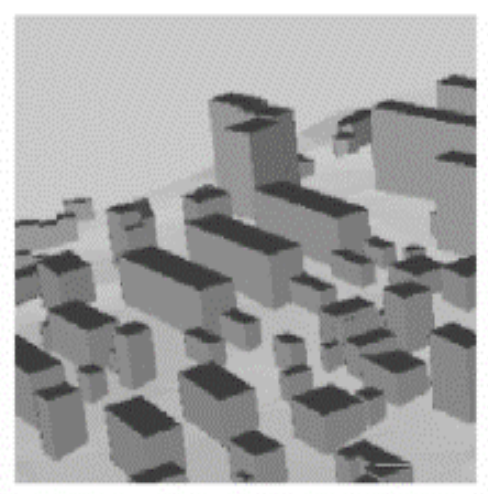

LoD1

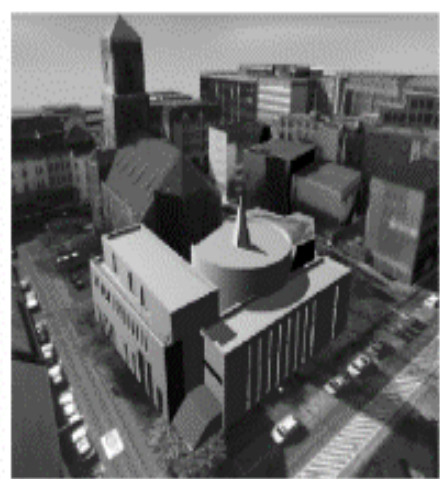

LoD2
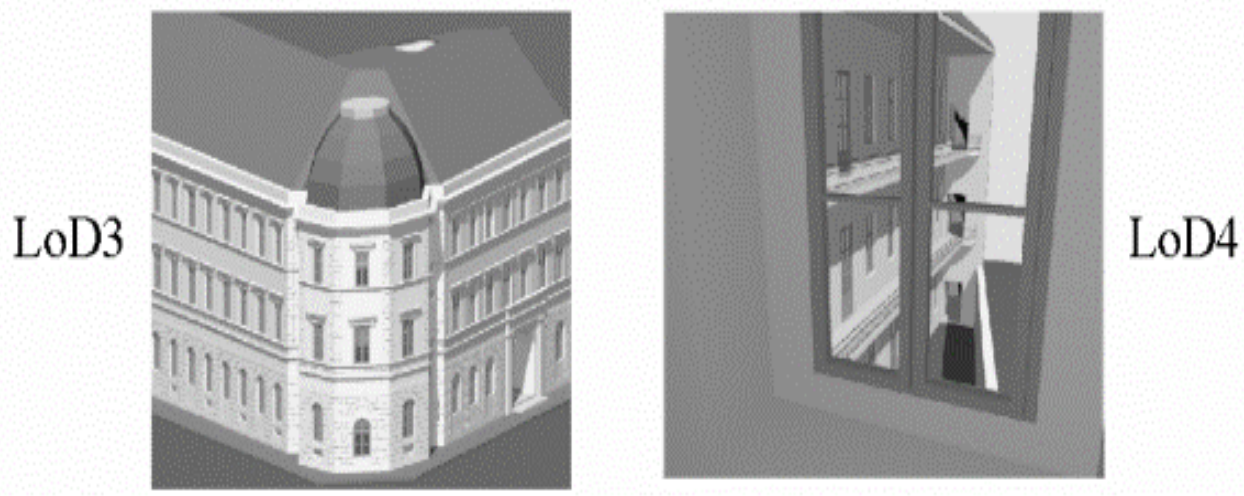

Figura 17 - Os cinco níveis de detalhe definidos (LOD) pelo "CiyGML". Fonte: GRÖGER, G; KOLBE, T; E CZERWINSKI, A. 2006, p. 11.

Ao nos depararmos com um problema arquitetônico, procuramos estabelecer ligação entre um repertório de projeto (que inclui componentes construtivos, processos, métodos e soluções arquitetônicas) com os condicionantes de projeto, suas metas, funções, contextos e restrições, além de normas e requisitos. Esta aproximação entre o repertório de soluções de projeto e a complexidade do problema arquitetônico, ocasiona variação de combinações e tentativas, nas quais normalmente criatividade, intuição e raciocínio procuram se manifestar. Por esta razão, a representação de componentes construtivos e a conexão entre conjuntos de soluções e seus respectivos contextos semânticos é essencial na elaboração de componentes nos sistemas BIM, se desejamos utilizá-los em todas as fases de um projeto. Semelhantemente, o raciocínio projetual procura se valer de "diálogo" entre a semântica das coisas e sua aplicação contextual, seja física ou funcional. Os sistemas computacionais que servem de ambiente de projeto devem fornecer níveis de abstração de informação e diferenças de representação gráfica dos componentes construtivos. Visando avaliar a contribuição que a integração dos sistemas BIM e SIG pode trazer ao processo de projeto de aeroportos no Brasil, realizamos projeto-piloto de expansão para uma torre de controle, na seção 4.4- Simulação de expansão do terminal existente por meio de três alternativas de expansão do terminal existente - projeto (TWR), com o propósito de simular o processo de projeto na INFRAERO. 


\section{9- COMPONENTES BIM}

O processo de implantação dos sistemas BIM no mercado brasileiro está em desenvolvimento e precisa de melhorias para que possa de fato propiciar avanços à construção civil brasileira. A possibilidade de extrair informação e propriedades geométricas de um modelo do edifício, que é utilizada em processo de análise e de planejamento da construção e da fabricação beneficiará toda a indústria da AEC. Gehry argumenta que o computador, ao contrário do que acreditam alguns, pode aproximar o arquiteto tanto do processo de construção quanto dos clientes, além de ajudar a "manter o ímpeto e a variedade formal". (STEELE, 2001, p. 144).

A Gehry Technologies (GT) está entre os ganhadores do prestigiado "Building Information Model Awards", conferido pelo Instituto Americano de Arquitetos (AIA) em Tecnologia Arquitetônica para a Prática do Conhecimento (TAP). O projeto premiado é uma torre comercial de escritórios em Hong Kong. A “Swire, Properties Ltd”, proprietária, impulsionou o uso de um modelo de informações do edifício para esse projeto, visando a reduzir os custos e o tempo de construção, aumentar a eficiência e reduzir os resíduos em toda a concepção, construção e nos processos de gestão (Figura 18) (GEHRY TECHNOLOGIES, 2009.)

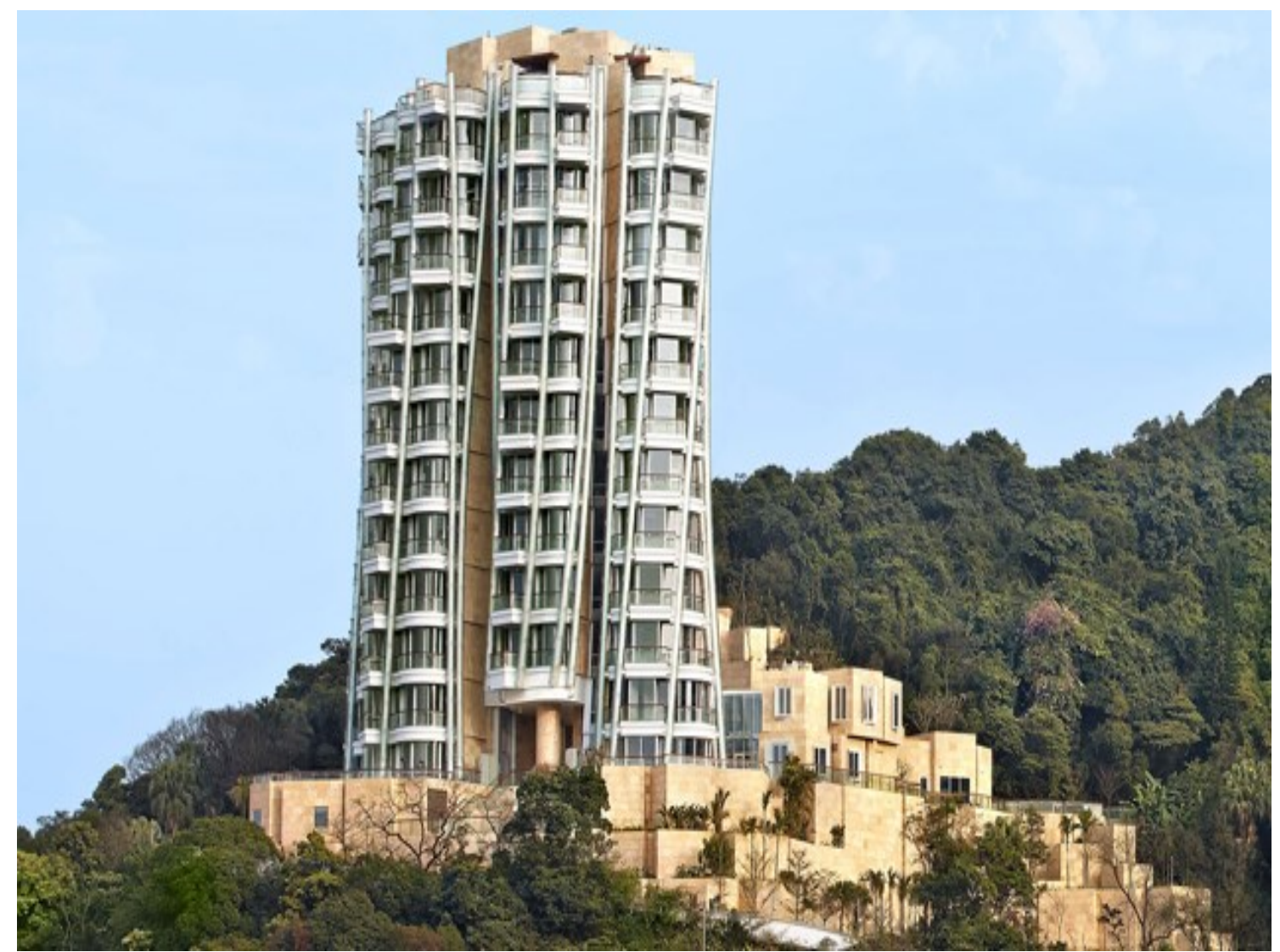

Figura 18 - "One Island East Tower", Swire, Properties Ltd. Fonte: OPUS Hong Kong. 
A concepção dos projetos pela GEHRY PARTNERS ${ }^{\circledR}$ LLP começa sempre a partir de modelos reduzidos e sua posterior digitalização por meio de scanners tridimensionais. Os modelos obtidos neste processo são então parametrizados no sistema BIM Digital Project ${ }^{\circledR}$ (EASTMAN et al, 2008, p. 60).

Estes modelos podem ser reconfigurados e modificados em várias fases do projeto. O modelo é geralmente construído pelo arquiteto. O coordenador do projeto irá estabelecer modelo esquemático. A partir deste modelo genérico, o engenheiro estrutural irá dimensionar e projetar o seu sistema estrutural.

Da mesma forma, os componentes construtivos e acessórios aa edificação devem possuir modelos BIM representando não apenas sua geometria, como ainda informações referentes a suas características e propriedades físicas, como camadas internas e materiais.

Os fabricantes deverão conceber, projetar e construir modelos digitais dos seus produtos e integrar o sistema. Os participantes das diversas áreas complementares do projeto podem extrair informações do modelo mestre e contribuir com informações de volta para o modelo. "Portanto, o modelo é quase como uma coisa viva que continua crescendo através do projeto durante todo o ciclo de vida". (CECCATO, 2001, p. 3 a 5).

Por outro lado, a biblioteca de famílias, incorporadas nas ferramentas BIM, representam as práticas atualmente padronizadas pela indústria. Várias organizações têm tomado iniciativas para desenvolver uma tecnologia de dados, "workflows" de processos de negócios genérico e padrões de conteúdo.

Uma das tarefas mais importantes do "NATIONAL BIM STANDARD" (NBIMSUS) é coordenar estes esforços e harmonizar o trabalho entre as diversas organizações com interesses semelhantes.

Muitas organizações profissionais estão endossando o NBIMS-US ativamente como também promovendo perícias de assunto e recursos importantes de desenvolvimento. Além disso, a maioria dos fabricantes dos sistemas BIM anunciou apoio aos padrões BIM e tem participado ativamente no comitê. (www.wbdg.org/bim/nibs bim.php, The Whole Building Design Guide, acessado em 30/03/2015).

Algumas das metas do NBIMS-US são orientar o escopo e o planejamento de produtos para o processo de projeto, ao invés de concentrá-los em uma base de conhecimento fixa, bem como recomendar que o contratante assuma e estimule os envolvidos a participarem ativamente em todas as fases do ciclo de vida do edifício. 
Uma meta primária do NBIMS-US é maximizar o valor por todos os participantes de processo envolvidos no ciclo de vida do edifício. O NBIMS-US apoia a abordagem em que o ciclo de vida do edifício não seja um processo estritamente linear, mas um processo principalmente cíclico com avaliação e acumulação de conhecimento. Há pelo menos três formas possíveis de criação de componentes paramétricos (famílias) a partir dos sistemas BIM. A primeira abordagem envolve a contratação de fornecedor BIM para construir os componentes adicionais necessários ao projeto. Isto irá garantir um fluxo contínuo de informações de construção, mas vai exigir o dispêndio de recursos durante todo o ciclo de vida do projeto.

A segunda abordagem, comumente encontrada em aplicações BIM existentes, é exportar modelo nativo como um arquivo de dados com base em padrão aberto, que por sua vez podem ser importados e utilizados pelos módulos de projeto independentes desenvolvidos por especialistas diversos. Porém, a ausência de um "link" de dados dinâmico significa que as alterações em um desses projetos complementares não podem ser refletidas de forma ativa e automaticamente nos campos de informação do projeto central BIM (TSE \& WONG, 2004, apud FILHO, CERVANTES, A. 2009, p. 1314). A terceira abordagem é o desenvolvimento dos componentes em padrões abertos (TI "open source") em um projeto BIM. Esta opção permite que a equipe de projeto ganhe "know-how" em uma linha de tempo, além de possibilitar a replicação dos componentes paramétricos em projetos futuros. Este método exige o domínio do usuário na concepção, modelagem e configuração dos componentes dos sistemas BIM (TSE \& WONG, 2004, apud FILHO, CERVANTES, A. 2009, p. 13-14).

Tendo em vista a necessidade de transferência de informação no ambiente da INFRAERO, esta pesquisa defende o uso de padrões abertos para desenvolver componentes paramétricos, centrados na modelagem de apoio (micro modelagem) do modelo central. O objetivo disto é aproveitar a estrutura e organização existentes na empresa, entre as diferentes especialidades de arquitetura e de engenharia, para a aplicação de componentes usualmente empregados na infraestrutura aeroportuária. $O$ grande desafio está em entender como podemos compartilhar o conhecimento e as responsabilidades entre as diversas áreas da empresa, de modo a atender as demandas dos processos e dos projetos ao mesmo tempo. A utilização de componentes paramétricos de equipamentos, somada à disponibilidade de elementos construtivos comuns, possibilita que o processo de projeto aeroportuário torne-se possível no Brasil. Isto se torna ainda mais relevante em função dos componentes de infraestrutura aeroportuária não serem usuais e, portanto, certamente, por sua especificidade, carecerem de desenvolvimento adequado para que sejam passiveis de utilização em projetos BIM. 


\subsection{0- ASSOCIAÇÃO DOS SISTEMAS BIM E SIG}

Segundo PAUWELS (2012), os sistemas BIM permitem o desenvolvimento de processos de tradução e interpretação de informação entre especialistas e/ou usuários dos diversos campos de conhecimento. "Sistemas Especialistas" podem ser postos em prática, para representar e transferir informação sobre cada um desses campos de conhecimento (PAUWELS, 2012). Um sistema especialista é aquele que é projetado e desenvolvido para atender a uma aplicação determinada e limitada do conhecimento humano, através do agrupamento de objetos/módulos, cada qual com sua especialidade, com o objetivo de fornecer resposta o mais factível possível da real resposta esperada (PREZOTO, L., 2010, p.2). Os sistemas especialista tem como premissa principal solucionar um problema que normalmente são solucionados por 'especialistas humanos', o sistema é capaz de emitir uma decisão, com o apoio em conhecimento justificado, a partir de uma base de informação, tal qual um especialista de determinada área do conhecimento. Por meio desses sistemas todos os participantes utilizam um mesmo protocolo de comunicação da informação. Desta forma erros de comunicação ou de interpretação podem ser evitados, como por exemplo, na importação do modelo entre diferentes aplicativos.

Neste sentido a metodologia de processo de projeto semântico chamado, "STREAMER" pertencente a "European Research on Energy-efficient Healthcare Districts", conforme SEBASTIAN et al, permite que todos os participantes de um projeto possam otimizar sua compreensão e atuação em diferentes níveis de abstração, observando a escala do edifício, da vizinhança, do bairro, ou da cidade. Ferramentas de gerenciamento de dados em diferentes níveis de abstração só são possíveis se associarmos as áreas de conhecimento dos sistemas BIM e SIG de forma a permitir representar os parâmetros e as características geométricas dos objetos em diferentes níveis de abstração. O "STREAMER" visa permitir a captura, o intercâmbio, a partilha, a comparação e o armazenamento de informações relevantes para a construção de modelos SIG para projetar a edificação com melhor eficiência energética. Até recentemente, a interoperabilidade de informações era limitada ao mesmo domínio. Cada modelo de informação era normalmente projetado para um domínio específico, por exemplo, planejamento urbano. A conexão dos dados do modelo em diferentes níveis de detalhe (LOD) até hoje é difícil; e, além disso, nenhum dos modelos de informação existentes abrange uma abordagem holística para a construção contemplando todo seu ciclo de vida (SEBASTIAN et al, 2013, p. 256-257). Um padrão aberto, que permita descrever as relações entre diferentes modelos de informações semânticas (por exemplo, entre o "IFC" e o "CityGML"), especialmente em ambientes de rede ainda não foi desenvolvido (VAN BERLO, \& DE LAAT, 2011, p. 211-227). 
O "STREAMER" adota a abordagem de modelagem conjunta das áreas relacionadas, utilizando o modelo ideal para cada processo, para todo o ciclo de vida, levando em conta os relacionamentos destes. Esta abordagem permite que todos os participantes possam contribuir para otimizar os projetos de edifícios em um nível complexo de construção. A relação entre os diferentes modelos, por exemplo, do detalhado, de construção (por meio dos sistemas BIM) e sua vizinhança (em SIG), deve considerar todos os níveis de abstração e especificação envolvidos no projeto. Diversos sistemas BIM e SIG estão atualmente no mercado. No contexto nacional apenas dois fabricantes de sistemas BIM encontram-se estabelecidos como representantes nacionais e, portanto, podendo fornecer soluções através de licitações públicas como no caso da INFRAERO.

LISTAMOS ABAIXO OS DIVERSOS SISTEMAS EXISTENTES QUE FORAM AVALIADOS NESTA PESQUISA PARA O DESENVOLVIMENTO DE PROJETO PILOTO DE AEROPORTOS:

1- REVIT $^{\circledR}$ (BIM) - é considerado o líder de mercado e talvez a melhor ferramenta atualmente para uso dos sistemas BIM no processo de projeto arquitetônico. Seus pontos fortes são a facilidade de aprendizagem e interface amigável com o usuário, além de possuir uma grande variedade de bibliotecas disponíveis, inclusive para terceiros. Os pontos fracos são a forma como utiliza da memória do computador (com perdas significativas de desempenho para grandes projetos) e também não oferece suporte para superfícies curvas complexas. Por ser um aplicativo baseado no uso da memória do computador, oferece restrições no escalonamento de grandes projetos Aconselha-se a dividir grandes projetos em módulos de acordo com áreas, ou melhor, para facilitar o desempenho. Outra limitação consiste em não permitir a visualização de modelos em perspectiva, em modo de edição, mas somente em axonométricas, Isto tem implicações profundas, como por exemplo, a impossibilidade de navegar através dos modelos em modo de edição (EASTMAN et al, 2008, p. 57 a 64);

2- $A R C H I C A D^{\circledR}$ (BIM) - possui uma interface intuitiva, que facilita o aprendizado, sendo relativamente simples sua utilização (EASTMAN et al, 2008, p. 57 a 64). É o mais antigo sistema BIM no mundo e o mais utilizado na União Europeia. Possui grande diversidade de bibliotecas de objetos Conta ainda com atualização automática de documentação e suporta operações simultâneas de mais de um utilizador. Permite visualização de modelos em perspectiva, em modo de edição para navegar através dos modelos ainda neste modo (EASTMAN et al, 2008, p. 57 a 64); 
3- DIGITAL PROJECT foi desenvolvida pela Gehry Technologies, representa uma customização para edifícios do CATIA ${ }^{\circledR}$ Dassault $^{\circledR}$, a plataforma de modelagem paramétrica mais utilizada no mundo nas indústrias aeroespacial e automotiva. A estrutura lógica do CATIA $^{\circledR}$ divide-se em módulos, chamados de "Workbenches". A customização feita pela Gehry Technologies trouxe uma série de novas famílias de objetos específicos para a construção civil à base CATIA de gerenciamento de infraestrutura e projeto. A Digital Project oferece poderosa capacidade de modelagem paramétrica, sendo este um dos seus pontos mais fortes. Possui também a capacidade de modelagem direta de grandes complexos de informação do edifício. Seus pontos fracos são a dificuldade de aprendizado de sua utilização, além de possuir uma biblioteca de objetos bastante limitada. Ainda é uma ferramenta em desenvolvimento, que aos poucos irá conquistando seu espaço no mercado e gerando novas bibliotecas de objetos por terceiros (EASTMAN et al, 2008, p. 57 a 64);

4- TEKLA ${ }^{\circledR}$ STRUCTURES, plataforma desenvolvida pela Tekla Corp ${ }^{\circledR}$, companhia finlandesa fundada em 1966, com escritórios espalhados por todo o mundo. Possui divisões de edifícios, construção, infraestrutura e energia. Para atender à demanda dos fabricantes de concreto pré-fabricado, representados pela "Precast Concrete Software Consortium", a funcionalidade do "software" foi estendida para suportar interfaces de fabricação digital para estruturas de concreto e fachadas de edificações. Seus pontos fortes são principalmente sua grande versatilidade em modelar diferentes estruturas que incorporem todo tipo de materiais e detalhamentos das estruturas. Como fator negativo, como toda ferramenta complexa, exige significativo tempo em treinamento para que 0 usuário possa utilizar de todas as funcionalidades do programa (EASTMAN et al, 2008, p. 57 a 64$)$;

5- DPROFILER ${ }^{\circledR}$, desenvolvida pela Beck Technologies, localizada em Dallas, Texas. Baseia-se em plataforma de modelagem paramétrica adquirida da "Parametric Technologies Corporation ${ }^{\circledR ” ~-~(P T C), ~ e m ~ m e a d o s ~ d o s ~ a n o s ~ 90 . ~ F o i ~}$ introduzida no mercado como ferramenta para estudos preliminares em edificações, anteriores ao desenvolvimento dos projetos. A habilidade em gerar diferentes soluções ou partidos de projeto é única entre todos os softwares citados nesta análise. Seus pontos negativos devem-se ao fato do DProfiler ${ }^{\circledR}$ não ser uma ferramenta de uso genérico para utilização dos sistemas BIM, mas apenas para estudos iniciais (EASTMAN et al, 2008, p. 57 a 64); 
6- BENTLEY ${ }^{\circledR}$ ARCHITECTURE é o sistema BIM da Bentley ${ }^{\circledR}$ para arquitetura introduzido em 2004, sendo uma evolução do programa Triforma ${ }^{\circledR}$. Possui módulos que se integram ao projeto de arquitetura, como: "Bentley ${ }^{\circledR}$ Structural, Building, Mechanical Systems, Electrical Systems, Facilities, Power Civil (para planejamento do sítio) e Generative Components". São aplicativos baseados em arquivos, salvando as alterações de forma que se utilizam pouco da memória do computador. Como ponto forte, a ferramenta BIM da Bentley ${ }^{\circledR}$ oferece ampla gama de aplicativos que abrangem, de forma genérica, todo o escopo da área da Arquitetura e Construção. Constitui-se numa ferramenta indicada para grandes empreendimentos. Seus pontos fracos são a dificuldade de utilização dos variados aplicativos, tornando difícil seu aprendizado. Ele também possui número limitado de biblioteca de objetos, se comparado com produtos similares (EASTMAN et al, 2008, p. 57 a 64);

7- INFRAWORKS ${ }^{\circledR}($ SIG) - pode importar grandes modelos de infraestrutura a partir de plantas CAD 2D, modelos feitos nos sistemas BIM, ou outros formatos de arquivos existentes como "CityGML" ou nuvens de pontos. Assim torna-se possível trabalhar com representações abstratas nos estágios iniciais de projeto. Possibilita simular o resultado das alternativas de projeto no processo de construção por meio de interatividade e visualização. Permite que usuários visualizem as infraestruturas existentes e a topografia. Isto permite avaliar as condições existentes e melhorar a tomada de decisões (AutoDesk).

Em razão do emprego comercial, no Brasil, dos sistemas BIM estar difundido majoritariamente pela Autodesk ${ }^{\circledR}$ - Revit $^{\circledR}$ e de forma menos expressiva por meio da Graphisoft $^{\circledR}$ - ArchiCAD $^{\circledR}$, optamos pela utilização do Revit ${ }^{\circledR}$ nesta pesquisa. Em parte, devido ao fato da "suíte" oferecida pela AutoDesk ${ }^{\circledR}$ contemplar soluções não apenas para arquitetura, como ainda as especialidades de engenharia através de módulos específicos do Revit $^{\circledR}$ (Structure e MEP). Outra forte razão reside na utilização pela INFRAERO dos "softwares" da AutoDesk ${ }^{\circledR}$, o que pode vir a tornar os dados obtidos nesta pesquisa de maior utilidade em eventual adoção dos sistemas BIM pela INFRAERO. O autor, enquanto servidor público da INFRAERO, coordenou propostas tanto da AutoDesk ${ }^{\circledR}$ (Revit ${ }^{\circledR}$ ) como da Graphisoft $\left(\right.$ ArchiCAD $^{\circledR}$ ) de projeto-piloto envolvendo os sistemas BIM nas práticas de projeto da empresa. Apesar de ambas aas soluções serem possíveis e viáveis para o ambiente organizacional da INFRAERO, a utilização dos "softwares" da AutoDesk parece mais viável num primeiro momento, em razão de sua difusão previa e conhecimento técnico pelos funcionários da empresa. 
"Ambos os programas são ferramentas para a produção de objetos paramétricos BIM de alta qualidade. Porém, existe grande diferença na forma como os programas funcionam tecnicamente. O Revit ${ }^{\circledR}$ é mais técnico do que $A r c h i C A D^{\circledR}$ porque utiliza cadeias de medição contínuas que são fixas aos objetos paramétricos. Apesar de mais preciso, é também mais trabalhoso para construção um modelo, se comparado ao $\operatorname{ArchiCAD}{ }^{\circledR}$, onde as distâncias podem ser digitadas, tornando o modelo mais flexível para incorporar ajustes. O Revit ${ }^{\circledR}$ apresenta biblioteca de objetos a partir do qual é possível inserir janelas e outros objetos de construção. Mas não há nenhuma janela padrão para Revit $^{\circledR}$ que possa ser inserida em uma parede curva. Não é possível construir tal janela no Revit ${ }^{\circledR}$, nem mesmo através de edição da "Família" (objeto do grupo) a partir da biblioteca, ou através de controles de cortina. Já no $A r c h i C A D^{\circledR}$ as janelas podem ser inseridas em paredes retas e/ ou curvas, paredes que não têm lados paralelos, paredes inclinadas. Além disso podem ter vidros curvos" (http://bimequity.com/en/cases/ engineers-contractors/revit-vs-archicad/).

A flexibilidade maior de modelagem do $\operatorname{ArchiCAD}^{\circledR}$ perfaz diferencial a seu favor. No entanto, apesar da limitação em formas complexas, o Revit ${ }^{\circledR}$ permite que isto ocorra em ambiente de massa nativo. Ou seja, existem formas de contornar esta diferença entre os dois modeladores BIM, como descrito abaixo.

"No Revit ${ }^{\circledR}$, não se pode modelar uma parede inclinada sem utilizar ferramenta de "massa" e a inclinação da parede inclinada não pode ser alterada posteriormente. No $A r c h i C A D^{\circledR}$, é possível modelar uma parede inclinada reta ou curva e ajustar a inclinação conforme necessário. Isto significa que os projetos de formas mais elaboradas são claramente mais fáceis de modelar no $\operatorname{ArchiCAD}^{\circledR}$ que no Revit $^{\circledR}$. Os dois programas também utilizam objetos de maneiras muito diferentes. O $\operatorname{ArchiCAD}^{\circledR}$ apresenta mais de 2.000 objetos internos enquanto o Revit $^{\circledR}$ apresenta um número menor de componentes padrão, apesar de existirem vários sites para "download" dos mesmos. Uma grande restrição do $\operatorname{ArchiCAD}^{\circledR}$ é que só existe em uma versão adequada para todas as disciplinas de projeto, enquanto o Revit ${ }^{\circledR}$ apresenta diferentes versões para arquitetos, engenheiros civis e engenheiros de sistemas elétricos, Hidrossanitários e mecânicos. O ArchiCAD ${ }^{\circledR}$ apresenta capacidade limitada para manipular estruturas, e requer um "plug-in" para as especialidades complementares a de arquitetura" (http://bimequity.com/en/cases/engineers-

contractors/revit-vs-archicad/). 
A limitação expressa no sistema BIM - Revit $^{\circledR}$ em relação a biblioteca préexistente-existente apoia a hipótese desta pesquisa, no viés de desenvolvimento de componentes paramétricos específicos para aeroportos. Os SIG podem propiciar a comparação e análise de diferentes componentes construtivos ou módulos funcionais de um aeroporto, em diferentes níveis de detalhe e consequentemente de abstração. Estes também pode servir como ferramenta de adequação de projeto ao Plano Diretor Aeroportuário. Por fim, podem ainda servir como ferramenta para georreferenciamento de forma remota dos diversos aeroportos da rede INFRAERO, espalhados pelo país. Neste contexto, os sistemas BIM podem ser usados para representar o projeto quando associado ao SIG. O ambiente de associação dos sistemas BIM e SIG suportaria diferentes ferramentas de análise e de simulação, como, por exemplo, conforto ambiental, análises estruturais, de custos e de viabilidade de obras, relacionamento com o entorno imediato, adequação ao Plano Diretor do aeroporto, entre outras.

KUNZ E RITTEL (1972) descrevem o projeto como um processo onde os profissionais da AEC simultaneamente formulam definições de problemas de projeto, bem como definições de soluções para esses problemas. (RITTEL, 1972, Apud MUSTOE, 1990, p. 3-5.) O arquiteto HORST RITTEL (1967) caracterizou os problemas de projeto e o processo de projetação como "wicked-problems", ou problemas "nãoestruturados", indefinidos por natureza, em contraste com os problemas relativamente "simples", como os de soluções matemáticas, xadrez ou quebra-cabeças. As onze propriedades que caracterizam os problemas "não-estruturados", inclusive as de projetos de arquitetura, foram listadas por RITTEL em 1972, como a seguir:

1-Problemas "não-estruturados" não tem uma formulação definida; 2- Toda formulação do problema "não-estruturado" corresponde a formulação da solução e viceversa; 3- Problemas "não-estruturados" não possuem regras para parar; 4- As soluções dos problemas "não-estruturados" não são certas ou erradas; 5- Na solução dos problemas "não-estruturados" há uma lista interminável de operações possíveis; 6- Para cada problema "não-estruturado" há sempre mais de uma explanação; 7- Cada problema "não-estruturado" é um sintoma de outro problema maior; 8- Nenhum problema "não-estruturado" e nenhuma solução para ele tem um teste definitivo; 9- Cada problema "não-estruturado" é uma operação única; 10- Cada problema "nãoestruturado" é único; 11- A solução do problema "não-estruturado" não é "certa" ou “errada" (RITTEL, 1972 apud MUSTOE, 1990, p.3 a 5).

As ferramentas de suporte à decisão de projeto - como a matriz semântica desta pesquisa - se relacionadas a um ambiente SIG podem oferecer suporte para a classificação e o rastreio de informação dos componentes aeroportuários, em diferentes níveis de detalhe e abstração. 
ALEXANDER (1964), negando a teoria que havia apresentado anteriormente, afirma que os problemas de projeto não podem ser decompostos em pequenas partes para obter solução. Isso significa que mesmo que possamos subdividir um problema maior em várias representações simbólicas menores, particularmente, em projeto de arquitetura, não podemos resolver a complexidade do problema maior por meio da resolução de suas subdivisões. A atividade de projeto precisa enfrentar, por inteiro, a complexidade do problema e tentar enxergá-lo por diferentes ângulos, sob diferentes níveis de informação, detalhe e contexto. A primeira referência importante de CHRISTOPHER ALEXANDER (1964) foi o livro "Notes on the Syntesis of Form", em que afirmou que os problemas de projeto poderiam ser subdivididos em problemas menores, em vários níveis, em um processo que ele representou como uma árvore invertida. $A$ resolução individual dos problemas menores culminaria na resolução dos problemas maiores. Esta teoria de projeto recebeu muitas críticas porque logo ficou evidente que a resolução de problemas menores não era independente das demais e interferiam umas nas outras. O próprio ALEXANDER, mais tarde, em 1965, reconheceu que o seu modelo de projetação não era viável e escreveu o artigo denominado "A City is not a Three". Neste último ele nega a possibilidade de resolver os problemas maiores a partir da subdivisão dos mesmos em problemas menores. (ALEXANDER, 1965, p. 58 a 62).

Os esforços representados por iniciativas como o "CityGML" no suporte de relações entre objetos e conjuntos de informação (data base) demonstram a importância de se estabelecer um ambiente colaborativo multidisciplinar. $O$ banco de dados relacional que integra um arquivo central BIM a um ambiente SIG "CityGML", via exportação "IFC", serve ao propósito de perseguir melhores soluções criativas e inovadoras de projeto, que ao utilizarem diferentes dimensões e domínios de conhecimento possam expressar o estado da arte na resolução de determinado problema de projeto. Os sistemas BIM poderão auxiliar a INFRAERO, em caso de sua adoção, uma vez que esta empresa costuma contratar o desenvolvimento dos projetos de muitos de seus aeroportos, mas também desenvolve internamente outros tantos, como por exemplo o Terminal Regional do Brasil objeto desta pesquisa. Torna-se importante preservar um espaço para que as ambiguidades e abstrações possam se manifestar nos processos criativos das equipes de projeto, sobretudo nos estágios iniciais. Os SIG possuem a capacidade de descrever características geográficas, não apenas de forma gráfica, mas também por meio de informações topográficas, possibilitando análises do modelo digital em relação ao mundo real, por meio de combinação de objetos existentes (estradas, árvores, elevações, etc.) e dados digitais. Existem duas divisões de objetos reais: os objetos individuais (por exemplo, uma árvore) e campos contínuos (como elevações). 
Ressalta-se a possibilidade de associarmos os sistemas BIM e SIG em um ambiente de trabalho, onde diversas ferramentas e "softwares" de projeto e análise podem ser utilizados. Os diferentes níveis de abstração consistem em representações dos objetos em uma relação variada de contextos e conexões. Envolve aspectos semânticos, fornecendo ao projetista diferentes visões e contextos de um mesmo problema arquitetônico. A associação entre os sistemas BIM e SIG pode auxiliar na representação, processamento ou simulação dos campos referentes aos componentes paramétricos, em diferentes níveis de abstração de informação e de representação geométrica. Segundo Espindola, em artigo intitulado: "A importância da Modelagem de Objetos no Desenvolvimento de Sistemas", "abstração" é conceituada como um processo seletivo de determinados aspectos de um problema, com o objetivo de isolar aspectos que sejam importantes para algum propósito e suprimir os que não forem (ESPINDOLA, 2001, p.1-2).

As informações estruturais pouco definidas e com alto nível de relacionamento (alta abstração) possuem inúmeras conexões, as quais podem ser representadas com diferentes níveis de detalhes. Isto torna possível a criação de alternativas de projeto que respondam não apenas aos requisitos conhecidos, mas também ao contexto relacional e à sua complexidade. Esta última precisa ser traduzida e filtrada para que os parâmetros de análise sejam definidos. Por exemplo, ao imaginarmos uma fachada, podemos estar interessados na criação de aberturas para propiciar a entrada de luz e ar natural, sem, no entanto, desejarmos nos estágios iniciais de projeto adicionar informações referentes ao tipo de janela que deverá preencher essas aberturas. Este exemplo mostra que desejamos abstrair da composição arquitetônica as informações sobre as esquadrias, sem prejudicar a composição funcional, estética e de eficiência energética em curso. Tais abstrações são fundamentais para que o arquiteto possa ter liberdade de relacionar diferentes significados, como imaginar a relação do edifício com a influência solar, sem no entanto lidar com a complexidade maior que significa se pensar em que tipo de fechamento deverá ser pensado para as esquadrias. Da mesma forma, pode-se simular diferentes contextos ou situações de projeto, como por exemplo as relações entre a edificação e o terreno, em caso de se adotar um partido térreo, que ocupe maior área de solo, ou de mais de um pavimento. Estes exercícios projetais que envolvem variação na informação e na representação geométrica dos componentes perfaz um requisito fundamental para que os projetistas possam propor diferentes alternativas em busca da solução que melhor se adapte aos requerimentos de projeto. Por meio de manipulação no nível de detalhe na representação dos elementos construtivos o(a) arquiteto(a) realizam processo de análise que culminam na tomada de decisões em relação a determinadas soluções em detrimento das demais. 
Por exemplo, o projetista pode analisar diferentes soluções de fechamento de janelas, representando contextos como insolação, interferências e funcionalidade. $O$ nível de detalhe compõe os dados que serão utilizados para analisar o modelo. Portanto, se essa informação está omissa ou incorreta, as análises não poderão ser realizadas (WEYGANDT et al, 2005, p. 495-499). Os sistemas BIM envolvem componentes paramétricos, porém o desenvolvimento de conjuntos funcionais, ou módulos semânticos como, por exemplo, módulos de "check-in", de sanitários públicos, de tratamento de bagagem, de embarque, desembarque, de espera, entre outros, que representem os módulos funcionais de um aeroporto podem ser de grande valia para projetos e situações de projeto que se repetem, como o projeto de torres de controle, terminais de passageiros, terminais de carga, etc.

Os principais módulos funcionais de um aeroporto podem ser representados por conjuntos de componentes construtivos de projeto, podendo ser inseridos em projetos maiores. O que se almeja com os esforços de normatização da ABNT e classificação conceitual e de nível de detalhamento para os componentes BIM é criar ambiente de trabalho, de representação gráfica e de especificação e detalhamento construtivo. Basicamente o que ocorre é que os requerimentos são a única diretriz nesse processo, determinando o nível de comunicação entre os projetistas e os proprietários. No caso da INFRAERO, a comunicação é feita entre os projetistas a área de engenharia e suas especialidades (Sistemas Elétricos, Hidrossanitários, Eletromecânicos, Telemática, Estruturais, Orçamento, Infraestrutura, Arquitetura, Auxílios à Navegação Aérea e Eletrônicos) e SAC e ANAC, além do próprio conselho consultivo da empresa, que atuam na regulação e certificação das atividades aeroportuárias.

Segundo SEBASTIAN e BÖHMS (2013), "a nova geração de edifícios semânticos e de modelagem de informação georreferenciada permitirá a relação de processos inteligentes entre as percepções e experiências dos usuários sobre a operação, funcionalidade e problemas técnicos de uma edificação" (SEBASTIAN e BÖHMS, 2013, p. 256-257). A utilização de uma base de associação entre os sistemas BIM e SIG para os aeroportos brasileiros permite que os diferentes aeroportos da rede INFRAERO no país possam interagir na gestão da sua informação. Permite ainda o compartilhamento de protocolos de análise, como arquivos contendo modelos BIM, exportados em arquivos "open source" como o "IFC", componentes construtivos de aeroportos com validação contextual através da exportação para os SIG e de módulos funcionais para um aeroporto, como os expressos na matriz elaborada nesta pesquisa, que possam ser replicados segundo ontologia e semântica comuns a todos os envolvidos. 


\subsection{1 - APLICAÇÃO DOS SISTEMAS BIM - PRECEDENTES IMPORTANTES 2.11.1- "GARDERMOEN AIRPORT", OSLO, NORUEGA.}

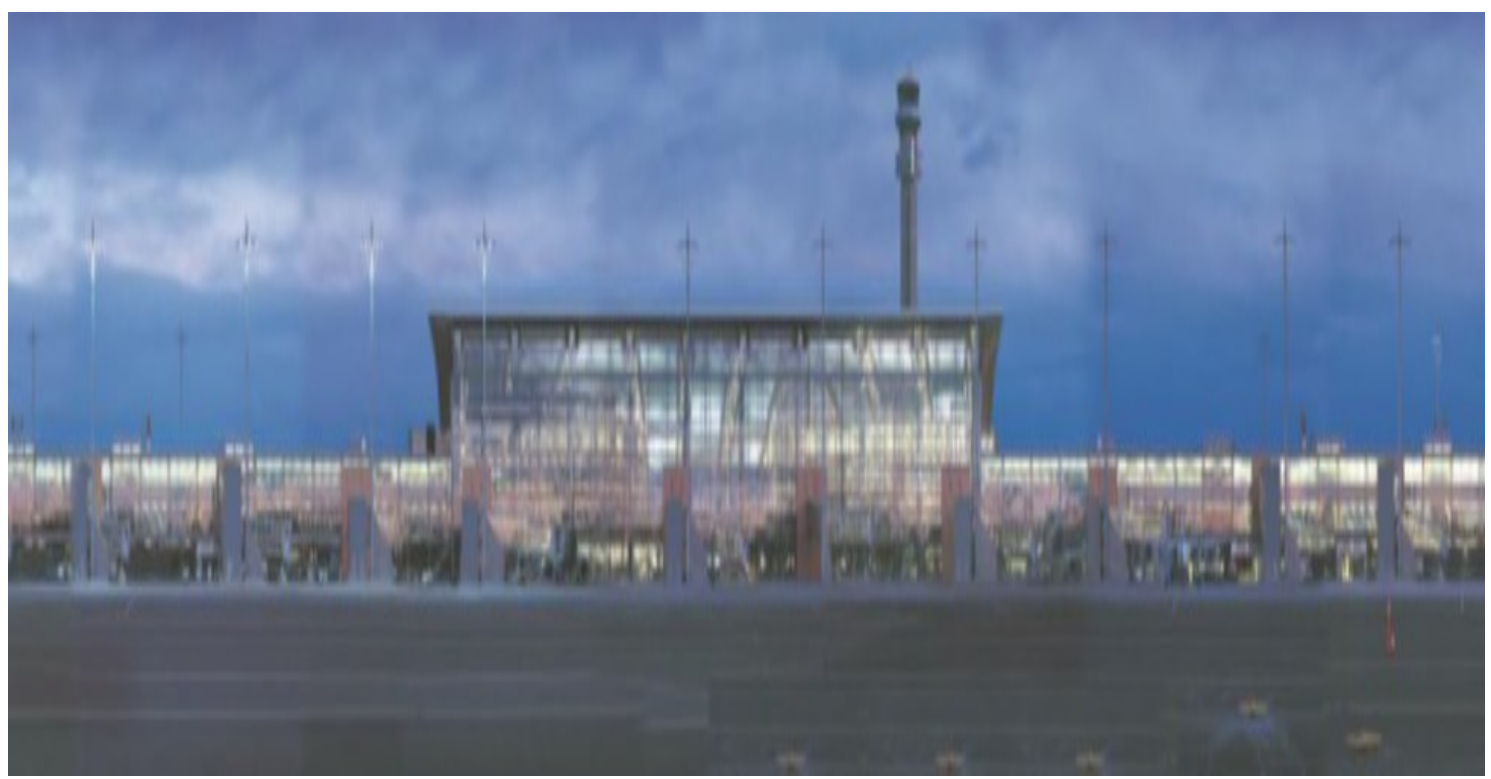

Figura 19- Aeroporto de GARDERMOEN, Oslo. Fonte: (RENGIFO et al, 2008, p. 6).

Neste projeto da AutoDesk, foi abordado o uso dos sistemas BIM (Revit ${ }^{\circledR}$ ) aplicados ao desenvolvimento dos projetos do atual aeroporto e de uma proposta de expansão de 180.000 metros quadrados. Obtivemos as informações sobre o Aeroporto de Gerdermoen do Estudo de Caso da AutoDesk ${ }^{\circledR}$ sobre o mesmo (Figura 19) (RENGIFO et al, 2008, p. 6). Localizado em Oslo, Noruega, empregou arquitetos de mais de vinte diferentes nacionalidades, tendo como premissas a abordagem colaborativa de trabalho e o benefício de contar com a participação de profissionais com formações diferentes.

Segundo os arquitetos ALFONSO D. RENGIFO, MORTEN RAEDER, BJØRNAR MARKUSSEN E AAS-JAKOBSEN - BRÍGIDA BRANCO, da NSW e da empresa norueguesa Narud Stokke Wiig com sede em Oslo, na Noruega:

\footnotetext{
"a expansão do Aeroporto Gardermoen com uma área projetada de 170000 metros quadrados exigiu que equipe fosse reestruturada para que se tornasse possivel ajustar os fluxos de trabalho $e$ as responsabilidades segundo o novo processo de projeto".
}

O novo terminal T2 foi construído no lado norte do edifício central, possuindo ligações funcionais com o Terminal existente T1. O processo utilizado teve início por meio da modelagem do terminal existente, de forma que o novo T2 pudesse ser compatibilizado e oferecesse soluções para que as interligações entre os dois edifícios fossem pensadas internamente, no sistema Revit ${ }^{\circledR}$ (Figura 19). 
Os rascunhos e esboços gráficos nas fases iniciais de projeto foram amplamente utilizados, principalmente nos processos de tomada de decisão, sendo depois seu resultado modelado de forma a propiciar maior compreensão espacial da equipe.

Pôde-se observar que nos sistemas BIM, existe a determinação de lidar com objetos altamente definidos, através de seus parâmetros específicos. Isto não se coaduna com a necessidade de abstração do arquiteto na fase inicial de representação desses objetos, para manter em aberto as diversas alternativas de solução. (Figura 20)

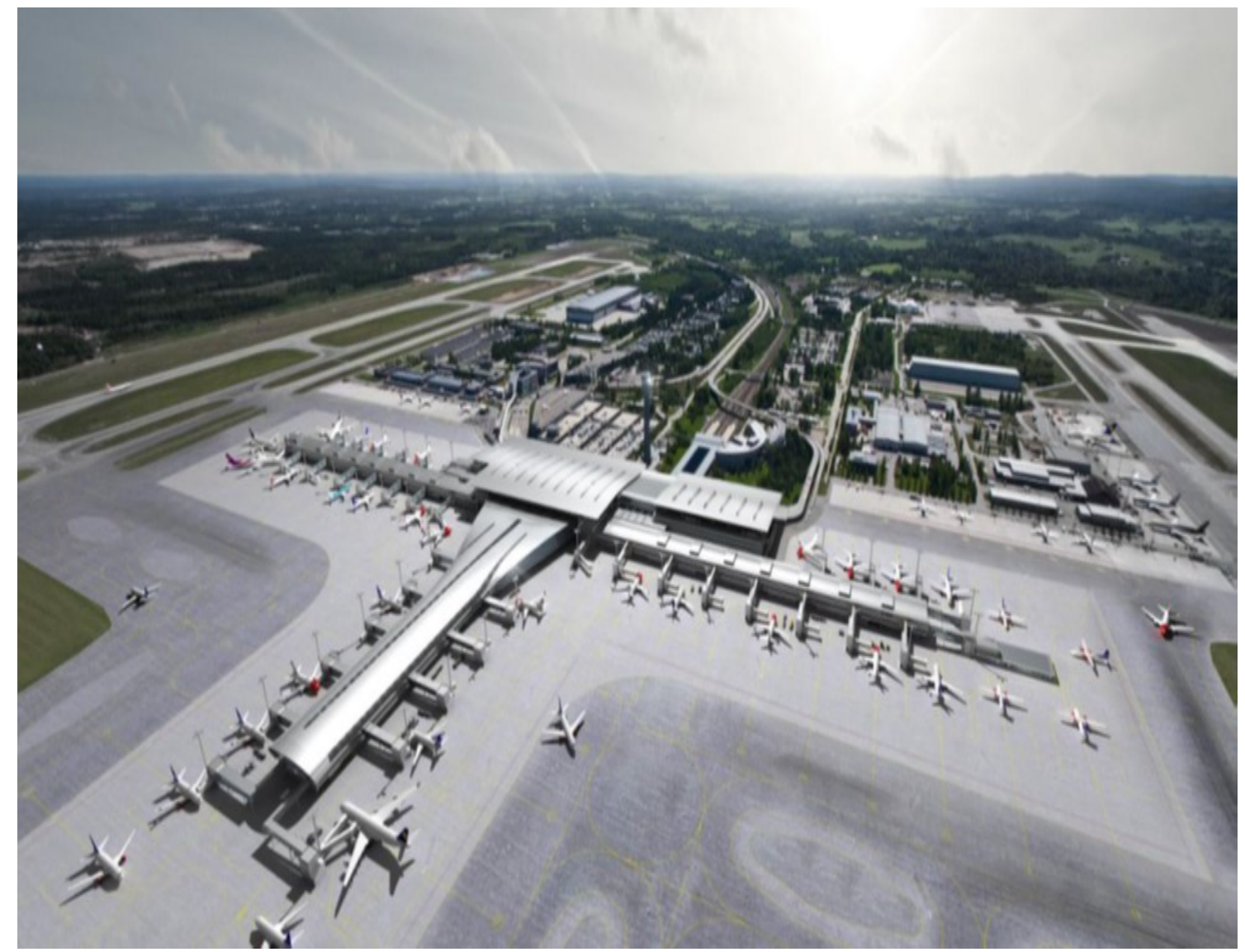

Figura 20- Vista do Terminal 2. Fonte: RENGIFO et al, 2008, p. 6.

Segundo os arquitetos da NSW, a implantação dos sistemas BIM foi gradual e para isso os seguintes postos de trabalho foram criados com as seguintes atribuições:

1- GESTOR BIM: visão geral do processo e dos sistemas BIM, testes, cursos e compras;

2- COORDENADOR BIM DO PROJETO: responsável por um ou dois projetos, configuração dos arquivos e apoio às equipes;

3- ESPECIALISTA BIM: responsável pela criação das famílias paramétricas, segundo requisitos específicos de cada projeto;

4- GERENTE CAD: responsável pela continuação do apoio a projetos a serem desenvolvidos tridimensionalmente e a extração de representações bidimensionais. 
Devido ao tamanho do arquivo e às dificuldades consequentes, como lentidão de computadores e servidores para lidar com os mesmos, foi necessário fazer uma modulação nos sistemas BIM.

Esta divisão foi feita em três partes principais, de forma a alcançar tamanhos gerenciáveis de dados e grupos de usuários. O escritório decidiu, em função do fluxo de trabalho, fracionar o modelo, ainda que isto aumentasse as dificuldades em relação ao fluxo de informação.

O fracionamento do modelo facilitou a edição e transmissão de dados, mas por outro lado dificultou o gerenciamento e a integração dos mesmos. O uso de ferramentas paramétricas BIM para a criação de famílias foi crucial para a eficiência e adaptabilidade de modelagem de grande escala, como o T2- GARDEMOEN.

O conhecimento adquirido pela equipe de projeto revelou que se tivessem se decidido, desde o início do processo, a dividir o modelo em módulos funcionais e semânticos para o Projeto, isto teria facilitado as coisas.

Desta forma, as informações referentes ao projeto são disseminadas por três arquivos distintos. A novidade aqui reside na integração necessária entre os diferentes modelos BIM para que as soluções propostas não sejam conflitantes.

Convenções de nomenclatura (padronização) devem ser consistentes para todos os arquivos de modelo, mesmo que os arquitetos em geral adotem sua própria "lógica" de nomear objetos, deve-se aplicar rigorosa convenção de nomenclatura para todos os objetos.

Como parte dos requisitos para a entrega dos produtos realizados em BIM, o cliente realizou especificação descrevendo o que entregar. E grande parte desses requisitos exigia formatos abertos de trocas de arquivos e de servidor, como o Open BIM e o IFC. Além disso, todas as disciplinas tiveram liberdade para escolher quais aplicativos BIM atenderiam melhor as suas necessidades (RENGIFO et al, 2008, p. 6).

Neste projeto a equipe teve que organizar um mergulho profundo no mercado e testar programas capazes de preencher a necessidade precisa de cada disciplina.

A figura a seguir exemplifica por cores diferentes arquivos BIM, representando o fracionamento do modelo utilizado (Figura 21).

Fracionando o modelo, apesar de uma coordenação mais trabalhosa, os computadores puderam trabalhar de forma menos demorada em relação ao tamanho dos arquivos gerados. 


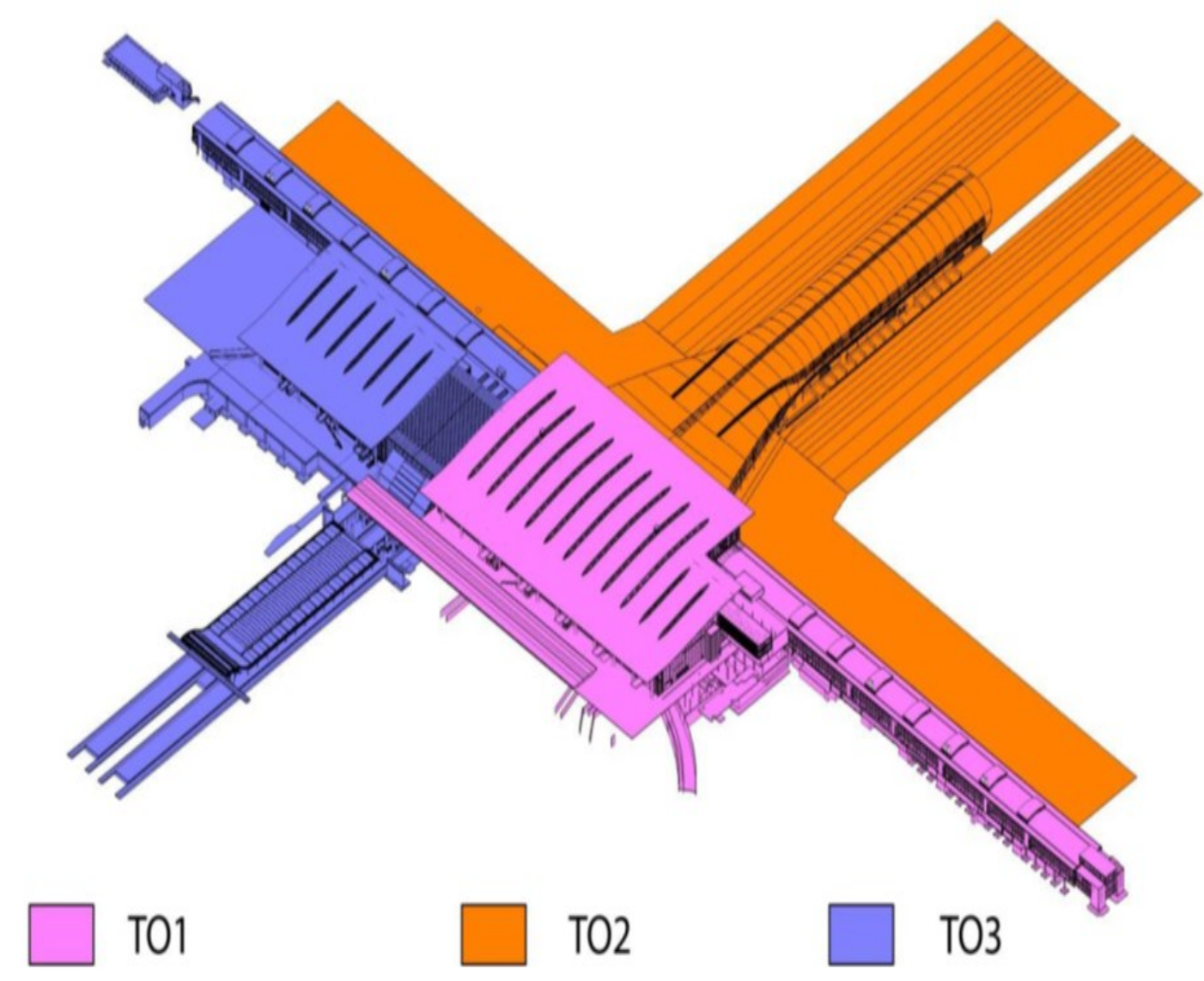

Figura 21- Arquivo de Modelo após dividir áreas. Estudo de Caso AutoDesk: Aeroporto de GARDERMOEN, Oslo, Noruega. Fonte: RENGIFO et al, 2008, p. 6.

O uso de ferramentas paramétricas BIM para criação de famílias é extremamente crucial para eficiência e adaptabilidade de modelagem de grande escala, como o T2, GARDEMOEN. Os processos de desenvolvimento de estética, funcional e estrutural para os componentes da biblioteca são complexos e criam elementos que podem flexionar, adaptar e registrar informações que podemos melhorar o atual nível de precisão dentro do modelo. O projeto paramétrico de componentes permite que 0 modelo cresça ao longo do seu desenvolvimento através de cada fase do projeto.

Variáveis desconhecidas podem ser testadas, testadas e validadas com o uso da flexibilidade dos componentes paramétricos. Ao longo do processo de projeto, como importantes decisões de projeto são feitas, os componentes puderam ser editados e atualizados, e agrupados em tipos semelhantes para permitir que uma mesma família torne-se parte do projeto conceitual e dos desenhos de detalhamento e construção. Isso é benéfico, quer em termos de tempo, de eficiência e de manutenção permitido pela colocação precisa dos elementos dentro do modelo. A estrutura do aeroporto englobou muitos elementos repetitivos, tipos similares de elementos e contínua adaptação técnica dos repetidos detalhamentos (Figura 22 a seguir). 

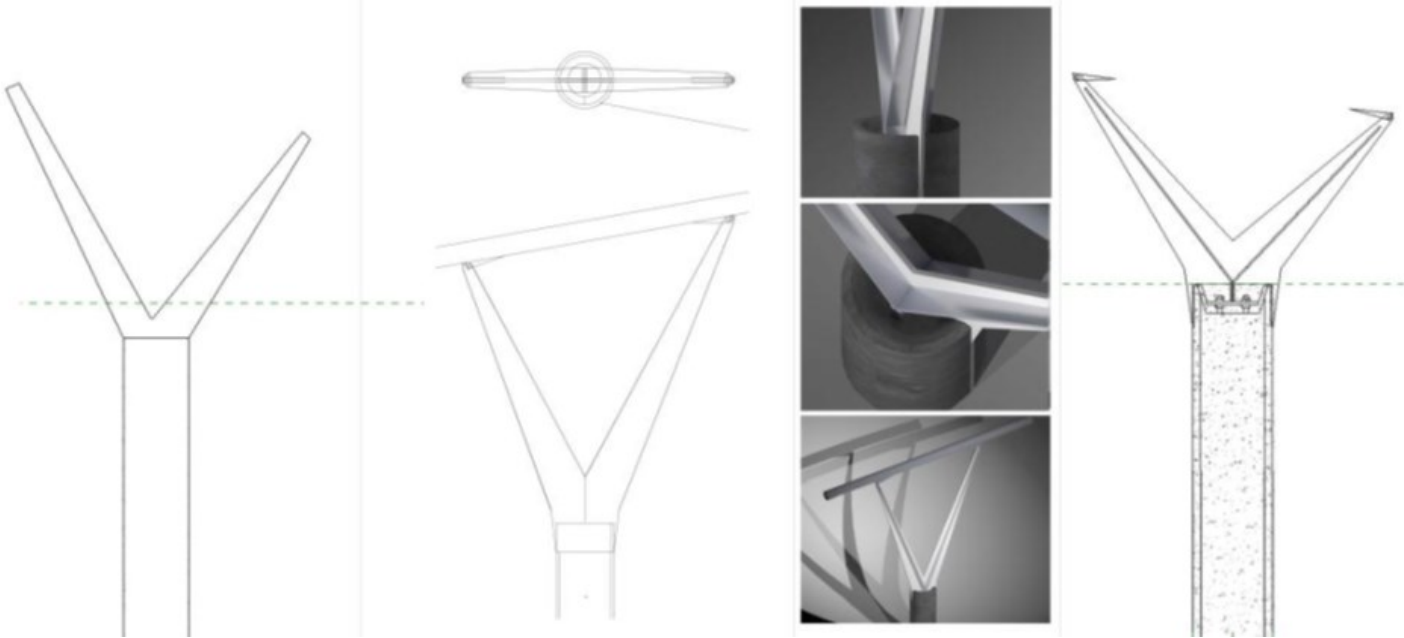

Figura 22 - Detalhamento e repetição de elementos construtivos. Fonte: RENGIFO et al, , p. 6).

Por esta razão, muitos componentes criados foram projetados para adaptar-se parametricamente às diferentes circunstâncias dentro do modelo do T2. Tamanho, cálculo, materialidade, além de outras opções de componente permitem que uma família possa ser repetida e sofrer alterações, para refletir a geometria desejada e também permitir que o arquivo fique de tamanho menor. $\mathrm{O}$ grande tamanho do arquivo, quando muitos componentes são adicionados, é problemático em projeto como esse por causa da variedade de componentes necessários, equipamentos especializados, detalhes e estrutura complexa (Figura 23).

É possível citar exemplos que incluem equipamentos especiais de aeroportos, tais como esteiras de bagagens, equipamentos de segurança, principais elementos estruturais (no sentido de cálculos necessários), peles de vidro e componentes de mobiliário. Através das variações paramétricas, podemos utilizar vasta gama de opções dentro de uma mesma família, conforme o projeto é desenvolvido, e assim refinar o componente de forma específica e salvá-lo como arquivo diferente, para que todos os arquivos sejam mantidos no banco de dados para posterior utilização.
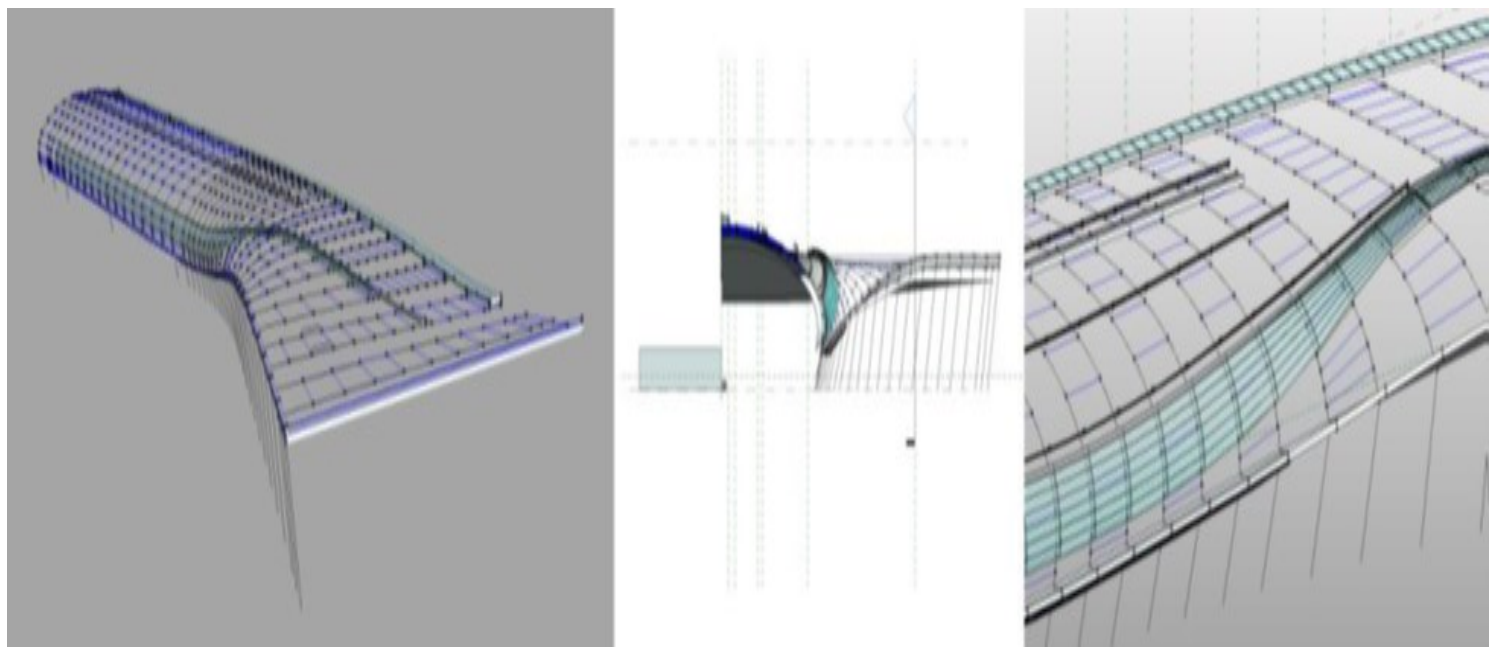

Figura 23- Família 1 - Componentes adaptativos. Fonte: RENGIFO et al, 2008, p. 6. 
Por isso, todas as famílias paramétricas, informações e catálogos estão disponíveis, como base de dados que pode ser adaptada facilmente para novas situações.

Por meio dos recursos dos sistemas BIM, os projetistas criaram diferentes famílias de componentes com diferentes níveis de detalhe e diferentes soluções para um mesmo problema de projeto (Figura 23 a 25).

Isto possibilitou o teste de diferentes alternativas e ainda a representação e a reunião de informações à medida que a tomada de decisões ia acontecendo e consequentemente, ao longo do desenvolvimento do projeto (Figuras 23 a 25).
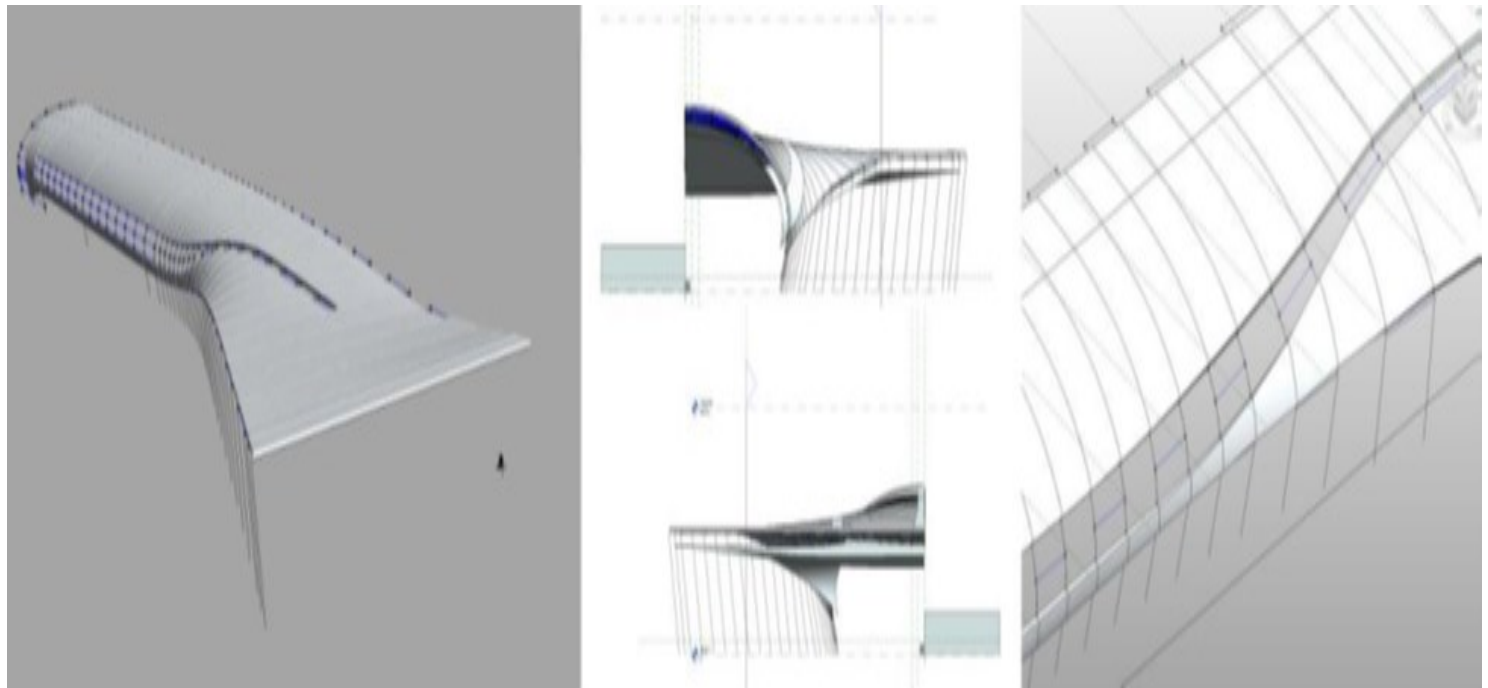

Figura 24- Família 2 - Coluna e viga da estrutura. Fonte: RENGIFO et al, 2008, p. 6.

As Figuras 23 a 25 ilustram diferentes famílias de componentes que foram criadas para os projetos do T2, permitindo representar diferentes níveis de detalhamento e desenvolvimento do aeroporto.
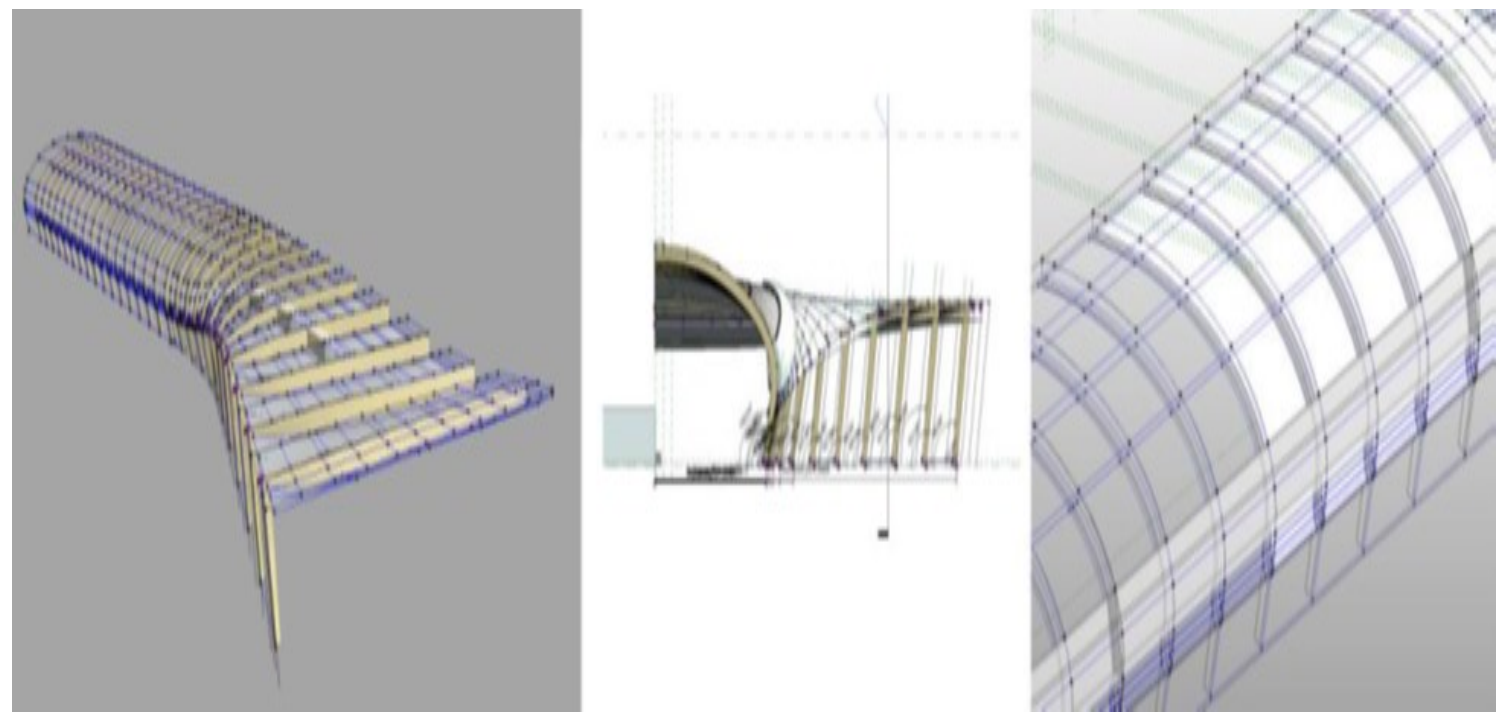

Figura 25- Família 3 - Estrutura do Telhado. Fonte: RENGIFO et al, 2008, p. 6. 


\section{3- MATERIAL E MÉTODOS}

\section{1- MATRIZ SEMÂNTICA DE REGRAS DE ABSTRACAO DA INFORMAÇÃO}

A matriz semântica foi elaborada visando suprir a deficiência explícita dos sistemas BIM, em representar diferentes níveis de abstração e especificação de componentes construtivos. Uma vez que os sistemas BIM requerem especificação precisa desde o início do projeto, impossibilitam representações ambíguas. A construção da matriz semântica foi feita para representar o ambiente organizacional da INFRAERO, envolvendo os processos de projeto e aprovação, relacionados às partes, ou módulos funcionais de um aeroporto. O programa $\mathrm{Xmind}^{\circledR}$, desenvolvido em novembro de 2008 por uma empresa de negócios de Hong Kong, permitiu a elaboração da matriz semântica de regras de abstração e, ainda, a criação de gráficos do tipo Gantt, úteis para relacionar cada uma das partes ou tarefas em uma linha de tempo (BARROS, 2003, p.3). É um método relativamente antigo, pois foi criado em 1918, mas ainda bastante praticado.

CONSISTE EM ENCONTRAR A MELHOR MANEIRA POSSÍVEL DE POSICIONAR AS DIFERENTES TAREFAS DE UM PROJETO A EXECUTAR NUM PERÍODO DETERMINADO, EM FUNÇÃO:

1- DURAÇÕES DE CADA UMA DAS TAREFAS;

2- RELAÇÕES DE PRECEDÊNCIA ENTRE AS DIFERENTES TAREFAS;

3- PRAZOS A RESPEITAR (BARROS, 2003, P.3).

Representar as tarefas de projeto integradas com os requisitos necessários de aprovação é uma das funções previstas dessa matriz. Os recursos presentes na versão digital da matriz permitem que o usuário possa interagir com o "software" e realizar consultas sobre diferentes partes do aeroporto, de forma simultânea. Isto permite, por exemplo, relacionar um módulo de "check-in" do aeroporto, às tarefas e premissas de projeto de arquitetura e de engenharia. A ideia é utilizar a matriz como ferramenta de suporte não apenas na tomada de decisão, mas ainda para "guiar" os projetistas, definindo a extensão das atividades previstas para cada profissional e a inter-relação entre as mesmas.

A matriz de semântica foi composta por camadas ou níveis de informação distintos particularmente no que se refere a aprovação e tarefas de projeto. Torna possível controlar a complexidade da informação, removendo detalhes desnecessários e ainda facilitando seu gerenciamento. Todas as informações sobre o conhecimento são derivadas da aplicação de uma ou mais lentes e/ou filtros. Tais informações foram consolidadas em sistema computacional de suporte ao projeto (Matriz Semântica), elaborada no "software" XMind ${ }^{\circledR}$ (Figura 26 a seguir). 


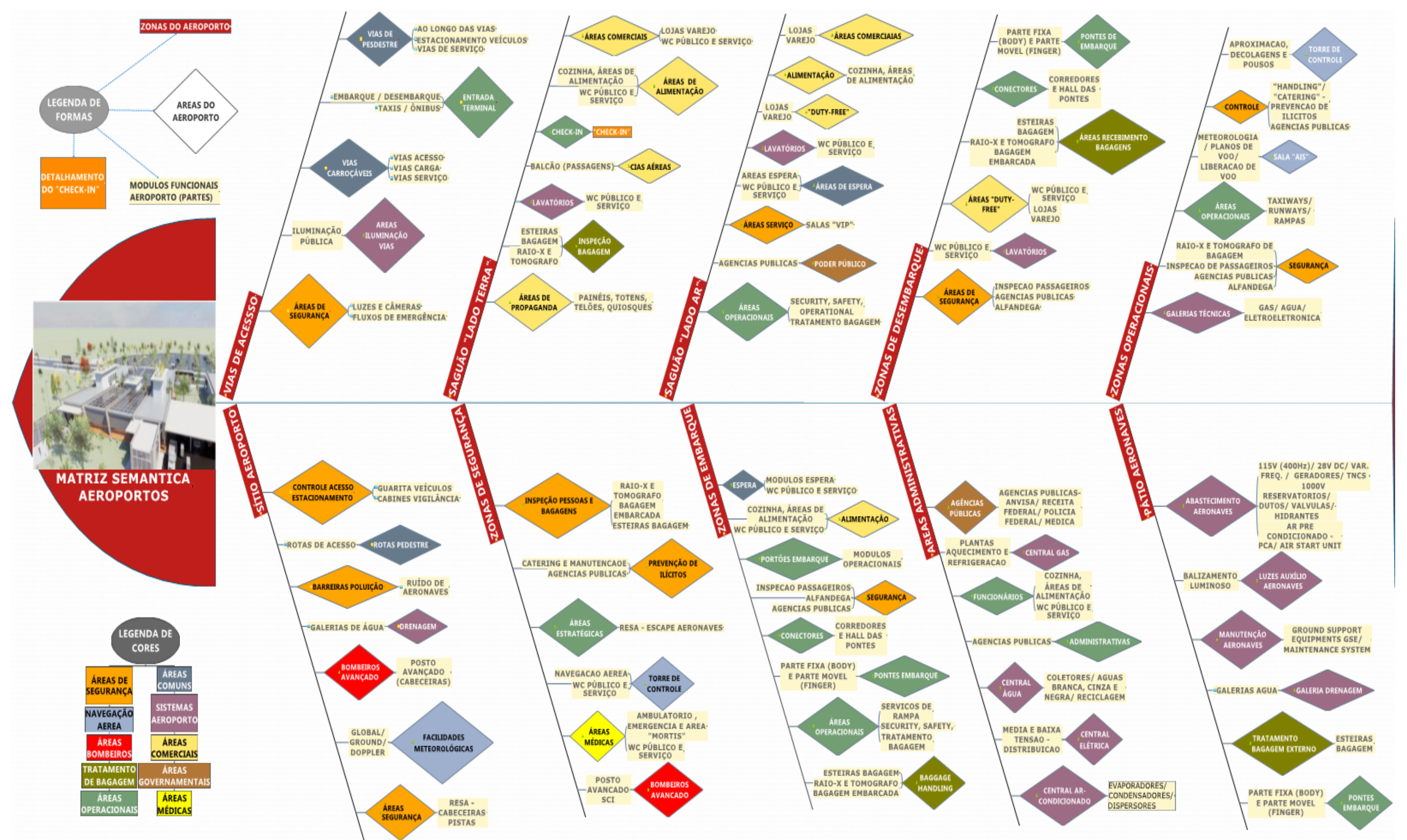

Figura 26- Ilustração de tela de acesso da versão digital da Matriz Semântica onde pode ser vista a organização das zonas (setores), áreas e partes de um aeroporto. 


\section{A MATRIZ TEVE INÍCIO NO PAPEL, ONDE FORAM ESTRUTURADAS INFORMAÇÕES SOBRE QUATRO DIMENSÕES DE PROJETO:}

1- SETORES (ou ZONAS) do aeroporto descritas na Tabela 1 na página seguinte, mostrando ainda suas partes e módulos funcionais;

2- REQUERIMENTOS de projeto, (descritos na Tabela 3);

3- TAREFAS de PROJETO (descritos na Tabela 3);

4- PROCESSOS de APROVAÇÃO de projeto (descritos na Tabela 3).

A transposição das anotações do caderno para ambiente digital, no programa XMind ${ }^{\circledR}$ permitiu entrelaçar as informações das diferentes dimensões de forma a permitir consulta simultânea sobre mais de uma tela, além de permitir hierarquizar e relacionar as dimensões descritas acima de forma a integrar a informação sobre as tarefas e processo de projeto, sob a ótica de um arquiteto e em interação com as demais disciplinas de projeto da INFRAERO.

Em razão de uma maior compreensão dos usuários, a versão digital da matriz foi ordenada, priorizando a dimensão dos Setores do Aeroporto para compor a tela inicial. Desta forma, o autor acredita que a consulta sobre informações referentes ao processo de projeto possa ser realizada de forma mais objetiva, uma vez que o objeto de projeto e o aeroporto e suas partes. Portanto, torna-se possível que ao se projetar determinada parte ou modulo funcional, o arquiteto ou projetista tenha oportunidade de se utilizar dos recursos da matriz para se informar sobre as relações entre as partes do aeroporto, relacionadas de forma hierárquica com os sistemas da edificação implicados e finalmente obre os requerimentos (normativos) e sobre os processos de aprovação com base nesses requerimentos (decisórios).

"O Xmind ${ }^{\circledR}$ é um "software" para a construção de fluxograma no formato de mapas mentais, onde o usuário pode acrescentar relacionamentos, limites, sumários, observações e marcadores. Os mapas gerados podem ser exportados para diversos formatos, como "PDF". "WORD", "EXCEL" entre outros." (http://rafaelnink.com/blog/ 2010/08/05/xmindbrainstorming-e-mapas-mentais/, acessado em 04/04/2015).

Foram incluídos na matriz todos os módulos funcionais de um terminal de passageiros de pequeno porte, como o Terminal de Passageiros Regional, em diferentes áreas do aeroporto, as quais são distribuídas em 11 setores (Tabela 1). As informações referentes aos processos de aprovação de projetos variaram entre os módulos funcionais, através de diferentes funções do aeroporto e abrigaram diferentes sistemas e equipamentos que são específicos a cada uma das áreas da INFRAERO. 
TABELA 1 - CLASSIFICAÇÃO DOS MÓDULOS FUNCIONAIS, DISTRIBUÍDOS POR SETORES E ÁREAS DE UM AEROPORTO DE PEQUENO PORTE, UTILIZADA NA MATRIZ SEMÂNTICA.

\begin{tabular}{|c|c|c|}
\hline $\begin{array}{l}\text { SETORES DO } \\
\text { AEROPORTO }\end{array}$ & $\begin{array}{c}1^{\circ} \text { NIVEL } \\
\text { (PARTES DO } \\
\text { AEROPORTO) }\end{array}$ & $\begin{array}{c}2^{\circ} \text { NIVEL } \\
\text { (MÓDULOS } \\
\text { FUNCIONAIS) }\end{array}$ \\
\hline \multirow{5}{*}{ VIAS DE ACESSO } & ÁREAS DE SEGURANÇA & $\begin{array}{l}\text { LUZES E CÂMERAS DE } \\
\text { SEGURANÇA } \\
\text { SAÍDAS E/OU FLUXOS } \\
\text { EMERGÊNCIA }\end{array}$ \\
\hline & ILUMINAÇÃO DE VIAS & $\begin{array}{l}\text { PISTAS, TAXYWAYS, } \\
\text { ACESSOS E } \\
\text { ESTACIONAMENTO }\end{array}$ \\
\hline & VIAS DE ACESSO & $\begin{array}{c}\text { VIAS PARA CARROS } \\
\text { VIAS PARA CARGA/ DESCARGA } \\
\text { VIAS DE SERVIÇO }\end{array}$ \\
\hline & ENTRADA DO TERMINAL & $\begin{array}{c}\text { EMBARQUE/ DESEMBARQUE } \\
\text { TAXIS E ÔNIBUS }\end{array}$ \\
\hline & CALÇADAS DE PEDESTRE & $\begin{array}{l}\text { AO LONGO DAS VIAS } \\
\text { ESTACIONAMENTO } \\
\text { VIAS DE SERVIÇO }\end{array}$ \\
\hline \multirow{7}{*}{$\begin{array}{c}\text { SÍTIO DO } \\
\text { AEROPORTO }\end{array}$} & $\begin{array}{l}\text { CONTROLE ACESSSO } \\
\text { ESTACIONAMENTO } \\
\end{array}$ & $\begin{array}{l}\text { GUARITA DE VEÍCULOS } \\
\text { CABINE DE VIGILÂNCIA }\end{array}$ \\
\hline & ROTAS DE PEDESTRE & ACESSOS DE PEDESTRES \\
\hline & $\begin{array}{c}\text { BARREIRAS PROTEÇÃO } \\
\text { AMBIENTAL }\end{array}$ & SOM, VISUAL E POLUIÇÃO \\
\hline & DRENAGEM & GALERIAS PLUVIAIS \\
\hline & $\begin{array}{l}\text { BOMBEIROS - POSTO } \\
\text { AVANÇADO }\end{array}$ & GRUPAMENTO AVANÇADO \\
\hline & $\begin{array}{c}\text { FACILIDADES } \\
\text { METEOROLÓGICAS }\end{array}$ & GLOBAL, TERRA E DOPPLER \\
\hline & $\begin{array}{l}\text { ÁREAS DE SEGURANÇA } \\
\text { VOO }\end{array}$ & RESA/ ESCAPE \\
\hline \multirow{7}{*}{$\begin{array}{c}\text { SAGUÃO "LADO } \\
\text { TERRA" }\end{array}$} & ÁREAS DE "MARKETING" & $\begin{array}{c}\text { PAINÉIS, TOTENS, TELÕES E } \\
\text { KIOSKS }\end{array}$ \\
\hline & $\begin{array}{l}\text { TRATAMENTO DE } \\
\text { BAGAGEM }\end{array}$ & RAIO-X/ TOMÓGRAFO \\
\hline & SANITÁRIOS (WC) & PÚBLICOS E DE SERVIÇO \\
\hline & COMPANHIAS AÉREAS & $\begin{array}{l}\text { ÁREAS DE VENDAS E } \\
\text { OPERACIONAIS }\end{array}$ \\
\hline & ÁREAS DE "CHECK-IN" & POSTOS DE "CHECK-IN" \\
\hline & ÁREAS DE ALIMENTAÇÃO & $\begin{array}{c}\text { WC - PÚBLICOS E DE SERVIÇO } \\
\text { COZINHA/ ALIMENTAÇÃA E } \\
\text { SERVIÇO }\end{array}$ \\
\hline & ÁREAS COMERCIAIS & LOJAS DE VAREJO \\
\hline
\end{tabular}




\begin{tabular}{|c|c|c|}
\hline \multirow{8}{*}{$\begin{array}{c}\text { ÁREAS DE } \\
\text { SEGURANÇA }\end{array}$} & \multirow{2}{*}{$\begin{array}{l}\text { INSPEÇÃO DE PESSOASE } \\
\text { BAGAGEM }\end{array}$} & \multirow{2}{*}{$\begin{array}{c}\text { RAIO-X/ TOMÓGRAFO } \\
\text { ESTEIRAS DE BAGAGEM }\end{array}$} \\
\hline & & \\
\hline & PREVENÇÃO DE IÍCITOS & \multirow{3}{*}{$\begin{array}{c}\text { PASSAGEIROS/ BAGAGEM/ } \\
\text { CHECK-IN } \\
\text { AGÊNCIAS PÚBLICAS } \\
\text { EMBARQUE/ DESEMBARQUE } \\
\text { NAVEGAÇÃO AÉREA/ } \\
\text { METEOROLOGIA }\end{array}$} \\
\hline & ÁREAS ESTRATÉGICAS & \\
\hline & \multirow[t]{2}{*}{ TORRE DE CONTROLE TWR } & \\
\hline & & WC - PÚBLICOS E DE SERVIÇO \\
\hline & ÁREAS MÉDICAS & $\begin{array}{l}\text { AMBULATÓRIO/ NECROTÉRIO } \\
\text { WC - PÚBLICOS E DE SERVIÇO }\end{array}$ \\
\hline & $\begin{array}{l}\text { SEÇÃO COMBATE } \\
\text { INCÊNDIO }\end{array}$ & GRUPAMENTO PADRÃO \\
\hline \multirow{9}{*}{$\begin{array}{c}\text { SAGUÃO "LADO } \\
\text { AR" }\end{array}$} & \multirow{2}{*}{ ÁREAS OPERACIONAIS } & ÁREAS DE SEGURANÇA \\
\hline & & TRANSFERÊNCIA DE BAGAGEM \\
\hline & ÁREAS GOVERNAMENTAIS & AGÊNCIAS PÚBLICAS \\
\hline & ÁREAS DE SERVIÇO & ÁREAS "VIP" \\
\hline & ÁREAS DE ESPERA & $\begin{array}{c}\text { SAGUÃO DE ESPERA } \\
\text { (LONGARINAS) } \\
\text { WC - PÚBLICOS E DE SERVIÇO }\end{array}$ \\
\hline & SANITÁRIOS (WC) & WC - PÚBLICOS E DE SERVIÇO \\
\hline & $\begin{array}{l}\text { ÁREAS DE LOJAS "DUTY- } \\
\text { FREE" }\end{array}$ & ADMINISTRATIVO E VENDAS \\
\hline & ÁREAS DE ALIMENTAÇÃO & $\begin{array}{c}\text { WC - PÚBLICOS E DE SERVIÇO } \\
\text { COZINHA/ ALIMENTAÇÃO E } \\
\text { SERVIÇO }\end{array}$ \\
\hline & ÁREAS COMERCIAIS & LOJAS DE VAREJO \\
\hline \multirow{9}{*}{$\begin{array}{l}\text { ÁREAS DE } \\
\text { EMBARQUE }\end{array}$} & ÁREAS DE ESPERA & $\begin{array}{c}\text { SAGUÃO DE ESPERA } \\
\text { (LONGARINAS) } \\
\text { WC - PÚBLICOS E DE SERVIÇO }\end{array}$ \\
\hline & ÁREAS DE ALIMENTAÇÃO & $\begin{array}{c}\text { WC - PÚBLICOS E DE SERVIÇO } \\
\text { COZINHA/ ALIMENTAÇÃO E } \\
\text { SERVIÇO }\end{array}$ \\
\hline & PORTÕES DE EMBARQUE & $\begin{array}{l}\text { ÁREAS OPERACIONAIS CIAS } \\
\text { AÉREAS }\end{array}$ \\
\hline & ÁREAS DE SEGURANÇA & $\begin{array}{c}\text { INSPEÇÃO DE PASSAGEIROS } \\
\text { ALFÂNDEGA } \\
\text { AGÊNCIAS PÚBLICAS } \\
\end{array}$ \\
\hline & CONECTORES & $\begin{array}{c}\text { CORREDORES E HALL PONTE } \\
\text { EMBARQUE }\end{array}$ \\
\hline & PONTES DE EMBARQUE & $\begin{array}{c}\text { PARTE FIXA (BODY) E MÓVEL } \\
\text { ("FINGER") }\end{array}$ \\
\hline & ÁREAS OPERACIONAIS & $\begin{array}{c}\text { SERVIÇOS DE RAMPA } \\
\text { ABASTECIMENTO AERONAVES } \\
\text { TRANSPORTE DE BAGAGENS }\end{array}$ \\
\hline & \multirow[t]{2}{*}{$\begin{array}{l}\text { TRATAMENTO DE } \\
\text { BAGAGEM }\end{array}$} & $\begin{array}{l}\text { TRANSF. DE BAGAGENS } \\
\text { ESTEIRAS DE BAGAGEM }\end{array}$ \\
\hline & & RAIO-X/TOMÓGRAFO \\
\hline
\end{tabular}




\begin{tabular}{|c|c|c|}
\hline & ÁREAS DE SEGURANÇA & $\begin{array}{c}\text { INSPEÇÃO DE PASSAGEIROS } \\
\text { ALFÂNDEGA } \\
\text { AGÊNCIAS PÚBLICAS }\end{array}$ \\
\hline & SANITÁRIOS (WC) & WC - PÚBLICOS E DE SERVIÇO \\
\hline$A ́ R F A S D F$ & $\begin{array}{l}\text { ÁREAS DE LOJAS "DUTY- } \\
\text { FREE" }\end{array}$ & $\begin{array}{l}\text { ADMINISTRATIVO E VENDAS } \\
\text { WC - PÚBLICOS E DE SERVIÇO }\end{array}$ \\
\hline DESEMBARQUE & RECEBIMENTO BAGAGEM & $\begin{array}{c}\text { TRANSFERÊNCIA DE } \\
\text { BAGAGENS } \\
\text { FSTEIRAS DF BAGAGFM }\end{array}$ \\
\hline & CONECTORES & $\begin{array}{l}\text { CORREDORES E HALL PONTE } \\
\text { EMBARQUE }\end{array}$ \\
\hline & PONTES DE EMBARQUE & $\begin{array}{c}\text { PARTE FIXA (BODY) E MÓVEL } \\
\text { ("FINGER") }\end{array}$ \\
\hline & AGÊNCIAS PÚBLICAS & $\begin{array}{l}\text { ANVISA/ RECEITA/ POLICIA } \\
\text { FEDERAL }\end{array}$ \\
\hline & CENTRAL DE GÁS & $\begin{array}{l}\text { AQUECIMENTO E } \\
\text { REGRIGERAÇÃO }\end{array}$ \\
\hline ÁREAS & ÁREAS DE FUNCIONÁRIOS & $\begin{array}{c}\text { WC - PÚBLICOS E DE SERVIÇO } \\
\text { COZINHA/ ALIMENTAÇÃO E } \\
\text { SERVIÇO }\end{array}$ \\
\hline ADMINISTRATIVAS & ÁREAS ADMINISTRATIVAS & AGÊNCIAS PÚBLICAS \\
\hline & CENTRAL DE ÁGUA & $\begin{array}{c}\text { ÁGUAS BRANCAS, CINZAS E } \\
\text { NEGRAS }\end{array}$ \\
\hline & CENTRAL DE FORÇA - KF & ALTA, MÉDIA E BAIXA TENSÃO \\
\hline & $\begin{array}{l}\text { CENTRAL DE AR - } \\
\text { CONDICIONADO }\end{array}$ & $\begin{array}{c}\text { EVAP; CONDENSADORES E } \\
\text { DISPERSORES }\end{array}$ \\
\hline & GALERIAS TÉCNICAS & $\begin{array}{c}\text { GÁS/ ÁGUA/ } \\
\text { ELETROELETRÔNICO }\end{array}$ \\
\hline & ÁREAS DE SEGURANÇA & $\begin{array}{c}\text { INSPEÇÃO DE PASSAGEIROS } \\
\text { ALFÂNDEGA } \\
\text { AGÊNCIAS PÚBLICAS }\end{array}$ \\
\hline ÁREAS & ÁREAS OPERACIONAIS & PISTAS, TAXYWAYS E PÁTIOS \\
\hline OPERACIONAIS & SALA AIS & $\begin{array}{l}\text { LIBERAÇÃO VÔO/ } \\
\text { METEOROLOGIA }\end{array}$ \\
\hline & ÁREAS DE CONTROLE & $\begin{array}{c}\text { "HANDLING" E "CATERING" } \\
\text { AGÊNCIAS PÚBLICAS }\end{array}$ \\
\hline & $\begin{array}{c}\text { TORRE DE CONTROLE - } \\
\text { TWR } \\
\end{array}$ & $\begin{array}{c}\text { POUSOS E DECOLAGENS } \\
\text { ESPAÇO AÉREO }\end{array}$ \\
\hline PÁTIO DE & $\begin{array}{l}\text { SUPRIMENTO DE } \\
\text { AERONAVES }\end{array}$ & $\begin{array}{c}115 V(400 \mathrm{hz}) / 28 \mathrm{~V} \text { DC/ TNCS } \\
1000 \mathrm{~V} \\
\text { RESERVATÓRIO/ VÁLVULAS/ } \\
\text { HIDRANTES } \\
\text { AR PRECONDICIONADO - } \\
\text { "STARTER" }\end{array}$ \\
\hline AERONAVES & ÁREAS DE DRENAGEM & GALERIAS DE ÁGUA \\
\hline & $\begin{array}{l}\text { TRATAMENTO DE } \\
\text { BAGAGEM EXTERNO }\end{array}$ & $\begin{array}{c}\text { TRANSPORTE DE BAGAGENS } \\
\text { TRANSFERÊNCIA DE } \\
\text { BAGAGENS } \\
\text { ESTEIRAS DE BAGAGEM }\end{array}$ \\
\hline
\end{tabular}


Foram utilizados na construção da matriz as informações da INFRAERO obtidas por meio de consulta bibliográfica aos termos de referência de contratação de projetos aeroportuários, manuais e normas internas da empresa, memoriais descritivos (técnicas gerais e específicas), memoriais de critérios e condicionantes que descrevem os pormenores do empreendimento (Tabela 2).

Além disso, foi realizada consulta às normas brasileiras NBR para infraestrutura aeroportuária, para nortear a representação das informações de projetos. (Tabela 3).

Na matriz semântica foram configuradas informações relativas aos manuais de projeto, obras e de manutenção, normas de edificações e de acessibilidade, planilhas de preços, como a SICAERO e SINAPI entre outros. Um projeto na INFRAERO obedece a normas e práticas internas (SEAP/ MAGES), normas internacionais (OACI) e nacionais (SAC/ ANAC).

As planilhas de preços SICAERO/ SINAPI representam os valores normativos estabelecidos pelo Governo Federal para a licitação de componentes aeroportuários e construtivos, nesta ordem.

Devido ao fato dos aeroportos incluírem componentes que não se encontram em outros tipos de edificação, a planilha SICAERO é a fonte de consulta para a cotação de preços.

Outros tipos de normas, como de acessibilidade, sinalização visual, entre outros, são de caráter generalista, assim como os manuais de projeto, construção e manutenção.

A matriz foi elaborada para fornecer informações de projeto, relacionando as responsabilidades de quem projeta (representado pelas disciplinas da INFRAERO) e de quem realiza os processos de aprovação (representado pelas áreas da INFRAERO). Isto foi feito com base em requerimentos e normas sobre projeto de aeroportos e considerando as características específicas de cada empreendimento, constantes do "Termo de Referência" elaborado pela INFRAERO.

No caso de um aeroporto de pequeno porte, o terminal de passageiros se confunde com o próprio aeroporto, pois inexistem outras edificações no sitio aeroportuário, à exceção das casas de força $(\mathrm{KF})$, estações de tratamento de resíduos e centrais de ar condicionado. Isso fez com que a estruturação da matriz, baseada no terminal de passageiros regional represente também as funções de um aeroporto de pequeno porte. 
TABELA 2- DOCUMENTOS UTILIZADOS NA MATRIZ SEMÂNTICA.

\section{NOME DO DOCUMENTO}

CóDIGO

1- ANTEPROJETO PARA TERMINAL DE PASSAGEIROS REGIONAL V.1

GE.06/010.75/01381/00

2- MEMORIAL GERAL PARA TERMINAIS DE PASSAGEIROS (TPS)

3- MEMORIAL DE REQUISITOS DE INFRAESTRUTURA OPERACIONAL - MRIE

4- MEMORIAL NÚMERO 6 OSTENSIVO DOPL BALCÕES DE ATENDIMENTO

N/A

N/A

N/A

5- MEMORIAL DE CRITÉRIOS SUSTENTÁVEIS PARA EMPREENDIMENTOS

GE.01/000.75/001064/01

6- RELATÓRIO - ACESSIBILIDADE

N/A

7- MEMORIAL DE CRITÉRIOS E CONDICIONANTES ARQUITETURA

GE.01/201.75/00947/02

8- MCC - SISTEMAS HIDROSSANITÁRIOS/ ÁGUAS PLUVIAIS

GE.01/502.75/00865/04

9- MCC - ARQUITETURA / TPS até 1.000 .000 passageiros/ano

GE.01/201.75/00000/00

10- ESPECIFICAÇÃO TÉCNICA ESPECÍFICA

CF.06/000.92/15510/00

11- ESPECIFICAÇÃO TÉCNICA GERAL

CF.06/000.92/15509/00

12- MEMORIAL DESCRITIVO DAS SOLUÇÕES CONSOLIDADAS

CF.06/000.73/15511/00

13- MANUAL DE OBRAS PÚBLICAS: MANUTEÇÃO CONSTRUÇÃO - PROJETO

N/A

14- MANUAL GESTÃO ENGENHARIA - INFRAERO

N/A

15- ACESSIBILIDADE DA PESSOA PORTADORA DE DEFICIÊNCIA NO TRANSPORTE AÉREO COMERCIAL

16- ELABORAÇÃO DE PROJETOS DE EDIFICAÇÕES ARQUITETURA

17- SISTEMA DE ILUMINAÇÃO DE EMERGÊNCIA

18- ANEXO 14 - OACI

N/A

19- REGULAMENTO BRASILEIRO DA AVIAÇÃO CIVIL 
OS DOCUMENTOS LISTADOS ABAIXO FORAM UTILIZADOS COMO FONTE DE CONSULTA PARA A ESTRUTURAÇÃO LOGICA DA MATRIZ, AUXILIANDO NA FORMATAÇÃO DO AEROPORTO E SUAS PARTES:

a- MCC - ARQUITETURA / TPS até 1.000 .000 passageiros/ano GE.01/201.75/00000/00;

b- MEMORIAL DE CRITÉRIOS SUSTENTÁVEIS PARA EMPREENDIMENTOS GE.01/000.75/001064/01;

c- RELATÓRIO - ACESSIBILIDADE;

d- MEMORIAL DE CRITÉRIOS E CONDICIONANTES - ARQUITETURA GE.01/201.75/00947/02;

e- MCC - SISTEMAS HIDROSSANITÁRIOS/ ÁGUAS PLUVIAIS GE.01/502.75/00865/04;

f- ANTEPROJETO PARA TERMINAL DE PASSAGEIROS REGIONAL V.1 GE.06/010.75/01381/00;

g- MEMORIAL GERAL PARA TERMINAIS DE PASSAGEIROS (TPS);

h- ESPECIFICAÇÃO TÉCNICA ESPECÍFICA - CF.06/000.92/15510/00;

i- ESPECIFICAÇÃO TÉCNICA GERAL - CF.06/000.92/15509/00.

OS DOCUMENTOS LISTADOS ABAIXO AUXILIARAM NAS CONSULTAS SOBRE A INFRAESTRUTURA NECESSÁRIA PARA UM TERMINAL DE PASSAGEIROS:

a- MEMORIAL DE REQUISITOS DE INFRAESTRUTURA OPERACIONAL MRIE;

b- ANEXO 14 - OACl;

c- REGULAMENTO BRASILEIRO DA AVIAÇÃO CIVIL - 154;

d- ACESSIBILIDADE DA PESSOA PORTADORA DE DEFICIÊNCIA NO TRANSPORTE AÉREO COMERCIAL NBR 14273.

OS DOCUMENTOS LISTADOS ABAIXO FORAM CONSULTADOS PARA ESPECIFICIDADES EM OBRAS E SERVIÇOS DE ENGENHARIA, INCLUSIVE PROJETOS, PARA EMPRESAS PÚBLICAS COMO A INFRAERO:

a- ELABORAÇÃO DE PROJETOS DE EDIFICAÇÕES - ARQUITETURA - NBR 13532;

b- MANUAL DE OBRAS PÚBLICAS: MANUTEÇÃO - CONSTRUÇÃO PROJETO;

c- MANUAL GESTÃO ENGENHARIA - INFRAERO. 
No presente estudo, a inserção de informações foi limitada à ótica do arquiteto.

\section{A PROPOSTA FOI RELACIONAR AS ÁREAS ENVOLVIDAS NAS TAREFAS DE APROVAÇÃO, QUE SÃO LISTADAS SEPARADAMENTE PARA CADA ÁREA E REPRESENTAR COMO AS MESMAS DEVEM SER REALIZADAS:}

1- SE POR MEIO DE PROJETO, ANÁLISE OU SÍNTESE;

2- QUAL O TIPO DE AÇÃO, SE DE EXECUÇÃO OU DE INFORMAÇÃO;

3- O IMPACTO NO PROCESSO DE PROJETO, SE ALTO, MÉDIO OU BAIXO.

No campo de processos de aprovação de projetos foram descritas as tarefas desenvolvidas em cada área envolvida da INFRAERO, informações sobre as etapas necessárias para criação de cada módulo (projeto, análise ou síntese), qual o tipo de ação prevista (execução ou comunicação) e ainda qual o impacto no processo de projeto dessas atividades (alto, médio ou baixo).

TABELA 3 - ESTRUTURA ORGANIZACIONAL DOS DIFERENTES PROCESSOS DE APROVAÇÃO DE PROJETO DA MATRIZ SEMÂNTICA CONSTRUÍDA PARA O TERMINAL DE PASSAGEIROS REGIONAL DA INFRAERO.

\begin{tabular}{|c|c|c|c|c|}
\hline \multirow{9}{*}{$\begin{array}{c}\text { APROUACLO DE } \\
\text { PROETOS }\end{array}$} & \multirow{9}{*}{$\begin{array}{l}\text { AREA DA } \\
\text { INFAESO }\end{array}$} & \multirow{9}{*}{ 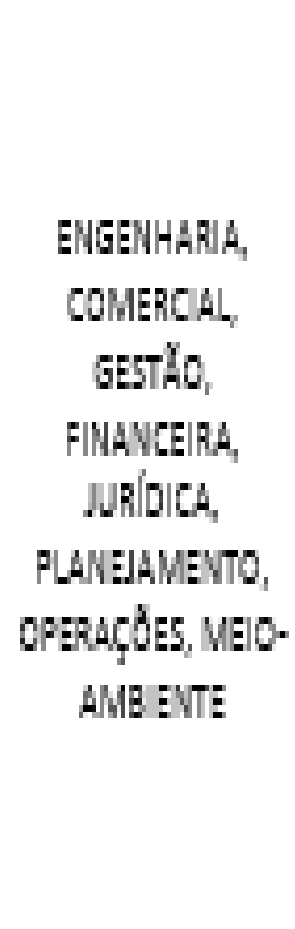 } & \multirow{3}{*}{ GMD } & POETO \\
\hline & & & & ANAISE \\
\hline & & & & SWTE: \\
\hline & & & \multirow{3}{*}{ 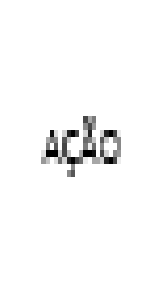 } & EETUTAR \\
\hline & & & & NFORHAR \\
\hline & & & & MADA \\
\hline & & & \multirow{3}{*}{ MATT } & ALTO \\
\hline & & & & MEDO \\
\hline & & & & $34 \times$ \\
\hline
\end{tabular}

No campo de tarefas de projeto foram configuradas informações relevantes a cada uma das disciplinas envolvidas na projetação dos módulos funcionais do aeroporto.

Essas informações foram detalhadas para diferentes fases do processo de projeto (conceitual e básico). 
TABELA 4 - ESTRUTURA ORGANIZACIONAL DOS DIFERENTES PROCESSOS DE PROJETO DA MATRIZ SEMÂNTICA CONSTRUÍDA PARA O TERMINAL DE PASSAGEIROS REGIONAL DA INFRAERO.

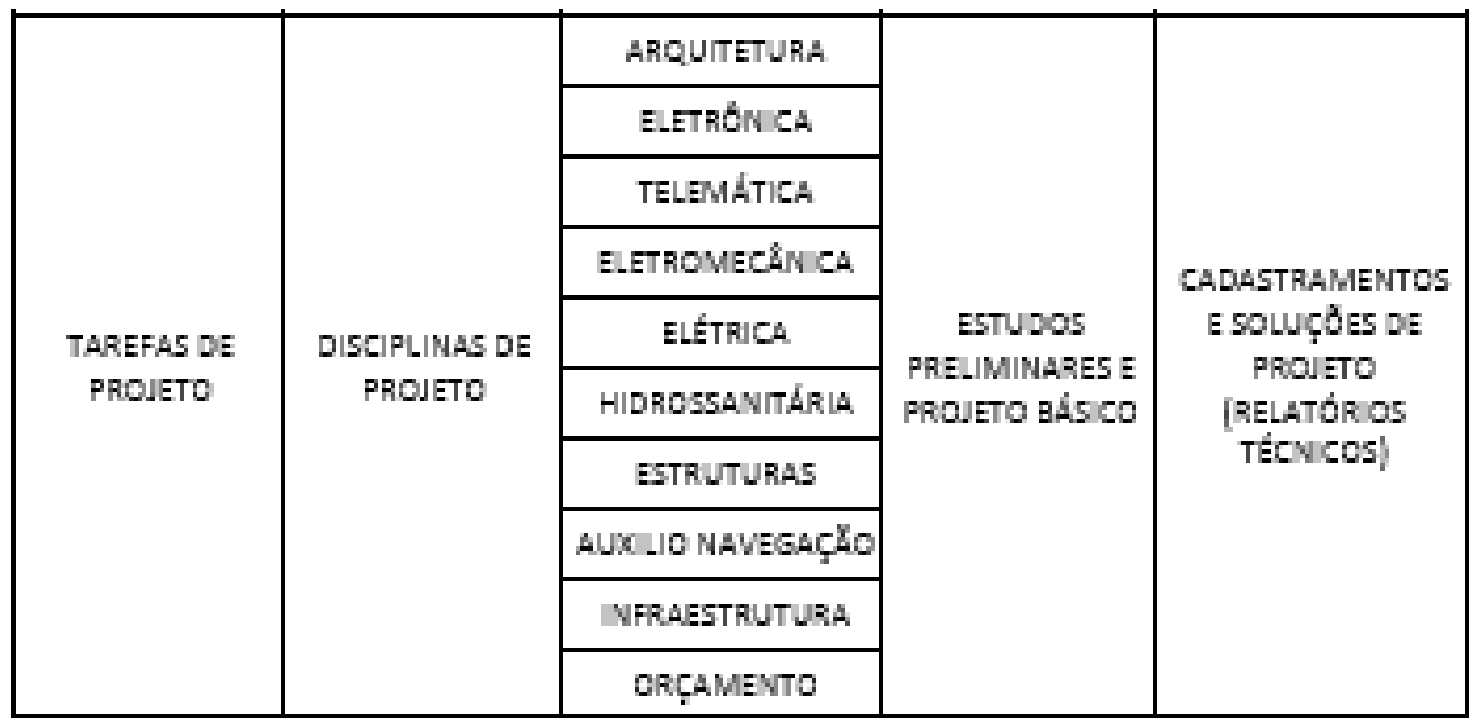

No campo de processos de requerimentos e normas de projeto foram configurados os documentos, normas, manuais e legislações específicas para cada módulo funcional, permitindo a consulta da documentação através de "hyperlinks". Para cada um dos processos foram descritas, de forma hierarquizada, as estruturas, agentes intervenientes, as classes e tipos de atividades envolvidas (Tabela 3)

TABELA 4 - ESTRUTURA ORGANIZACIONAL DOS DIFERENTES PROCESSOS DE PROJETO DA MATRIZ SEMÂNTICA CONSTRUÍDA PARA O TERMINAL DE PASSAGEIROS REGIONAL DA INFRAERO.

\begin{tabular}{|c|c|c|c|c|}
\hline PROCESSO & ESTRUTURAS & AGENTES & CLASSE & TIPO \\
\hline \multirow{10}{*}{$\begin{array}{c}\text { REQUERIMENTOS } \\
\text { DE PROJETO }\end{array}$} & \multirow{10}{*}{$\begin{array}{l}\text { DOCUMENTOS } \\
\text { DE REFERÊNCIA }\end{array}$} & SICAERO/SINAPI & ORÇAMENTAÇÃO & PLANILHA REF. \\
\hline & & LUZES EMERGÊNCIA & PROJETO & MANUAL \\
\hline & & SINALIZAÇÃO & SEGURANÇA & MANUAL \\
\hline & & ESTRADAS RODAGEM & ACESSO VIÁRIO & MANUAL \\
\hline & & ACESSIBILIDADE & $\begin{array}{c}\text { NECESSIDADES } \\
\text { ESP. }\end{array}$ & MANUAL \\
\hline & & CONSTRUÇÃO & OBRA & MANUAL \\
\hline & & PROJETO & PLANEJAMENTO & MANUAL \\
\hline & & MANUTENÇÃO & OPERAÇÃO & MANUAL \\
\hline & & $\begin{array}{l}\text { ACESS. TRANSP. } \\
\text { AÉREO }\end{array}$ & FLUXOS AVIAÇÃO & MANUAL \\
\hline & & MAGES INFRAERO & PRÁTICAS & MANUAL \\
\hline
\end{tabular}




\subsection{1- ESTRUTURA DA MATRIZ SEMÂNTICA - EXEMPLO DE CONSULTA}

A matriz pode ser alterada e reconfigurada a cada empreendimento com a respectiva documentação, e ainda em relação aos campos de informação de cada uma de suas partes, podendo facilmente ser personalizada para diferentes usos e destinações em diferentes organizações e projetos. A matriz é interativa, de forma que ao "clicar" em cada um dos módulos funcionais (Figura 27) abre-se janela que permite o acesso às informações respectivas aos processos de aprovação, de projetos e seus requerimentos.

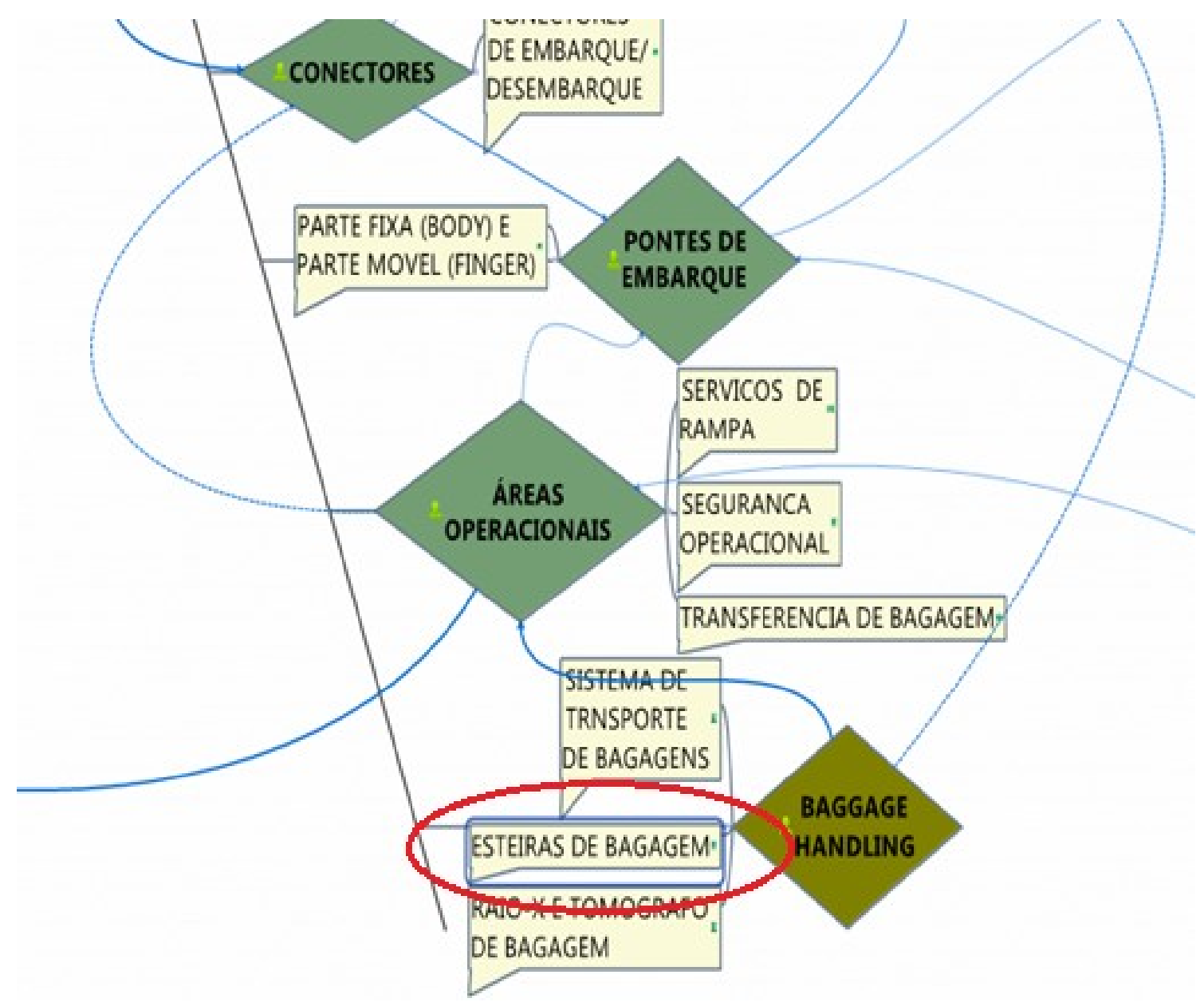

Figura 27 - Tela de acesso aos Módulos Funcionais da Matriz Semântica.

A utilização das informações da matriz correspondentes ao nível de detalhamento geral permite que se confrontem os processos de aprovação de projeto com o dimensionamento das tarefas de realização do mesmo. Um panorama geral da organização da matriz foi descrito a seguir. No primeiro nível de informação da matriz encontramos os "links" para os processos de arquitetura e para os processos relativos a cada uma das especialidades, conforme detalhado anteriormente na metodologia. Uma contribuição importante desta pesquisa foi o estabelecimento das regras de organização e da estrutura de informações, de forma a espelhar o ambiente organizacional e de projeto da INFRAERO. 
No primeiro nível de informação da matriz, encontram-se os "links" para os processos de arquitetura e para os processos relativos a cada uma das especialidades. Ao selecionar, por exemplo, um determinado módulo funcional, é possível saber quais são as áreas responsáveis pelos processos de aprovação, com base em quais requisitos e ainda quem são os responsáveis por gerar as soluções de projeto (disciplinas) e quais são os condicionantes do empreendimento, ou suas especificidades (termo de referência). A escolha de quais campos de informação serão consultados contém informações sobre outras partes ou funções ao longo do processo de projeto do aeroporto. A consulta à matriz semântica permitiu construir alguns componentes paramétricos que correspondem a um módulo funcional do aeroporto com representação de informação e detalhe em diferentes níveis de abstração/especificação. A Figura 28 representa a tela de acesso do módulo funcional Esteira de Bagagem.

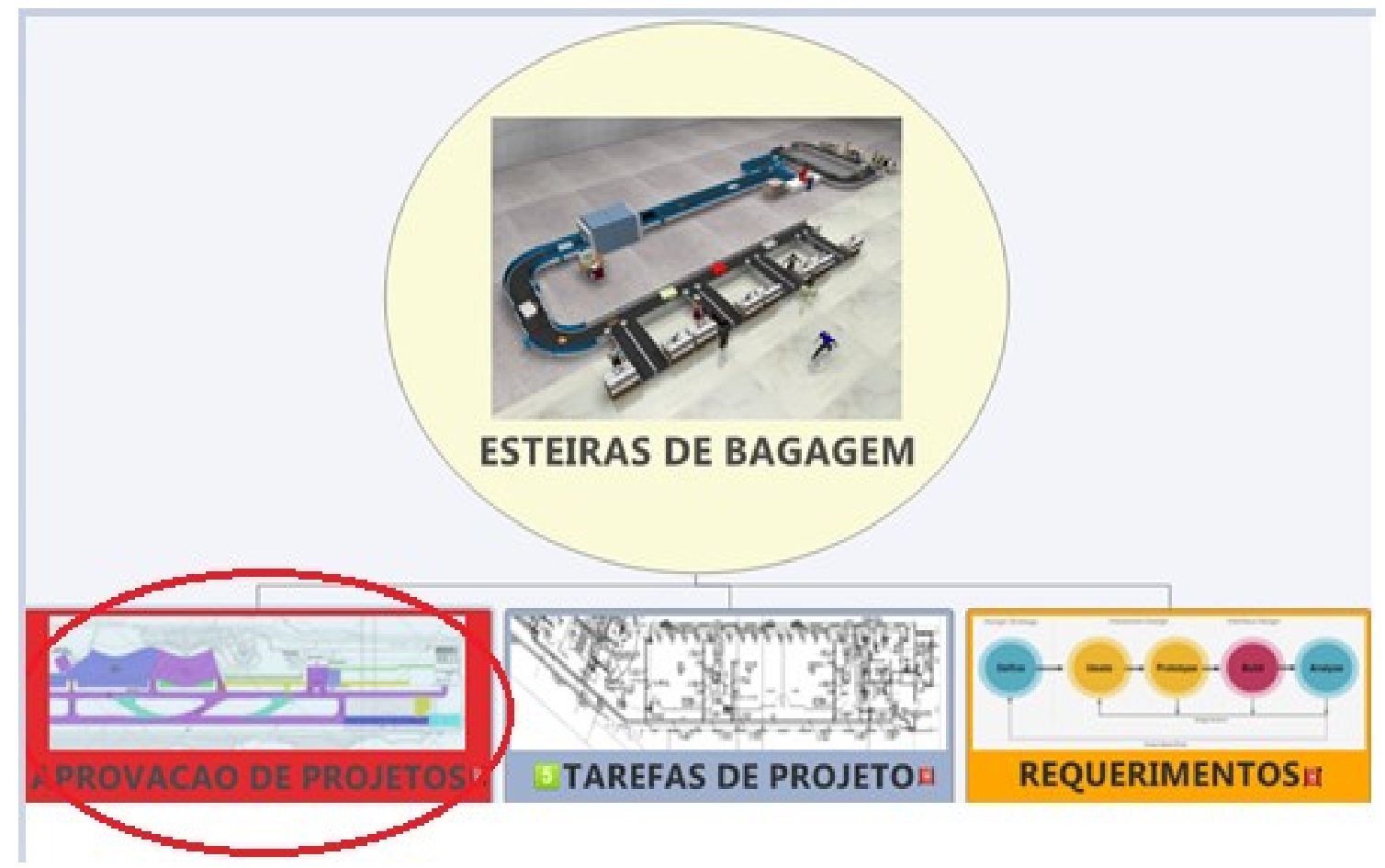

Figura 28 - Tela do Módulo Funcional "Esteiras de Bagagem", com acesso aos campos de Processos de Aprovação, Tarefas de Projeto e Requerimentos de Projeto.

Para todos os módulos funcionais do aeroporto, foram incluídas as informações referentes às tarefas de projeto, relacionadas ao desenvolvimento de soluções para obras e serviços de engenharia, no tocante aos sistemas, requisitos e normativos disponíveis no "Termo de Referência" de um projeto. A Figura 29 a seguir exemplifica as informações referentes as tarefas de projeto do módulo funcional para Esteiras de Bagagem (embarcada e desembarcada). Para cada área foram descritas quais tarefas são necessárias para os processos de aprovação, como as mesmas devem ser realizadas, o tipo de ação e os níveis de impacto (alto, médio e baixo). 


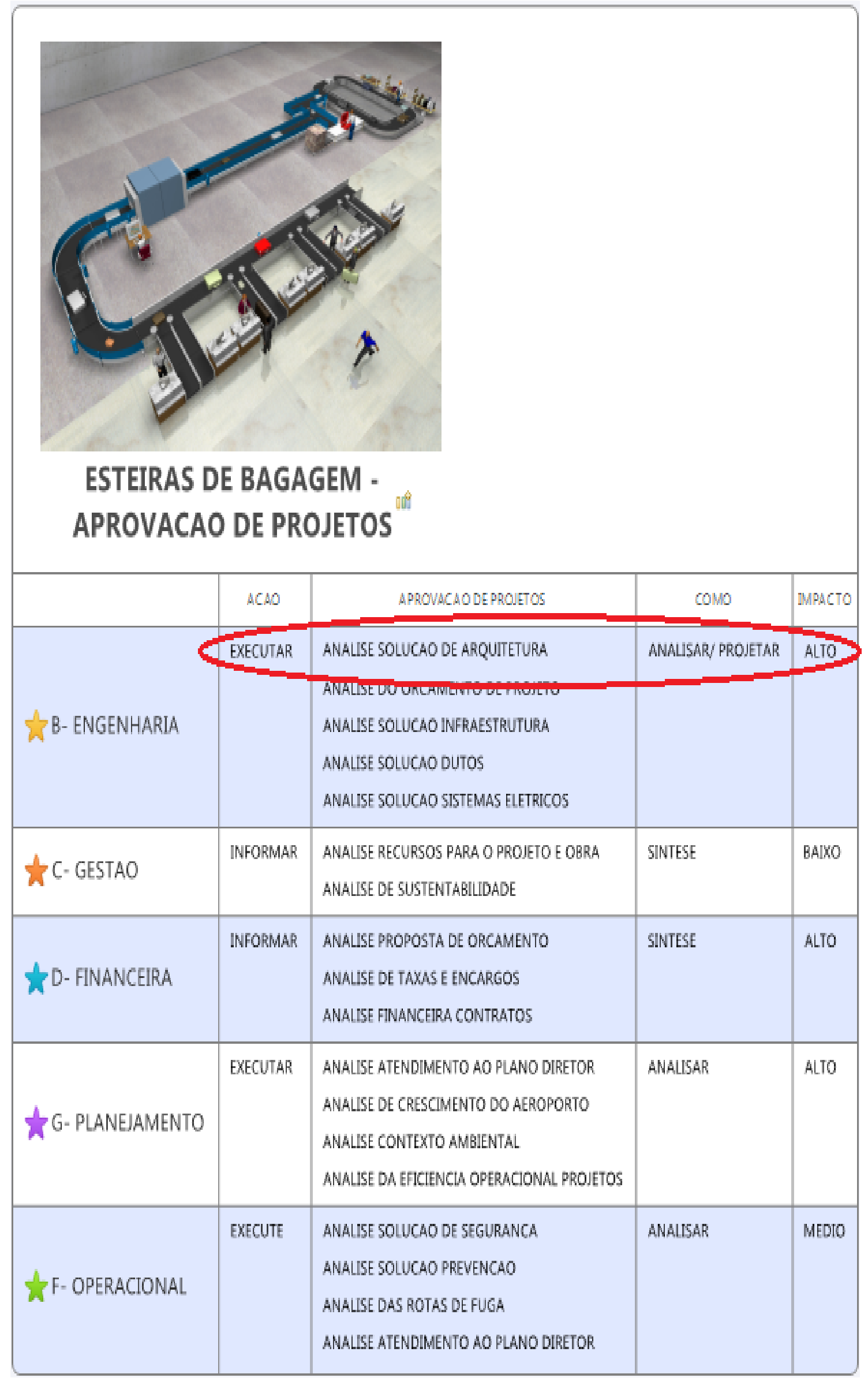

Figura 29 - Informações referentes ao Módulo Funcional "Esteiras de Bagagem" de um Terminal de Passageiros de pequeno porte. 
Conforme pode ser observado na Figura 29 da página anterior, a análise da solução de arquitetura deve ser executada e aprovada internamente pela área de engenharia, pois a mesma possui atribuições tanto de análise quanto de projeto.

Pode-se ainda observar que a matriz informa que o impacto dessa atividade é alto.

As demais áreas listadas (GESTÃO, FINANCEIRA, PLANEJAMENTO e OPERACIONAL) possuem atribuições especificas de aprovação que estão detalhadas em relação a que tipo de ação deve ser feita para cada tarefa de análise.

Assim como no exemplo apresentado acima, define se será por meio de análise, síntese ou atividade de projeto. Lista ainda o impacto que cada tarefa representa.

Em relação a todas as áreas do aeroporto, a tela de acesso também permite consultar os critérios, constantes na documentação de referência citada anteriormente, das tarefas de projeto de cada uma das disciplinas, tanto para o estudo preliminar como para o projeto básico.

O módulo funcional das "ESTEIRAS DE BAGAGEM" foi detalhado para informar sobre a diferenciação entre as dimensões das disciplinas de engenharia e de arquitetura.

Nesse nível de detalhamento, o usuário tem acesso às tarefas de projeto, os sistemas e partes do aeroporto que se relacionam, associados aos processos de projeto e de aprovação.

A Figura 30 a seguir informa sobre a estrutura lógica dos dados referentes aos módulos funcionais do aeroporto.

Pode-se observar que as disciplinas de projeto são divididas entre tarefas de projeto para duas fases distintas do processo de projeto: estudo preliminar e projeto básico.

A Figura 30 a seguir não faz parte da versão digital da matriz, mas foi elaborada para explicar como a representação dos dados se divide entre diferentes fases do projeto, para cada disciplina de projeto. 


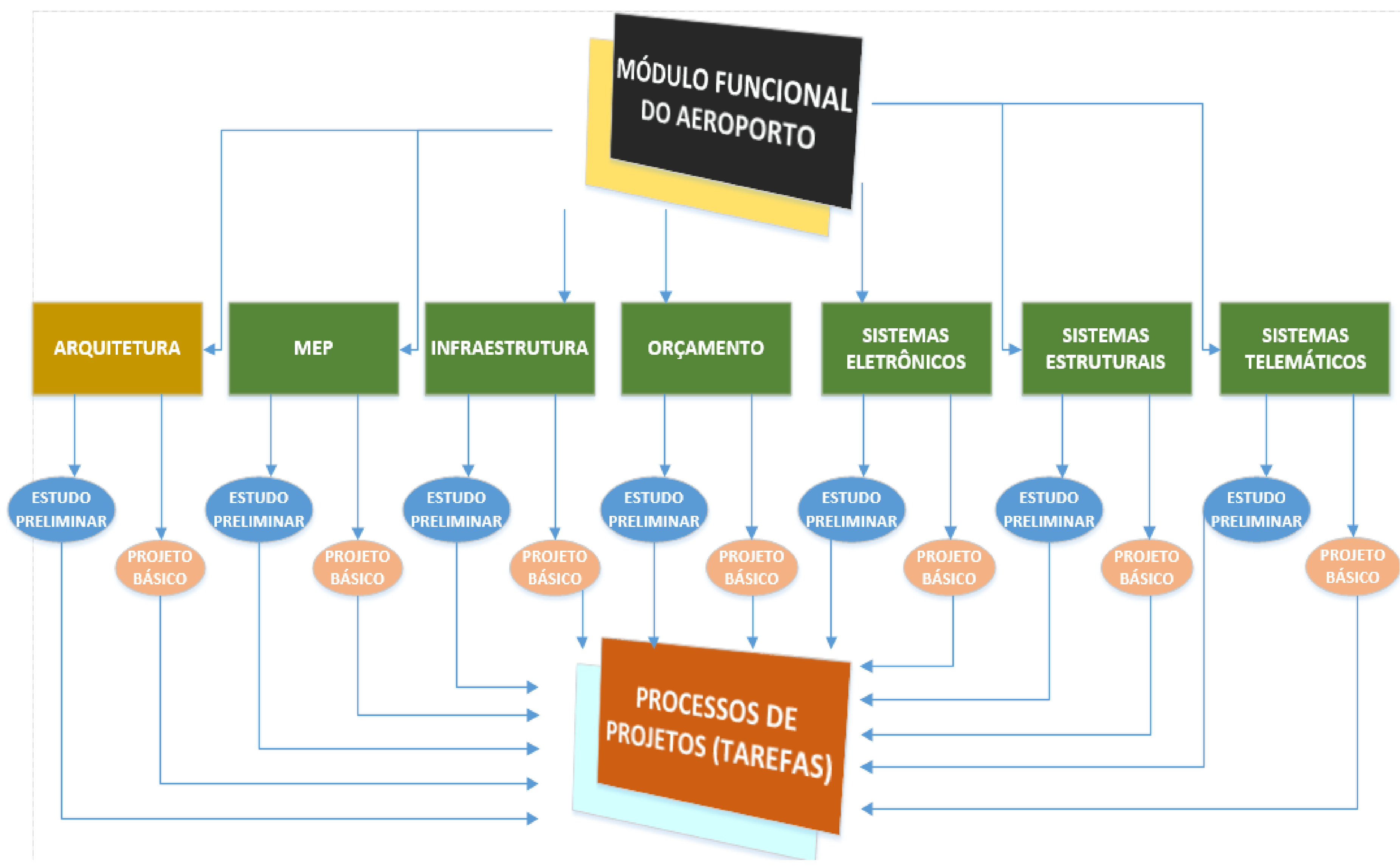

Figura 30 - Estruturação lógica de informação na Matriz Semântica nos Tarefas de Projeto. 
A Figura 30, na página anterior, demonstra a estrutura lógica de organização que foi utilizada para representar as tarefas de projeto de um módulo funcional. Quando o usuário clica na aba de Tarefas de Projeto, destacada na Figura 31 abaixo, obtém como consequência uma nova tela representada pela Figura 32 na página seguinte.

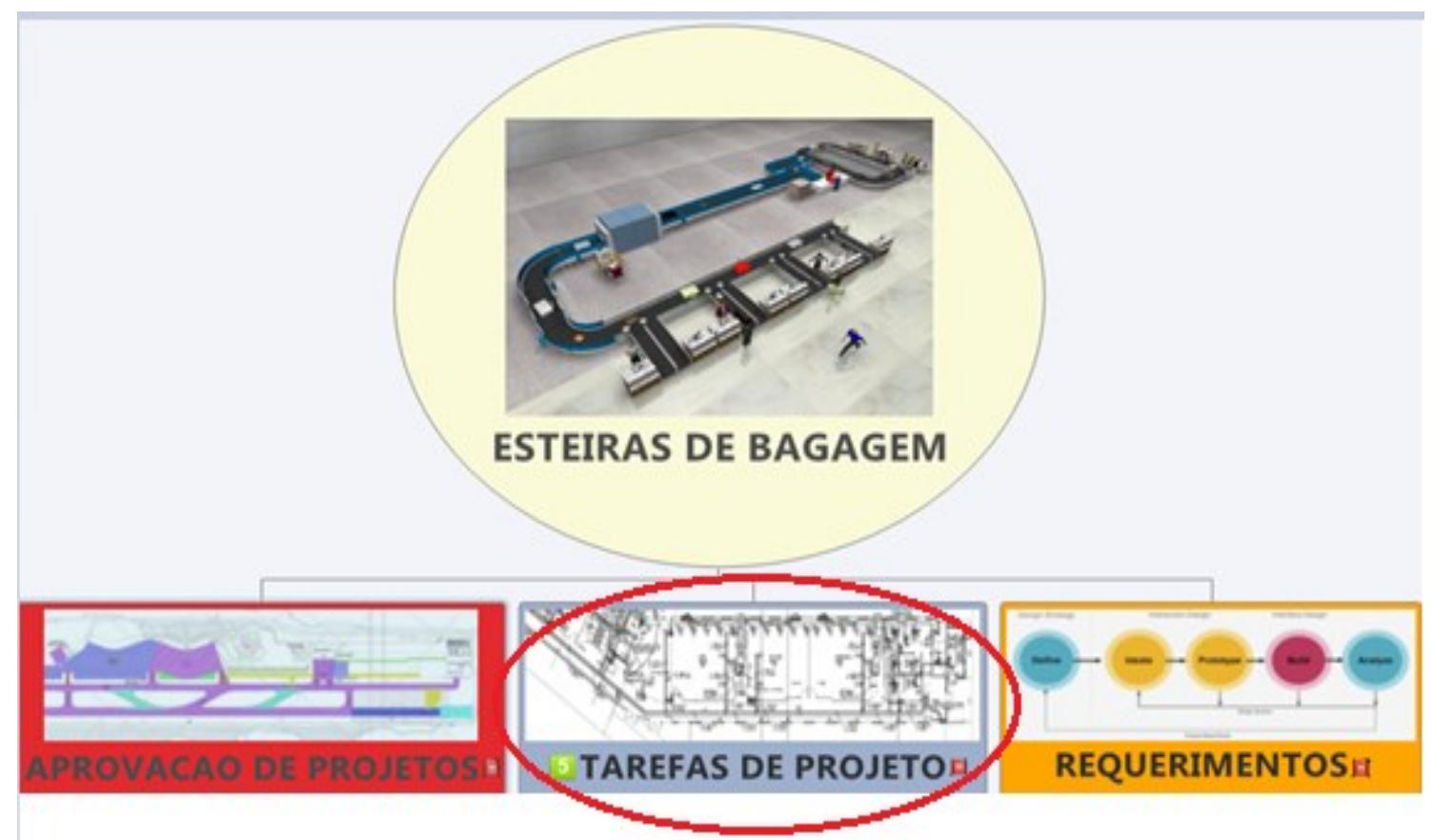

Figura 31- Tela de acesso na versao digital da Matriz Semântica para as Tarefas de Projeto Esteiras de Bagagem.

NA FIGURA 32 A SEGUIR, PODE SER OBSERVADA A ESTRUTURA PARA UMA "ESTEIRA DE BAGAGEM" AEROPORTUÁRIA QUE ABRANGE AS DISCIPLINAS DE:

1- ARQUITETURA;

2- SISTEMAS ELETROMECÂNICOS;

3- SISTEMAS ELÉTRICOS;

4- SISTEMAS HIDROSSANITÁRIOS;

5- ORÇAMENTO;

6- INFRAESTRUTURA;

7- SISTEMAS ELETRÔNICOS;

8- TELEMÁTICA.

A Figura 32 a seguir ilustra a organização das tarefas de projeto de um módulo de Esteiras de Bagagem. Cada módulo funcional apresenta, na matriz, as disciplinas que estão envolvidas nos seus processos de projeto.

No caso do "check-in" encontram-se listadas as disciplinas de Arquitetura, Sistemas Elétricos, Infraestrutura, Orçamento, Sistemas Eletrônicos, Sistemas Estruturais e de Telemática. 


\begin{tabular}{|c|c|}
\hline \multicolumn{2}{|c|}{ ESTEIRAS DE BAGAGEM TAREFAS DE PROJETO } \\
\hline \multirow{3}{*}{ ARQUTTETURA } & TPRODUCTION \\
\hline & PROJETO BASICO DE ARQUUTETURA. PROJETO DE SINALIZACAO* \\
\hline & CADASTRAMENTO DE ARQUUTC(URA. ESTUDO CONCETUAL ARQUTTETURA. \\
\hline \multirow{3}{*}{ SISTEMAS ELETRLCOS, HIDROSSANTTARIOS E MECANICOS } & *CADASTR DE DUTOS CADASTR ElETRLCO ESTUDO CONCETUAL ElETRLCO E HIDRAULICO \\
\hline & \$PROOUCTION \\
\hline & *PROIETO BASICO ELETRECA PROJETO BASICO HIDRAULLA \\
\hline \multirow{4}{*}{ INFRAESTRUTURA } & APRODUCTION \\
\hline & PROJETO BASICO ORENAGEM" :PROJETO BASICO PAVIMENTACAO* \\
\hline & VCONCEPTUAL \\
\hline & CADASTR. INFRAESTRUTURA-MARCOS TOPOGRAFICOS' ESTUDO CONCETUAL INFRAESTRUTURA \\
\hline \multirow{4}{*}{ ORCAMENTO } & VCONCEPTUAL \\
\hline & ESTUDO CONCETUAL ORCAMENTO. \\
\hline & \$RODUCTION \\
\hline & PROJETO BASICO ORCAMENTO. \\
\hline \multirow{4}{*}{ SISTEMAS ELETRONICOS } & TPRODUCTION \\
\hline & ¿PROJETO BASICO ELETRONICA \\
\hline & VCONCEPTUAL \\
\hline & ESTUDO CONCETUAL ELETRONCA' \\
\hline \multirow{4}{*}{ TELEMATICA } & IPRODUCTION \\
\hline & PROJETO BASICO TELEMATICA: \\
\hline & VCONCEPTUAL \\
\hline & ESTUDO CONCETUAL TELEMATICA. \\
\hline
\end{tabular}

Figura 32 - Tarefas de Projeto para Esteiras de Bagagem na Matriz Semântica.

$\mathrm{Na}$ coluna referente às tarefas de projeto (Figura 32) estão separadas as informações referentes ao Estudo Preliminar e ao Projeto Básico. Para cada fase de projeto estão listadas as respectivas atividades, ou tarefas de projeto. Por exemplo, para a especialidade de arquitetura, referente ao estudo conceitual, é possível acessar, clicando no campo desejado, as tarefas relativas ao estudo conceitual de Arquitetura. 
A CONTRATADA deverá elaborar todos os desenhos com o conteúdo e consistência das informaç̧̄es técnicas de acordo com o que prescrevem as normas da INFRAERO para esta etapa de projeto. Deverão ser apresentados no minimo:

- Planta de Situaçäo/Locaçăo.

- Planta Baixa de todos os pavimentos, cotada, na escala adequada (minimo 1:100), contendo:

- Indicaçăo de todos os ambientes, com suas funçọes definidas.

- Área dos ambientes e cotas de nivel.

- Legenda com especificação dos materiais de acabamento.

- Legenda com especificaçăo de esquadrias.

Cortes elucidativos dos ambientes (minimo 04), Cotados, na escala adequada, para methor compreensăo das alturas resultantes em funçăo da escala humana, e deveräo apresentar:

- Rampas e/ou escadas (quando houver), áreas molhadas ou qualquer outro

detathe necessário à compreensäo da soluçăo adotada. - Elevaçoes.

- Planta de cobertura com os detathes necessários à compreensão a soluçăo adotada.

- Planta Baixa da galeria técricca com os detahes necessários.

- A planta Geral de todos os pavimentos, cotada, na escala adequada

(mínimo 1:250), apresentando todos os ambientes com suas funçōes

definidas, a disposiçăo de todos os equipamentos necessários para as

atividades a serem exercidas e a discriminaçäo das especificaçōes dos

revestimentos e das aplicaçoes propostas.

Catálogos à disposiçăo do mercado para ilustraç̧ăo da proposta e,

eventualmente, amostras.

- Desenhos especificos em forma de apresentaçăa livere, quando for o caso, para methor compreensä̃o da proposta.

- Orçamento detalhado dos componentes baseado em quantitativos de

materiais e fornecimento.

Figura 33 - Requisitos de Estudo Conceitual de Arquitetura na Matriz Semântica. 
A Figura 33 na página anterior ilustra a representação dos requisitos de projeto para estudo conceitual de arquitetura na INFRAERO.

Define critérios de representação de projeto, escalas e ainda o escopo mínimo que deve ser apresentado, de forma que o produto final possa obedecer ao preconizado na Lei de Licitações - Lei 8666/93 | Lei n 8.666, de 21 de junho de 1993 - que exige comprovação da viabilidade, relacionada aos custos envolvidos do projeto.

Os requerimentos e normas de projeto, disponibilizados na matriz, por meio do acesso aos "hyperlinks", apresentam as normas, manuais e determinações referentes ao projeto de aeroportos, seus sistemas técnicos, legislação e meio ambiente.

A Figura 34 a seguir ilustra a tela de acesso a dimensão dos requerimentos de projeto, para Esteiras de Bagagem.

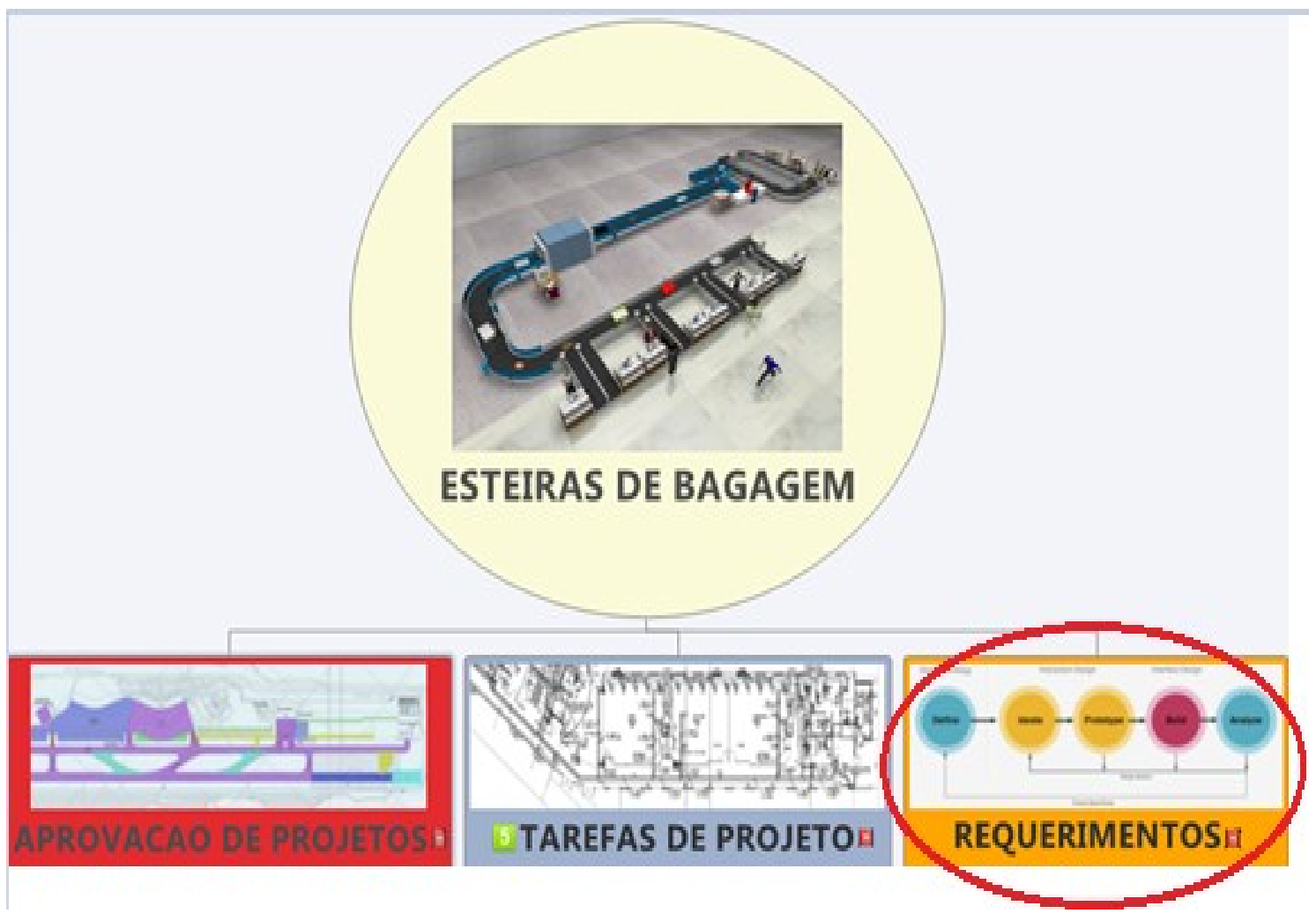

Figura 34- Exemplo de tela de acesso na versao digital da Matriz Semantica para os Requerimentos de Projeto para Esteiras de Bagagem.

Os documentos cedidos pela INFRAERO, como Memoriais Descritivos, Manuais de projeto e de obras públicas, Acessibilidade do transporte aéreo, entre outros, foram configurados por meio dos "hyperlinks" representados na Figura 35 da página seguinte.

Cada um dos documentos cedidos pela INFRAERO está acessível ao se clicar em cima dos mesmos, de forma a permitir acessar simultaneamente diversos documentos. 


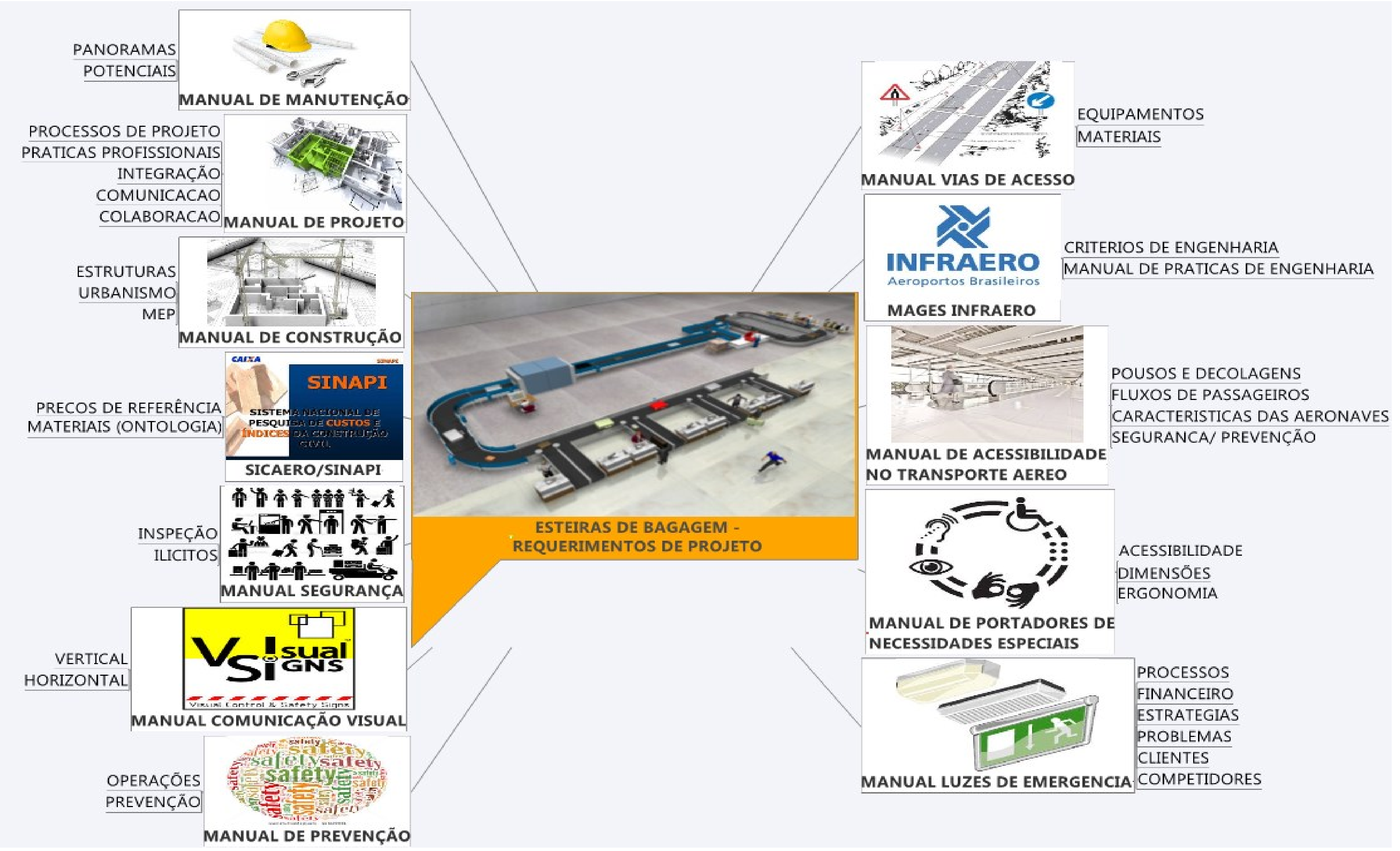

Figura 35 - Tela de acesso aos Requerimentos de Projeto para Esteiras de Bagagem na Matriz Semântica. 
A Figura 36, a seguir, apresenta o acesso a um dos documentos de referência da matriz, no caso o Manual de Acessibilidade da pessoa portadora de necessidades especiais no transporte aéreo comercial, pode ser consultado e salvo em diretório local pelo usuário.

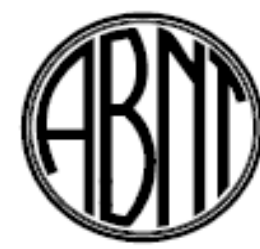

ABNT-Associação Brasileira de Normas Técnicas

sede

Rlo de Janeiro

A 2000 de Maio, 13 - $28^{\circ}$ and - Caja Poata 1680 - Fid

Tel: PABX (021) 210-3122

Far (021) 220-17622220-6436 Endereço Teiegrstco: NOAMATECNICA
Copyright $\odot 1999$ AENT-Aasociagto Brasleirs de Normas Tennicas Pitnted in Brazly Impresso no Bras

\section{Acessibilidade da pessoa portadora de deficiência no transporte aéreo comercial}

Origem: Projeto 16:009.06-003:1997

CB-16 - Comitê Brasileiro de Transporte e Tráfego

CE-16:009.06 - Comissão de Estudo de Pessoas Portadoras de Deficiência

NBR 14273 - Acessibility to air transportation for handicapped disabled persons

Descriptors: Acessibility. Airport. Aircraft. Disabled person

Válida a partir de 01.03.1999

Palavras-chave: Acessibilidade. Aeroporto. Aeronave. Pessoa 5 páginas portadora de deficiência
Sumário

Prefácio

1 Objetivo

2 Referências normativas

3 Definições

4 Acesso aos aeroportos

5 Embarque e desembarque

6 Acessibilidade no interior das aeronaves

7 Comunicação e sinalização

ANEXO

A Figuras

Prefácio

A ABNT - Associação Brasileira de Normas Técnicas - é - Fórum Nacional de Normalizaçäo. As Normas Brasileiras, cujo conteúdo é de responsabilidade dos Comitês Brasileiros (CB) e dos Organismos de Normalização Setorial (ONS). säo elaboradas por Comissões de Estudo (CE), formadas por representantes dos setores envolvidos, delas fazendo parte: produtores, consumidores e neutros (universidades, laboratórios e outros).

Os Projetos de Norma Brasileira, elaborados no âmbito dos CB e ONS, circulam para Votação Nacional entre os associados da ABNT e demais interessados.

Esta Norma inclui o anexo A, o qual tem caráter informativo. 1 Objetivo

Esta Norma estabelece os padrões e critérios que visam propiciar às pessoas portadoras de deficiência condições adequadas e seguras de acessibilidade autônoma ao espaco aeroportuário e às aeronaves das empresas de transporte aéreo público regular, regional e suplementar.

2 Referências normativas

As normas relacionadas a seguir contêm disposições que, ao serem citadas neste texto, constituem prescrições para esta Norma. As ediç̋es indicadas estavam em vigor no momento desta publicação. Como toda norma está sujeita a revisäo, recomenda-se àqueles que realizam acordos com base nesta que verifiquem a conveniência de se usarem as ediçöes mais recentes das normas citadas a seguir. A ABNT possui a informação das normas em vigor em um dado momento.

Facilitaçäo - Anexo 9 à Convenção de Aviação Civil
Internacional. Departamento de Aviação Civil do Ministério da Aeronáutica. $9^{\circ} \mathrm{ed}$., julho de 1990

NOSER IAC 2508-0796 (01.11.95) - Acesso ao transporte aéreo de passageiros que necessitam de assistência especial

IATA Resolution 700 - Acceptance and carriage of incapacitated passengers

IATA Recommended Practice 1700 - Acceptance and carriage of incapacitated passengers

NBR 9050:1994 - Acessibilidade de pessoas portadoras de deficiência a edificações, espaços, mobiliários e equipamentos urbanos - Procedimento

Figura 36 - Documento acessado via "hyperlink" (requerimento) na Matriz Semântica. Fonte: INFRAERO. 


\subsection{2- RELACAO ENTRE OS COMPONENTES PARAMÉTRICOS E A MATRIZ}

A matriz é uma fonte de consulta sobre informações relacionadas ao módulo funcional em que o componente deve ser inserido. Na matriz encontra-se especificado quais as disciplinas complementares estão envolvidas, assim como quais são os requisitos de aprovação, separados por áreas.

Existem dois tipos de aprovação de projeto na INFRAERO: um no qual a área de engenharia que elaborou o projeto analisa e realiza a tomada de decisão sobre alternativas. Outro no qual a área cliente atesta que as soluções de projeto escolhidas atendem aos requisitos exigidos.

Semelhantemente, engenheiros e arquitetos das diferentes especialidades podem atuar tanto nos processos de projetação como de aprovação, representando diferentes áreas da empresa e interagindo entre si.

Imaginamos que pela natureza sistêmica e de planejamento operacional, as áreas de Operações e de Planejamento devam assumir a gestão do ambiente SIG na INFRAERO, estabelecendo base compartilhada de informações espaciais, podendo informar sobre relevo, recursos hídricos e geológicos, infraestrutura, vegetação, vias de acesso e toda informação que desde a escala local até a regional.

Esta base de informações pode servir de suporte aos processos de cadastramento, inserção do aeroporto na malha urbana, conexão e/ou inversão de fluxos, gestão do "Plano Diretor do Aeroporto", entre outros.

As áreas de Engenharia e de Gestão da INFRAERO apresentam forte vocação para gerir os Sistemas BIM, de forma a distribuir as informações e conhecimento das equipes de projeto em torno dos empreendimentos e projetos da empresa.

A associação entre a elaboração de componentes e a consulta à matriz semântica poderia ocorrer de forma concatenada, informando sobre o contexto em que o componente se insere e sobre o desempenho esperado nos processos de aprovação e projetos compartilhados e simultâneos, em oposição aos atuais processos lineares e redundantes.

O conhecimento envolvido na modelagem não representa nenhuma novidade, nem a criação de novos parâmetros, pois utiliza recursos existentes nos sistemas BIM. O que representa contribuição ao conhecimento é a elaboração da matriz semântica e a associação dos sistemas BIM e SIG na elaboração de projeto aeroportuário no âmbito da INFRAERO. 


\section{2- FORMACAO DE COMPONENTES PARAMÉTRICOS AEROPORTUÁRIOS}

Nesta tese modelamos oito componentes aeroportuários nos sistemas BIM utilizando o "software" Revit ${ }^{\circledR}$.

OS COMPONENTES MODELADOS SÃO LISTADOS A SEGUIR (FIGURA 37).

1- BALCÃO DE CHECK-IN;

2- ESTEIRA DE BAGAGEM DESEMBARCADA;

3- RAIO-X DE BAGAGEM EMBARCADA;

4- PONTE DE EMBARQUE;

5- ESTEIRA DE BAGAGEM GERAL;

6- PÓRTICO DE SEGURANÇA;

7- CARRINHO DE BAGAGEM;

8- PORTA GIRATÓRIA DE ACESSO.
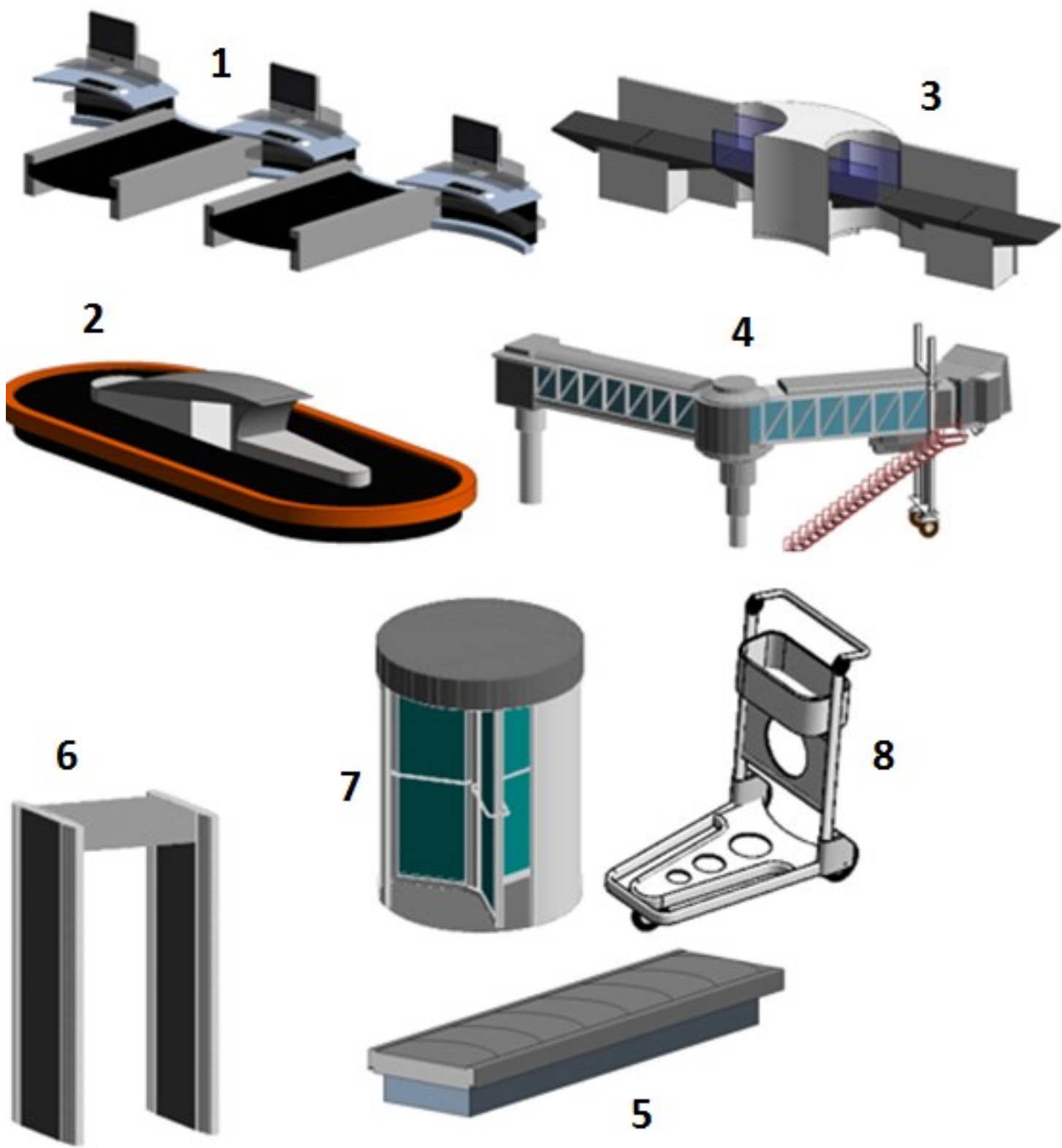

Figura 37 - Ilustração dos componentes paramétricos modelados nesta pesquisa. 


\subsection{1- A SELEÇÃO DOS COMPONENTES ACIMA OBEDECEU AOS CRITÉRIOS LISTADOS ABAIXO.}

1- ESFORÇO DE DESENVOLVIMENTO: quanto esforço é necessário para desenvolver o objeto (em termos de horas de trabalho);

2- UNIFORMIZAÇÃO/CRITICIDADE: quão comum ou crítico o objeto é na produção de projetos de infraestrutura aeroportuária;

3- EFICÁCIA: o quão benéfico o objeto é para o ganho de produtividade e redução de erros.

A elaboração dos componentes construtivos obedeceu a consulta às especificações técnicas gerais e específicas contidas no Termo de Referência dos aeroportos da INFRAERO, referentes as especificações, bem como aos memoriais descritivos.

A parametrização dos componentes, da mesma forma, seguiu os critérios estabelecidos na documentação técnica usualmente adotada pela empresa. Por exemplo, ao incluir um novo parâmetro em um dos componentes modelados pelo autor, como a esteira de bagagem, representando um código de correspondência com esse componente construtivo na planilha SICAERO, é possível estabelecer o custo do componente, atualizado mensalmente, que serve como preço de referência em processos licitatórios na INFRAERO.

Os componentes acima foram exportados do Revit $^{\circledR}$ para o InfraWorks ${ }^{\circledR}$, que é um "software" SIG, para efeito de simulação do processo de projeto. O aplicativo InfraWorks ${ }^{\circledR}$ permite variar o nível de detalhe destes componentes.

A conexão dessas variações pode vir a ser importante nas diferentes fases do processo de projeto, sobretudo nos estágios iniciais, permitindo que a discussão sobre variáveis referentes ao contexto onde a edificação deverá ser inserida, esteja associada às informações e suas conexões com as responsabilidades dessas tarefas de projeto na INFRAERO.

A matriz semântica desenvolvida nesta pesquisa pode atuar como um repositório de informação e de classificação e ainda de consulta a diferentes níveis de detalhes, com maior ou menor ambiguidade, em função das atividades de projeto. É um dos objetivos do recorte desta pesquisa a constituição de novos componentes paramétricos e a criação de novos parâmetros, de forma a superar as barreiras de interoperabilidade entre as variadas ferramentas utilizadas pelas equipes de projeto. 


\section{APRESENTAMOS A SEGUIR DIFERENTES TIPOS DE CRITÉRIOS UTILIZADOS NA ELABORAÇÃO DOS COMPONENTES BIM:}

1- GEOMETRIA - nível de detalhe; precisão; detecção de interferências ("hard / soft clash");

2- ESPECIFICAÇÕES - parâmetros não geométricos: preço, fabricante, material, código, resistência ao fogo, resistência à infiltração, cor, peso, reciclados, etc.

3- SIMULAÇÃO E ANÁLISE - com base em relatórios de área, custos, volumes e quantidades, além de informações precisas sobre especificações de materiais.

\subsection{1- ELABORAÇÃO DE COMPONENTES NOS SISTEMAS BIM}

A disponibilidade de objetos paramétricos (famílias), que atendam às necessidades específicas de cada projeto, é um dos fatores primordiais para o sucesso de projetos baseados nos sistemas BIM. A elaboração de componentes paramétricos nos sistemas BIM ocorre em duas etapas distintas: a primeira representada pela modelagem ou importação da geometria e a segunda por nova parametrização dos mesmos. A seguir estão descritos dois tipos de família no Revit ${ }^{\circledR}$, sendo a primeira de componentes existentes no sistema, "default", e a segunda de componentes personalizados:

1- FAMÍLIAS DO SISTEMA: são predefinidas no Revit $^{\circledR}$, sendo apresentadas como elementos da construção (paredes, coberturas, forros, pisos, escadas e rampas). Não é possível criar famílias de sistema através do comando "New Family", bem como não é possível alterar e adicionar mais parâmetros a estas famílias.
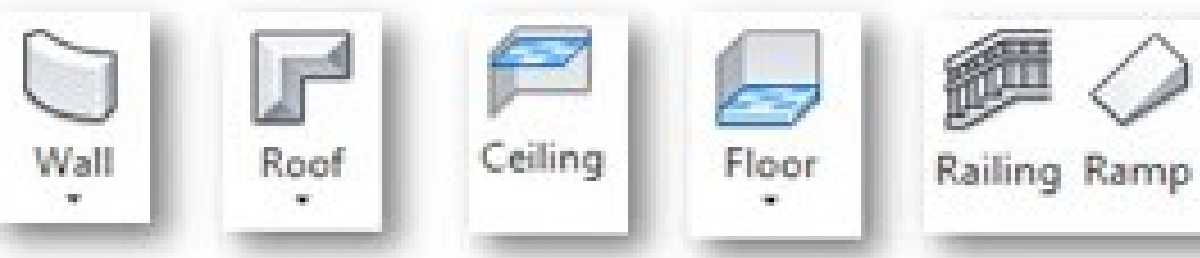

Railing Ramp Stairs

Figura 38 - Exemplos de famílias do sistema no Revit $^{\circledR}$. Fonte: AutoDesk.

2- FAMÍLIAS CARREGÁVEIS (“LOAD FAMILY”): classe de família utilizada para a modelagem dos componentes nesta pesquisa. São famílias criadas com os "templates" através do comando "New Family". São criadas em arquivos "RFA" externos, podendo ser importadas ou carregadas em outros projetos, além de possibilitarem que os parâmetros sejam editados, apagados ou adicionados. Representam os componentes de construção que normalmente seriam comprados, entregues e instalados em uma construção, como janelas, portas, gabinetes, materiais, mobiliário e vegetação. 

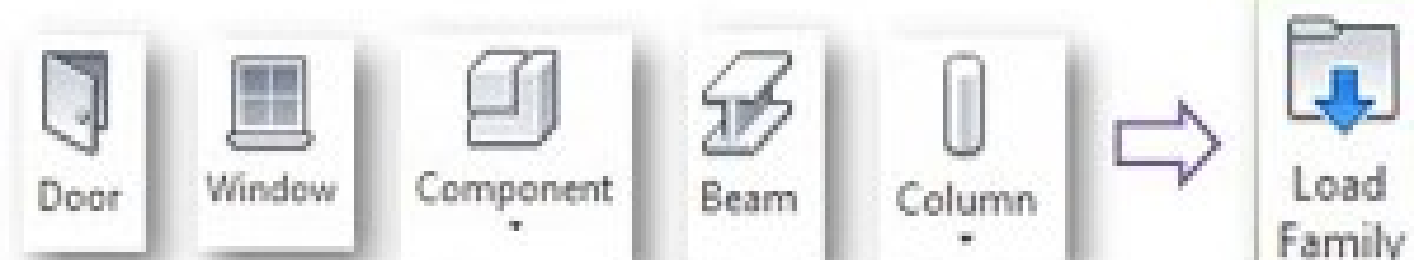

Load

Family

Figura 39 - Exemplos de famílias carregáveis do Revit ${ }^{\circledR}$. Fonte: AutoDesk.

A SEGUIR APRESENTAMOS OS PASSOS UTILIZADOS PARA MODELAGEM DOS COMPONENTES NO REVIT ${ }^{\circledR}$ :

1- INICIAR UMA NOVA FAMÍLIA com o "template" - "Metric Generic Model.rft".

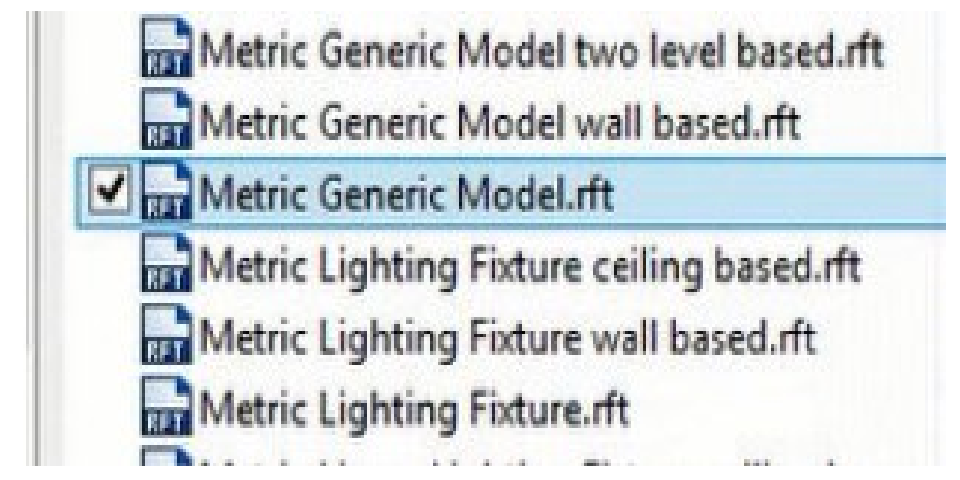

Figura 40 - "Templates "para uma nova família no Revit ${ }^{\circledR}$. Fonte: AutoDesk.

2- SELEÇÃO DO MODELO DE FAMÍLIA;

3- ANTES DA CRIAÇÃO DA GEOMETRIA DOS COMPONENTES, É PRECISO ESTABELECER PLANOS E LINHAS DE REFERÊNCIA;

4- INSERIR E EXPLODIR O ARQUIVO DWG > selecionando todas as linhas criadas e alterando em "Subcategory" o tipo da linha que aparece " $O$ " inicialmente, devendo ser mudado para o tipo de família desejada;

5- INÍCIO DA CRIAÇÃO DA GEOMETRIA SÓLIDA USANDO uma extrusão ou operação "booleana";

6- VERIFICAÇÃO E DEFINIÇÃO DO PLANO DE TRABALHO para a geometria conceitual;

7- DEFINIÇÃO DAS PROPRIEDADES DO OBJETO;

8- COLOCAÇÃO DE COTAS;

9- DESENHO DE LINHAS DE REFERÊNCIA;

10- CONFIGURAÇÕES DE VISIBILIDADE.

Os passos anteriores encontram-se pormenorizados no capitulo de resultados. 


\subsection{2- ELEMENTOS PARA ELABORAÇÃO DE FAMÍLIAS}

1- PLANOS DE REFERÊNCIA: são planos do sistema cartesiano que determinam onde os objetos arquitetônicos serão inseridos. São úteis para restringir os parâmetros e definir onde os mesmos serão utilizados e quais são as modulações. Em suas propriedades consta uma que utilizamos frequentemente: "Is Reference", nela fornecemos a informação sobre a intensidade da referência. Sua representação na vista é feita por uma linha tracejada verde;

2- COTAS: servem para informar quais são as dimensões dos planos, faces ou linhas. Podemos transformar as cotas em "Labels" para assim as utilizarmos como parâmetros. Podemos ainda direcionar a cota para algum parâmetro já existente;

3- TIPOS DE FORMAS: existem dois tipos de formas, os "solids" e os "voids". Por meio dos "solids" pode-se moldar os objetos. Os "voids" são os espaços vazios entre os "solids". Eles permitem esculpir o "solid" para chegar à forma desejada;

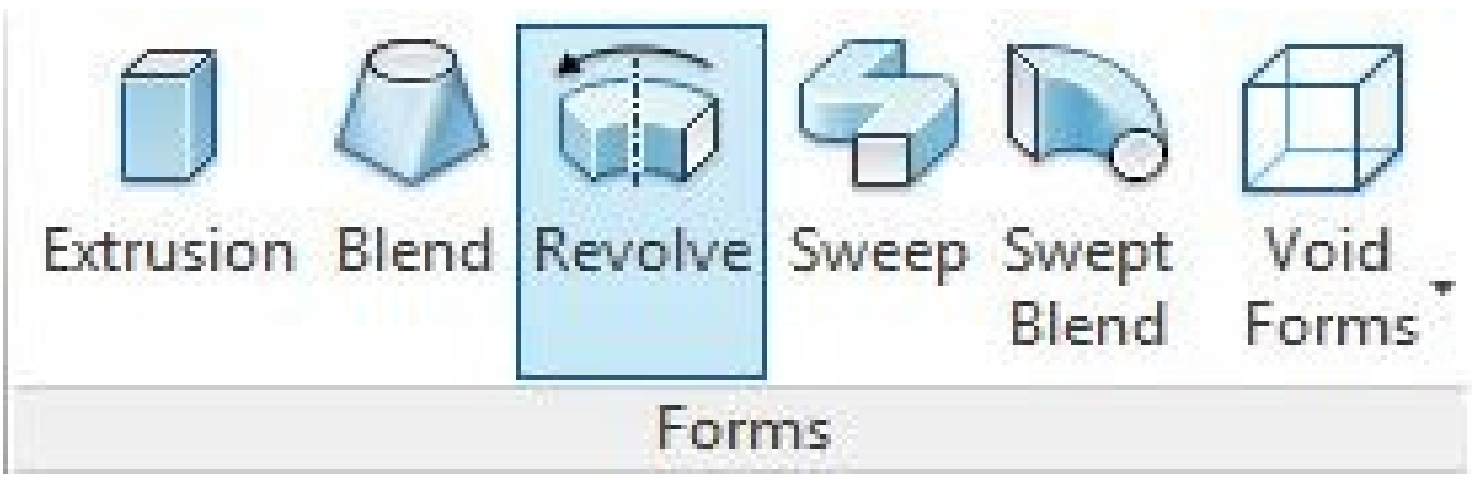

Figura 41 - Exemplo de extrusores no Revit ${ }^{\circledR}$. Fonte: AutoDesk.

4- TIPOS DE LINHAS: no projeto temos linhas "model" para ser utilizada como uma linha do modelo, aparecendo assim em todas as vistas, e "Symbolic Lines" que são utilizadas para simbologia e só aparecem na vista que foi criada, isto é, planta baixa, elevação.

A criação de novos parâmetros pode ser realizada por meio da tela de propriedades de parâmetros.

A Figura 42, a seguir, representa a criação do parâmetro para o código SICAERO, referente à planilha referencial de preços para componentes aeroportuários do Governo Federal.

Existem configurações de campos para o tipo de parâmetro desejado, bem como elementos necessários para caracterizar a informação contida nas mesmas: 
Parameter Type

(6) Family parameter

(Cannot appear in schedules or tags)

OShared parameter

(Can be shared by multiple projects and families, exported to ODBC, and appear in schedules and tags)

\section{Select...}

Parameter Data

Name:

\section{Codigo SICAERO - Esteira Bagagem \\ (9) Type}

Discipline:

\section{Common}

Type of Parameter:

\section{Integer}

Group parameter under:

Analytical Model

Tooltip Description:

No tooltip description, Edit this parameter to write a custom tooltip, Custom t. ..
Edit Tooltip...

$$
\text { OK }
$$

Cancel

Help

Figura 42 - Tela de acesso às propriedades na criação de novos parâmetros no sistema BIM Revit ${ }^{\circledR}$. Fonte: AutoDesk. 


\subsection{3- CRIAÇÃo DE NOVOS PARÂMETROS NO APLICATIVO REVIT ${ }^{\circledR}$}

1- “NAME" - Na ilustração anterior, podemos observar que o novo parâmetro destina-se ao código SICAERO para uma esteira de bagagem;

2- "DISCIPLINE" - Por meio dessa escolha as informações de "TYPE OF PARAMETER" serão alteradas. As opções são: "COMMON, STRUCTURAL E ELECTRICAL";

A disciplina escolhida neste exemplo foi a "Common", pelo fato do parâmetro referir-se à gestão de informação de projeto e por isto destinar-se à coordenação e compatibilização do projeto como um todo.

3- "TYPE OF PARAMETER" - Este campo definirá a informação contida no parâmetro, informará se é unidade de distância, número decimal, número inteiro, material, entre outros;

Este campo é muito importante, pois quando utilizarmos o parâmetro em fórmulas temos que nos certificar que os tipos não interferem no cálculo.

Por exemplo, se elaborarmos uma fórmula com parâmetros de distância e se um deles for referente a área, o resultado será incorreto.

O tipo de parâmetro escolhido no exemplo citado foi o "ÏNTEGER", que significa que podemos utilizar letras e números para representar o código SICAERO proposto.

4- “GROUP PARAMETER UNDER” - Refere-se a qual grupo o parâmetro pertence. Serve para organizar os parâmetros na janela;

Foi escolhido o modelo analítico para representar o grupo ao qual o parâmetro pertence, indicando que esta informação destina-se a análise de orçamento do modelo. 
5- “TYPE” - O parâmetro estará contido na janela de edição do tipo, sendo assim, quando alteramos a informação de um tipo ela será alterada em todo o projeto que contenha este tipo;

Por exemplo, se alterarmos os valores dos parâmetros do componente, todas as esteiras de bagagem com a mesma especificação (tipo) sofrerão alterações automáticas.

6- “INSTANCE” - O parâmetro é definido a cada instância, ou seja, aplicação específica do objeto paramétrico;

Os parâmetros passam a ser visíveis logo que selecionamos a família no projeto na janela de "PROPERTIES".

Retornando ao exemplo anterior, verificamos que se o parâmetro de largura fosse definido como "INSTANCE" teríamos que selecionar cada porta e alterar o valor.

No entanto é recomendado não utilizar uma informação que está configurada como "INSTANCE" no campo do "TYPE", já que pode estar em discordância com uma situação real.

7- “REPORTING” - Não são utilizados não para inserir informações.

Tem o objetivo de relatar informações que podem ser utilizadas em outro caso.

Por exemplo, a espessura da parede que é definida no projeto, se necessária para elaborar uma família a mesma pode ser relatada como um parâmetro.

A seguir descreve-se a metodologia para a modelagem do terminal regional de passageiros da INFRAERO 


\section{3- MODELAGEM DO TERMINAL DE PASSAGEIROS REGIONAL DA INFRAERO NOS SISTEMAS BIM E TESTE DO USO DA BIBLIOTECA DE COMPONENTES EM SEUS MÚLTIPLOS NÍVEIS DE DETALHE}

Em termos científicos, a descrição sobre a reprodução de projeto existente nos sistemas BIM, como é o caso da modelagem do terminal regional nesta pesquisa não é novidade. Ainda assim, a descrição metodológica dessa etapa não apenas permite detalhar os passos para uma possível replicação, mas traz consigo informações sobre quais foram os caminhos percorridos pelo autor para tais fins.

A Figura 43 abaixo ilustra a complexidade logica dos setores do terminal regional, onde pode-se observar a entrada de acesso ao Saguão "Lado Terra" e a nítida divisão da edificação, por meio de áreas administrativas e operacionais, separando e restringindo o acesso ao Saguão do "Lado Ar" do aeroporto.

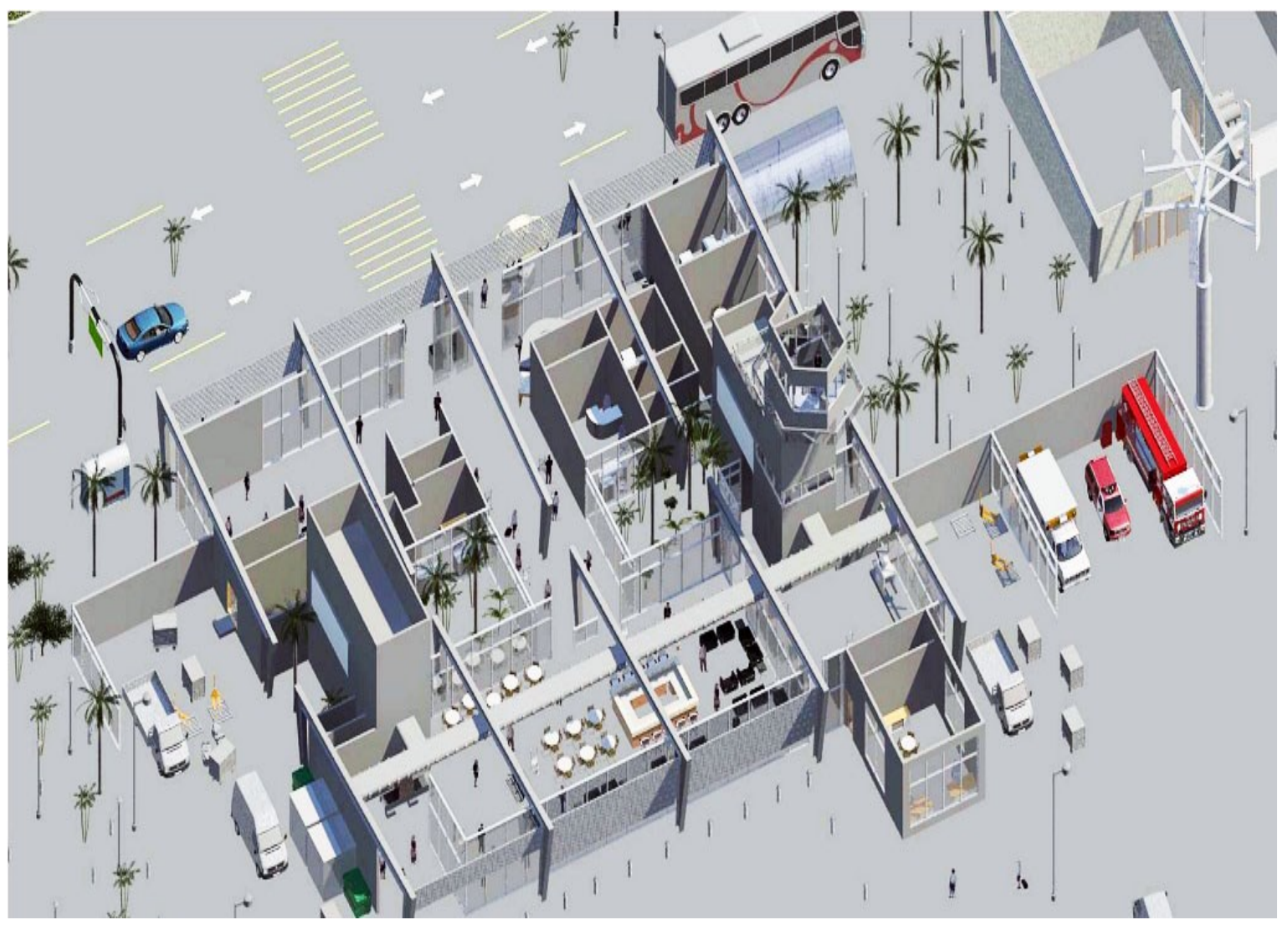

Figura 43- Exemplo de modelagem do Terminal Regional no Revit ${ }^{\circ}$.

Para efetuar a modelagem do terminal regional foi necessário efetuar a consulta ao projeto cedido pela INFRAERO, que além de conter arquivo tridimensional $\left(\right.$ Sketchup ${ }^{\circledR}$ ) e bidimensional $\left(\right.$ AutoCAD ${ }^{\circledR}$ ), possui Caderno Técnico detalhando as soluções de projeto e contendo o Programa de Necessidades do terminal regional, como ilustrado, a seguir, na Figura 44. 


\section{PROGRAMA DE NECESSIDADES - M1}

\begin{tabular}{|c|c|}
\hline \multicolumn{2}{|l|}{ 1 - Geral - Ad ministração } \\
\hline $\begin{array}{l}\text { Gerência de Operações/ } \\
\text { Credenciamento }\end{array}$ & 28,30 \\
\hline COA/ AIS/ Tarifa/ Tripulação & 25,00 \\
\hline Depósito de Operaçöes & 4,50 \\
\hline $\begin{array}{l}\text { Depósito de Prevenção e } \\
\text { Emergência }\end{array}$ & 9,00 \\
\hline Posto de Saúde & 17,00 \\
\hline Sala de Múltiplo Uso & 26,30 \\
\hline Balcäo informaçồes & 4,00 \\
\hline Ärea Técnica & 7,40 \\
\hline Areas Administrativas * & *Fora do TPS \\
\hline Célula de Manutenção & 9,00 \\
\hline Area apoio pessoal segurança & 4,50 \\
\hline Inspecăo/ Visto ria & 32,55 \\
\hline \multicolumn{2}{|l|}{2 - Geral - Empresas aéreas } \\
\hline Check-in & 39,20 \\
\hline Back office & 28,50 \\
\hline BVRI & 7,00 \\
\hline Gate/ Portä́o de embarque & 25,35 \\
\hline Manutenção de linha & 21,00 \\
\hline $\begin{array}{l}\text { Area de apoio para pessoal e } \\
\text { suprimento de rampa* }\end{array}$ & $\begin{array}{c}\text { *Apenas para M-2 e } \\
\text { M-3 }\end{array}$ \\
\hline \multicolumn{2}{|l|}{ 3 - Geral - Órgã os públicos* } \\
\hline \multicolumn{2}{|c|}{$\begin{array}{l}\text { *Em virtude do novo conceito do terminal, as áreas } \\
\text { destinadas a este fim funcionarão de forma simultânea } \\
\text { na Sala de Múltiplo Uso. }\end{array}$} \\
\hline \multicolumn{2}{|c|}{4 - Geral - Processamento para passageiros e } \\
\hline $\begin{array}{l}\text { Saguão Embarque/ } \\
\text { Desembarque }\end{array}$ & 215,85 \\
\hline $\begin{array}{l}\text { Calçada meio-fio embarque/ } \\
\text { desembarque }(\mathrm{m})\end{array}$ & 24,00 \\
\hline Area Filas Check-in & 57,40 \\
\hline Praça Bagagem embarcada & 37,95 \\
\hline $\begin{array}{l}\text { Praça Bagagem } \\
\text { desembarcada }\end{array}$ & 38,50 \\
\hline $\begin{array}{l}\text { Sala Embarque (sala do } \\
\text { cliente) }\end{array}$ & 294,50 \\
\hline $\begin{array}{l}\text { Sala Desem barque } \\
\text { (restituição) }\end{array}$ & 110,50 \\
\hline
\end{tabular}

Figura 44 - Programa de Necessidades do Terminal Regional. Fonte: INFRAERO 


\subsection{1- UTILIZAÇÃO DE COMPONENTES NATIVOS NO REVIT ${ }^{\circledR}$ ENVOLVEM:}

1- CONSTRUÇÃO DE TERRENOS: pode ser feita por meio da importação de curvas de nível, em formato DWG, para geração do terreno tridimensional no Revit $^{\circledR}$. Pode ser feita ainda por meio da importação de um terreno tridimensional modelado externamente. No entanto, no segundo caso, o terreno não oferece informações paramétricas e de informação automática, como movimento de terra ou volume da mesma, a partir do modelo. Nesta pesquisa foi utilizado um plano genérico construído no $\operatorname{Revit}^{\circledR}$ para a modelagem do aeroporto regional.

Obs- Na seção 4.3.3- Teste de modelagem do terreno para processos de análise nos estágios iniciais no Autodesk ${ }^{\circledR}$ InfraWorks ${ }^{\circledR}$ (SIG), detalhamos os testes com relevo construído no ambiente SIG para teste de inserção do terminal regional. Abaixo encontra-se ilustrada a formação do terreno no Revit ${ }^{\circledR}$, por meio de criação de linhas (bordas) para criação de geometria tridimensional paramétrica.

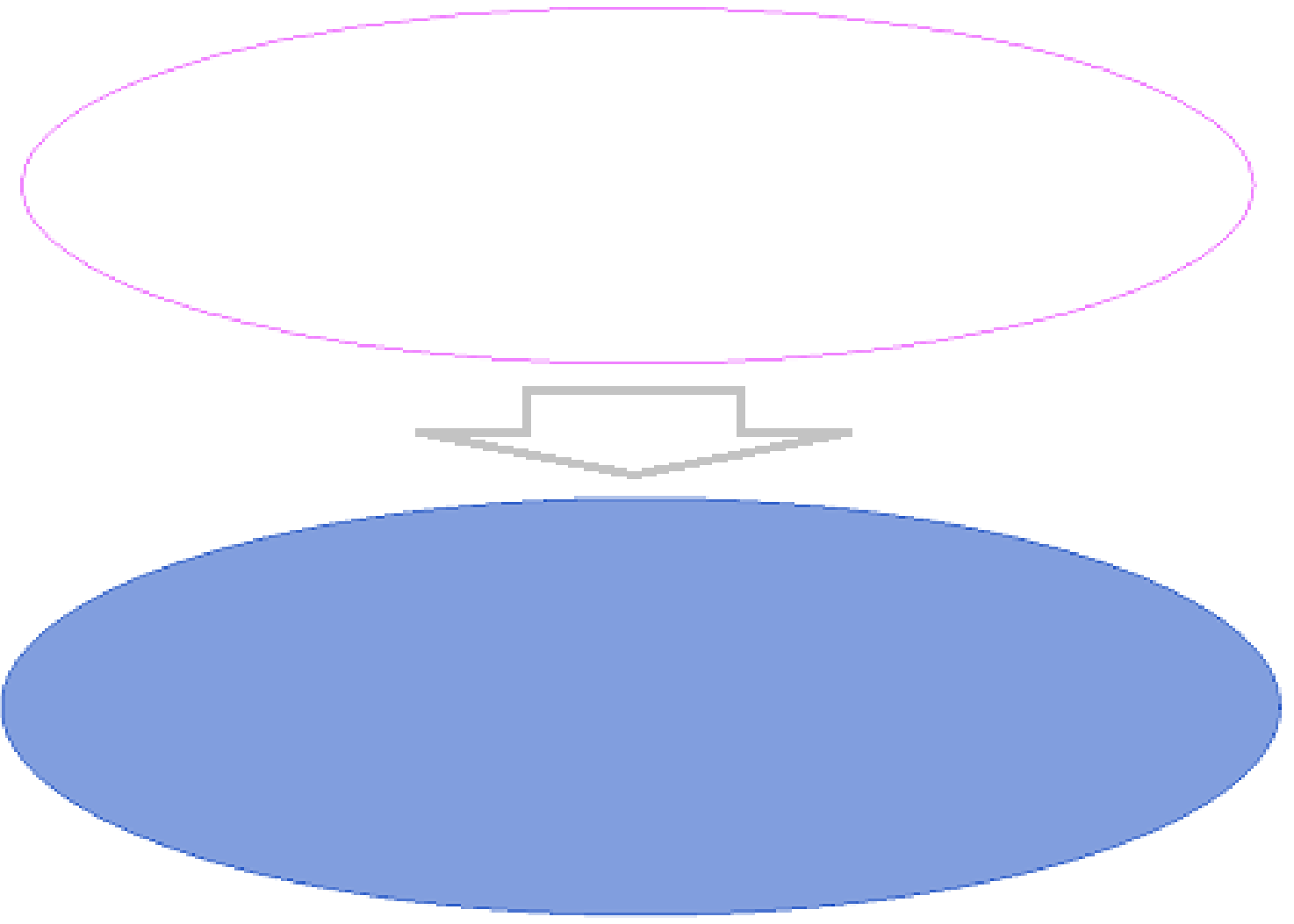

Figura 45- Ilustração da modelagem do terreno do Terminal Regional da INFRAERO, no Revit ${ }^{\circledR}$.

A Figura 45 acima representa a criação do terreno para a reprodução do terminal regional. Uma vez que na etapa seguinte de pesquisa foi testado terreno advindo de SIG para associação com o BIM - Revit ${ }^{\circledR}$, o terreno plano foi suficiente para reprodução do projeto cedido pela INFRAERO. 
2- CONSTRUÇÃO DE PILARES E VIGAS: FUNCIONALIDADE NATIVA.

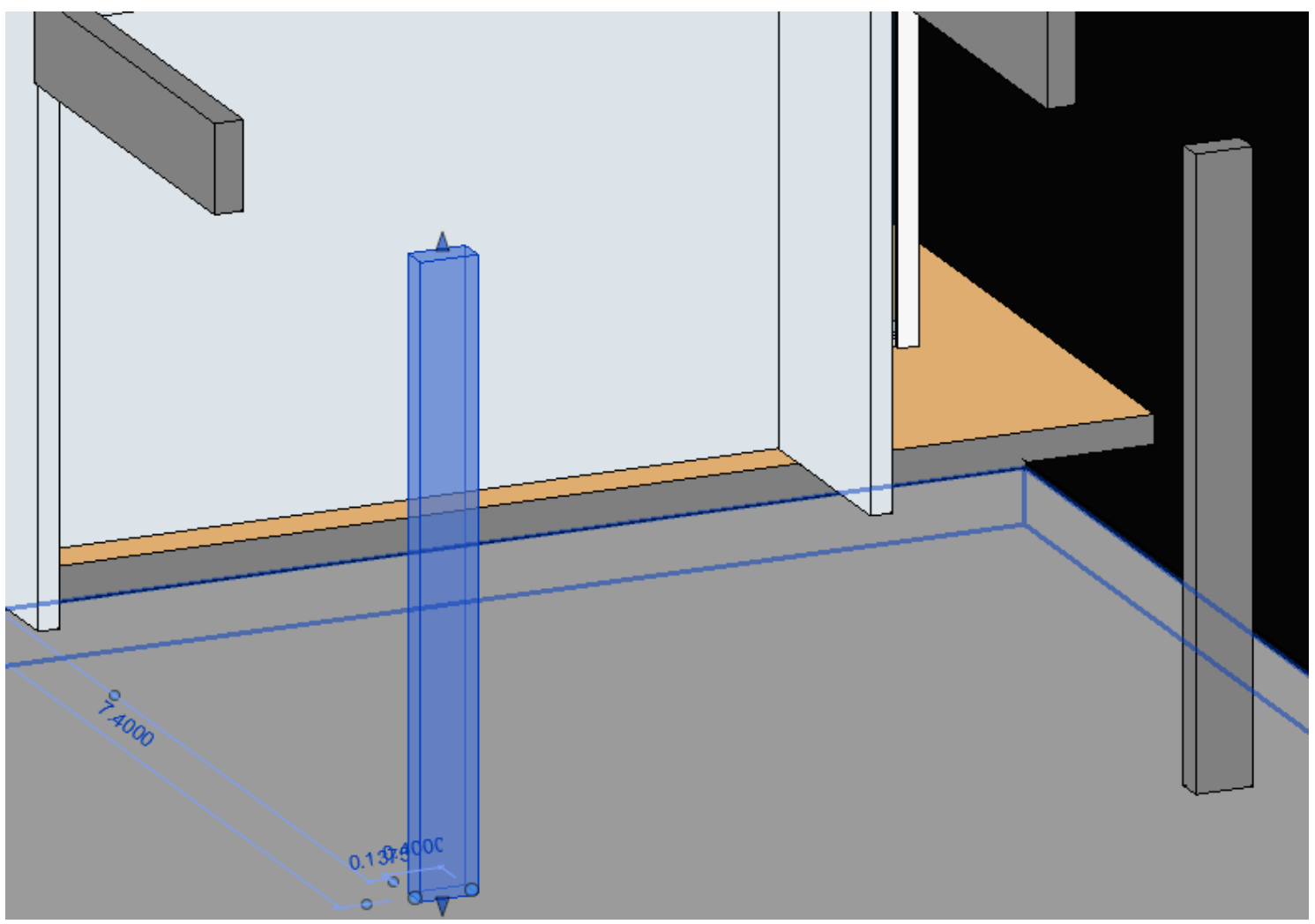

Figura 46- Ilustração da modelagem dos pilares e vigas do Terminal Regional, no Revit

3- CONSTRUÇÃO DE PAREDES: FUNCIONALIDADE NATIVA.

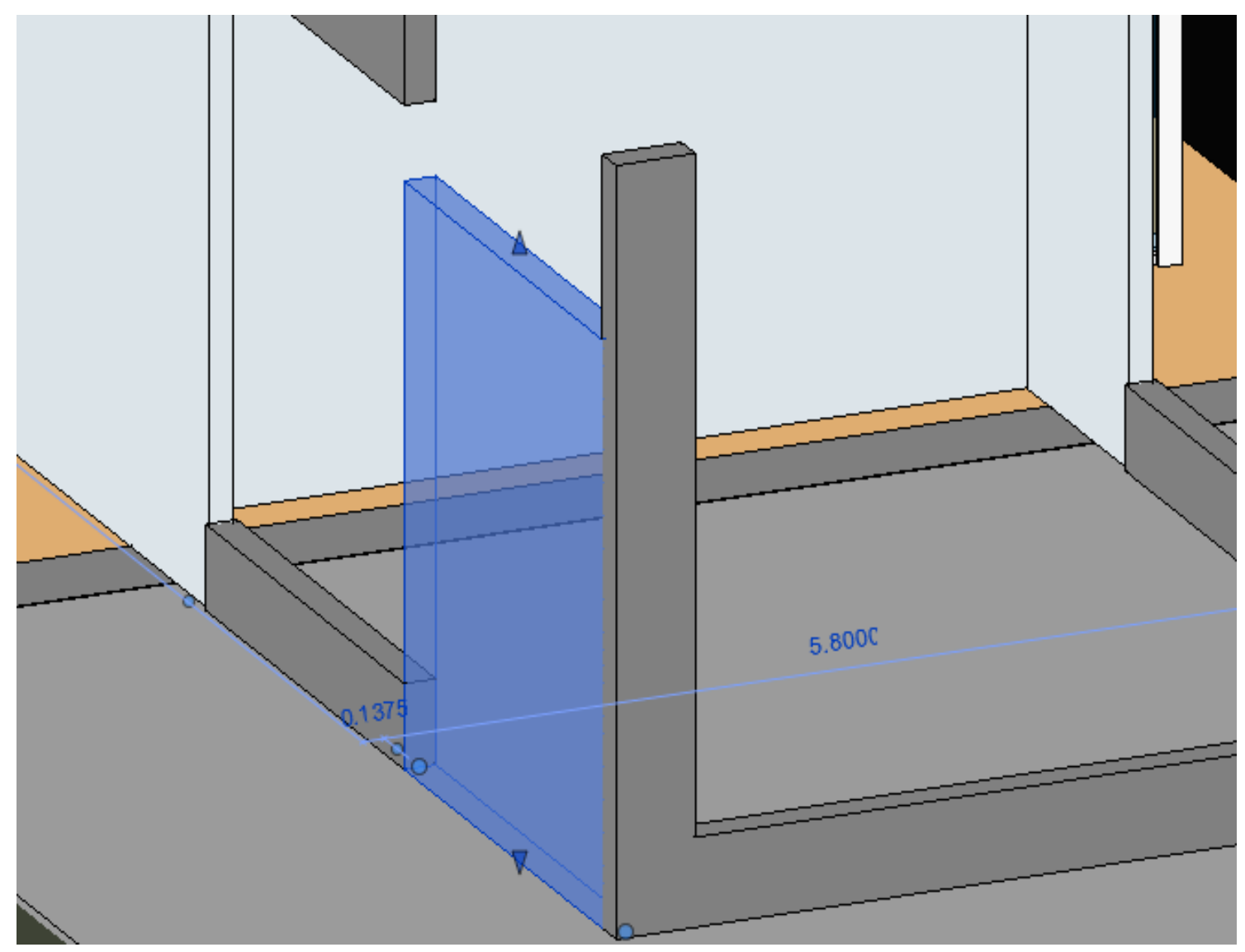

Figura 47- Ilustração da modelagem das paredes do Terminal Regional, no Revit ${ }^{\circledR}$. 
4- ADIÇÃO DE PORTAS E JANELAS: FUNCIONALIDADE NATIVA.

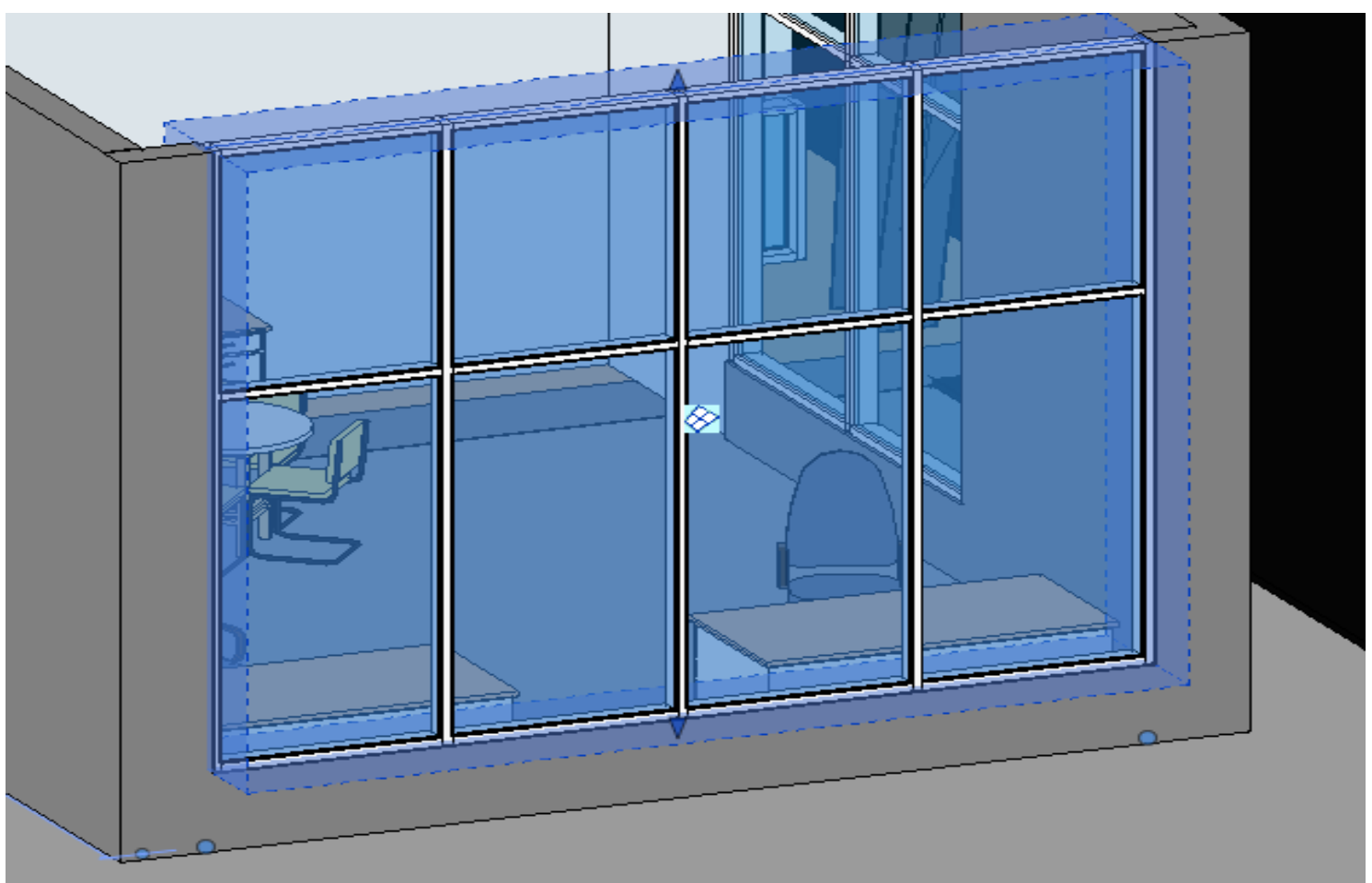

Figura 48- Ilustração da modelagem das esquadrias do Terminal Regional, no Revit ${ }^{\circledR}$.

5- CONSTRUÇÃO DE COBERTURAS: funcionalidade nativa, que oferece a possibilidade de criação e parametrização de lajes e telhados. Oferece ainda a possibilidade de importação de geometria externa, no ambiente de massas do $\operatorname{Revit}^{\circledR}$, ou seja, objetos genéricos contendo apenas geometria, para "transformação" dessa geometria em um componente paramétrico específico.

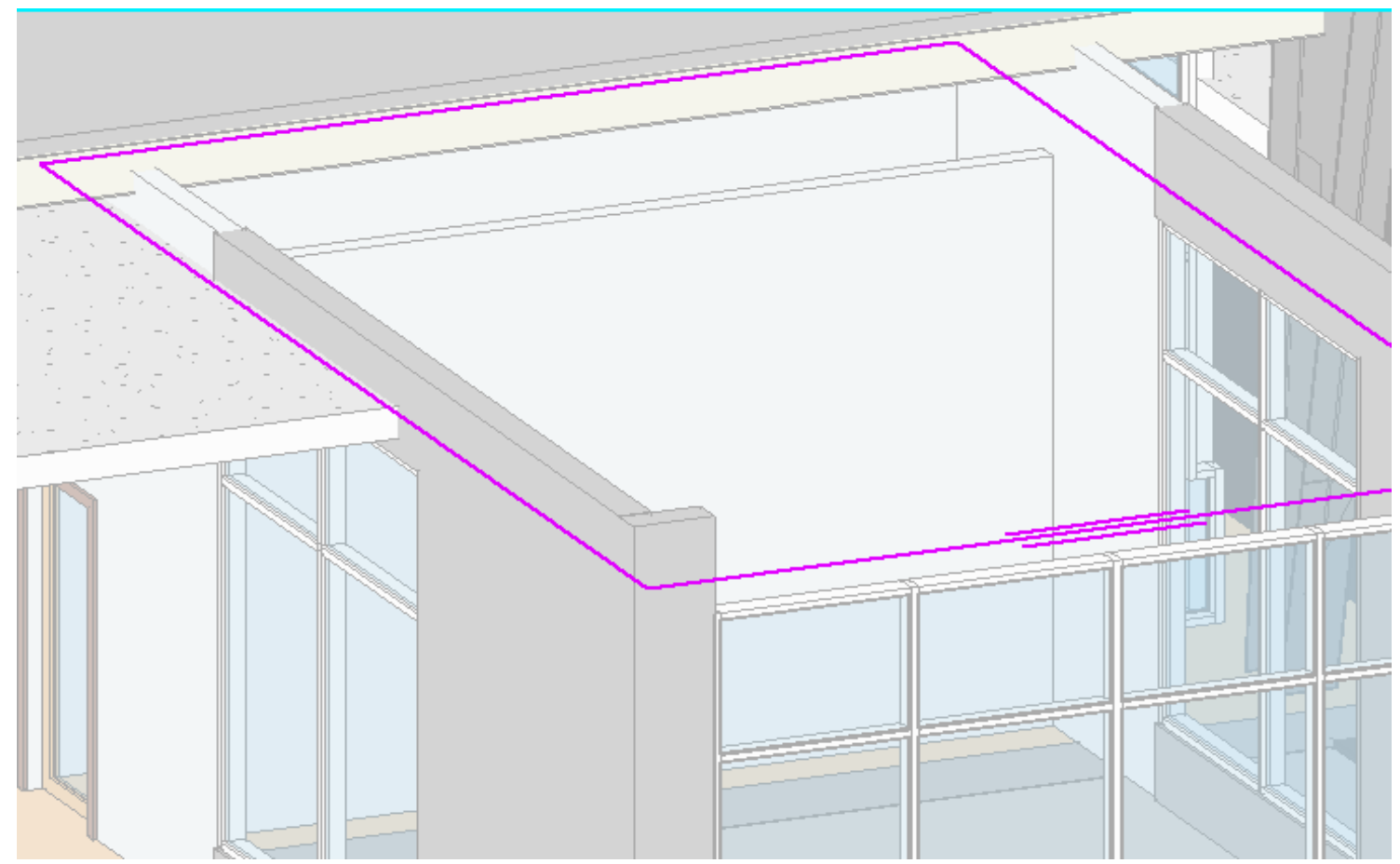

Figura 49- Ilustração da modelagem das coberturas (lajes) do Terminal Regional no Revit ${ }^{\circledR}$. 
6- ADIÇÃO DE OBJETOS: pode-se tanto importar componentes pré-existentes como criar novos componentes e parâmetros.

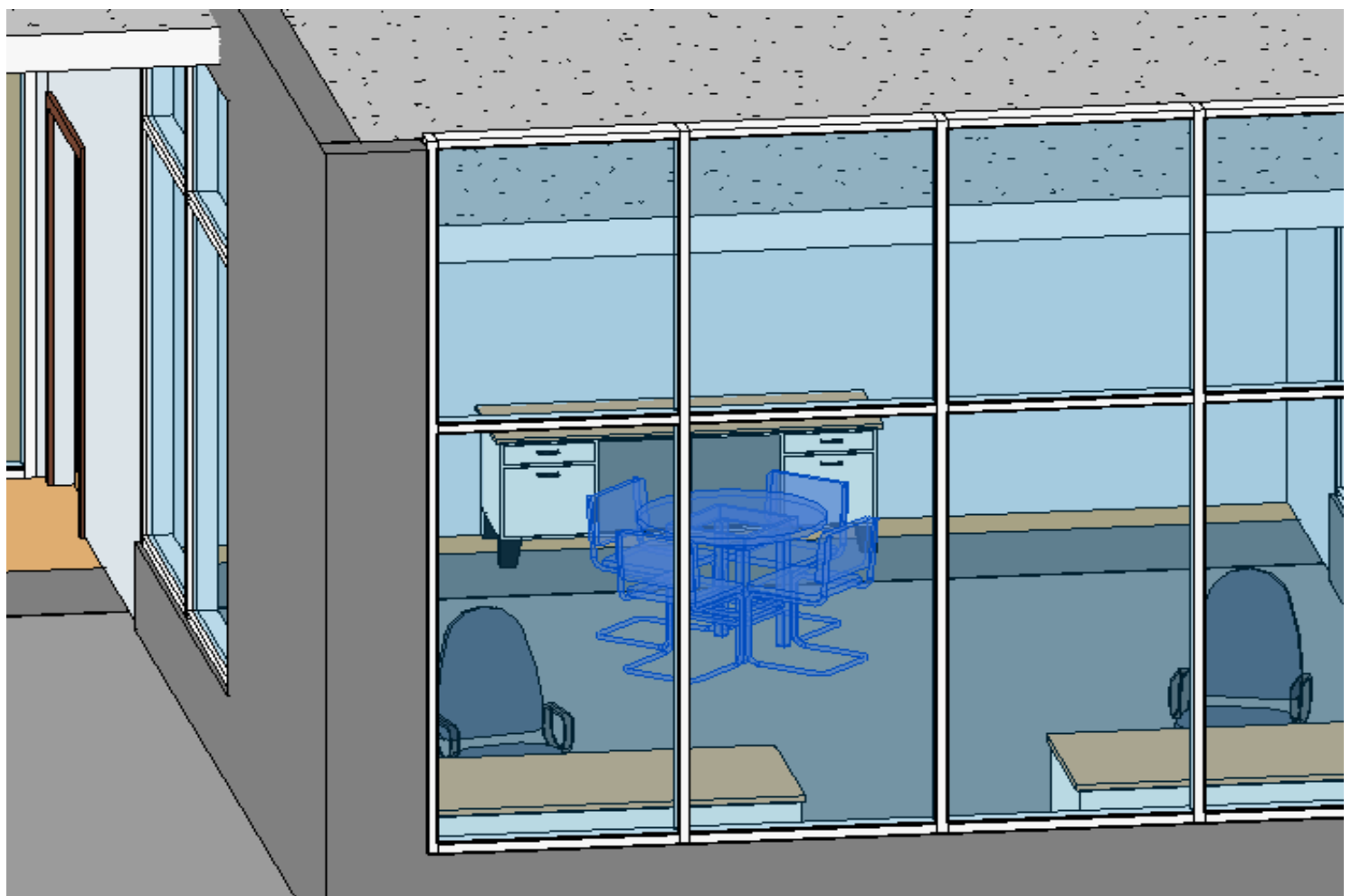

Figura 50- Ilustração da adição de componentes (objetos) do Terminal Regional, no Revit ${ }^{\circledR}$.

7- REPRESENTAÇÃO DO MODELO: planta, cortes, fachadas.

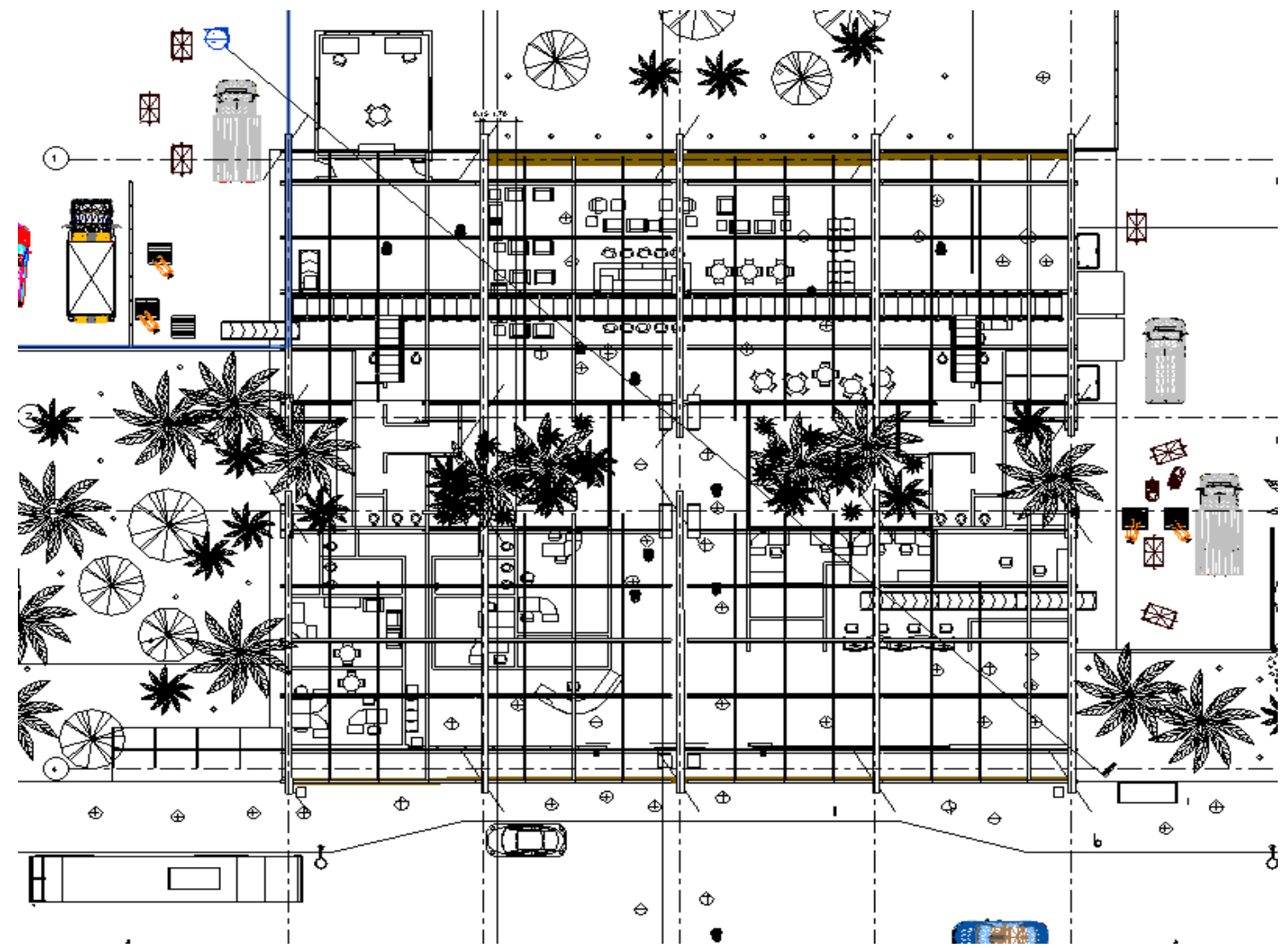

Figura 51- Representação bidimensional (automática) do Terminal Regional no Revit ${ }^{\circledR}$. 


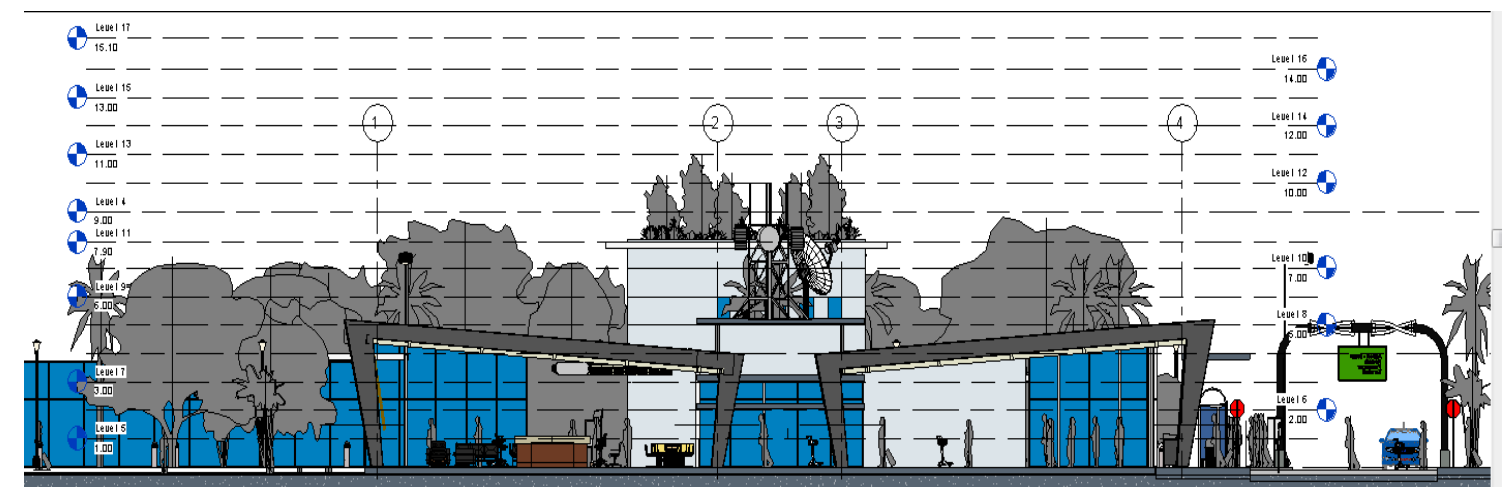

Figura 52- Representação 2D(automática) do Terminal Regional da INFRAERO no Revit ${ }^{\circledR}$.

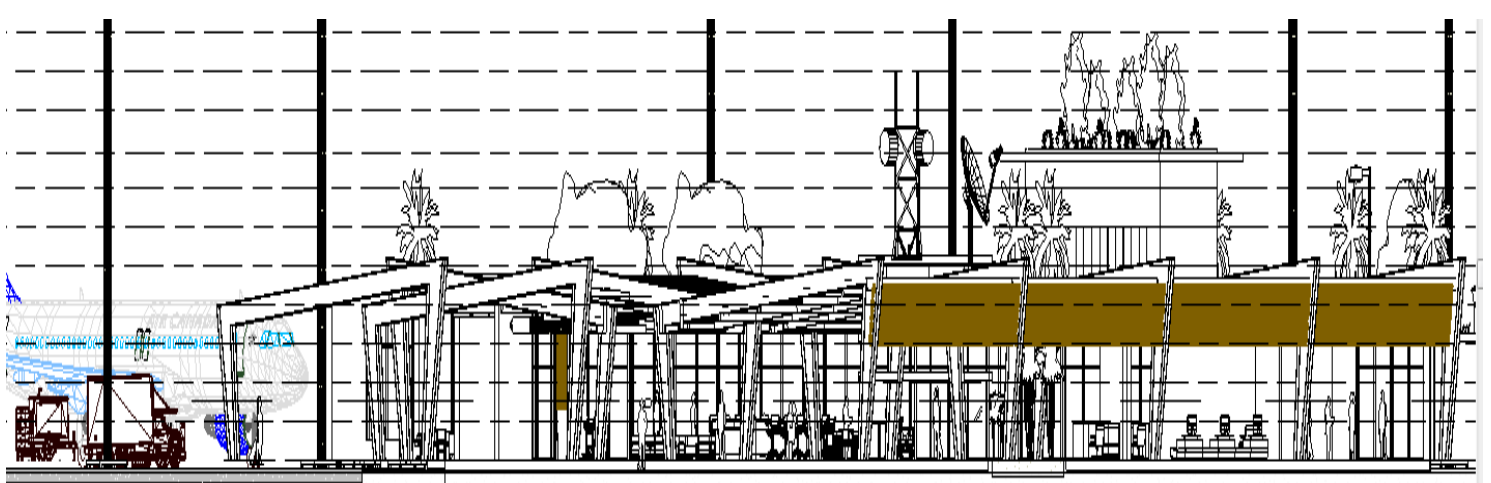

Figura 53- Representação 2D (automática) do Terminal Regional da INFRAERO no Revit ${ }^{\circledR}$.

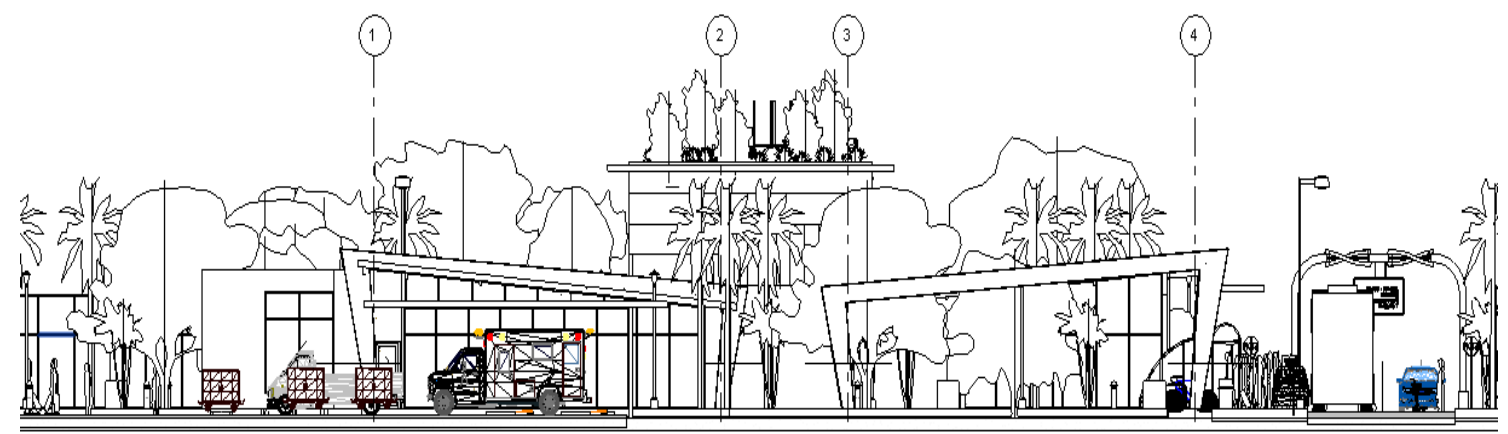

Figura 54- Representação 2D (automática) do Terminal Regional da INFRAERO no Revit ${ }^{\circledR}$.

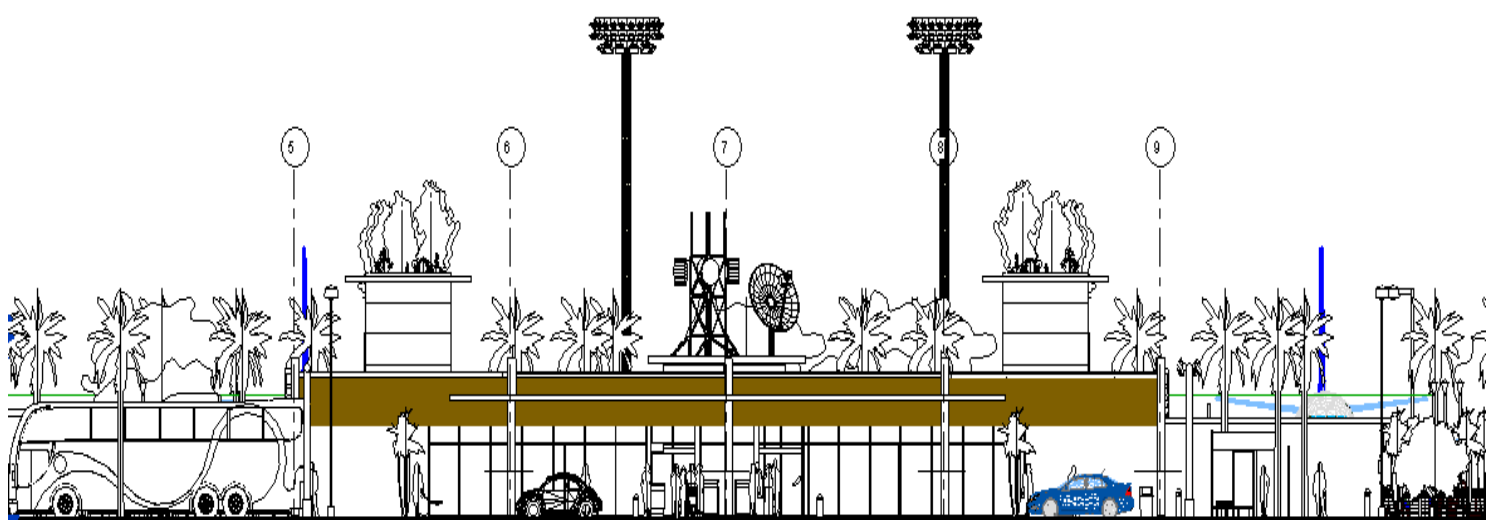

Figura 55- Representação 2D(automática) do Terminal Regional da INFRAERO no Revit ${ }^{\circledR}$. 


\section{IMAGENS RENDERIZADAS - GUARDAR VISTAS.}

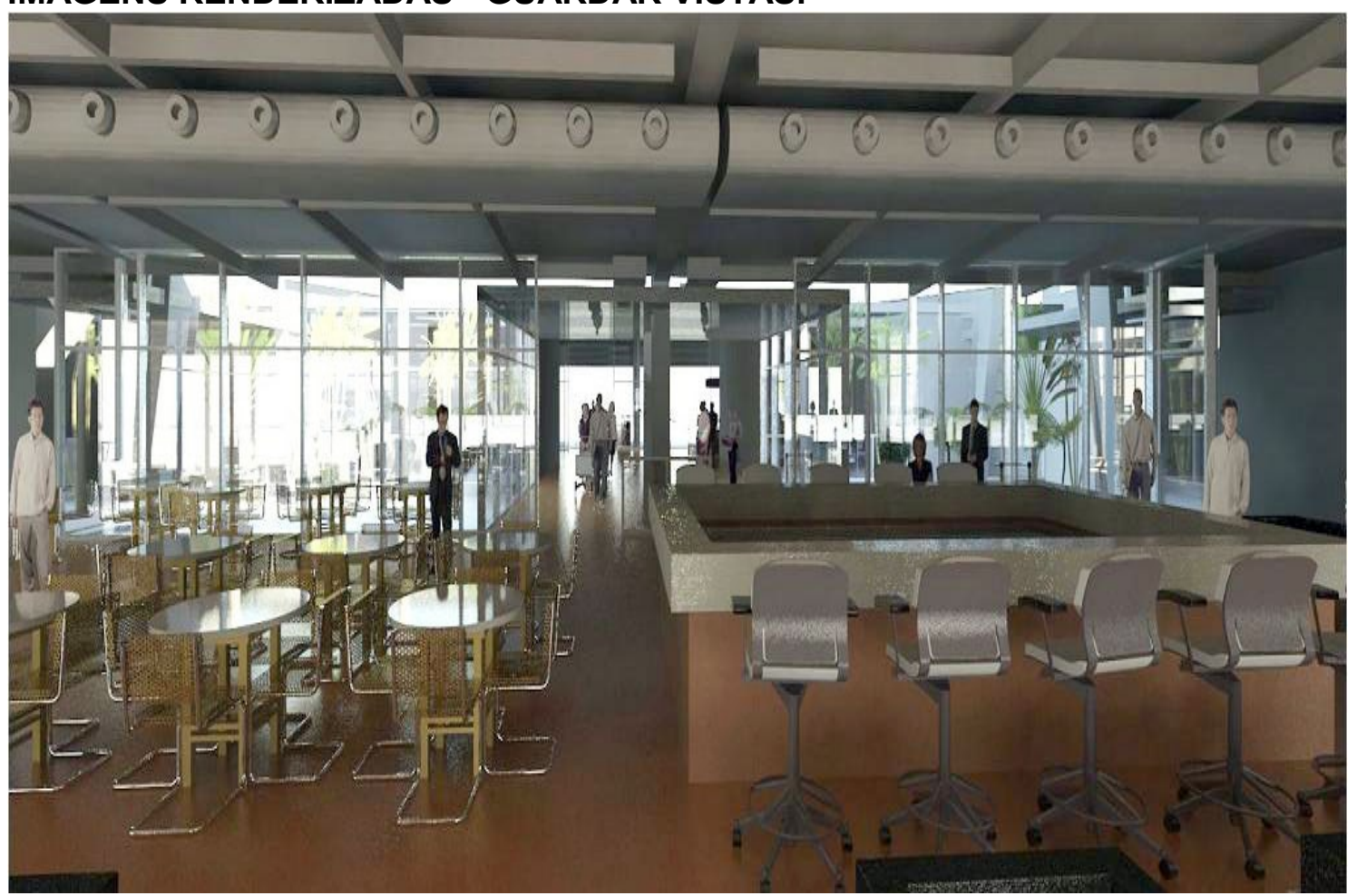

Figura 56- Representação 3D (automática) do Terminal Regional da INFRAERO no Revit ${ }^{\circledR}$.

\section{OPÇÕES DE VISUALIZAÇÃO DO MODELO.}

VISUALIZAÇÃO PARCIAL DA ESTRUTURA.

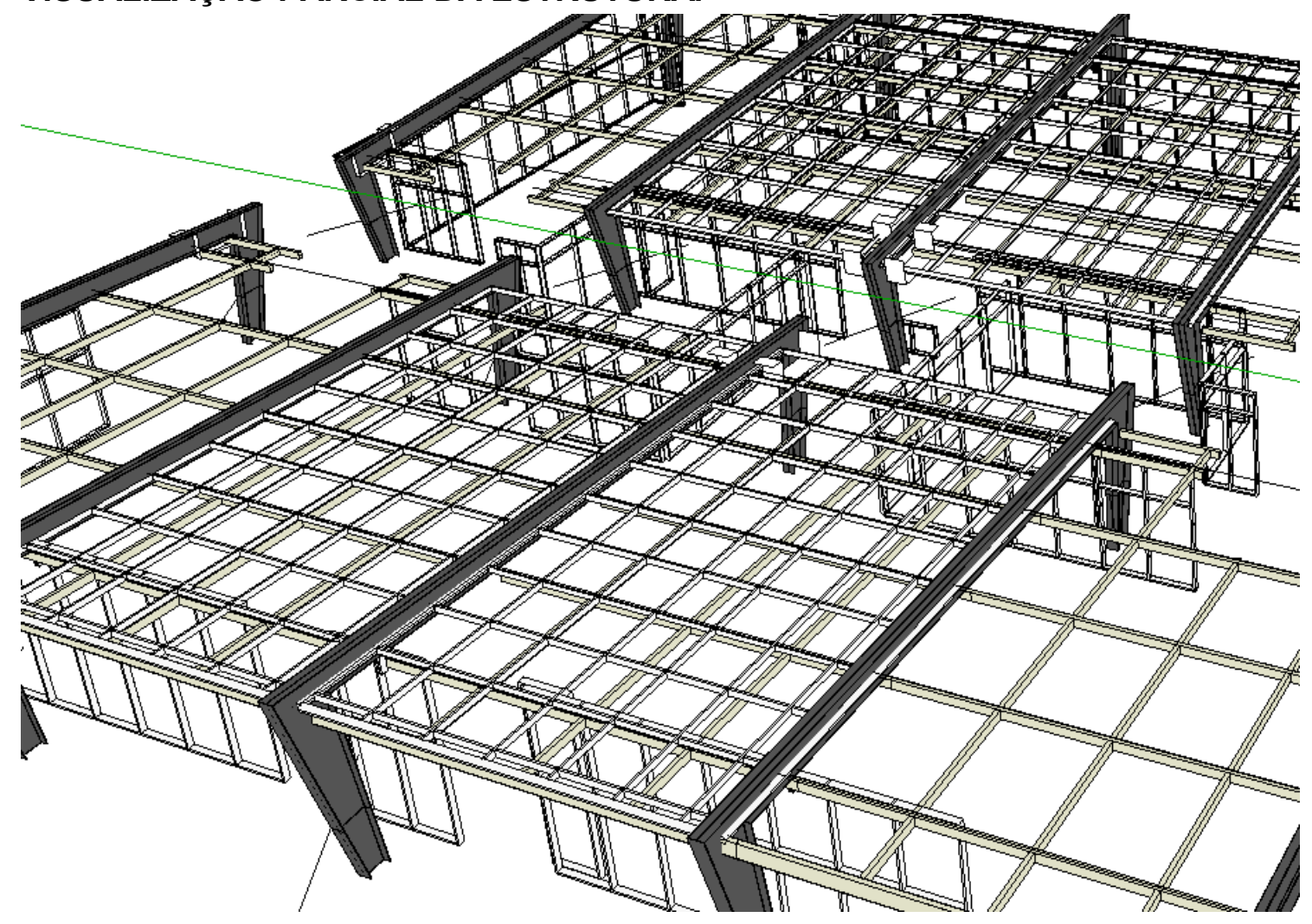

Figura 57- Representação parcial da estrutura do Terminal Regional da INFRAERO no Revit ${ }^{\circledR}$.

Como pode ser observado na Figura 57 acima, pode-se isolar determinadas partes do modelo, como por exemplo, apenas os elementos estruturais para melhor compreensão do projeto. 
3.4- SIMULAÇ̃̃O DE ALTERAÇ̃̃ES DE PROJETO NO DESENVOLVIMENTO DE ALTERNATIVAS PARA A CRIAÇÃO DE TORRE DE CONTROLE (TWR) NO TERMINAL DE PASSAGEIROS REGIONAL
A VALIDAÇÃO DOS COMPONENTES PARAMÉTRICOS AEROPORTUÁRIOS FOI REALIZADA POR MEIO DA SIMULACAO DE RETRABALHO NA EXPANSÃO PARCIAL DO TERMINAL DE PASSAGEIROS REGIONAL, CONFORME AS FIGURAS 58 E 59:

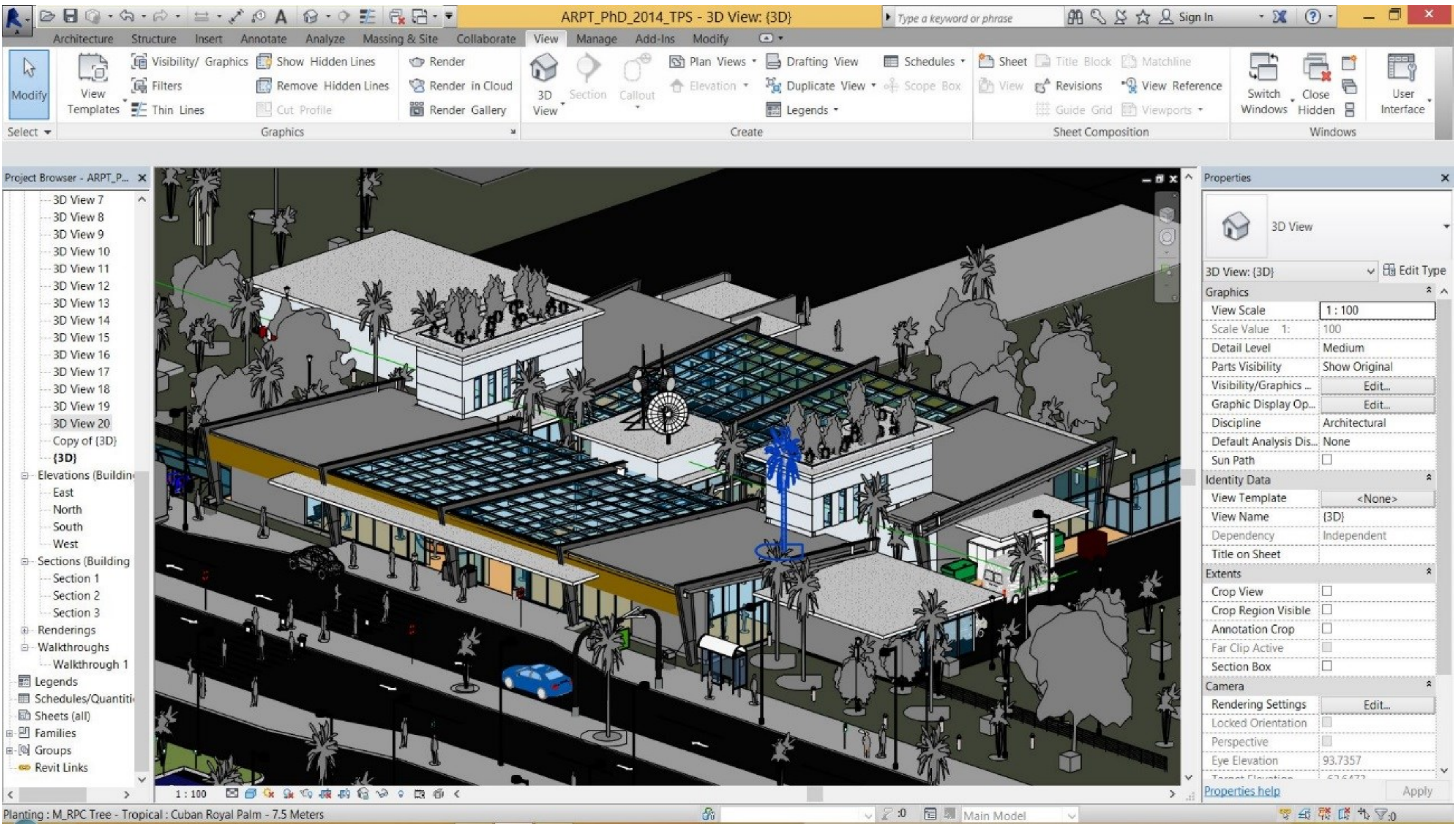

Figura 58 - Ilustração do Terminal Regional da INFRAERO, antes do acréscimo das alternativas de projeto de Torre de Controle, no Revit ${ }^{\circ}$. 

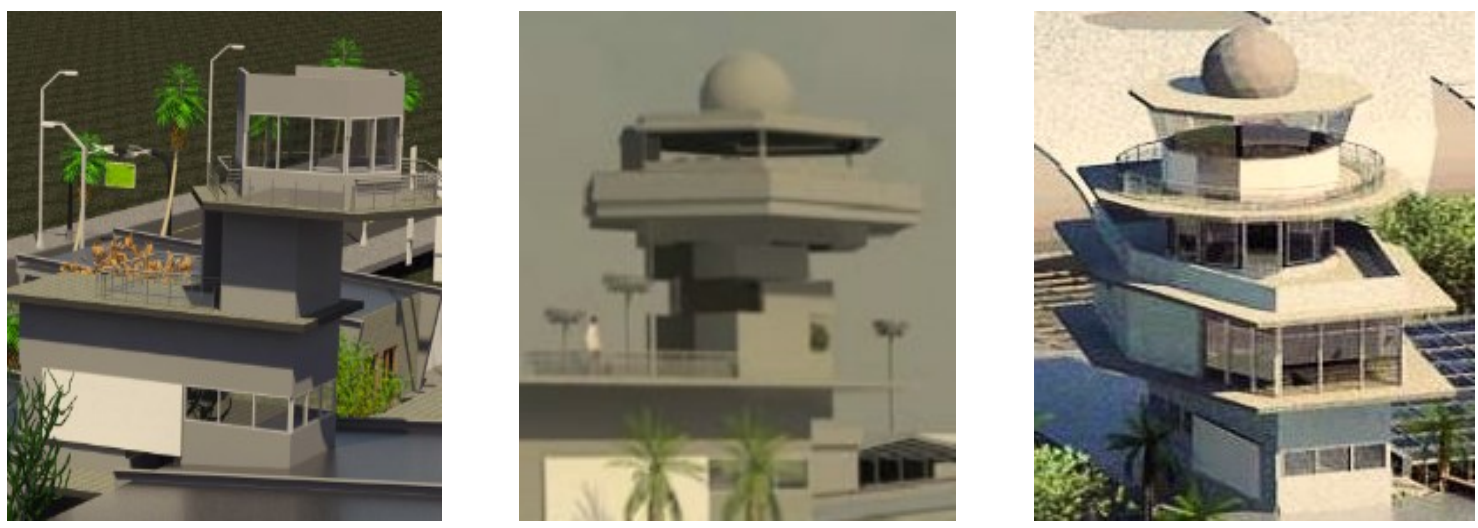

Figura 59- Diferentes alternativas para Torre de Controle (simulação de alteração projeto).

$\mathrm{Na}$ simulação de retrabalho utilizamos os componentes paramétricos, tanto aqueles nativos do aplicativo, como foram adicionadas as pontes de embarque para que se pudesse contemplar a visualização do pátio a partir da torre de controle. A adição das pontes de embarque exigiu ainda a modelagem de um "concourse", conector, para ligação dos fluxos de passageiros entre as pontes e o edifício do terminal, a fim de se verificar a aplicabilidade da biblioteca para o provimento de infraestrutura aeroportuária. Os componentes default correspondem aos pilares, vigas, paredes, esquadrias, pisos e coberturas. As torres exigiram a inserção de blocos como mobiliário, representação humana, equipamentos e elementos acessórios a edificação (Figura 60).

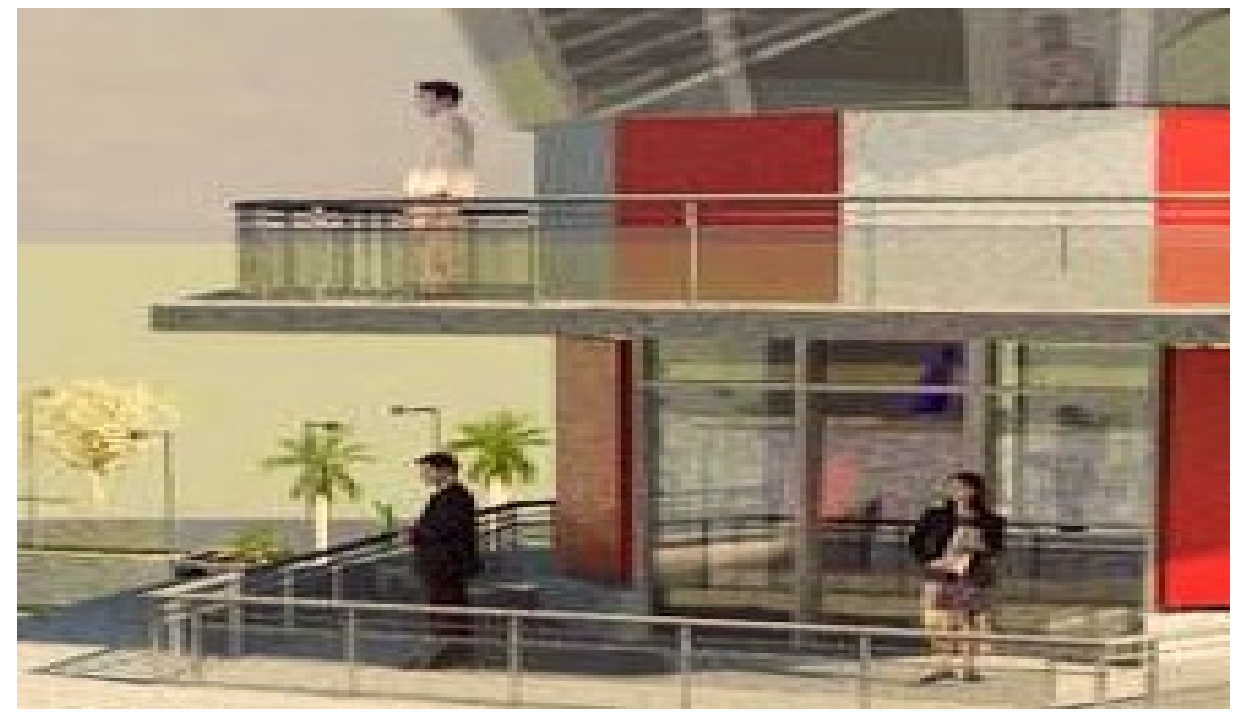

Figura 60 - Exemplo de inserção de componentes da biblioteca nativa para compor a escala humana na modelagem das Torres de Controle.

Além da adequação técnica dos componentes e famílias, também serão avaliados os desenhos de processos resultantes do método linear tridimensional e do método tridimensional paramétrico. Pode-se observar na Figura 61 a seguir, os projetos obtidos com a modelagem global foram objetos de simulação de processo de projeto no programa Revit ${ }^{\circledR}$ da AutoDesk. Processos de projeto analisados (flexibilidade): 
Além da adequação técnica dos componentes e famílias, também serão avaliados os desenhos de processos resultantes do método linear tridimensional e do método tridimensional paramétrico. Pode-se observar na Figura 61 a seguir, os projetos obtidos com a modelagem global foram objetos de simulação de processo de projeto no programa Revit ${ }^{\circledR}$ da AutoDesk. Processos de projeto analisados (flexibilidade):

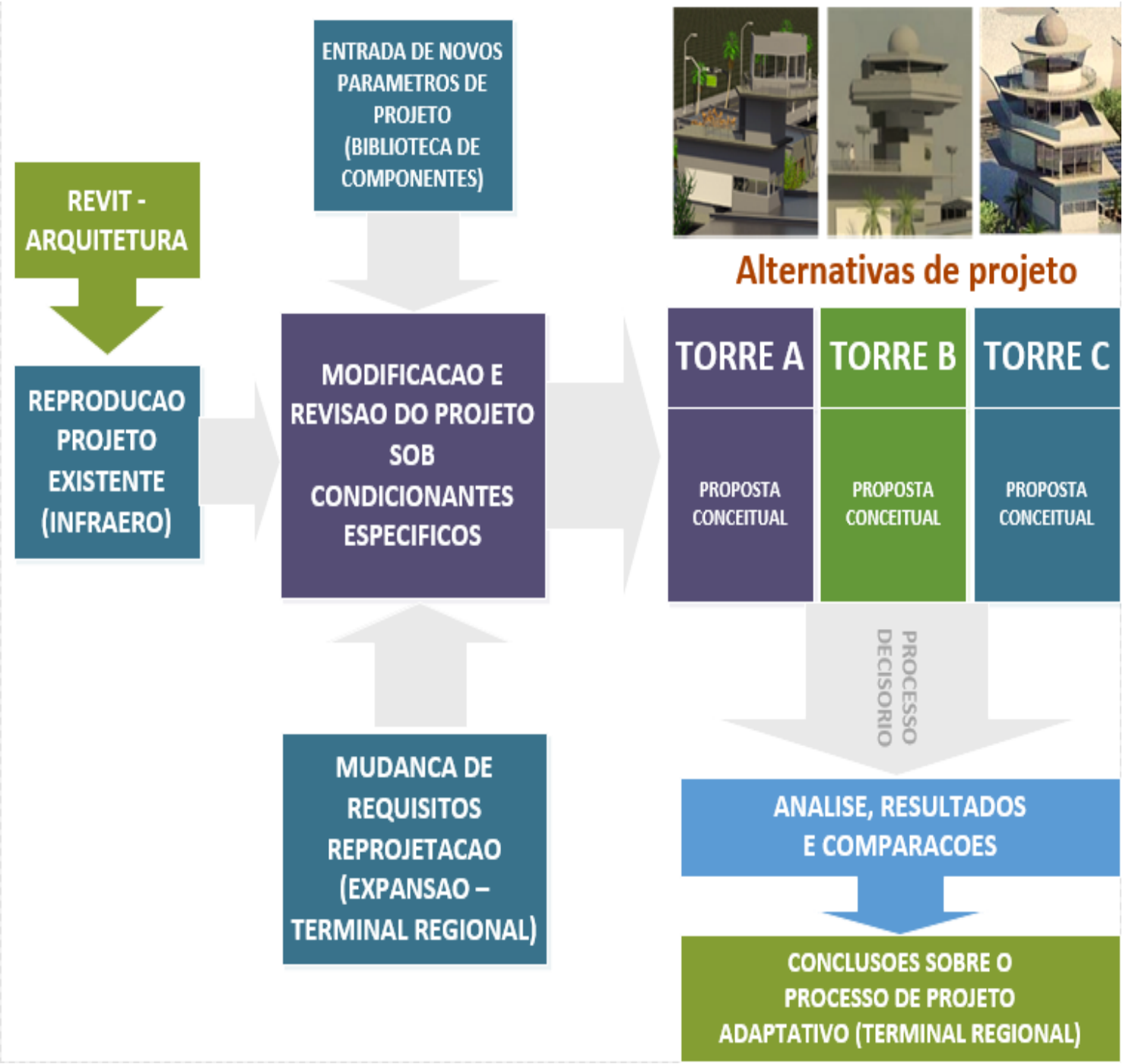

Figura 61 - Metodologia de projeto - múltiplas alternativas para TWR.

A figura 61 acima representa os passos desenvolvidos nesta pesquisa numa situação de projeto, em um terminal de passageiros aeroportuário, com o objetivo de apresentar uma simulação dos estágios iniciais de projeto. Uma vez que a modelagem do aeroporto constituiu apenas uma reprodução pura e simples do projeto desenvolvido pela INFRAERO, concebidas três diferentes alternativas de projeto de uma torre de controle no terminal. Esta torre era inexistente no projeto original. Estas alternativas apresentam um nível crescente de complexidade. A primeira é uma torre com cabine do tipo A, que apresenta apenas um nível operacional. As alternativas dois e três apresentam cabines dos tipos $\mathrm{B}$ e $\mathrm{C}$, que possuem dois níveis operacionais para os trabalhos de navegação aérea. 
Essa divisão de classificação de cabines é utilizada como norma pela INFRAERO e pela SAC - CINDACTA, em decorrência da movimentação de aeronaves (demanda esperada) nos aeroportos. Serve ainda como possibilidade de expansão da infraestrutura instalada, podendo uma torre ser ampliada para atingir uma nova classe de atendimento operacional. Os critérios foram estabelecidos por meio dos documentos cujas páginas iniciais são mostradas a seguir e cujo documento representado pela Figura 62 consta no anexo 10 desta tese. Os documentos representados pelas Figuras 63 e 64 não foram incluídos nos anexos devido ao número excessivo de páginas (Figuras 62 a 64).

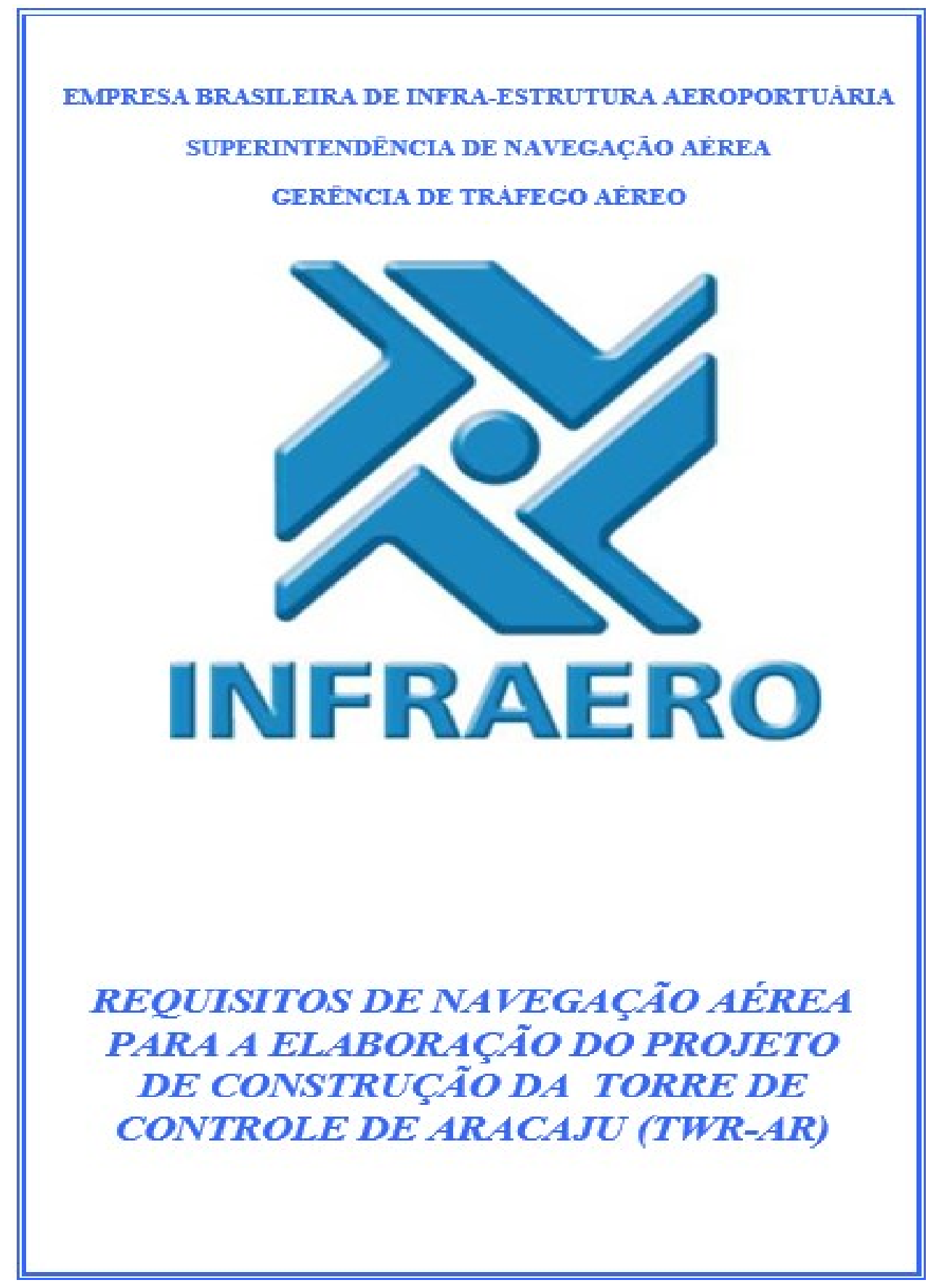

Figura 62- Documento de Requisitos de Navegação Aérea acessado via "hyperlink" na Matriz Semântica. Fonte: INFRAERO. 


\begin{tabular}{|c|c|c|c|c|}
\hline Revisio & Modiflcaçdo & Data & Autor & Aprovo \\
\hline & & & & \\
\hline & & & & \\
\hline & & & & \\
\hline & & & & \\
\hline & & & & \\
\hline & & & & \\
\hline
\end{tabular}

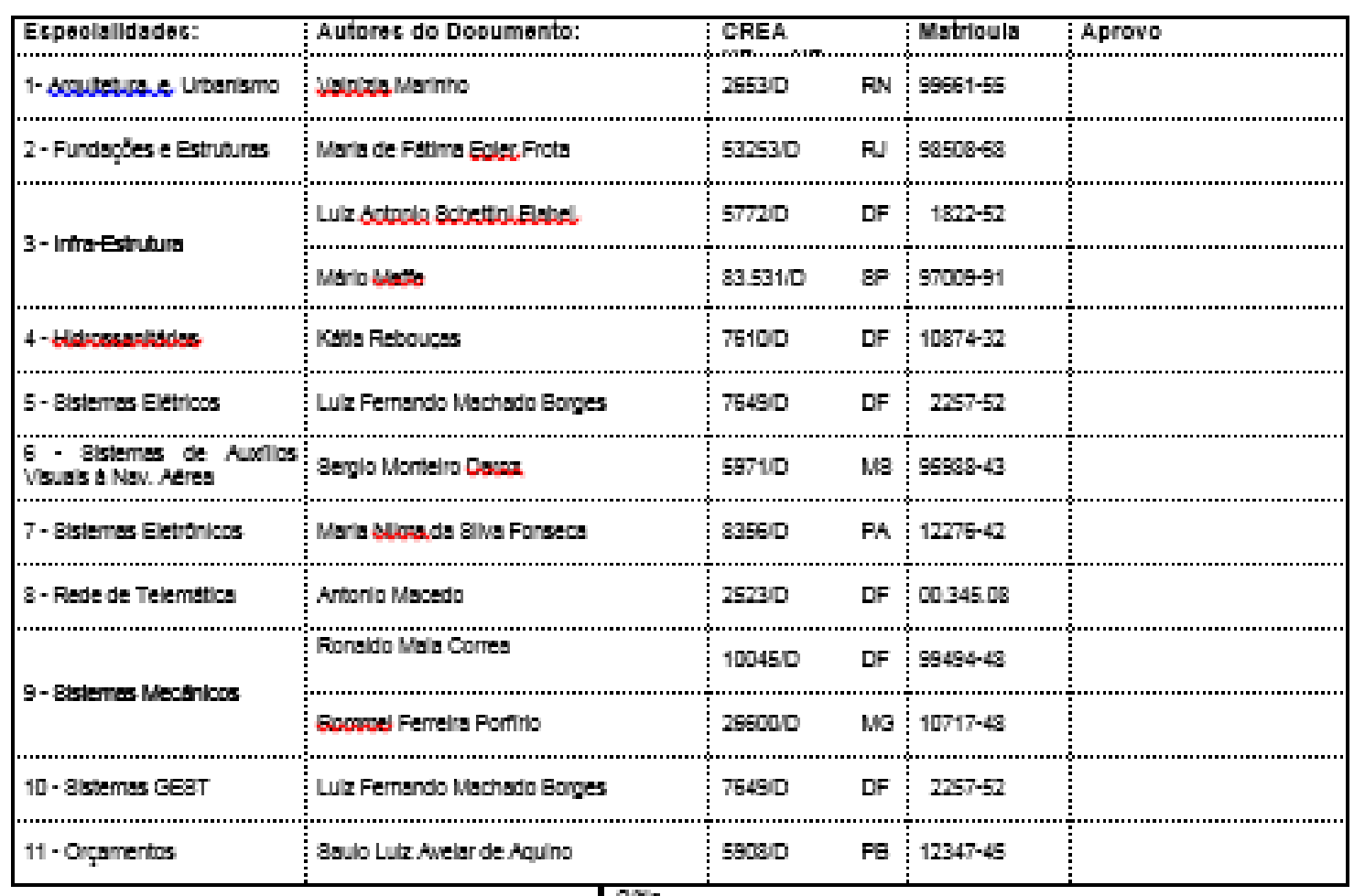

\begin{tabular}{|c|c|c|c|}
\hline \multirow{2}{*}{\multicolumn{2}{|c|}{ 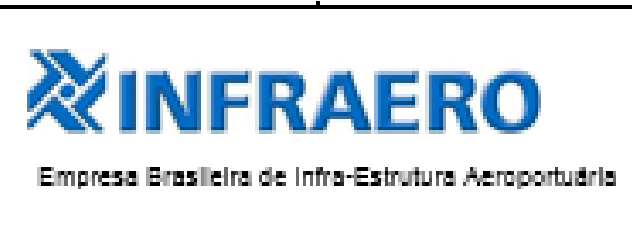 }} & \multicolumn{2}{|c|}{ AEROPORTO DE ARACAJU - SE } \\
\hline & & \multicolumn{2}{|c|}{$\begin{array}{l}\text { Treado stro } \\
\text { TORRE DE CONTROLE - TWR }\end{array}$} \\
\hline \begin{tabular}{l|l} 
Dsta & MARÇORCo9
\end{tabular} & & \multicolumn{2}{|c|}{$\begin{array}{l}\text { Especlsidsde / 8ubespeclsidsde } \\
\text { PROJETO BA SICO PARA CONTRATAÇAO DOS } \\
\text { E.P.IP.B.JP.E. }\end{array}$} \\
\hline CDEOR de Fro] to & & \multicolumn{2}{|c|}{$\begin{array}{l}\text { Tlpo IEspecrcaçbo do documento } \\
\text { ESPECIFICAÇÖES TĖCNICAS -(ET) }\end{array}$} \\
\hline 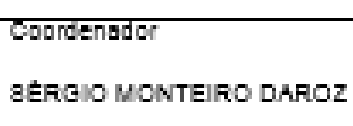 & & Tipode abra & $\begin{array}{l}\text { Closse geral do projeto } \\
\text { PROJETO BASICO }\end{array}$ \\
\hline \multicolumn{4}{|l|}{$\begin{array}{l}\text { BUDEIVISOT } \\
\text { ANTONIO MILANEZ RAMO8 }\end{array}$} \\
\hline \multicolumn{2}{|c|}{$\begin{array}{l}\text { Gerente de Projeto } \\
\text { ANTONIO MILANEZ RAMOS }\end{array}$} & gubsotul : & Bubstiduds por \\
\hline Fubrca do Austor & RGg. Do Arquivo & \multicolumn{2}{|c|}{ AR. 30 / $000.81 /$ xxxxx / 00} \\
\hline
\end{tabular}

Figura 63 - Documento de Especificações Técnicas para Torre de Controle acessado via "hyperlink" na Matriz Semântica. Fonte: INFRAERO. 


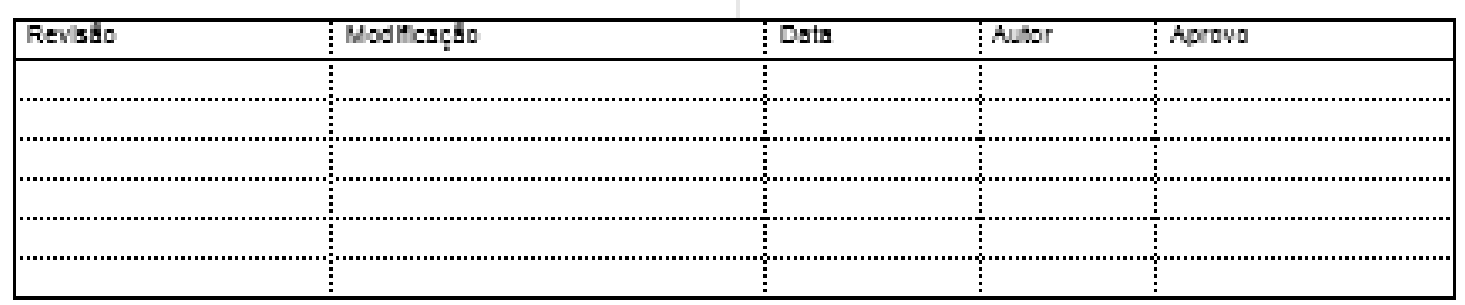

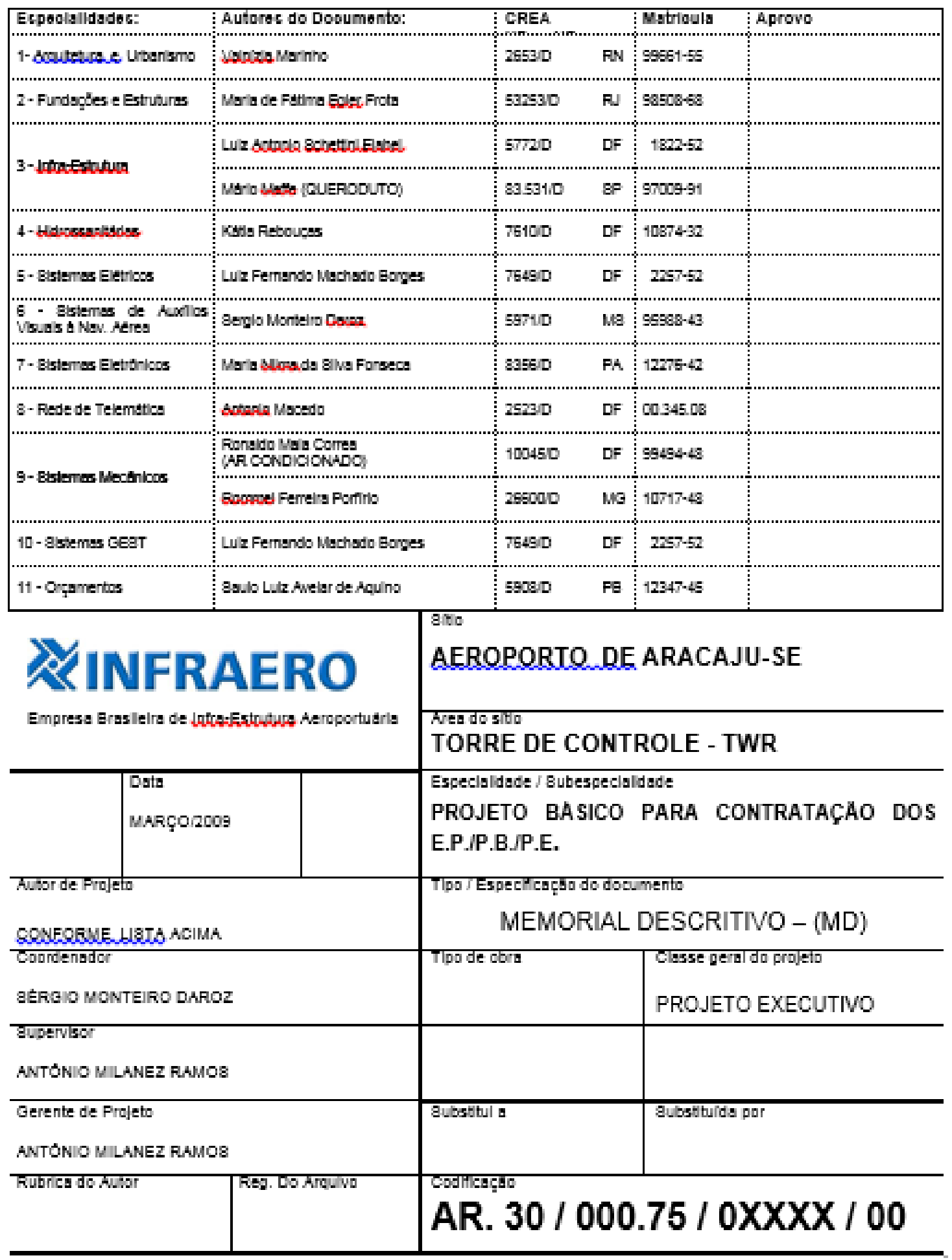

Figura 64- Documento de Memorial Descritivo para Torre de Controle acessado via "hyperlink" na Matriz Semântica. Fonte: INFRAERO. 


\subsection{1- MODELAGEM DE EXPANSÃO DO TERMINAL REGIONAL}

Por meio do uso do Revit ${ }^{\circledR}$ "Architecture", procedemos a modelagem do estudo conceitual de cada uma das propostas, para então adicionar a entrada de novos parâmetros ao projeto do terminal como um todo. Foram adicionados componentes modelados que constituem a biblioteca paramétrica desenvolvida nesta pesquisa, representando a entrada de novos parâmetros no processo de projeto.

\section{ANÁLISE ITEM A ITEM DOS PASSOS NECESSÁRIOS EXECUTADOS:}

1- Apagar os elementos "a demolir": consiste na eliminação dos elementos construtivos que devem ser readequados para que a nova proposta seja implementada;

2- Modelar os pisos da Torre de Controle: consistiu na criação do piso térreo e do primeiro pavimento referentes à torre de controle;

3- Modelar os pilares da Torre de Controle: a tarefa foi a criação da estrutura de pilares em cada piso do projeto;

4- Modelar as vigas da Torre de Controle: a tarefa foi a criação da estrutura de vigas em cada piso das torres de controle;

5- Modelar as paredes da Torre de Controle: a tarefa foi a criação da estrutura de paredes em cada piso do projeto;

6- Modelar os elementos de fechamento (esquadrias): consistiu na inserção de diferentes componentes para colocação de portas e janelas do projeto;

7- Modelar os elementos acessórios à Torre de Controle: consistiu na modelagem ou na inserção de componentes, como mobiliários internos ou urbanos, vegetação, pessoas e veículos, de forma a auxiliar na compreensão do projeto, sua escala e funções desempenhadas pelo mesmo;

8- Modelar a cobertura da Torre de Controle: a tarefa foi a criação da estrutura da cobertura do projeto.

As atividades projetuais das três alternativas de torres de controle funcionou como uma revisão e modificação do projeto existente. Incluíram a mudança de requisitos originais com o objetivo de atender a condicionantes específicos, pertinentes aos requisitos como visibilidade do pátio, altura mínima, tamanho das cabines e acesso ao edifício principal. A simulação de desempenho foi realizada por meio da exportação das alternativas ao ambiente SIG para avaliar a variação de LOD oferecida pelo InfraWorks ${ }^{\circledR}$, descrita nos resultados desta tese, bem como as limitações encontradas neste processo. 
Apresentamos a análise dos resultados na seção específica para esta finalidade nesta tese. Naquela seção discorreremos sobre as consequências da inserção de cada uma dessas diferentes alternativas no edifício existente (terminal). Informaremos também sobre como a consulta à matriz semântica possibilitou apoiar os processos decisórios, ainda que numa situação de projeto em que os profissionais das demais especialidades complementares às de arquitetura não estejam representados.

Tais consultas teriam o objetivo de informar sobre a dimensão projetual de cada componente ou módulo funcional e ainda sobre a extensão e dependência das soluções de arquitetura face aos projetos de especialidades complementares. Realizamos uma simulação de readequação do projeto existente.

Uma vez que o projeto de um aeroporto é algo complexo, a etapa de retrabalho atua como um recorte para que a análise acima descrita seja possível. A utilização dos componentes paramétricos aeroportuários, previamente modelados, contribuíram para a realização de uma pequena alteração no escopo do terminal de passageiros regional. Isto permitiu uma maior clareza na definição das diferenças entre os sistemas BIM e SIG como ambiente de processo de projeto e as potencialidades de cada um deles. (Figura 65).

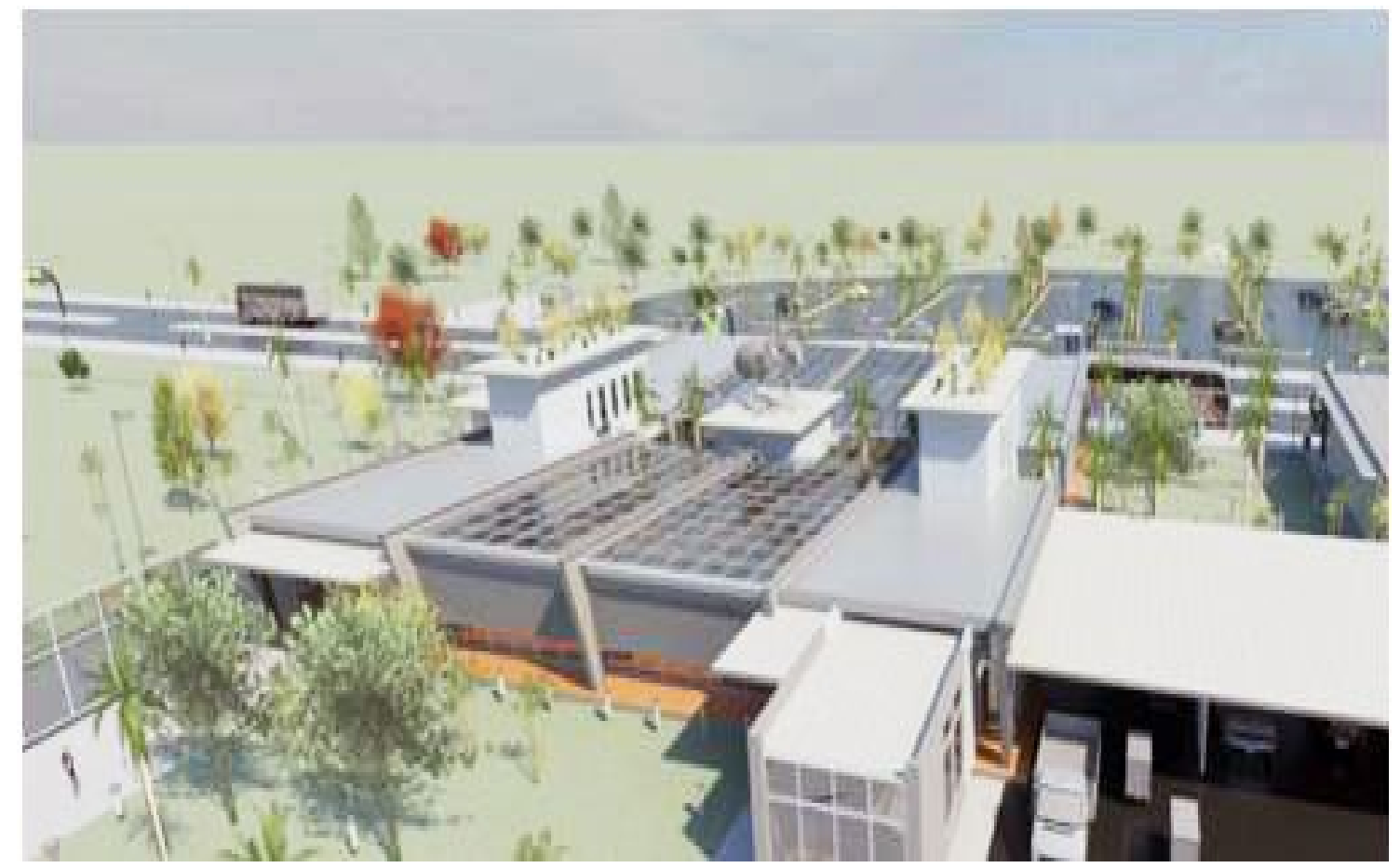

Figura 65- Exemplo do aeroporto modelado antes da criação das Torres de Controle.

A simulação da ampliação do terminal teve por objetivo, inicialmente, gerar três propostas diferentes para uma Torre de Controle - TWR no aeroporto. Projetamos então, com uso dos sistemas BIM três alternativas de projeto, sendo que as mesmas apresentam níveis crescentes de complexidade (Figura 66 a 68) 


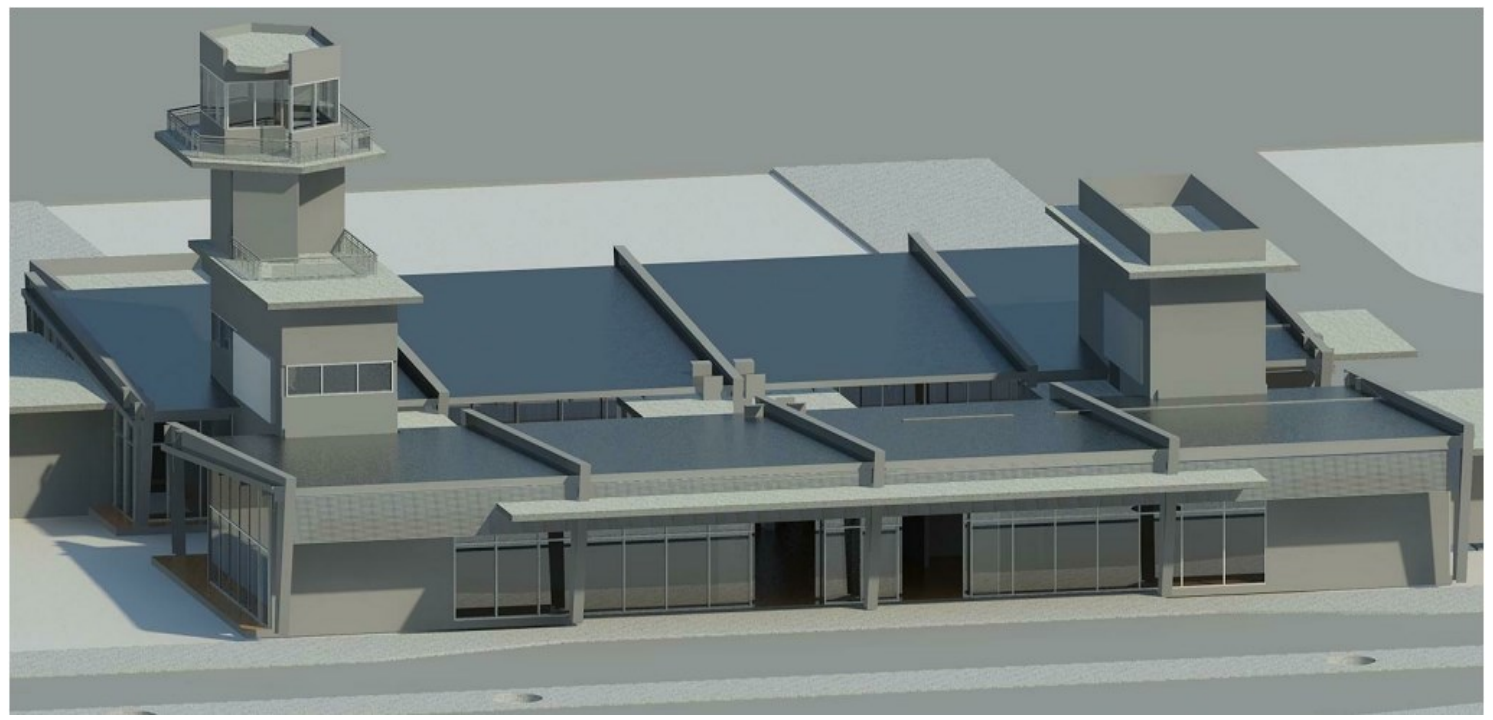

Figura 66- Vista do Terminal de Passageiros Regional modificado - TWR1.

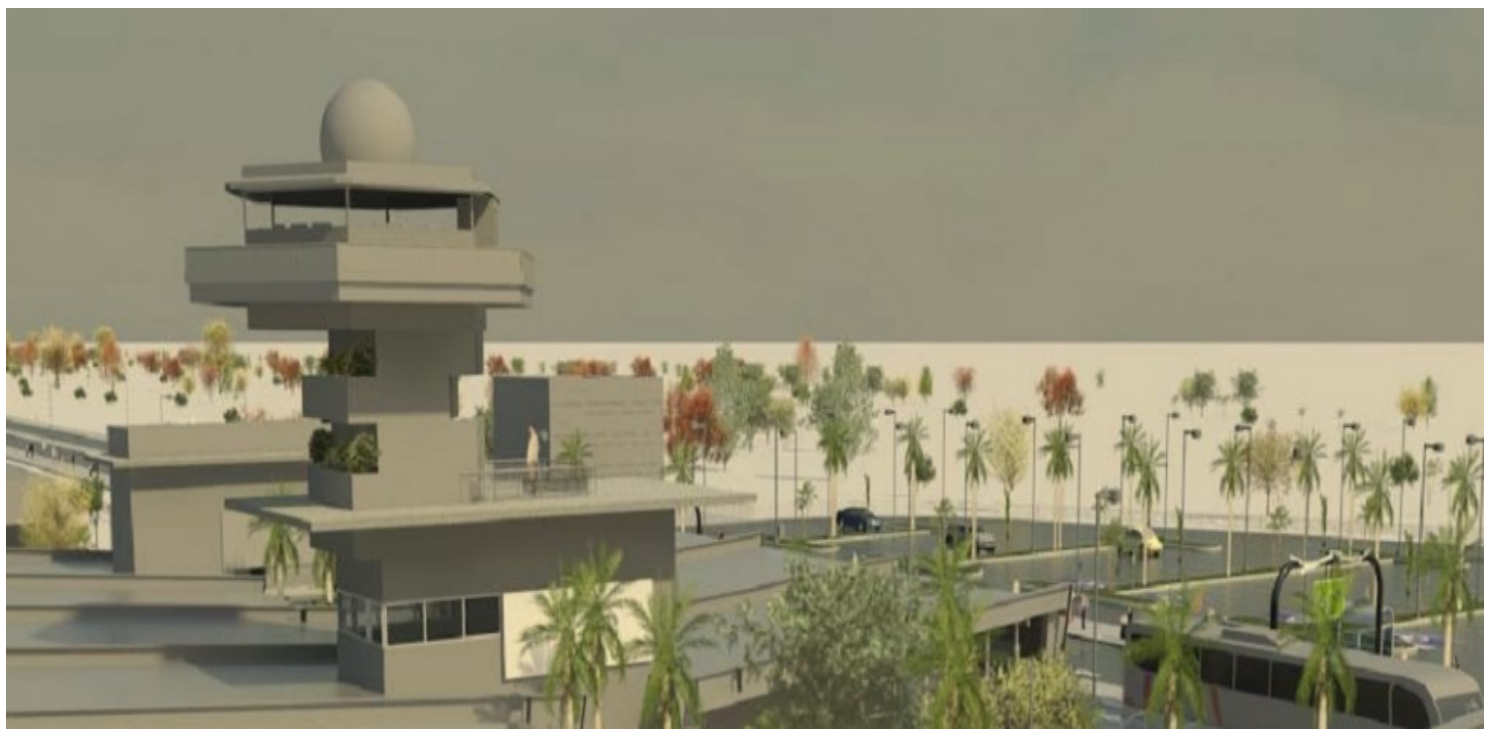

Figura 67- Vista do Terminal de Passageiros Regional modificado - TWR2.

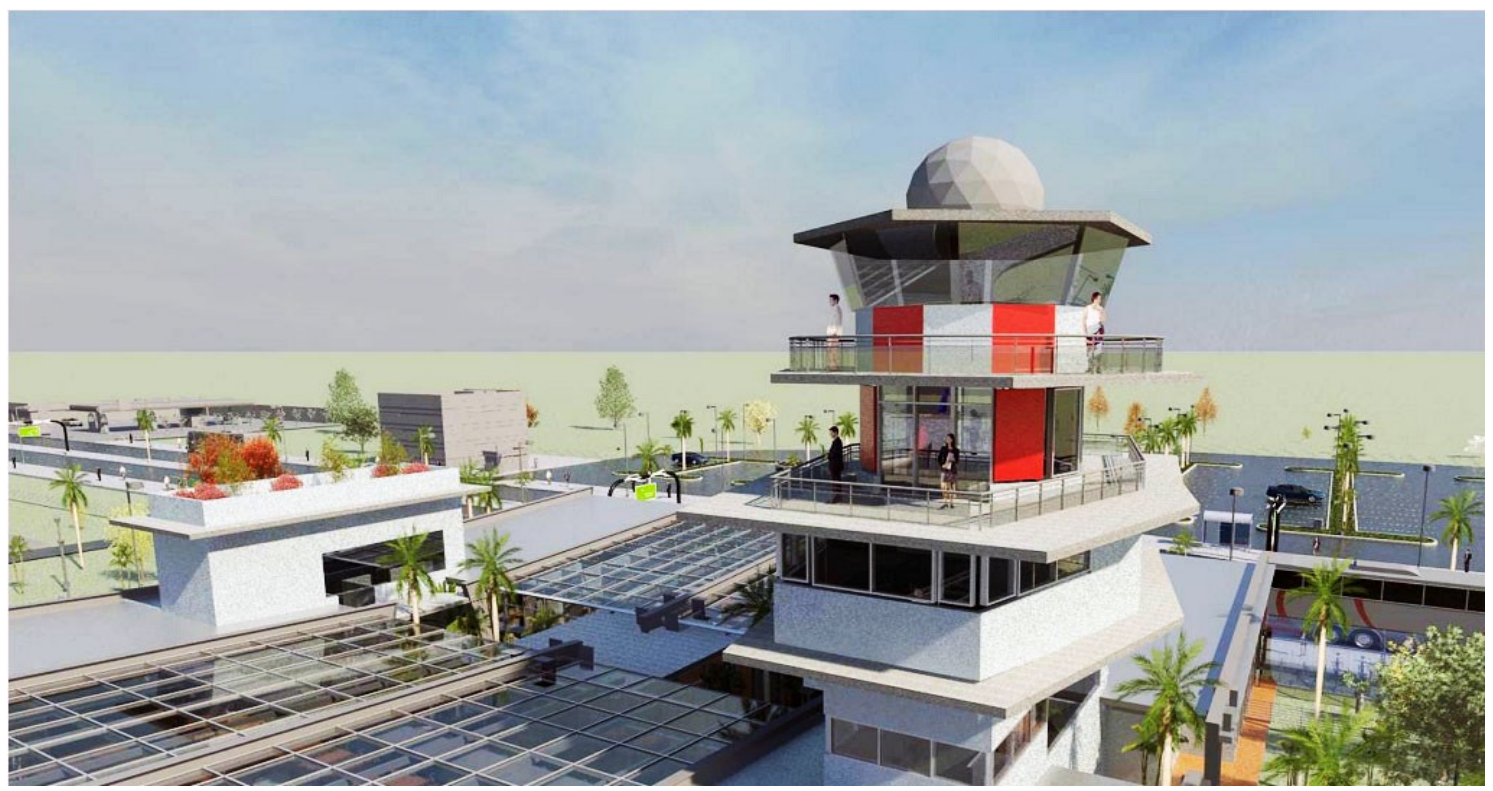

Figura 68- Vista do Terminal de Passageiros Regional modificado - TWR3. 


\section{4- DISCUSSÃO DOS RESULTADOS}

\section{1- RELAÇÕES DA MATRIZ SEMÂNTICA COM O PROCESSO DE PROJETO - RESULTADOS DO DETALHAMENTO DO “CHECK-IN"}

A elaboração de uma matriz semântica vem de encontro às lacunas identificadas nos sistemas BIM no sentido de permitir as ambiguidades necessárias para os processos de análise nos estágios inicias de projeto. Uma vez que a matriz estabelece paralelos entre as especificidades que as partes de um aeroporto apresentam em relação ao contexto de projeto na INFRAERO.

A matriz desenvolvida nesta pesquisa propõe-se a informar sobre as regras de abstração envolvidas no projeto de aeroportos. Para tanto, premissas foram estabelecidas como listadas a seguir.

1- Permitir consulta simultânea de mais de um campo de informação;

2- Apresentar as informações de forma hierárquica e relacional;

3- Permitir seu uso em rede, em uma ambiente intranet" ou extranet".

Para que o projeto aconteça, diversos processos de projetação e analise são necessários, por diferentes profissionais, envolvidos tanto nas tarefas de projeto (arquitetura e engenharias) como na elaboração de requisitos e análise das soluções apresentadas para efetuar aprovação de projetos. A INFRAERO, enquanto empresa de natureza publica, deve se ater às soluções mais vantajosas para obras e serviços de engenharia.

A busca por soluções eficientes de projeto envolve ambiguidades na representação dos componentes construtivos, seja ela espacial ou de parâmetros relevantes aos mesmos.

A manipulação da informação de projeto pode ser amparada pela matriz semântica, uma vez que é possível realizar consulta sobre as informações relevantes aos módulos funcionais, expressas na matriz. Isso significa a abstração das informações não-essenciais para o projeto de cada um dos módulos funcionais do aeroporto.

Dessa forma, a matriz é capaz de relacionar apenas informações concernentes a partes do aeroporto que estão sendo projetadas, de forma a estabelecer as conexões semânticas entre as mesmas e ainda sua implicação em termos de responsabilidades e escopos no processo de projeto do ambiente organizacional da INFRAERO. 
As variações dos componentes construtivos devem acontecer não apenas no sentido gráfico, de representação bidimensional ou tridimensional. As informações associadas aos componentes construtivos, no ambiente de projeto devem responder a diferentes perguntas e associações de ideias do projetista.

No detalhamento do módulo "check-in" foi possível verificar que, por meio das conexões e fronteiras estabelecidas na matriz, esta facilita a multidisciplinaridade entre as diferentes especialidades. Isto ocorre em razão da facilidade de consulta simultânea a mais de um modulo funcional, que por sua vez possibilita cruzar informações sobre requerimentos de projetos, tarefas de projeto e ainda sobre os critérios de aprovação de projeto para cada uma das áreas da INFRAERO envolvidas. A ideia consiste em estabelecer uma fonte interativa de consulta, que além de poder ser atualizada, pode indicar as interfaces existentes entre os profissionais de uma equipe de projeto de forma a concatenar suas responsabilidades, dado um determinado escopo de tarefas.

Permite uma visão mais aprofundada sobre como ocorre a ligação entre o profissional de projeto, que procura atender determinado requisito e está exposto a condicionantes específicas de projeto (contexto) e o profissional responsável pela aprovação das soluções propostas, representado pelas áreas da INFRAERO. A necessidade de se entrelaçar informações sobre as tarefas de projeto e de aprovação reside na deficiência dos sistemas BIM de o fazerem por si próprios. A criação de ferramenta de apoio ao processo de projeto que possa estabelecer regras de abstração para os módulos funcionais de um aeroporto pode estabelecer parâmetros confiáveis para representação dos componentes construtivos, não apenas em termos geométricos, como semânticos.

A seguir, na Tabela 5, a matriz é apresentada em relação a organização das informações relevantes para as interações que um arquiteto e os engenheiros de diferentes disciplinas da INFRAERO desempenham ao longo de um processo de projeto. A Tabela 5, a seguir, apresenta o resultado do detalhamento do check-in, separado em dois níveis principais: a dimensão do arquiteto e as dimensões das engenharias (disciplinas complementares de projeto). Estes níveis foram configurados com informações relativas aos processos de aprovação e de projetos, detalhando as associações existentes entre os mesmos.

$\mathrm{Na}$ dimensão relativa aos processos de aprovação de projetos, cada área da INFRAERO está relacionada com as tarefas correspondentes, identificando quais partes do aeroporto estão envolvidas, bem como quais sistemas encontram-se direta ou indiretamente relacionados. (Tabela 5.) 


\section{DETALHAMENTO DO “CHECK-IN” - MATRIZ SEMÂNTICA}

\begin{tabular}{|c|c|c|c|c|}
\hline \multirow[b]{2}{*}{ ESTRUTURA } & \multicolumn{2}{|c|}{$\begin{array}{l}\text { DIMENSÃO DE } \\
\text { ARQUITETURA }\end{array}$} & \multicolumn{2}{|c|}{$\begin{array}{l}\text { DIMENSÃO DAS } \\
\text { ENGENHARIAS }\end{array}$} \\
\hline & $\begin{array}{l}\text { APROVAÇÃO } \\
\text { DE PROJETOS }\end{array}$ & $\begin{array}{l}\text { TAREFAS DE } \\
\text { PROJETO }\end{array}$ & $\begin{array}{l}\text { APROVAÇÃO DE } \\
\text { PROJETOS }\end{array}$ & $\begin{array}{l}\text { TAREFAS DE } \\
\text { PROJETO }\end{array}$ \\
\hline $\begin{array}{l}\text { PARTES DO } \\
\text { AEROPORTO }\end{array}$ & \multicolumn{4}{|c|}{$\begin{array}{c}\text { MEIO FIO DE ENTRADA - SAGUÃO "LADO TERRA" - ÁREA DE ESPERA } \\
\text { (FILAS) DO “CHECK-IN “- ÁREA DE “CHECK-IN" - ÁREAS } \\
\text { ADMINISTRATIVAS (“BACKOFFICE”) - ÁREAS DE TRATAMENTO E } \\
\text { TRANSFERÊNCIA DE BAGAGEM }\end{array}$} \\
\hline $\begin{array}{l}\text { SISTEMAS DO } \\
\text { AEROPORTO }\end{array}$ & \multicolumn{4}{|c|}{$\begin{array}{c}\text { CHEGADA E SAÍDA DE USUÁRIOS NO MEIO FIO - SISTEMA DE FLUXOS } \\
\text { DO SAGUÃO “LADO TERRA” - SISTEMA DE TRIAGEM DE FILAS - } \\
\text { SISTEMA DE TRATAMENTO E TRANSPORTE DE BAGAGEM - SISTEMA } \\
\text { DE INFORMAÇÕES AEROPORTUÁRIAS - SISTEMA DE “CHECK-IN” - } \\
\text { SISTEMA DE SEGURANÇA E VIGILÂNCIA }\end{array}$} \\
\hline $\begin{array}{l}\text { ÁREAS DA } \\
\text { INFRAERO }\end{array}$ & $\begin{array}{l}\text { COMERCIAL - } \\
\text { ENGENHARIA - } \\
\text { GESTÃO - } \\
\text { JURÍDICA - } \\
\text { PLANEJAMENTO } \\
\text { - OPERAÇÕES - } \\
\text { MEIO AMBIENTE }\end{array}$ & $\begin{array}{l}\text { COORD. E } \\
\text { COMPATIB. }\end{array}$ & $\begin{array}{l}\text { COMERCIAL - } \\
\text { ENGENHARIA - } \\
\text { GESTÃO - JURÍDICA - } \\
\text { PLANEJAMENTO - } \\
\text { OPERAÇÕES - MEIO } \\
\text { AMBIENTE }\end{array}$ & $\begin{array}{l}\text { COORD. E } \\
\text { COMPATIB. }\end{array}$ \\
\hline $\begin{array}{l}\text { DISCIPLINAS DA } \\
\text { INFRAERO }\end{array}$ & $\begin{array}{r}\text { ARQUITETURA } \\
\text { SISTEMAS E } \\
\text { INFRAESTRUTU } \\
\text { AÉREA - ORÇAME }\end{array}$ & $\begin{array}{l}\text { - SISTEMAS ELÉ } \\
\text { STRUTURAIS - } \\
\text { IRA - SISTEMAS } \\
\text { NTO - SISTEMA } \\
\text { TELE }\end{array}$ & $\begin{array}{l}\text { TRICOS - SISTEMAS EL } \\
\text { ISTEMAS HIDROSSAN } \\
\text { DE AUXÍLIO VISUAL À } \\
\text { S ELETROMECÂNICOS } \\
\text { MÁTICA }\end{array}$ & $\begin{array}{l}\text { ETRÔNICOS - } \\
\text { ITÁRIOS - } \\
\text { NAVEGAÇÃO } \\
\text { - SISTEMAS DE }\end{array}$ \\
\hline
\end{tabular}


Vale ressaltar que as áreas da INFRAERO são responsáveis pela formação dos critérios e requisitos de projeto. São responsáveis também pela aprovação dos projetos efetuados pela área de engenharia. Por isto precisam verificar se os requisitos foram cumpridos e se as soluções técnicas apresentadas respondem satisfatoriamente aos problemas de projeto. As disciplinas da INFRAERO por sua vez, são responsáveis pela realização das tarefas de projeto, de cada uma das especialidades de engenharia e arquitetura. As tarefas de projeto contêm informações oriundas das especificações técnicas da INFRAERO para as disciplinas e/ou especialidades de projeto da empresa. Estas disciplinas estão representadas na matriz por meio das tarefas previstas para a realização do processo de projeto.

A matriz apresenta uma estrutura geral que permite o futuro desenvolvimento da mesma, em termos de subdivisões das tarefas envolvidas no processo de projeto como, por exemplo, a separação entre estudo conceitual e preliminar. Atualmente a INFRAERO ainda utiliza procedimentos lineares, onde, no estudo conceitual, o projetista analisa o cadastramento de cada especialidade e a solução inicial de projeto (proposta) e, no estudo preliminar preenche o Relatório Técnico que condensa os pormenores das soluções técnicas empregadas nos projetos de cada uma das especialidades. A estrutura e organização dos dados detalhados no check-in poderá, futuramente, a título de pesquisa e/ou ensino, ou para fins de utilização em uma empresa de aeroportos, atingir seu desenvolvimento completo. Isto ocorrerá por meio da contribuição de diferentes profissionais, para que possa atingir suas potencialidades máximas e de fato ser efetivada para todas as especialidades envolvidas em um projeto de aeroportos.

Foram estabelecidas conexões entre as especialidades e as partes e sistemas do aeroporto. Ao mesmo tempo, a matriz indica as fronteiras entre os diferentes módulos funcionais, que podem não estar diretamente relacionados nas atividades projetuais, mas estarem fortemente conectados nas etapas de construção, operação ou disposição final da edificação. Os módulos funcionais a exemplo do "check-in" representam um conjunto de componentes construtivos que obedecem a uma função definida.-A fim de demonstrar as regras de abstração específicas dos componentes aeroportuários, a matriz foi construída com alto nível detalhamento no módulo funcional de "check-in". Nos demais módulos funcionais, foi utilizado apenas um nível básico de detalhamento. Este foi um recorte adotado em nossa pesquisa devido às limitações de tempo próprias de um curso de doutorado. A escolha do "check-in" se justifica por ser um módulo funcional que possui grande representatividade, uma vez que integra a participação de diversas especialidades e diferentes áreas. A proposta desta pesquisa reside em demonstrar a estrutura de organização das informações na matriz de forma a representar a participação das diversas áreas da INFRAERO. 
Uma vez que o "software" utilizado oferece a possibilidade de visualização simultânea de mais de um campo de informação da matriz, pode-se combinar informações sobre diferentes partes ou sistemas de um aeroporto.

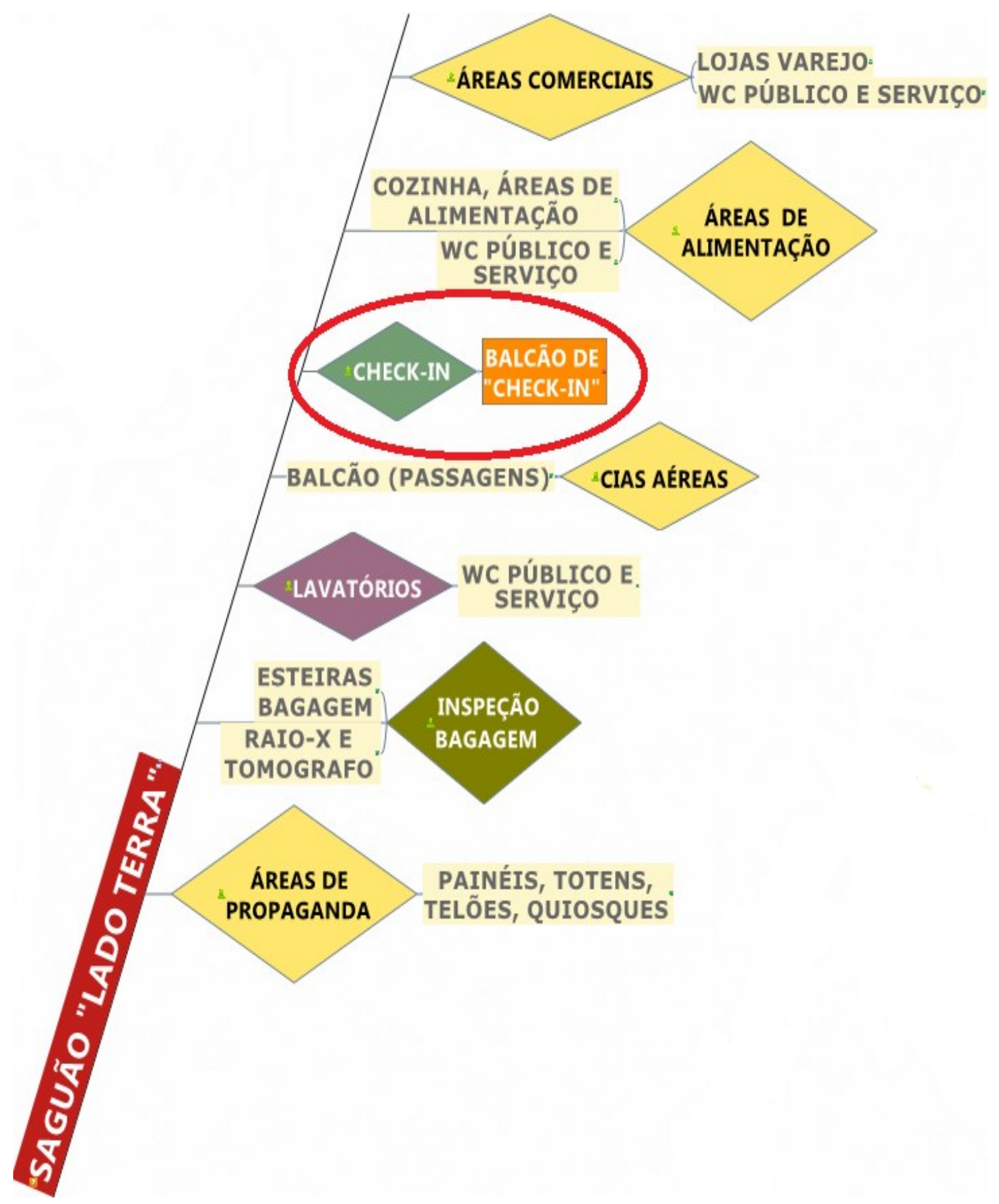

Figura 69- Ilustração parcial da tela de acesso principal da Matriz Semântica, destacando o modulo de "check-in".

Ao clicarmos em um dos campos da tela representada na Figura 69 acima, acessamos as informações referentes ao mesmo, por meio de uma nova tela representada na Figura 70, a seguir. Esta tela representa todas as especialidades envolvidas no projeto do módulo funcional, separadas em fases distintas do processo de projeto, estudo conceitual, ou preliminar e projeto básico. 


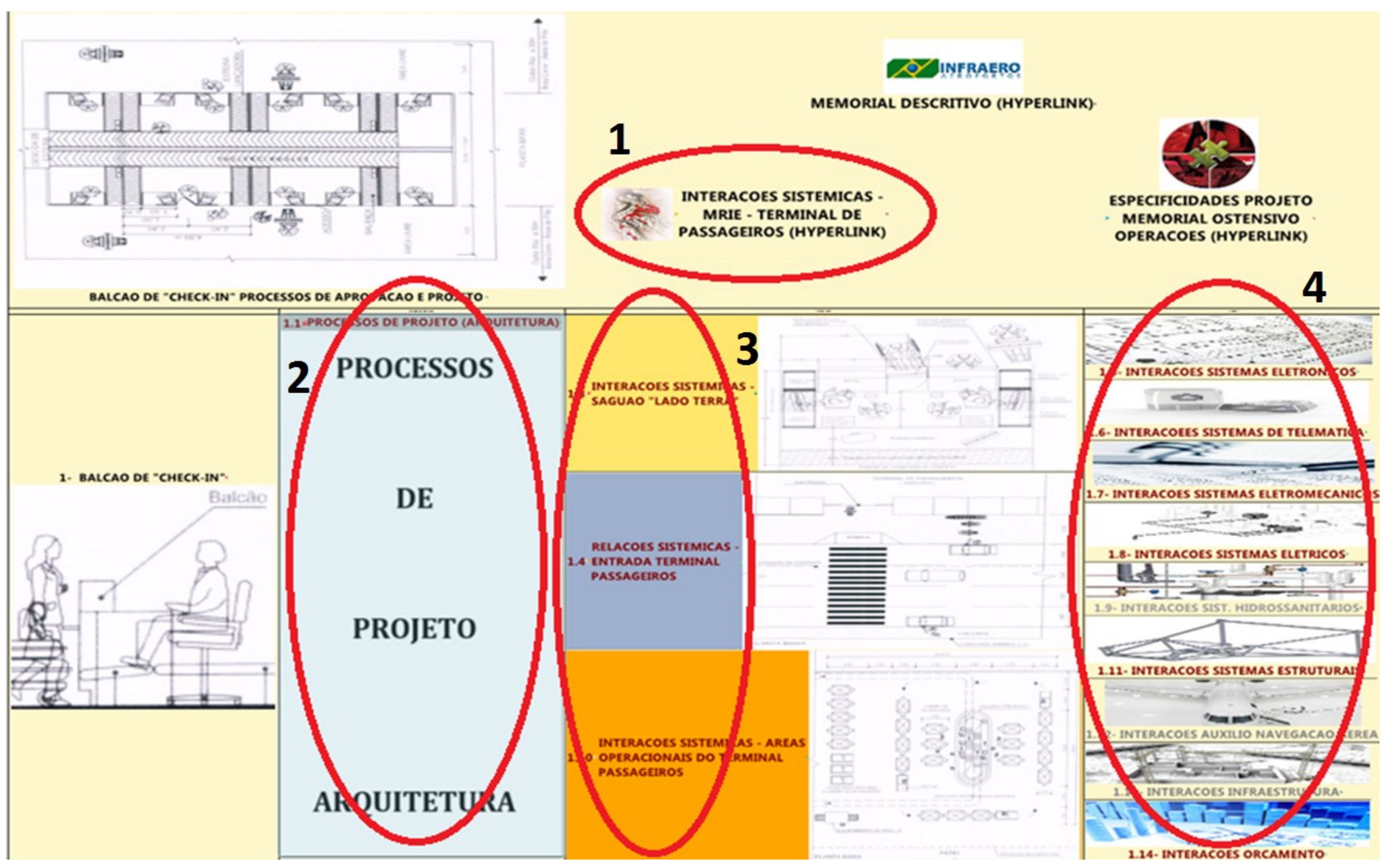

Figura 70 - Tela de acesso ao Detalhamento do “Check-in” na Matriz Semântica. 


\subsection{1- "HYPERLINKS (1)}

Os recursos contidos na matriz semântica oferecem ainda a possibilidade de fácil acesso à documentação de referência e/ou complementar de projeto, por meio dos "hyperlinks", o que consolida em um só ambiente digital as informações primordiais. Isso traz alguns benefícios, como a ampla divulgação e atualização da base de dados, a redução de erros de interpretação e, ainda, facilidade de consulta não apenas às normas e manuais, como ainda às informações específicas sobre os requerimentos de projeto como, por exemplo, memorial de requisitos operacionais de infraestrutura (Figura 71).

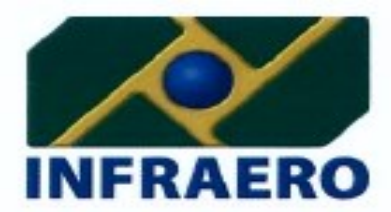

DIRETORIA DE AEROPORTOS

MEMORIAL Nº 06 / OSTENSIVO / DOPL

Data: 09 de SETEMBRO de 2011

Projeto: BALCÕES DE ATENDIMENTO

Documento: MEMORIAL DE REQUISITOS OPERACIONAIS DE INFRAESTRUTURA (MRIE)

CONTROLE DE REVISŌES:

\begin{tabular}{|l|l|l|l|}
\hline N. & REVISÃo & página (s) & Data \\
\hline- & emissão inicial & - & $01 / 06 / 2009$ \\
\hline 01 & Revisão & Todas & $09 / 09 / 2011$ \\
\hline
\end{tabular}

INDICE

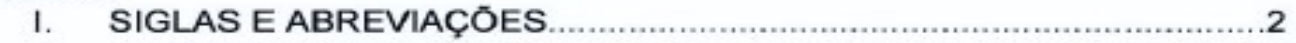

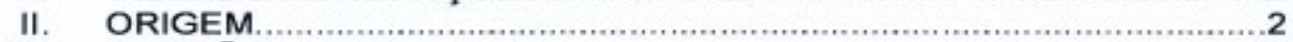

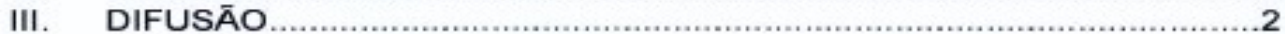

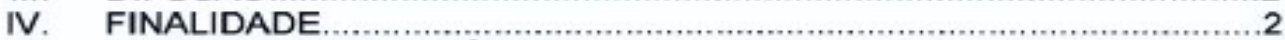

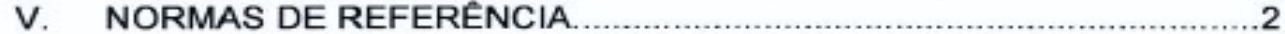

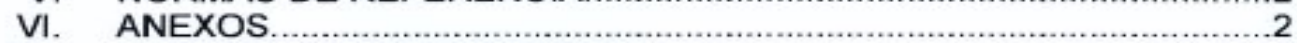

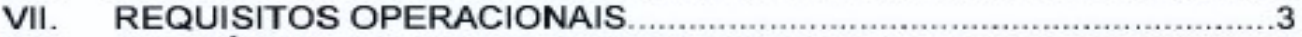

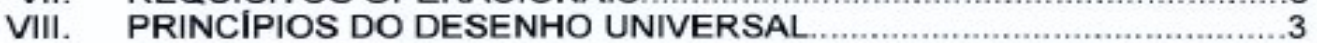

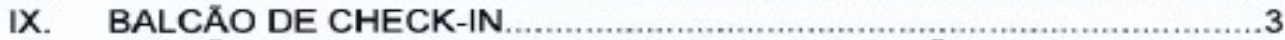

X. BALCÃO DE VENDA, RESERVA E INFORMAÇŌES DE EMPRESAS AÉREAS (BVRI) E BALCĀO DE ATENDIMENTO DE ÓRGĀOS

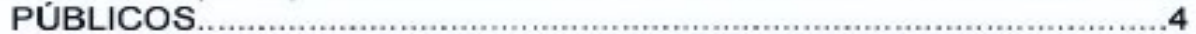

XI. BALCÃO DE INFORMAÇOESS "INFO INFRAERO"

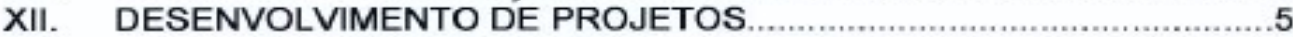

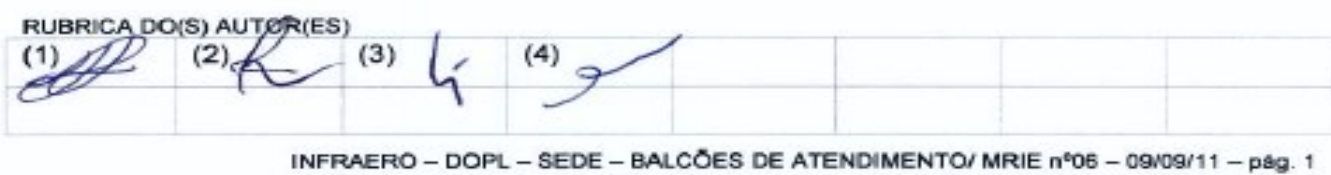

Figura 71- Memorial Ostensivo número 06 - Fonte: DOPL/ INFRAERO. 


\subsection{2- PROCESSOS DE PROJETO DE ARQUITETURA (2)}

Ao clicar no campo da tela principal do módulo de "check-in", correspondente aos processos de projeto de arquitetura, ilustrado na Figura 26 da página 79, a matriz permite o acesso a duas outras telas, de abertura sequencial.

A primeira diz respeito aos processos de aprovação de projetos específicos para as atividades projetuais do arquiteto. A segunda apresenta as atividades de análise envolvidas nos processos de aprovação (Figura 72).

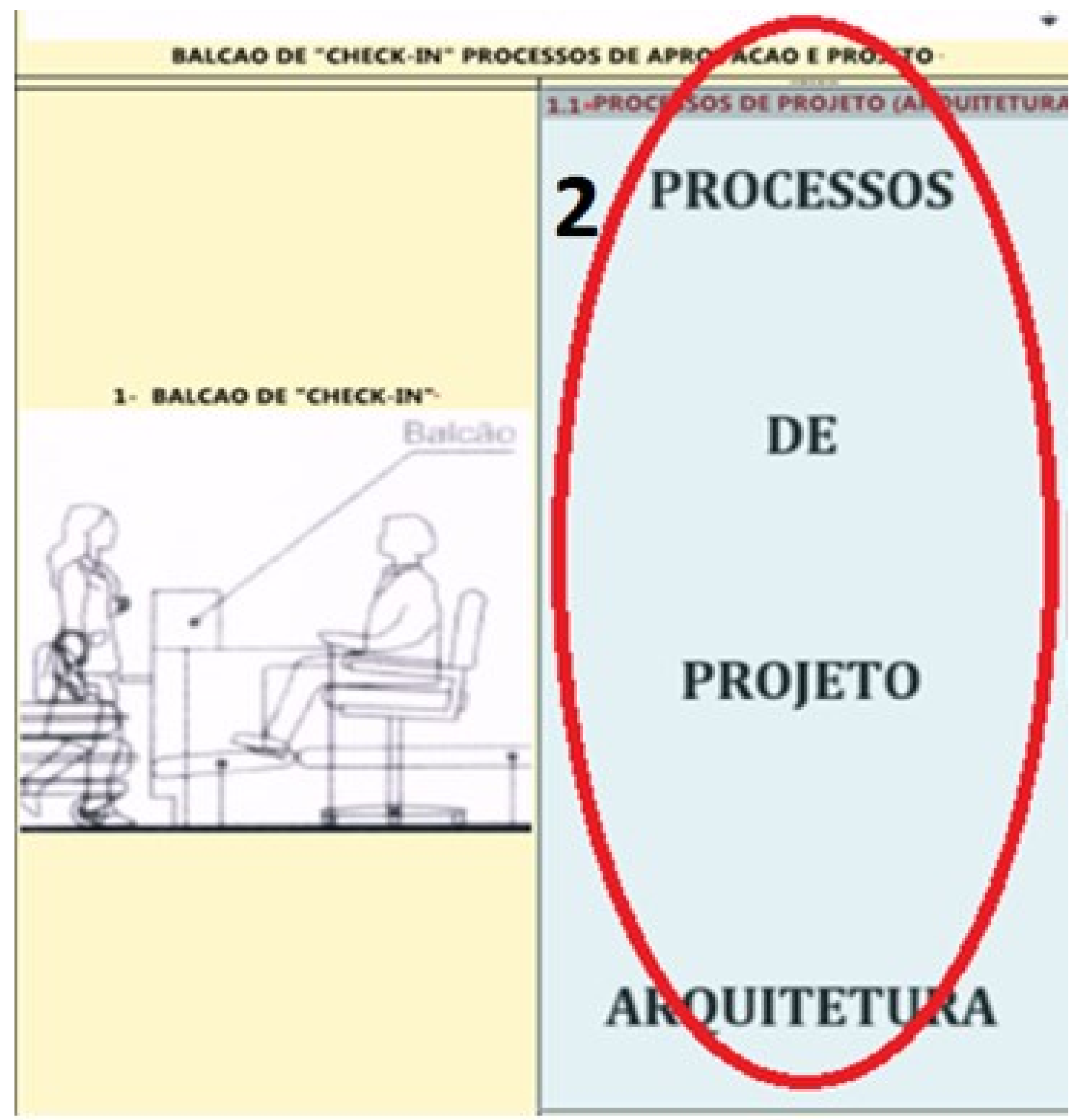

Figura 72- Campo de acesso aos Processos de Projeto de Arquitetura na Matriz Semântica.

Visando à separação da percepção do arquiteto das demais especialidades, as informações de "check-in" estão separadas em diferentes dimensões, mostrando a vinculação entre os grandes conjuntos de atividades. 


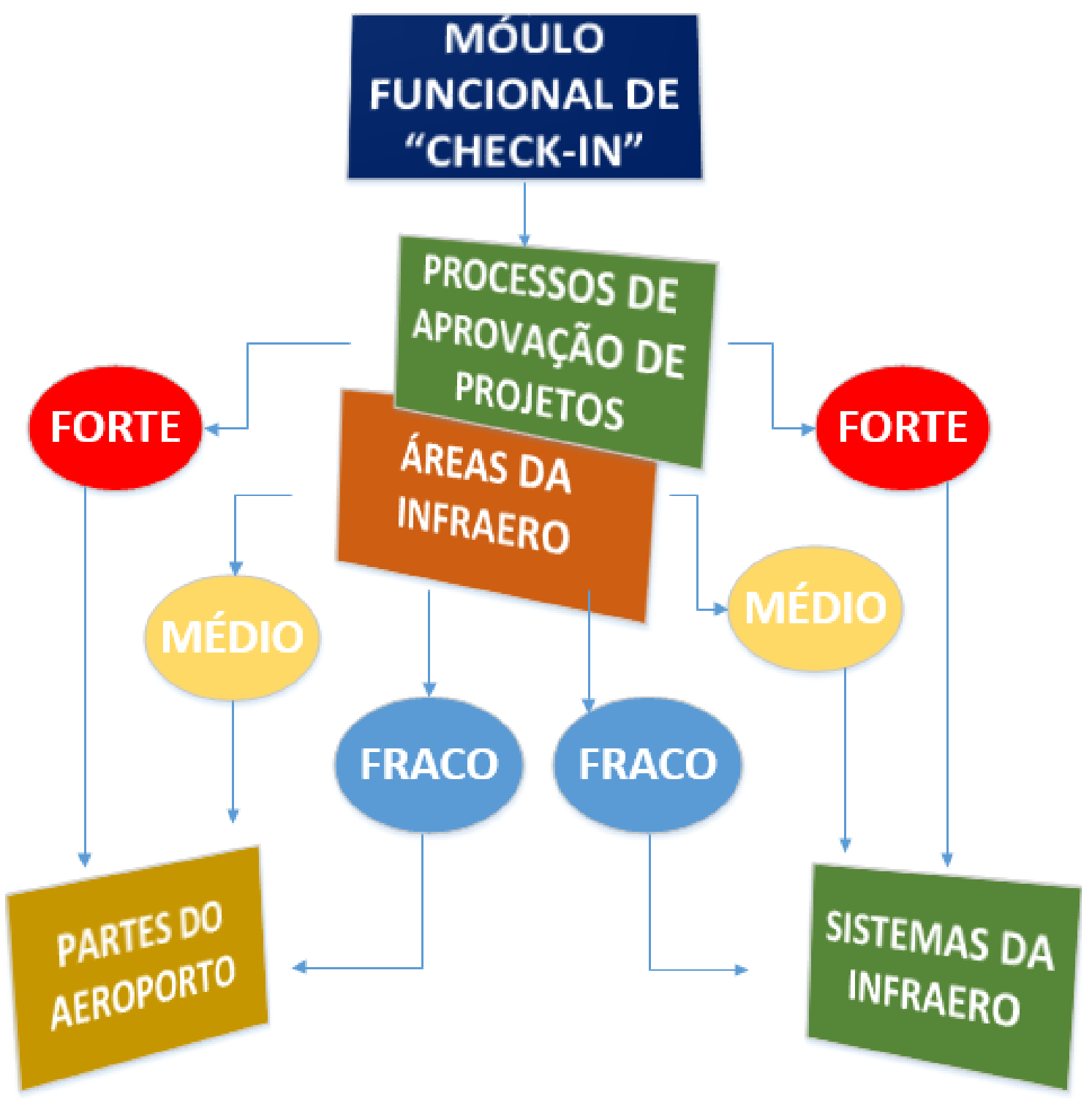

Figura 73- Exemplo de estruturação lógica dos dados na Matriz Semântica referente aos Processos de Aprovação.

Tais informações são referentes à contribuição esperada ou às lacunas naquilo que o arquiteto precisa para projetar um determinado módulo funcional.

A lógica estrutural da matriz reside na diferenciação entre essas diversas dimensões e "lentes", que filtram informações diferentes para projetar um mesmo módulo do aeroporto. As partes do aeroporto ("check-in") estão relacionadas com os sistemas da edificação e hierarquizados conforme sua relevância no processo de projeto.

Em vermelho aparecem as informações sobre as partes e os sistemas altamente significativos para o módulo funcional de "check-in" (FORTE). Em amarelo (MEDIO), ligações medianas e em azul (FRACO) as ligações com baixo teor de relacionamento (Figura 73 acima). 
A classificação FORTE, MÉDIO e FRACO classifica as partes e sistemas referentes ao modulo funcional escolhido, em diferentes graus de afinidade com as tarefas de aprovação de projetos. Isto permite ao projetista saber quais seriam as prioridades envolvidas no projeto de um aeroporto e suas partes. A matriz fornece ainda caracterização sobre as ações (Colaboração, Execução ou Nada), impactos (Alto, Médio ou Baixo) e sobre a forma como como essas ações acontecem (Analise, Projeto ou Síntese) (Figura 74).

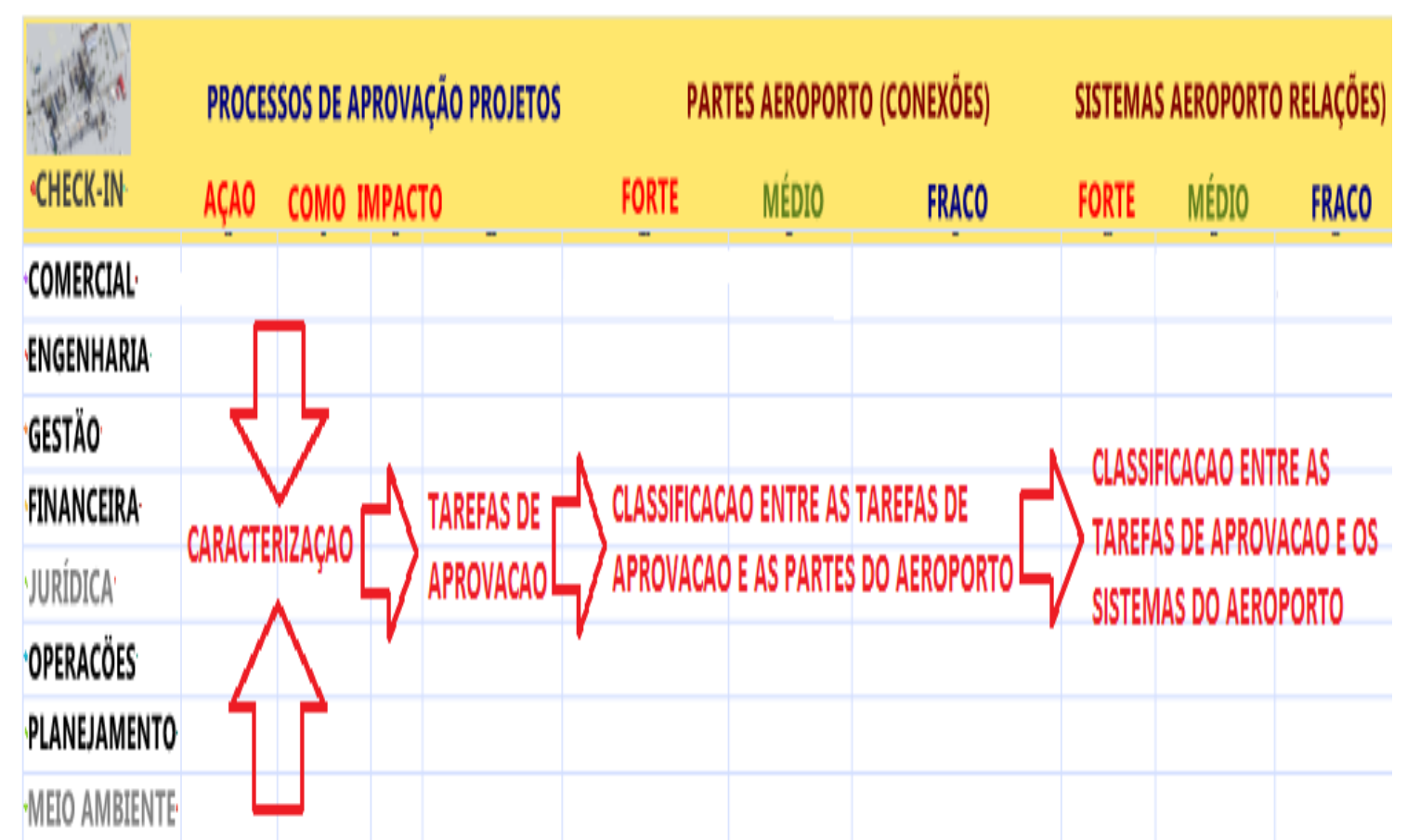

Figura 74- Caracterização e classificação de Tarefas de Aprovação de Projeto para a INFRAERO.

A possibilidade de se relacionarem diferentes campos, de forma a gerar um panorama ou enfoque sobre determinados processos de aprovação, torna a matriz uma ferramenta de auxílio ao processo de projeto, configurada para o ambiente organizacional da INFRAERO. Isto porque a partir da matriz pode-se consultar sobre as informações simultâneas sobre a conexão existente entre as partes do aeroporto e a pratica de arquitetura e de engenharia na INFRAERO.

Na Figura 75, na próxima página, pode-se observar que as áreas jurídica e de meio ambiente não estão diretamente envolvidas no desenvolvimento de soluções de projeto e na aprovação para o módulo de "check-in". A permanência das áreas "desligadas", na cor branca é importante para informar ao projetista, que não precisa atuar diretamente com essas áreas, delimitando seu campo de análise e de contribuição no processo de projeto. A primeira tarefa de aprovação descrita na Figura 75, a seguir, (análise da solução de arquitetura para o atendimento da demanda e do processamento de passageiros no "check-in"), pertence à área comercial e está configurada segundo diferentes níveis de afinidade com as partes e os sistemas do aeroporto. 

FORTE

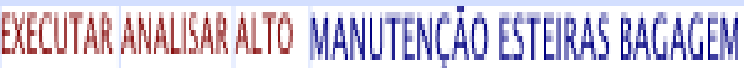

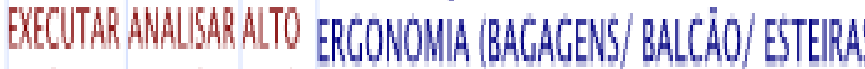

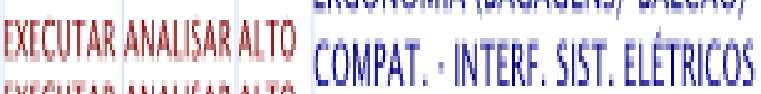

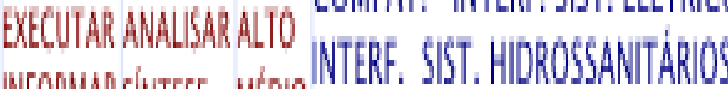

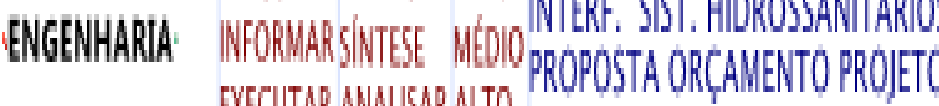

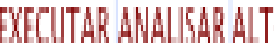

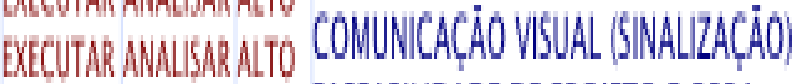

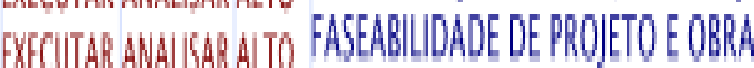
LLWNACAOAOAMGELTES: NORMAS

GESTAO

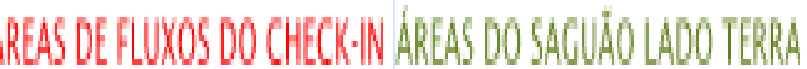
AREAS DO SACULAOL LADO AR

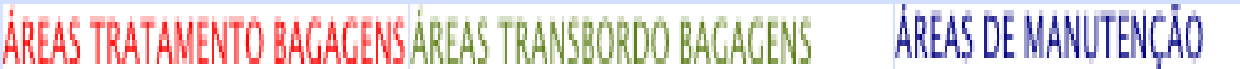

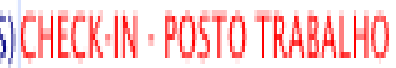
AREA DO CHECKN AREA DEE BACKOOFFCE TODO TERM. PASSAGEROROS

AREAS DE CHEECKN

AREASDECHECKN

AREAS DE CHEECKN

AREAS DE CHEECEN

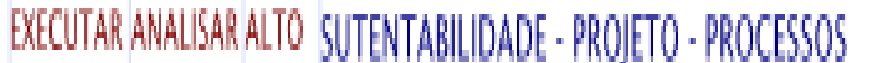

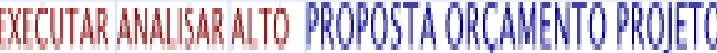

FNANEERA

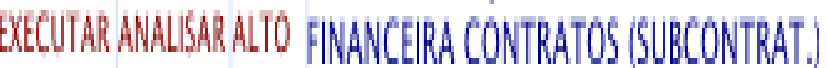

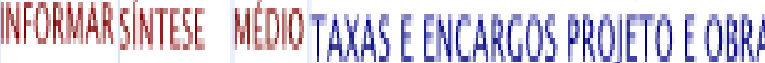

TODD TFP PASSAGEROS

APEAS DE CHECK.N

AREAS DE CHEECK.N

AREAS DE CHECK.NN

\section{SACUDEE LADO TFERA EAR}

ARREAS DE CALEERAST TEECNCÁS

OUTTIOE IN THE STE CONTEXT

SAGUAOOLL LADOTERRA

SACLOEES LADO TERRE E AR

SACDOEE LADO TERRA EAR

SACUOEES LADO TERRE EAR

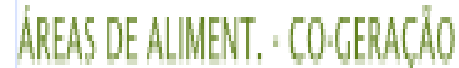

AREAS TRAT BACACENS

SACUOEES LADO TERRA EAR SALUDEES LADO TERRAEAR

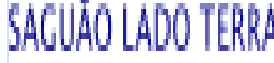

\section{SACUAOAOL LADOOAR}

AREASTRAT. BQGAGENS

AREASTRAT, BQGAGÉNS

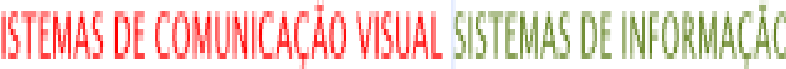

SISTEMAS DE LUWNAGCAO

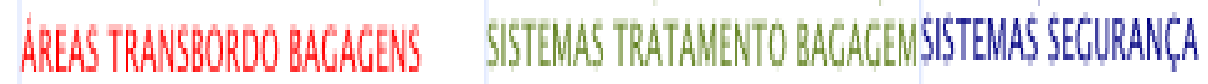

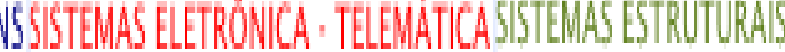

SITTEMAS MEP

RESTANTE TERM. PASSAEERORS SISTEMAS WEP

SISTEMAS ESTRUTURALS

SIST. ELETRONONCOS TEEEMATCA

SISTEMAS DE GESTAOO

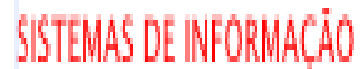

SISTEMAS CONTTRUTVOS

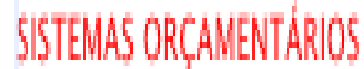

SISTEMAS DE ACESSO

SITTEMSSEEUURANCA

SISTEMAS ELETTRCOS. ESTRUTURAL SISTEMAS MEP

SISTEMAS DE AEESSO

AREASTRAT. BAGGEENS SISTEMAS DE ORCAMENTO SISTEMAS DE GESTAO

SISTEMAS ELETRONONCOS

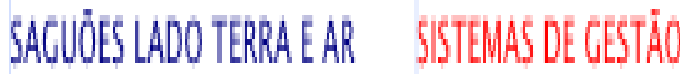

SISTEMAS CONSTRUTVOS

SISTEMAS DO AEROPORTO

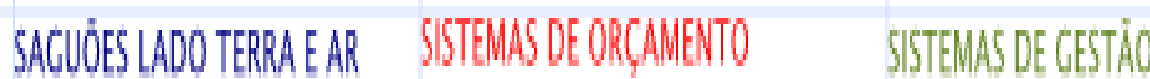

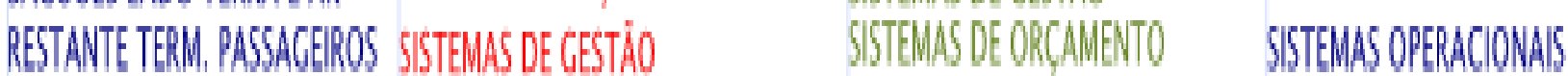

RESTANTE TEM, PASSAGEROS SISTEMAS DE ORCAMENTO SITTEMASDECESTAO

SITEMAS OPERACOONAIS

JURIDLCA: 〈U ÁREA DESLGGADA

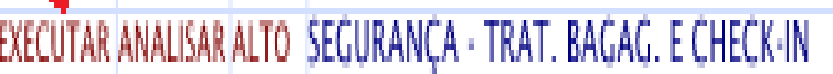

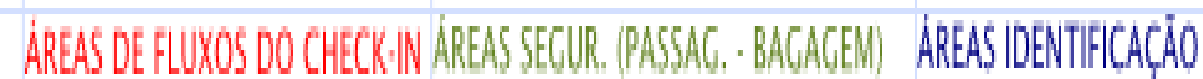

SITEMAS DE SECURANCA

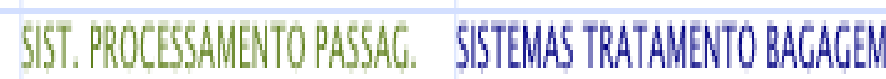

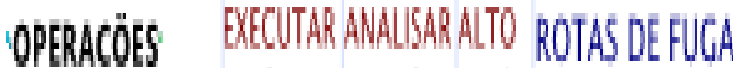

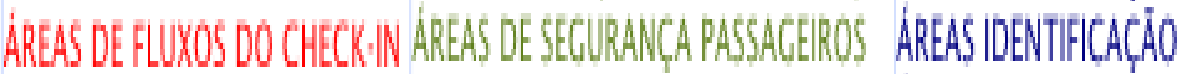

SITEMAS DE SEGURANCA

SIST, PROCESSAMENTO PASSAG,

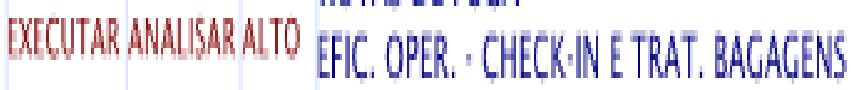

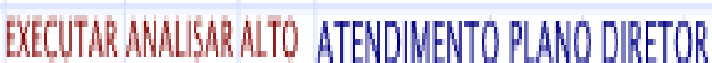

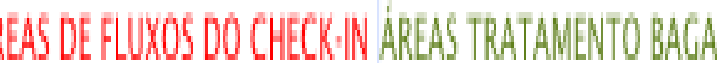

AREASSEGURANCA MPAX/BAC,

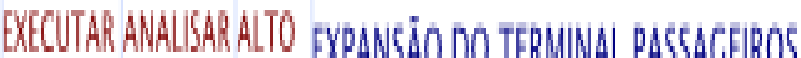

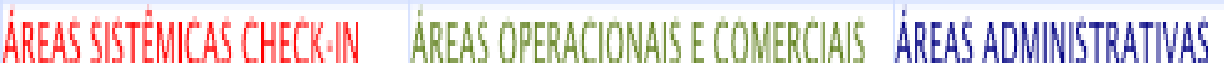

SIST. PROCESSAMENTO PASSGEROBOSITTEMAS DE SELIRANCA

STEMASSECURANCA

PLANESAMENTO

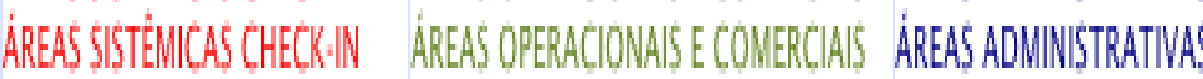

SIST, PROCESAMENTO PASSAGEROS ITTEMAS DE SEGURANCA

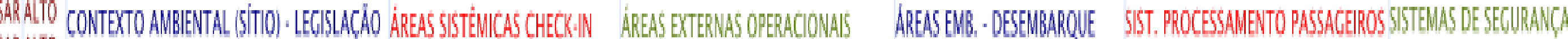

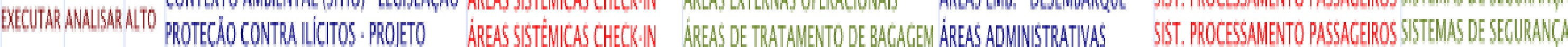

SISTEMAS TRATAMENTO BACACEN

SITEMAS TRATAMENTO BACACEM

SISTEMAS TRATAMENTO BACACEM

SISTEMAS TRATAMENTO BACAGEM

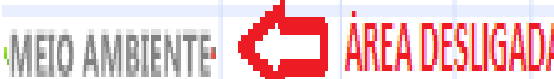

Figura 75 - Tela de acesso na Matriz Semântica aos Processos de Aprovação da INFRAERO. 
Os processos de aprovação de projeto são diferenciados pela caracterização das ações (execução, informação ou não se aplica ou n/a), pela forma (projeto, síntese ou análise) e pelo impacto (alto, médio ou baixo) (Figura 74). Cada área da INFRAERO está representada e associada diretamente aos processos de aprovação de projetos correspondentes à sua esfera de atuação. Na Figura 74 na página anterior, observa-se que as áreas com letras em preto encontram-se ativas, ou seja, participam do processo de projeto do módulo funcional. As áreas que aparecem com letras cinzas estão "desligadas" por não estarem diretamente relacionadas aos sistemas de "check-in", mas podem ser ativadas se, por alguma razão, essa associação for criada.

A primeira tarefa de aprovação descrita na Figura 76, a seguir, (análise da solução de arquitetura para o atendimento da demanda e do processamento de passageiros no “check-in"), pertence à área comercial e está configurada segundo diferentes níveis de afinidade com as partes e os sistemas do aeroporto.

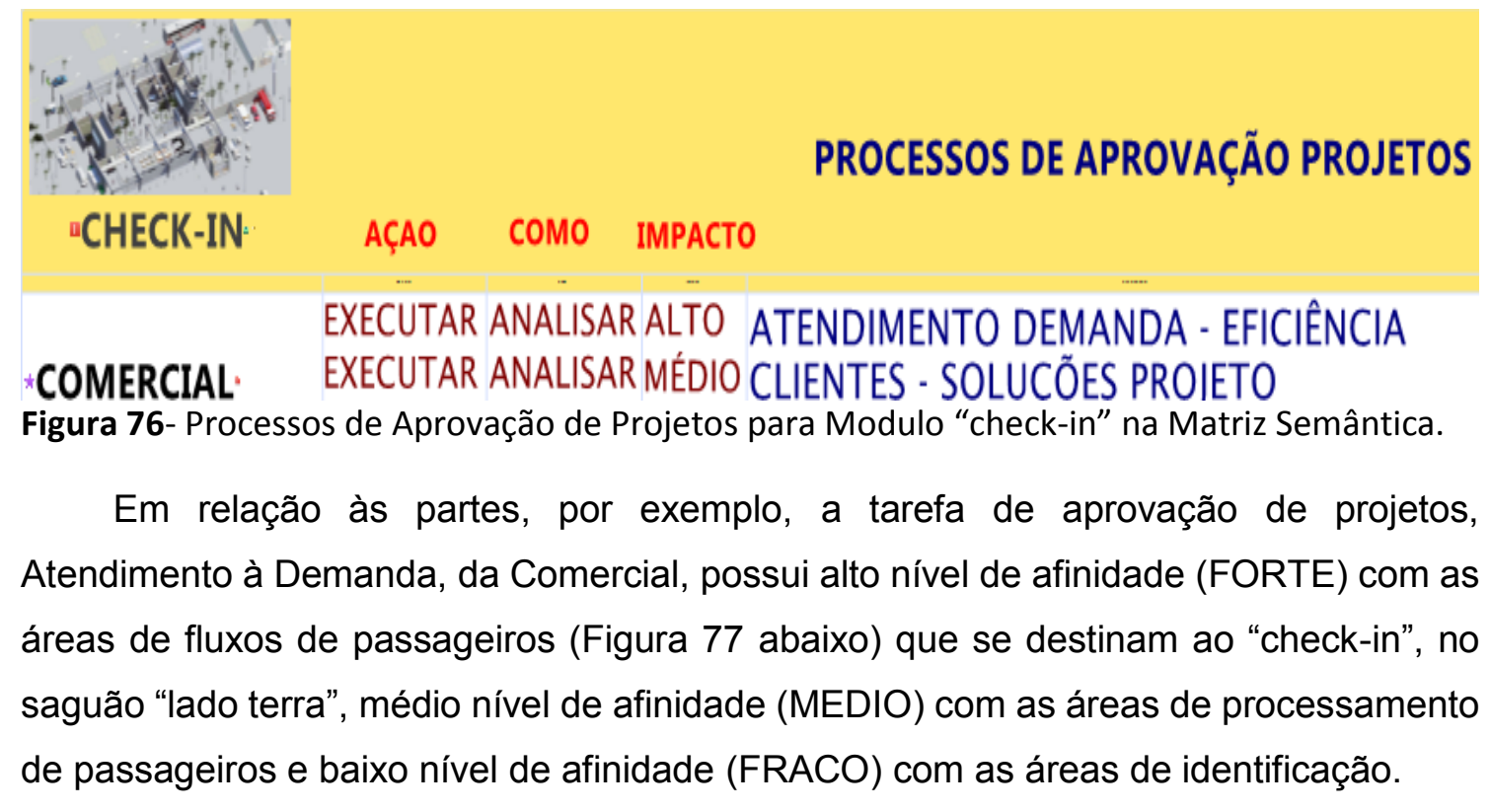

\section{PARTES AEROPORTO (CONEXÕES)}

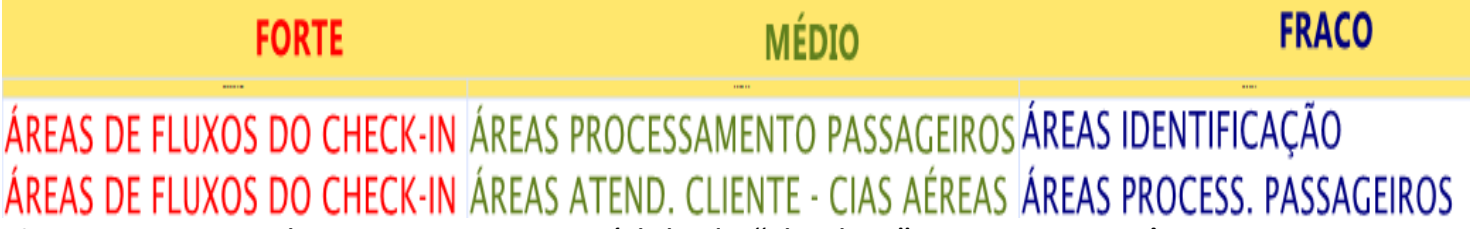

Figura 77- Partes do Aeroporto para Módulo de "check-in" na Matriz Semântica.

Em relação aos sistemas do aeroporto, a tarefa de aprovação descrita acima possui alto nível de afinidade (FORTE) com os sistemas de tratamento de bagagem, médio nível de afinidade (MEDIO) com os sistemas de processamento de passageiros e baixo (FRACO) com os sistemas de informação do aeroporto (Figura 78 a seguir). 
SISTEMAS AEROPORTO RELAÇÕES)

FORTE

MÉDIO

FRACO

SISTEMAS TRATAMENTO BACACEM SISTEMAS DE PROC. PASSAG. SISTEMAS DE INFORMAÇÃO SISTEMAS DE PASSAGENS

SISTEMAS TRATAMENTO BACACEMSISTEMAS DE INFORMACÃO

Figura 78- Sistemas do Aeroporto para Módulo de "check-in" na Matriz Semântica.

Por meio da consulta aos campos de informação descritos acima é possível estabelecer um determinado grau de abstração/especificação de projeto, uma vez que a matriz delimita os envolvidos e o modo como ocorre a participação dos mesmos. Isto esconde, momentaneamente, o restante da informação associada ao aeroporto, para efeito de projeto (ver Figuras 75). Como pode ser observado na Figura 79 a seguir, as áreas jurídica e de meio-ambiente encontram-se excluídas (desligadas) na representação do balcão de "check-in".

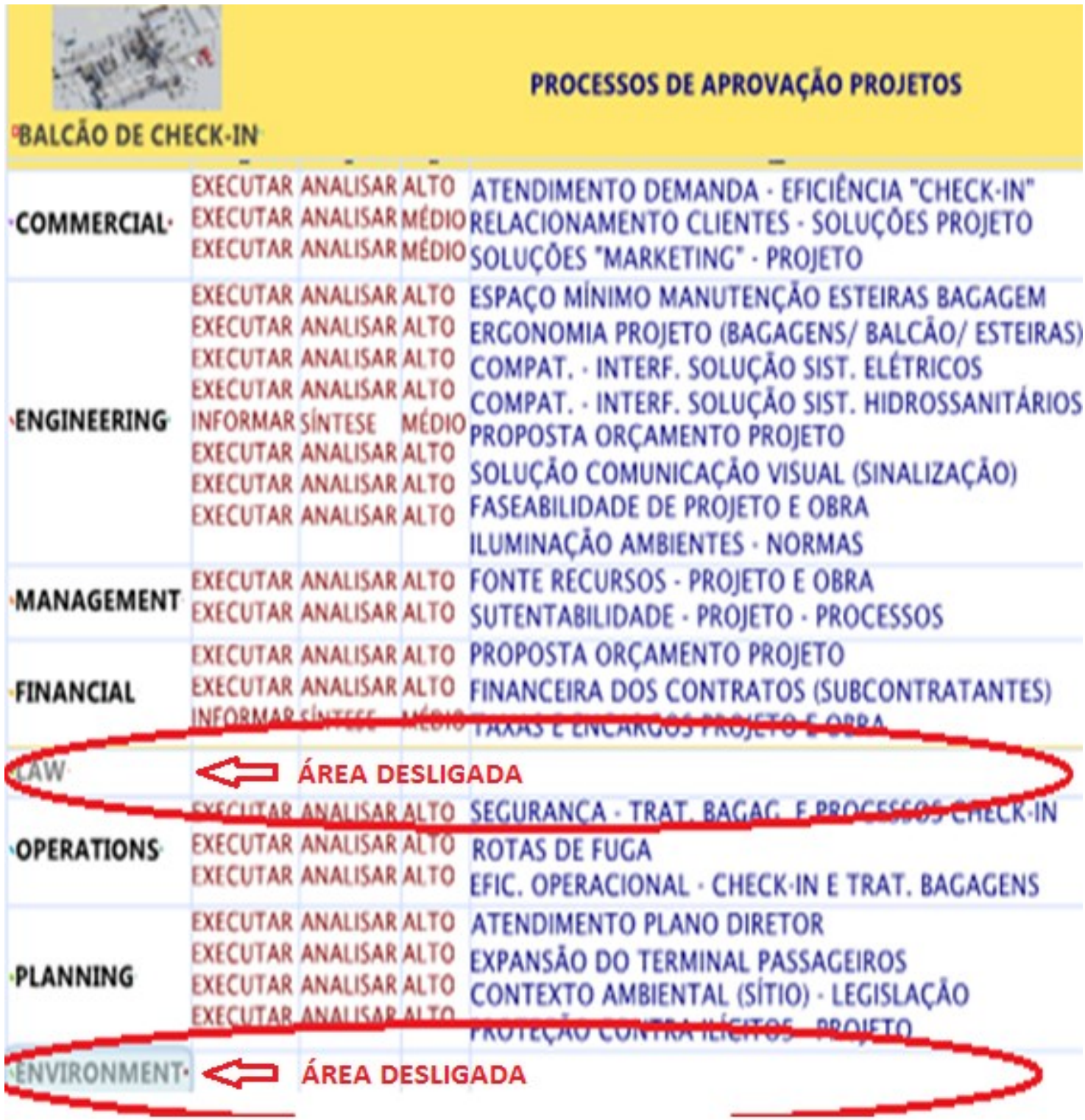

Figura 79 - Processos de Aprovação de Projetos para Módulo “Check-in” na Matriz Semântica 
As tarefas de aprovação de projeto para um módulo de "check-in" estão organizadas na matriz. Nesta estão registradas informações sobre as conexões entre duas dimensões: a das partes do aeroporto, que do ponto de vista de projeto, representa a ligação do módulo funcional em projeto com outros módulos funcionais; ou aquelas que influenciam de alguma forma no processo de projeto do primeiro.

Ao informar sobre as conexões entre os módulos funcionais, a matriz o faz por meio do estabelecimento das hierarquias FORTE, MEDIO e FRACO. Assim faz indicação de quais partes do aeroporto possuem uma ligação projetual de maior intensidade, média, ou ainda fraca com o módulo em questão.

A classificação FORTE, MÉDIO e FRACO classifica as partes e sistemas referentes ao modulo funcional escolhido, em diferentes graus de afinidade com as tarefas de projetos.

Isto permite ao projetista saber quais seriam as prioridades envolvidas no projeto de um aeroporto e suas partes (Figura 80).

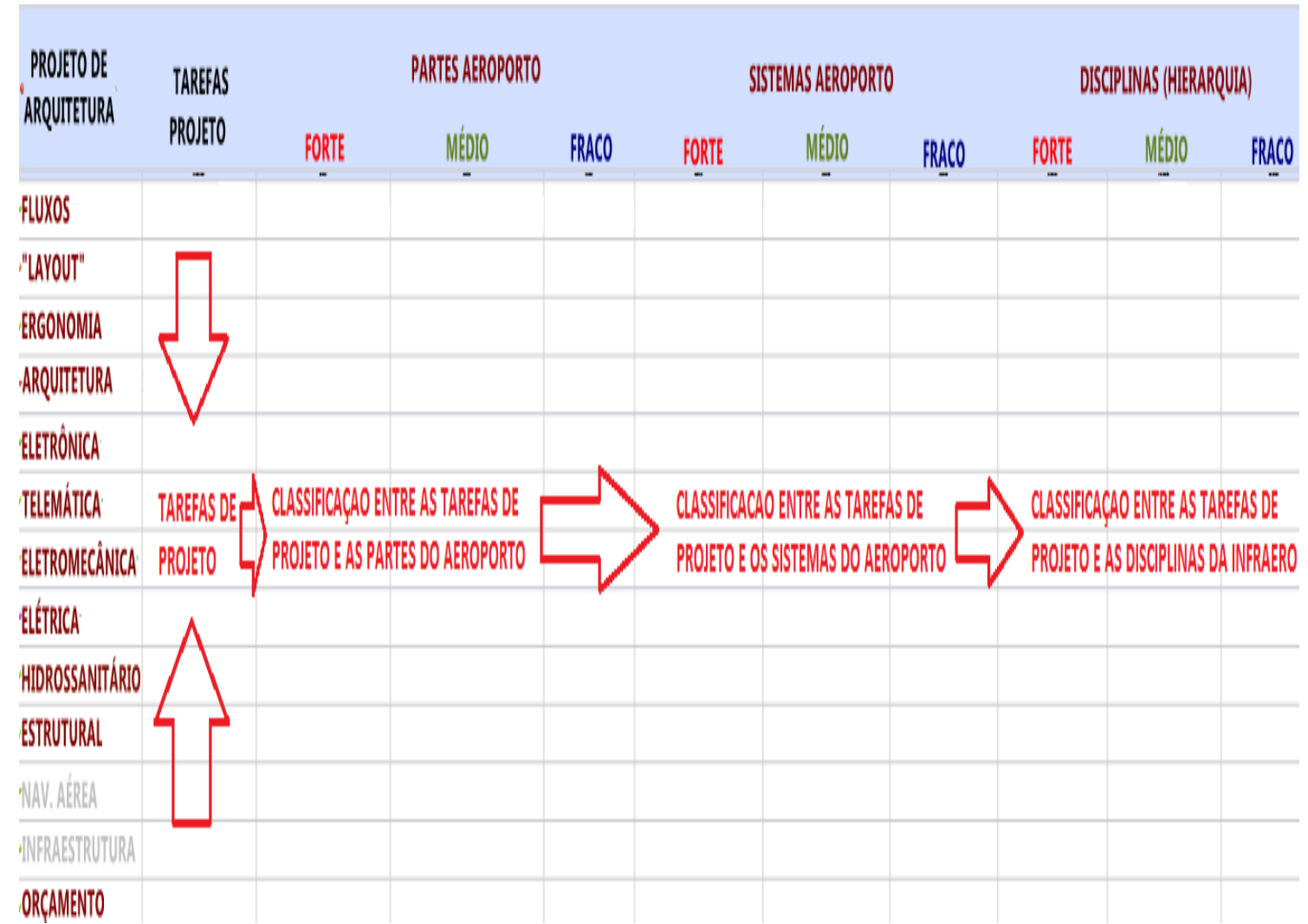

Figura 80- Classificação das Tarefas de Projeto para Módulo de "check-in" da INFRAERO na Matriz Semântica.

A união entre a classificação e a caracterização das tarefas de aprovação de projeto com as tarefas de projeto, permitem que se possa, no âmbito da estrutura organizacional da INFRAERO, estabelecer premissas no processo de projeto relativas as responsabilidades e escopos associados as partes e sistemas de um aeroporto. 
A Figura 81, na página seguinte, ilustra como as informações foram estruturadas para relacionar as tarefas de projeto com as partes e os sistemas do aeroporto, hierarquizando a afinidade existente entre os mesmos (forte, médio ou fraco). Considerando que as tarefas de projeto dependem das áreas responsáveis pelos processos de aprovação da INFRAERO, a matriz relaciona as mesmas e às respectivas disciplinas responsáveis pelos processos de projeto.

As áreas e disciplinas da INFRAERO interagem no processo de projeto. As primeiras são responsáveis pela formação de critérios e pelos processos de aprovação de projetos. As últimas são responsáveis pelas tarefas de projeto. Em relação aos sistemas do aeroporto, a Figura 81 , a seguir, indica que o processo de definição do "layout" conceitual do "check-in" apresenta graus diferentes de relacionamento expresso por afinidades em relação às atribuições/tarefas ou espaço físico que está sendo projetado:

1- Alto grau (FORTE) com o sistema de tratamento de bagagem;

2- Médio grau (MEDIO) com os sistemas e processos de aviação civil; e, ainda;

3- Baixo grau (FRACO) com o processamento de passageiros (embarque e desembarque).

A Figura 81 a seguir fornece informações sobre as tarefas de projeto de arquitetura, dividindo, para o módulo de "check-in", as mesmas em campos distintos:

1- Fluxo de interações dos processos de projeto;

2- Estudo de "layout" conceitual;

3- Interações de ergonomia;

4- Produção do projeto arquitetônico;

5- Interações dos sistemas Eletrônicos;

6- Interações dos sistemas Telemáticos;

7- Interações dos sistemas Eletromecânicos;

8- Interações dos sistemas Elétricos;

9- Interações dos sistemas Hidrossanitários;

10-Interações dos sistemas Estruturais;

11- Navegação Aérea (Desligada);

12- Infraestrutura (Desligada);

13- Interações do Orçamento. 


\begin{tabular}{|c|c|c|c|c|c|c|c|c|c|c|}
\hline \multirow{2}{*}{$\begin{array}{l}\text { PROJETO DE } \\
\text { ARQUTTETURA }\end{array}$} & \multirow{2}{*}{ TAREFAS PROJETO } & \multicolumn{3}{|c|}{ PARTES AEROPORTO (CONEXÓES) } & \multicolumn{3}{|c|}{ SISTEMAS AEROPORTO (RELACÓEES) } & \multicolumn{3}{|c|}{ DISCIPLINAS (HIERARQUIA) } \\
\hline & & FoRTE & $\$$ wimolo & mate & Foprie & W1000 & Feraco & ForT & wiblic & Patco \\
\hline \multirow{3}{*}{ FLUXOS } & 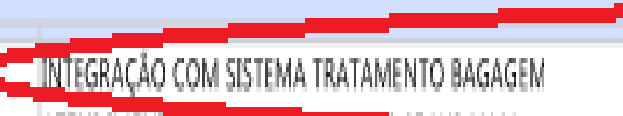 & ARES OPRBLOONALS ETRATMMGGGGEN & 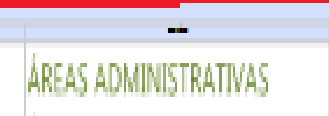 & 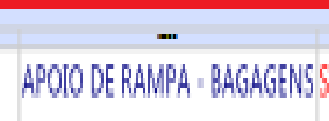 & 5ISTEMASTRATAMUNTO BGGGGW & 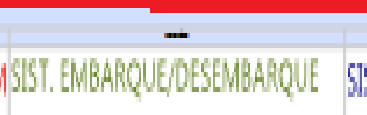 & SIST PROCES PASSAGEROS & EleTROMECANCA & AGQ ENGENHARAA & $A R Q O P B A C D E=$ \\
\hline & 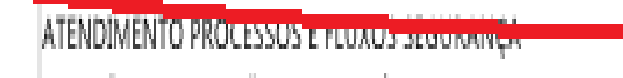 & Py & 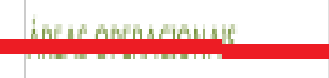 & 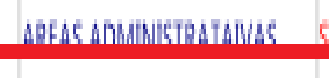 & 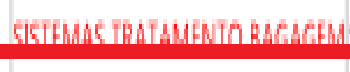 & 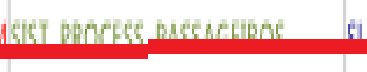 & 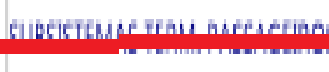 & 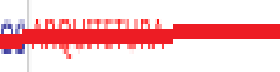 & 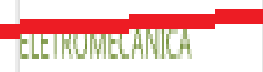 & 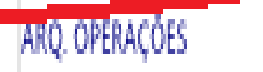 \\
\hline & 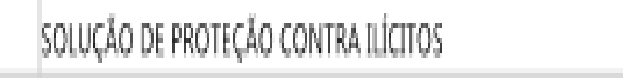 & ARESG OFRPACONAS & MCKOFICE & SAGUAO 'LQDO TERRA' & SISTMMSTRATAMENTO BGGGGM & 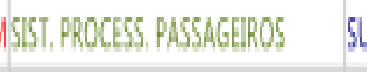 & 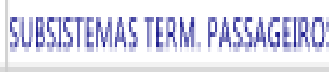 & OS ARQUNTEURA & Elitromichnea & ARQ OPRACQDis \\
\hline \multirow{4}{*}{ "LAYOUT" } & 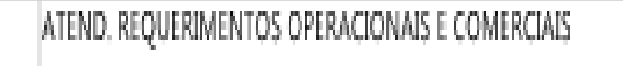 & 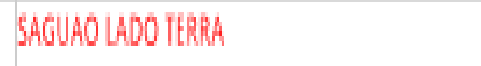 & 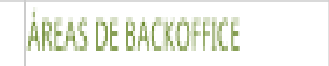 & 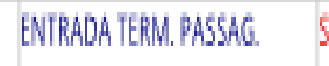 & 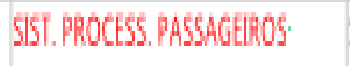 & 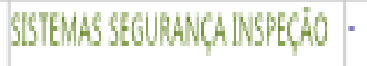 & & OFERTDWS COMMERTA & WARQ ENGENHARA & MRQ PLANEMMENTO \\
\hline & 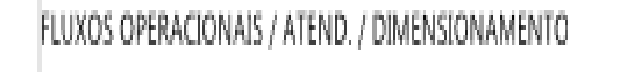 & 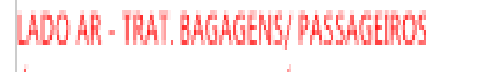 & SHGUAOL LADO KR & APOOD DE RAMPA & 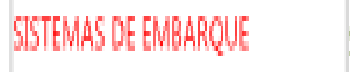 & 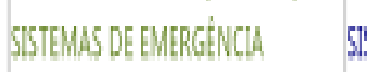 & SISTTMLS DE EMERGENGA & OPEATIONS COMMERCA & WLARQ ENGENHARAA & ARQP PANEAMEENO \\
\hline & 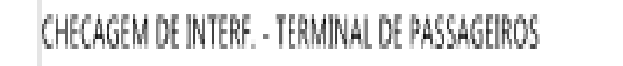 & 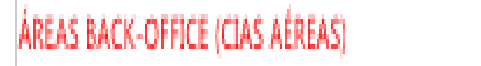 & ENTRADA AR: PQRTIOQ "G" & AREAS ADMNISTATIUASS S & SISFMHSOPERACOONAS & 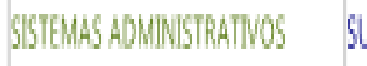 & SUBSISEMAS FEM PASSAGERO & O51- ENGNEEAMG ARCH. & ARQ OPERER.PLANEE. & WFARESTIUUNARA \\
\hline & 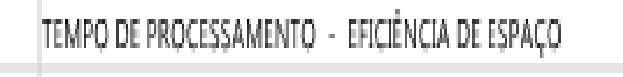 & AREAS OFERACOONAS TRAT. BaGGGENS & ARrLG De EEGURNGA & APDOD DERMPA & SIST.TRRTMANTO BGGGGNS & SISTEMAS OPERACONAS & SISTTMS DESEGURANCA & 1. DPERATONS & ARQ WNGENHARA & ARQ PANEMMENONO \\
\hline ERGONOMIA & 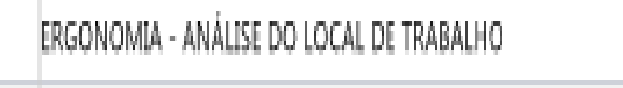 & 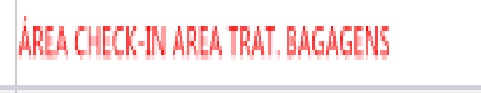 & ARESES DE BACOCOFLE & SGGUROLL LADO TERBA & 1. WORWING PROCESES & & ISTTMLS ADMNITIRATVOS & ARQ ENGENHARTA & elliromichnea & \\
\hline \multirow{4}{*}{ ARQQUTTETURA } & 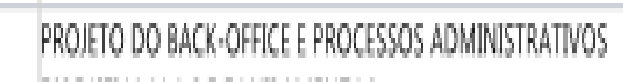 & ARESS OPERACOONAS E ADMNISTRATIVS & \multirow{4}{*}{ 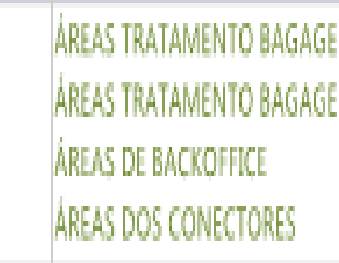 } & \multirow{2}{*}{ FESAGUAO' 'ADO TERRA' } & SIST. ADWNISTRATVOSG CHECWNN & 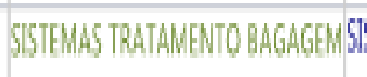 & MSTTEMS DES SEVURANCA & ARQ OPRARCDES & ARQ OPRRAd & \\
\hline & 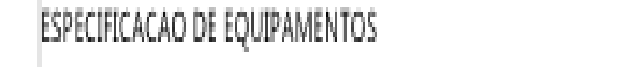 & AREST TATAMENTO GAGAGENS & & & 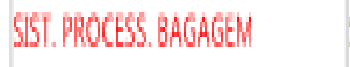 & 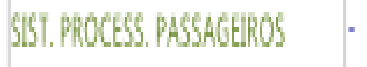 & & ARQ OPERACOCS & ARQ EQ ENGENHABRA & ARQ PILANEMMENTO \\
\hline & \multicolumn{2}{|c|}{ 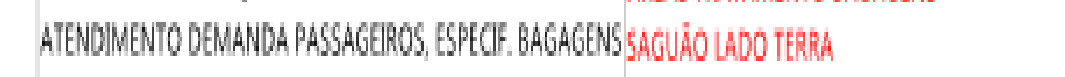 } & & 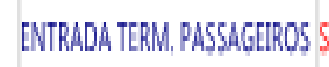 & 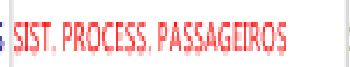 & SIST, TRATAMENOQ BGGGENS SI: & SITTMES DE SEGURANA & ARQ OPERACOES & ARQ EGGENHARIA & ARQ PLANEAMENTO \\
\hline & 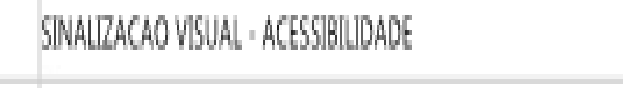 & 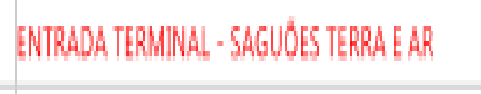 & & 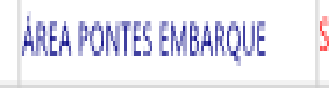 & 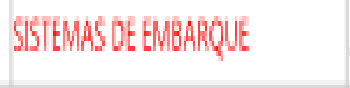 & 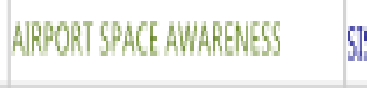 & glTTEMS DE EMERGENGA & ARQQ ENGEHHAllA & ARQ OPERQCOSOS & ARQ PLAEEAMENTO \\
\hline ELETRÔNICA' & 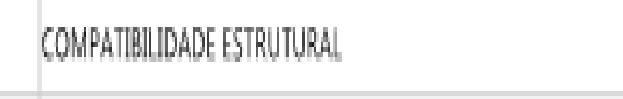 & 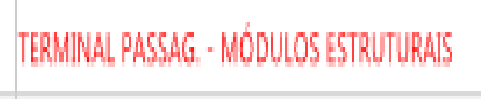 & 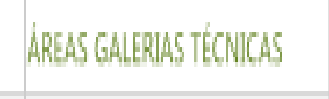 & ARELS DESHAFSS & SISTMUS ETRUTURALIS & 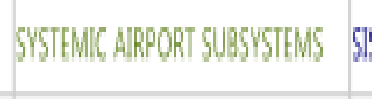 & 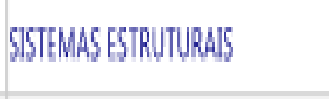 & ENG ETRUUTRRAL & ARQ ENGGEHARAA & WFRAESTRUTURA \\
\hline 'TELEMÁTICA' & COMPATILLDADEE ESTUUTURML & 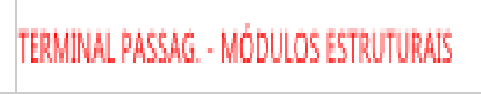 & 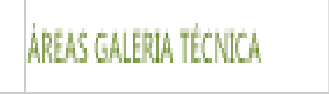 & AREA DE SHAFTS & SISTIMAS EsTRUTURAS & SYSTEMC MRPORT SUESYYTIEMS : & & eng EsTRUTHRal. & ARQ ENGEHARPAA & WFRAETRUUURA \\
\hline & 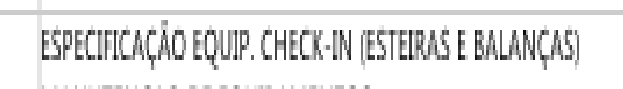 & BaCOFFICI: & SAGUAOLDOT FERA & 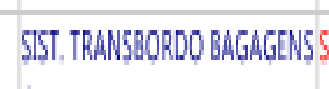 & SISTT, TRATAMNANTO BGGGGNS & 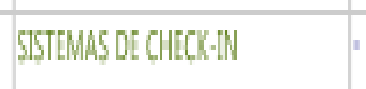 & & ELERPMUCinICA & ENG ElLTR. ELETRONONCA & ARQ ENGENHARAL \\
\hline ELETROMECANICA & 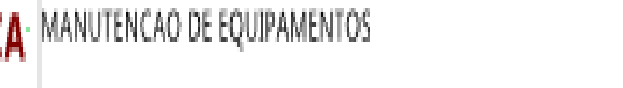 & BHS & SHGUUOLOLDOTERRA & AREAS DE BAOOOFFEC S & SIST: TRATAMENTO BGGGGENS & SISTTWAS DE CHECK.JN & & Alerpow:ChNiCA & ARQ ENGENHARAA & ENG ELTR, EleTONOCA \\
\hline \multirow{3}{*}{ ELETRICA } & 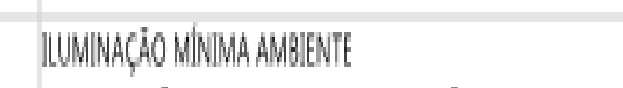 & SHGULOLOLDOTERRA & ABES DE BACKOFFCE & & SISTTMAS DECHECWN & MISTEMAS SHGUAO "ADOTTERRA" - & & ENG ELTRCA & ARQQ EMGEEHAREA & ENG ELTPRONCA \\
\hline & 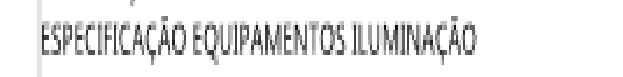 & 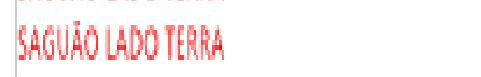 & 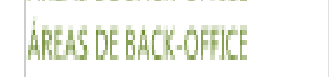 & & 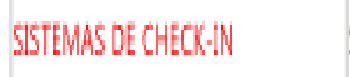 & 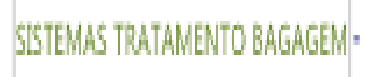 & & eng ellitich & ARQ NGGNHBRA & engelefrowica \\
\hline & 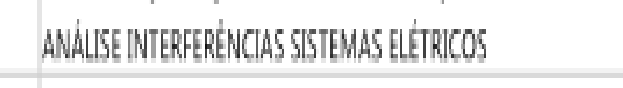 & TERMINGL PASSGGGROS- SISTIENCO & TODO TERM DE PASSAGGEROS & TODOOTEMM, DE PASSAGERORS S & SISTMAS CHECHN-ISTTMCO & 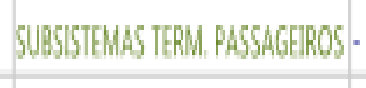 & & ENG EIITRCA & AHQ EMGENHARIA & ENG EleTronica \\
\hline \multicolumn{2}{|c|}{ 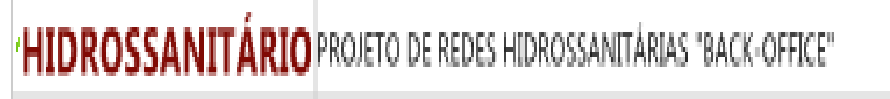 } & 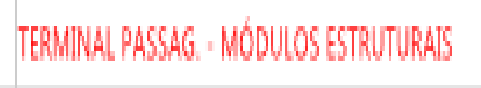 & ARESG GALPRA TENTCA & AREAS DESHAFS & SISTMABS ETRUUURALS & 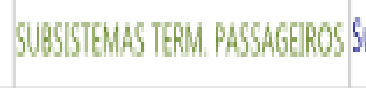 & Suttopicits & 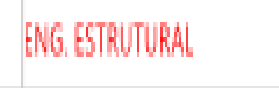 & ARQQENGEHARAA & WNARESTRUUNRA \\
\hline ESTRUTURAL & 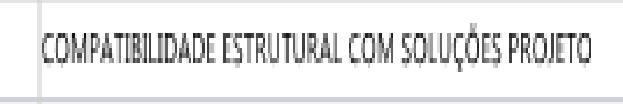 & 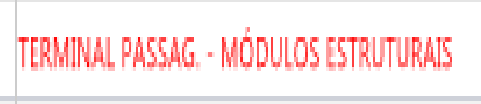 & 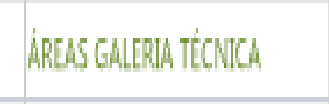 & ARRLASDEFHAFS & SISTMAS ETRUTURAS & 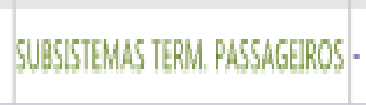 & & ENG ETRUTURRAL & ARQ ENGENHARIA & WFPAGSTUUUYRA \\
\hline \multicolumn{11}{|l|}{ NAV, AEREA } \\
\hline \multicolumn{11}{|c|}{ INERAESTRUTURA ÁREA DESLIGADA } \\
\hline ORCAMENTO & 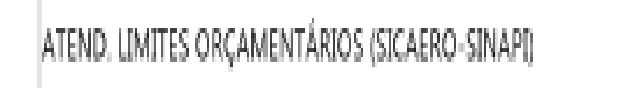 & 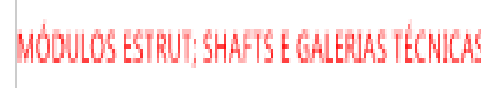 & ASSivtonic 16 & Subtopicit? & SISTMASESTRUTURAS & 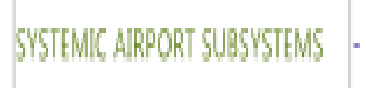 & & ANG ETRUTURAR & ARQ EMGENHARAG & WFRAESTUUTURA \\
\hline
\end{tabular}

Figura 81- Tela de acesso as Tarefas de Projeto para Módulo de "check-in" da INFRAERO na Matriz Semântica. 
A primeira tarefa de projeto representada na Figura 81 na página anterior, integração com o sistema de tratamento de bagagem e monitoramento dos processos e fluxos de segurança no "check-in". Esta tarefa de projeto está relacionada com a disciplina de eletromecânica pois é o profissional de eletromecânica que especifica e projeta as esteiras de bagagem, raio $\mathrm{X}$, detector de metais, etc. Encontra-se representada na linha intitulada fluxos na Figura 82 apresentada a seguir.

\section{PROJETO DE ARQUITETURA \\ TAREFAS PROJETO \\ FLUXOS \\ INTEGRAÇÃO COM SISTEMA TRATAMENTO BAGAGEM}

Figura 82- Tarefas de Projeto para um Módulo de "check-in" na Matriz Semântica.

As partes do aeroporto descritas na matriz correspondem a estrutura lógica apresentada na tela inicial, como por exemplo, a de um Saguão no "Lado Terra", composta de áreas de propaganda, inspeção de bagagens, lavatórios, Companhias aéreas, "check-in" e áreas de alimentação (Figura 83).

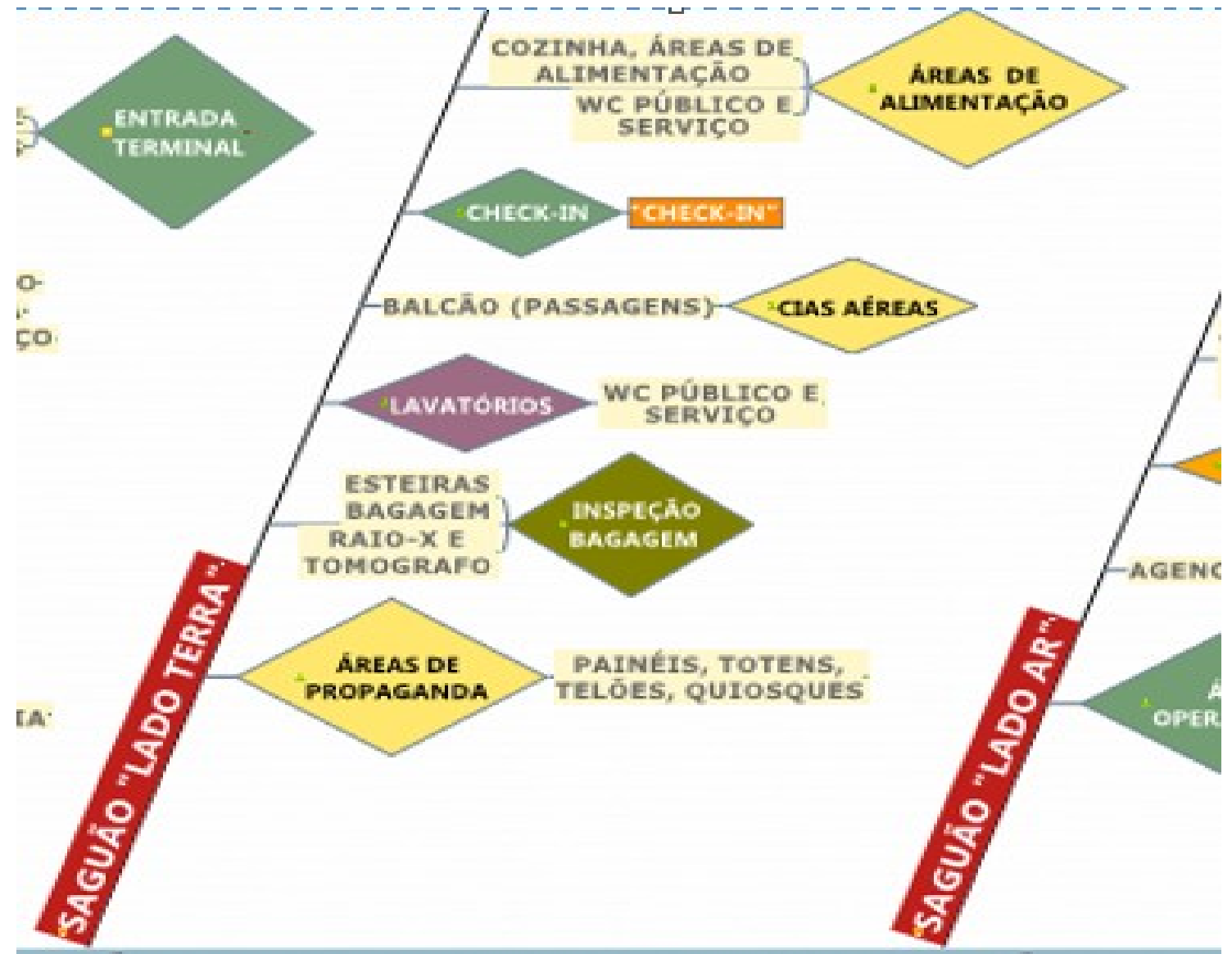

Figura 83- Exemplo de Partes para Saguão "Lado Terra" de um aeroporto na Matriz Semântica.

Já os sistemas do aeroporto são empregados pela INFRAERO, para o gerenciamento operacional, predial e de segurança no terminal de passageiros, pistas e pátio de aeronaves. 
A figura 84 a seguir ilustra a relação entre as partes do aeroporto na matriz. Mostra alto nível de afinidade (FORTE) com os as áreas operacionais e de tratamento de bagagem, médio nível (MEDIO) com as áreas administrativas e baixo nível de afinidade (FRACO) com as áreas de equipamentos de rampa.

\section{PARTES AEROPORTO (CONEXÕES)}

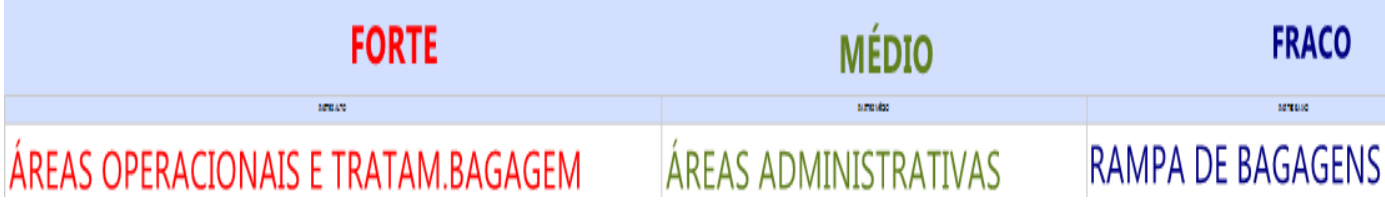

Figura 84- Partes do Aeroporto para um Módulo de "check-in" na Matriz Semântica.

Em relação aos sistemas do aeroporto, a tarefa de projeto descrita acima possui alto nível de afinidade (FORTE) com os sistemas de tratamento de bagagem, médio nível (MEDIO) com os sistemas de embarque e desembarque e baixo nível (FRACO) com o sistema de processamento de passageiros, conforme mostra a Figura 85 abaixo.

\section{SISTEMAS AEROPORTO (RELAÇÕES)}

\section{FORTE \\ MÉDIO \\ FRACO \\ SISTEMAS TRATAMENTO BAGAGEM SIST. EMBARQUE/DESEMBARQUE SIST. PROCESS. PASSAGEIROS}

Figura 85- Sistemas do Aeroporto para um Modulo de "check-in" na Matriz Semântica.

Finalmente, a Figura 86 abaixo ilustra a hierarquia entre as disciplinas. Esta tarefa tem alto grau de relacionamento (FORTE) com a especialidade de eletromecânica, grau médio (MEDIO) com a especialidade de arquitetura da área de operações e baixo grau de relacionamento (FRACO) com a especialidade de arquitetura da área de engenharia, uma vez que o projetista de eletromecânica deve cumprir requisitos estabelecidos pelas áreas de operações e comercial, sendo portanto as tarefas de projeto dirigidas a aprovação destas áreas.

\section{DISCIPLINAS (HIERARQUIA)}

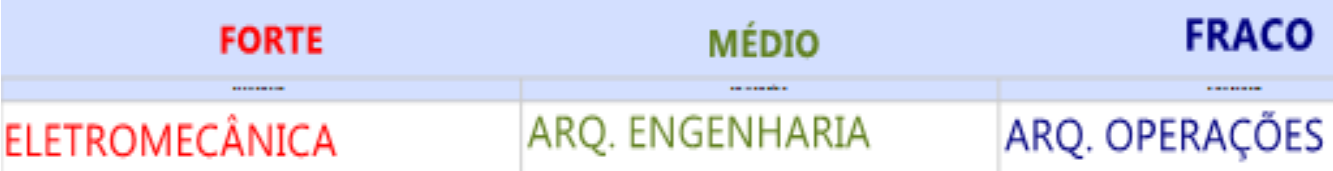

Figura 86- Disciplinas da INFRAERO para um Módulo de “check-in” na Matriz Semântica. 


\subsection{3- INTERAÇÕES SISTÊMICAS (3)}

A Figura 87 abaixo ilustra consulta às interações sistêmicas de projeto entre o modulo funcional de "check-in" e as áreas adjacentes ao mesmo, dentro do aeroporto.

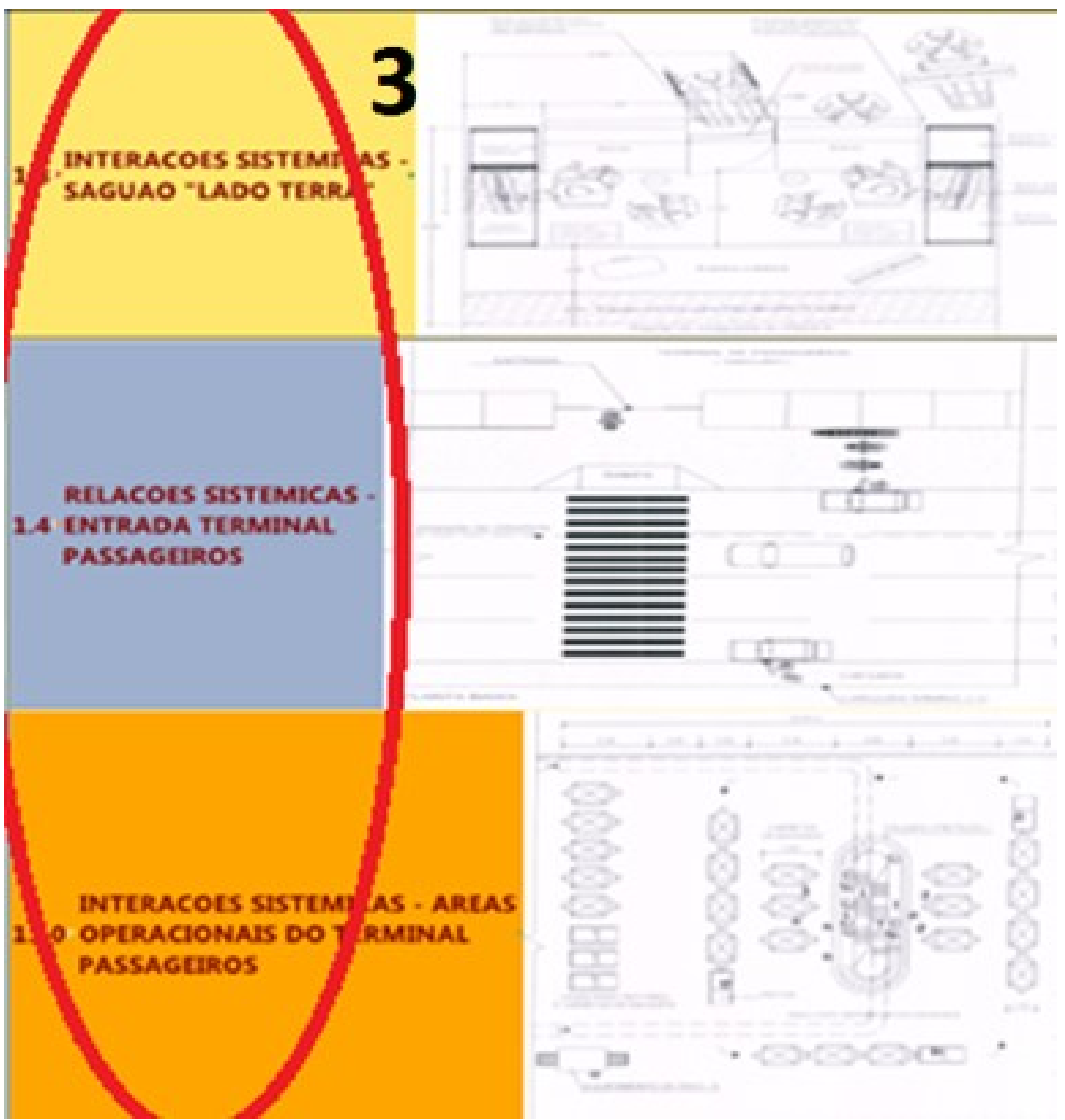

Figura 87- Interações de Projeto para um Módulo de "check-in" na Matriz Semântica.

No centro da tela representada pela Figura 70 (Tela de acesso ao detalhamento do "check-in" na matriz semântica) existem campos para informar sobre as interações sistêmicas de projeto, em relação ao módulo funcional do "check-in". A título de exemplo, pode-se observar a elipse vermelha na Figura acima que destaca as interações do "check-in" com o saguão "lado terra" do terminal de passageiros. Ao clicar naquele campo, a matriz abre uma nova tela listando os sistemas e os agentes intervenientes (Companhias Aéreas, Tratamento de Bagagens, Inspeção de Bagagens, Inspeção de Passageiros e Fluxos de Passageiros) no âmbito de projeto, conforme mostra a Figura 88 a seguir. 


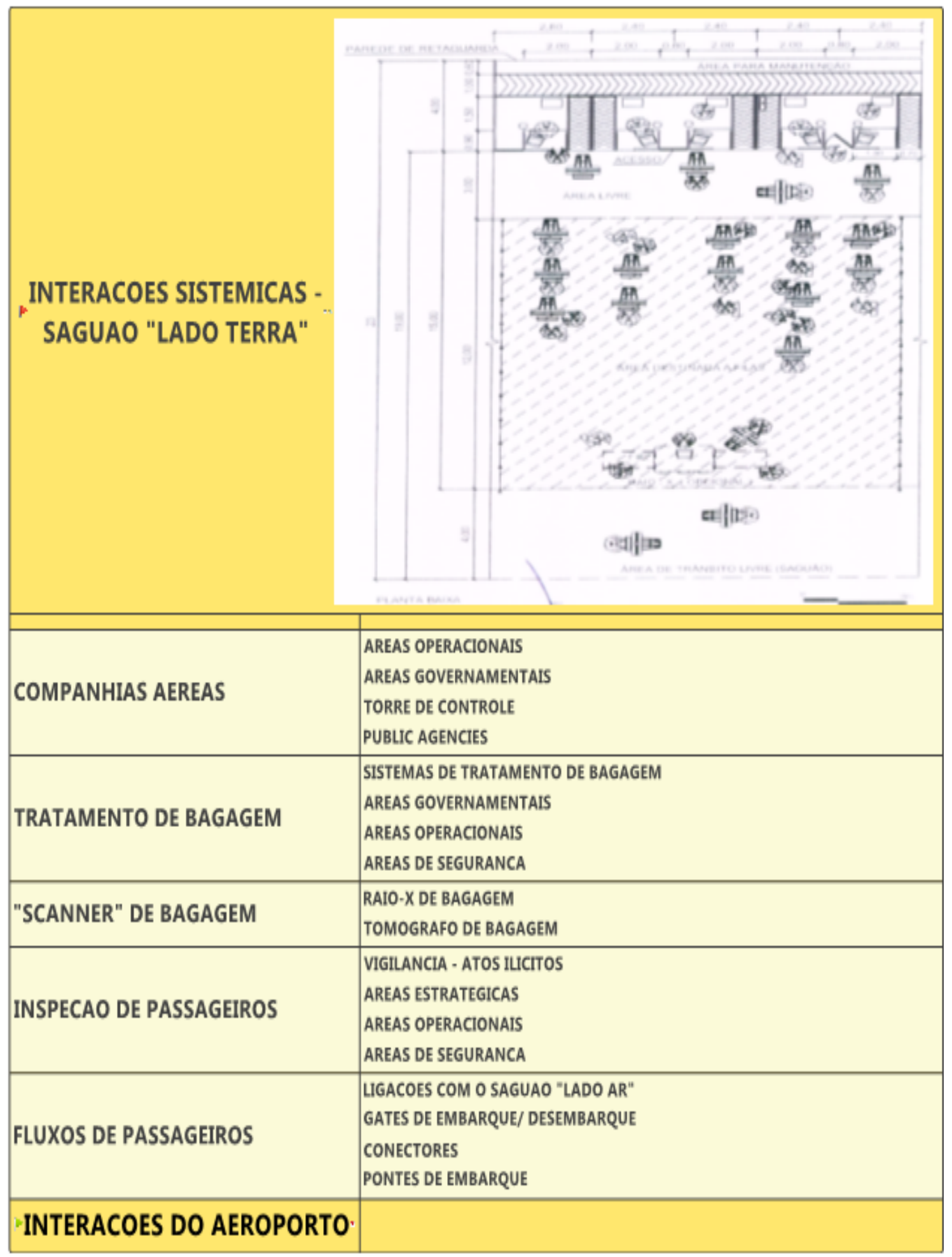

Figura 88- Interações Sistêmicas para Saguão "lado terra” de aeroporto na Matriz Semântica.

A Figura 88 acima ilustra consulta à tela de interações de projeto, referente ao saguão "lado terra". Apresenta as interações principais, na coluna da esquerda (companhias aéreas, tratamento de bagagem, inspeção de bagagem, inspeção de passageiros e fluxos de passageiros). Na coluna da direita, descreve os elementos principais de cada interação. Por exemplo, para o tratamento de bagagem, estão envolvidos os sistemas de tratamento de bagagem, as áreas governamentais, as áreas operacionais e de segurança de aviação civil. 


\subsection{4- INTERAÇÕES DAS ENGENHARIAS (4)}

A Figura 89 a seguir ilustra uma consulta às áreas de engenharias.

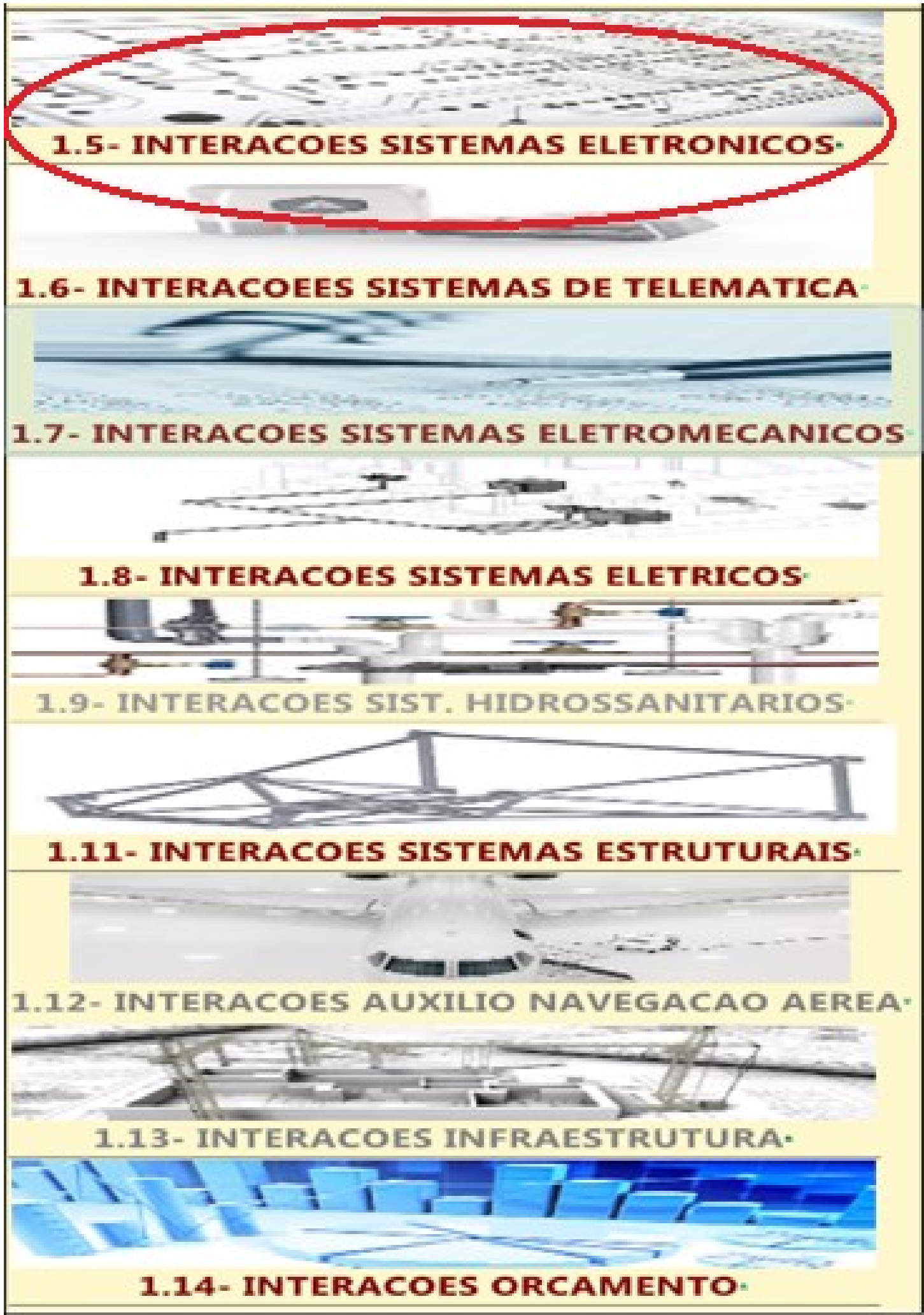

Figura 89- Tela de acesso às Dimensões das Engenharias na Matriz Semântica.

A Figura 89 acima representa a tela de acesso às interações de engenharias, complementares às tarefas de aprovação e projetos de arquitetura. 
$\mathrm{Na}$ presente tese, a matriz foi desenvolvida sob a ótica do profissional de arquitetura, tendo sido configurados os campos relativos aos processos de aprovação e projetos de arquitetura.

No entanto, tais atividades de projeto não ocorrem de forma isolada, mas de forma interativa com os profissionais das demais especialidades (áreas de engenharias).

A Figura 89, na página anterior, representa as especialidades de projeto concorrentes para o projeto do "check-in".

A ideia de se incluir na matriz informações sobre as tarefas de projeto e de aprovação, não apenas do ponto de vista de um arquiteto, mas ainda da ótica dos profissionais responsáveis pelas especialidades ou disciplinas complementares norteou o desenvolvimento da versão digital, de forma a criar um "software" de apoio e consulta ao processo de projeto.

A matriz construída nesta pesquisa propõe-se a demonstrar a estrutura lógica para uma ferramenta de consulta as regras de abstração para o projeto de um aeroporto no âmbito da INFRAERO.

Para isto escolhemos o modulo de "check-in" para detalhar a interação entre o arquiteto e os engenheiros, nas tarefas de aprovação e projeto. Selecionamos a disciplina de Sistemas Eletrônicos para explicitar as relações citadas acima.

Do ponto de vista acadêmico, a representação metodológica da matriz é suficiente.

Porém, em uma eventual adoção dos sistemas BIM pela INFRAERO, os demais módulos funcionais da matriz poderão ser configurados da mesma forma como demonstrado com o modulo de "check-in", para que possa atingir seu potencial pleno de utilização.

A título de ilustração, a Figura 90 a seguir mostra a tela de acesso contendo informações de aprovação de projetos para os Sistemas Eletrônicos.

Pode-se observar que as especialidades de Sistemas Hidrossanitários, de Auxílios Visuais à Navegação Aérea e de Infraestrutura apresentam escritas na cor cinza. Isso significa que não participam do processo de projeto de um "check-in" diretamente.

Apesar de poderem apresentar conexões de projeto com o mesmo, o escopo do projeto do "check-in" não necessita da participação dos profissionais dessas especialidades. 


\begin{tabular}{|c|c|c|c|c|c|c|c|c|c|}
\hline \multirow{2}{*}{$\begin{array}{l}\text { "CHECK-NN". } \\
\text { INTERACOES DOS } \\
\text { SIST:ELTRONICOS } \\
\text { APROVACAO DE } \\
\text { PROJETOS }\end{array}$} & \multirow{2}{*}{\multicolumn{3}{|c|}{ TAREFAS APROVACAO }} & \multicolumn{3}{|c|}{ PARTES DO AEROPORTO (CONEXOES) } & \multicolumn{3}{|c|}{ SISTEMAS DO AEROPORTO (RELACOES) } \\
\hline & & & & porite & Medio & FraCO & FORTE & MEDO & FRACO \\
\hline 든든은 & Xevitar & AMALISBAS: & MTO SEGURANCA & 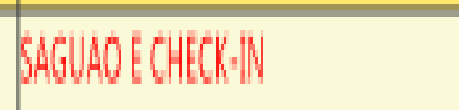 & 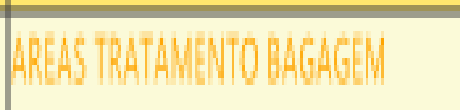 & 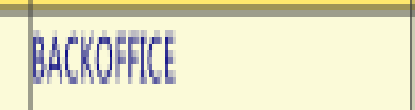 & JISA (SEGURANCA) & 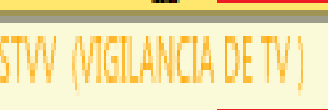 & ICA (CONTROLEDEACESO) \\
\hline ENGENHARIA & 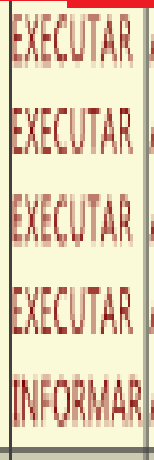 & 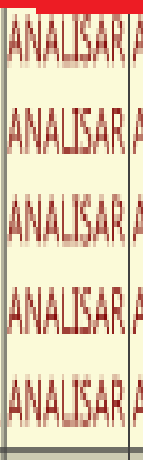 & 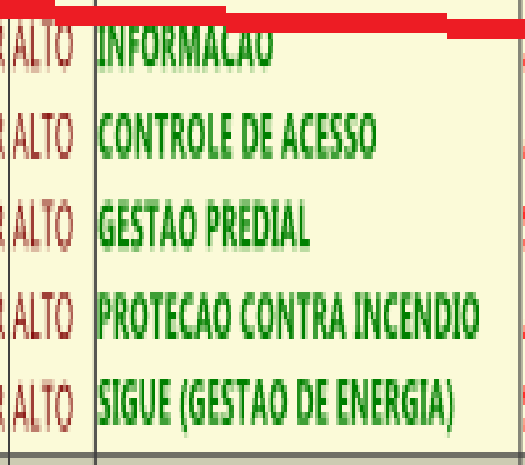 & 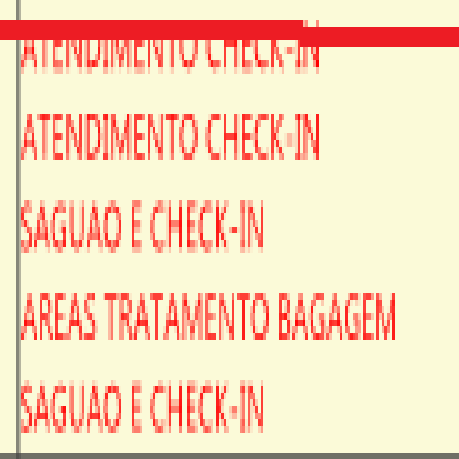 & 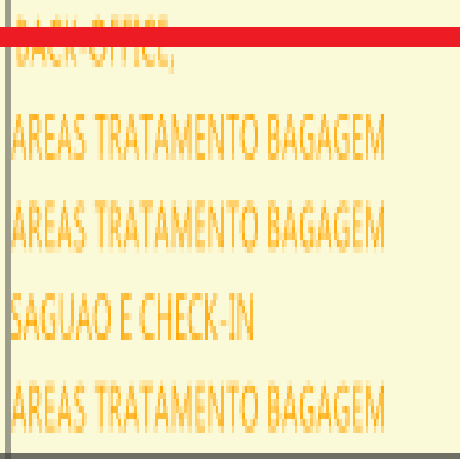 & 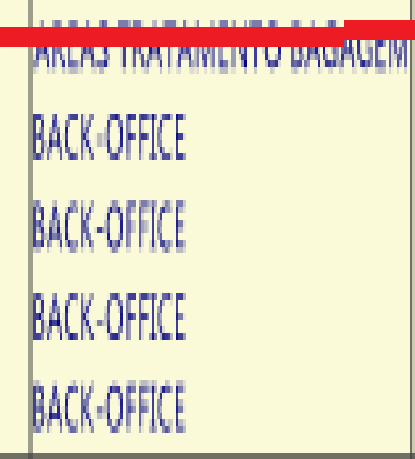 & 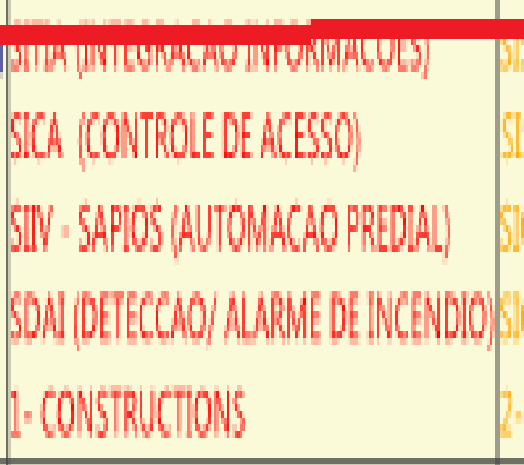 & 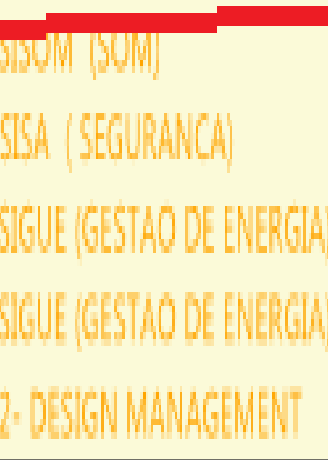 & 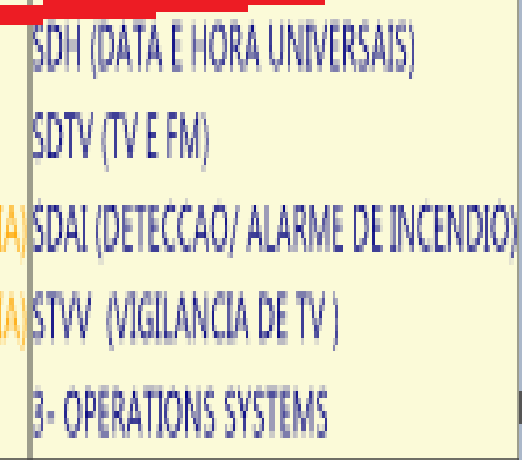 \\
\hline COMERCAL: & & & & & & & & & \\
\hline GESTAO & & & & & & & & & \\
\hline FNANCERA & yecutar & ANALISAR: & MEDIO ANALISE ORCAMENTARA & ATENDMENTOCHEEKIN & 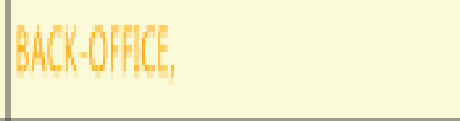 & AREAS TRATAMENTO BAGAGEM & SITTEAS NFPAERO & MTEMASHEDKN & MISTEMASTRATAMENTO BAGAGEM \\
\hline UURDiCA & 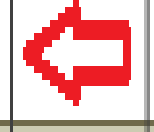 & ÁREA DE: & ESLGADA & & & & & & \\
\hline OPERACOES & Exeutien & ANLLSG & HTO SEGURANCA - SIST ELETRONIOOS & SDNTFLACAO/MPECAOCHEQR & 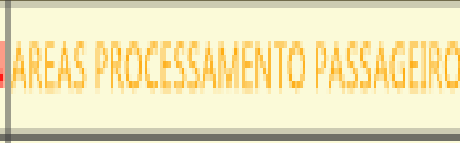 & AREAS TRTAMANENOO BAGGGEM & SEA (SEGUANCA) & TW NGGANGA DETVI & 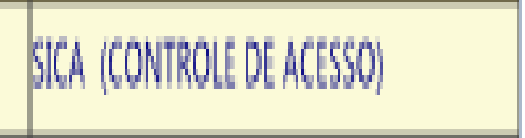 \\
\hline PLANEJAMENTO & & & & & & & & & \\
\hline & $\nabla$ & AREADE: & FllGaA & & & & & & \\
\hline
\end{tabular}

O CAMPO REFERENTE AS TAREFAS DE APROVACÃO DE PROJETOS. CLASSIFCA AS ACOES (EXECUTAR E INFORMAR) E SOBRE COMO DEVE SER EXECUTADA A TAREFA (ANALISE, PROJETO

NOS CAMPOS ACIMA (PARTES E SISTEMAS DO AEROPORTO) RELACIONAM-SE AS AREAS QUE TEM RELACAO COM O PROJETO DO MODULO FUNCIONAL DE "CHECK-IN" BEM COMO OS OU SINTESE) E AINDA SOBRE O IMPACTO (ALTO, MEDIO OU BAIXO). 
Os processos de aprovação de projeto são diferenciados pela caracterização das ações (execução, informação ou n/a), pela forma (projeto, síntese ou análise) e pelo impacto (alto, médio ou baixo) (Figura 88 da página anterior). Cada área da INFRAERO está representada e associada diretamente aos processos de aprovação de projetos correspondentes à sua esfera de atuação. Na Figura 88 na página anterior, observa-se que as áreas com letras em vermelho encontram-se ativas, ou seja, participam do processo de projeto do módulo funcional. As áreas que aparecem com letras cinzas estão desligadas, porque não estão diretamente relacionadas aos sistemas de "checkin", mas podem ser ativadas se, por alguma razão, essa associação for criada. A primeira tarefa de aprovação, descrita na Figura 91 a seguir (análise da segurança), pertence à área de engenharia e está configurada segundo diferentes níveis de afinidade com as partes e os sistemas do aeroporto.

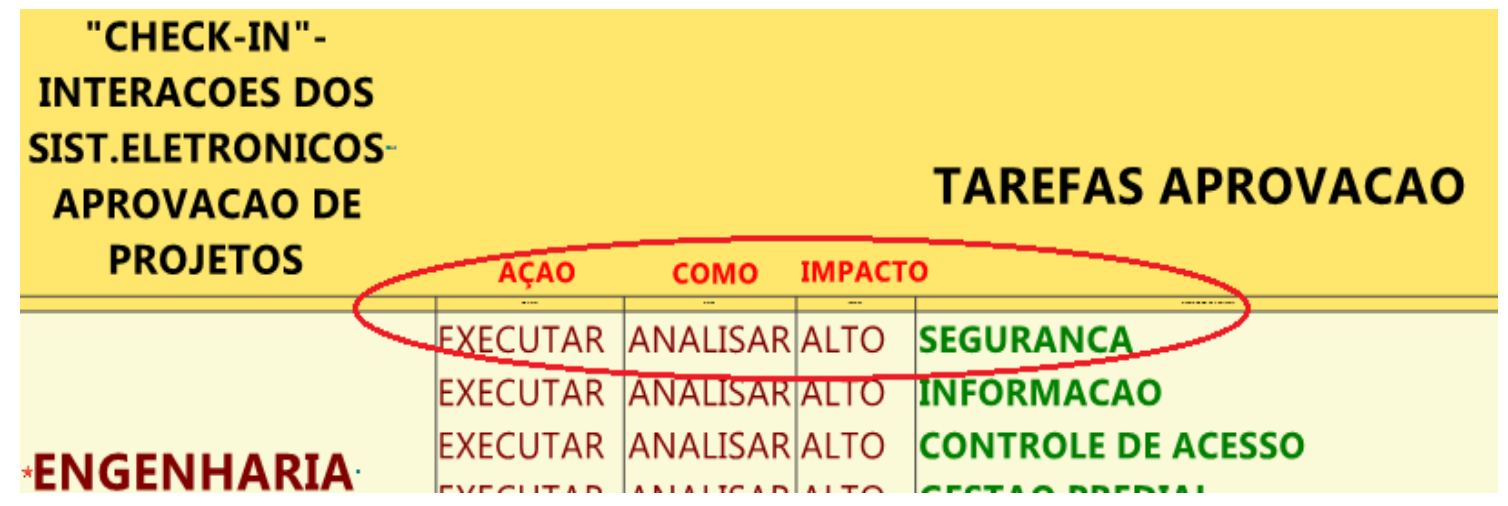

Figura 91- Processos de Aprovação de Projetos para Módulo "check-in” na Matriz Semântica.

Em relação às partes do aeroporto, por exemplo, possui alto nível de afinidade com as partes do "check-in", no saguão "lado terra"; médio nível de afinidade com as partes ou áreas de tratamento de bagagem e baixo nível de afinidade com as áreas de "BackOffice" (apoio ao "check-in"), conforme mostra a Figura 92, abaixo.

\section{PARTES DO AEROPORTO (CONEXOES)}

\begin{tabular}{c|c|c}
\multicolumn{2}{c}{ FORTE } & \multicolumn{1}{c}{ MEDIO } \\
\hline
\end{tabular}

Figura 92- Partes do Aeroporto para Módulo de “check-in" na Matriz Semântica.

Em relação aos sistemas do aeroporto, a tarefa de aprovação possui alto nível de afinidade com o SISA - Sistema de Segurança da INFRAERO, médio com o STVV (Vigilância de TV) e baixo com o SICA de controle de acesso (Figura 93 a seguir). 


\section{SISTEMAS DO AEROPORTO (RELACOES)}

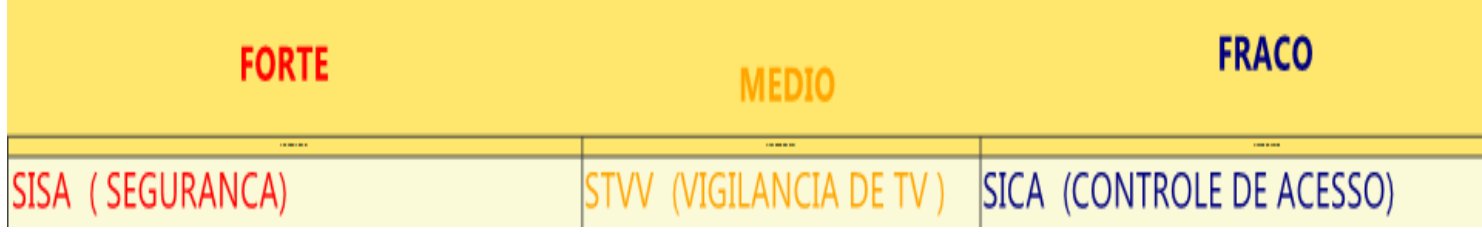

Figura 93- Sistemas do Aeroporto para Módulo de "check-in" na Matriz Semântica.

As afinidades estabelecidas neste exemplo, pela matriz semântica se devem a relação projetual que o modulo de "check-in" estabelece com os sistemas eletrônicos.

Para a primeira tarefa de aprovação, ilustrada nesse exemplo, de Segurança Predial, o SISA - Sistema de Segurança da INFRAERO apresenta a maior afinidade com o modulo de "check-in".

O sistema STVV - de vigilância de TV, por monitores e câmeras espalhados pelo terminal, apresenta médio grau de afinidade com o "check-in".

O sistema SICA - de controle de acesso apresenta baixa afinidade, uma vez que o controle de acesso não ocorre no processo de "check-in", mas o cartão de embarque que permite este processo é fornecido no momento em que o passageiro apresenta-se no balcão.

Da mesma forma como foram apresentadas as interações entre um profissional de sistemas eletrônicos e um projetista de arquitetura para as tarefas de aprovação de projeto, a seguir estão descritas as interações em relação as tarefas de projeto (Figura 94 a seguir).

Como a disciplina de arquitetura é complementar as demais disciplinas das áreas de engenharia, como, por exemplo, a de eletrônica, o arquiteto precisa interagir com os engenheiros para troca de informação e tomada de decisão.

Esta interação ocorre tanto em relação ao cumprimento de requisitos comuns as especialidades para aprovação de projetos, como em relação a especificidades das soluções para os sistemas empregados, como:

1- Elétricos;

2- Telemáticos;

3- Hidrossanitários;

4- Eletromecânicos, entre outros, variando em ralação a cada modulo funcional. 


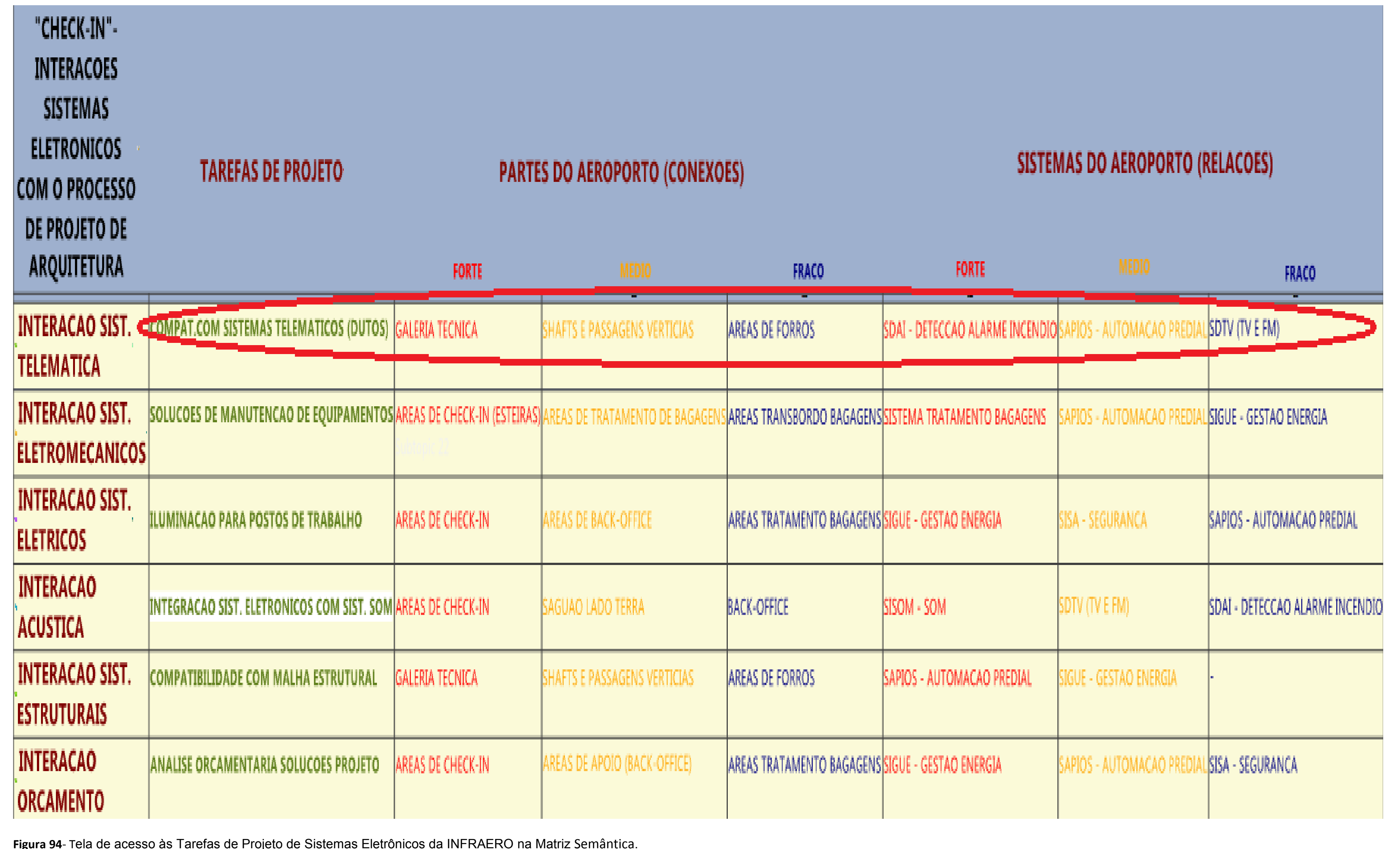


A primeira tarefa de projeto representada na Figura 94 da página anterior (compatibilização com os sistemas de telemática e dutos), está ilustrado na linha intitulada interação dos sistemas de telemática na Figura 95 abaixo.

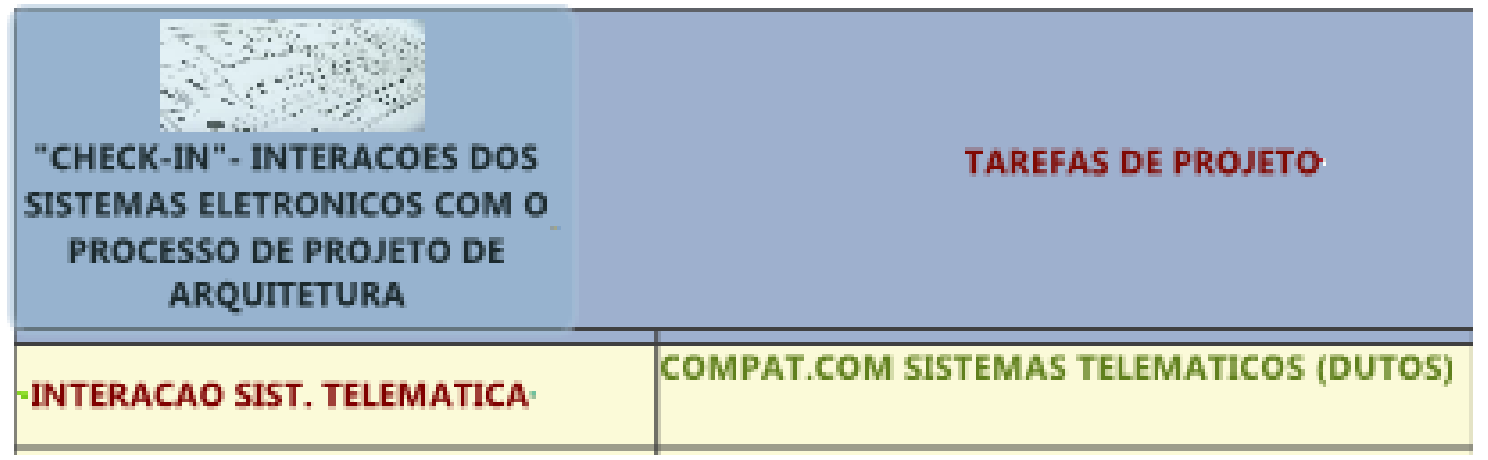

Figura 95- Tarefas de Projeto (Engenharias) para Módulo de "check-in" na Matriz Semântica.

A Figura 96 a seguir ilustra diferentes níveis de afinidade com as partes do aeroporto. A compatibilização dos sistemas eletrônicos do módulo de "check-in" com os sistemas de telemática apresenta alto grau de conexão com a galeria técnica, médio grau de conexão com os "shafts" e passagens verticais e baixa conectividade com as áreas de forros do aeroporto (Figura 96 abaixo).

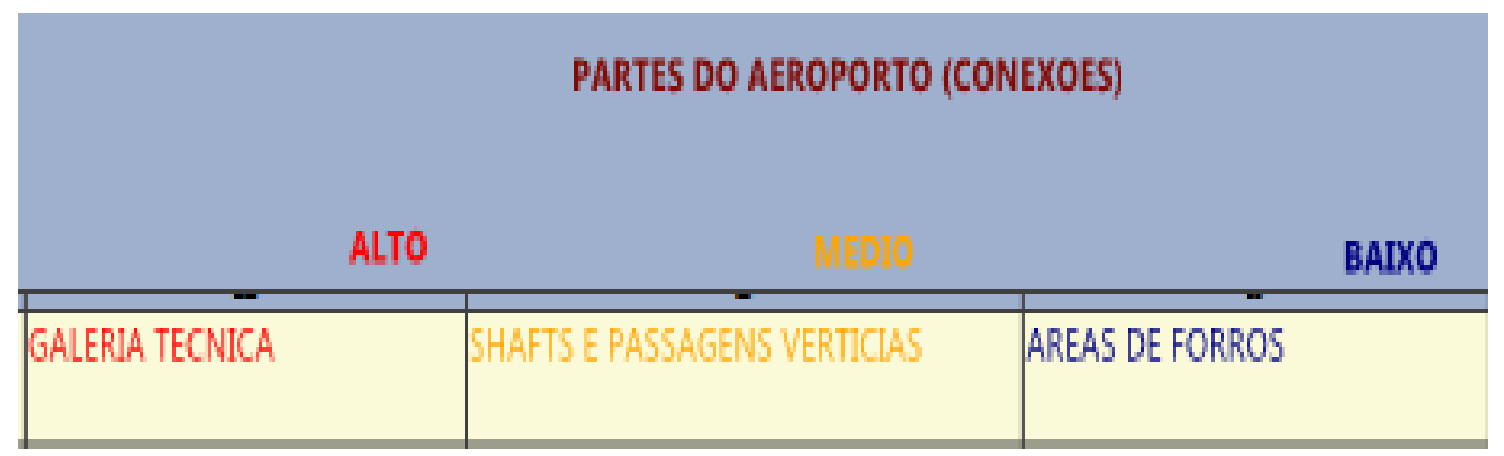

Figura 96- Partes do Aeroporto (Engenharias) para Módulo de "check-in" na Matriz Semântica.

Em relação aos sistemas do aeroporto, a tarefa de projeto descrita acima possui alto nível de afinidade com o SDAI, sistema de detecção e alarme de incêndio da INFRAERO, médio nível de afinidade com o SAPIOS, sistema de automação predial da INFRAERO e baixo nível de afinidade com o SDTV, sistema de TV e FM da INFRAERO, conforme ilustra a Figura 97 abaixo.

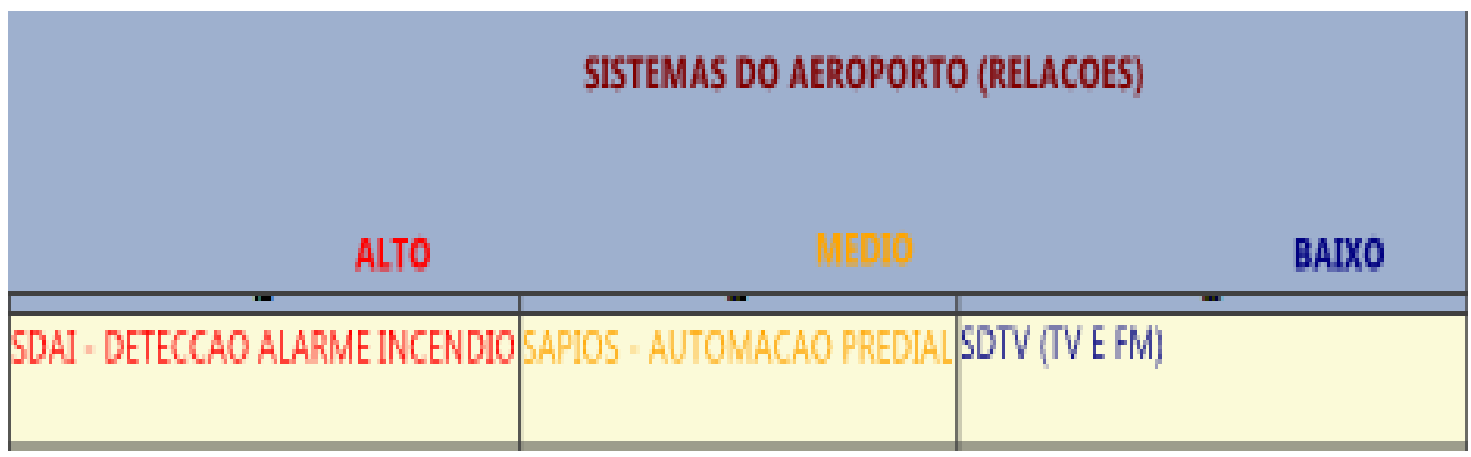

Figura 97- Sistemas do Aeroporto (Engenharias) para Módulo "check-in" na Matriz Semântica. 
A consulta às demais tarefas de projeto descritas na Figura 90 na página anterior (soluções de manutenção de equipamentos, iluminação para postos de trabalho, integração dos sistemas eletrônicos com os sistemas de som, compatibilidade com a malha estrutural e análise orçamentária das soluções de projeto) são semelhantes aos ilustrados acima e podem ser relacionadas com a aprovação de projetos. Os recursos da matriz acima descrita ilustram a capacidade dessa ferramenta computacional em tecer uma rede de hierarquia e relacionamentos entre os agentes intervenientes no processo de projeto da INFRAERO. As informações relativas aos sistemas e às partes do aeroporto fornecem ao projetista uma visão sistêmica sobre a interligação entre os projetos das diferentes especialidades confrontadas com a de arquitetura.

Permite, ainda, obter uma noção mais precisa da extensão e do impacto no projeto que a especificação de determinados sistemas acarreta, bem como quais as partes do aeroporto são afetadas pelos equipamentos e sistemas presentes no projeto. Conforme o usuário pode selecionar simultaneamente mais de um campo de informação da matriz, isto possibilita a compreensão de determinados módulos funcionais no processo de análise. Isto ocorre, por exemplo, nas ilustrações de cada tela da matriz acima apresentados. Ao selecionar um processo de aprovação e comparar o mesmo com a tarefa de projeto correspondente, temos uma visão precisa sobre o escopo e os critérios que deverão ser adotados para aceite da solução técnica a ser desenvolvida.

No detalhamento do "check-in", observa-se que a matriz permite obter informação sobre as interações que uma tarefa de arquitetura causa em relação às tarefas das especialidades complementares. A caracterização das interfaces entre o projeto do "check-in", com os sistemas eletrônicos que fazem parte dos processos de identificação, segurança, tratamento de bagagens, etc., permite que o arquiteto possa considerar as variáveis decorrentes de tais sistemas em seu processo de projeto. A matriz vem suprir a carência da INFRAERO em representar seu processo de projeto no ambiente digital. Somado a isso, encontra-se a inexperiência da empresa na utilização de tecnologias associadas ao processo de projeto, como por exemplo, o uso dos sistemas BIM.

A compatibilização entre os processos de aprovação e a estrutura organizacional da INFRAERO (áreas e especialidades de projeto) permite que a matriz semântica integre as informações do ambiente de projeto da empresa, em uma ferramenta de consulta e de suporte à tomada de decisão. Outra importante vantagem da matriz semântica refere-se à limitação existente dos sistemas BIM em representar diferentes níveis de detalhe dos componentes paramétricos. Por meio da utilização da matriz podese obter informações sobre regras de projeto referentes às partes e módulos funcionais de um aeroporto. Permite ainda relacionar os sistemas e profissionais envolvidos na elaboração dos projetos. 


\section{2- RESULTADOS DA ELABORAÇÃO DE NOVOS COMPONENTES NOS SISTEMAS BIM}

Três componentes, Pórtico de segurança, Carrinho de bagagens e "Raio-x" de bagagem embarcada, tiveram suas geometrias importadas. Neste sentido foi utilizada a ferramenta "pick" para definir os planos dos elementos geométricos com propriedades paramétricas. A decisão de criar as referidas geometrias no Revit $^{\circledR}$ ou importá-las não interfere na utilização dos componentes nos sistemas BIM e SIG. Portanto, se a modelagem envolve formas muito complexas, como a dos três componentes acima citados, vale a pena realizar a importação da referida geometria. A geometria importada está disponível em "sites" da internet como o http://www.revitcity.com/ downloads.php?action=view\&object id=12974 ou "https://www.bimstore.co.uk/".

O Revit ${ }^{\circledR}$ permite modelar formas livres por meio do ambiente de massa. No entanto, existem limitações relativas ao resultado dessa modelagem, cuja geometria não está associada ainda a campos de informação paramétrica. Para que estes modelos de massa possam ser de fato objetos BIM precisam ser transformados para assumir características de um dos componentes nativos, chamados de sistemas de famílias. $O$ ideal seria que pudéssemos criar uma família totalmente personalizada, ao invés de dividir o componente modelado em um conjunto de famílias disponíveis. Isto ocorre porque o Revit ${ }^{\circledR}$ apenas consegue transformar geometria não paramétrica em geometria paramétrica de alguma família nativa do programa, como pilares, vigas, paredes, cortinas de vidro, pisos, coberturas e/ ou lajes. Ainda assim, o ambiente de modelagem do $\operatorname{Revit}^{\circledR}$ não apresenta vantagens em relação a modeladores externos como Rhinoceros $^{\circledR}$ ou Form- $Z^{\circledR}$. Além do fato de que ambas as geometrias, tanto as modeladas no ambiente de massas do $\operatorname{Revit}^{\circledR}$ quanto as importadas, devem ser transformadas para se tornarem paramétricas, é razoável que a escolha sobre a forma de modelagem seja livre, pois uma metodologia não apresenta ganhos significativos sobre a outra.

A modelagem tridimensional foi realizada por meio de extrusões e de operações "booleanas" para obtenção das formas desejadas. A criação de novos parâmetros permitiu personalizar os componentes BIM de forma a expressar informações relevantes a cada um deles e, ao mesmo tempo, comuns à INFRAERO ou ao mercado aeroportuário. A inserção de campos para as planilhas SINAPI e SICAERO permite a realização do orçamento usualmente utilizado na empresa. Iniciamos a criação dos componentes utilizando um arquivo "DWG", que não deve ser inserido diretamente na família, mas permite transferir suas linhas para o Revit ${ }^{\circledR}$. 
PLANTA CEDIDA PELA INFRAERO PARA SERVIR DE "GUIA" DE REFERENCIA PARA A

MODELAGEM NO SISTEMA BIM - REVIT

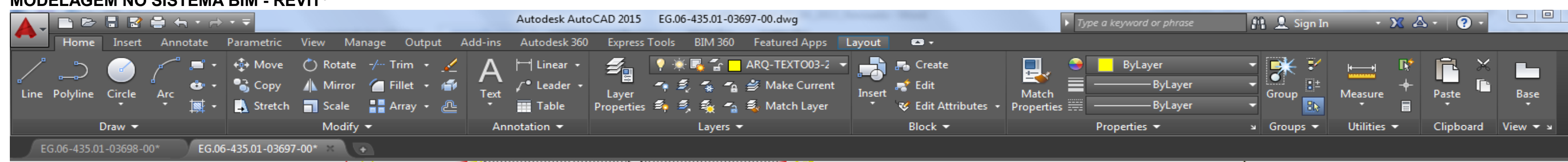

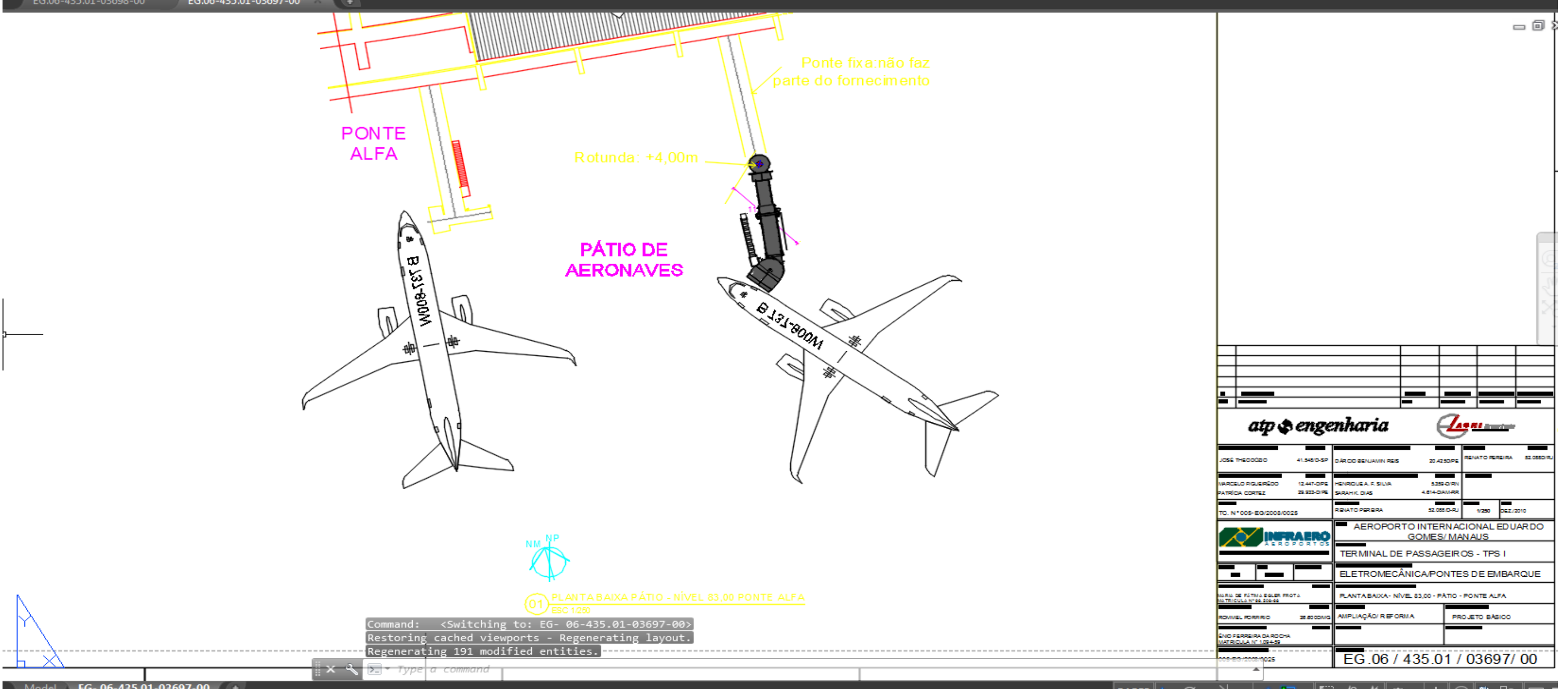

Figura 98- Planta utilizada como referência de modelagem originalmente no AutoCAD ${ }^{\circledR}$ - AutoDesk. Fonte: INFRAERO.

A FIGURA 98 ACIMA ILUSTRA A PLANTA ORIGINAL CEDIDA PELA INFRAERO PARA EFEITO DE MODELAGEM DE NOVA FAMÍLIA DE COMPONENTE NO SISTEMA BIM - REVIT ${ }^{\circledR}$. NO AUTOCAD FOI

A PLANTA FOI MODIFICADA DE FORMA A APAGAR OS ELEMENTOS DESNECESSARIOS, COMO A REALIZADA SIMPLIFICAÇÃO DE INFORMAÇÕES NÃO RELEVANTES PARA A MODELAGEM. 


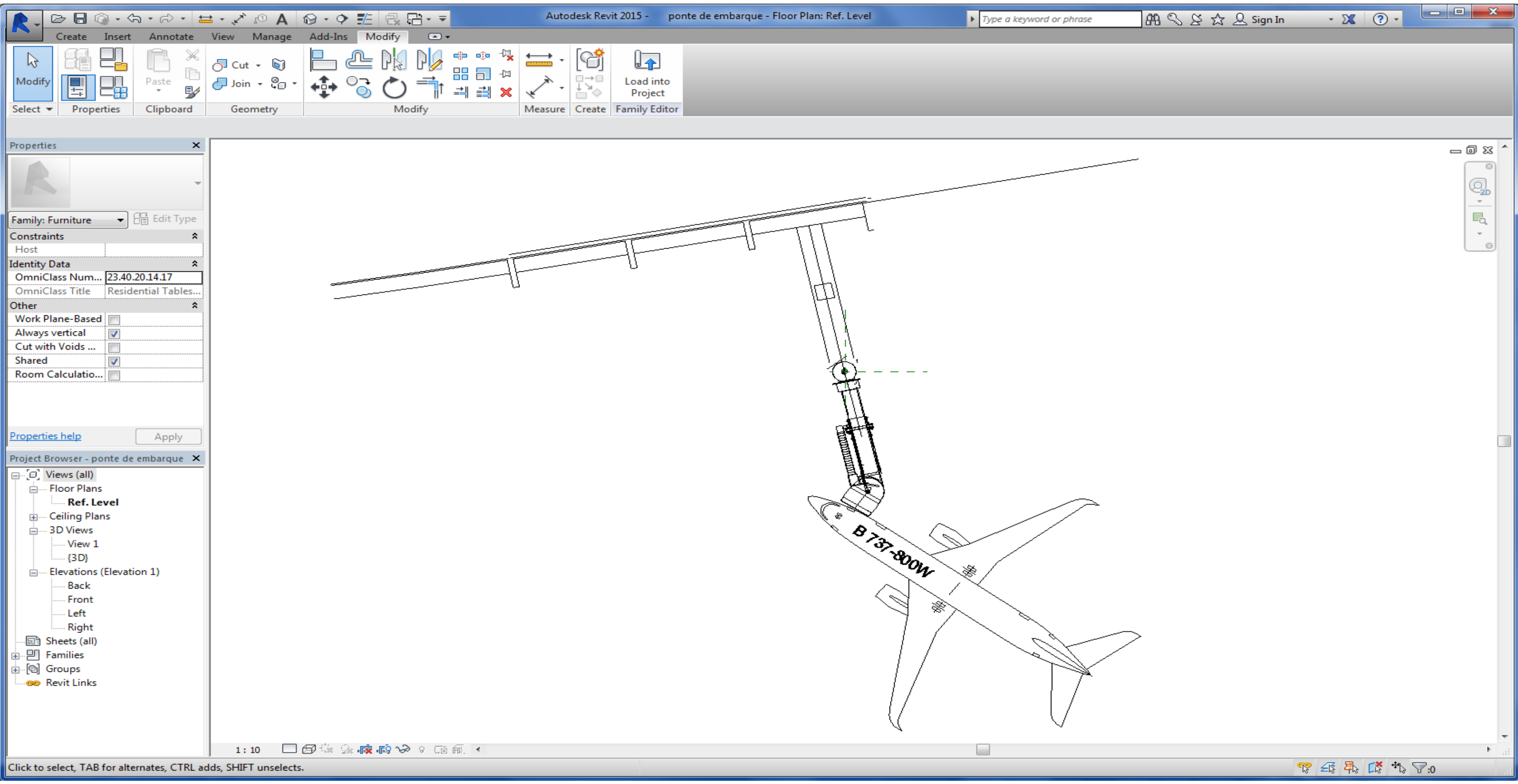

Figura 99- Plantas de referência para modelagem proveniente do AutoCAD ${ }^{\circledast}$ e inserida no sistema BIM - Revit'. Fonte: INFRAERO.

NA FIGURA 99 ACIMA, PODE-SE OBSERVAR A PLANTA SIMPLIFICADA DE REFERÊNCIA INSERIDA NO REVIT ${ }^{\circledR}$ PARA MODELAGEM DE UMA NOVA FAMÍLIA DE PONTE DE EMBARQUE.
UMA VEZ DEFINIDOS OS PLANOS DE TRABALHO (VER FIGURA 107 NA PÁGINA 161), FORAM INSERIDAS PLANTAS DE REFERENCIA, QUE FUNCIONAM COMO MARCAS D'ÁGUA, DE FORMA A FACILITAR E GUIAR A MODELAGEM. 
Isto foi necessário porque os componentes modelados deveriam seguir as especificações técnicas colhidas junto a INFRAERO, cuja especificação já estava concluída e cuja documentação era bidimensional. $\mathrm{Na}$ criação de componentes inteiramente originais, que não apresentem especificação técnica previa esta etapa não se torna necessária.

Foi realizada a modelagem geométrica de cinco dos componentes (esteira de bagagem desembarcada, esteira de bagagem geral, balcão de check-in, porta giratória e pórtico de segurança) por meio de ferramentas para criação de formas - extrusões, combinações, varreduras ou revoluções. Um outro caminho que foi utilizado corresponde a importação de massa de um componente modelado tridimensionalmente em um modelador de superfícies, como o Sketchup ${ }^{\circledR}$, sem no entanto possuir os recursos paramétricos que os componentes BIM apresentam. O Revit ${ }^{\circledR}$ possui um ambiente de massa, que permite a importação e posterior transformação das superfícies em componentes paramétricos nativos do programa, como paredes, paredes cortina e de vidros, pilares, vigas, pisos e coberturas. Dessa forma, podemos "transformar" um componente puramente tridimensional em um componente BIM. A modelagem tridimensional foi realizada por meio de extrusões e de operações booleanas para a obtenção das formas desejadas.

As impressões obtidas nesta pesquisa indicam que a utilização do ambiente de "massa" no Revit ${ }^{\circledR}$ e a imposição de se transformar superfícies não paramétricas em família necessariamente nativas do "software" indicam uma forte limitação da ferramenta para criação de componentes paramétricos de famílias inteiramente originais (novas) no aplicativo. Apesar de reconhecer que a grande maioria dos componentes podem ser representados através da combinação de diferentes famílias nativas, como por exemplo na utilização de cortinas de vidro e de paredes para o fechamento de uma ponte de embarque, inexiste a possibilidade, no $\operatorname{Revit}^{\circledR}$, de criação de uma superfície paramétrica totalmente personalizada, em termos da natureza das famílias utilizadas para compor 0 componente, como, figurativamente, poder-se-ia imaginar uma família paramétrica totalmente nova, como uma chapa divisória de fechamento lateral de uma ponte de embarque.

No Revit ${ }^{\circledR}$, a criação de um novo componente paramétrico (para montar novas famílias de objetos) ocorre como uma "colagem" ou união de diferentes famílias préexistentes assumindo as formas desejadas de uma geometria ainda não paramétrica.

A seguir são apresentados os componentes modelados para esta pesquisa para utilização desde o estudo conceitual, projeto básico até o executivo, conforme as Figuras 100 a 105. 


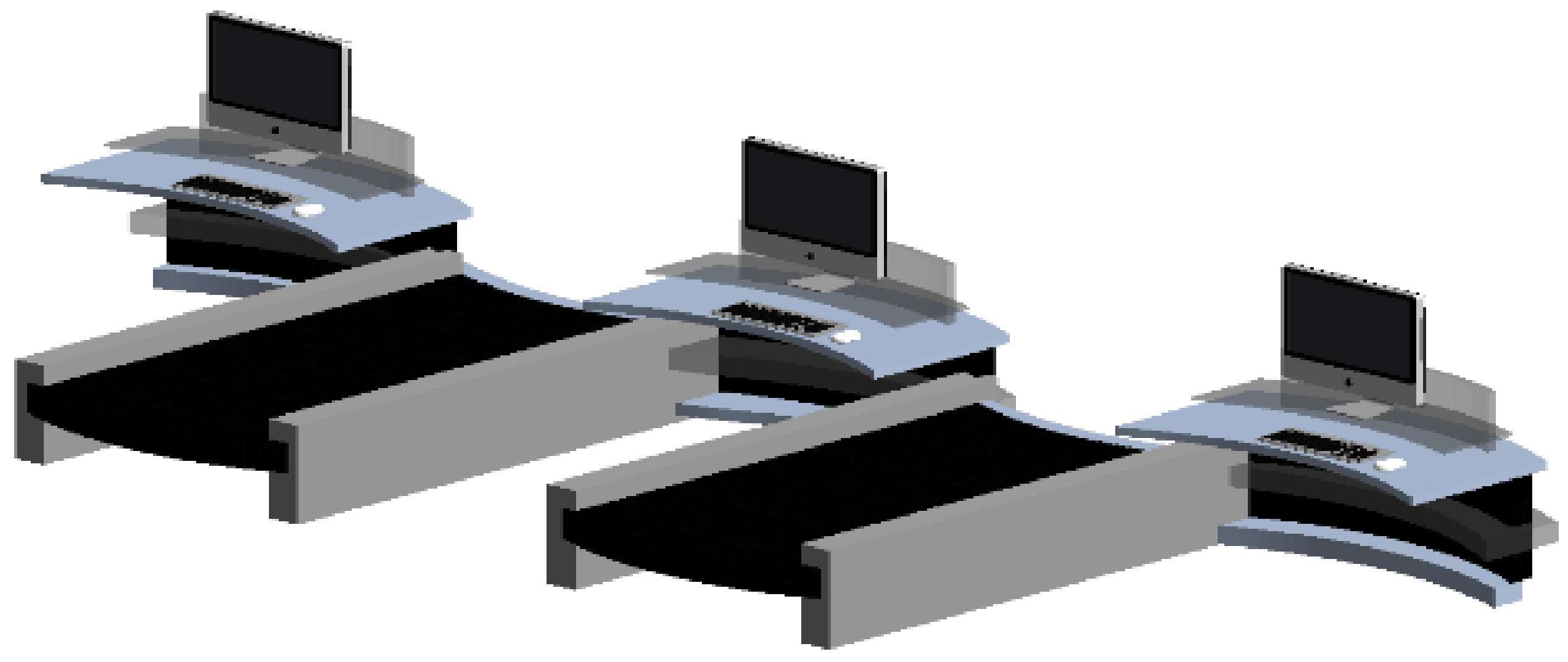

Figura 100- Balcão de "check-in" de aeroporto modelado no Revit ${ }^{\oplus}$.

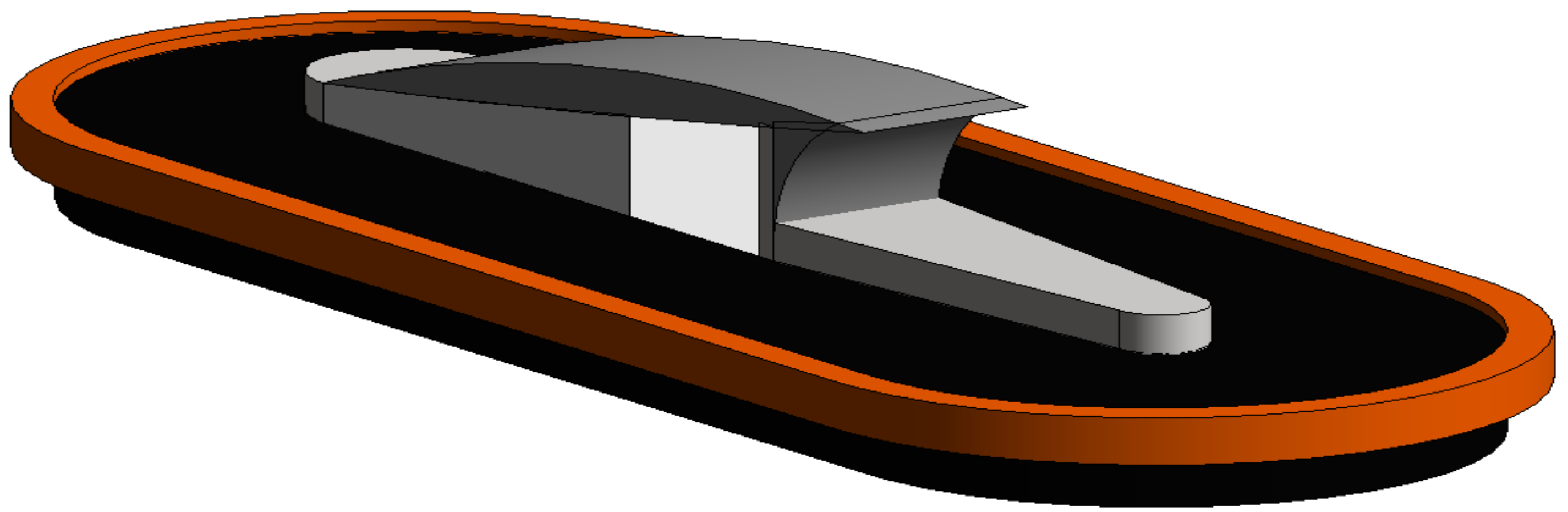

Figura 101- Esteira de Bagagem Desembarcada de aeroporto modelado no Revit ${ }^{\circ}$.

157 


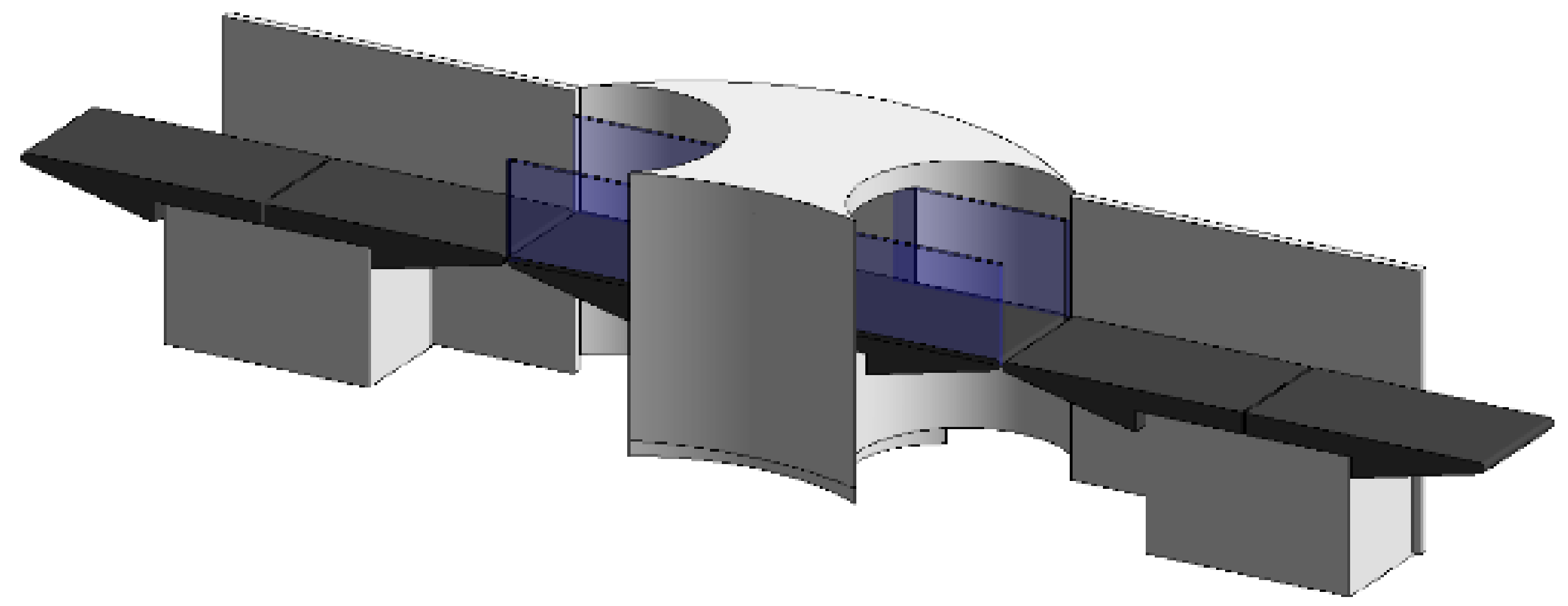

Figura 102- Raio-X de Bagagem Passageiro de aeroporto modelado no Revit ${ }^{\circ}$

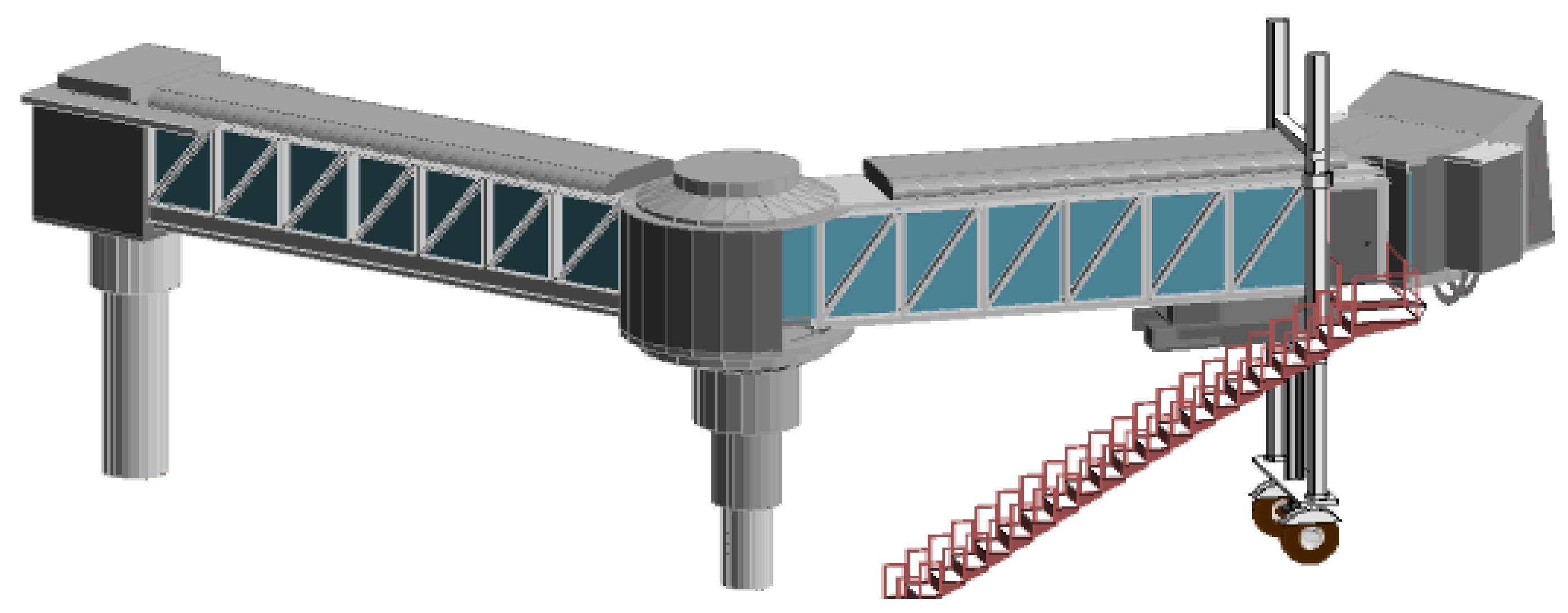

Figura 103- Ponte de Embarque de aeroporto modelado no Revit ${ }^{\circ}$. 


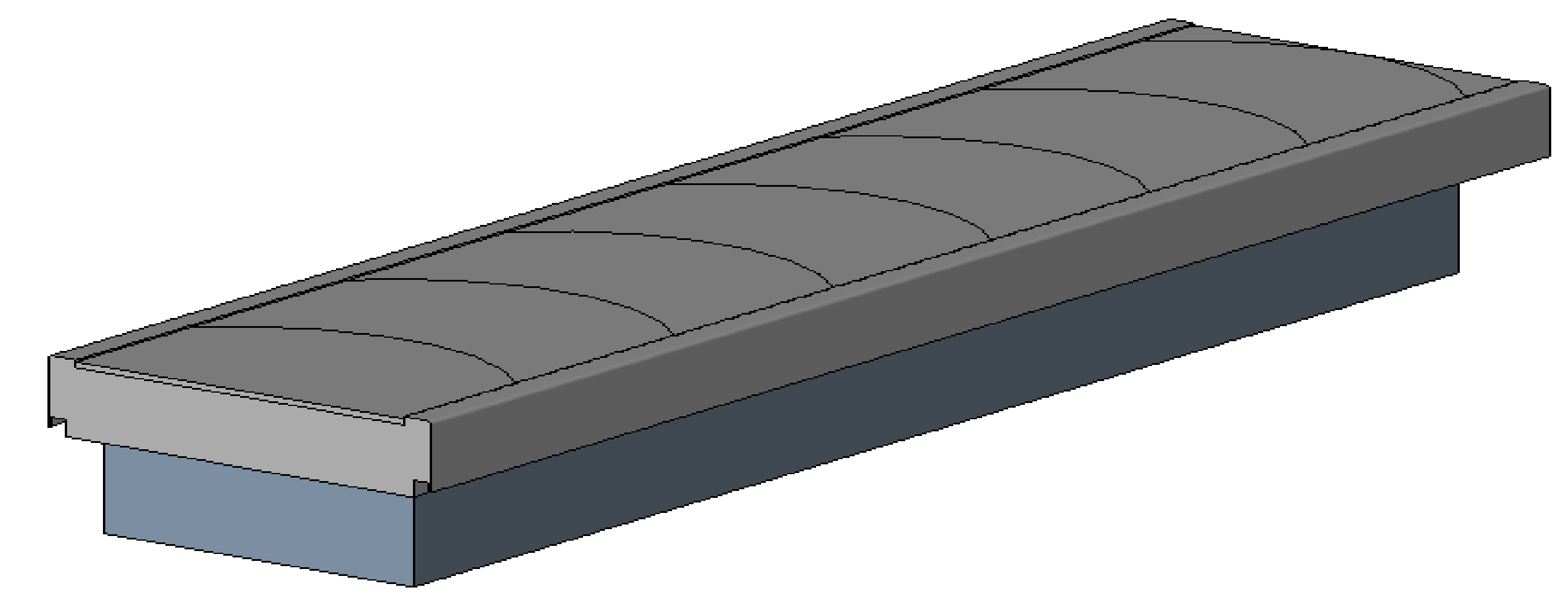

Figura 104- Esteira de Bagagem Geral de aeroporto modelado no Revit.
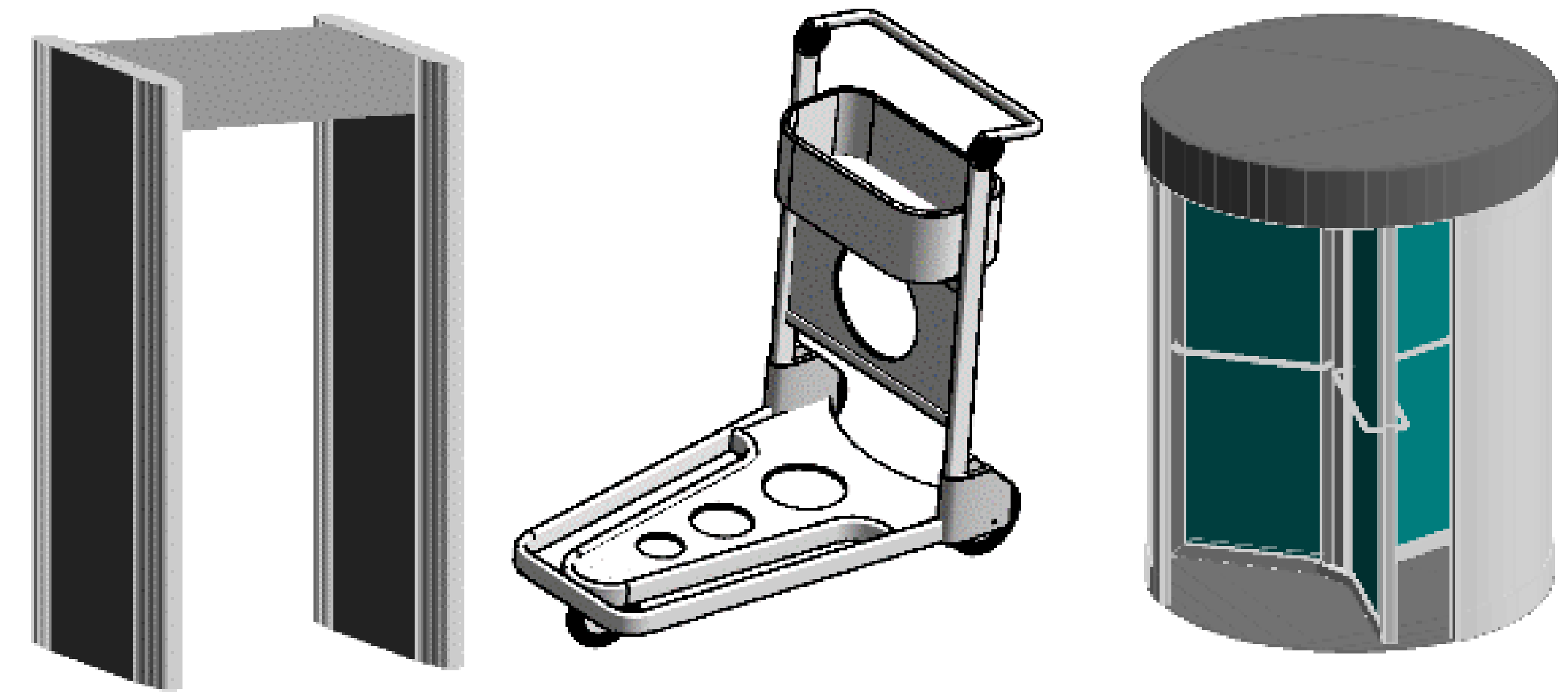

Figura 105- Pórtico, Carrinho e Porta Acesso de aeroporto modelado no Revit 


\subsection{1- ILUSTRACAO E DISCUSSÃO DOS PASSOS REALIZADOS PARA CRIAÇÃO DE NOVOS COMPONENTES PARAMÉTRICOS}

O mesmo processo básico, descrito a seguir, foi utilizado para criação de todos os componentes, embora cada um deles possa variar em complexidade e características:

\section{1- SELEÇÃO DO MODELO DE FAMÍLIA: ESTA FOI A PARTE MAIS IMPORTANTE NA CRIAÇÃO UMA FAMÍLIA.}

O modelo determinou não somente a categoria (e, portanto, os parâmetros disponíveis) da família, mas também a forma como o componente se comporta e interage com os outros. O tipo de família escolhido para representar os componentes aeroportuários foi o tipo carregável, que permite definir parâmetros customizados e reutilizar estas famílias em vários projetos. Deve-se clicar no ícone do Revit ${ }^{\circledR}>$ "New > Family" e escolher a família desejada (Figura 106).

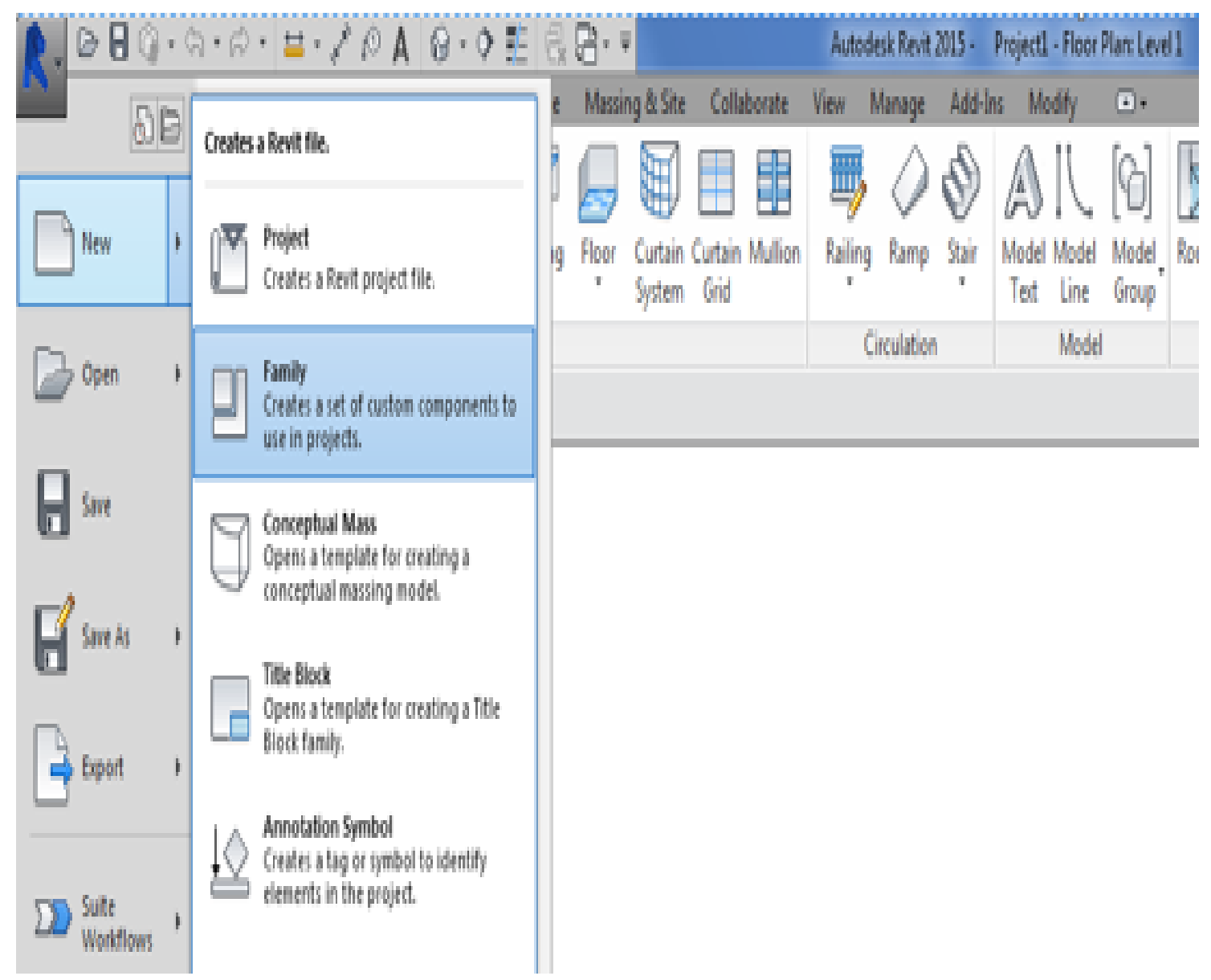

Figura 106- Seleção do modelo de família no Revit ${ }^{\circledR}$

Na vista da planta ("Ref. Level"), foi inserido o arquivo "DWG", clicando na aba "Insert" > "Import CAD", selecionando o arquivo "DWG" que representa esta vista e realizando ainda as configurações de importação. O desenho foi alinhado com os planos de referência (Figura 107 a seguir). 
2- ANTES DA CRIAÇÃO DA GEOMETRIA DOS COMPONENTES, É PRECISO ESTABELECER PLANOS E LINHAS DE REFERÊNCIA.
PLANOS DE REFERENNCIA SÃO PLANOS ESPACIAIS QUE SERVEM PARA REFERENCIAR OS PARÂMETROS E DEFINIR POSSIVVIS ALINHAMENTOS E CONSISTEM EM LINHAS DE DADOS QUE SE PROLONGAM ALÉM DAS BORDAS DA ÁREA DE DESENHO VISÍVEL.

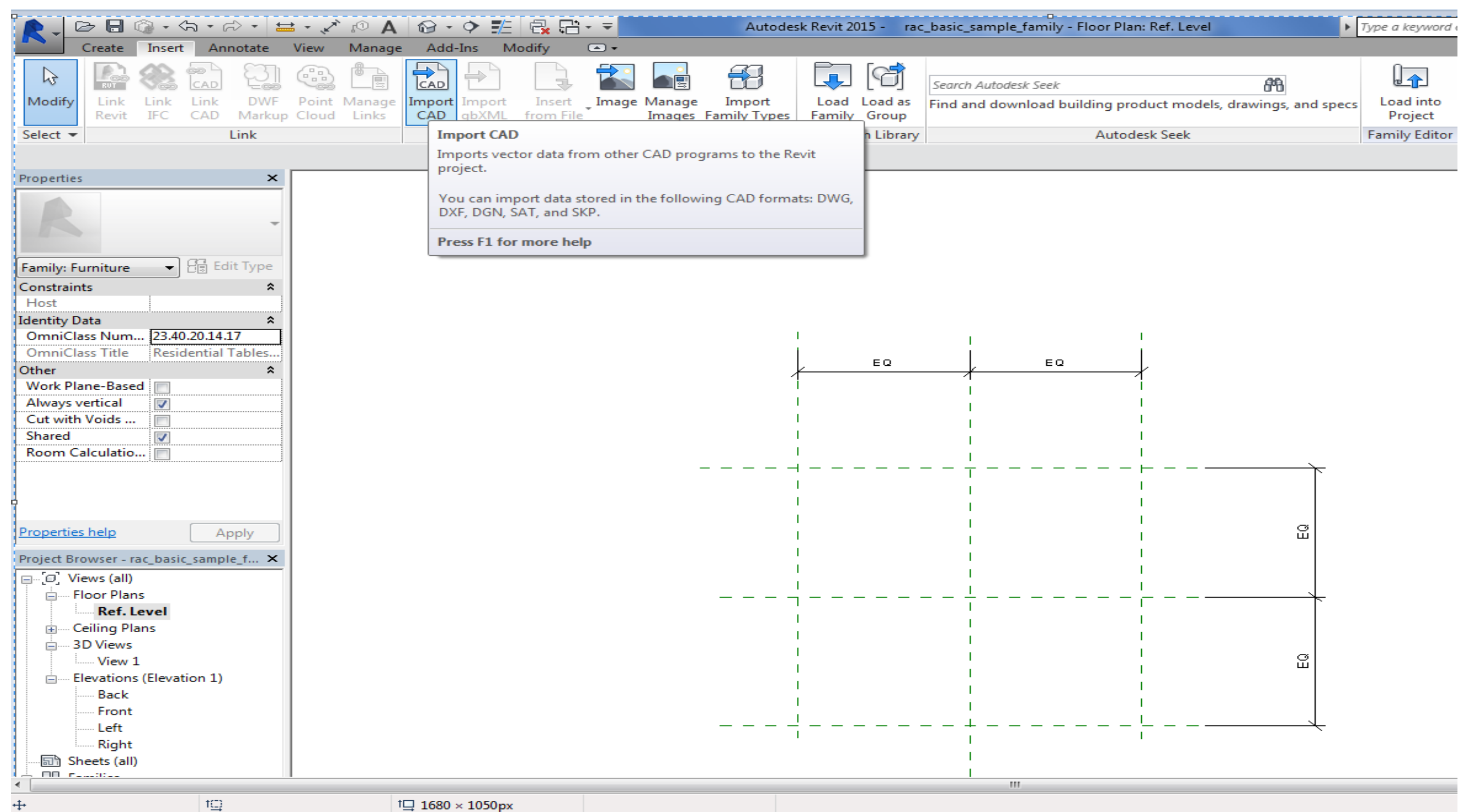

Figura 107- Criação de planos e linhas de referência no Revit 
3- INSERIR E EXPLODIR O ARQUIVO DWG > SELECIONANDO TODAS AS LINHAS CRIADAS E ALTERANDO EM "SUBCATEGORY"
OBS. O TIPO DA LINHA QUE APARECE 0 INICIALMENTE, DEVENDO SER MUDADO PARA O TIPO DE FAMÍLIA DESEJADA.

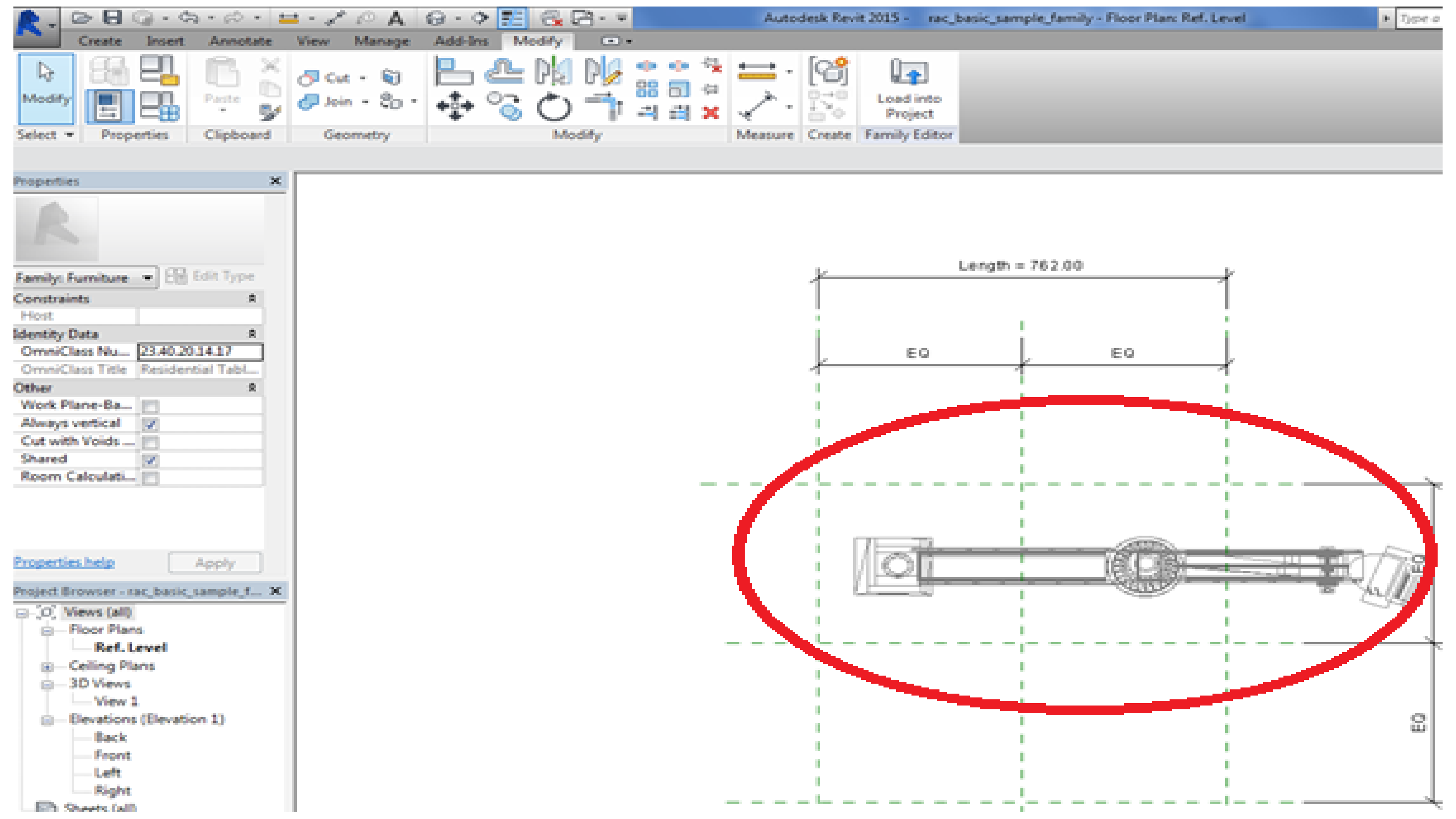

Figura 108- Inserção e edição de arquivo “. DWG" no Revit ${ }^{\circ}$. 
4- INÍCIO DA CRIAÇÃO DA GEOMETRIA SÓLIDA USANDO UMA EXTRUSÃO OU OPERAÇÃO "BOOLEANA".

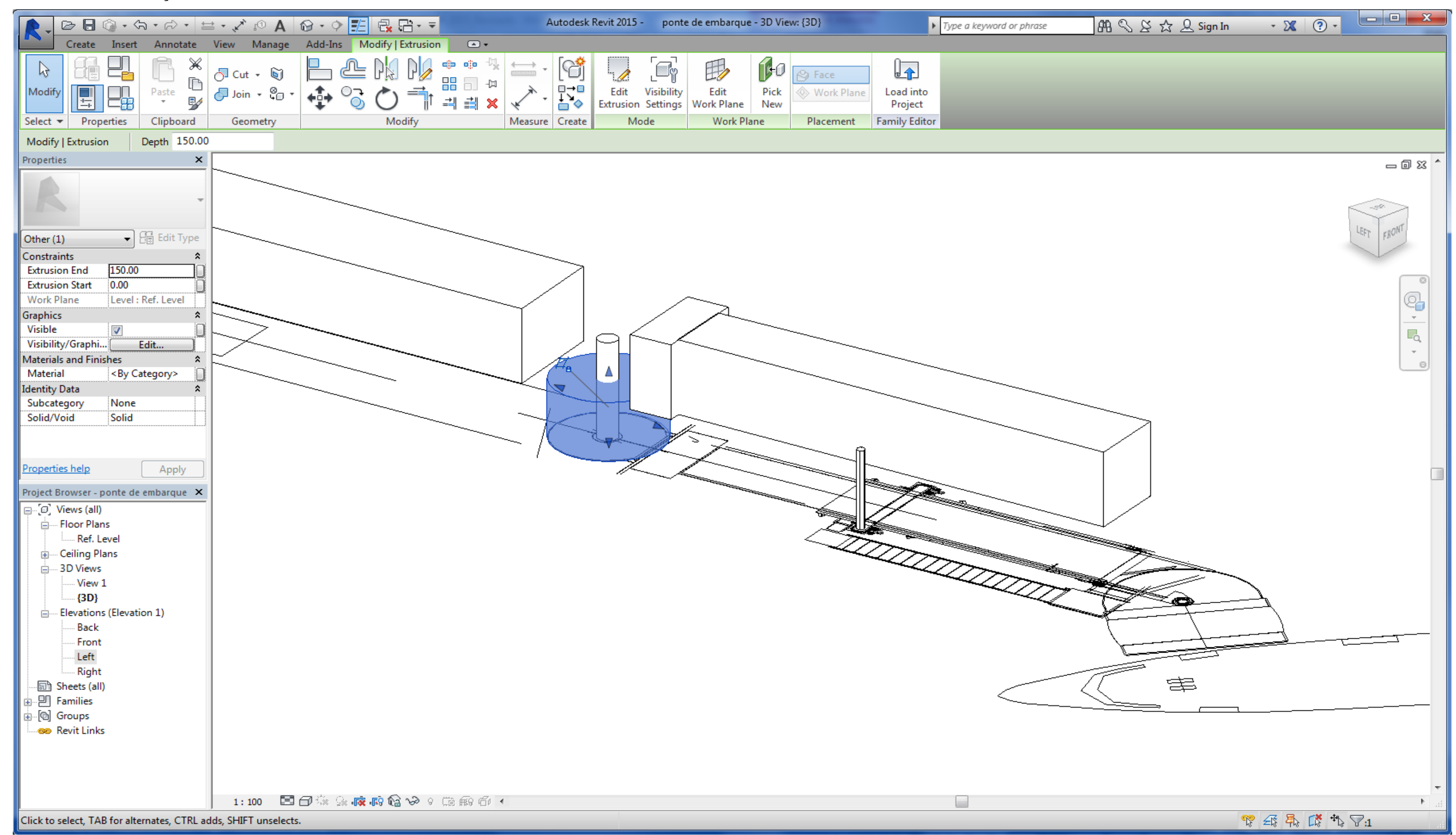

Figura 109 - Exemplo de extrusão simples no Revit ${ }^{\circ}$. 
5- VERIFICAÇÃO E DEFINIÇÃO DO “PLANO DE TRABALHO” PARA A GEOMETRIA CONCEITUAL.
PODE-SE AINDA DEFINIR O PLANO DE TRABALHO ATUAL, A QUALQUER MOMENTO, SELECIONANDO O PLANO DE TRABALHO POR MEIO DA FERRAMENTA DISPONÍVEL EM "CRIAR".

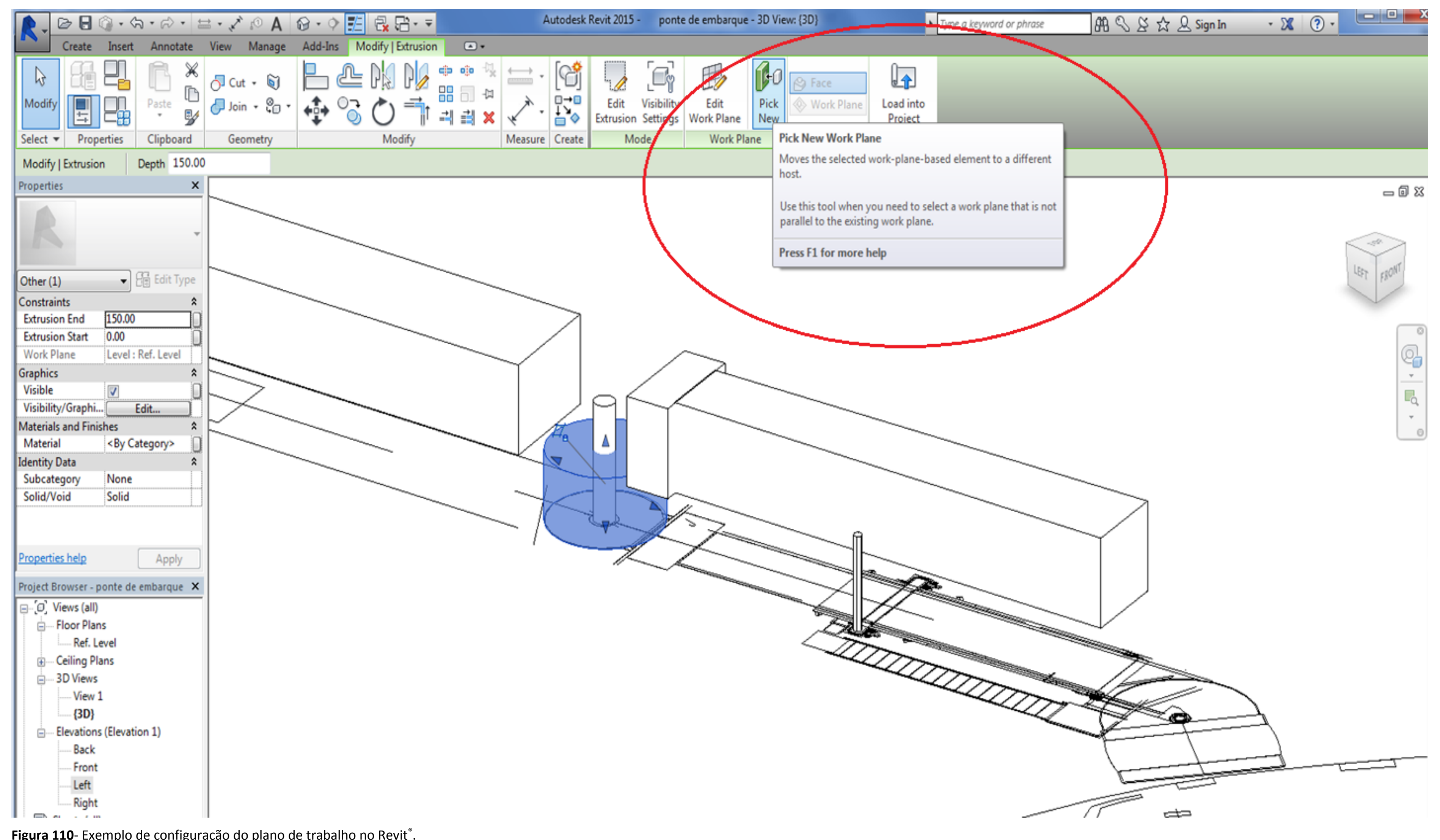




\section{6- DEFINIÇÃO DAS PROPRIEDADES DO OBJETO.}

Deve-se selecionar o método "propriedades específicas" para incluir a profundidade (no caso de uma extrusão, por exemplo), o material do objeto, visibilidade e subcategoria (se necessário). Pode-se também definir as propriedades depois que o objeto tenha sido criado. É importante notar que é possível vincular propriedades aos parâmetros.

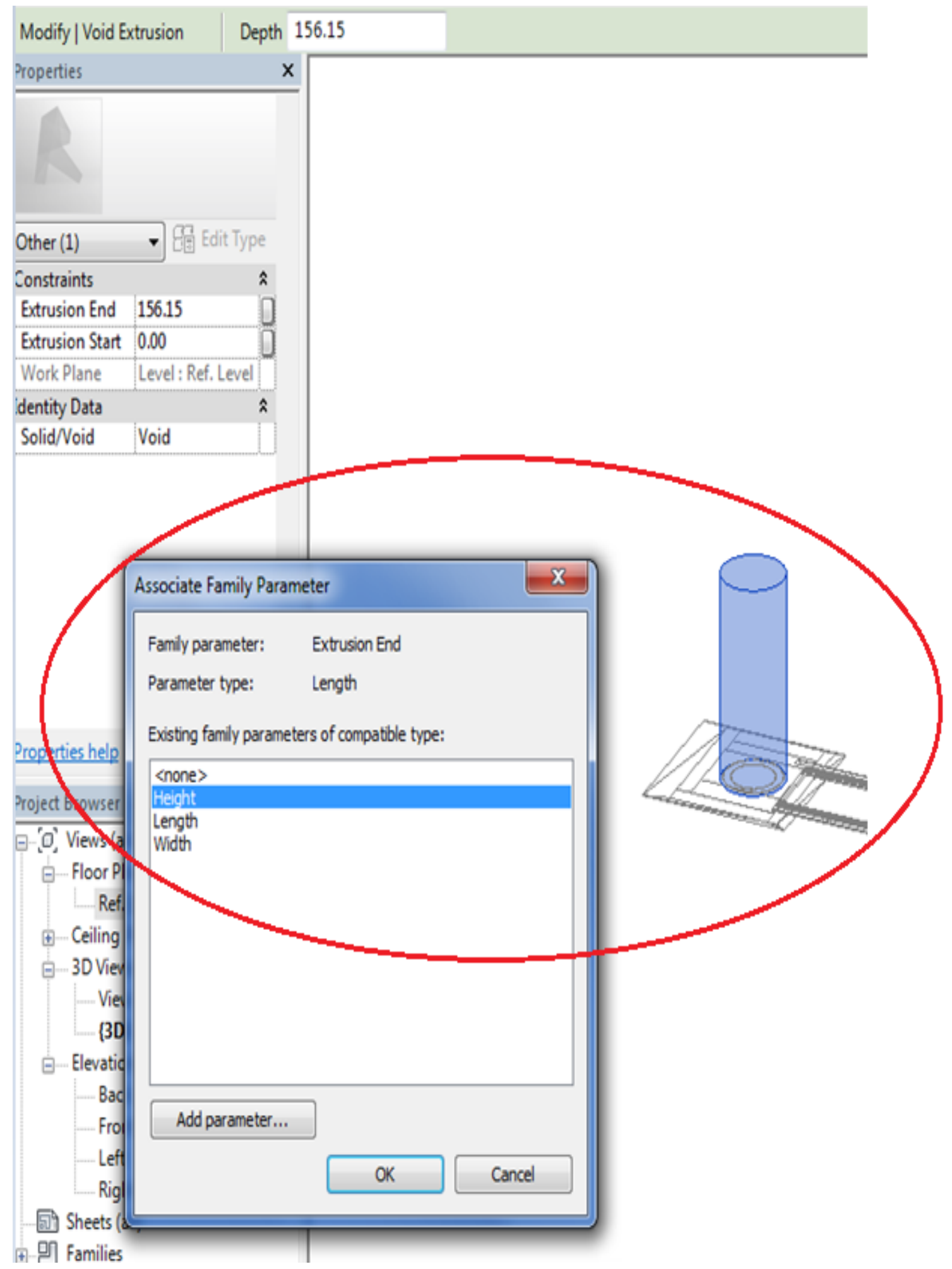

Figura 111 - Exemplo de extrusão no Revit ${ }^{\circ}$ controlada para direção no eixo de altura. 
As Figuras 107 a 111, anteriores, ilustram as diferentes formas disponíveis para modelar geometria no Revit ${ }^{\circledR}$. Ressaltamos que estes recursos de extrusão e de operações booleanas entre as formas modeladas também são comuns em outros aplicativos.

1- COTAS: na ilustração abaixo podemos ver as cotas utilizadas na ponte de embarque modelada.

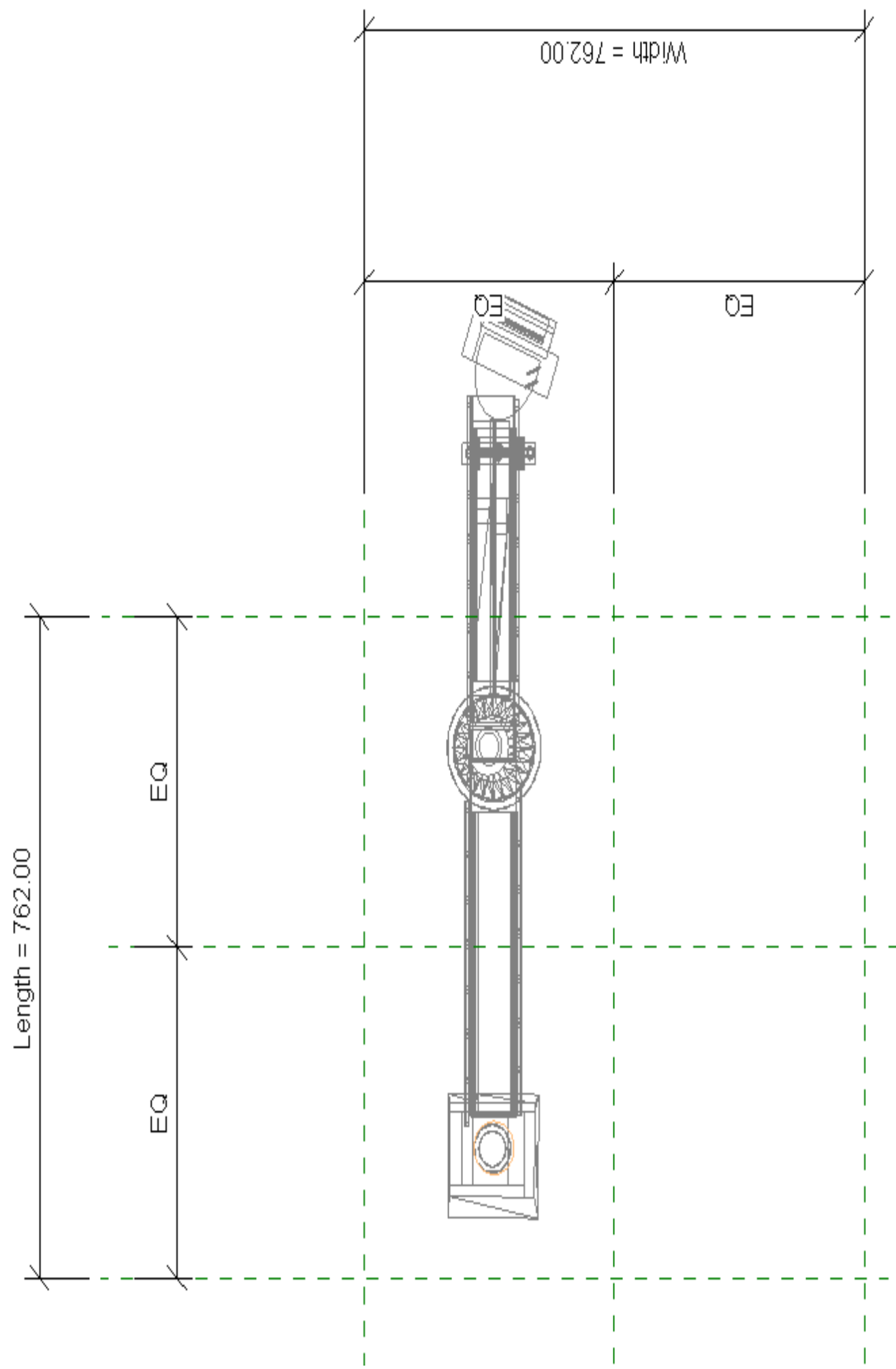

Figura 112- Exemplo de inserção de cotas no Revit . 
2- LINHAS: utilizamos linhas "model" no modelo (que aparecem em todas as vistas), e "symbolic lines" que aparecem apenas na vista que foi criada a partir do modelo (planta, elevação).

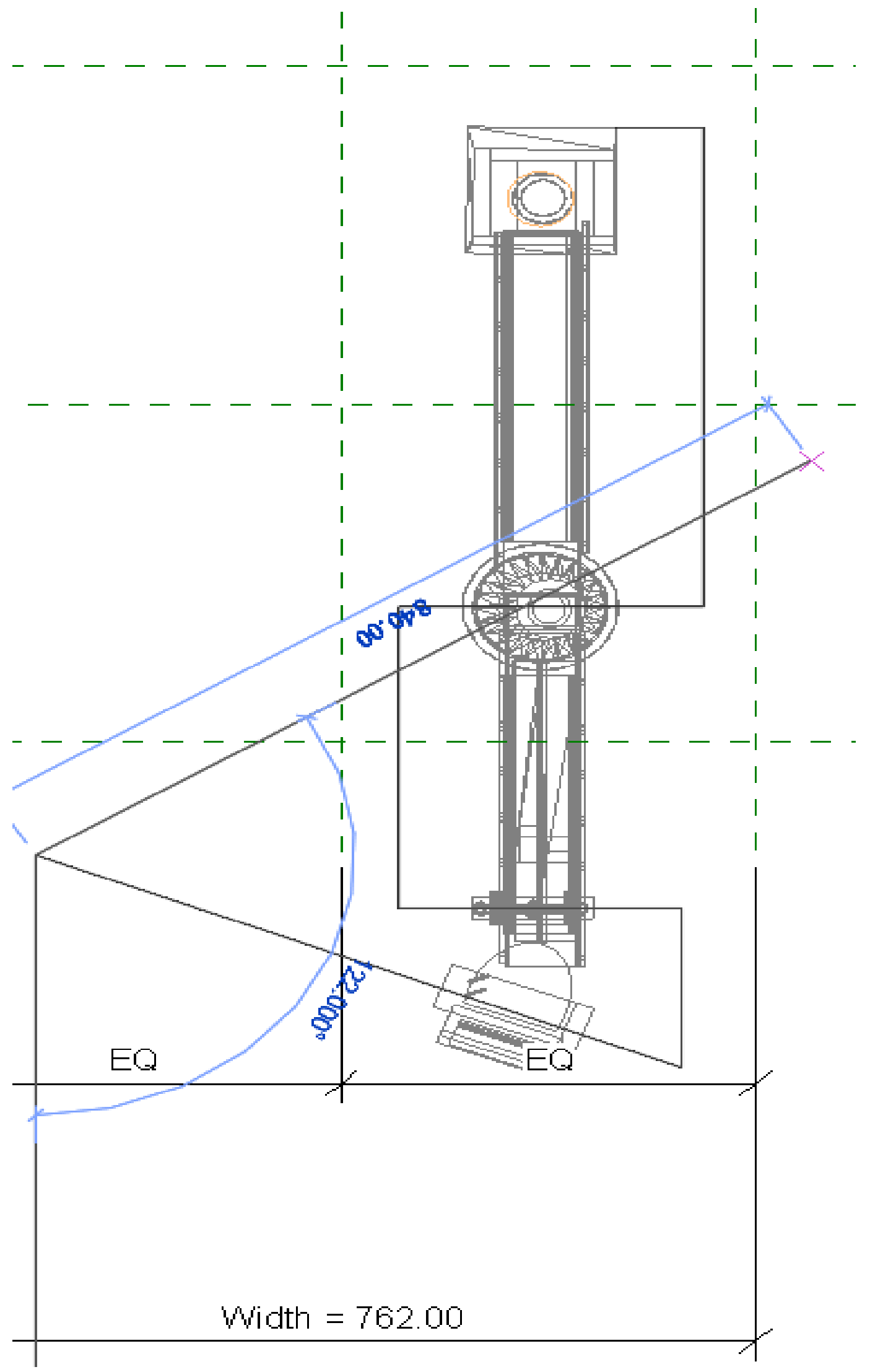

Figura 113 - Exemplo de utilização de linhas como guias de modelagem para uma Ponte de Embarque no Revit ${ }^{\circ}$. 
A FIGURA 114 ABAIXO REPRESENTA O COMPONENTE DE PONTE DE EMBARQUE

INTEIRAMENTE MODELADO.

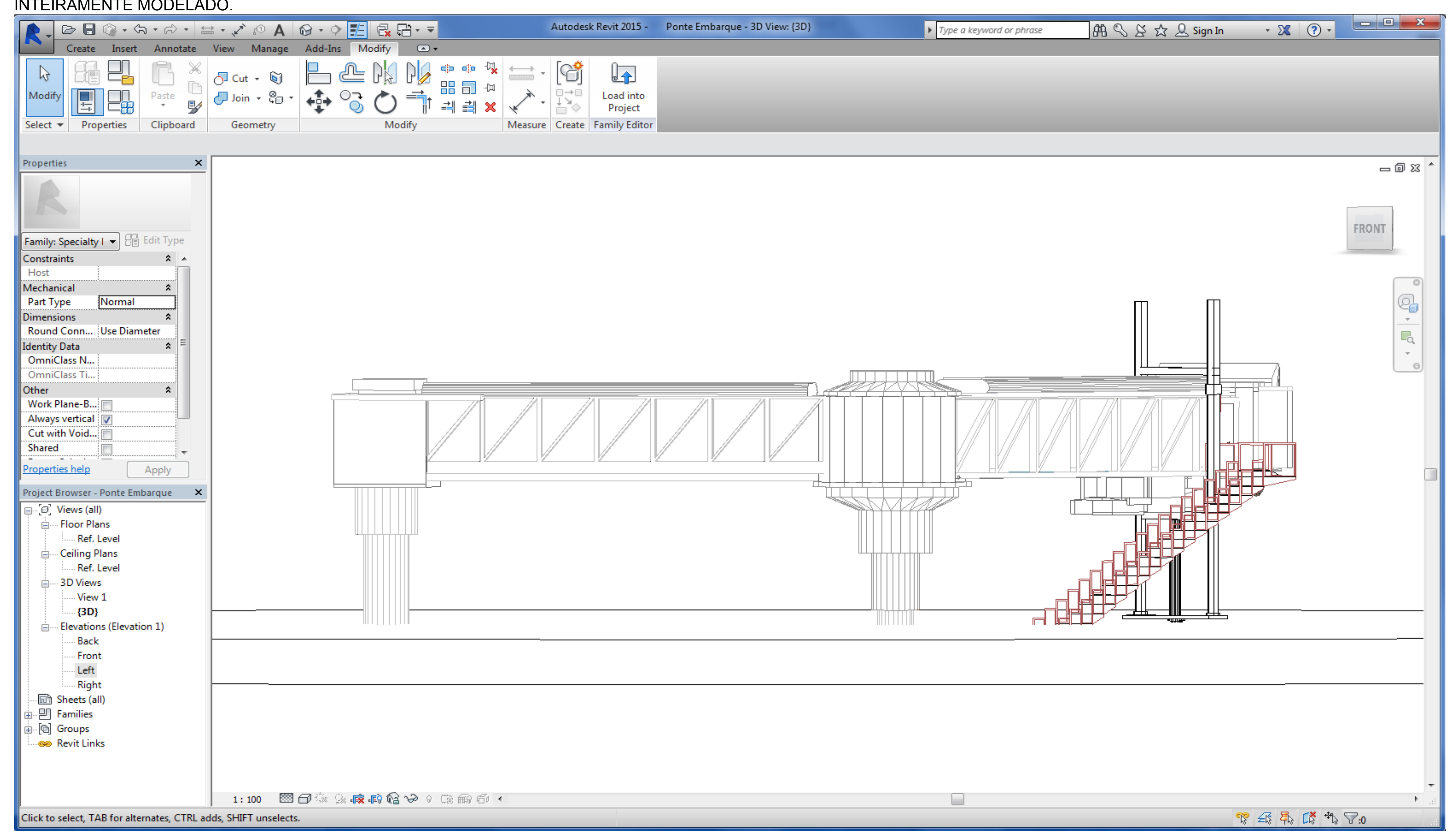

Figura 114- Ponte de Embarque modelada no Revit ${ }^{\circ}$ segundo Especificacoes Tecnicas usualmente empregadas pela INFRAERO 
3- CONFIGURAÇÕES DE VISIBILIDADE: por meio dessa ferramenta podemos escolher em que vista e nível de detalhamento o elemento vai aparecer ("coarse, medium e fine").

A determinação do nível de detalhe de cada componente ocorreu por meio da configuração do Revit ${ }^{\circledR}$ em três possíveis níveis de detalhe, baixo (LOD-100), médio (LOD-200) e alto (LOD-300) e detalhados na seção 2.8- O CONCEITO DE LOD, “Level of detail” e "Level of development", na página 51.

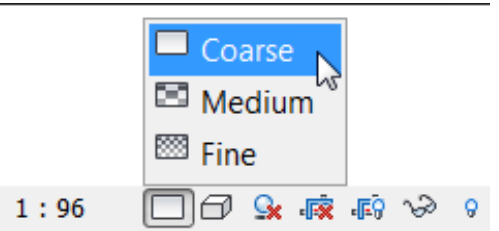

Figura 115 - Exemplo de acesso as configurações de visibilidade no Revit ${ }^{\circledR}$.

Isto deveria corresponder aos LOD`s 100, 200 e 300 (Estudo Preliminar, Projeto Básico e Executivo). Na pratica, o Revit ${ }^{\circledR}$ oferece apenas variação temporária na visualização geométrica de cada componente. As limitações dos sistemas BIM em representar diferentes graus de abstração repercutem na gestão de informação dos próprios componentes construtivos. A seguir está descrito como ocorre a variação de LOD no Revit ${ }^{\circledR}$, que corresponde apenas ao nível de desenvolvimento, conforme descrito na literatura, sendo que o aplicativo não consegue representar adequadamente esta variação, porque o nível de detalhe, que representa a variação de informação associada ao modelo não está disponível.

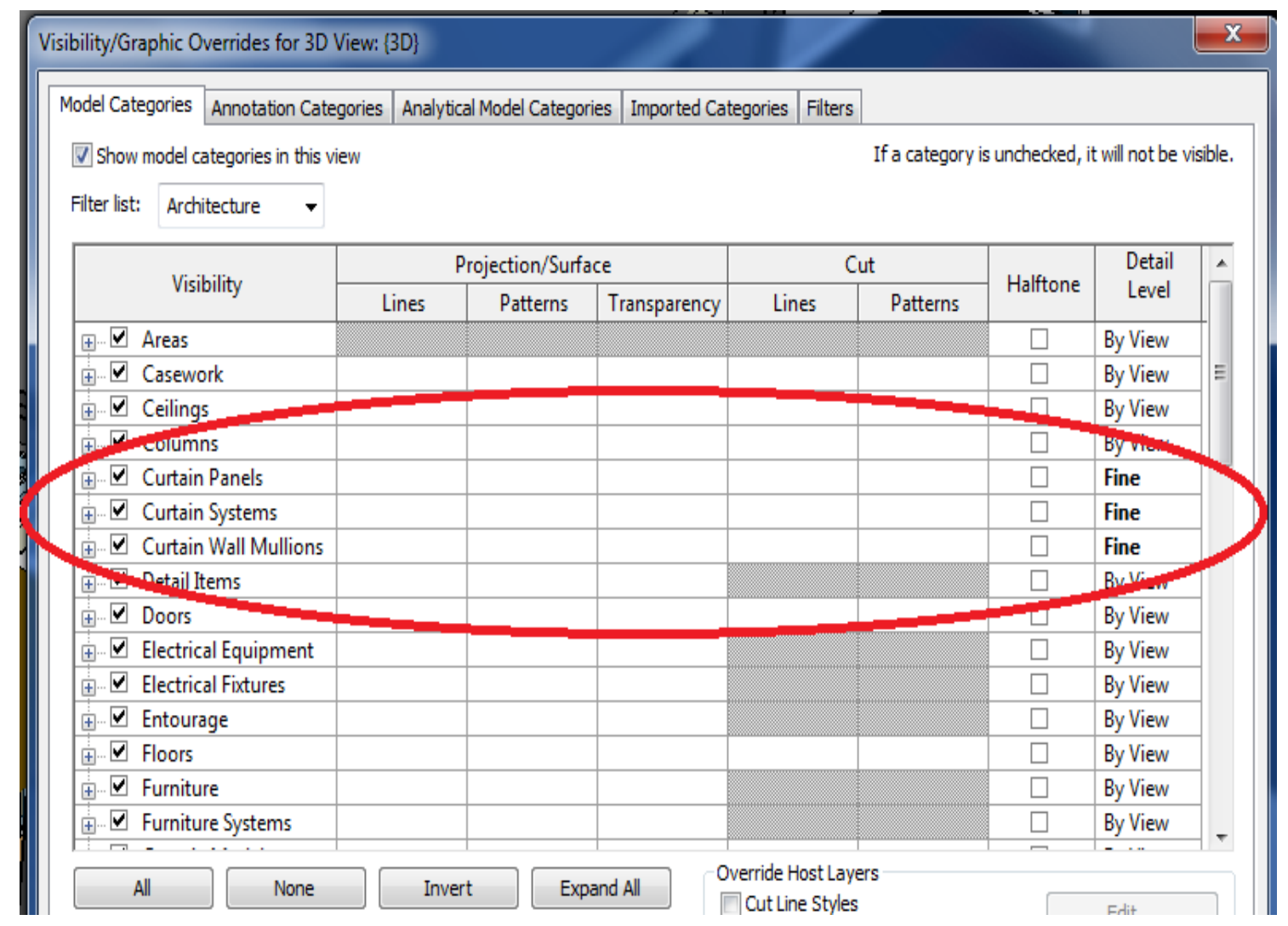

Figura 116 - Configuração das características correspondente ao LOD300. 
É possível configurar os três modos de visibilidade ("coarse, médium, fine") para partes especificas dos componentes paramétricos. Ou seja, além de poder controlar a visibilidade do componente como um todo, e possível revelar ou ocultar partes do mesmo. Porém, isso ainda representa uma limitação, dado que o correto seria poder controlar diferentes representações (nível de desenvolvimento) e diferentes graus de informação (nível de detalhe) para um mesmo componente construtivo. Em suma a variação de níveis de detalhe é possível apenas como recurso de visualização, uma vez que os parâmetros especificados para cada componente permanecem os mesmos independentemente se eles são vistos como "coarse, médium, fine". Sendo assim impedem fazer representações realmente ambíguas que permitem múltiplas interpretações.

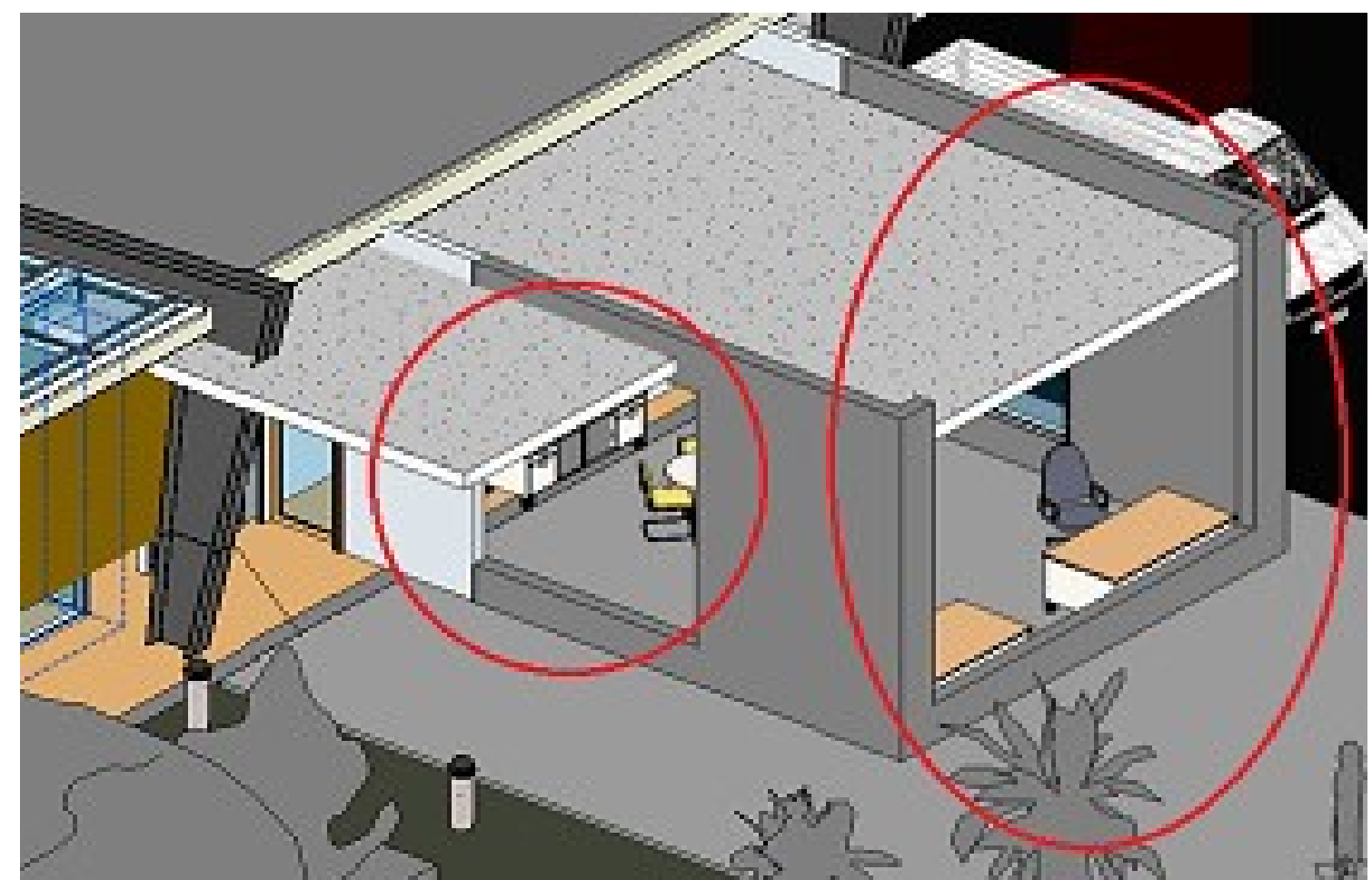

Figura 117- Visualização do resultado da configuração de LOD no Revit .

Conforme pode ser observado na Figura 117 acima, o Revit ${ }^{\circledR}$ permite visualizar diferentes níveis de LOD, porém o que acontece é a ocultação completa dos elementos de esquadrias, ou de partes deles. No exemplo acima vemos a ocultação das portas e janelas da edificação. Não se pode, no aplicativo, em um mesmo componente, ligar ou desligar instâncias que ocupem o mesmo lugar no espaço. Ainda que seja possível visualizar apenas partes de um elemento, isto não corresponde ao conceito de LOD de que o mesmo componente pode assumir diferentes representações, não apenas gráficas, mas também na informação/especificação associada ao mesmo (parâmetros). Esta deficiência do Revit $^{\circledR}$ constitui uma limitação para seu emprego em projetos aeroportuários, como no ambiente de projeto da INFRAERO, por não cumprir de forma plena com a especificação de LOD preconizada pelo AIA americano, por exemplo. 


\subsection{2- TESTE DE VARIAÇÃO DE LOD NOS SISTEMAS BIM - REVIT ${ }^{\circledR}$}

Cada componente pode ser visualizado de forma a apresentar diferentes níveis de detalhe de forma gráfica, a partir da ferramenta de visibilidade do $\operatorname{Revit}^{\circledR}$ (LOD) para "responder" aos requisitos dos níveis de desenvolvimento "100-200-300.

Porém, os resultados desta pesquisa indicaram que o Revit $^{\circledR}$ realiza apenas uma variação na representação gráfica dos componentes, ocultando partes dos mesmos sem, no entanto, conseguir representar os diferentes graus de ambiguidade por meio da transformação de sua geometria ou da alteração dos parâmetros de especificação. Em outras palavras, ele apenas liga ou desliga partes do componente sem de fato alterar nenhum dos seus parâmetros incluindo as suas propriedades, comportamentos e interrelações.

O correto seria que a geometria pudesse ser representada nos três níveis diferentes, como se pudéssemos ligar ou desligar o nível de representação geométrica e de informação associada de acordo com a fase do projeto. Da forma como a função encontra-se estruturada no Revit ${ }^{\circledR}$, podemos tirar partido da habilidade de mostrar apenas partes de um componente, quando isso coincide com os processos construtivos ou de montagem.

Por exemplo, podemos configurar como "coarse" o caixilho de uma esquadria, como "medium" sua armação interna e como "fine" os vidros, permitindo que no estudo conceitual possa-se trabalhar apenas com as aberturas (caixilhos), no Projeto Básico com a armação e estrutura interna das esquadrias e no Projeto Executivo com a esquadria completa (vidros). No entanto este resultado continua sendo apenas um recurso de visualização, sem alteração dos parâmetros associados aos componentes.

No entanto, o que deve ser ressaltado é a impossibilidade dos sistemas BIM em representar de forma ambígua seus componentes. Ainda que seja possível uma variação na representação gráfica para efeito de visualização, carece de recursos que permitam representar um componente, que ocupa um mesmo lugar no espaço, com diferentes níveis de LOD Geométrico e semântico.

A determinação do nível de detalhe de cada componente ocorreu por meio da configuração do Revit ${ }^{\circledR}$ em três possíveis níveis de desenvolvimento (LOD Geométrico), baixo (LOD-100), médio (LOD-200) e alto (LOD-300) detalhados na seção 2.8- 0 CONCEITO DE LOD, “Level of detail” e "Level of development”, na página 51.

Na figura 118, a seguir, observam-se as variações na representação gráfica de uma esteira de bagagem de aeroporto. 

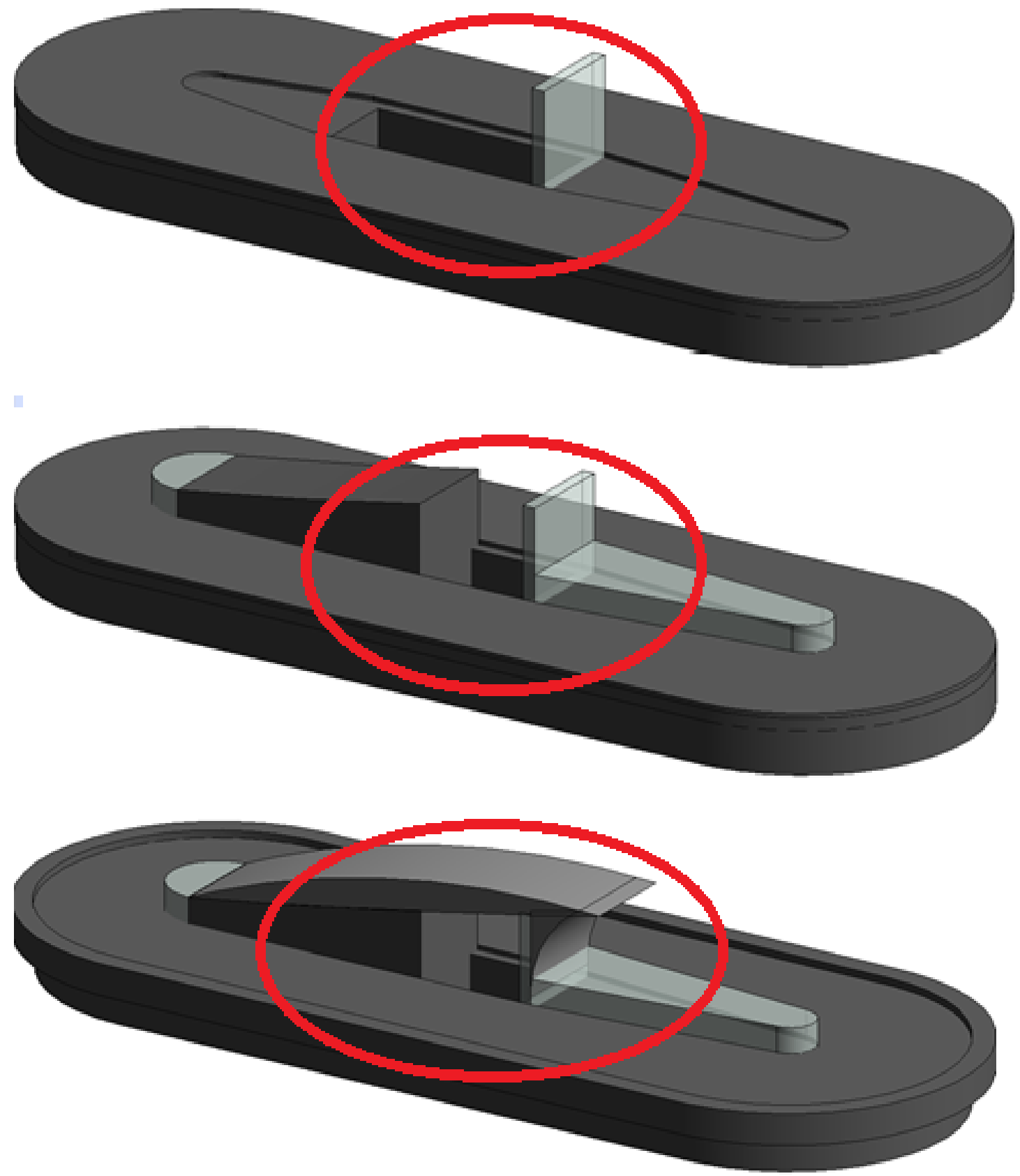

Figura 118- Diferentes representações gráficas um mesmo objeto nos sistemas BIM.

O Revit ${ }^{\circledR}$ apresenta limitações na visualização do LOD geométrico e na impossibilidade de estabelecer nos sistemas BIM representações abstratas associadas ao modelo. Para cumprir as especificações da tabela LOD, o Revit ${ }^{\circledR}$ necessita criar diferentes arquivos para um mesmo componente, cada um destes representando um nível LOD especifico, sendo que o ideal seria poder desligar ou ligar os diferentes níveis de LOD no mesmo arquivo. Esta limitação endossa o desenvolvimento de ferramentas e metodologias auxiliares, como a matriz semântica, que pode servir para informar as especificidades e diferentes regras de abstração para os módulos funcionais de um aeroporto, onde encontram-se os componentes construtivos (Figura 118). Nos objetos estão configurados os campos dos parâmetros geométricos e ainda dos parâmetros não geométricos, como código do fabricante, códigos SINAPI e SICAERO, cor, peso, etc. 
Os parâmetros são propriedades dos elementos para adicionar ou retirar informações. Podem ser parâmetros da família. Neste caso, o parâmetro só terá informações referentes àquela família (como largura e altura de objetos). Pode haver também parâmetros compartilhados, quando precisamos transpor informações entre famílias diferentes ou entre a família e o projeto como, por exemplo, o código SINAPI, que consta de um número de referência, sendo que a informação sobre o custo está associada ao projeto por meio de um banco de dados. (Figura 119). No sentido de testar as potencialidades e ainda pesquisar o desenvolvimento dos componentes paramétricos nos sistemas BIM foram configurados novos parâmetros nos componentes modelados: código SINAPI, código SICAERO.

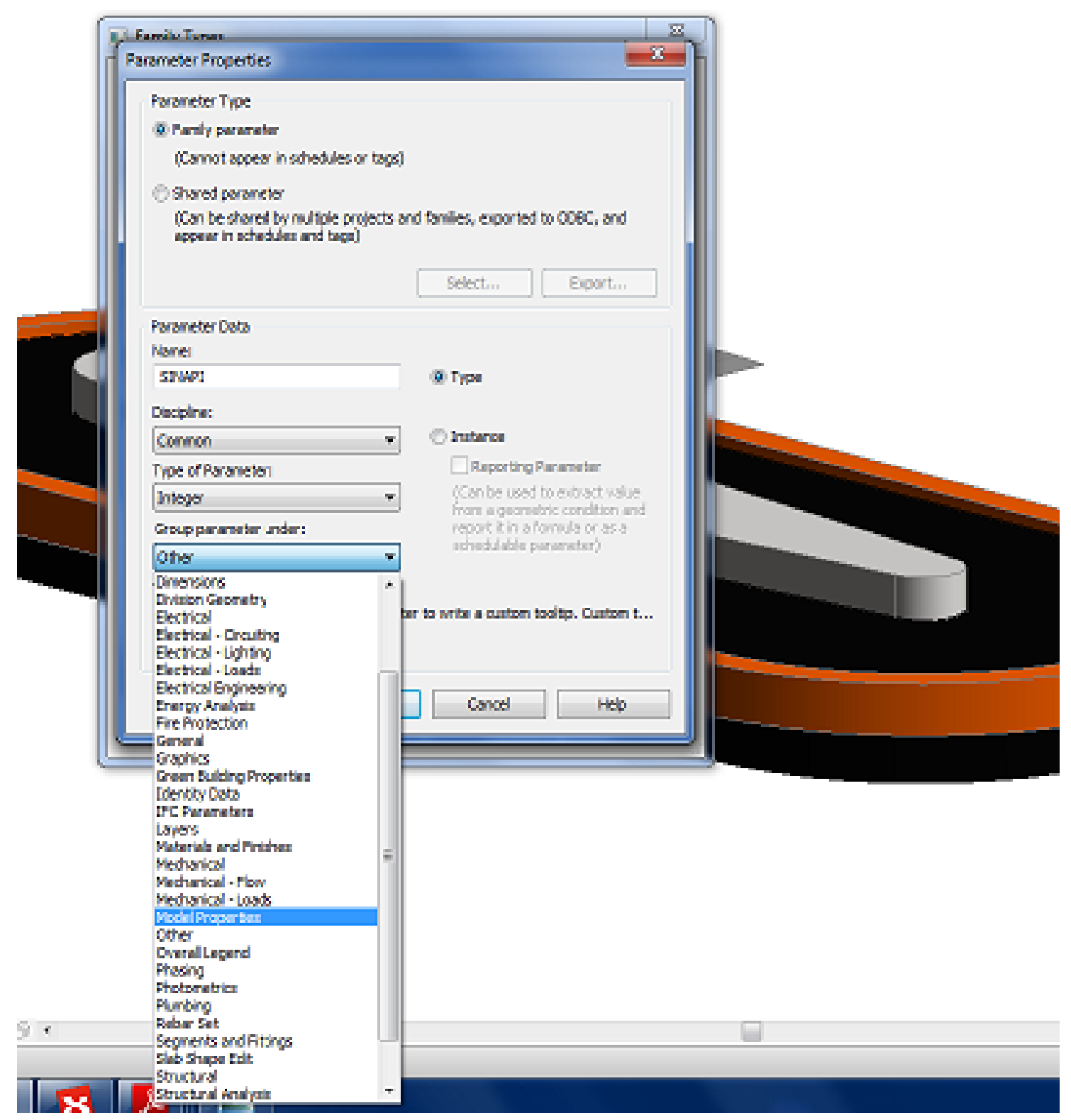

Figura 119- Demonstração da criação do parâmetro SINAPI para Esteira de Bagagem.

O código SINAPI refere-se às informações constantes da planilha de preços licitatórios do Governo Federal. A criação de parâmetro no componente possibilita relacioná-los ao projeto para realizar, por exemplo, a orçamentação automática. 
A inserção do código SICAERO obedece aos mesmos princípios do anterior. Entretanto, uma vez que alguns componentes não existem na base de preços geral do Governo Federal, a planilha SICAERO estabelece preços de referência para equipamentos exclusivos de aeroportos. A existência dos dois campos, deve-se à possibilidade futura do equipamento vir a ser incluído na planilha SINAPI. Por esta razão os campos foram configurados de forma a coexistirem.

Pode contribuir na quantificação de materiais e orçamentação e para o aprimoramento da gestão, uma vez que podemos parametrizar as informações de projeto. Por exemplo, apenas utilizando códigos de informações saberemos sobre os componentes de um dado projeto. Na criação de novos parâmetros existem campos que possibilitam configurar a que disciplina de projeto e a que grupo de informação o parâmetro pertence. No exemplo da Figura 120, a seguir, foi criado para uma esteira de bagagem desembarcada um novo parâmetro chamado SICAERO e foi relacionado ao mesmo todas as disciplinas, em um grupo de informação de dados.

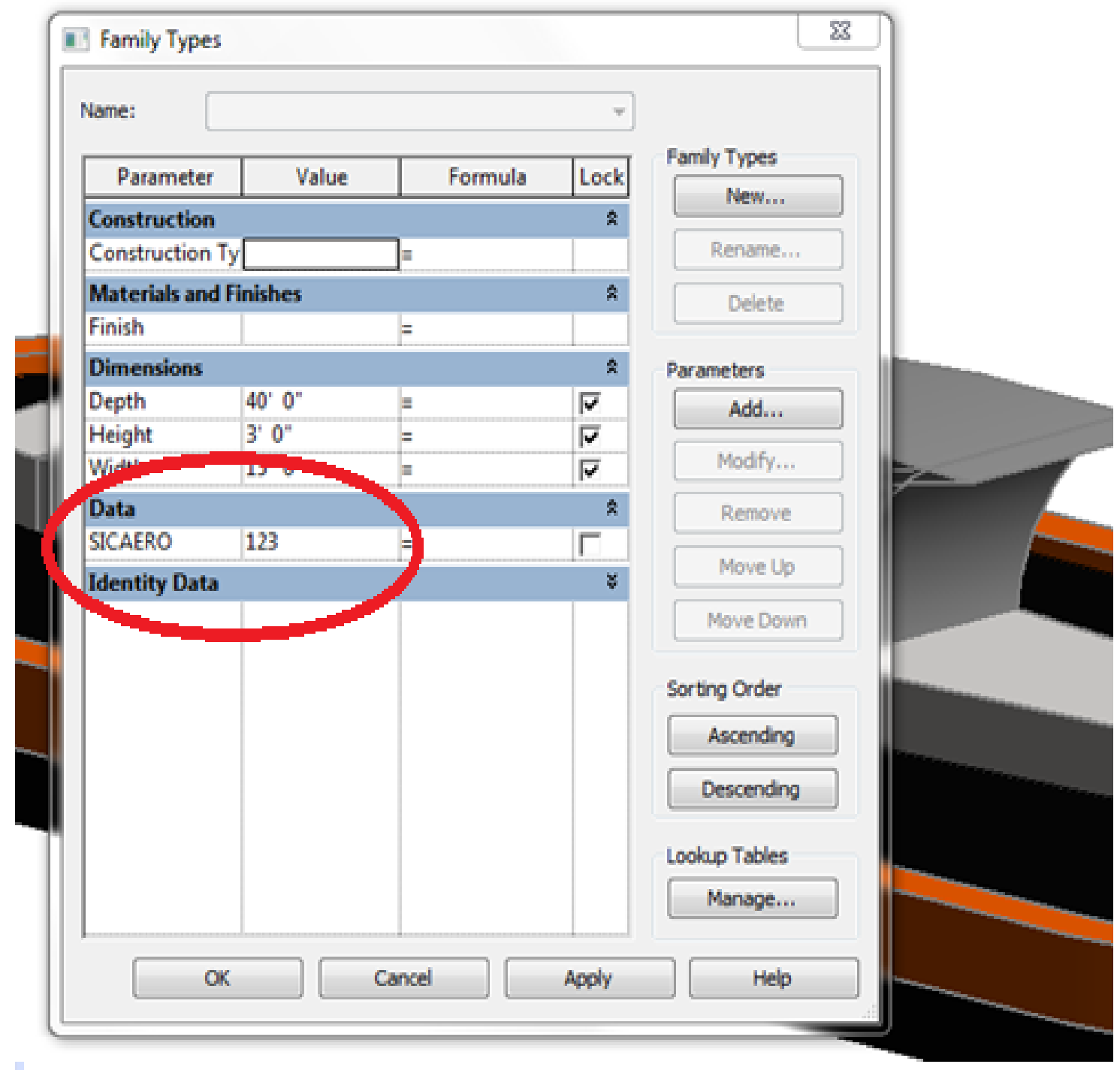

Figura 120-Configuração de novo parâmetro (SICAERO) no Revit ${ }^{\circ}$ 


\subsection{3- IMPORTAÇÃO DE COMPONENTES NOS SIG}

A formação dos componentes em bases SIG ocorreu por meio da exportação do modelo REVIT ${ }^{\circledR}$ em um arquivo "FBX", formato de propriedade da AutoDesk. Testamos ainda a exportação, por meio de arquivos "open source IFC". O teste de representação dos componentes modelados ilustra a utilização dessas ferramentas no projeto do terminal de passageiros regional do Brasil, e ainda apresenta os resultados da tentativa de simulação dos níveis de detalhe nos SIG, de forma a acompanhar as fases conceptivas, de desenvolvimento e de detalhamento de um projeto de arquitetura.

O SIG - InfraWorks ${ }^{\circledR}$ apresentou limitações, de certa forma, semelhantes aos sistemas BIM, para a representação de diferentes LOD's, uma vez que não permitiram aos objetos importados do Revit ${ }^{\circledR}$, via "IFC", representar variação controlada nos LOD semântico e geométrico, mas apenas variação temporária nos mesmos ("zoom" de detalhe). A variação de representação, nesses casos, é apenas geométrica, chamada nos manuais do aplicativo como variação de distância, ou de "zoom". Na literatura está descrito que no ambiente "CityGML" estes recursos estão presentes.

Dessa forma, concluímos que em futuras pesquisas ou aplicações na área, devese priorizar o ambiente SIG que trabalhe de forma nativa com os arquivos "CityGML". Apesar da ferramenta da AutoDesk (InfraWorks ${ }^{\circledR}$ ) poder manipular tais parâmetros, se os mesmos estiverem presentes, pois importa os arquivos "CityGML", a importação direta dos arquivos oriundos de um sistema BIM não soluciona o problema de representação de projeto em diferentes níveis de abstração.

Os resultados, portanto, indicam que possivelmente a exportação de componentes no ambiente BIM para um ambiente "CityGML' permitiria a adição de aspectos topológicos e semânticos ao modelo.

Dessa forma, ao serem inseridos no aplicativo da AutoDesk InfraWorks ${ }^{\circledR}$ poderiam ter parâmetros ligados a sua natureza geométrica, suas conexões físicas com os objetos do entorno imediato e ainda informações, ou parâmetros, específicos de projeto (semânticos) manipulados em diferentes níveis de abstração.

Nesta pesquisa foram testados dois componentes modelados no $\operatorname{Revit}^{\circledR}$, que apesar das limitações de não trazerem consigo os parâmetros e as funcionalidades topológicas e semânticas, puderam ter sua representação geométrica testada no aplicativo InfraWorks ${ }^{\circledR}$.

A interface entre os dois sistemas, BIM e SIG, por meio do arquivo "IFC" e a possibilidade de controle na variação do grau de abstração das informações associadas 
ao modelo, foi a razão pela qual incluímos a representação geométrica e semântica nesta pesquisa. Após a modelagem e parametrização no sistema BIM, exportamos os componentes para o ambiente SIG (Figura 121).

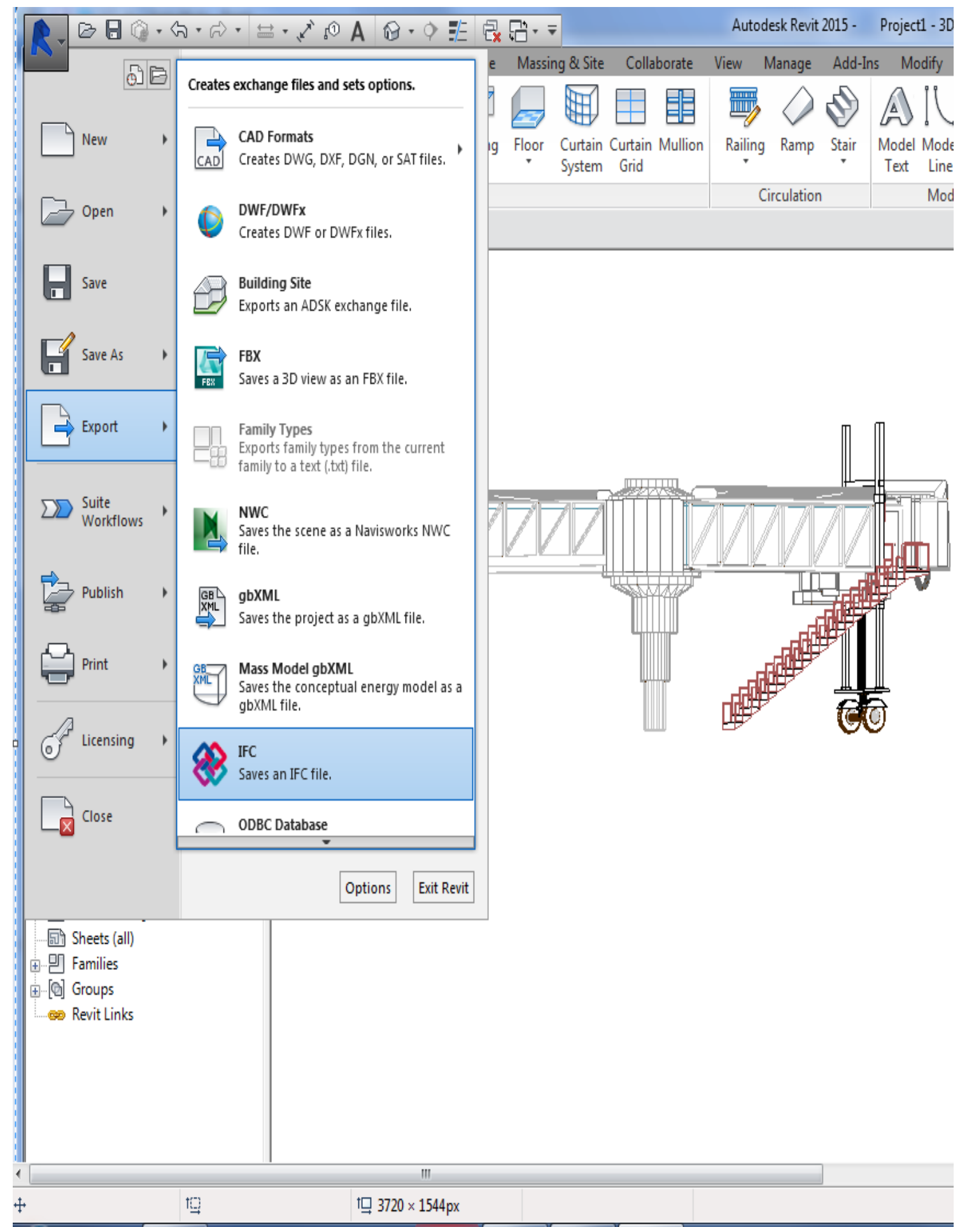

Figura 121- Exportação para arquivo do tipo "IFC" a partir do Revit

A seguir, inserimos, no terreno SIG, desde os componentes, de forma individual, módulos funcionais, como a torre de controle, até a totalidade do aeroporto, para efeito de análise e ainda de teste desses componentes modelados no ambiente de projeto (Figuras 122 e 123). 


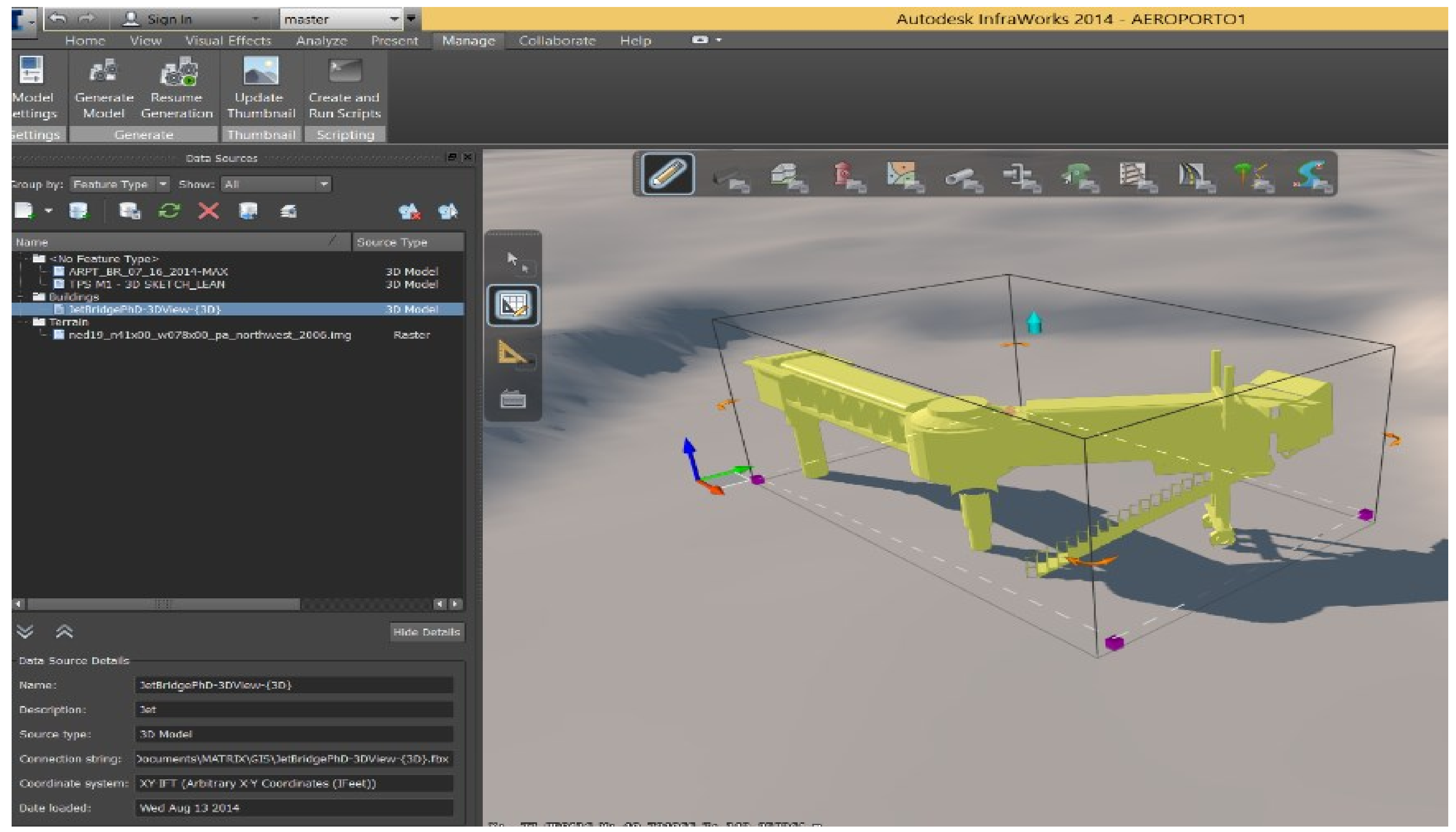

Figura 122- Demonstração de componente BIM importado no ambiente SIG - InfraWorks.

NAS FIGURAS 122 E 123 ESTÃO REPRESENTADOS OS DOIS COMPONENTES QUE FORAM ESCOLHIDOS PARA TESTE DA VARIAÇÃO NO NÍVEL DE DESENVOLVIMENTO DOS COMPONENTES MODELADOS NO BIM.

NA FIGURA 122 ACIMA PODE-SE OBSERVAR A SELECAO DO COMPOENTE DE PONTE DE EMBARQUE NO APLICATIVO INFRAWORKS ${ }^{\circledR}$. NO CANTO SUPERIOR ESQUERDO VEMOS A REFERENCIA A IMAGEM RASTER QUE COMPOE O TERRENO. 


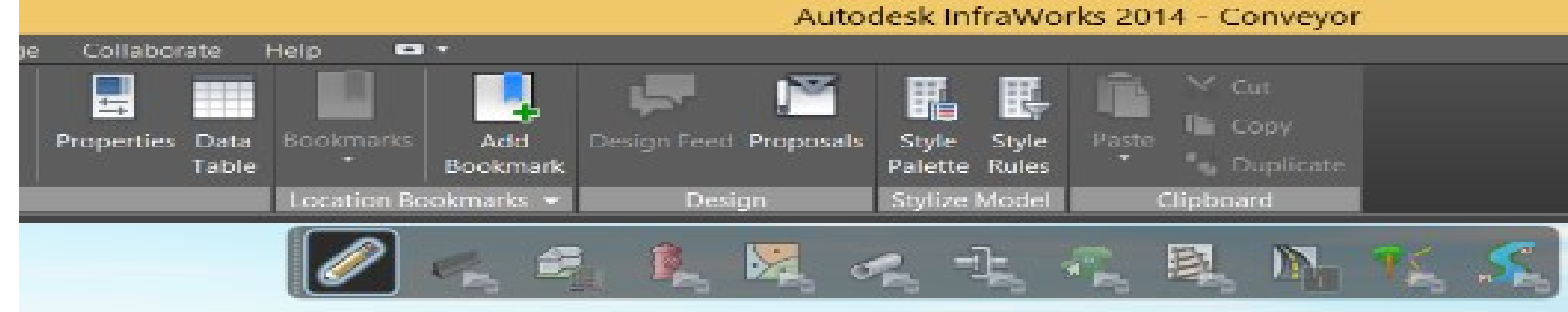

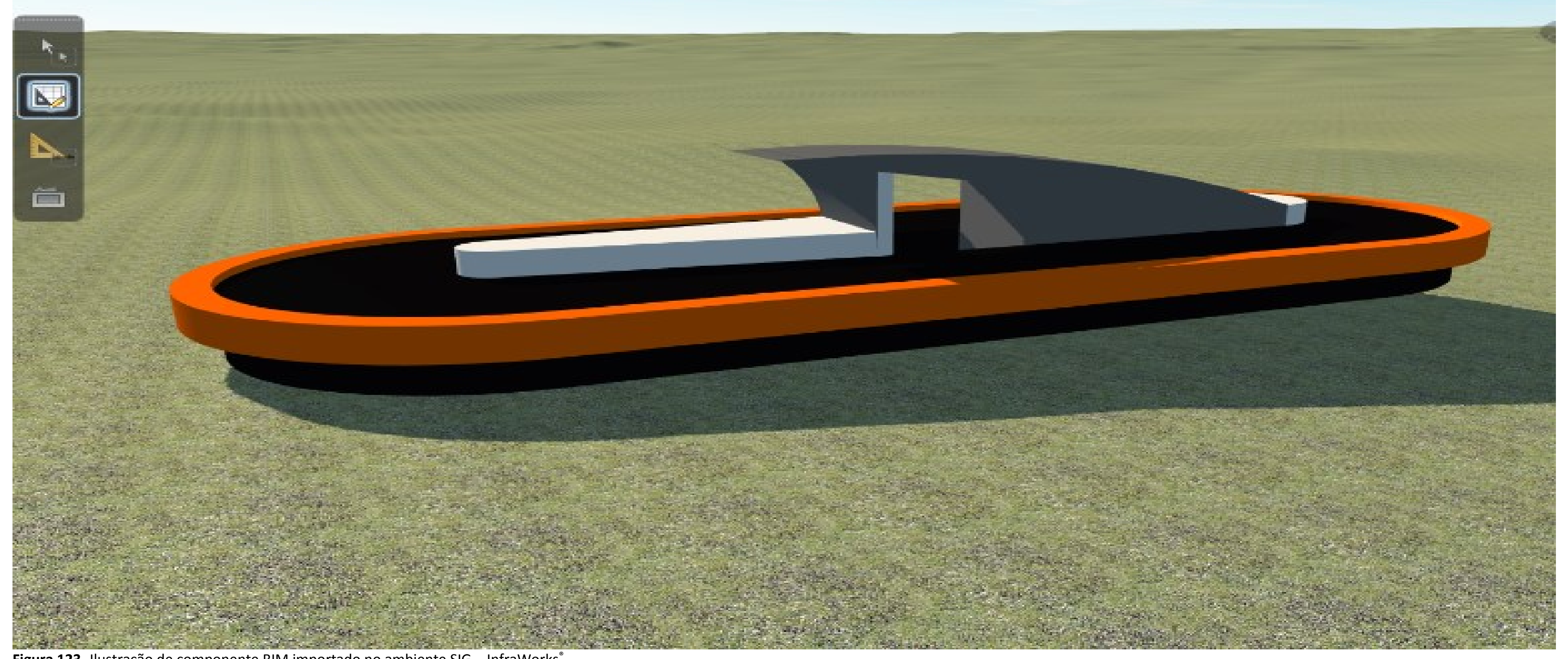
Figura 123- llustração de componente BIM importado no ambiente SIG - InfraWorks '.

A FIGURA 123 ACIMA DEMONSTRA A INSERCAO DE MODELO ORIUNDO DO BIM - REVIT NO SIG INFRAWORKS.
A SEGUIR SÃO APRESENTADAS IMAGENS DE INSERC̄̃̃O DOS COMPONENTES MODELADOS NOS SISTEMAS BIM - REVIT ${ }^{\oplus}$ E EXPORTADOS PARA O INFRAWORKS ${ }^{\circledR}$ (FIGURAS 124 A 126. 
Como pode ser observado na Figura 124 abaixo, a variação de LOD no InfraWorks ${ }^{\circledR}$ consegue realmente abstrair geometria do componente construtivo sem, no entanto, representar o efeito desejado de se poder assumir o controle sobre o que deve ser representado em diferentes níveis de abstração. Isso significa que a simples exportação de componentes oriundos dos sistemas BIM não representa um ganho direto de análise no sentido de variação no nível de desenvolvimento dos objetos.

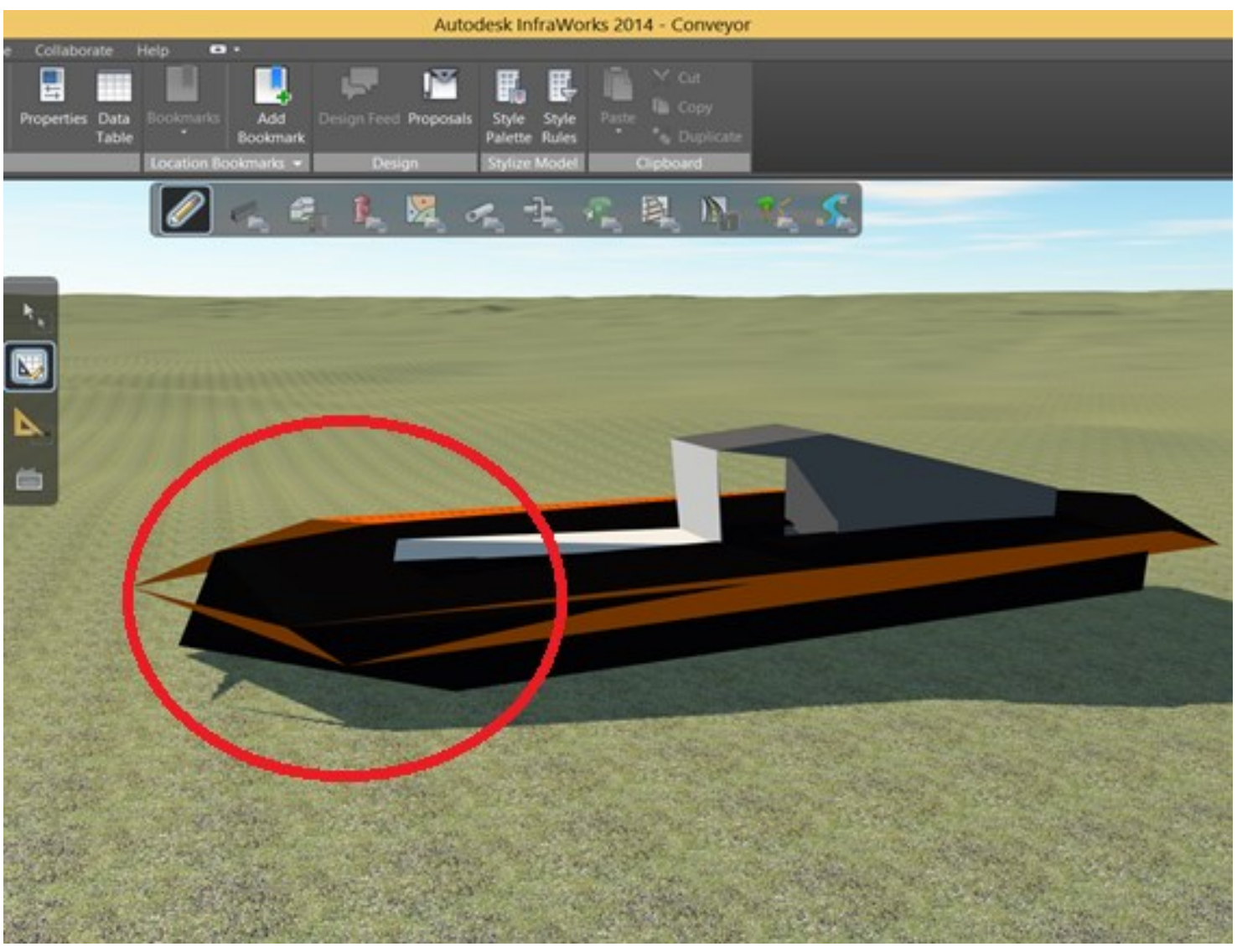

Figura 124- Exemplo de nível de detalhamento em LOD100 no InfraWorks ${ }^{\circledR}$.

Os "softwares" utilizados pertencem a um mesmo fabricante, o que implica na opção por uma gama de aplicativos vendidos como uma solução fechada, conhecida como "suíte" de aplicativos. No caso da opção por "softwares" de diferentes fabricantes, a escolha do caminho que se utiliza do "CityGML" passa a ser o mais viável, uma vez que se utiliza de protocolo "open-source" do tipo "IFC".

Os experimentos realizados nesta pesquisa demonstram como se comportam os componentes exportados do BIM diretamente para um SIG que pertence a "suíte" ou solução integrada de aplicativos do fabricante "AutoDesk" para a AEC.

Outra forma seria utilizar a interface oferecida pelo "CityGML", que oferece a possibilidade de inclusão de informações semânticas (parâmetros configurados nos sistemas BIM) no modelo. 
Ocorre que a variação no nível de detalhamento geométrico, descrito pelo fabricante como uma variação no "zoom" em relação ao objeto, permite, de fato, que se consiga abstrair partes da geometria dos componentes. Porém, o resultado obtido não indica que o aplicativo ofereça controle sobre quais partes do modelo deveriam ser ocultadas. Da mesma forma, a ausência de partes dos componentes testados, como partes de uma esteira de bagagem ou ainda os pilares de apoio de uma ponte de embarque (Figuras 124 e 126 respectivamente) não abstraiu informações sobre as partes ocultadas, mas apenas na visualização da geometria dos componentes.

Pode-se ainda observar nas Figuras 124 e 126 que apesar de somente algumas partes da geometria dos modelos ter sido abstraída, como por exemplo os apoios da ponte de embarque, toda a geometria foi também simplificada, apresentando redução de detalhes, aparentemente revelando as triangulações ocultas na malha de modelagem. Isto caracteriza-se como uma limitação, uma vez que a redução das características geométricas das partes não ocultadas não e de forma alguma desejável. Por fim, ressalta-se que a inserção de componentes modelados previamente nos sistemas BIM em um ambiente SIG representa uma boa oportunidade para confrontar os mesmos com as características do relevo natural.

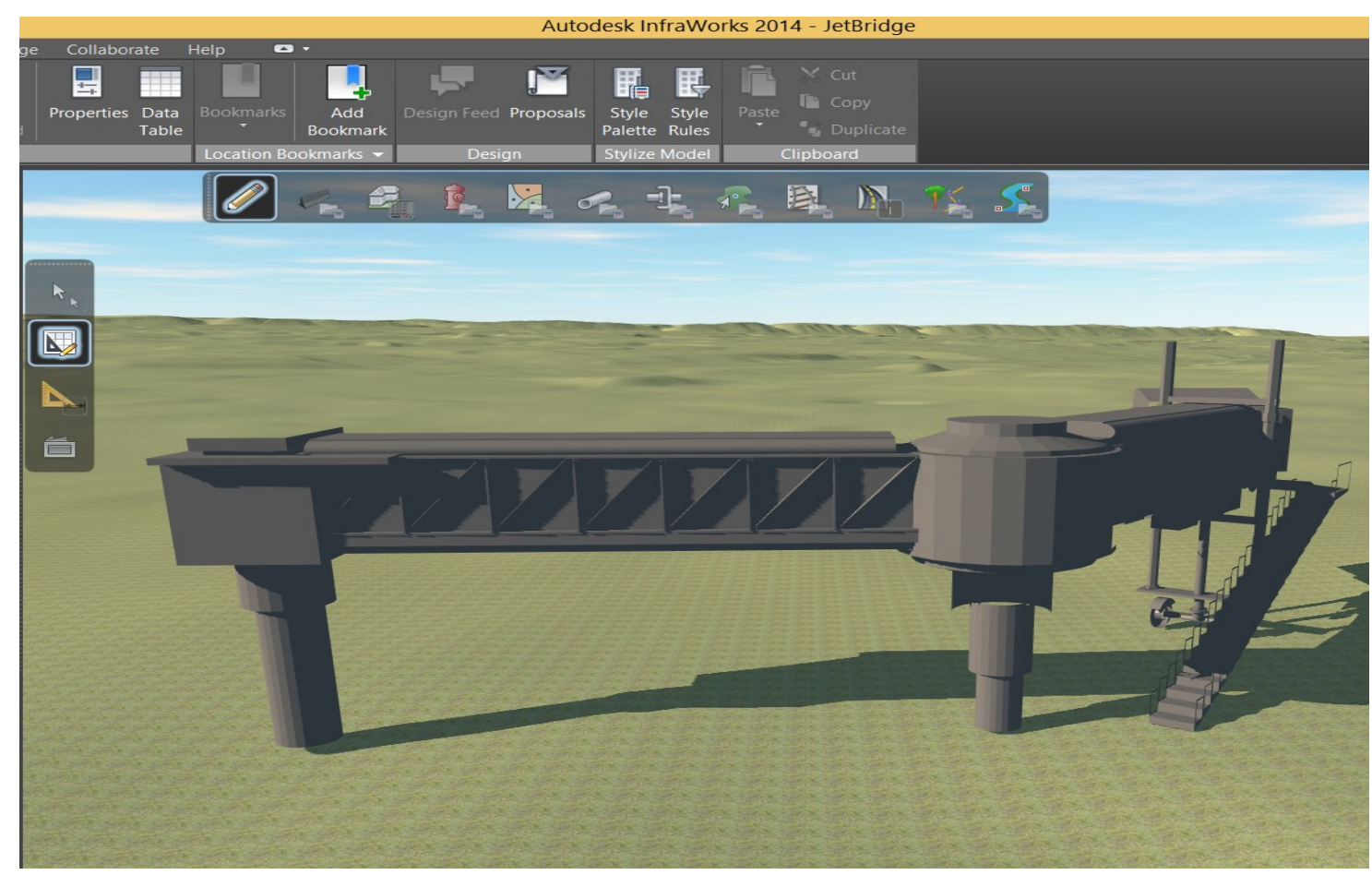

Figura 125- Exemplo de variação de nível de detalhamento em LOD300 no InfraWorks.

Conforme pode ser observado na Figura 125 e 126, a variação de LOD no InfraWorks ${ }^{\circledR}$, chamada nos manuais do "software" como variação de "zoom", permite uma representação abstrata da geometria, mas cujo controle deixa a desejar na seleção do que será ocultado. No exemplo a seguir (Figura 126), a ponte de embarque oculta partes importantes de sua estrutura de forma indesejável (elipses vermelhas). 


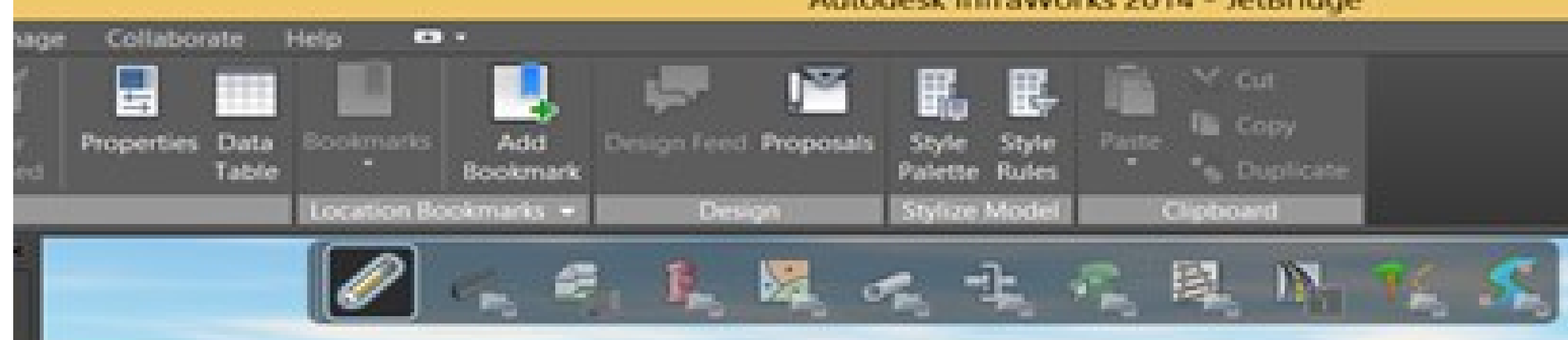

D.

$\Delta$.

是 


\section{3- MODELAGEM DO TERMINAL DE PASSAGEIROS REGIONAL NOS SISTEMAS BIM E TESTE DE EMPREGO DE COMPONENTES EM SEUS MÚLTIPLOS NÍVEIS DE DETALHE}

A modelagem do terminal regional ocorreu devido a necessidade de se adotar uma base gráfica de dados onde fosse possível efetuar testes com os componentes modelados.

Da mesma forma, esse modelo digital permite simular processo de projeto que se utiliza dos sistemas BIM.

Face a problemática exposta na pesquisa, acerca das limitações dos sistemas BIM em representar diferentes graus de abstração da informação associada aos componentes construtivos, estabelecemos a escolha do terminal regional de passageiros da INFRAERO como forma de investigar as ligações entre as partes do aeroporto e suas conexões semânticas com as responsabilidades e tarefas envolvidas nos processos de aprovação e projetos desenvolvidos pela empresa.

A reprodução no Revit $^{\circledR}$ do projeto cedido pela INFRAERO possibilitou conhecimento aprofundado dos diversos setores, ou zonas de um pequeno aeroporto.

A consulta ao material complementar, como especificações técnicas, memoriais de critérios e condicionantes, constantes do Termo de Referência de Projeto, foi possível estabelecer paralelos entre cada um dos módulos funcionais do edifício e os sistemas prediais e operacionais usualmente empregados pela INFRAERO.

Nesta pesquisa a modelagem do terminal regional encontra-se conectada, como ferramental de "input" de dados na matriz semântica desenvolvida pelo autor.

A ideia de relacionar o modelo único de informação em base BIM com um "software" de apoio ao processo de projeto, como a versão digital da matriz, no aplicativo $\mathrm{Xmind}^{\circledR}$, que permite consulta sobre diferentes campos de informação sobre o aeroporto e suas partes, especialmente em relação aos processos de aprovação e projetos e aos requerimentos.

Da mesma forma, o modelo BIM do terminal regional amparou o desenvolvimento de simulação do processo de projeto através da criação de três alternativas para uma torre de controle, inexistente no projeto original. A simulação permitiu investigar aspectos relacionados com os estágios iniciais de projeto, desde a geometria conceitual até a utilização da matriz semântica para consulta sobre as interferências e impactos que as novas torres significam no terminal regional. 


\subsection{1- CONSTRUÇÃO DO MODELO BIM E PROCESSO DE ANÁLISE}

O processo envolveu tanto a modelagem, utilizando as ferramentas e potencialidades nativas do Revit ${ }^{\circledR}$, como a importação de geometria, que posteriormente foi transformada em componente paramétrico (Figura 127).

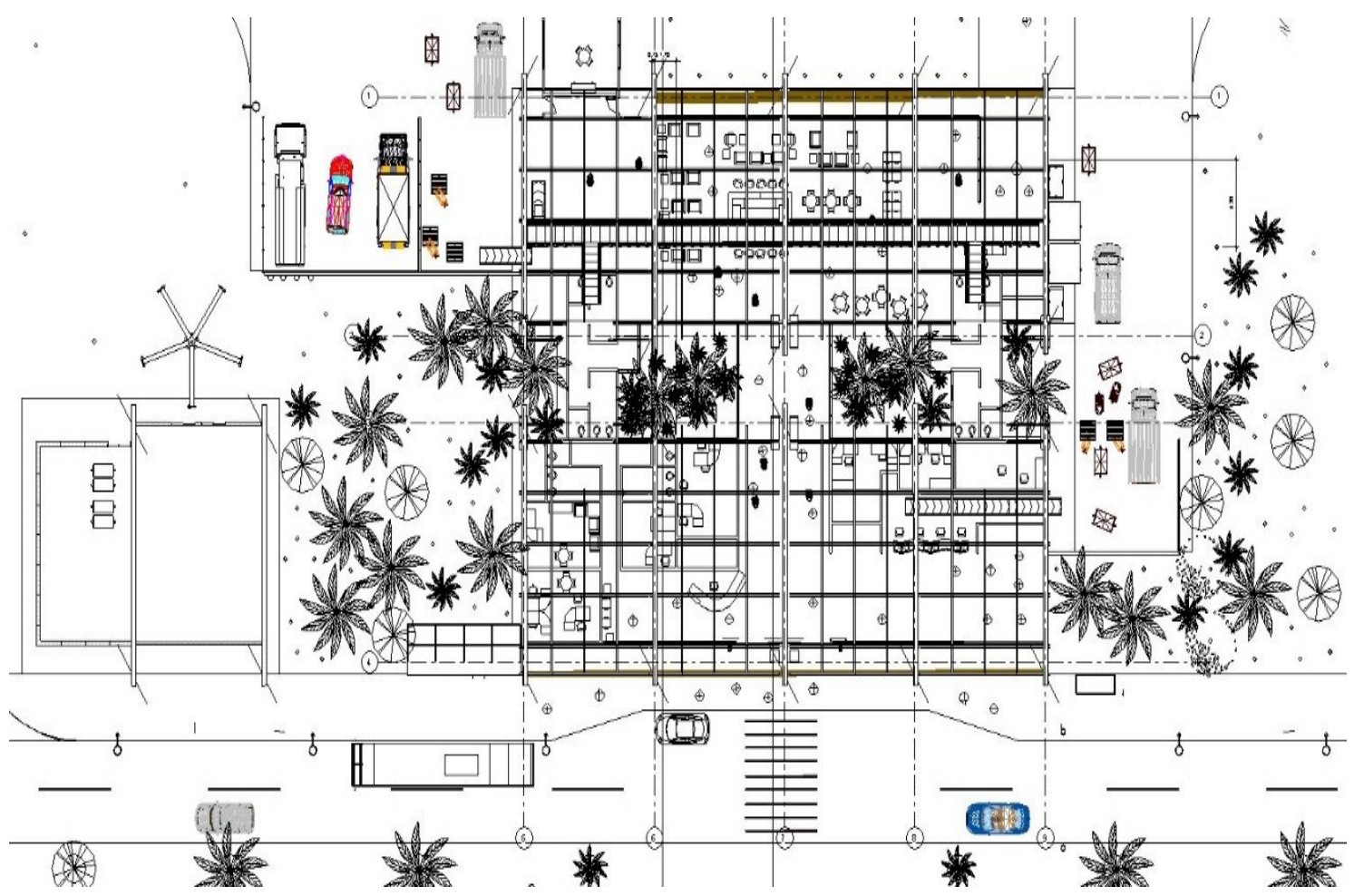

Figura 127- Modelagem do Terminal Regional em BIM. Planta baixa. Fonte: INFRAERO.

A Figura 127 acima representa a inserção de planta de referência cedida pela INFRAERO par servir como "guia" de modelagem no Revit ${ }^{\circledR}$. A modelagem do terminal regional ocorreu tanto através da utilização das famílias nativas do aplicativo como através da utilização do ambiente de "massa" para modelagem de formas curvas e/ou complexas.

\section{A MODELAGEM DO TERMINAL REGIONAL OCORREU EM DUAS ETAPAS:}

1- A PRIMEIRA ETAPA refere-se à modelagem nos sistemas BIM;

2- Na SEGUNDA ETAPA foi feita a importação de dados de satélite do terreno para visualizar a inserção do projeto no relevo existente e assim obter informação para escolher o melhor local de implantação e ainda dos impactos e interferências que poderiam existir. Foi então realizada a importação do aeroporto modelado previamente no Revit $^{\circledR}$ para o ambiente de trabalho do InfraWorks ${ }^{\circledR}(S I G)$, de forma a obter uma visão sistêmica da infraestrutura do terminal de passageiros e do contexto existente (entorno imediato). 


\subsection{2- MODELO BIM (REPRODUÇÃO POR MEIO DE MODELAGEM DO TERMINAL DE PASSAGEIROS REGIONAL - ARQUIVOS 2D CEDIDOS PELA INFRAER0)}

RESULTADOS DA MODELAGEM DO TERMINAL REGIONAL.

1- PREPARAÇÃo e CUSTOMIZAÇÃo do AMBIENTE de TRABALHO. Foi realizada a configuração da interface $\operatorname{Revit}^{\circledR}$, utilizando a unidade de medida correta, no caso em metros e das definições de "grid" e ainda dos níveis customizados de projeto. Os níveis conduzem a modelagem dos diversos pisos e cobertura, informando as alturas corretas dos componentes construtivos.

2- INSERÇÃO DE PLANTA REFERENCIAL DO PROJETO EXISTENTE. Foi realizada a inserção de uma planta de referência que correspondeu ao projeto adotado, servindo de "guia" para o desenvolvimento do projeto nos sistemas BIM. Isto funcionou como uma marca d'água orientando a modelagem das paredes, fechamentos e permitindo uma compreensão clara das funções na edificação, auxiliando o arquiteto a organizar e racionalizar seu ambiente de trabalho, pois muitos componentes devem ser inseridos e/ou modelados (Figuras 128 e 129).

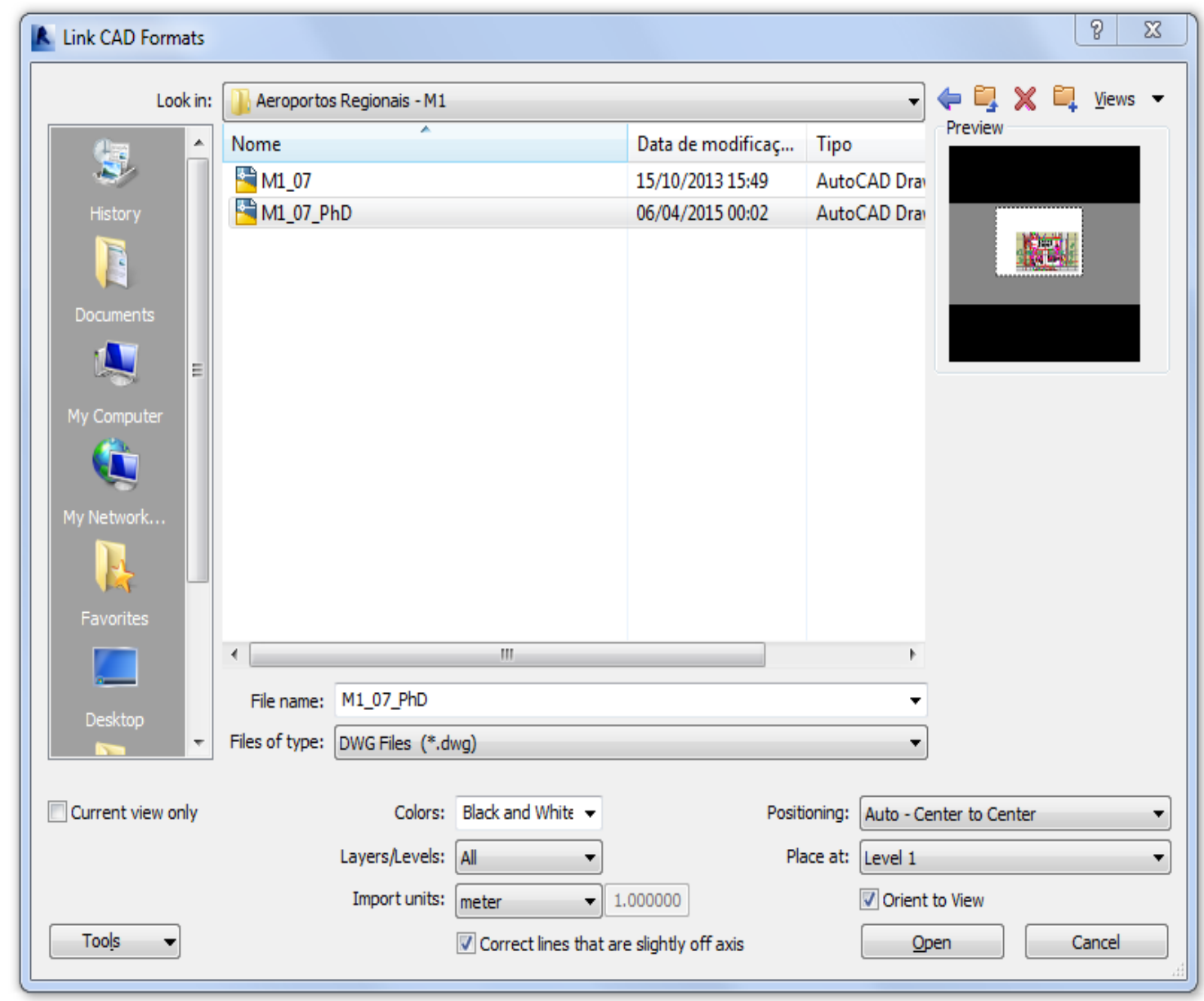

Figura 128- Inserção de planta bidimensional CAD como guia de modelagem no Revit ${ }^{\circ}$. 


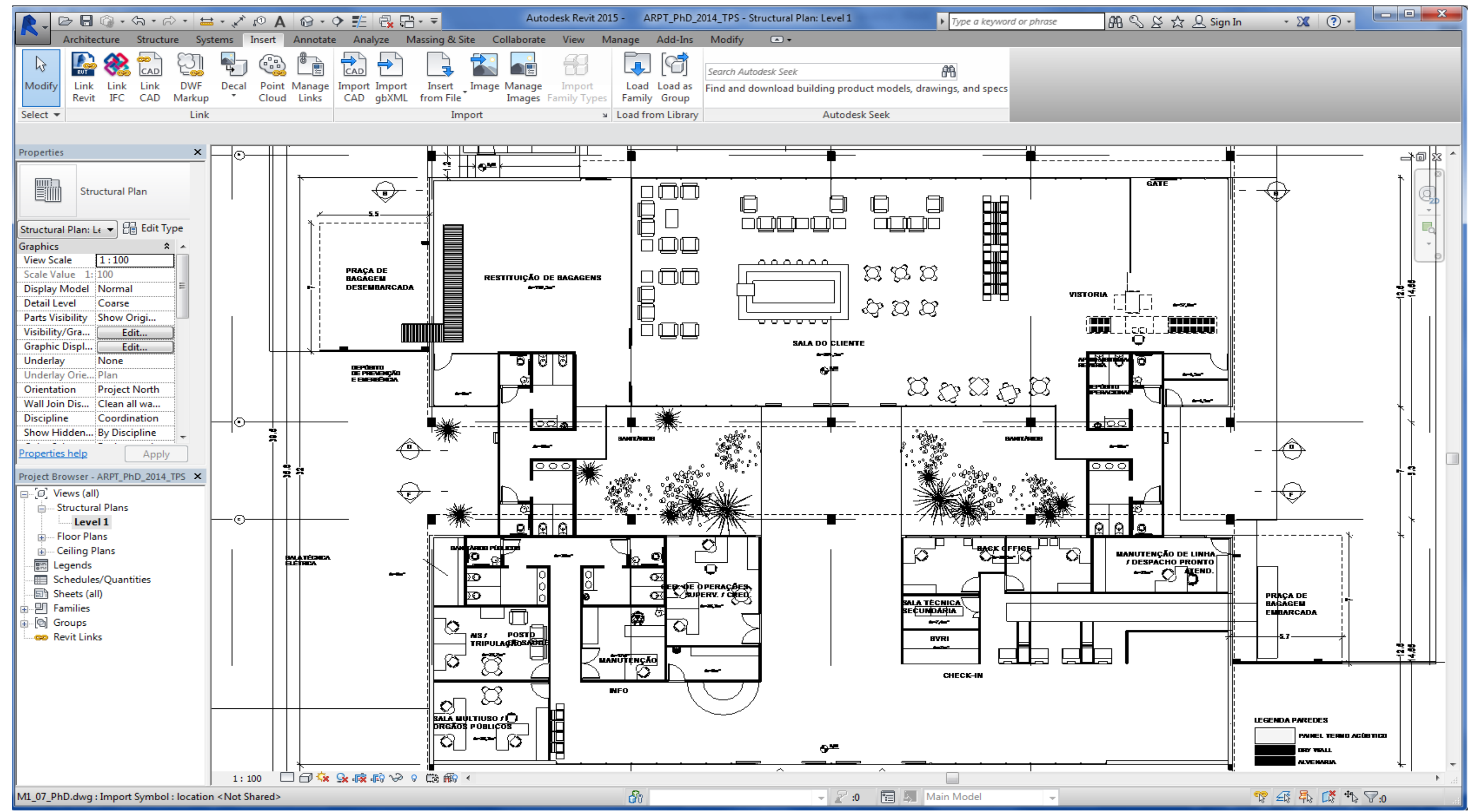

Figura 129- llustração de importação de planta baixa CAD-2D do Terminal Regional no Revit.

NA FIGURA 129 ACIMA PODE-SE OBSERVAR A PLANTA PROVENIENTE DO AUTOCAD ${ }^{\circledR}$ INSERIDA NO NÍVEL 1 DE PROJETO NO APLICATIVO REVIT ${ }^{\circledR}$ E SERVE COMO GUIA PARA AUXILIAR NA MODELAGEM TRIDIMENSIONAL PARAMÉTRICA.

CONSULTAS A INFORMAÇÕES COMPLEMENTARES COMO SEÇÕES, FACHADAS E DOCUMENTOS TÉCNICOS ANEXOS AO PROJETO DO TERMINAL REGIONAL, COMO MEMORIAIS DESCRITIVOS ESPECIFICAÇÕES TÉCNICAS FORAM TAMBÉM NECESSÁRIOS. 
3- PREPARAÇÃO DO ENTORNO IMEDIATO. MODELAGEM DO TERRENO, VIAS DE ACESSO E DEMAIS INFRAESTRUTURAS QUE CERCAM O TERMINAL DE PASSAGEIROS

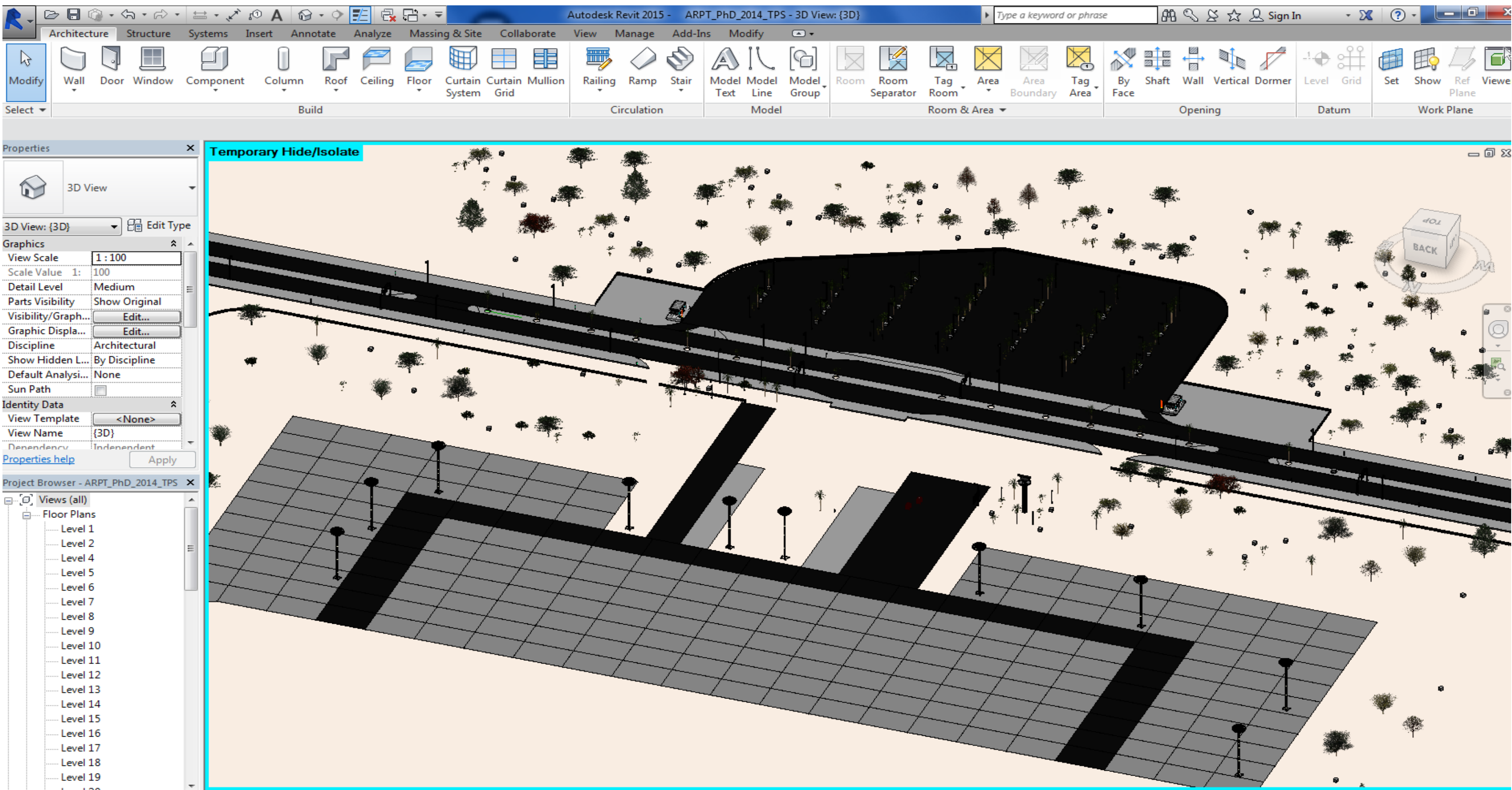

Figura 130- Ilustração do resultado gráfico da modelagem de Pátio, Calçadas e Vias de Acesso ao Terminal Regional no Revit .

NA FIGURA 130 ACIMA PODE-SE OBSERVAR A MODELAGEM DA INFRAESTRUTURA DE PAVIMENTAÇÃO, ACESSO VIÁRIOS E DE PEDESTRES, BEM COMO DO ESTACIONAMENTO DE VEÍCULOS, PISOS DO TERMINAL REGIONAL E DO PÁTIO DE AERONAVES.
A INFRAESTRUTURA AEROPORTUARIA MODELADA PODE SER EXPORTADA PARA APLICATIVOS COMO O CIVIL3D DA AUTODESK, QUE PERMITE O GERENCIAMENTO DE ASPECTOS TOPOGRAFICOS E GEOTECNICOS COMPLEMENTARES AO PROJETO DE ARQUITETURA. 


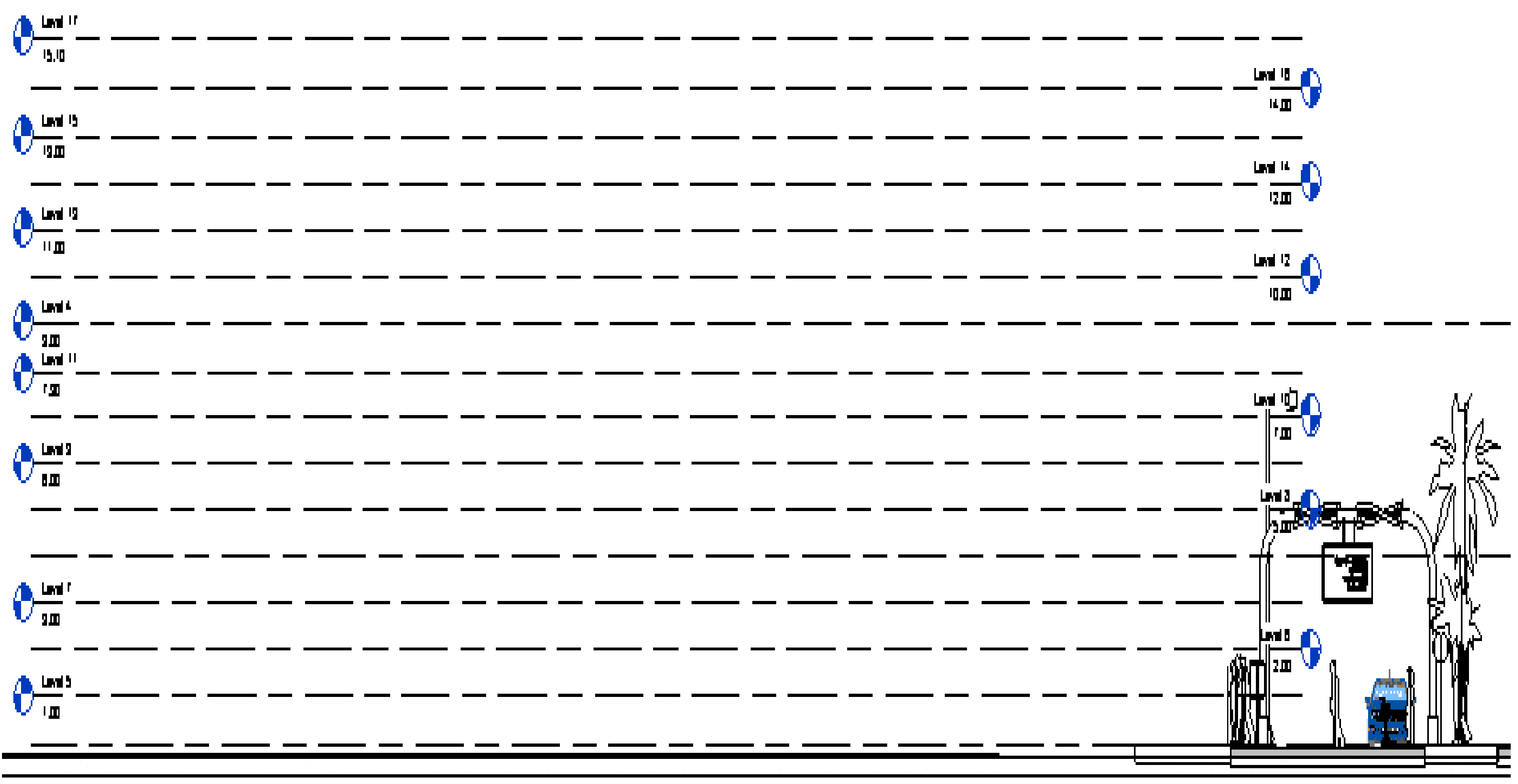

Figura 131- Ilustração da criação de diferentes níveis para a modelagem do Terminal Regional no Revitº.

A FIGURA 131 ACIMA ILUSTRA A CRIAÇÃO DOS DIVERSOS NIVEIS DO EDIFICIO, REFERENTES AOS PISOS E COBERTURAS DO TERMINAL REGIONAL. A FIGURA 132 A SEGUIR ILUSTRA A

A MODULAÇÃO DOS PILARES FACILITA O PROCESSO DE MODELAGEM. O MESMO TIPO DE MODELAGEM DOS PILARES DO TERMINAL REGIONAL, INSERIDOS NO PISO DA EDIFICAÇÃO. 


\section{5- CONSTRUÇÃO DE PILARES}

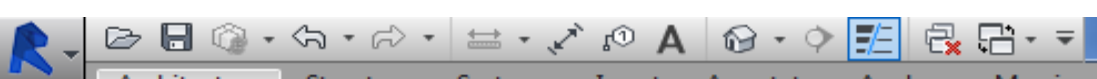

列

- Type a keyword or phrase

$\cdot x$ (2) a

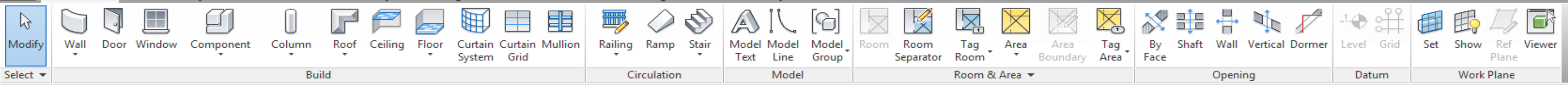
Properties

8 3D View

$3 \mathrm{DView:}\{3 \mathrm{D}\} \quad \nabla$ 䟺 Edit Type

$\begin{array}{lll}\text { Graphics } \\ \text { View Scale } & 1: 100 & \hat{3}\end{array}$

\begin{tabular}{ll}
\hline Scale value 1: & 100 \\
\hline Detail Level Medium &
\end{tabular}

Parts Visibility Show Original

Graphic Displa...

Discipline

Show Hidden L.... By Discipline

dentity Data

View Template <None>

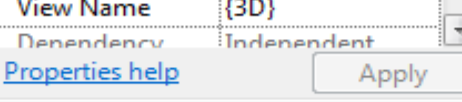

Project Browser - ARPT_PhD_2014__PS $\times$

3 Diew 20
Copy of $\{30\}$

[Dop\}
[D... Elevations (Building Elevation

East

North
South
West
West

- Sections (Building Section)

Section 1

Section 3

Thenderings

圆 Legends

贯 Schedules/Quantities

國 Sheets (all)

由. [ㅁ] Groups

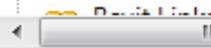
Circulation Room \& Area -

Opening Datum Work Plane

Figura 132- Ilustração de modelagem dos pilares no Terminal Regional - Revit.

NA FIGURA 132 ACIMA PODE-SE OBSERVAR OS PILARES MODELADOS, ATRAVÉS DA UTILIZAÇÃO DE FAMÍLIA NATIVA DO REVIT ${ }^{\circledR}$, PARA O TERMINAL REGIONAL.

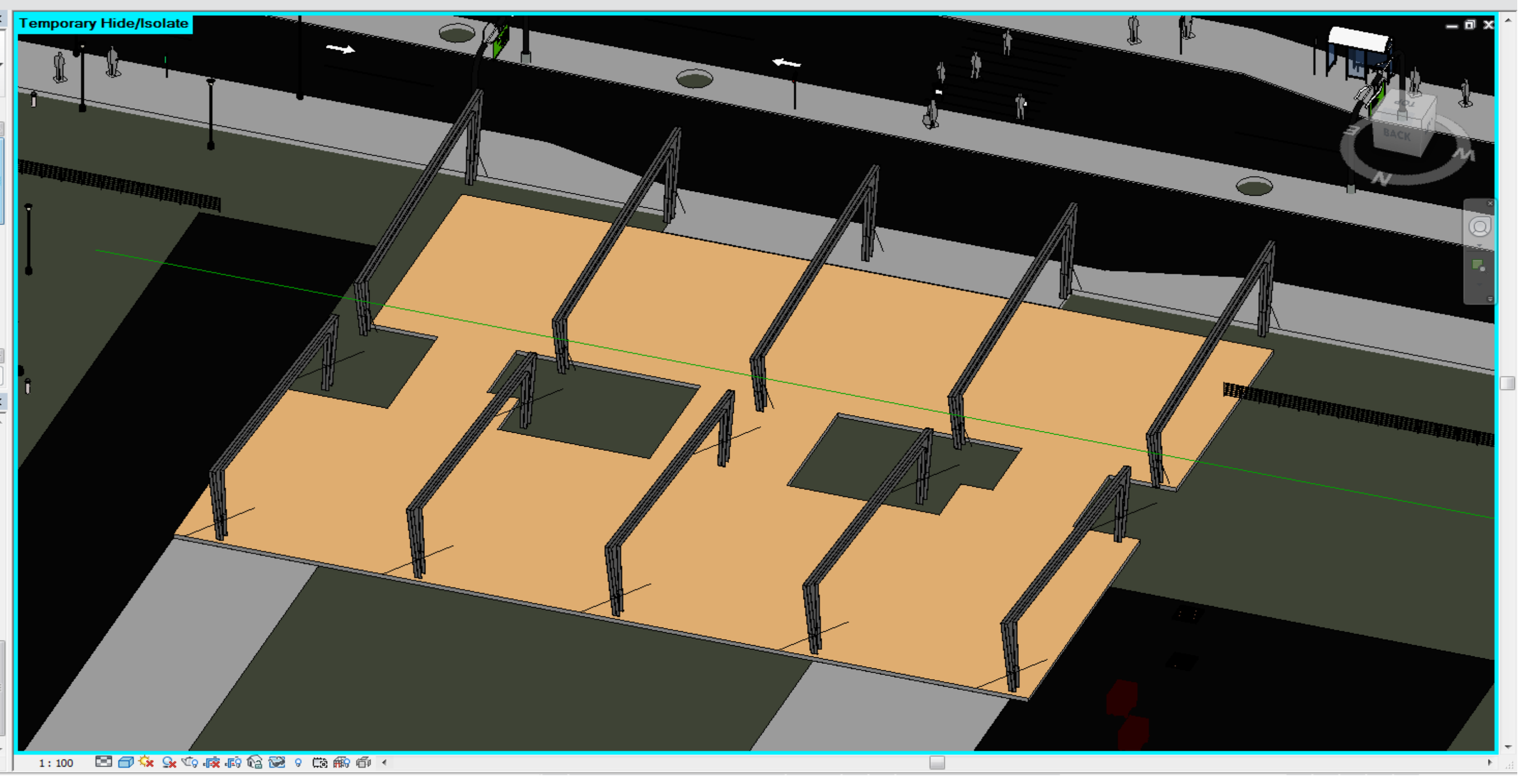

COMO OS PILARES SÃO MODULARES, FOI NECESSÁRIA A MODELAGEM DE APENAS UM ELEMENTO E DEPOIS FOI EFETUADA A COPIA DO ELEMENTO EM DIVERSAS INSTANCIAS NO PROJETO. 


\section{6- CONSTRUÇÃO DE PAREDES INTERIORES}

AS FIGURAS 133 A 135 REPRESENTAM A MODELAGEM DAS PAREDES E ESQUADRIAS E COBERTURA DO TERMINAL, RESPECTIVAMENTE.
AS PAREDES FORAM MODELADAS DE ACORDO COM A PLANTA BAIXA INSERIDA COMO "GUIA". FORAM CRIADAS PAREDES EM DIFERENTES NIVEIS DA EDIFICACAO.

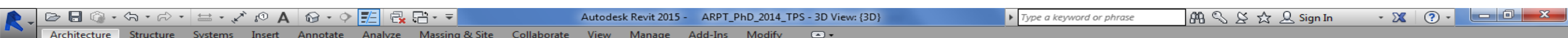

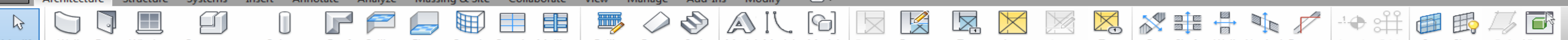

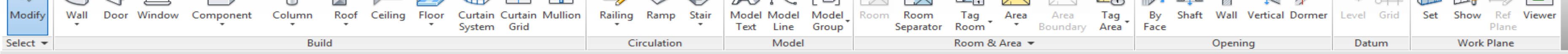

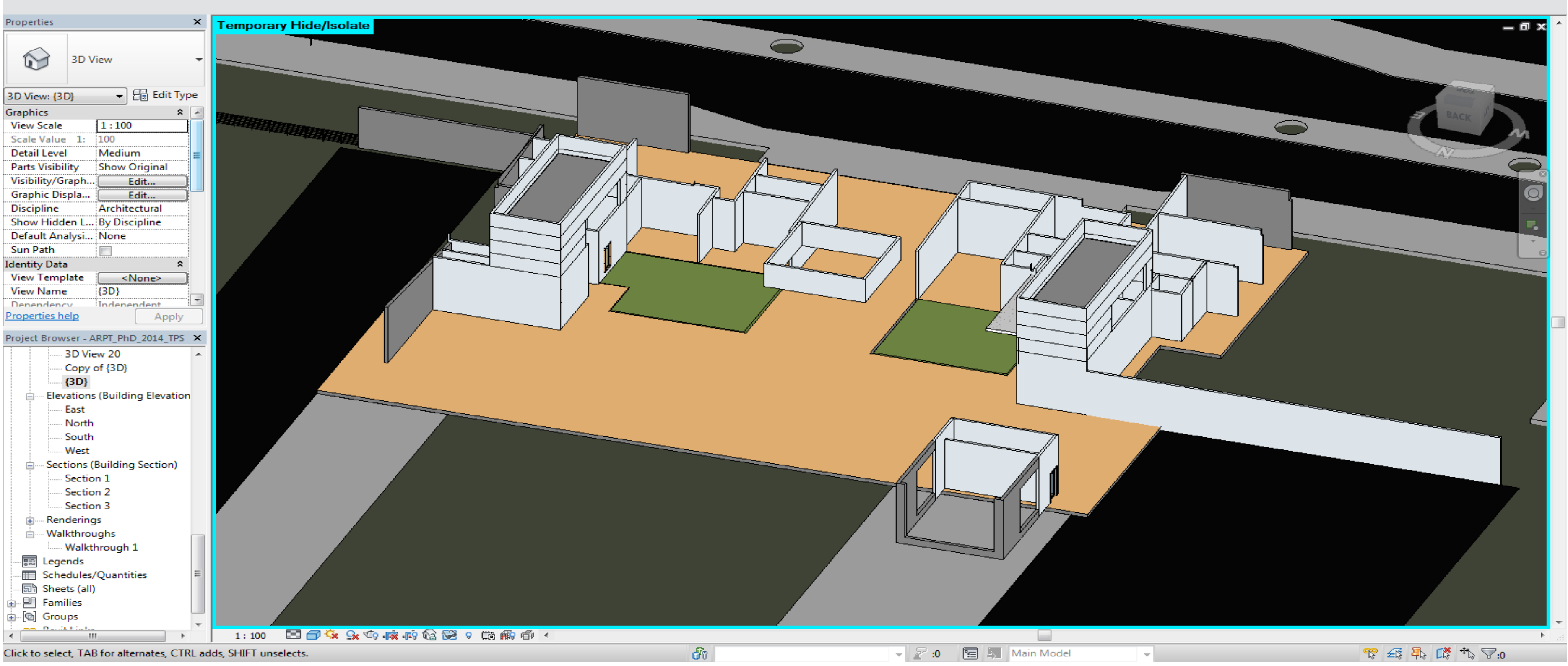

Figura 133- llustração de modelagem das paredes do Terminal Regional.

NA FIGURA 133 ACIMA PODE-SE OBSERVAR AS PAREDES MODELADAS DO TERMINAL REGIONAL NO REVIT ${ }^{\circledR}$.

OBSERVA-SE QUE ESTÃO PRESENTES EM MAIS DE UM NÍVEL E FORAM CRIADAS DENTRO DE CADA UM DESSES NIVVEIS DESCRITOS NA FIGURA 131). 


\section{7- ADICIONAR PORTAS / JANELAS E DEMAIS ELEMENTOS DE FECHAMENTO}

A-

Autodesk Revit 2015 - ARPT_PhD_2014_TPS - 3D View: \{3D\}

- Type a keyword or phrase

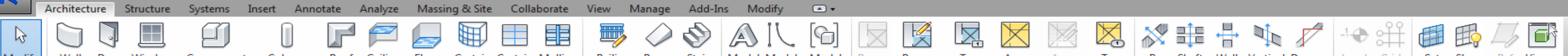

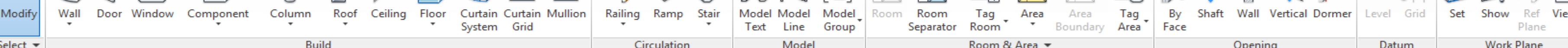

\begin{tabular}{|l|l|}
\hline Properties & \\
\hline \multicolumn{1}{|c|}{ 3D View } \\
\hline 3D View: $\{3 \mathrm{DD}\}$ \\
\hline Graphics \\
View Scale
\end{tabular}

Project Browser -ARPT_PhD_2014_TPS $x$

3D View 20

Copy of $\{3 \mathrm{D}\}$
\{3D\}
... Elevations (Building Elevation

Elevation

East

North
South

West

-.... Wections (Building Section)

Section 1
Section 2

Section

1..... Renderings

Walkthrough 1

圆 Legends

Schedules/Quantities

國 Sheets (all

[ø] Groups

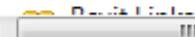

Build

Circulation

Model

Room \& Area

Opening

Datum

Click to select, TAB for alternates, CTRL adds, SHIFT unselects.

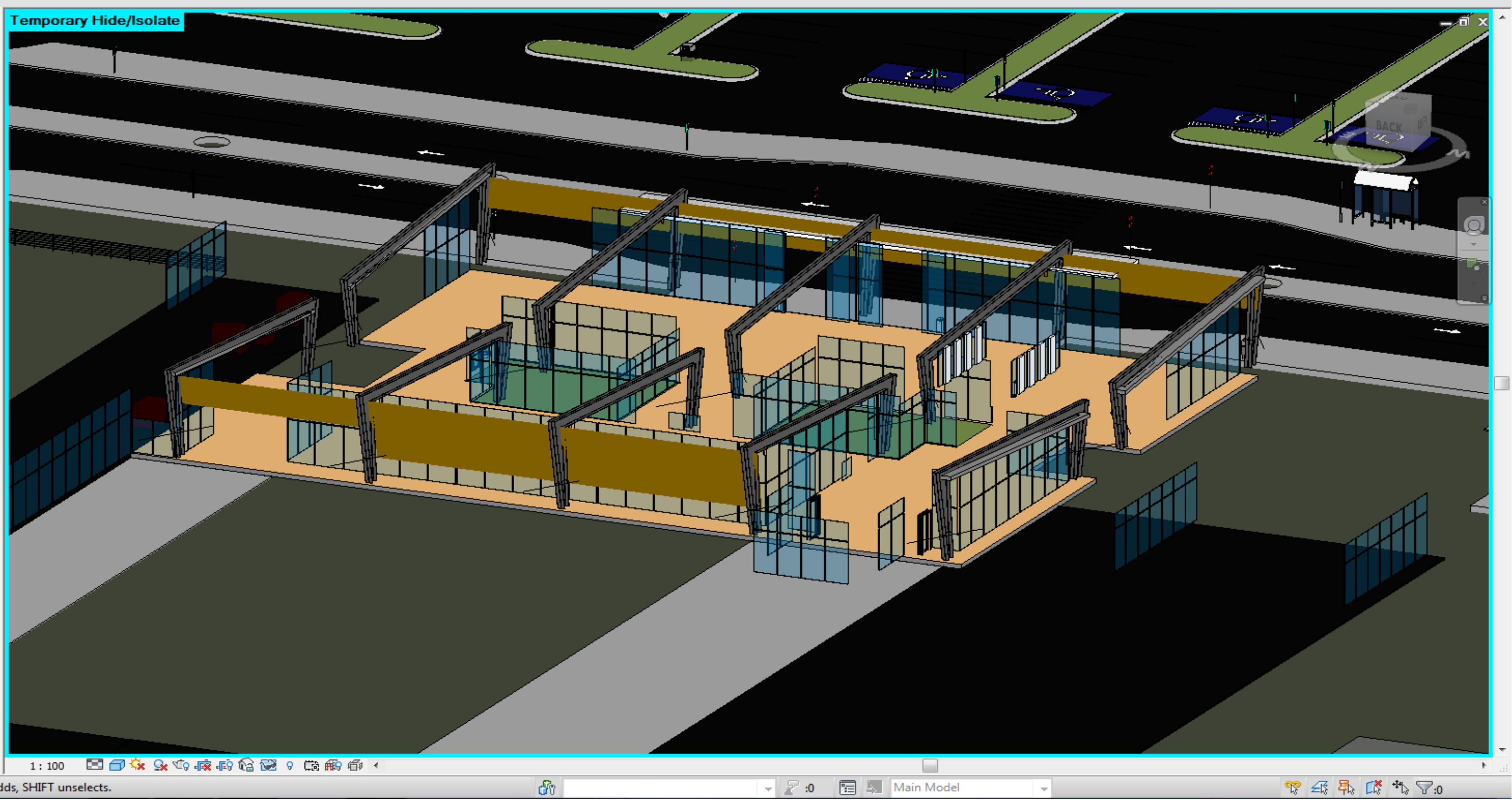

Figura 134- llustração de modelagem das esquadrias do Terminal Regional no Revit ${ }^{\circ}$.

NA FIGURA 134 ACIMA PODE-SE OBSERVAR A INCLUSÃO DE ESQUADRIAS (PORTAS E JANELAS) PARA O TERMINAL REGIONAL.

FORAM UTILIZADAS PORTAS DE CORRER E CORTINAS DE VIDRO, COMPONENTES NATIVOS DO APLICATIVO REVIT ${ }^{\circledR}$ 


\section{8- CONSTRUÇÃO DE COBERTURAS}

A.

Autodesk Revit 2015 - ARPT_PhD_2014_TPS - 3D View: $\{3 D\}$

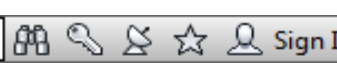

$x$ (3) Architecture Structure Systems Insert Annotate Analyze Massing \& Site Collaborate View Manage Add-Ins Modify $\square$ -

Select

$$
\text { Build }
$$

$$
\text { Circulation }
$$$$
\text { Model }
$$

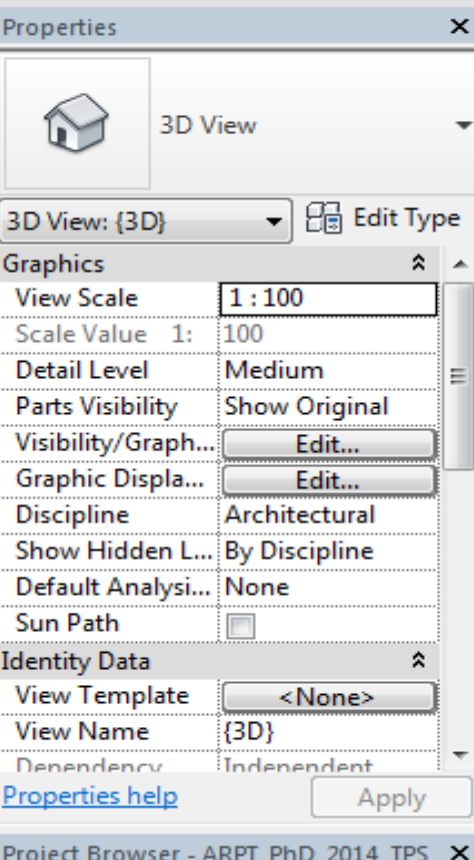

Project Browser - ARPT_PhD_2014_TPS $x$

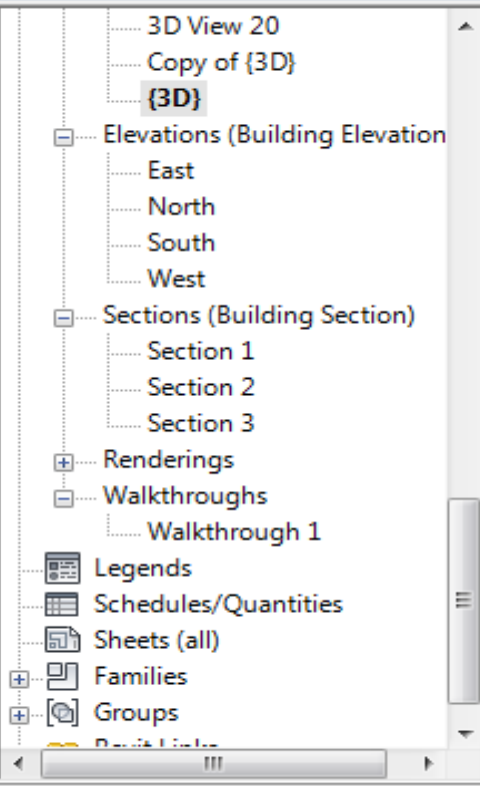

\section{Temporary Hide/lsolate}

Room \& Area $Y$

Opening

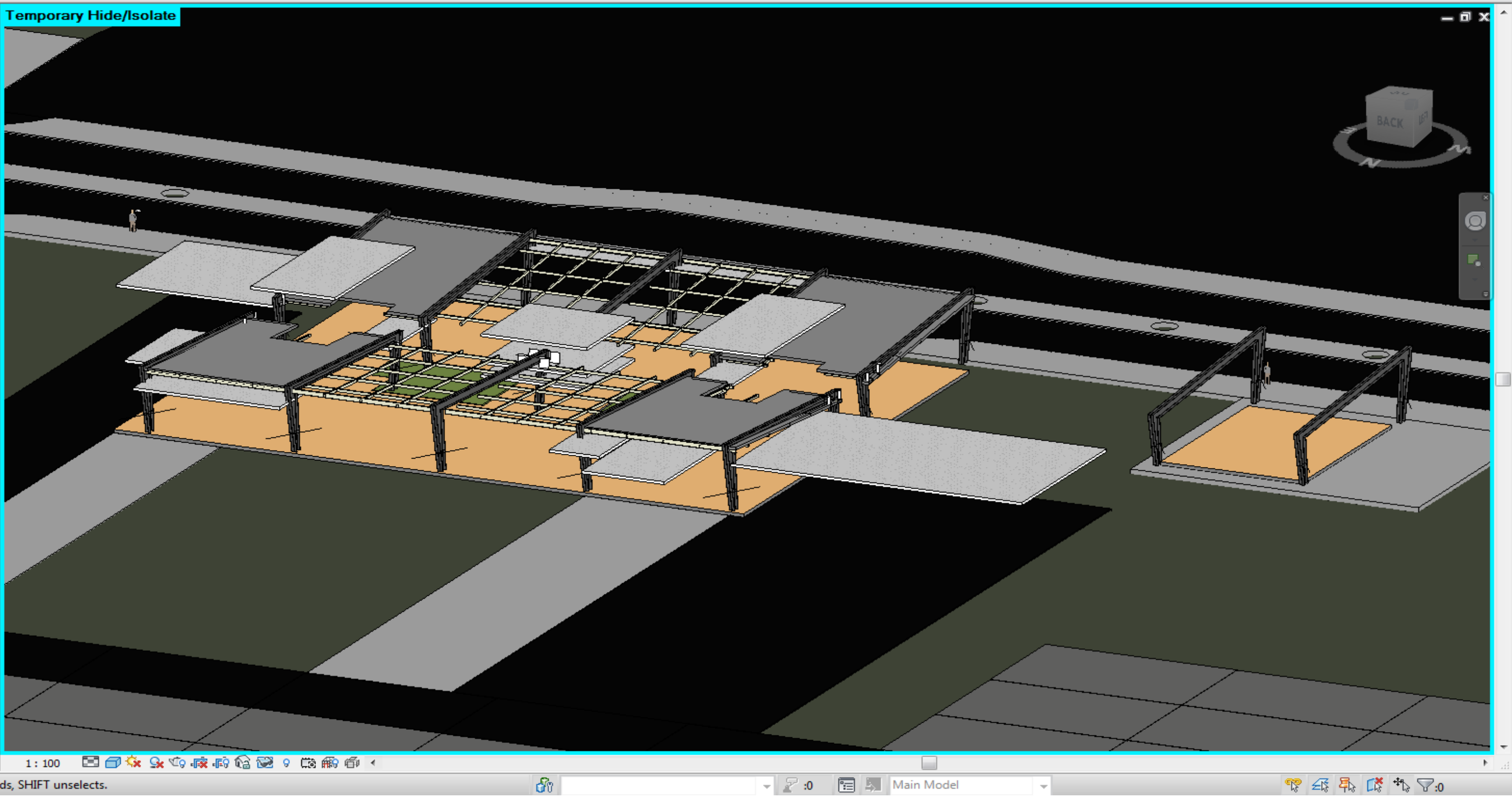

Click to select, TAB for alternates, CTRL adds, sH

NA FIGURA 135 ACIMA PODE-SE OBSERVAR A ILUSTRAÇÃO PARA A MODELAGEM PARAMÉTRICA DAS COBERTURAS DO TERMINAL REGIONAL NO APLICATIVO REVIT ${ }^{\circledR}$

AS COBERTURAS DO TIPO "STEEL-DECK”, FORAM MODELADAS EM FAMILIA NATIVA DOS SISTEMA NO APLICATIVO REVIT ${ }^{\circledR}$ ARCHITECTURE. 


\section{9- - ADICIONAR OBJETOS}

A FIGURA 136 E 137 REPRESENTAM A ADIÇÃO DE COMPONENTES NO TERMINAL REGIONAL

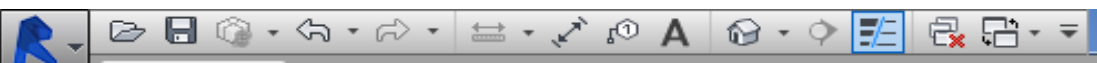

- Type a keyword or phrase

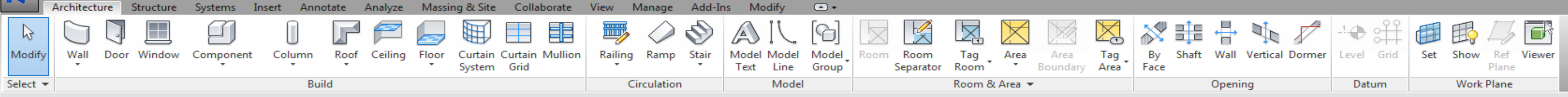

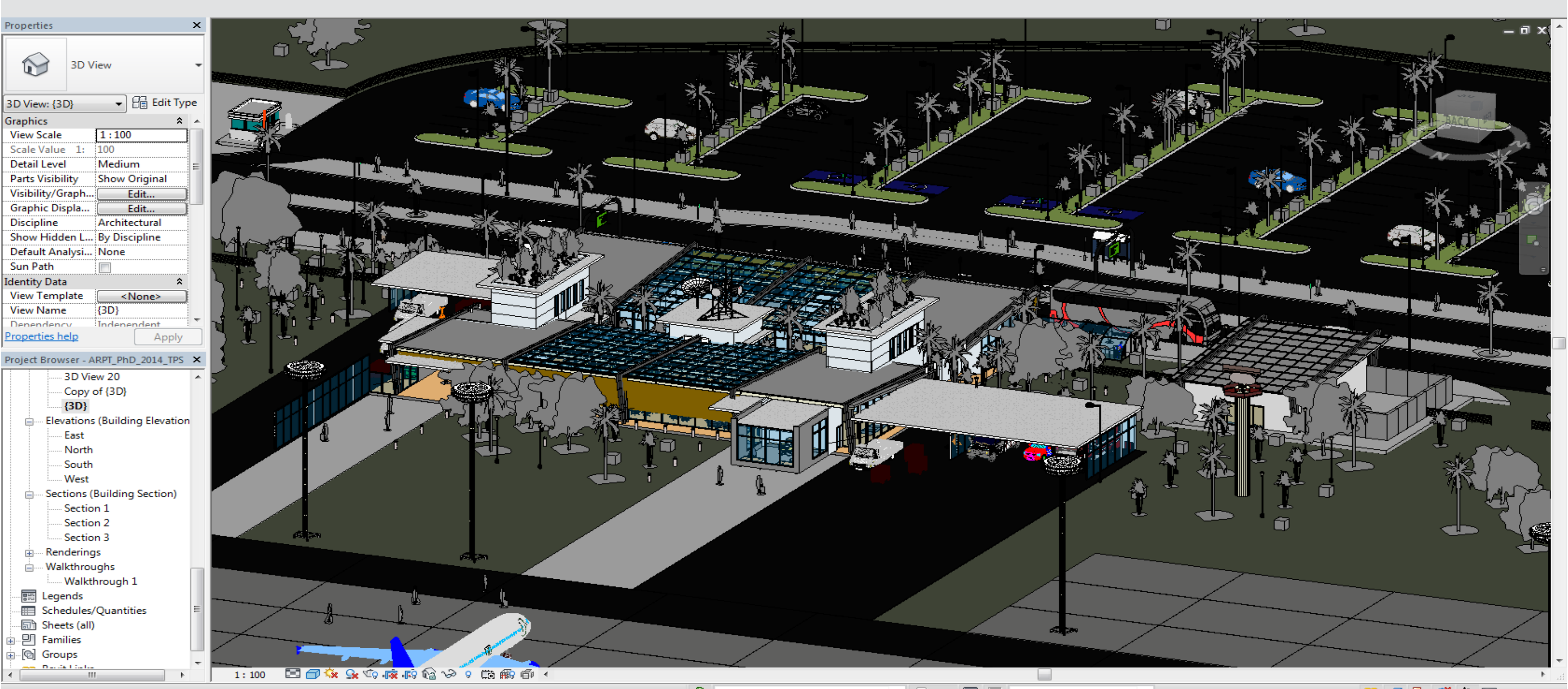

Tlors: Floor: Generic Floor - $400 \mathrm{~mm}$ - Filled :

80

5. 0 Main Mode

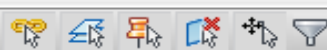

Figura 136- Ilustração de inserção de componentes no Terminal Regional. - Revit

NA FIGURA 136 ACIMA PODE-SE OBSERVAR DIVERSOS COMPONENTES DE DIFERENTES FAMÍLIAS QUE FORAM INSERIDOS NO TERMINAL MODELADO O GERENCIAMENTO DOS PARÂMETROS DE COMPONENTES INSERIDOS NEM SEMPRE É NECESSÁRIO.
POR EXEMPLO, OS AUTOMÓVEIS INSERIDOS, QUE NÃO OFERECEM INFORMAÇÃO RELEVANTE, PARA A CONSTRUÇÃO DO TERMINAL REGIONAL DE PASSAGEIROS. PORTANTO, NÃO INTERESSA GERENCIAR SEUS PARAMETROS NO CONTEXTO DE PROJETO DO TERINAL REGIONAL. 


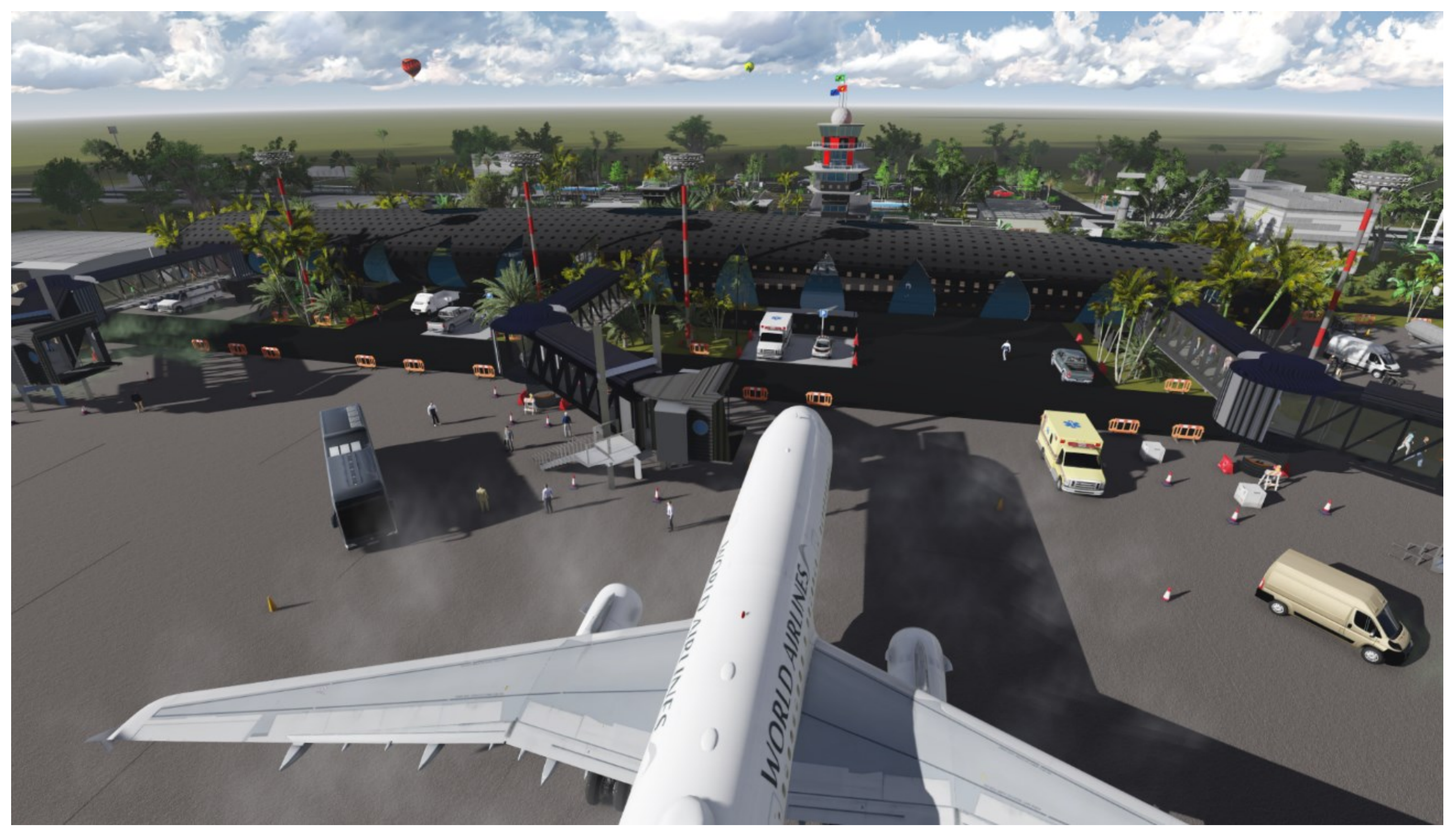

Figura 137- Ilustração da inserção de componentes complementares ao Terminal Regional no Revit.

NA FIGURA 137 ACIMA PODE-SE OBSERVAR, EM DETALHE, O PÁTIO DE AERONAVES, INCLUSIVE COM O APOIO DE RAMPA E SERVIÇO REMOTO DE EMBARQUE E DESEMBARQUE. RESSALTA-SE

A UTILIZAÇÃO DA PONTE DE EMBARQUE MODELADA PARA A CONEXÃO DOS PASSAGEIROS DA AERONAVE COM O EDIFÍCIO DO TERMINAL REGIONAL. 


\section{0-PARAMETRIZAÇÃO DOS ELEMENTOS CONSTRUTIVOS}

A parametrização refere-se ao ajuste dos parâmetros dos objetos criados ou inseridos no projeto em relação ao universo e contextos do projeto de arquitetura.

Em decorrência de alguma tomada de decisão em relação ao sistema construtivo adotado, ou a alguma definição de objeto ou de material, será necessário que os demais se harmonizem com esta mudança, refletida em seus parâmetros para que assumam uma nova configuração mais adequada para o empreendimento em que ela se encontra inserida.

A essência do processo de projeto paramétrico, desenvolvido nesta pesquisa, residiu nas relações de dependência entre os componentes construtivos e a função que desempenham na edificação, de forma a serem incorporados ao modelo no sistema BIM.

A parametrização dos objetos no Revit $^{\circledR}$ variou de acordo com o componente construtivo e situações específicas de projeto.

Componentes como paredes, pisos, pilares, vigas e coberturas são chamados "nativos" do sistema, e devem ser configurados quanto às relações de dependência em relação a outros componentes de sistema.

Por exemplo, foi necessário configurar as paredes para que estivessem conectadas às lajes e que fossem limitadas pelos níveis corretos, para que pudessem obedecer às alturas indicadas (Figura 138 a seguir).

Vigas e pilares foram configurados quanto ao piso de referência a que pertenciam (hospedeiros) e ainda quanto às suas características internas, altura e dimensões da base, bem como sobre o tipo de pilar escolhido, se estrutural ou de arquitetura apenas. Foi escolhido o do tipo estrutural.

A diferença reside no fato de que o tipo estrutural pode ser manipulado no Revit ${ }^{\circledR}$ Structure, de cálculo estrutural.

Rotineiramente foi duplicado o componente construtivo por meio da aba "Propriedades", ao clicar em "Editar tipo". Depois decidiu-se clicar em "Duplicar", inserindo um novo nome para o pilar, porque desta forma pode-se alterar características e parâmetros sem interferir com o componente default da biblioteca existente. 


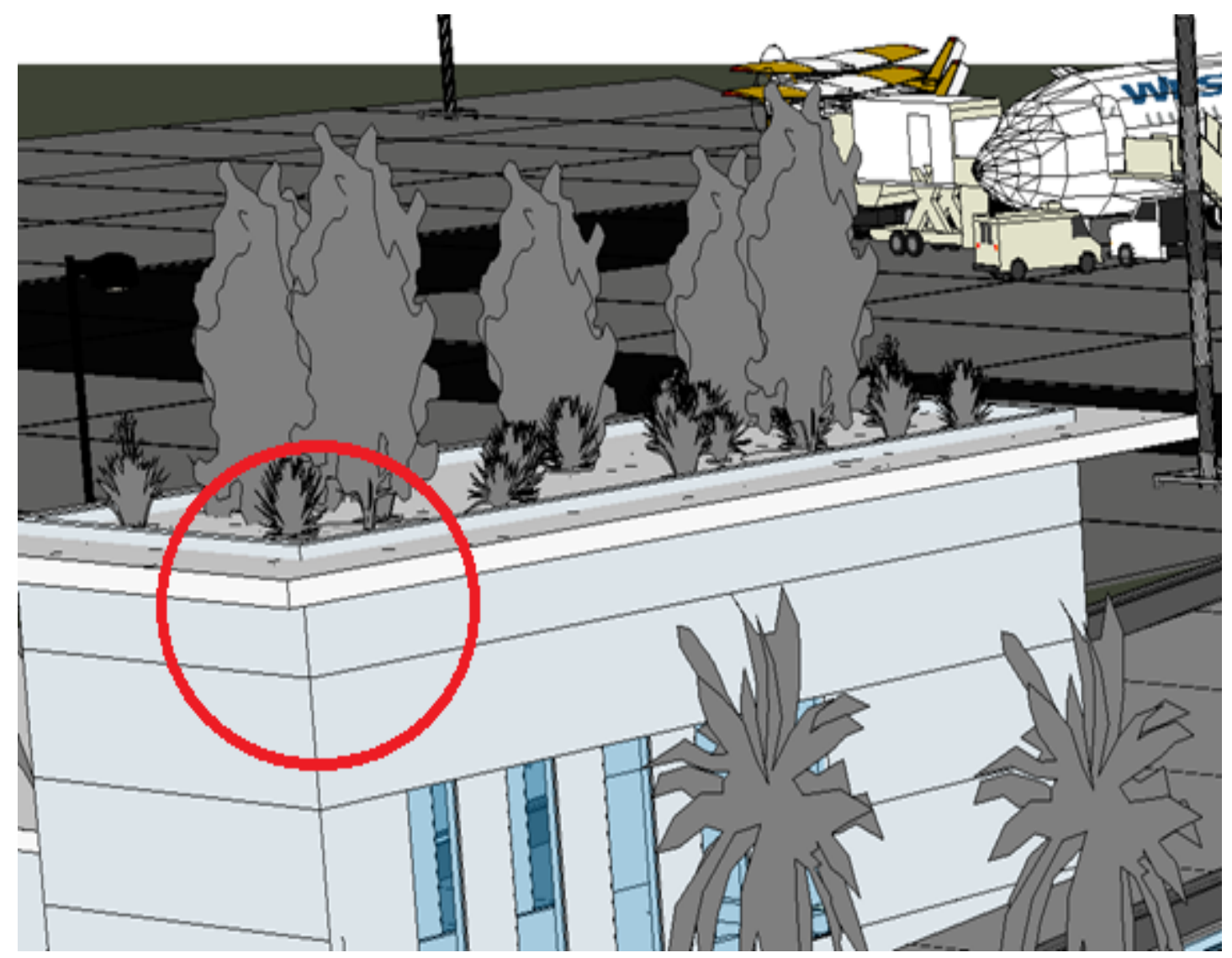

Figura 138- Ilustração da ligação paramétrica de relacionamento entre as paredes e lajes do Terminal Regional no Revit ${ }^{\circ}$.

A Figura 138 acima representa a conexão (dependência) entre duas instancias diferentes no Revit ${ }^{\circledR}$.

Através da configuração de parâmetros, torna-se possível estabelecer que as paredes do terminal regional estejam "conectadas" à face inferior das lajes, de forma que se, por ventura, a altura das lajes for modificada, as paredes deverão acompanhar automaticamente a modificação.

O objetivo é aproveitar um componente semelhante para "clonar" sua estrutura geral e depois personalizá-lo de acordo com as intenções de projeto.

Para todos os componentes existentes no Revit ${ }^{\circledR}$, como pilares, pisos, vigas, paredes, esquadrias, panos de vidro, etc., podemos aplicar essa mesma lógica de reaproveitamento de um componente pré-existente.

Procedemos então à configuração da "Altura": para determinar a altura da base e ainda vincular a parte superior do pilar à altura da laje ou cobertura superior (Figura 139 na página seguinte). 
10.2- CARACTERISTICAS INTRINSECAS DOS COMPONENTES

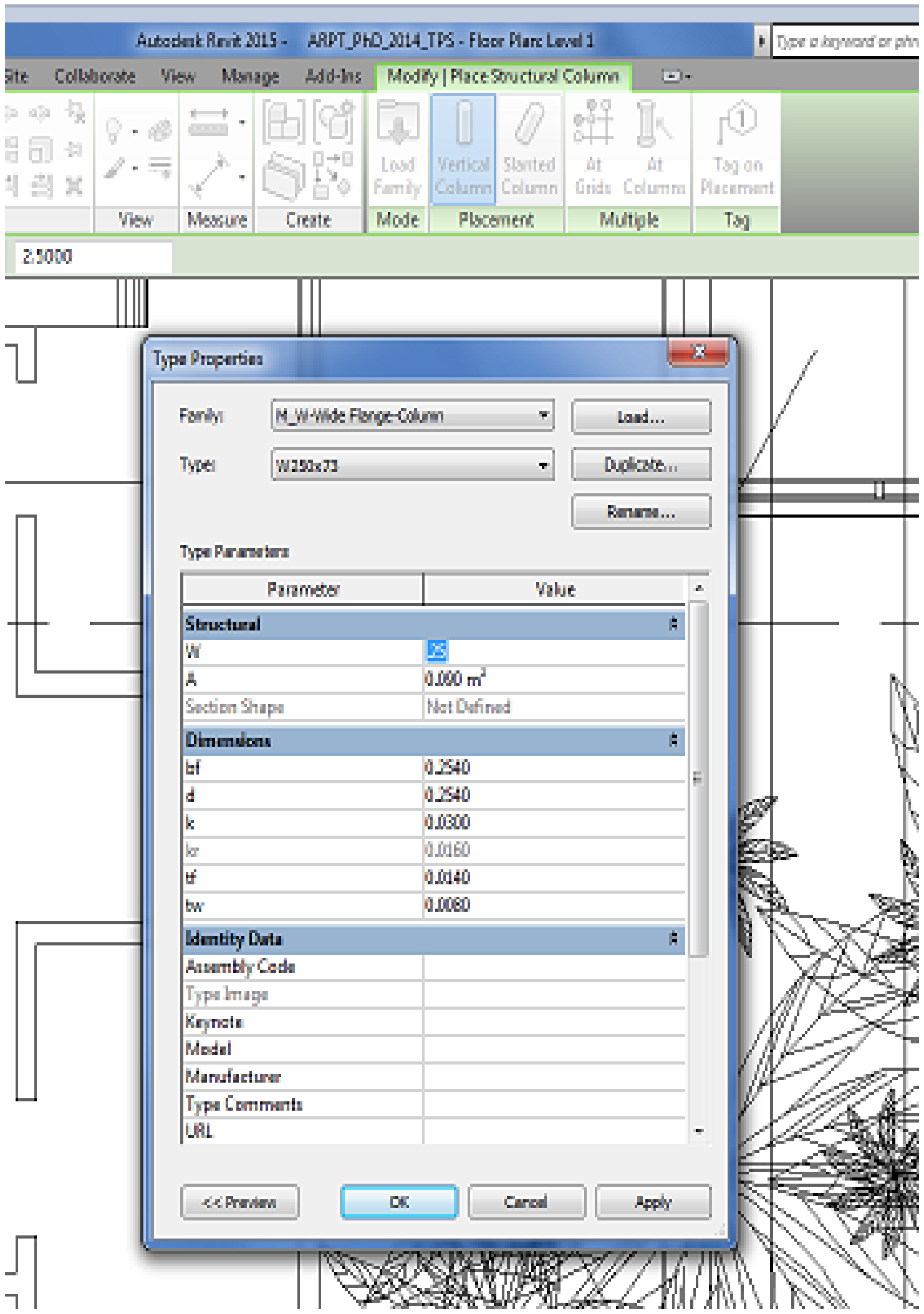

Figura 139- Configuração das dimensões da base em um pilar no Terminal Regional no Revit .

Inserimos então o pilar na área de trabalho rotacionando conforme a necessidade, se precisarmos alinhar os eixos do componente com os eixos de referência de projeto, além de utilizar a ferramenta "Mover" para colocar o pilar no local indicado na planta baixa que importamos do AutoCAD ${ }^{\circledR}$ (Figura 140 a seguir). 


\section{3- LOCACAO DOS COMPONENTES CONSTRUTIVOS}

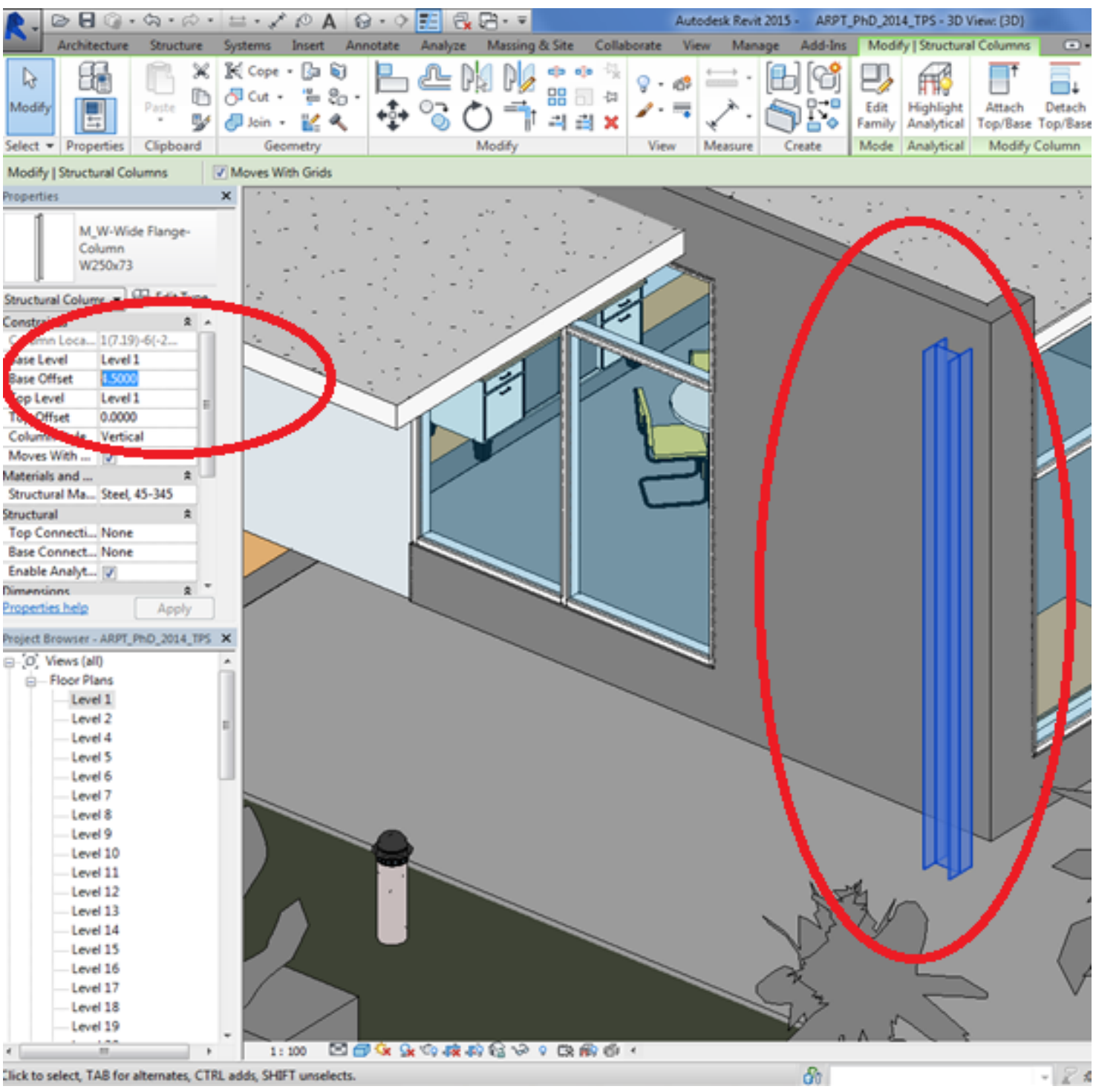

Figura 140- Ilustração da criação de um pilar do Terminal Regional com família nativa do sistema no Revit ${ }^{\circ}$.

Na Figura 140 acima observa-se exemplo de criação de um pilar por meio de família nativa do aplicativo Revit ${ }^{\circledR}$. Em destaque (elipse em vermelho) aparece a geometria e o parâmetro relacionado com a altura do pilar.

A modelagem do terminal serviu para amparar o emprego das bibliotecas e ainda o desenvolvimento de uma situação especifica de projeto em que pode-se avaliar processos de criação de projeto (torres) com o objetivo de simular os estágios iniciais de projetação.

Ressalta-se a inadequação apresentada pelos sistemas BIM - Revit $^{\circledR}$ na realização do que se chama "Little BIM" (onde só participa a especialidade de arquitetura), uma vez que diversos campos de parâmetros presentes nos componentes "default" devem ser preenchidos a partir da interação com os profissionais de outras especialidades. 
11-- CONSTRUÇÃO DO MODELO: CORTES, FACHADAS.

AS FIGURAS 141 E 142 APRESENTAM OS CORTES E FACHADAS OBTIDOS NO REVIT,

A FIGURA 142 APRESENTA A PLANTA BAIXA OBTIDA NO REVIT.

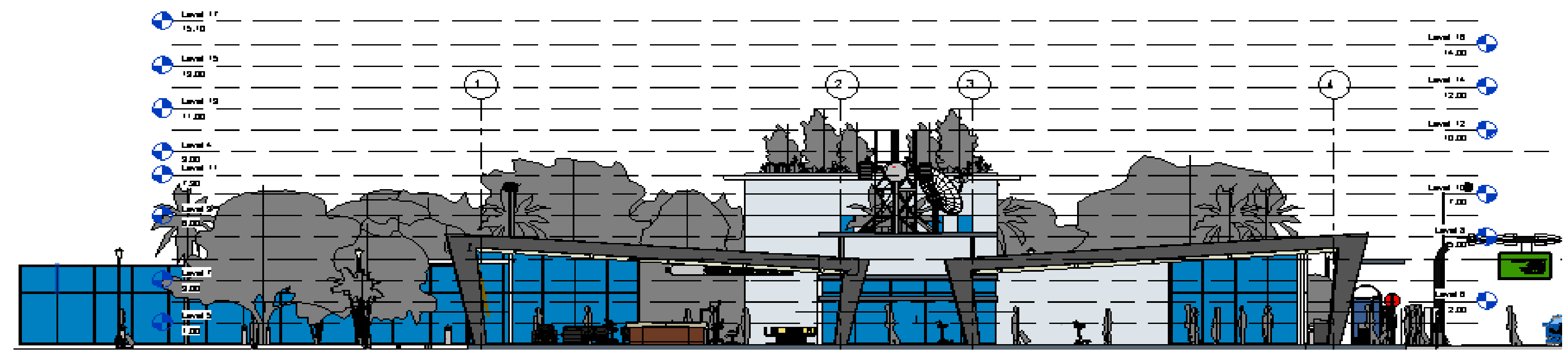

Figura 141- Corte do Terminal Regional obtido de forma automática no Revit .

NA FIGURA 141 ACIMA PODE-SE OBSERVAR SEÇÃO TRANSVERSAL DO TERMINAL REGIONAL,

NA FIGURA ACIMA PODE-SE DESTACAR AS INDICAÇÕES DE NÍVEL E DOS EIXOS PRINCIPAIS. OBTIDA DE FORMA AUTOMATIZADA.

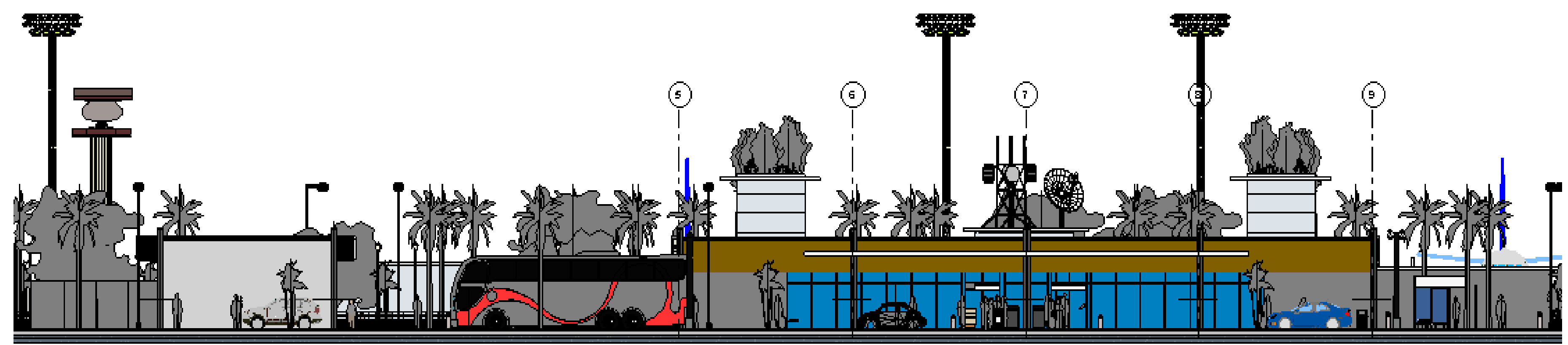

Figura 142- Fachada do Terminal Regional obtida de forma automática no Revit.

NA FIGURA 142 ACIMA PODE-SE OBSERVAR FACHADA OBTIDA DE FORMA AUTOMATIZADA, COM DESTAQUE PARA AS INDICAÇÕES DE ESCALA HUMANA, VEGETAÇÃO E EIXOS PRINCIPAIS DO PODE-SE OBSERVAR A INTEGRACAO, NA ELEVACAO, DO MEIO-FIO DE ACESSO AO TERMINAL DE PROJETO. 


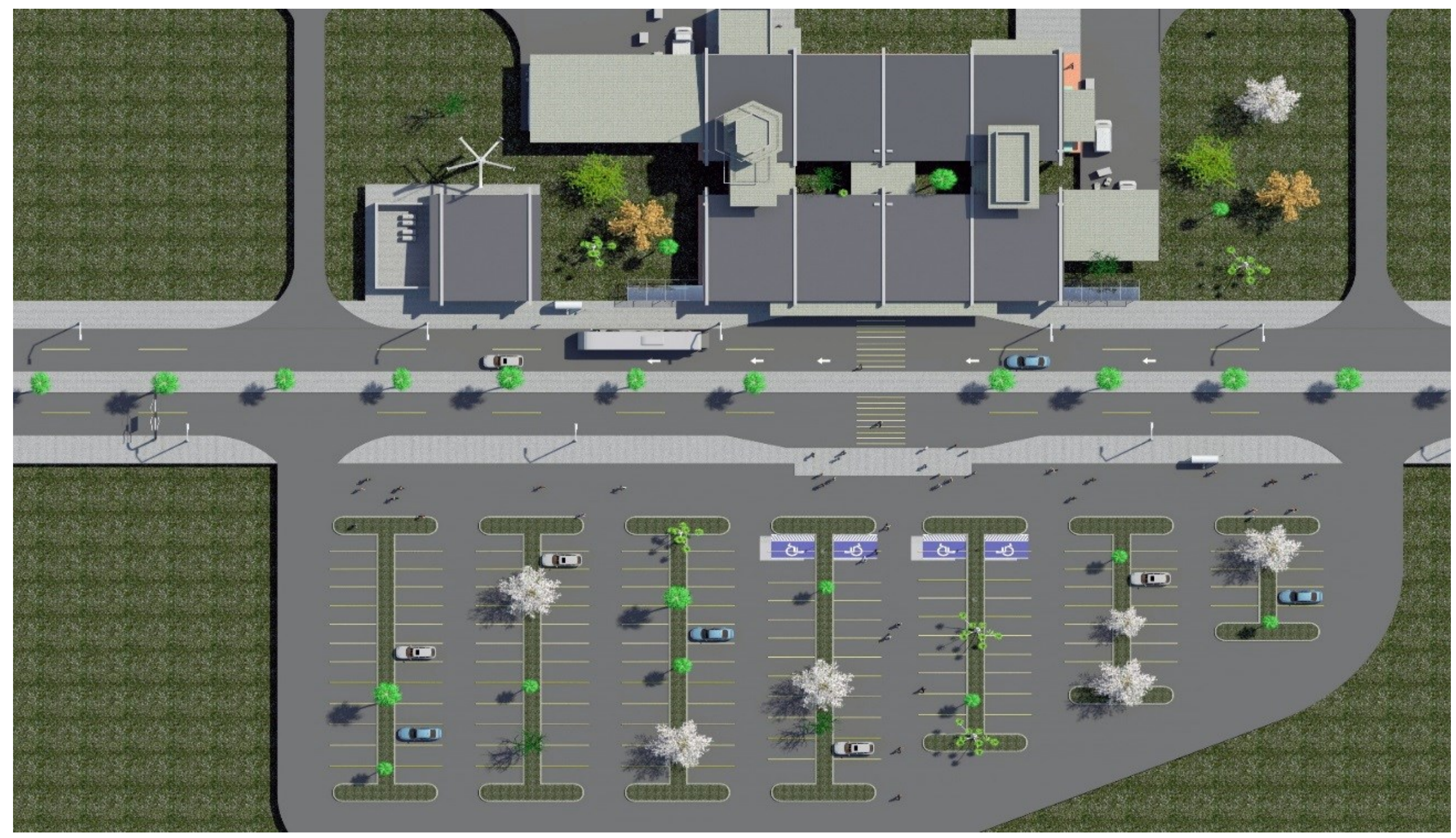

Figura 143- - Planta baixa do Terminal Regional obtida de forma automática no Revit.

NA FIGURA 143 ACIMA PODE-SE OBSERVAR PLANTA-BAIXA DO TERMINAL REGIONAL, OBTIDA DE FORMA AUTOMATIZADA NO REVIT ${ }^{\circledR}$.

OS SETORES DO AEROPORTO PODEM SER OBSERVADOS, COMO O ESTACIONAMENTO DE VEICULOS, AS VIAS DE ACESSO E O CORPO PRINCIPAL DO TERMINAL DE PASSAGEIROS. 


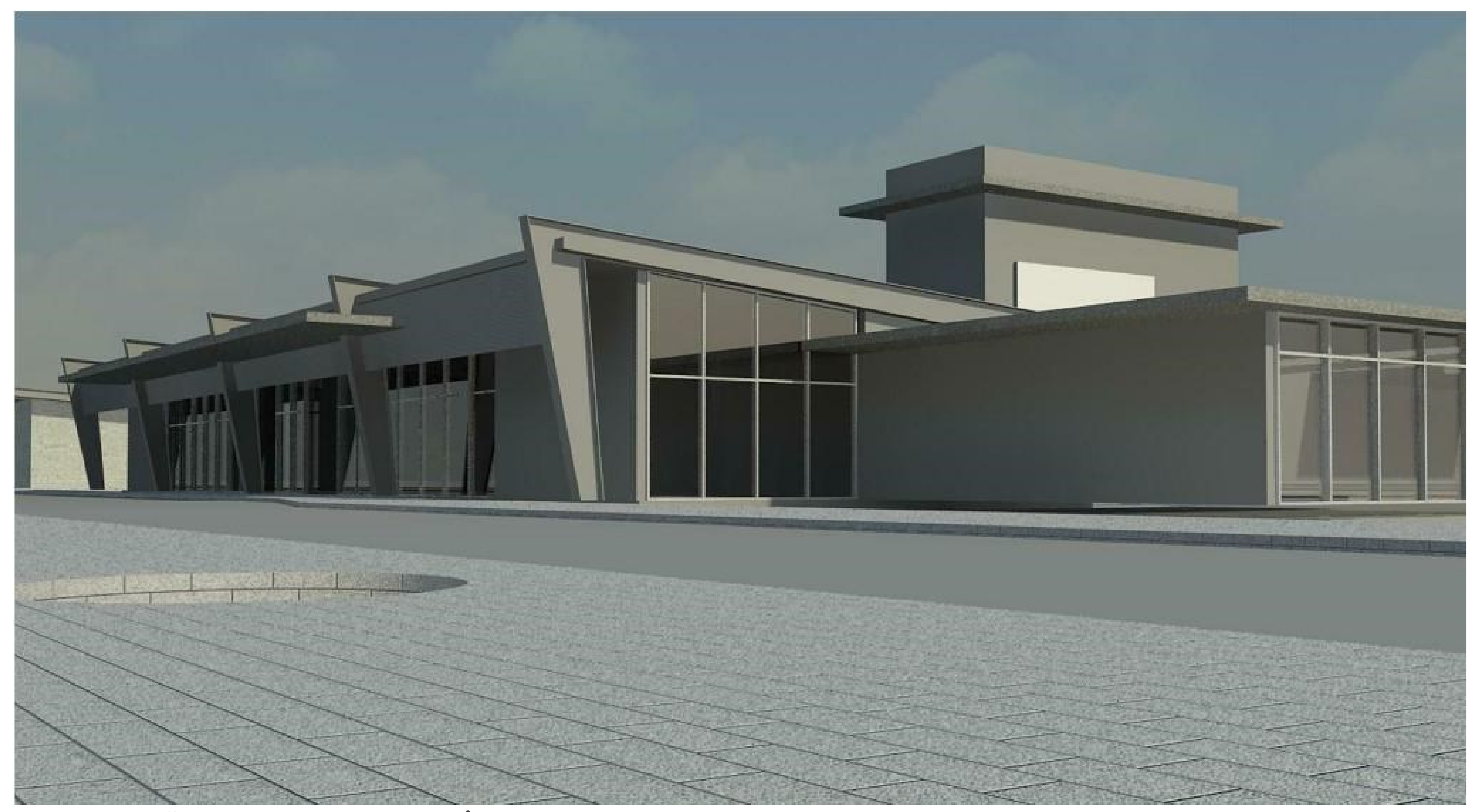

Figura 144- Ilustração gráfica da projetação do Terminal Regional no Revit".

NA FIGURA 144 ACIMA PODE-SE OBSERVAR IMAGEM PERSPECTIVA DO TERMINAL REGIONAL, RENDERIZADA NO APLICATIVO REVIT ${ }^{\circledR}$
NA FIGURA ACIMA ENCONTRA-SE EM DESTAQUE A ENTRADA DO TERMINAL REGIONAL, ATRAVES DO MEIO-FIO DE ACESSO AO SAGUAO "LADO TERRA". 


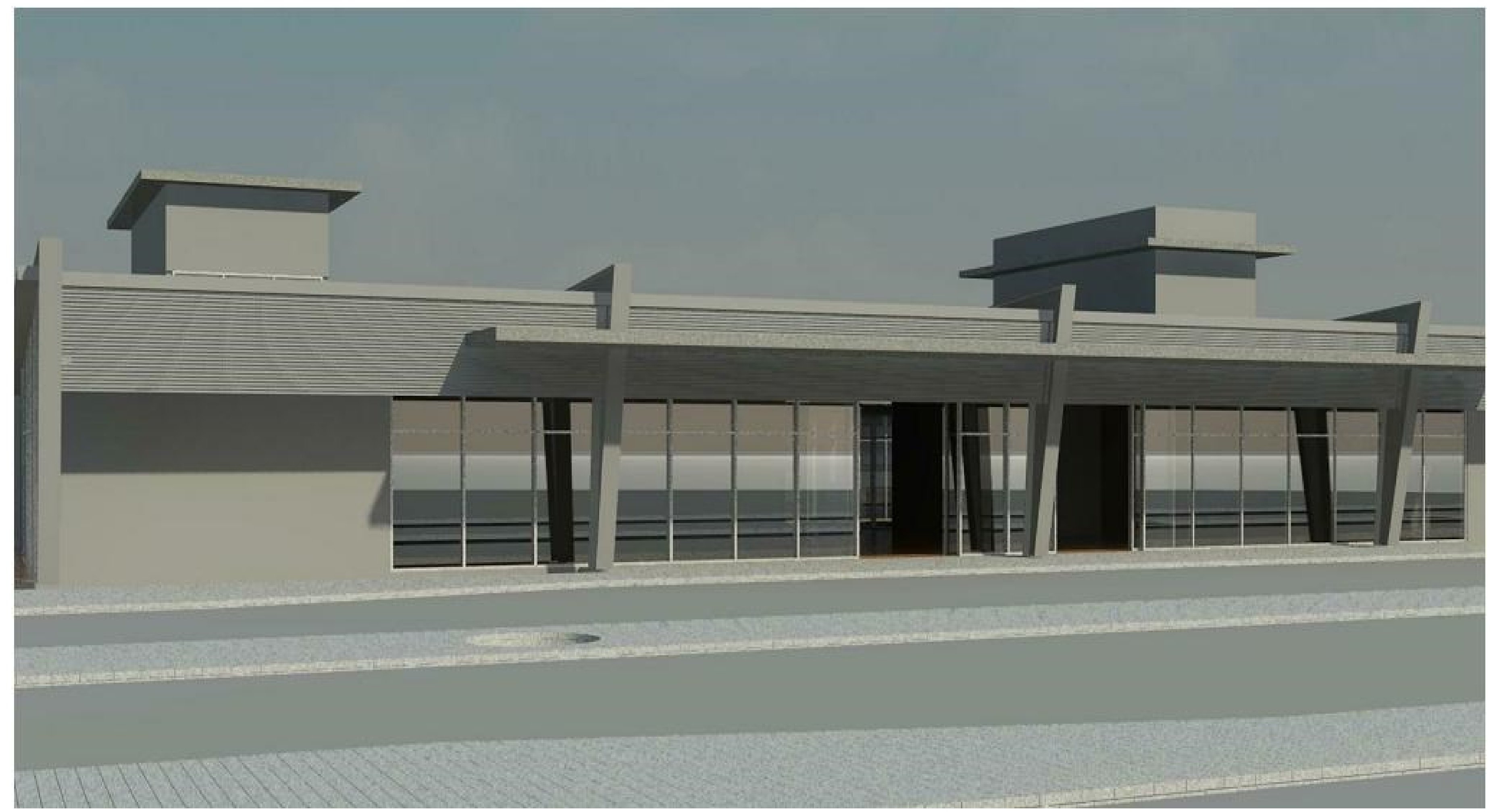

Figura 145- Ilustração gráfica da projetação do Terminal Regional no Revit

A FIGURA 145 ACIMA ILUSTRA IMAGEM PERSPECTIVA DO TERMINAL REGIONAL, RENDERIZADA NO APLICATIVO REVIT. PODE-SE OBSERVAR O "BRISE-SOLEIL" E A MARQUISE NA ENTRADA PRINCIPAL, RESGUARDANDO A EDIFICACAO E OS USUARIOS CONTRA A INSOLACAO EXCESSIVA.
NA FIGURA ACIMA PODE-SE OBSERVAR A FACHADA FRONTAL DO TERMINAL REGIONAL, COM DESTAQUE PARA AS DUAS PORTAS DE ACESSO, REFERENTES AOS FLUXOS DE EMBARQUE E DESEMBARQUE DE PASSAGEIROS. 


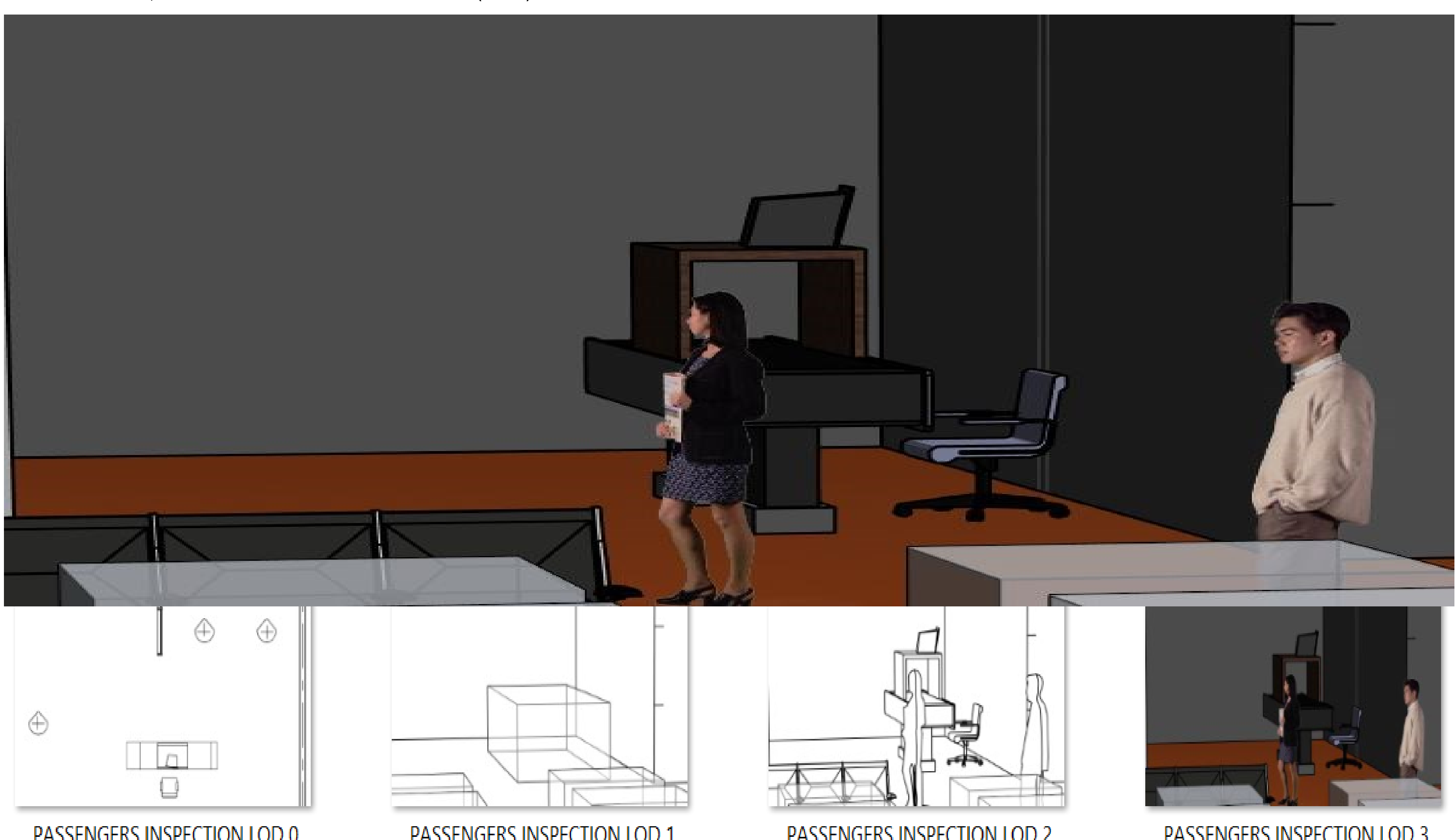

Figura 146- Componentes paramétricos BIM modelados durante a pesquisa, inseridos no ambiente de projeto do Terminal Regional. 
$\mathrm{Na}$ Figura 146, na página anterior, é possível observar o emprego do componente de inspeção de bagagem modelado nesta pesquisa, inserido de forma contigua ao edifício do terminal regional.

Pode ser observada a interface de ligação que a inspeção de passageiros representa entre a aeronave e o acesso ao terminal de passageiros.

Na parte inferior da Figura 146 observa-se a variação de LOD para equipamento de inspeção de bagagem, preconizada pelo AIA americano, onde estão expressos diferentes níveis de detalhe (geométrico G-LOD), desde o LOD100 (Estudo Preliminar ou Conceitual), LOD200 (Projeto Básico), LOD300 (Projeto Executivo) e LOD400 (Construção),

Ocorre que a variação de LOD efetuada no aplicativo Revit ${ }^{\circledR}$ só foi possível por meio da criação de arquivos diferentes, com geometrias modeladas em graus crescentes de complexidade. A variação nativa do aplicativo definida através dos recursos de "coarse, médium e fine" apenas simplificam a geometria existente no modelo sem no entanto permitir a variação preconizada pelo AIA americano.

A solução adotada pelo autor foi realizar a variação de LOD criando volumes simplificados com a variação de massa desejada.

Porém, as geometrias criadas em ambiente de massa não podem ser parametrizadas, a menos que sofram transformação para famílias paramétricas nativas do aplicativo Revit ${ }^{\circledR}$.

Isto significa que não será possível realizar abstração semântica total dos componentes, uma vez que deveremos assumir necessariamente as características intrínsecas de algum componente de família do Revit ${ }^{\circledR}$ para representar o novo componente modelado.

$\mathrm{Na}$ Figura 147, na próxima página, é possível observar o emprego do componente de balcão de "check-in" modelado nesta pesquisa, inserido no interior do edifício do terminal regional. Pode ser observada a função de atendimento ao público e a relação do balcão de "check-in" com o Saguão "Lado Terra" do terminal regional.

Na parte inferior da Figura 147 a seguir observa-se a variação de LOD para o balcão de "check-in", preconizada pelo AIA americano, onde estão expressos diferentes níveis de detalhe (geométrico G-LOD), desde o LOD100 (Estudo Preliminar ou Conceitual), LOD200 (Projeto Básico), LOD300 (Projeto Executivo) e LOD400 (Construção), 


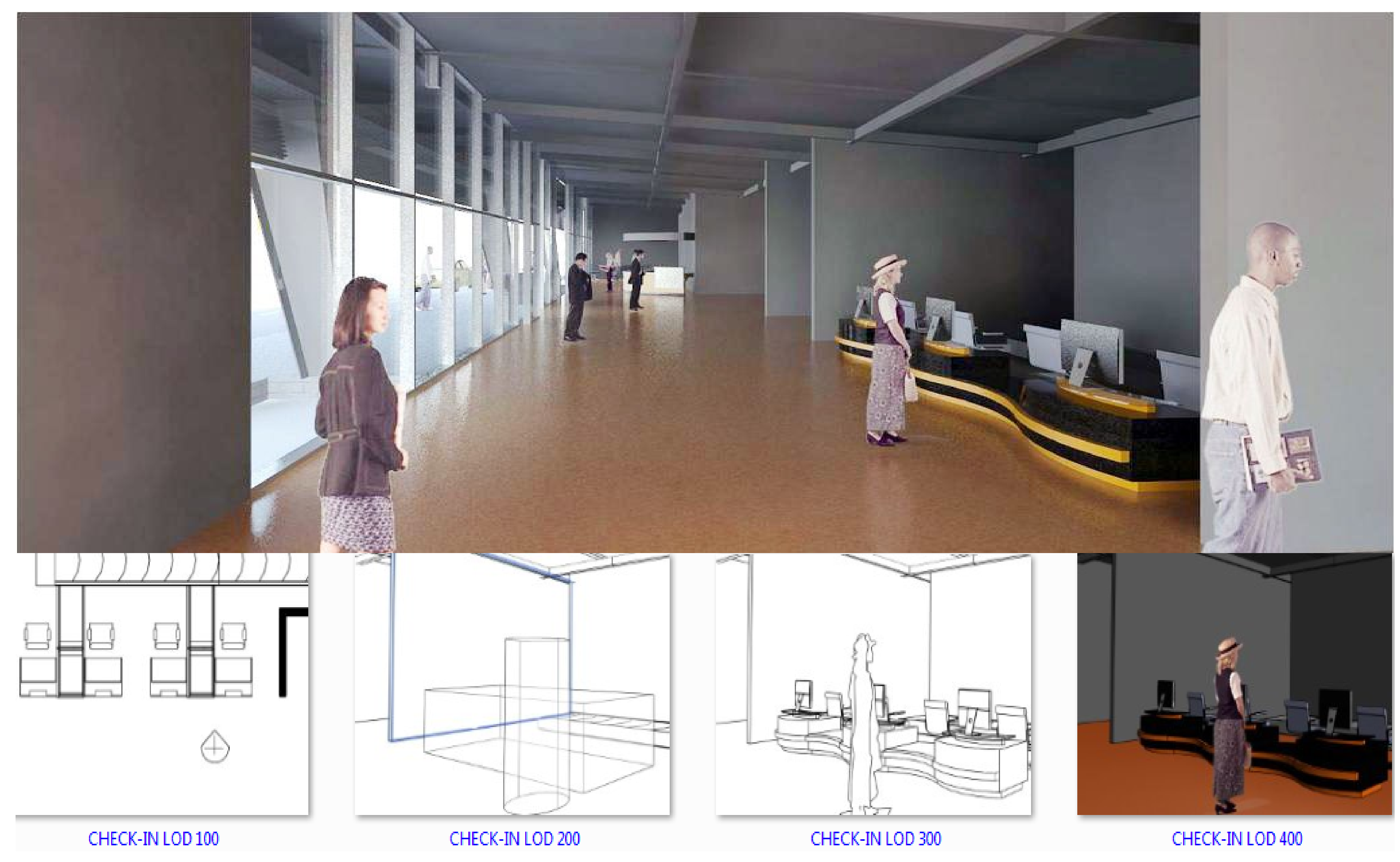

Figura 147- Componentes paramétricos BIM modelados durante a pesquisa, inseridos no ambiente de projeto do Terminal Regional. 


\subsection{4- TESTE DE MODELAGEM DO TERRENO PARA PROCESSOS DE ANÁLISE NOS ESTÁGIOS INICIAIS NO AUTODESK INFRAWORKS (SIG)}

Foi utilizado o AutoDesk InfraWorks ${ }^{\circledR}$, ferramenta que permite reunir informações oriundas de plataformas BIM e SIG, por meio da importação de arquivos "FBX" / "IFC" ou "CityGML".

O InfraWorks ${ }^{\circledR}$ permite a utilização de informação SIG, sob a forma de conjuntos, como os acessos viários, os sistemas pluviais, relevo, vegetação, edificações em variados níveis de detalhe, etc.

No caso dos componentes modelados nesta pesquisa, escolhemos um terreno na localidade de "State College", Pennsylvania (Figura 148 na página seguinte).

Como o terminal de passageiros regional é destinado a ser construído em várias localidades diferentes, não possui um terreno definido.

Portanto, a escolha do terreno não causou impacto nos resultados da pesquisa.

Além disto, a proximidade física do terreno do local de realização de nosso estágio doutoral foi um elemento facilitador.

Para importar um terreno no ambiente SIG, foram necessárias informações referentes ao relevo e da imagem correspondente ao mesmo.

Podemos ainda obter mais informação, como ruas, prédios, etc.

Os arquivos das malhas topográficas que foram utilizadas como base de dados para o terreno foram obtidos em:

\section{http://viewer.nationalmap.gov/viewer/.}

A confecção do terreno e a inserção de modelos advindos dos sistemas BIM possibilitaram importar e processar grandes quantidades de dados de satélite.

Os arquitetos podem apresentar e analisar seus projetos com as características que cercam o terreno, as redes de transportes e edifícios totalmente modelados no quarteirão, no bairro, na cidade, ou em nível regional. 


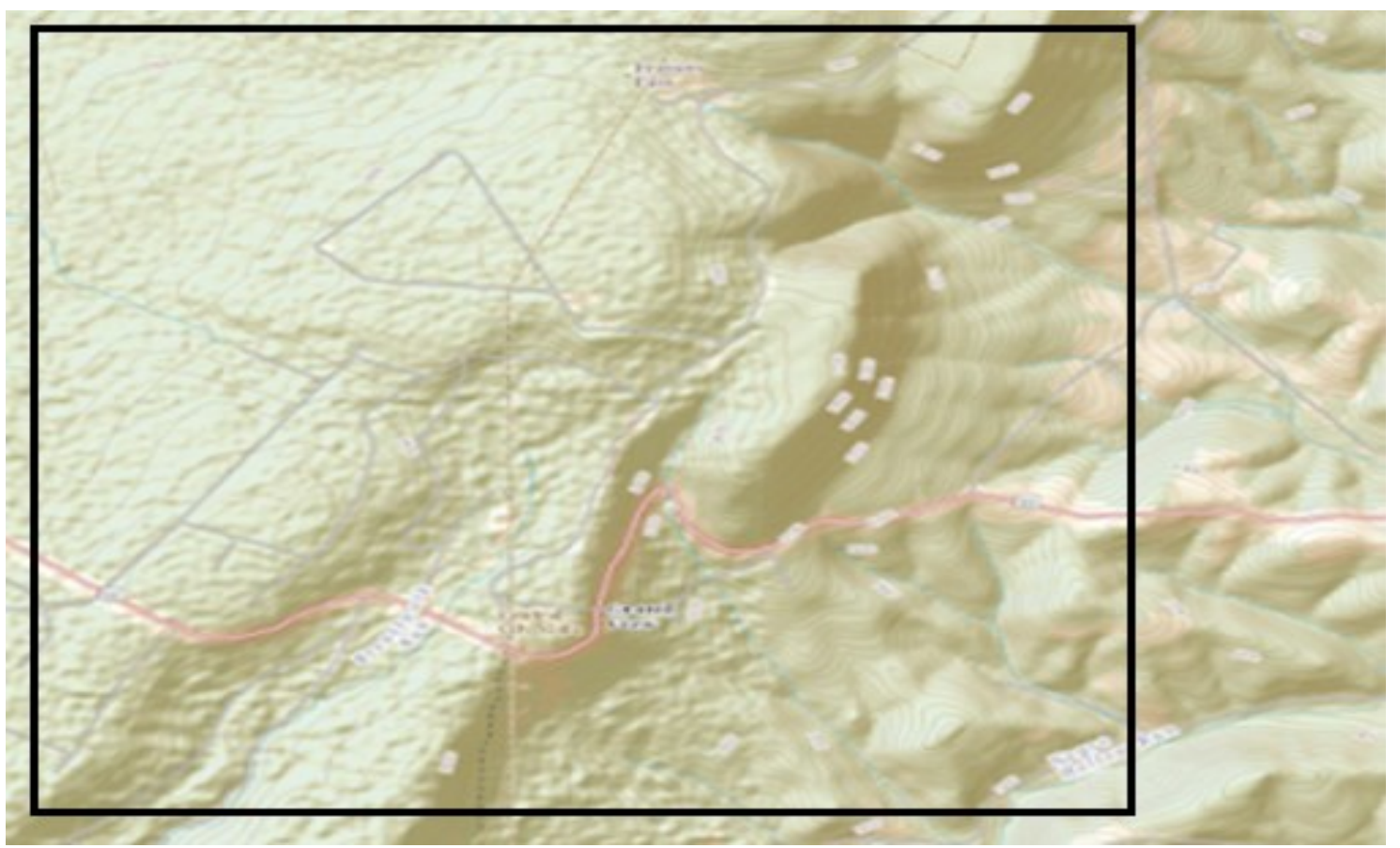

Figura 148- Seleção da área de influência para obtenção de dados de satélite. Fonte: http://viewer.nationalmap.gov/viewer/.

Na Figura 148 acima pode-se observar a seleção da área para realizar o "download" dos dados relativos ao terreno, como malha topográfica, camadas de informação de alturas e camadas de imagens de "pixels".

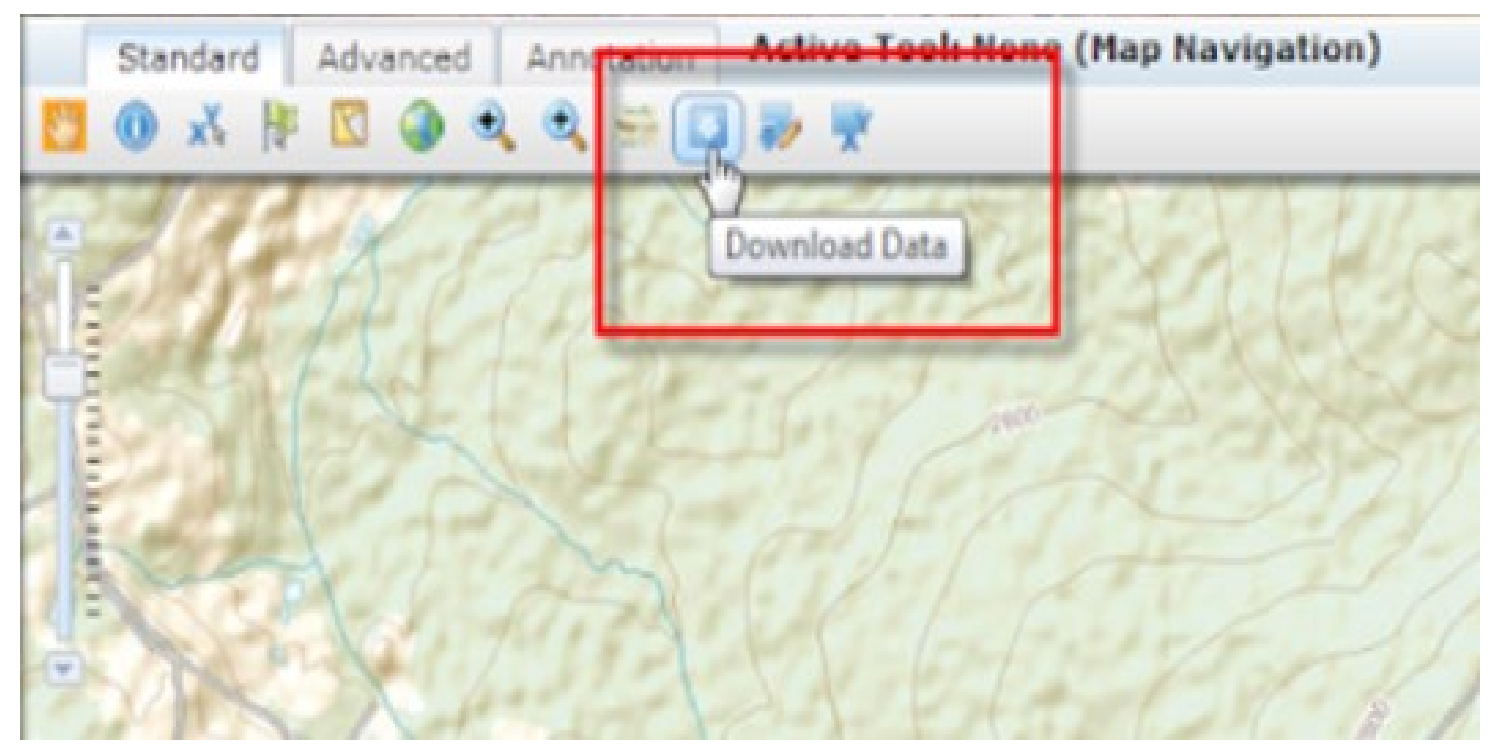

Figura 149- Opção de "download" de dados de satélite para o terreno selecionado.

Fonte: http://viewer.nationalmap.gov/viewer/.

Na Figura 149 acima pode-se observar no retângulo vermelho, em destaque, a opção para realizar "download" dos dados referentes a área selecionada previamente.

Após selecionar a área desejada foi necessário fazer o "download", de forma a transferir os arquivos para o computador do autor (Figura 149). Para a modelagem do terreno foram selecionados os dados referentes a topografia, como pode ser observado na Figura 150 a seguir. 


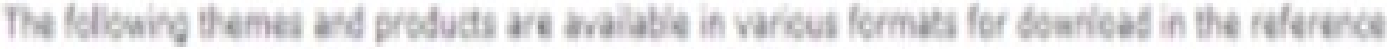
area polvos vou selected, Check che or more and did Next."

\section{Geledes tem typu Cureat Cotent}

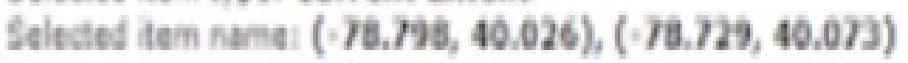

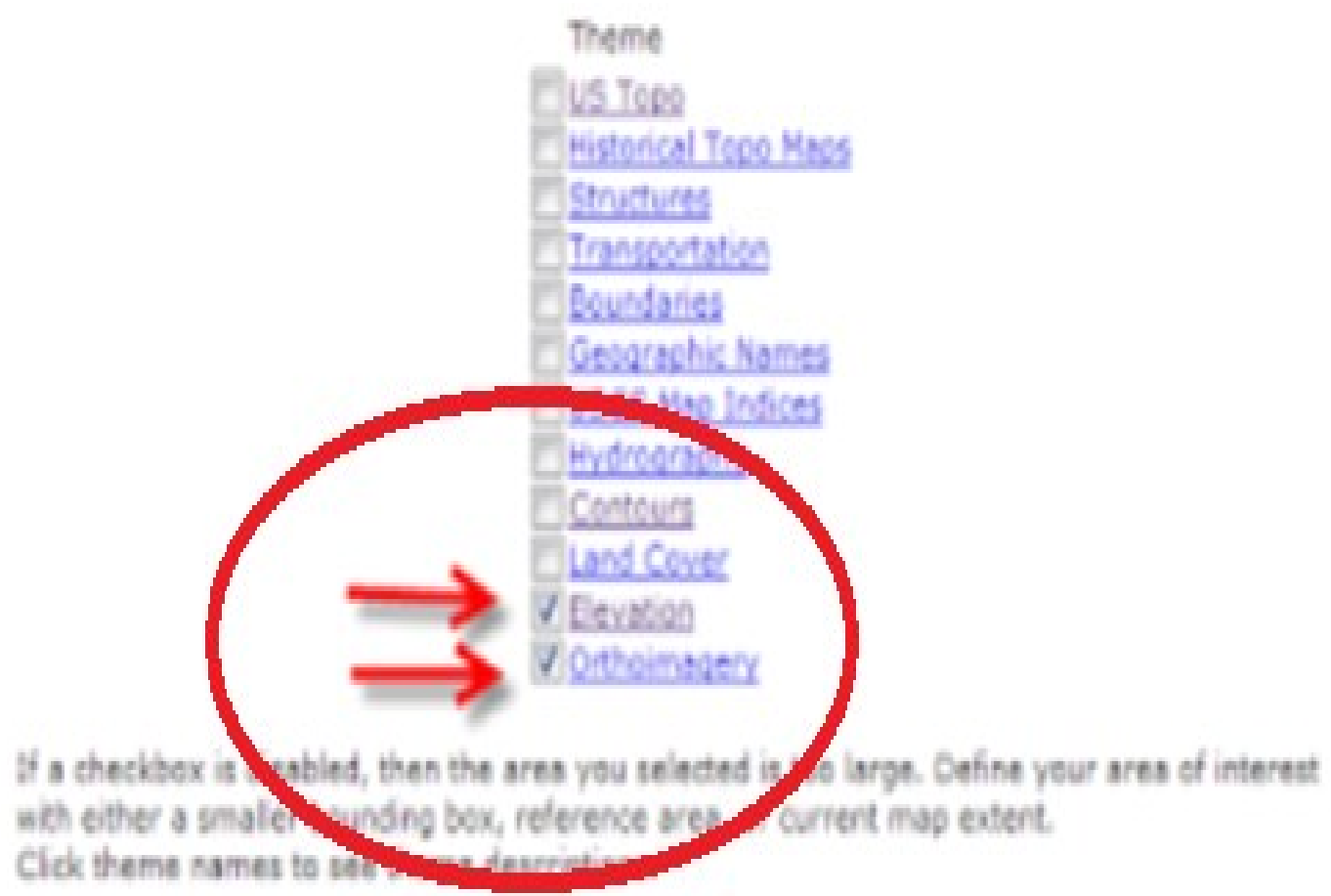

Figura 150- Seleção de camadas de informação para obtenção de dados de satélite do terreno selecionado. Fonte: http://viewer.nationalmap.gov/viewer/.

Após obter os dados do "site", efetuamos os passos descritos e ilustrados abaixo, para a modelagem do terreno tridimensional a partir dos dados de satélite.

\section{DEMONSTRAÇÃO DOS PASSOS REALIZADOS PARA A MODELAGEM DO TERRENO NO INFRAWORKS ${ }^{\circledR}$ :}

1- FOI ABERTO O PROGRAMA “AUTODESK INFRAWORKS ${ }^{\circledR}$ ” E AO CLICAR EM "NOVO" OU UTILIZAR O ATALHO "CTRL+N" REALIZA-SE A CRIAÇÃO DE UM ARQUIVO NOVO.

2- A JANELA “NOVO MODELO" IRÁ APARECER, CONFORME FIGURA 151 A SEGUIR. FOI SELECIONADA A PASTA DE TRABALHO EM "NOME", E SALVO O ARQUIVO; OS MODELOS DEVEM SER ARMAZENADOS NA PASTA MEUS DOCUMENTOS SEU COMPUTADOR, POR PADRÃO. 


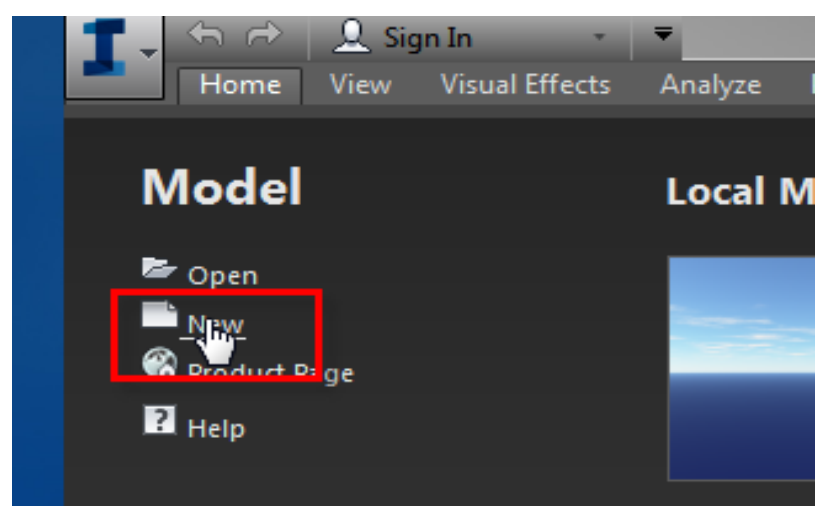

Figura 151- Demonstração de acesso a criação de novo modelo no aplicativo InfraWorks .

Na Figura 151 acima pode-se observar a criação de um novo modelo no InfraWorks ${ }^{\circledR}$.

3- APÓS ISSO, UTILIZOU-SE O COMANDO “ADICIONAR ORIGEM DE DADOS DO ARQUIVO" PARA ESCOLHER O TIPO DE ARQUIVO A SER CARREGADO. FOI SELECIONADA A OPÇÃO "RASTER" E IMPORTADOS OS ARQUIVOS OBTIDOS NO SITE. DEVE-SE VERIFICAR SE O CAMPO "TIPO" ESTÁ DEFINIDO COMO “TERRENO”, CONFORME FIGURA 152 ABAIXO.

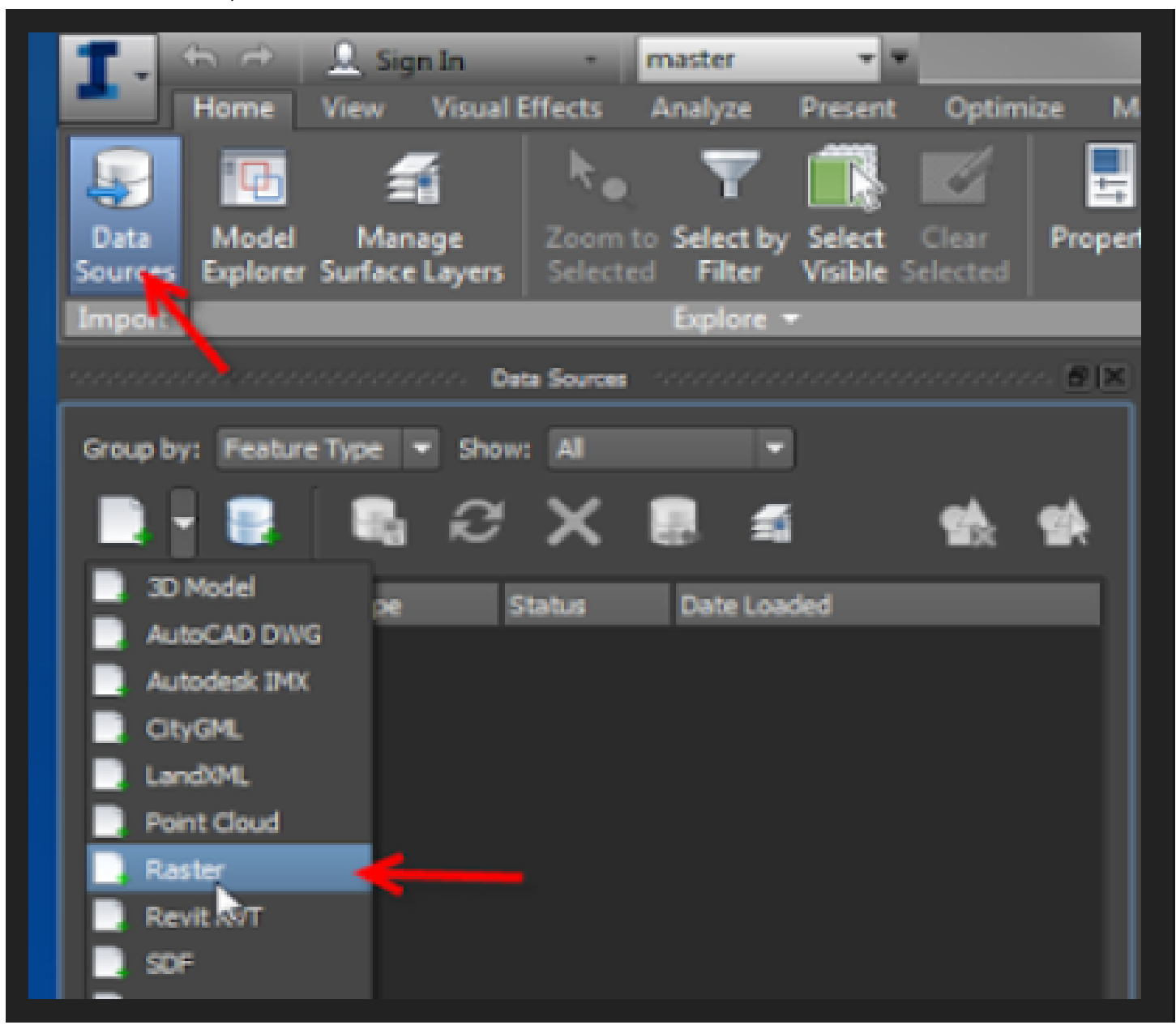

Figura 152- Ilustração de adição de dados do tipo "raster" na tela do aplicativo InfraWorks .

Arquivos "Rasters" que tenham Bandas de Altura associadas a eles, como no caso desta pesquisa, podem também ser importados como terrenos, ou como imagem de solo, o que permite a formação do relevo e correspondente informação de alturas do mesmo. (Figura 153 a seguir). 


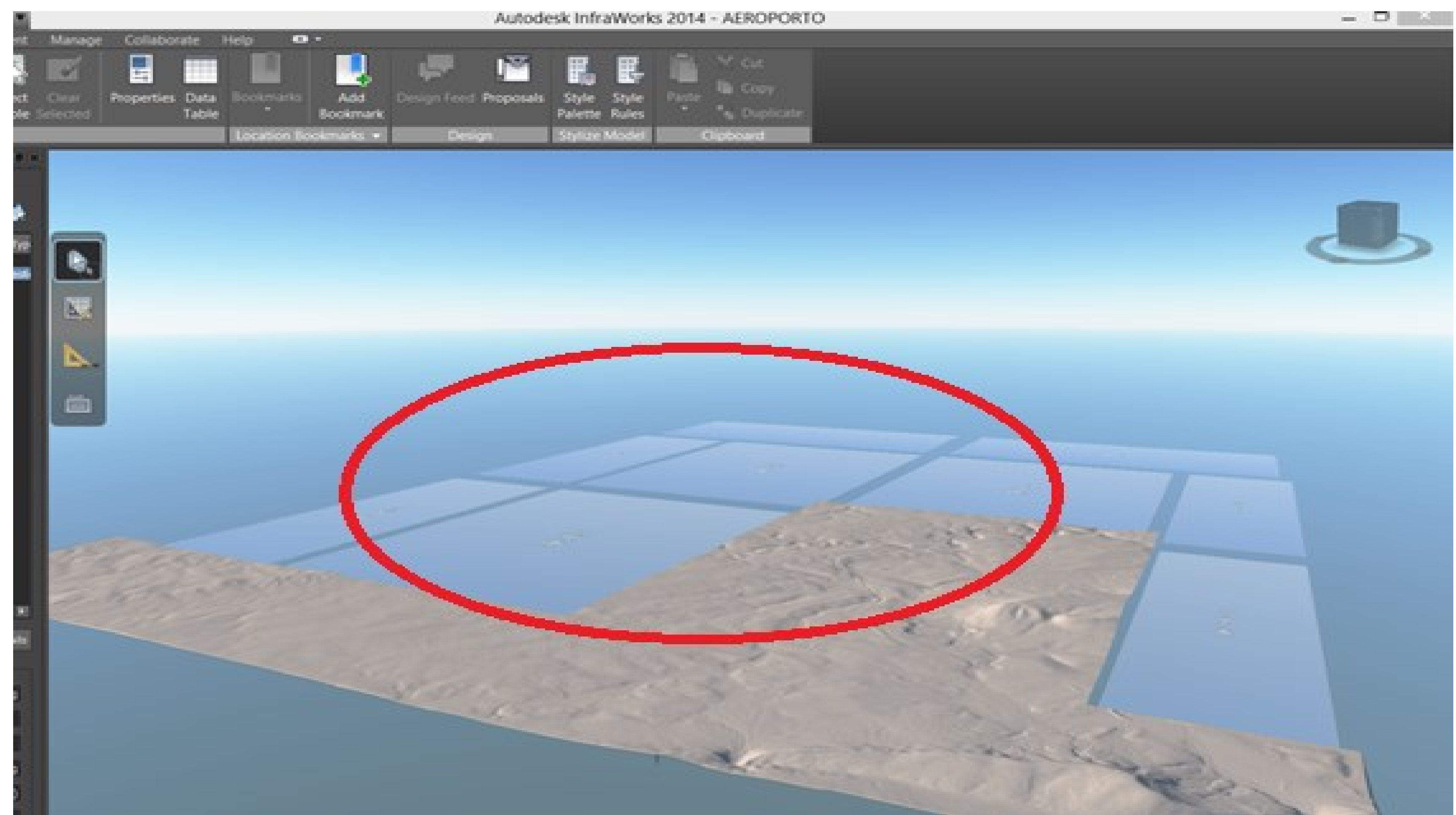

Figura 153- Ilustração de formação do terreno com os dados "raster" importados, na tela do aplicativo InfraWorks".

NA FIGURA 153 ACIMA PODE-SE OBSERVAR A FORMAÇÃO DO TERRENO A PARTIR DOS DADOS DO TIPO “RASTER" IMPORTADOS PELO APLICATIVO INFRAWORKS ${ }^{\circledR}$.
EM VERMELHO ENCONTRA-SE DESTACADO O RECORTE ONDE PODE-SE OBSERVAR PARTES DO TERRENO QUE AINDA NÃO FORAM TRANSFORMADAS EM RELEVO, NA COR AZUL CLARA, CONTIGUAS A PARTES QUE JÁ FORAM TRANSFORMADAS EM RELEVO DE FORMA GRÁFICA. 
4- FOI VERIFICADO SE A CAIXA "DEFINIR A EXTENSÃO DO MODELO" ESTAVA ATIVA, SELECIONANDO APENAS UMA ÁREA DE INFLUÊNCIA CORRESPONDENTE A SUA EXTENSÃO (FIGURA 154).

A imagem deve ser selecionada através da opção "Polígono", servindo para delimitar a área de influência que se deseja utilizar. Dessa forma excluem-se partes do terreno, ou ainda áreas que estão representadas na cor azul, por não conterem dados e informações sobre o relevo.

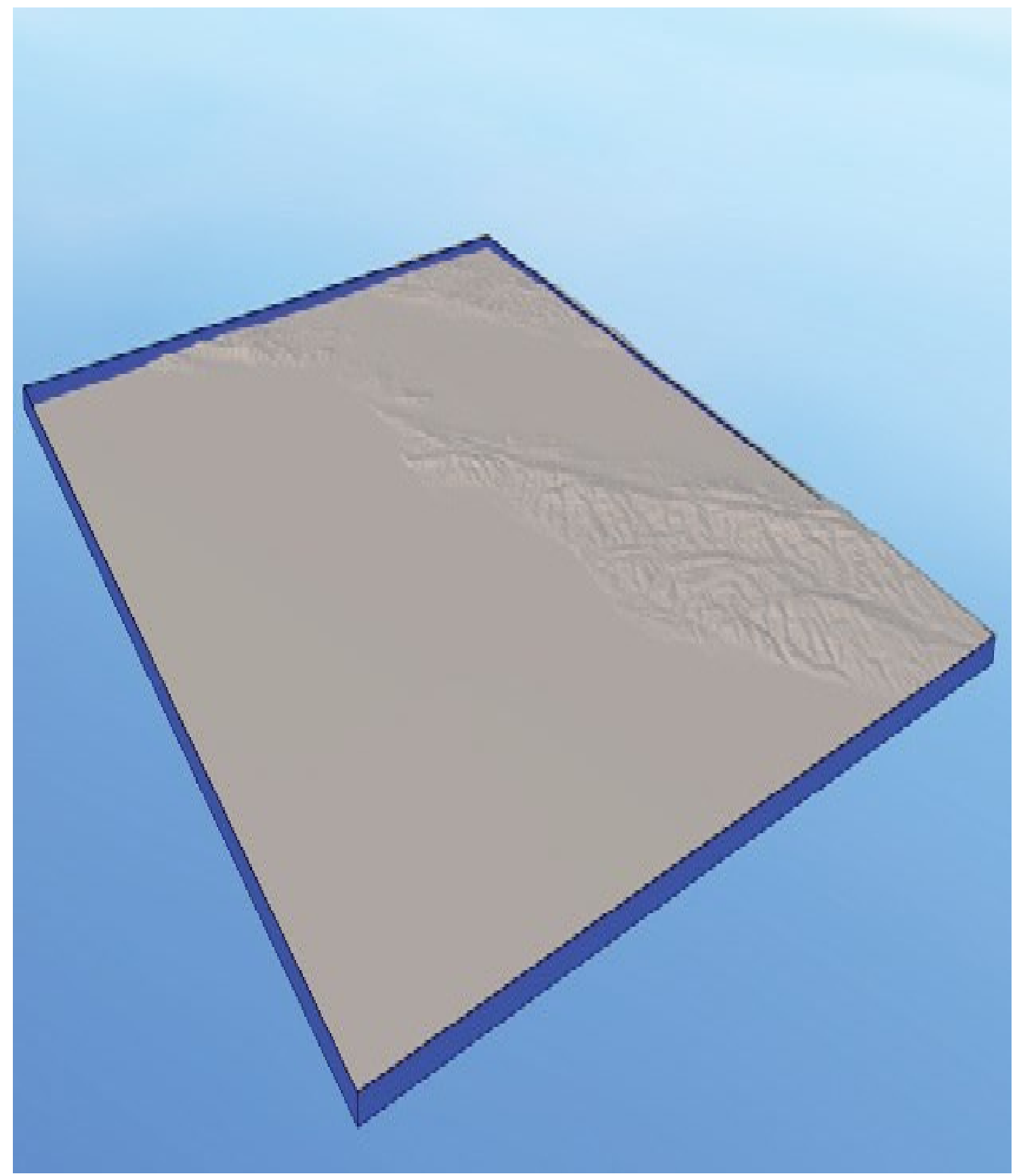

Figura 154 - Ilustração de área de influência na tela do aplicativo InfraWorks para o terreno importado. 
Na Figura 154, na página anterior, pode-se observar a seleção da área de influência do relevo importado de um arquivo do tipo "raster". Isto é importante para eliminar reduzir os limites do desenho para as bordas efetivas do terreno.

Após a modelagem do terreno no InfraWorks ${ }^{\circledR}$, foi possível inserir o aeroporto previamente modelado nos sistemas BIM, através da importação direta no aplicativo.

Isto permitiu avaliar diferentes opções de locação no terreno e ainda representar o relevo existente para efeito de visualização de interferências no projeto do terminal regional.

O objetivo desta simulação de inserção no terreno (Figura 153 a seguir) reside no teste de integridade sobre como os componentes modelados aparecem após o processo de exportação e importação entre os dois sistemas (BIM e SIG).

Os testes de inserção do modelo no terreno não indicaram deficiências nesse sentido, sendo que todos os componentes, partes integrantes do terminal regional, que foram modelados no Revit ${ }^{\circledR}$, apareceram corretamente representados no InfraWorks ${ }^{\circledR}$.

Finalmente, os testes serviram ainda para ilustrar os caminhos que o projetista deve realizar para que se possa unir em um ambiente de analise as informações de relevo (SIG) e do modelo (BIM) no processo de projeto.

Uma vez que o acesso as informações obtidas por satélite são de livre utilização, através da internet, pode-se realizar o "download" da área desejada e incorporar no ambiente de projeto as análises de compatibilidade e de interferência das propostas de projeto em relação ao entorno imediato.

A Figura a seguir representa as possibilidades de associação entre os sistemas BIM e SIG. Ainda que a importação direta de componentes apresente limitações para a variação no grau de abstração de componentes, e possa ser contornada pelo viés que se utiliza do "CityGML" como interface entre o BIM e o SIG, o InfraWorks oferece a possibilidade de leitura de dados associados aos pixels de imagens de satélite como índices pluviométricos, alturas de relevo, densidade e tipo de vegetação, entre outros, amplificando processo de análise, sobretudo nas áreas de infraestrutura.

No caso do projeto de aeroportos no Brasil, é comum as fronteiras do sitio aeroportuário estarem ocupadas por construções urbanas. Este tipo de análise do terreno possibilitaria incorporar informações atualizadas sobre o contexto urbano e o aeroporto (Figura 155 a seguir). 


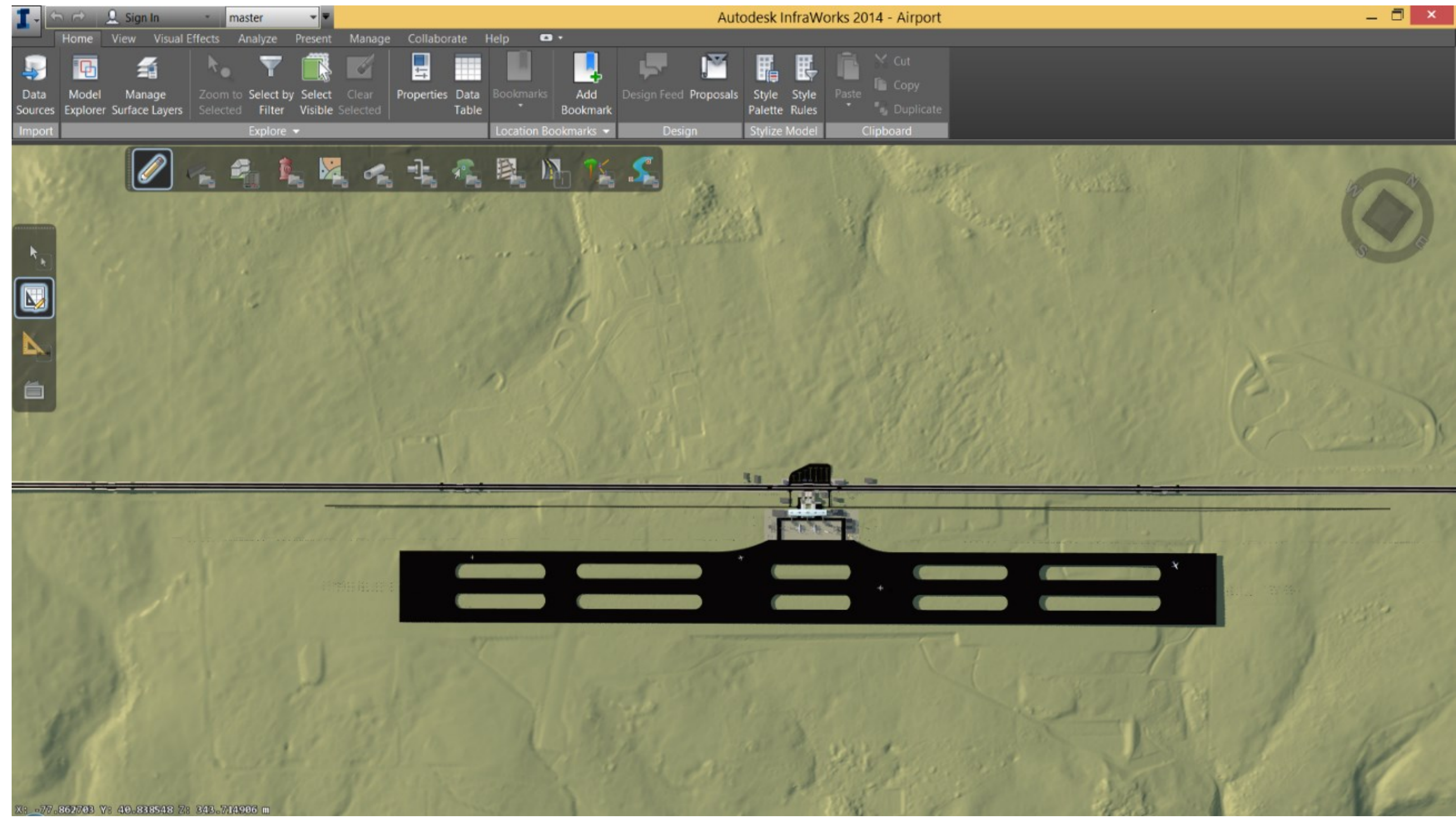

Figura 155 - Demonstração de inserção de um modelo BIM no relevo do SIG.

A FIGURA 155 ACIMA DEMONSTRA A INSERÇÃO, NA INTEGRA, DO TERMINAL REGIONAL NO SIG INFRAWORKS ${ }^{\circledR}$ ILUSTRANDO A CAPACIDADE DO APLICATIVO EM LIDAR COM GRANDE VOLUME

PODE-SE AINDA OBSERVAR NA FIGURA 155 A RELACAO ENTRE O TERMINAL MODELADO NO DE DADOS ORIUNDOS DO SISTEMA BIM - REVIT ${ }^{\circledR}$. 


\section{4- SIMULAÇÃO DE EXPANSÃO DO TERMINAL EXISTENTE POR MEIO DE TRES ALTERNATIVAS DE EXPANSAO DO TERMINAL EXISTENTE - PROJETO (TWR)}

Esta simulação visa a comparação de adaptabilidade frente às mudanças de requisitos ou de parâmetros ao longo do processo de projeto. No caso desta pesquisa, a mudança de parâmetros representa a inserção de novos requisitos referentes a uma torre de controle, inexistente no projeto do terminal existente cedido pela INFRAERO (Figura 156 e 157 a seguir).

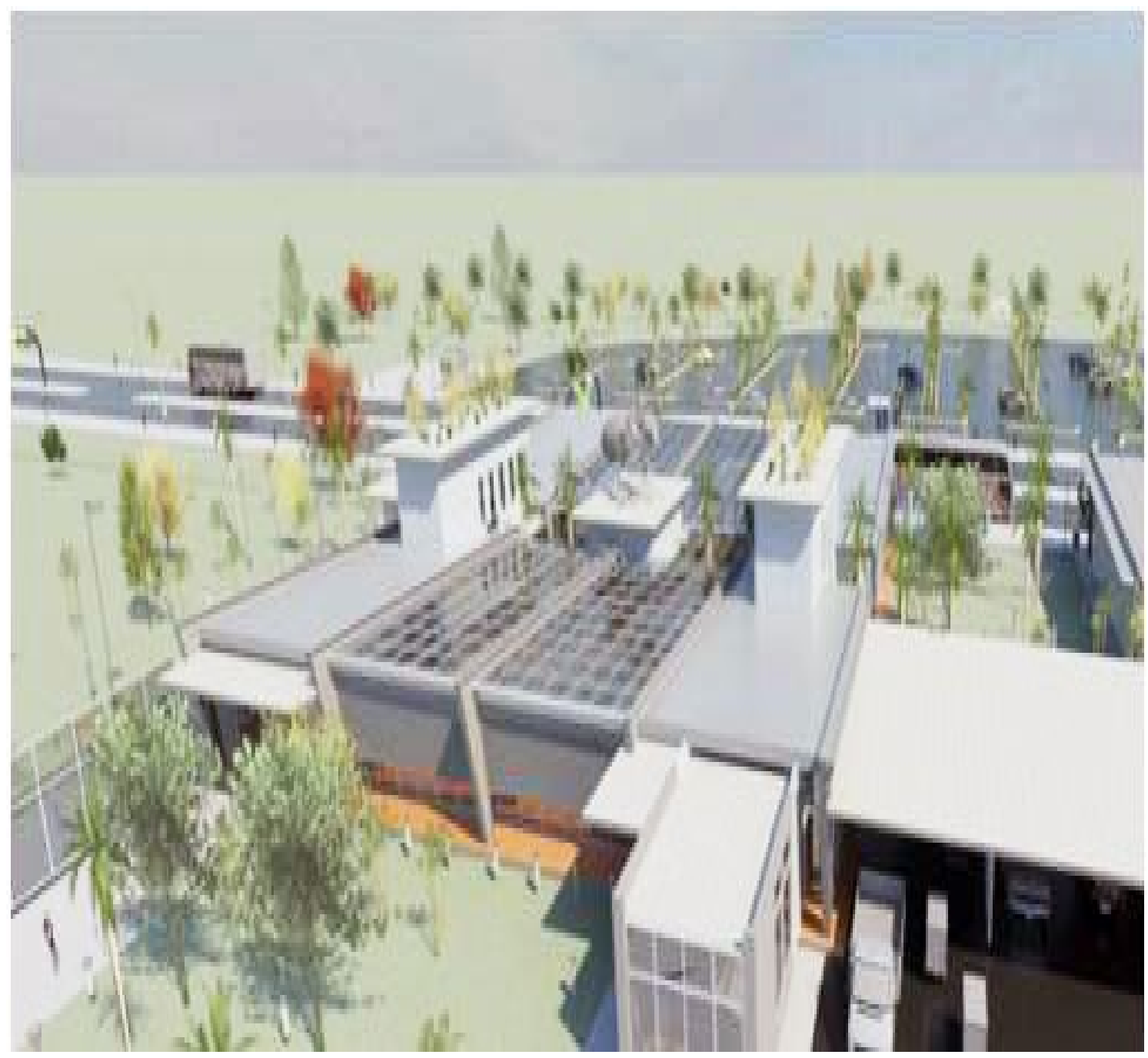

Figura 156 - Terminal regional sem a presença de Torre de Controle. Fonte: INFRAERO.

A Figura 156 acima demonstra o terminal regional inteiramente modelado no sistema BIM - Revit ${ }^{\circledR}$, pronto para sofrer os processos de modificação (expansão), através da criação de diferentes alternativas para uma torre de controle, não prevista anteriormente no projeto cedido pela INFRAERO. Os parâmetros estão aqui representados pelos componentes construtivos que constituem as bibliotecas de objetos modelados nesta pesquisa, ilustrados anteriormente. 

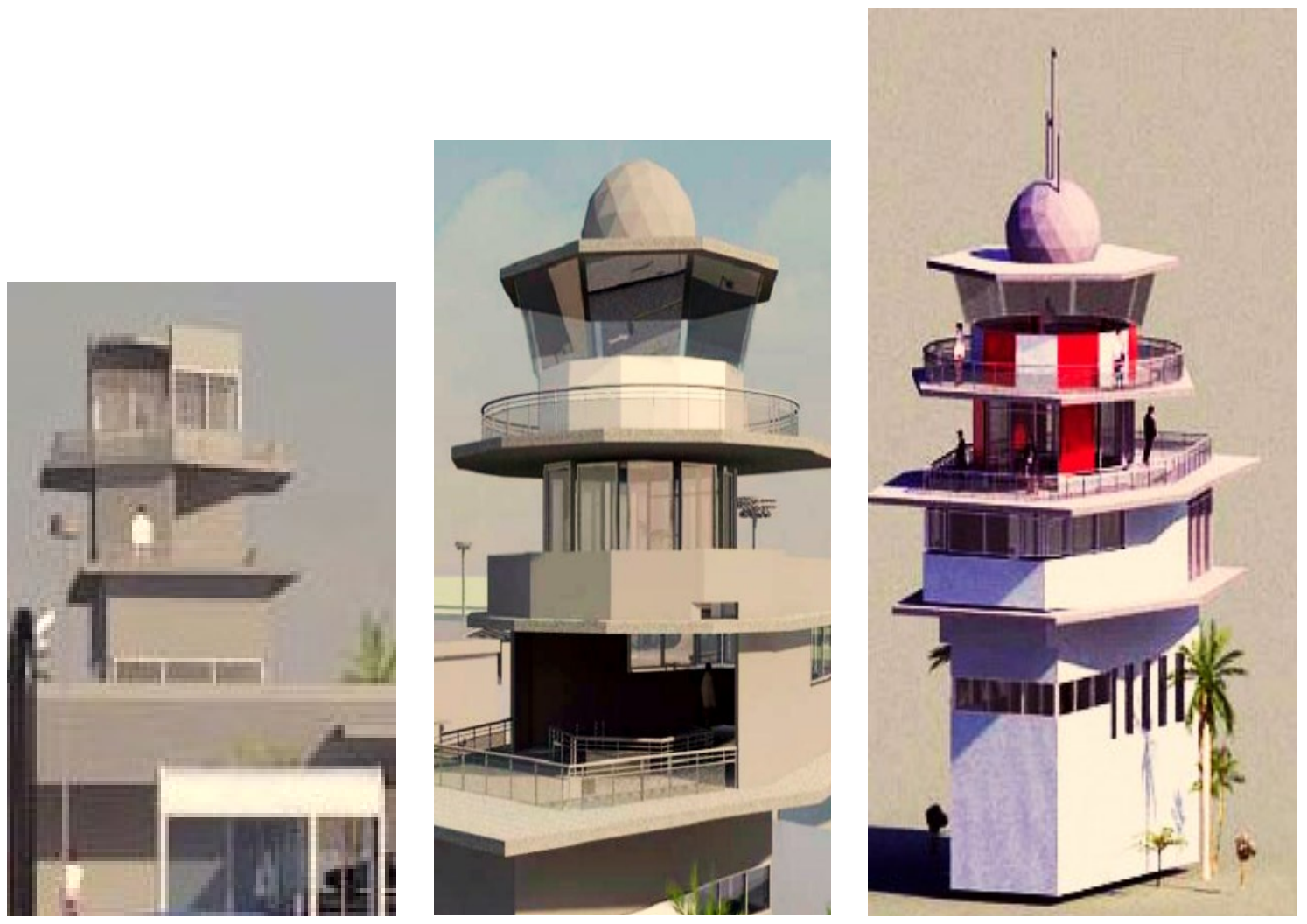

Figura 157 - Exemplificação das alternativas de Torre de Controle no Terminal Regional- Revit .

Os requisitos impostos possibilitam a ampliação do terminal regional para responder a um eventual aumento de demanda do número de passageiros.

Para avaliar a flexibilidade e a capacidade de adaptação das duas ferramentas frente à mudança de requisitos e consequente necessidade de novos parâmetros, propusemos a formulação de três alternativas de projeto, para avaliação daquela que melhor respondesse às premissas de projeto e desempenho da edificação (Figura 157).

O próximo passo foi a tomada de decisão em relação à melhor alternativa dentre as três desenvolvidas. Isto, portanto, representou a proposta de projeto mais eficiente em relação ao projeto do terminal existente e a auxiliar na simulação dos estágios iniciais de um projeto.

O contexto proposto refere-se a criação de uma infraestrutura nova (torre de controle) que estivesse diretamente ligada ao edifício principal. Assim, quando observamos a ausência de uma torre no projeto cedido pela INFRAERO, criamos como um novo requisito a elaboração de uma torre de controle a partir de documentação referencial da INFRAERO.

Os critérios encontram-se citados no Capitulo 3.4 da seção de Materiais e Métodos, podendo ser consultados como parte integrante dos anexos desta pesquisa. 


\subsection{1- RELACOES DA MATRIZ SEMANTICA E AS TORRES DE CONTROLE}

Num primeiro momento modelamos o terminal de passageiros regional e com base no conhecimento adquirido construímos uma matriz semântica representando seus principais componentes. O terminal de passageiros e suas partes principais estão descritos na matriz, representados pelos módulos funcionais e organizados para consulta sobre a relação com os processos de projeto. A atividade de projeto requer que as partes atuem com representatividade e harmonia, para que um denominador comum possa ser alcançado. A matriz semântica visa responder a esta lacuna, oferecendo uma pequena contribuição no caminho de integrar a informação de projeto e os processos da INFRAERO em bases comuns (Figura 158 abaixo).

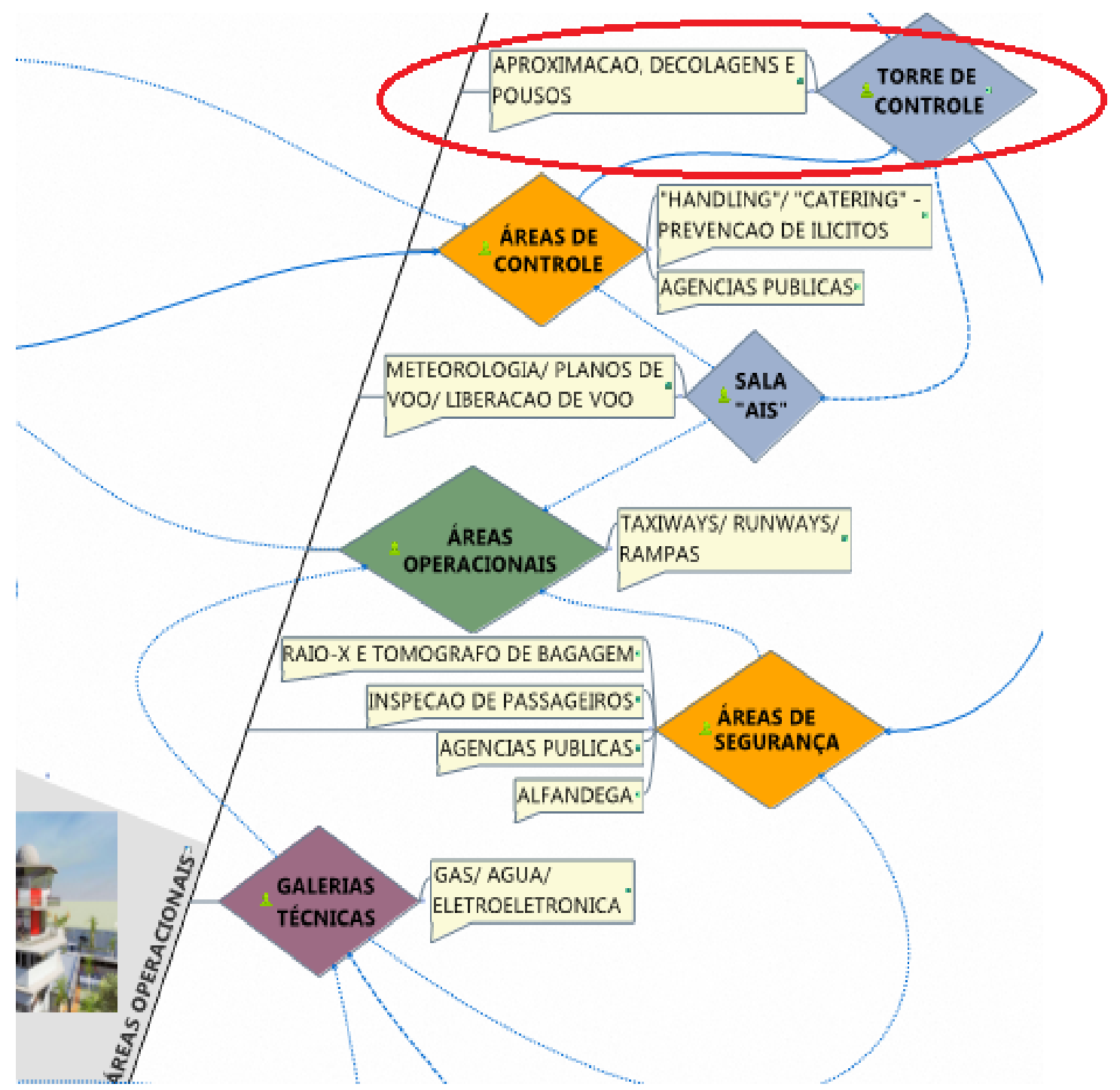

Figura 158 - Ilustração da tela de acesso à informações sobre a TWR na Matriz Semântica.

Ao se clicar no campo da torre de controle (Figura 158), a matriz permite o acesso a tela representada na Figura 159 a seguir, que por sua vez oferece acesso a três campos de informação sobre os processos de aprovação, tarefas de projeto e requerimentos da INFRAERO. 


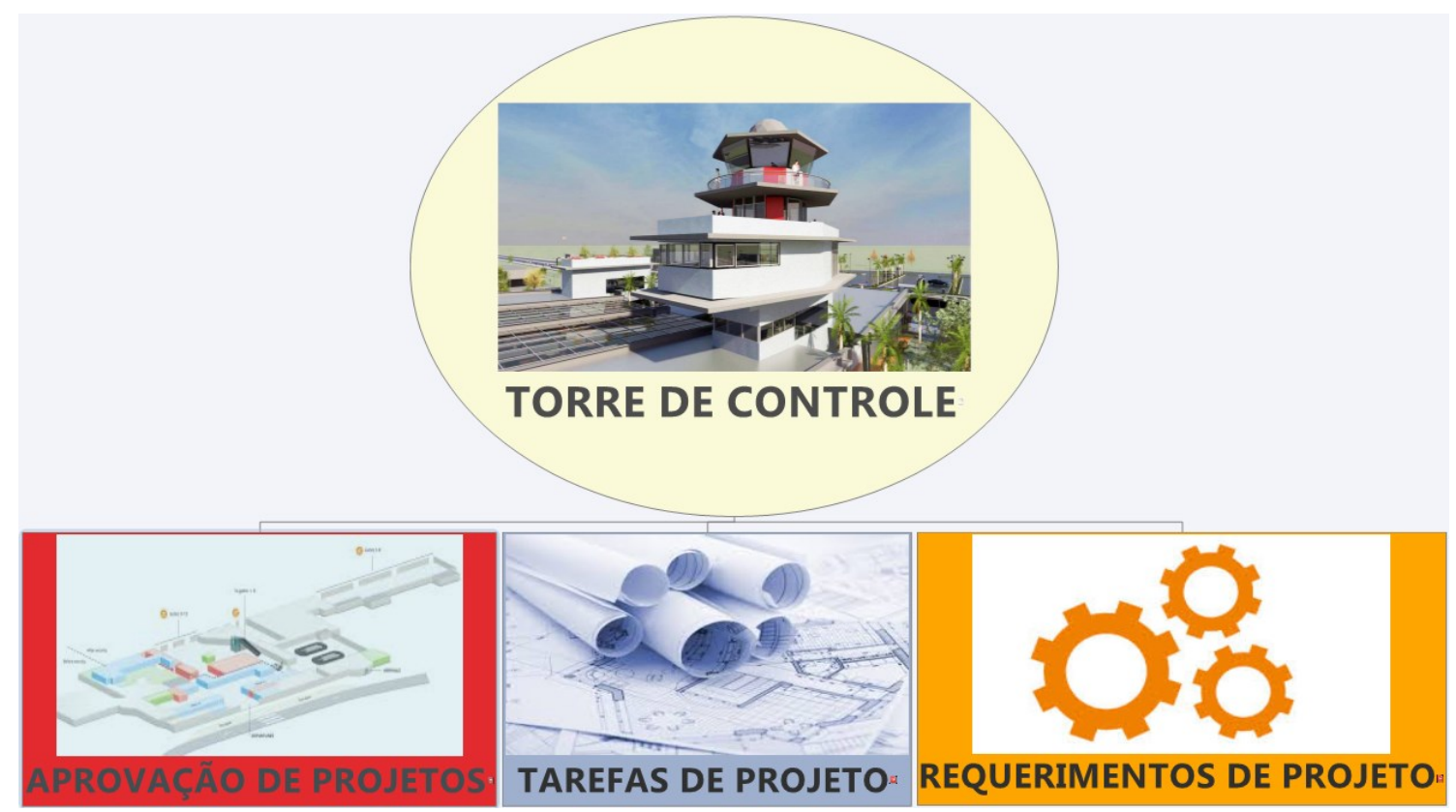

Figura 159 - Ilustração da tela de acesso aos campos de Aprovação, Tarefas e Requerimentos de Projeto para Torre de Controle na Matriz Semântica.

Há uma retroalimentação entre o desenvolvimento de um modelo e a organização de informações na matriz. Este processo pode resultar em um futuro sistema inteligente de suporte ao processo de projeto. A matriz procura responder às limitações dos sistemas BIM em representar diferentes níveis de abstração na informação associada ao modelo (semântica) e de especificação e representação geométrica. Para consultar informações sobre a torre de controle foi necessário clicar no campo de aprovação de projetos. A matriz abre uma nova tela representada na Figura 160 a seguir, que informa quais as áreas da INFRAERO estão envolvidas no projeto da torre e quais são os processos de analise que deverão ser efetuados por cada uma das mesmas.

Ao mesmo tempo, cada um dos processos de aprovação é classificado sobre como o processo de aprovação ocorre, se através de projetação, analise ou de síntese. Informa ainda sobre qual o tipo de ação, se de execução, de informação ou de inação. Por último, a matriz classifica o impacto do processo de aprovação quanto a alto, médio e baixo. Por exemplo, a área de Engenharia é responsável pela aprovação das soluções de arquitetura, mas também pelo seu desenvolvimento, devendo não apenas fornecer, mas aprovar internamente as soluções de engenharia. Esta ação é de execução e seu impacto é alto. Por outro lado, a área operacional deve aprovar a solução proposta quanto à eficiência operacional, em ação de análise, que deve ser executada por esta área e tem um impacto médio. Por meio da consulta a tela representada na Figura 160 acima foi possível visualizar a extensão dos requisitos de aprovação, ao ter noção de quais as áreas estão implicadas e quais são os processos de aprovação que as mesmas devem desenvolver. 


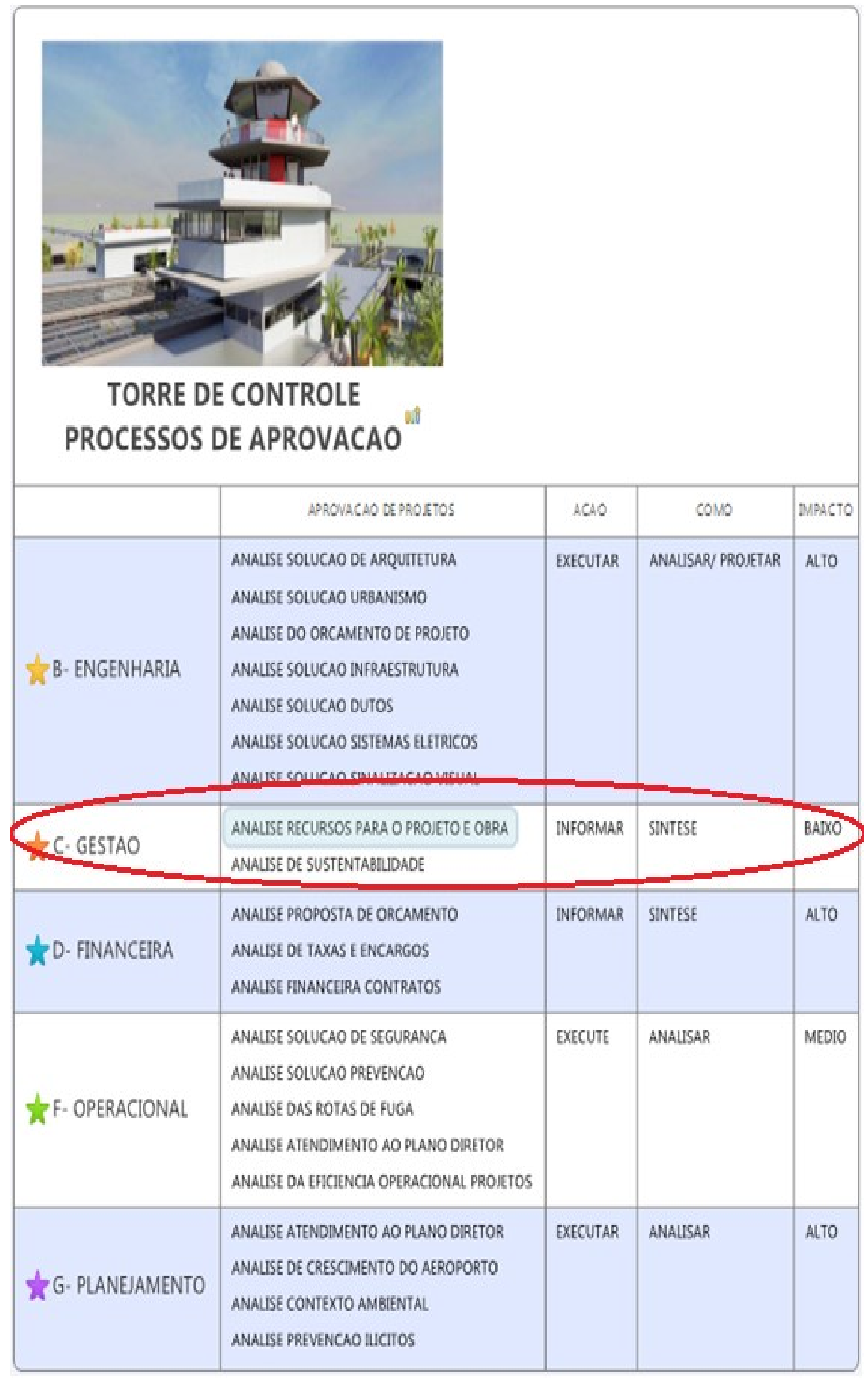

Figura 160- Ilustração da tela de acesso à informações sobre os Processos de Aprovação para uma Torre de Controle na Matriz Semântica. 
Por meio da consulta a tela representada na Figura 160, citada anteriormente, foi possível visualizar a extensão dos requisitos de aprovação, ao ter noção de quais as áreas estão implicadas e através da interação também ter noção de quais são os processos de aprovação que as mesmas devem desenvolver.

Por exemplo, a matriz informa que a área de Gestão deverá realizar analise sobre os recursos para o projeto e a obra, que deve ser comparado com a proposta orçamentaria expressa no projeto. A matriz permite ainda a consulta sobre as tarefas de projeto, como pode ser observado na Figura 161 a seguir, que exemplifica a consulta a especialidade de telemática.

A matriz apresenta a separação entre estudo conceitual e projeto básico, as tarefas de projeto constantes como parte das especificações técnicas de projeto da INFRAERO.

A Figura 161, na página seguinte, demonstra a organização das tarefas de projeto de um modulo Torre de Controle.

Pode-se observar informações sobre as disciplinas que estão envolvidas nos seus processos de projeto.

No caso da torre de Controle" encontram-se listadas as disciplinas de:

1- ARQUITETURA;

2- SISTEMAS ELÉTRICOS;

3- INFRAESTRUTURA;

4- ORÇAMENTO;

5- SISTEMAS ELETRÔNICOS;

6- SISTEMAS ESTRUTURAIS;

7- TELEMÁTICA.

$\mathrm{Na}$ coluna referente as tarefas de projeto estão separadas as informações referentes ao Estudo Preliminar e ao Projeto Básico. Para cada fase de projeto estão listadas as atividades, ou tarefas de projeto.

Por exemplo, para a especialidade de arquitetura, referente ao Estudo conceitual, é possível acessar, clicando no campo desejado, as tarefas relativas ao Estudo Conceitual de Arquitetura. 


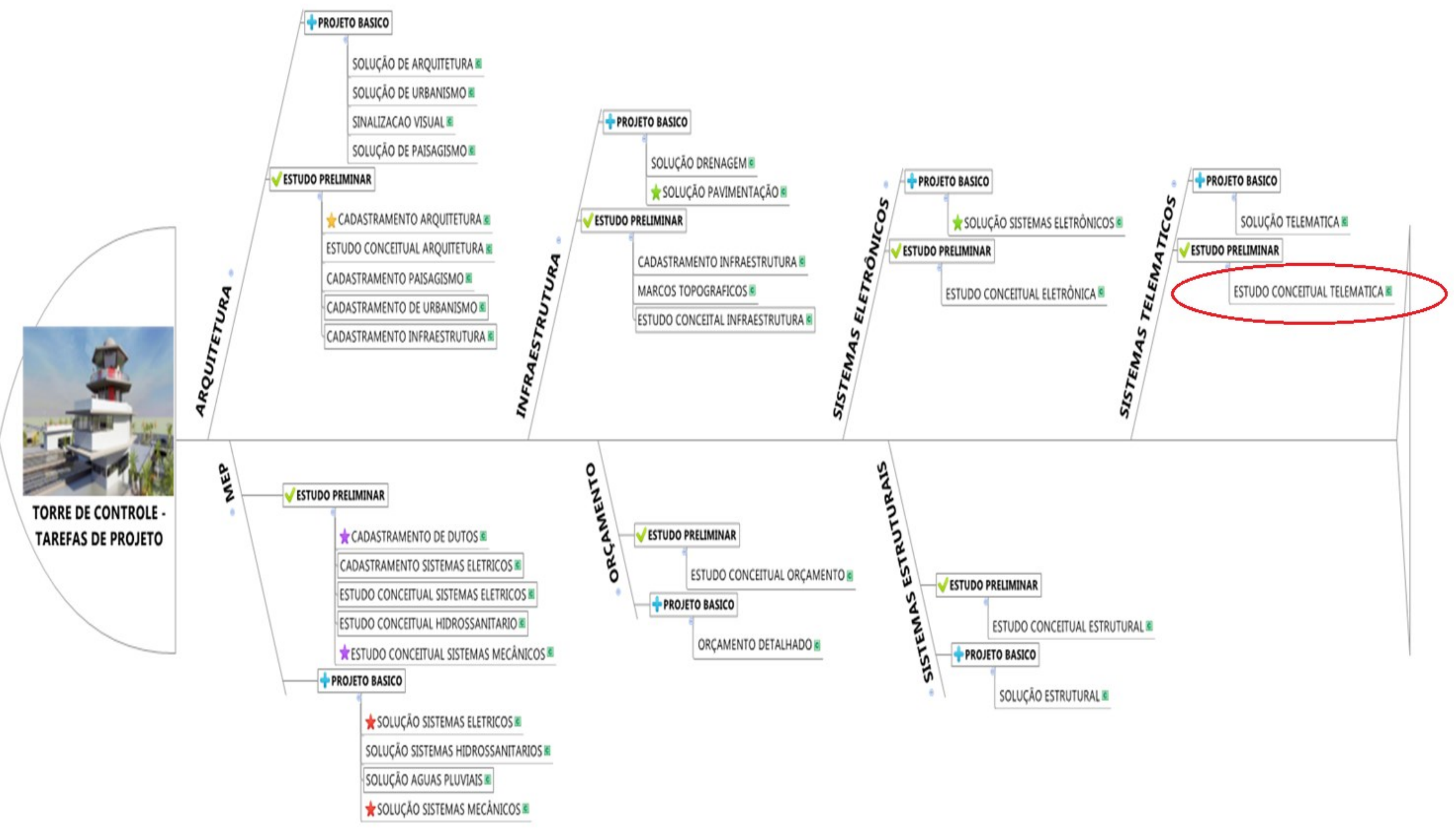

Figura 161- Ilustração da tela de acesso para as Tarefas de Projeto para uma Torre de Controle na Matriz Semântica.

A FIGURA 161 EXEMPLIFICA AS TAREFAS QUE DEVEM SER EXECUTADAS E O ESCOPO MÍNIMO PARA O PROJETO NA INFRAERO DOS SISTEMAS TELEMÁTICOS DE UMA TORRE DE CONTROLE 


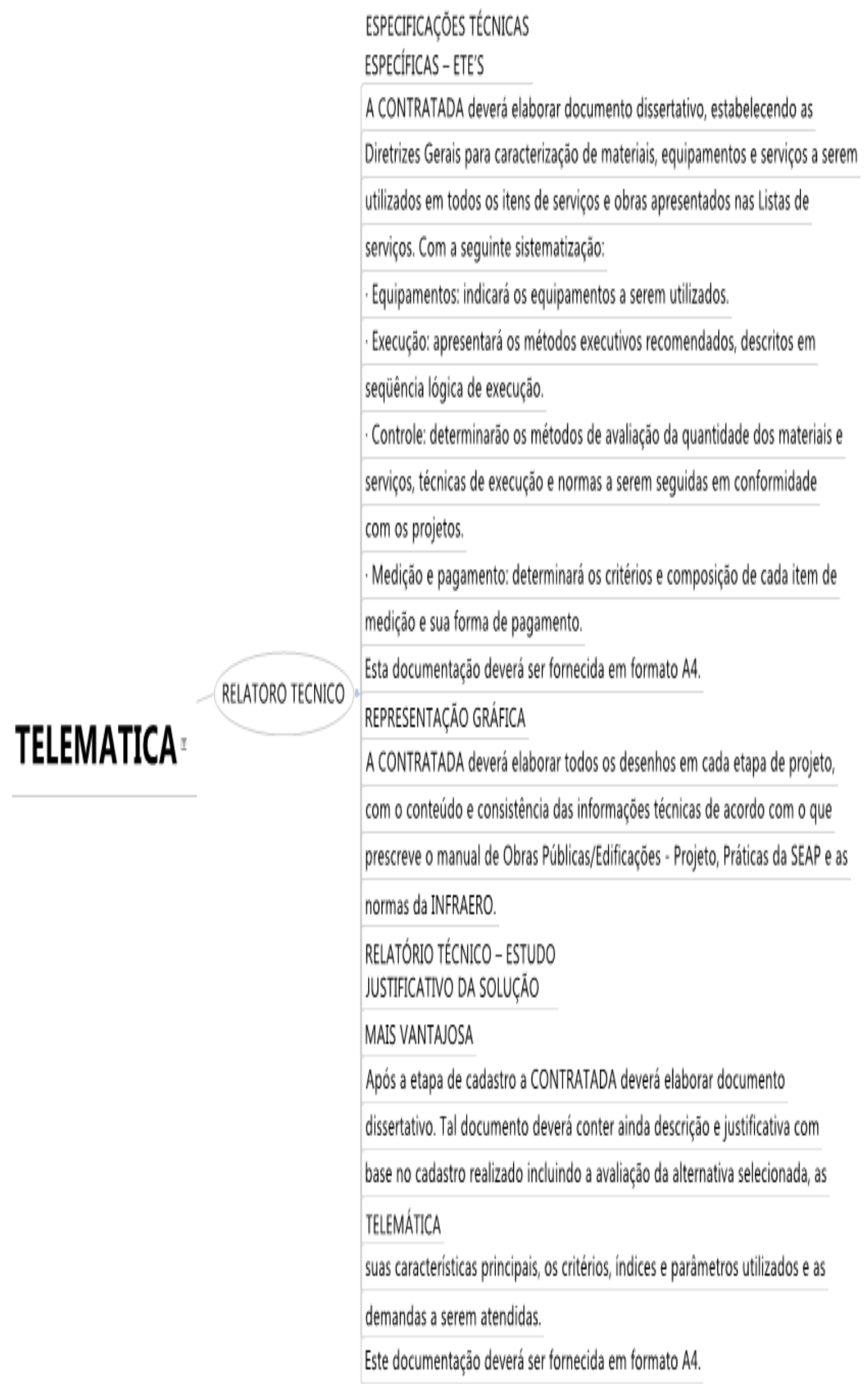

Figura 162 - Ilustração da tela da Matriz Semântica com as informações sobre o Estudo Conceitual de Telemática na Matriz Semântica. 
A Figura 163 a seguir apresenta os requerimentos de projeto para estudo conceitual de arquitetura na INFRAERO. Define critérios de representação de projeto, escalas e ainda o escopo mínimo que deve ser apresentado, de forma a que o produto final possa obedecer ao preconizado na lei 8.112 de licitações, que exige comprovação da viabilidade, obviamente ligada aos custos que um projeto acarreta.

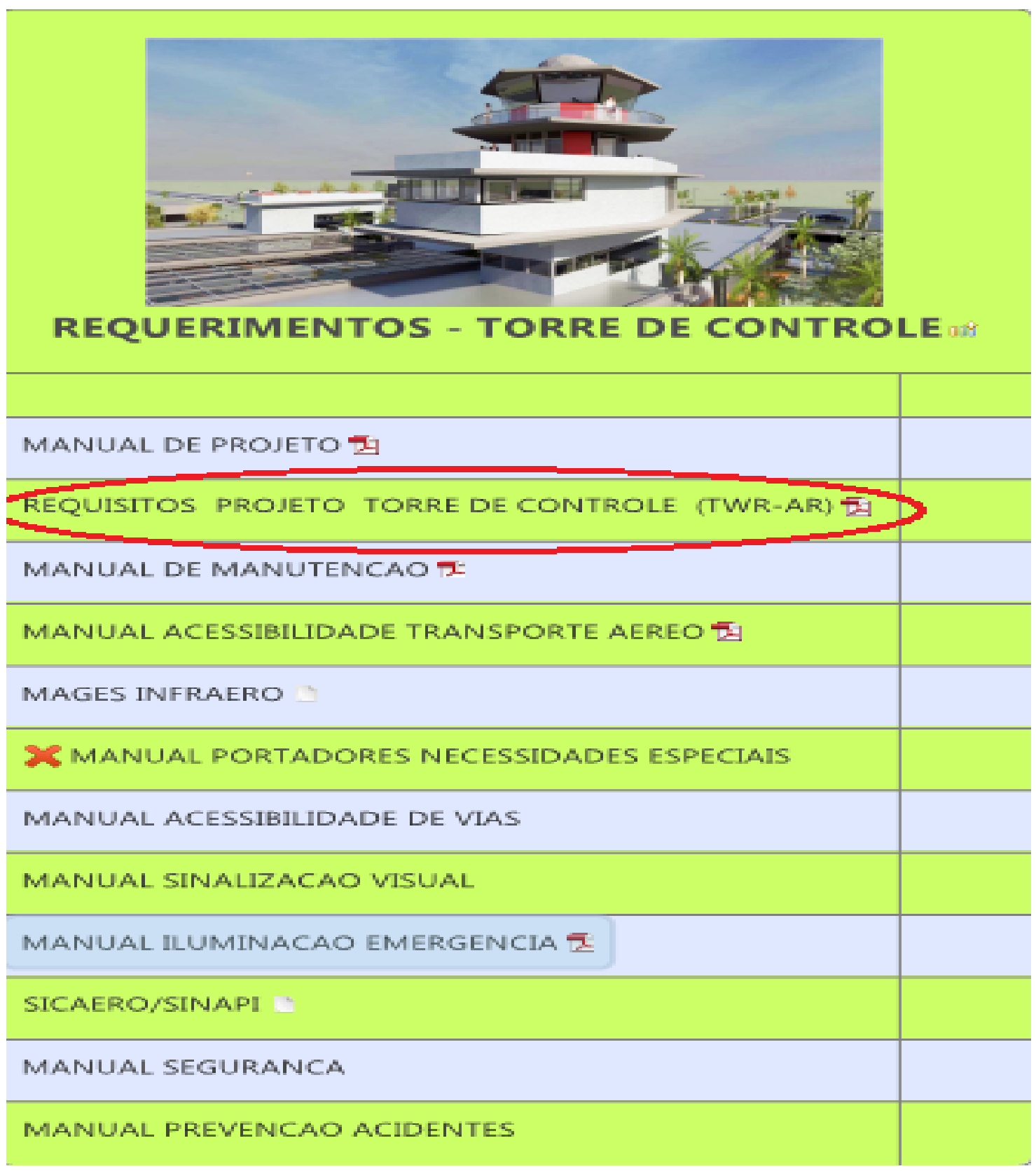

Figura 163 - Ilustração da tela de acesso aos Requerimentos de Projeto para uma Torre de Controle na Matriz Semântica.

Por meio da consulta a tela de requerimentos representada na Figura 161, (ilustração da tela de acesso para as tarefas de projeto para uma torre de controle na Matriz Semântica) pode-se obter informações como as contidas nas Figuras 164 e 165, através do documento utilizado como exemplo de "Requisitos de navegação aérea para a elaboração do projeto de construção da torre de controle de Aracaju (TWR-AR) da INFRAERO". 
As seguintes dependências e/ou detalhes deverão ser previstos, de forma a atender às necessidades operacionais e técnicas do órgão:

\section{a- Cabine}
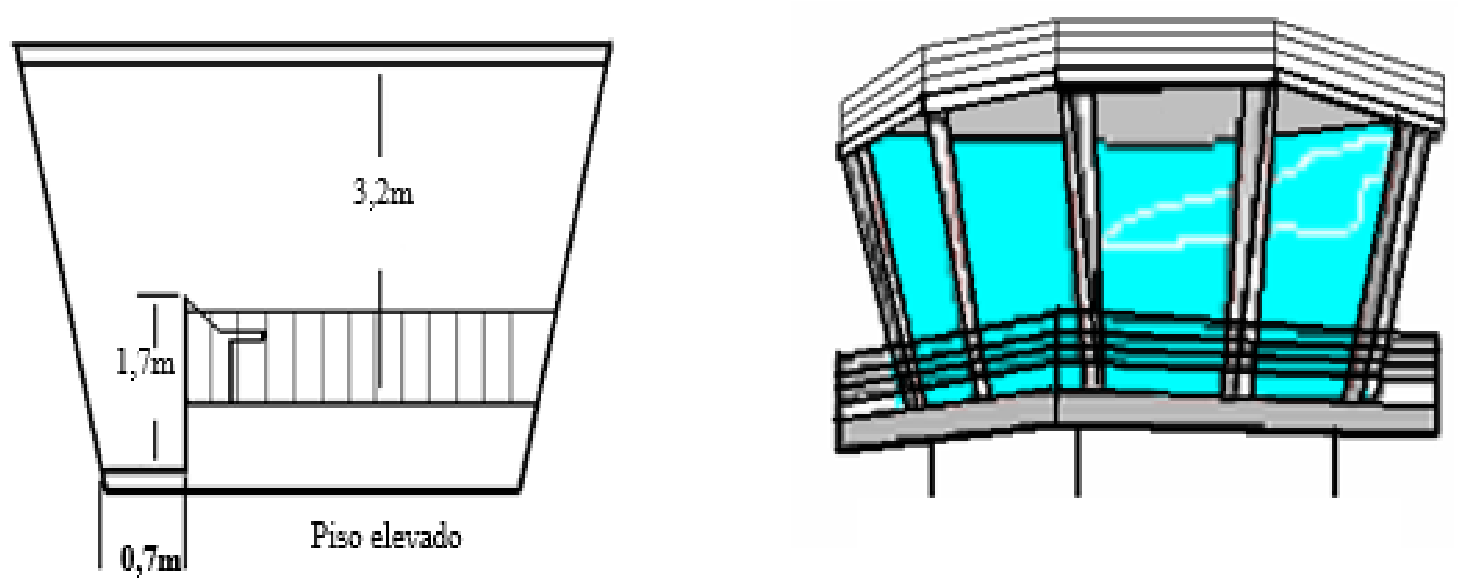

Fin 7 ín nxtnm

Figura 164 - Ilustração de Requerimento da INFRAERO para projeto de uma Torre de Controle. Fonte: INFRAERO

Para fins deste projeto, foi considerado que a área útil interna (piso operacional) engloba a área destinada para as consoles operacionais.

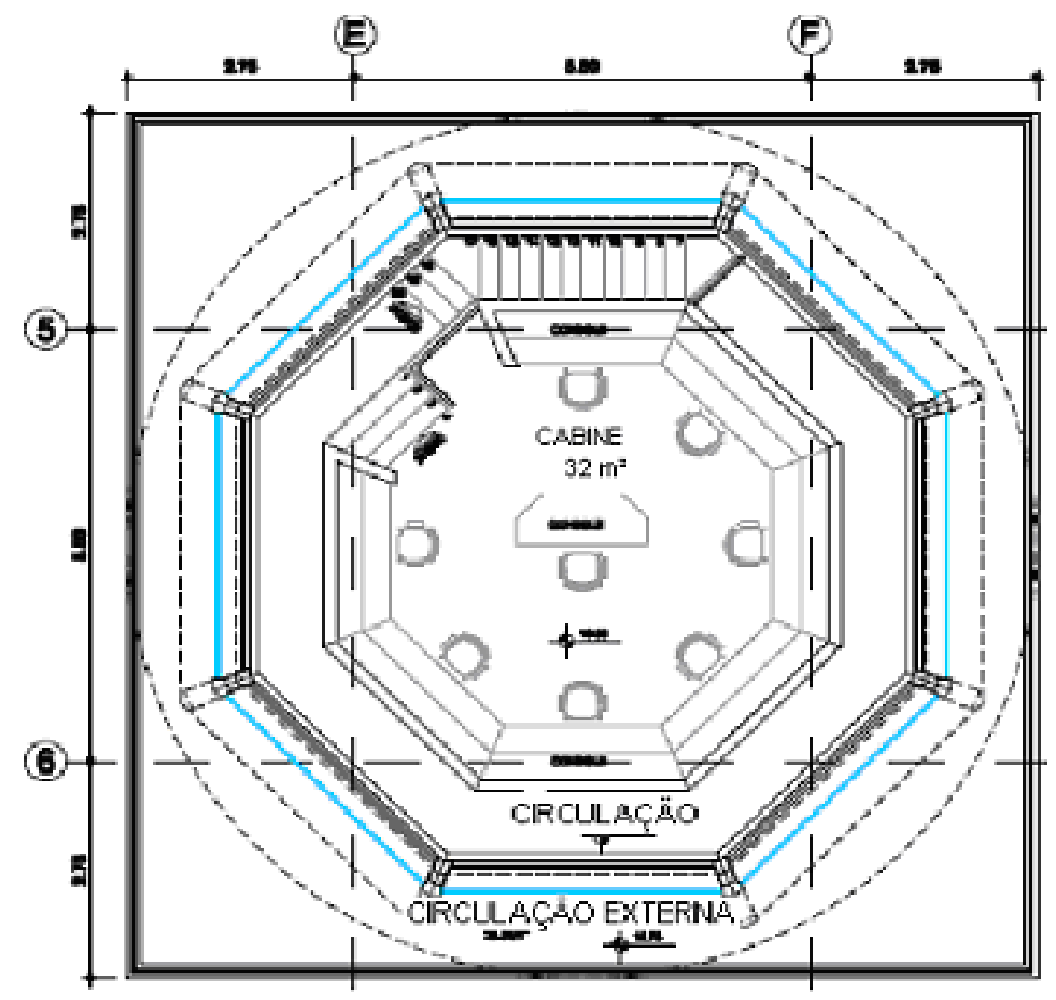

Fig 3- CABINE

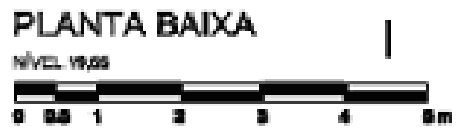

Figura 165 - Ilustração para projeto de uma Torre de Controle. Fonte: INFRAERO 


\subsection{2- DEMONSTRACAO DOS PASSOS PARA EXPANSAO DE UMA DAS TORRES}

\section{ANÁLISE ITEM A ITEM DOS PASSOS NECESSÁRIOS:}

1- APAGAR ELEMENTOS “A DEMOLIR”: consiste na eliminação dos elementos construtivos que devem ser readequados para que a nova proposta seja implementada (Figura 166).

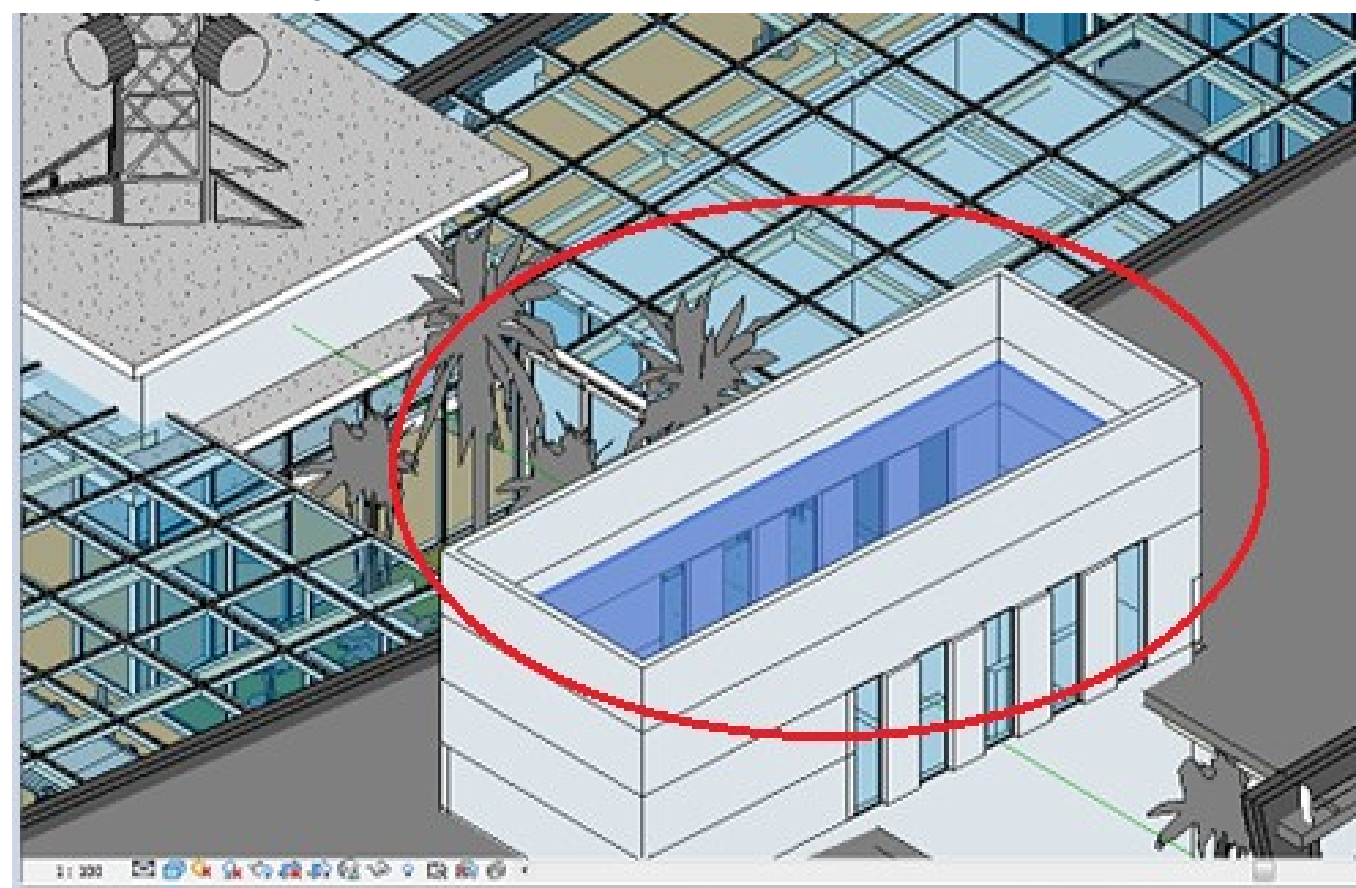

Figura 166- Detalhamento de elemento a ser retirado na modelagem de uma das alternativas de Torre de Controle no Revit ${ }^{\circ}$.

2- MODELAR OS PISOS DA TORRE DE CONTROLE: consistiu na criação do piso térreo e do primeiro pavimento referentes à torre de controle. Estes pisos foram configurados assumir localização espacial referente às suas cotas de nível. $O$ Revit $^{\circledR}$ representa iconograficamente os elementos construtivos em três dimensões, acrescidas de parâmetros que devem ser checados e reconfigurados caso necessário (Figura 167).

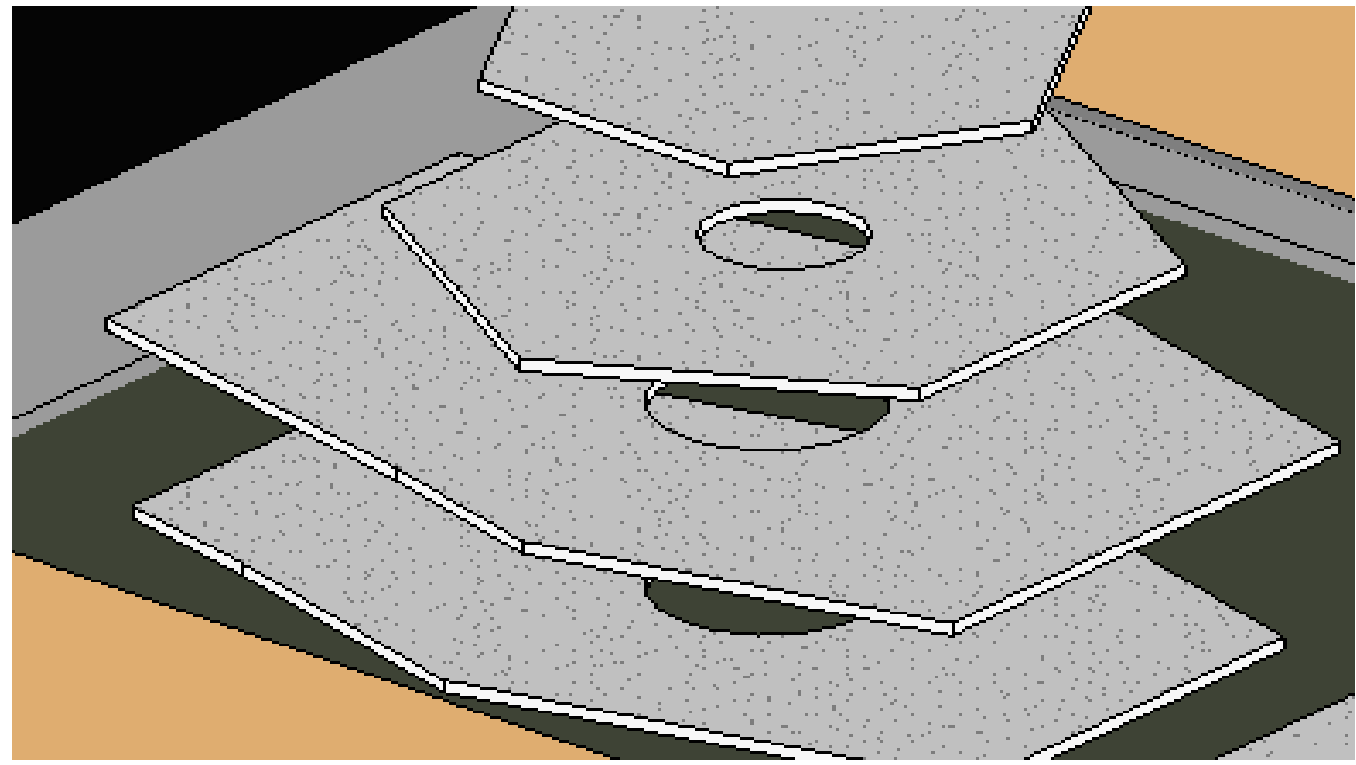

Figura 167- Detalhamento dos pisos de uma das alternativas de Torre de Controle no Revit ${ }^{\circ}$. 
3- MODELAR OS PILARES DA TORRE DE CONTROLE: a tarefa foi a criação da estrutura de pilares em cada piso do projeto. Os pilares foram parametrizados para assumirem restrições em relação à altura dos pisos, o que representa a possibilidade de ajustes automáticos caso ocorra alguma alteração (Figura 168).

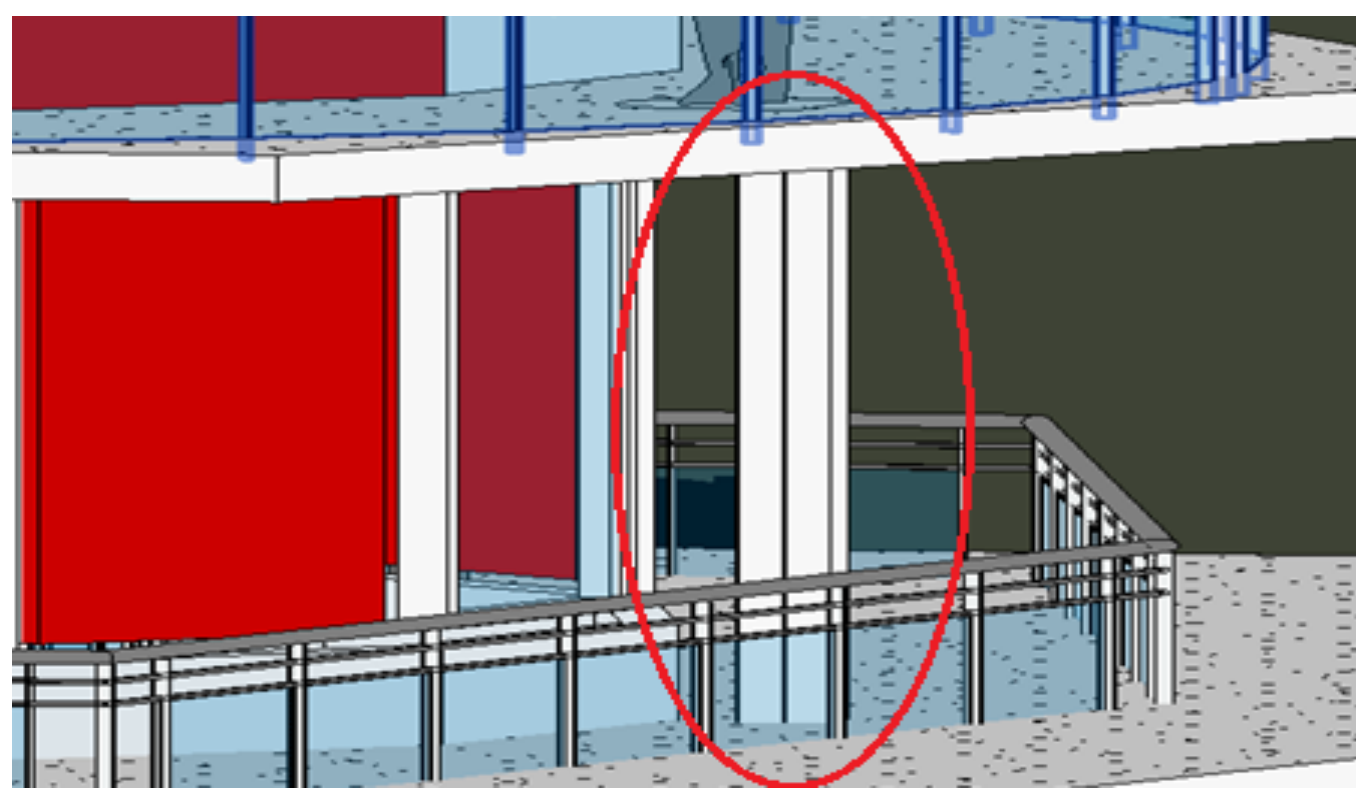

Figura 168- Detalhamento do pilar na modelagem de alternativa de TWR no Revit ${ }^{\circledR}$

4- MODELAR AS VIGAS DA TORRE DE CONTROLE: a tarefa foi a criação da estrutura de vigas em cada piso das torres de controle. As vigas puderam ser parametrizadas para assumirem vinculação ou conexão em relação à dimensão dos pisos, o que representa a possibilidade de ajustes automáticos em caso de alteração, compreendendo ainda o correto posicionamento e verificação de parâmetros das vigas no modelo virtual tridimensional (Figura 169).

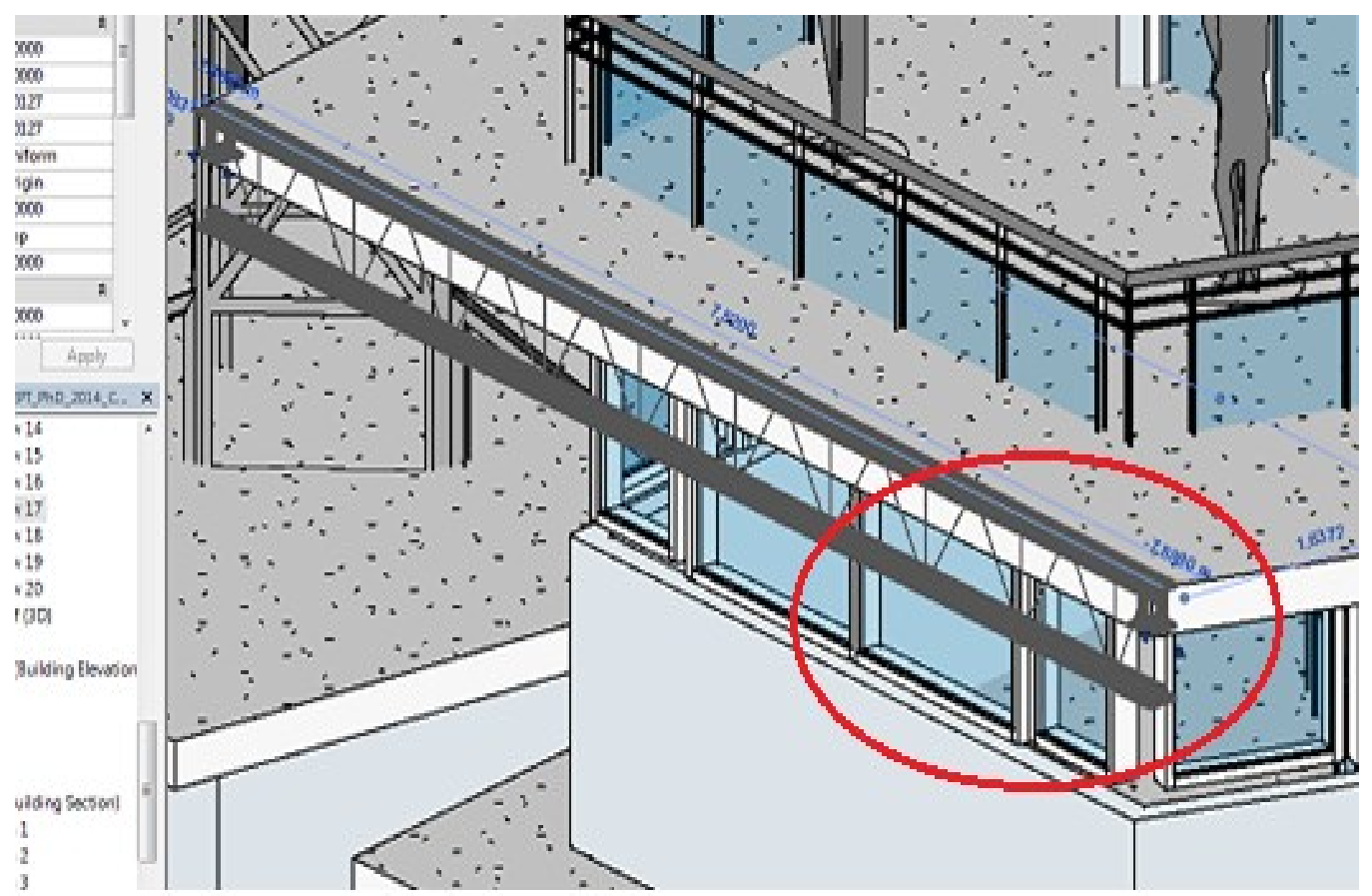

Figura 169 - Detalhamento da viga de uma das alternativas de TWR no Revit ${ }^{\circ}$. 
5- MODELAR AS PAREDES DA TORRE DE CONTROLE: a tarefa foi a criação da estrutura de paredes em cada piso do projeto. As paredes puderam ser parametrizadas para assumirem vínculos em relação à altura dos pisos, o que representa a possibilidade de ajustes automáticos em caso de alteração (Figura 170).

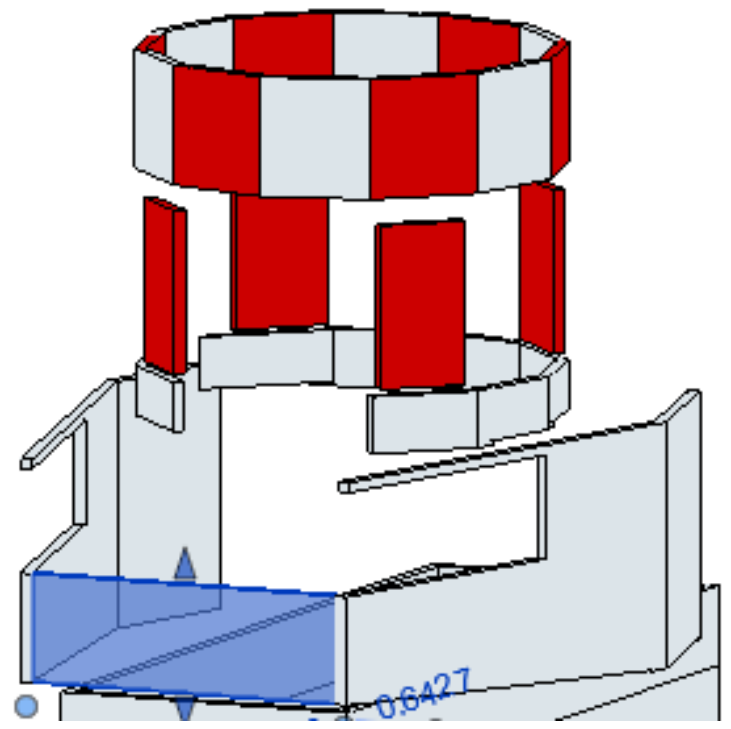

Figura 170 - Detalhamento das paredes de uma das alternativas de Torre de Controle no Revit ${ }^{\circ}$.

6- MODELAR OS ELEMENTOS DE FECHAMENTO: podendo ser componentes (portas e janelas): consiste na inserção de diferentes componentes para colocação de portas e janelas do projeto. Estes componentes podem ser configurados para que assumam parâmetros adequados ao projeto (Figura 171).

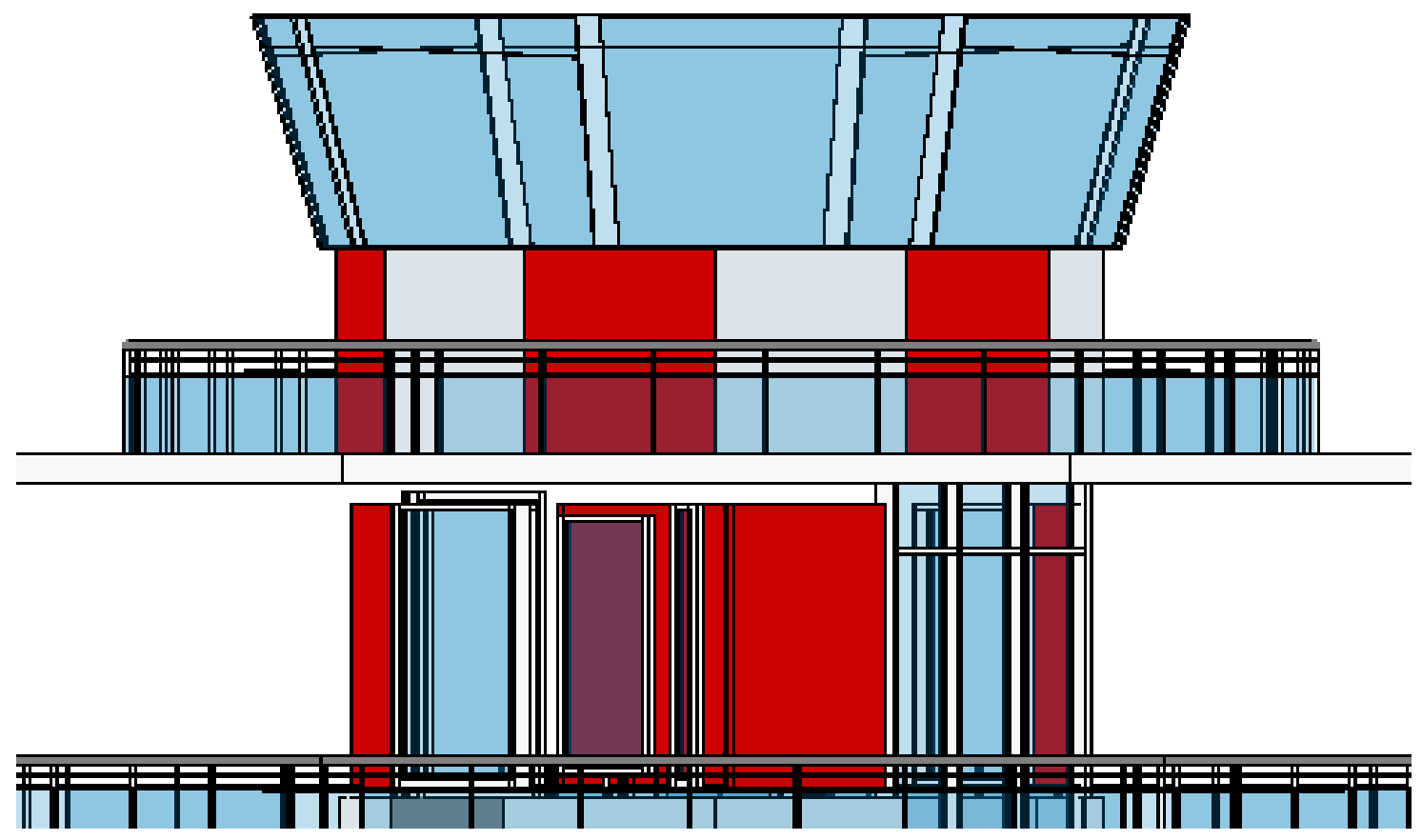

Figura 171 - Detalhamento dos elementos do fechamento na modelagem de uma das alternativas de Torre de Controle no Revit ${ }^{\oplus}$. 


\section{7- MODELAR OS ELEMENTOS ACESSÓRIOS À TORRE DE CONTROLE:}

consiste na modelagem ou na inserção de componentes, como mobiliários internos ou urbanos, vegetação, pessoas e veículos, de forma a auxiliar na compreensão do projeto, sua escala e funções desempenhadas por ele (Figura 172 abaixo). A inserção de elementos acessórios é uma tarefa complexa no Revit $^{\circledR}$ para que estes elementos se adéquem perfeitamente ao ambiente tridimensional (escala, posicionamento, e eventualmente textura).

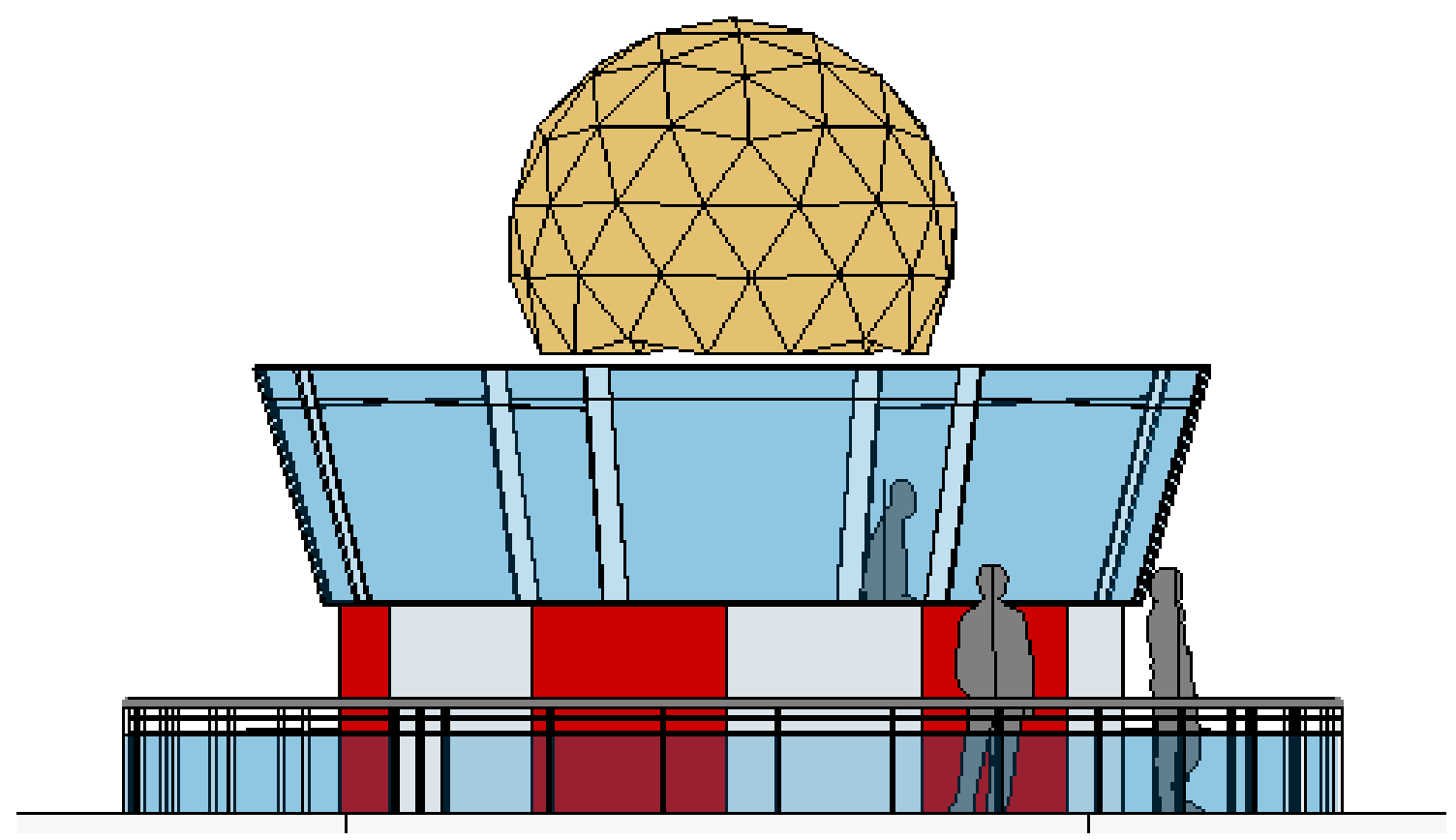

Figura 172 - Detalhamento de elementos acessórios de uma das alternativas de TWR no Revit.

8- MODELAR A COBERTURA DA TORRE DE CONTROLE: a tarefa é a criação da estrutura da cobertura do projeto. A cobertura pode ser parametrizada para assumir uma melhor configuração em relação a materiais, acabamentos, etc. de forma a uma melhor adequação ao escopo do projeto (Figura 173 abaixo).

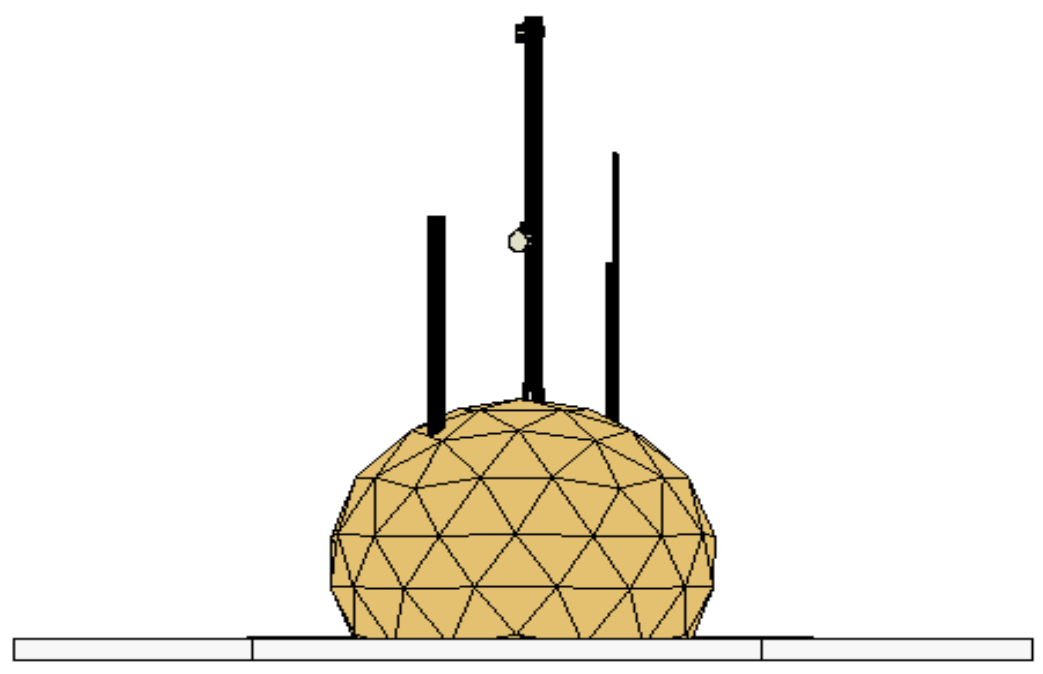

Figura 173 - Detalhamento da cobertura de uma das alternativas de TWR no Revit ${ }^{\circ}$. 
9- GERAR PLANTAS, CORTES E FACHADAS DO MODELO: nesta tarefa foi realizada a documentação técnica de projeto, como plantas, cortes e fachadas. No Revit ${ }^{\circledR}$, a formação de documentação bidimensional ocorre de forma de forma automática (Figuras 174 a 176).

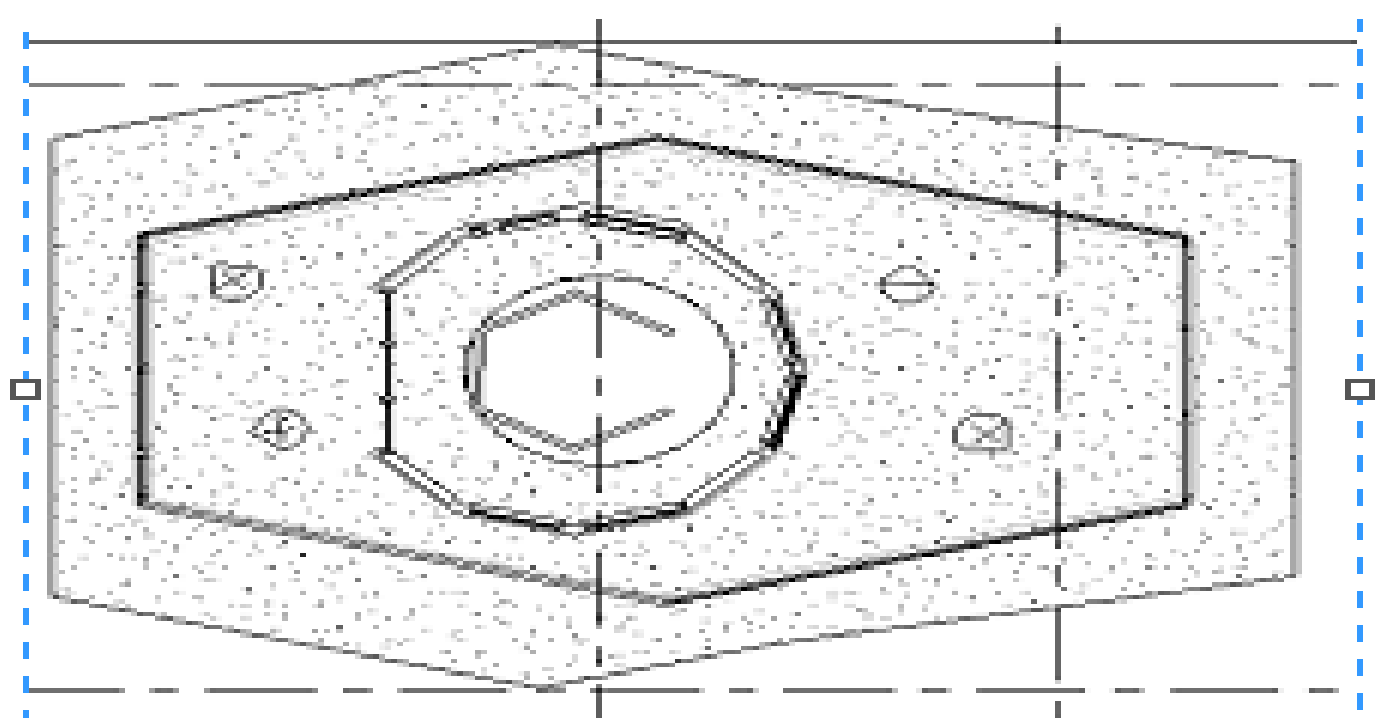

Figura 174 - Planta baixa gerada automaticamente pelo Revit ${ }^{\circ}$ da proposta 3 da TWR.

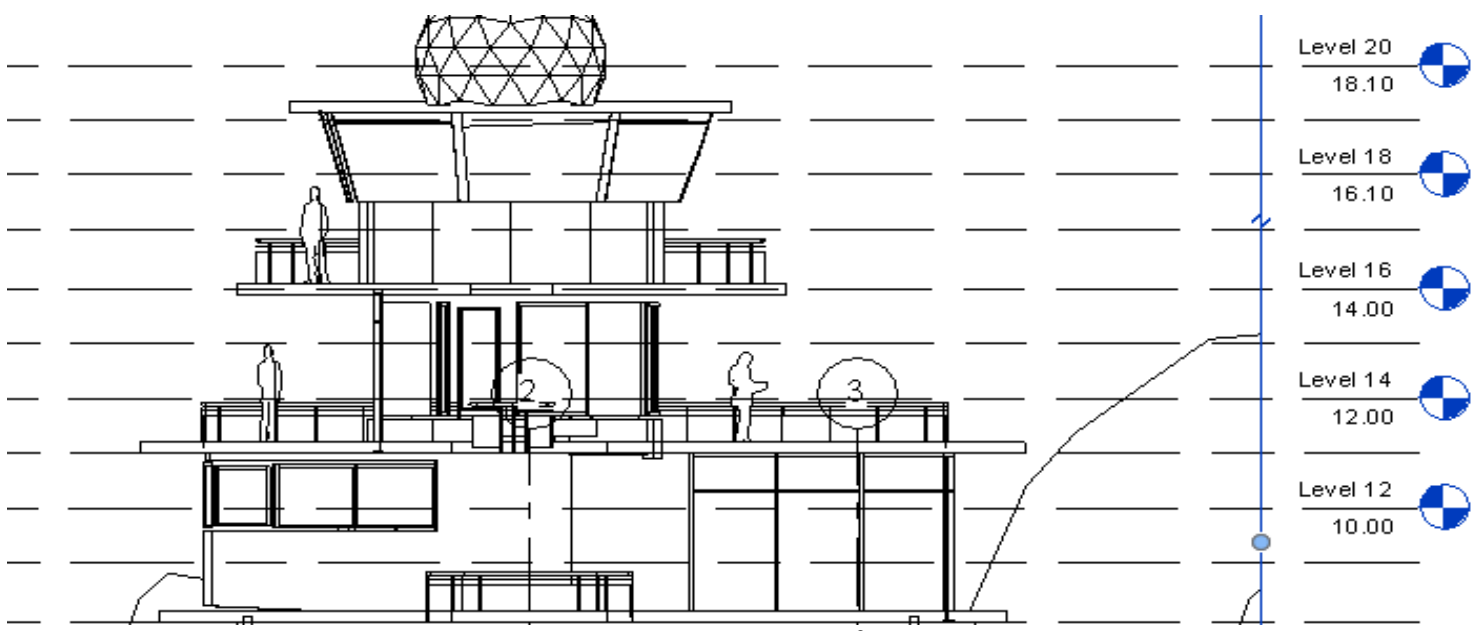

Figura 175 - Corte gerado automaticamente pelo Revit ${ }^{\circ}$ da proposta 3 da TWR.

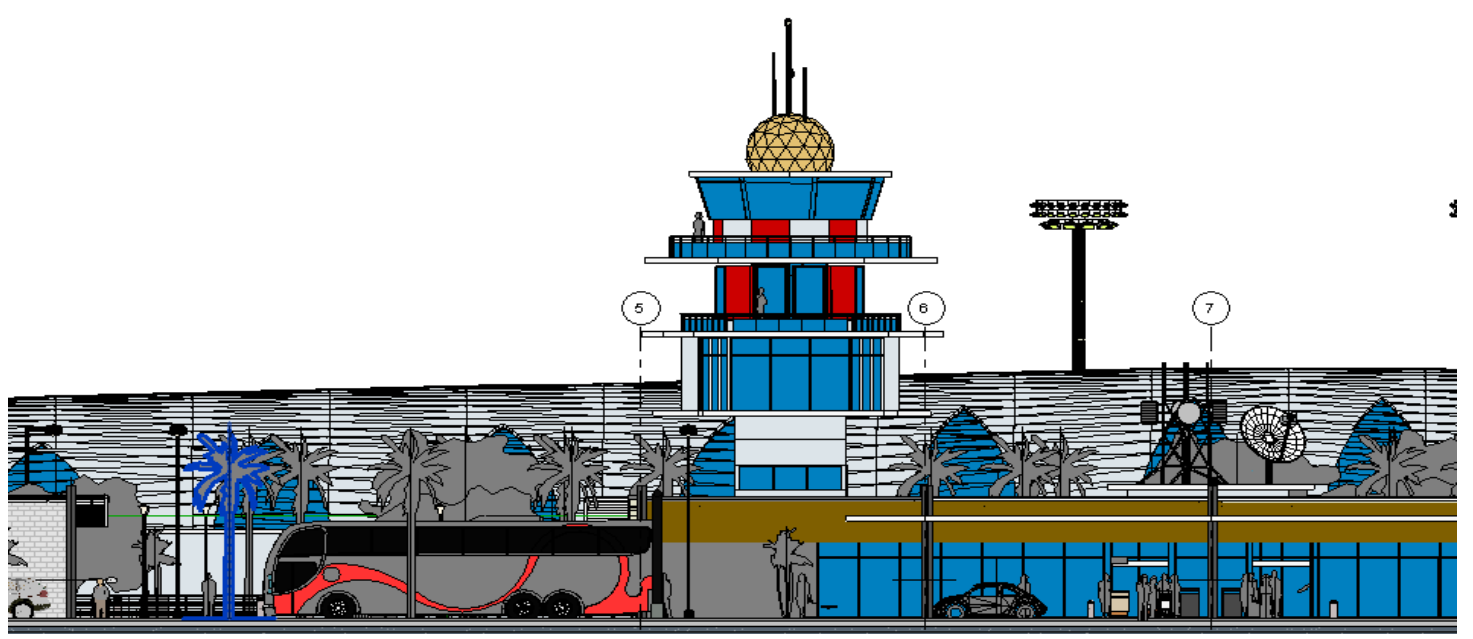

Figura 176 - Fachada gerada automaticamente pelo Revit ${ }^{\circ}$ da proposta 3 da TWR. 


\subsection{3- IMAGENS PERSPECTIVAS DAS ALTERNATIVAS DE PROJETO - TORRE DE CONTROLE (TWR)}

OS RESULTADOS DA MODELAGEM DAS TRÊS ALTERNATIVAS DE PROJETO DA

TORRE DE CONTROLE ESTÃO APRESENTADOS NAS FIGURAS177 A 179.

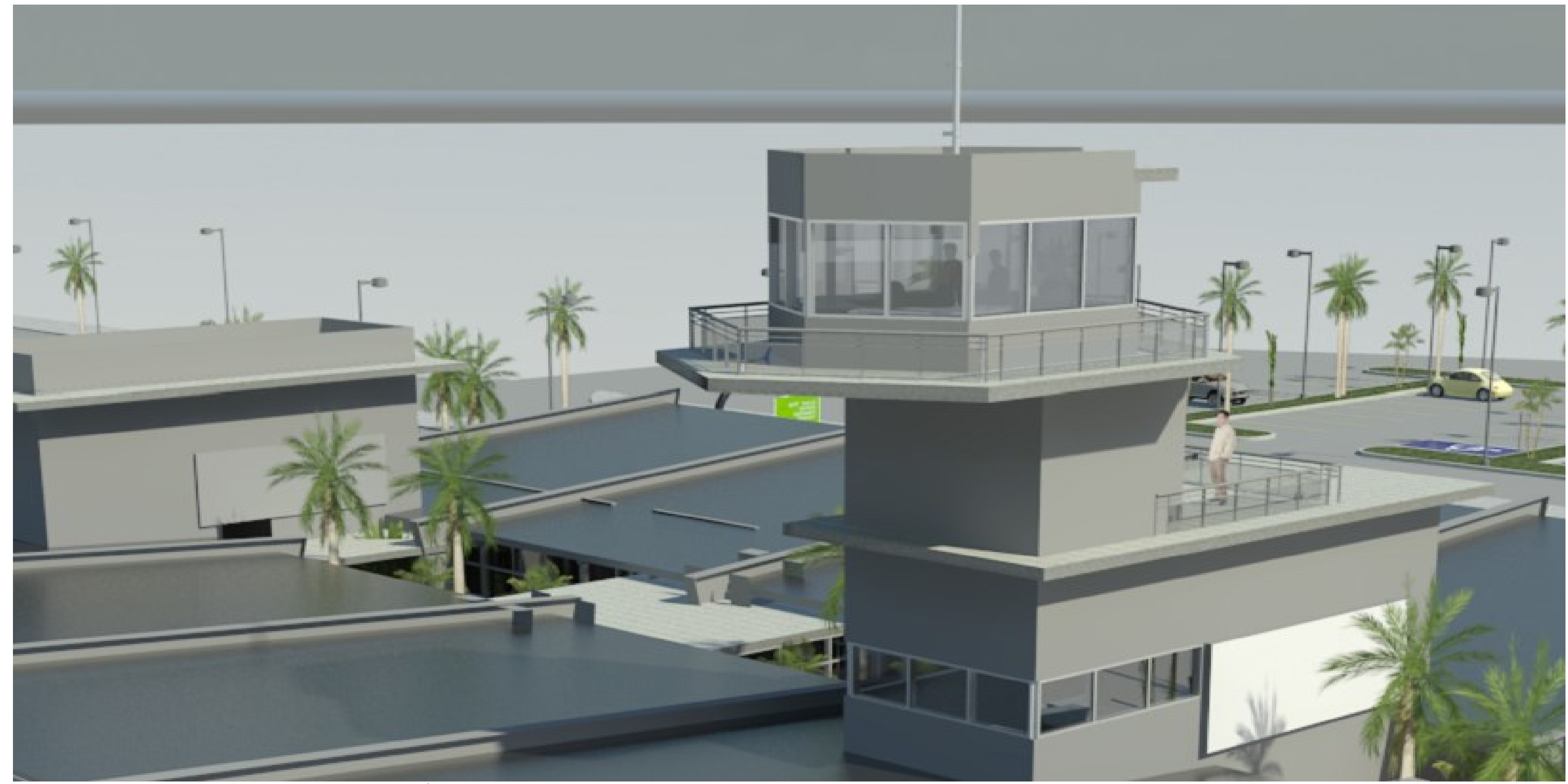

177 - Alternativa 1 de Projeto (TWR). Sistema BIM - Revit".

COMO PODE SER OBSERVADO NA FIGURA 177 ACIMA, O RESULTADO DE MODELAGEM DA PRIMEIRA ALTERNATIVA DE TWR APRESENTA MENOR COMPLEXIDADE, POSSUINDO UMA CABINE SIMPLES E TORRE DE SUBIDA EM DOIS NÍVEIS OPERACIONAIS.
A ALTERNATIVA 1 DE TORRE DE CONTROLE SEGUE A CLASSIFICACAO ADOTADA ELA INFRAERO, SENDO DO TIPO 1, APRESENTANDO MENOR COMPLEXIDADE ESTRUTURAL E MENOR ESPACO INTERNO DE CABINE DE CONTROLE. 


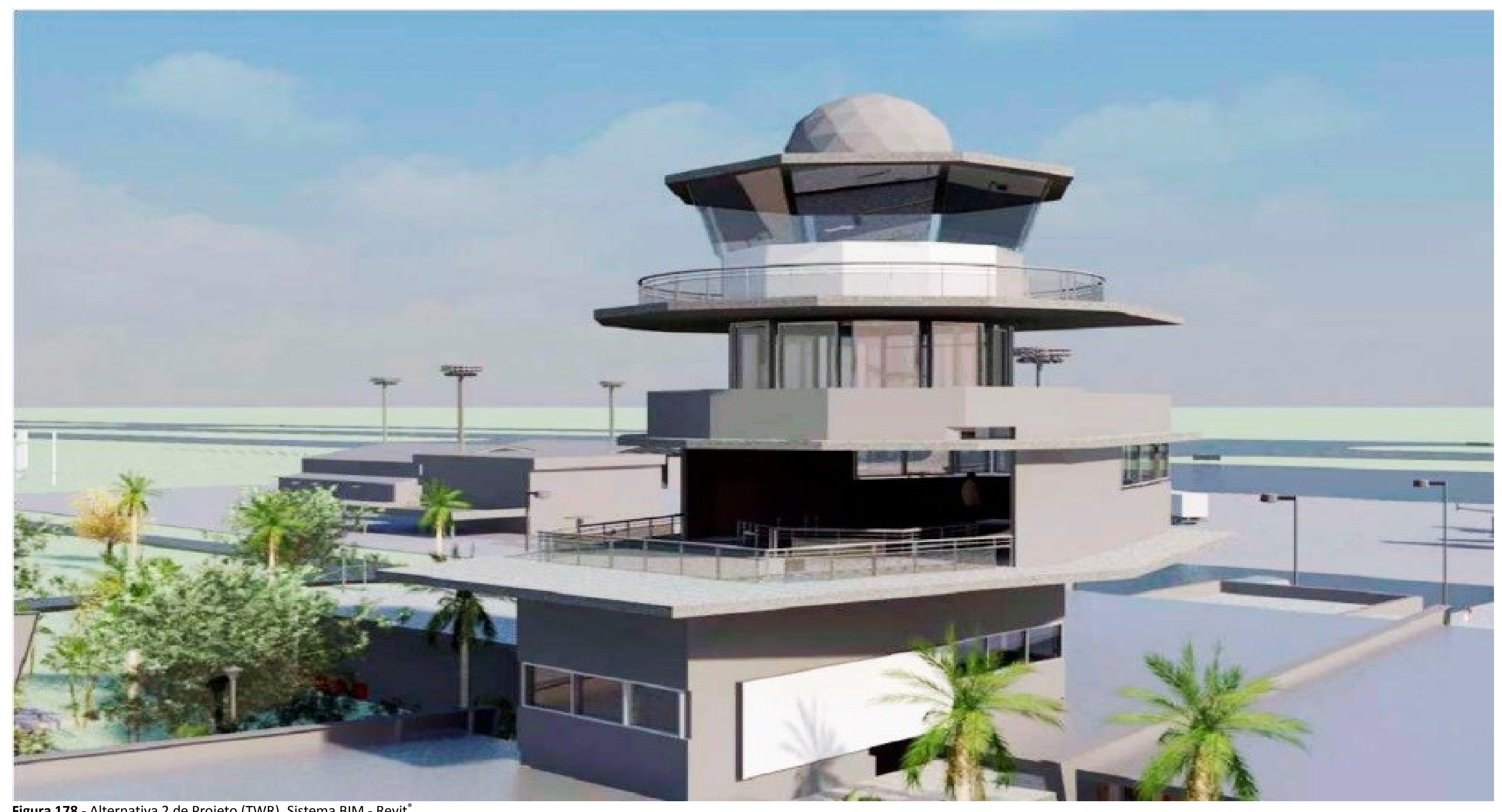

Figura 178 - Alternativa 2 de Projeto (TWR). Sistema BIM - Revit ${ }^{\circ}$.

NA FIGURA178 ACIMA PODE-SE OBSERVAR O RESULTADO DE MODELAGEM DA SEGUNDA ALTERNATIVA DE TWR APRESENTA COMPLEXIDADE MEDIA, APRESENTANDO CABINE MAIOR E TORRE DE SUBIDA EM TRÊS NÍVEIS OPERACIONAIS.
A ALTERNATIVA 2 DE TORRE CONTROLE CONDIZ COM AS ESPECIFICACOES DE TIPO 2, OFERECENDO DOIS NIVEIS DE APOIO AO CONTROLE AEREO E UM PISO DE CONTROLE E VIGILANCIA DE OPERACOES DE APROXIMACAO, POUSO E DECOLAGEM DE AERONAVES. 


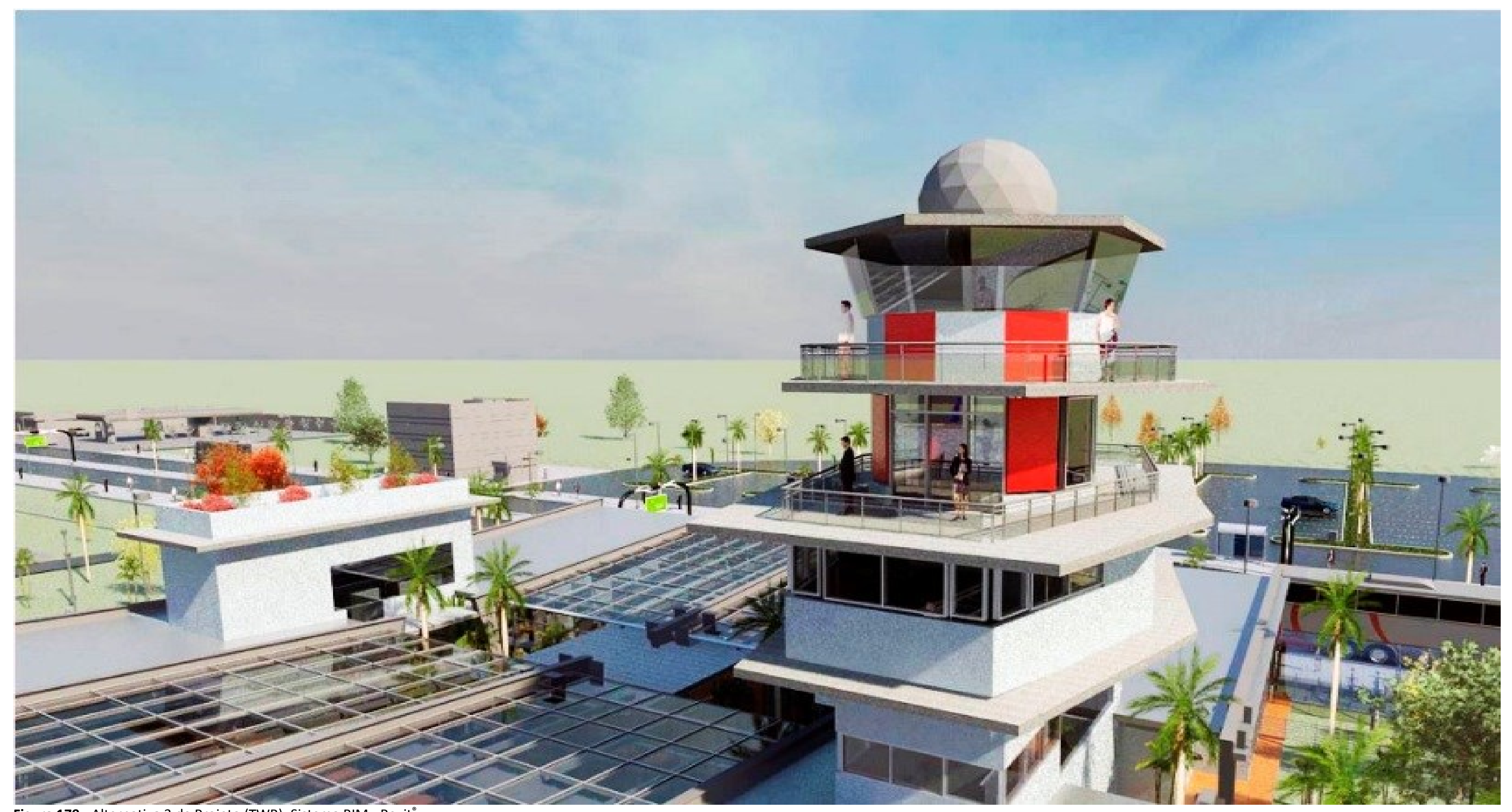

Figura 179 - Alternativa 3 de Projeto (TWR). Sistema BIM - Revit

COMO PODE SER OBSERVADO NA FIGURA 179 ACIMA, O RESULTADO DE MODELAGEM DA TERCEIRA ALTERNATIVA DE TWR APRESENTA COMPLEXIDADE ALTA, APRESENTANDO CABINE MAIOR E TORRE DE SUBIDA EM TRÊS NIVVEIS OPERACIONAIS.
A ATERNATIVA 3 DE TORRE DE CONTROLE CONDIZ COM A ESPECIFCACAO DE TORRE DO TIPO 3, OFERECENDO MAIOR ALTURA EM RELACAO AO SOLO E PORTANTO UMA VISAO AMPLIFICADA DO PATIO DE AERONAVES E DA PISTA DE POUSOS E DECOLAGENS 


\subsection{4- INFLUENCIA DOS SISTEMAS SIG NOS PROCESSO DE ANALISE E DE TOMADA DE DECISAO NOS ESTAGIOS INICIAIS DE PROJETO}

Esta etapa da pesquisa visou simular o processo de projeto BIM com auxílio do SIG, no desenvolvimento de alternativas e projeto, tarefa que se assemelha aos estágios iniciais de projeto, uma vez que envolve a criação de um novo módulo funcional, no caso a torre de controle - TWR. Realizamos um teste, utilizando o SIG como ferramenta de análise, em termos de variação de visualização de distância (LOD Geométrico) e a relação com o relevo.

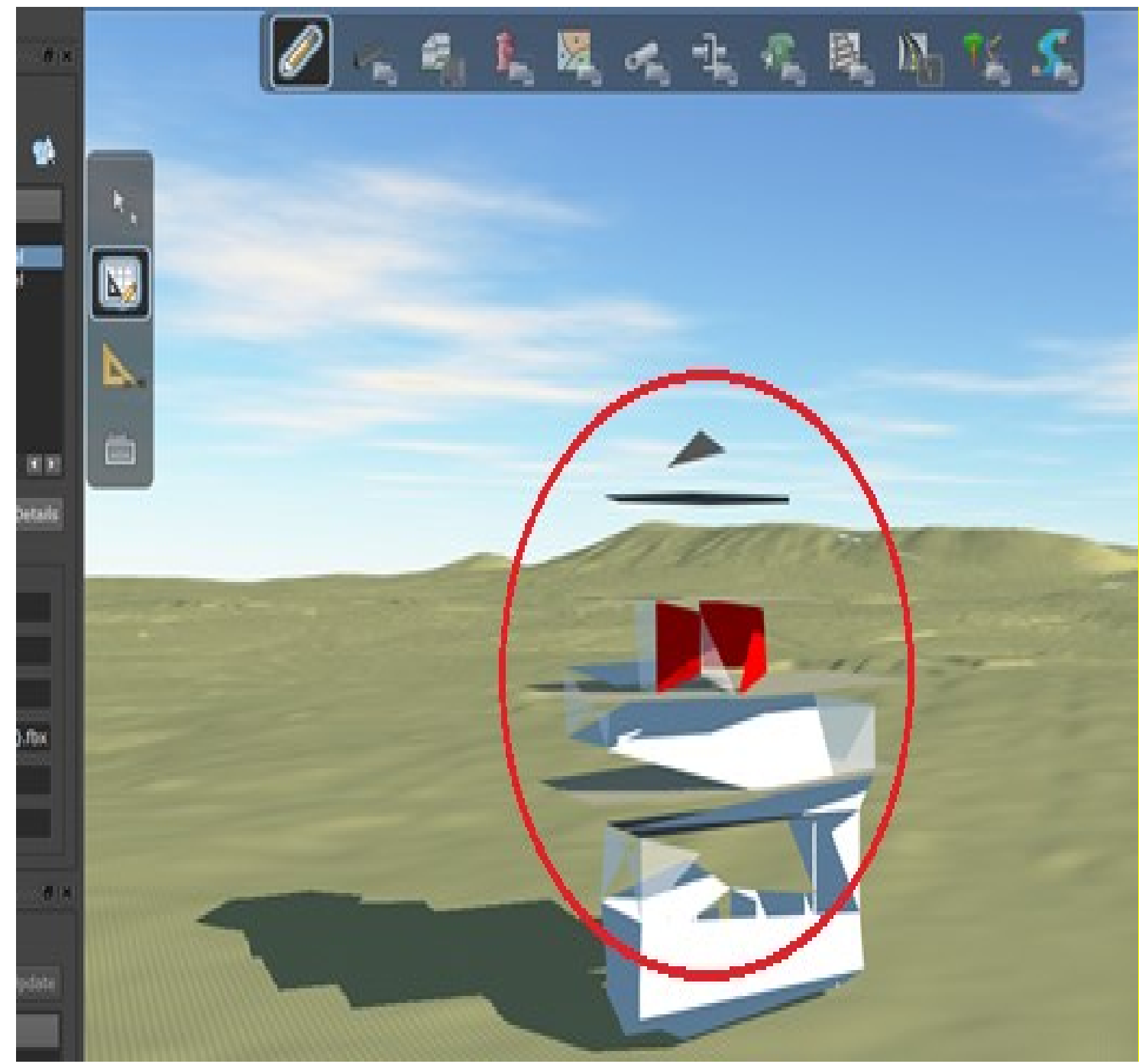

Figura 180 - Ilustração de teste de variabilidade no nível de detalhamento geométrico de um componente modelado nos sistemas BIM - Revit ${ }^{\circ}$ e importado no SIG - InfraWorks ${ }^{\circ}$.

Os testes indicaram que a facilmente se consegue efetuar analises em relação ao relevo natural construído no SIG e o modelo importado dos sistemas BIM. Em relação ao nível de detalhamento geométrico que apresentou limitações em relação ao gerenciamento de parâmetros, que não variam conforme o maior ou menor nível de detalhe. 
As Figuras 180 e 181 ilustram o teste de variação de LOD Geométricos (GLOD), que no InfraWorks ${ }^{\circledR}$ funciona como variação de "zoom", sendo que na Figura 180, o componente apresenta simplificação de sua geometria, o que possibilita a ocultação das esquadrias (elipse vermelha), por exemplo, sem no entanto garantir a integridade das outras partes do modelo, que apresentam falhas e falta de parte de seus componentes.

A representação de visualização de distância do InfraWorks ${ }^{\circledR}$ não corresponde ao preconizado nas tabelas sobre o LOD Geométrico (GLOD). O controle sobre a variação de representação geométrica fundamenta-se no princípio de representar um mesmo objeto em níveis crescentes de complexidade.

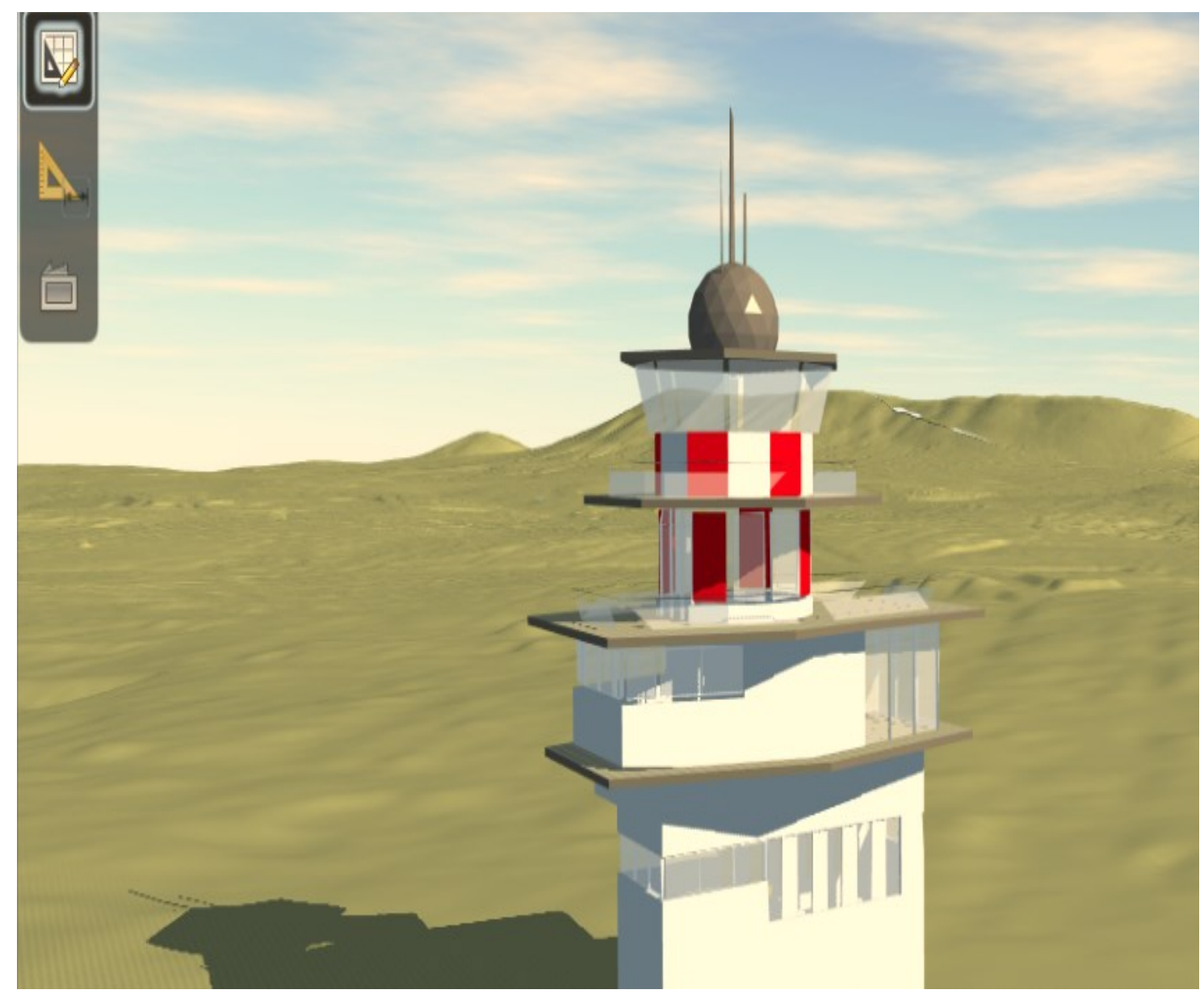

Figura 181- Ilustração de um componente modelado no sistema BIM - Revit ${ }^{\circ}$ e importado no SIG - InfraWorks sem alteração na variação de seu nível de desenvolvimento.

A abstração oferecida a componentes exportados diretamente via IFC ou FBX apresenta utilidade na visualização de eventuais estudos conceituais que o arquiteto possa empreender.

Porém a abstração da geometria deve obedecer a princípios de utilidade para o processo de projeto em suas fases definidas, como estudo conceitual, projeto básico e executivo. 
Para que isto ocorra, seria preciso que o projetista, ou usuário, detivesse o controle sobre como os componentes são representados e a configuração do nível de detalhamento dos mesmos em cada etapa de projeto.

Da forma como os testes indicaram, (ver Figura 180), a variação ocorre de forma aleatória, simplificando as superfícies e malhas do objeto, sem, no entanto, ter compromisso com a representação de cada componente individualmente.

Mais precisamente, as impressões do autor sugerem o desparecimento de partes dos componentes sem, no entanto, assumirem uma organização espacial logica de uma forma mais simplificada de representação, apresentando o componente de forma integra.

A Figura 182 a seguir representa a seleção do nível de detalhe, na qual esquadrias não aparecem na representação do modelo. No caso, foram ocultadas as janelas, mas ainda assim se pode analisar a edificação quanto ao volume, à insolação e aos detalhes.

Esta é uma vantagem nos estágios iniciais de projeto, os quais necessitam de maior liberdade conceitual.

Nesta pesquisa foi construído apenas o relevo, para efeito de teste, porém informações referentes a outras variáveis importantes como vegetação, acessos viários, edificações existentes, drenagem, etc., estão disponíveis para utilização da mesma forma que foi feito com a malha topográfica.

Como o terminal regional não possui, a priori, um terreno definido, pois está previsto para ser replicado em diferentes localidades do Brasil, sendo portanto um projeto conceitual, não teria sentido importar informações no teste sobre o entorno imediato.

O teste indicou ser reativamente simples testar o modelo BIM em relação a seu entorno imediato.

Como foi relatado na modelagem e expansão do terminal, a importação direta de componentes BIM no ambiente GIS não permite a manipulação de parâmetros de variação semântica, ou seja, consegue-se variar o nível de desenvolvimento geométrico, mas sem, contudo controlar informações do modelo.

A seguir representamos o terminal regional em sua integra no SIG - InfraWorks ${ }^{\circledR}$ (Figura 182 na página seguinte). 
VARIAÇÃO DE DETALHE GEOMÉTRICO DO TIPO “ZOOM” NO TERMINAL REGIONAL

EXPORTADO DO SISTEMA BIM - REVIT PARA 0 AUTODESK INFRAWORKS

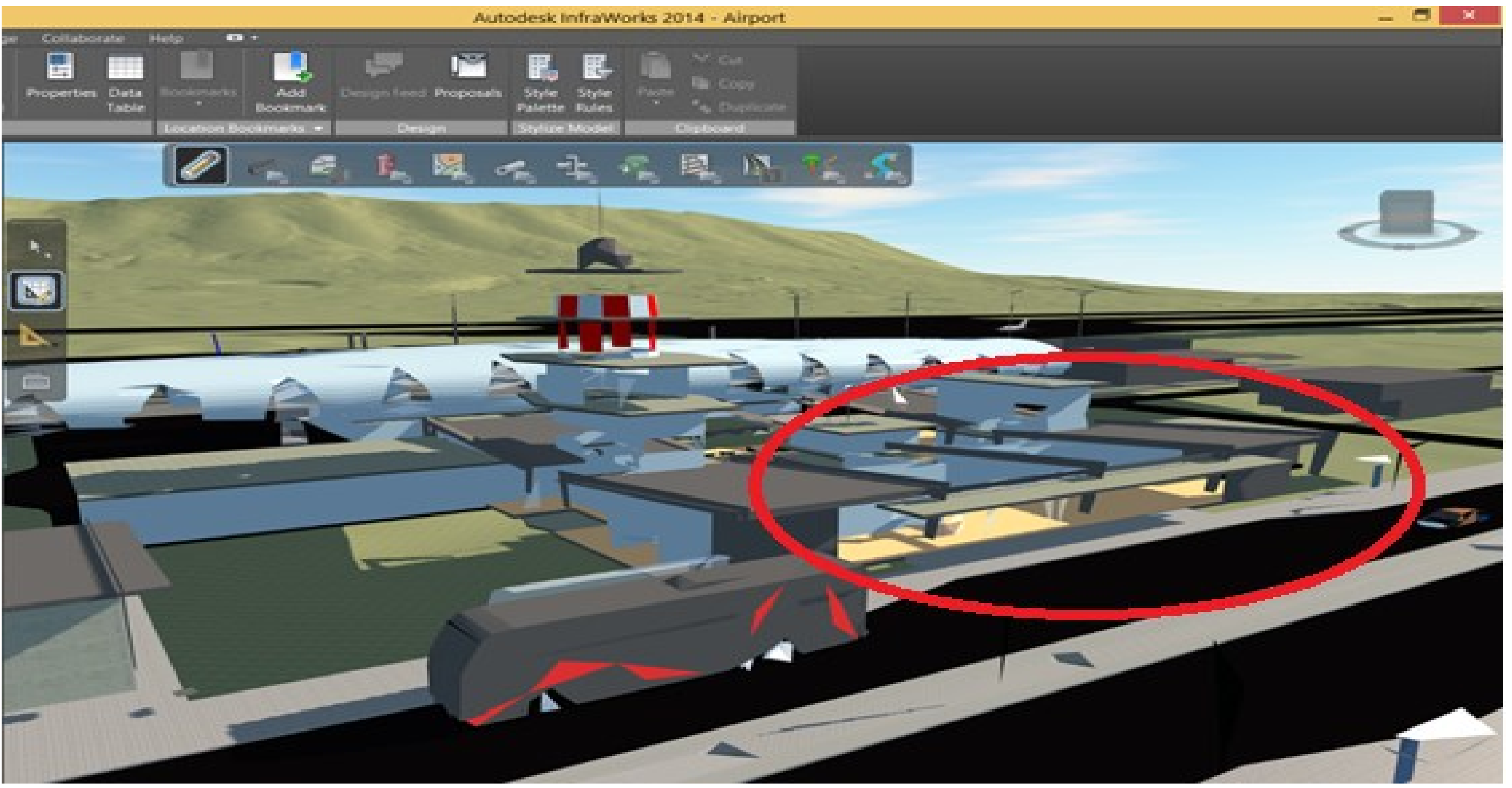

Figura 182 - Terminal de Passageiros configurado no InfraWorks em LOD 100 para "abstração" das esquadrias, que não aparecem no projeto.

A FIGURA 182 ACIMA REPRESENTA VARIAÇÃO DE DETALHE GEOMÉTRICO APLICADA NO MODELO DO TERMINAL REGIONAL. A ABSTRAÇÃO DAS ESQUADRIAS PERMITE QUE SE POSSA PRIORIZAR

A SEGUIR, NA FIGURA 183, ENCONTRA-SE REPRESENTADO O TERMINAL REGIONAL, EM SUA OS ESTUDOS DE VOLUME NO PROCESSO DE PROJETO. 


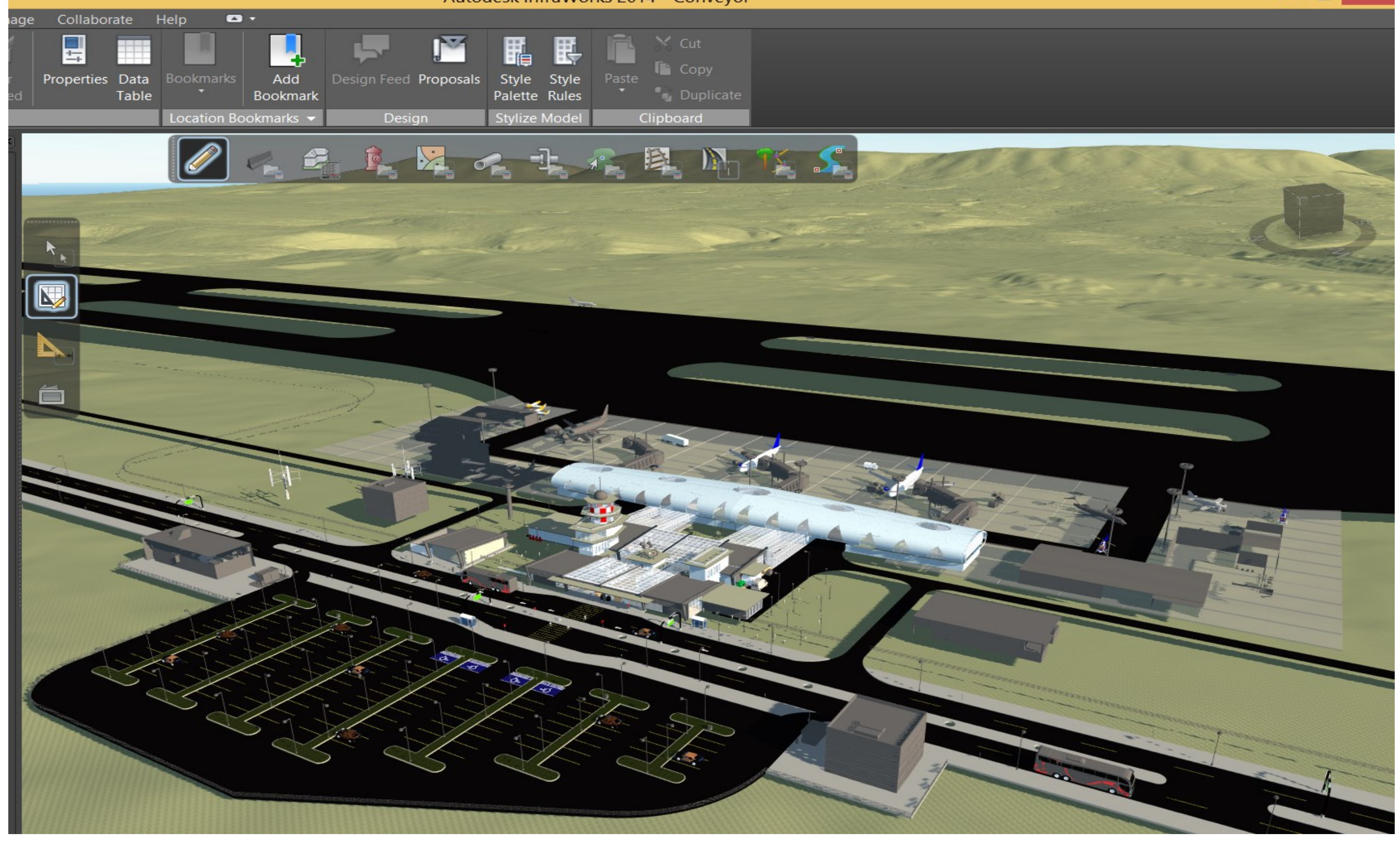

Figura 183 - Ilustração da inserção do Terminal Regional em sua integra no SIG - InfraWorks. 
Possivelmente a importação por um caminho não realizado nesta pesquisa, por meio do "CityGML", poderia contornar as limitações de variação no LOD semântico. Ressalta-se, no entanto, que para isto ocorrer é preciso definir previamente os protocolos de troca de informação, bem como uma ontologia comum para os formatos "IFC" e "CityGML" com base nos parâmetros específicos da INFRAERO. O resultado obtido nesta pesquisa para a associação direta entre os sistemas BIM e SIG, quanto à representação de vários níveis de abstração/especificação indica que a simples importação/ exportação entre os aplicativos utilizados (Revit ${ }^{\circledR}$ e InfraWorks $^{\circledR}$ ) não permite que se tenha controle efetivo sobre a variação nos graus de abstração da informação de forma relacional com a geometria do modelo.

A variação de nível de detalhe não deve ser apenas um recurso de visualização decorrente de "zoom in" e "zoom out", pois neste caso a base de dados dos componentes, inclusive geométrica, permanece inalterada. Ao longo de um processo de projeto, cresce gradativamente não apenas a complexidade de detalhamento das formas (GLOD), mas também a quantidade de informação sobre as propriedades, os comportamentos e as inter-relações das mesmas (SLOD).

Não se trata aqui de ocultar temporariamente partes de um componente ou sistema, mas de representar o mesmo edifício, em um mesmo arquivo, com diferentes níveis de detalhamento de suas propriedades, comportamentos e inter-relações. Portanto, a mudança de nível de detalhe deveria resultar não apenas na alteração da complexidade da geometria, mas também do tipo e quantidade de informação vinculada a cada um destes LOD's.

A matriz semântica pode ajudar nesta tarefa, se por ventura tiver seus campos de informação complementados pelos demais profissionais de projeto, além do arquiteto, que nesta pesquisa foi representado pelo autor. Da mesma forma, necessitaria que os demais módulos funcionais fossem detalhados assim como foi feito com o modulo de "check-in", pois desta forma todos os módulos funcionais poderiam responder à consulta de informações relativas tanto à dimensão de arquitetura como às dimensões das engenharias (especialidades complementares).

Dessa forma, seria possível estabelecer os critérios de qual informação deve ser associada a cada componente aeroportuário. Ferramentas de apoio ao processo de projeto, como a matriz semântica permitem que os componentes BIM sejam associados a forma como devem ser inseridos no projeto de um terminal de passageiros, bem como qual a relação de trabalho (projetual) que os profissionais devem desempenhar para projetar um modulo especifico do aeroporto. 


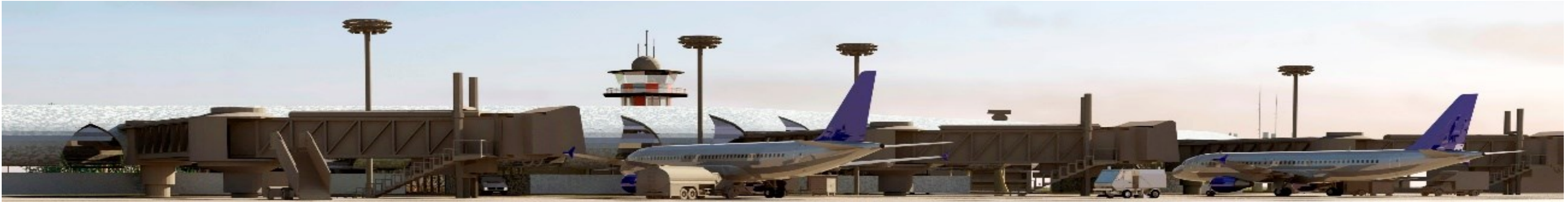

Figura 184 - Terminal Regional da INFRAERO (adaptado). Vista do Pátio de Aeronaves e Pontes de Embarque.

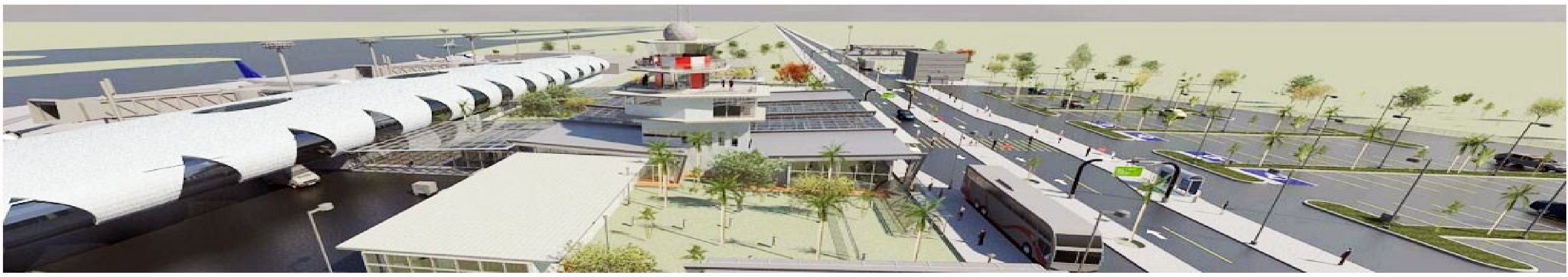

Figura 185 - Terminal Regional da INFRAERO (adaptado). Vista lateral do Terminal de Passageiros.

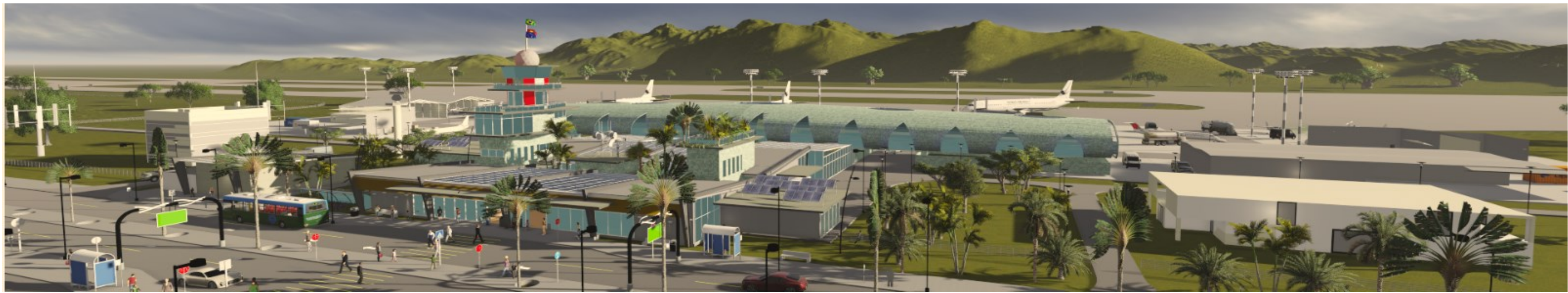

Figura 186 - Terminal Regional da INFRAERO (adaptado). Vista perspectiva da entrada do Terminal de Passageiros. 


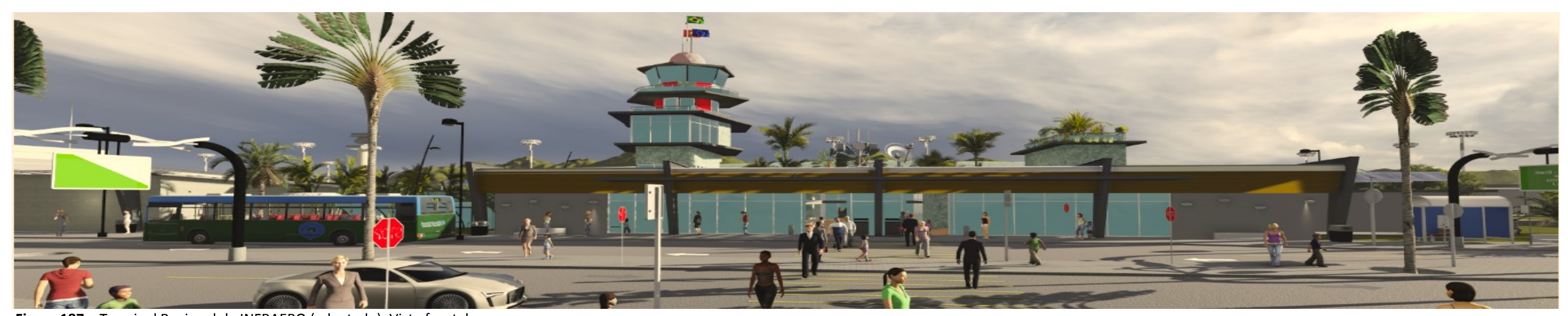

Figura 187 - Terminal Regional da INFRAERO (adaptado). Vista frontal.

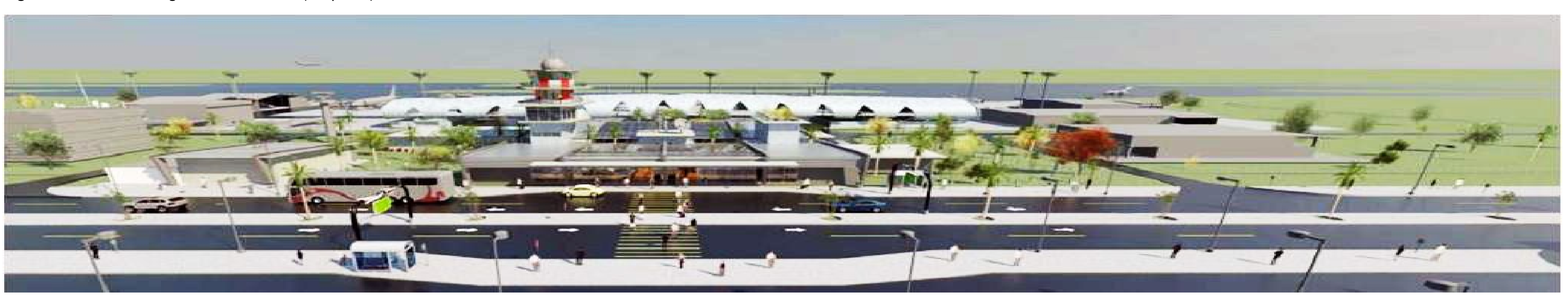

Figura 188 - Terminal Regional da INFRAERO (adaptado). Vista perspectiva frontal do Terminal de Passageiros

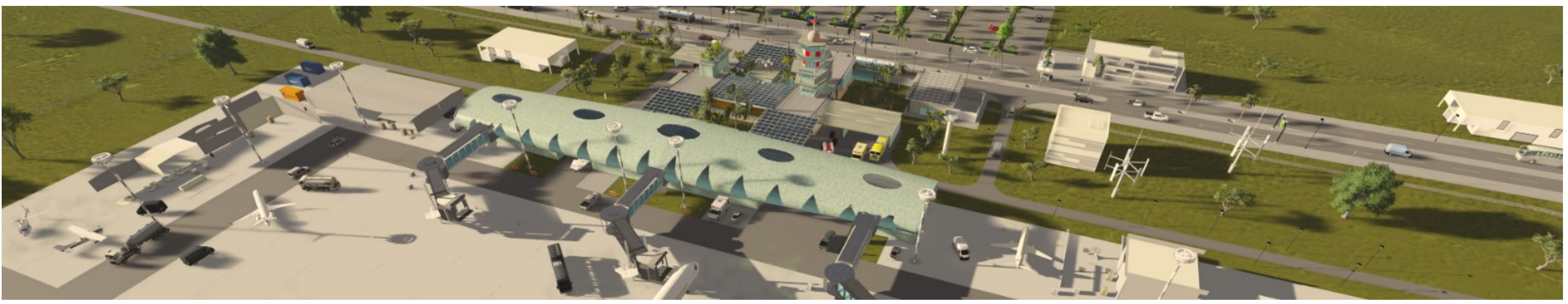

Figura 189 - Terminal Regional da INFRAERO (adaptado). Vista perspectiva superior do Terminal de Passageiros. 


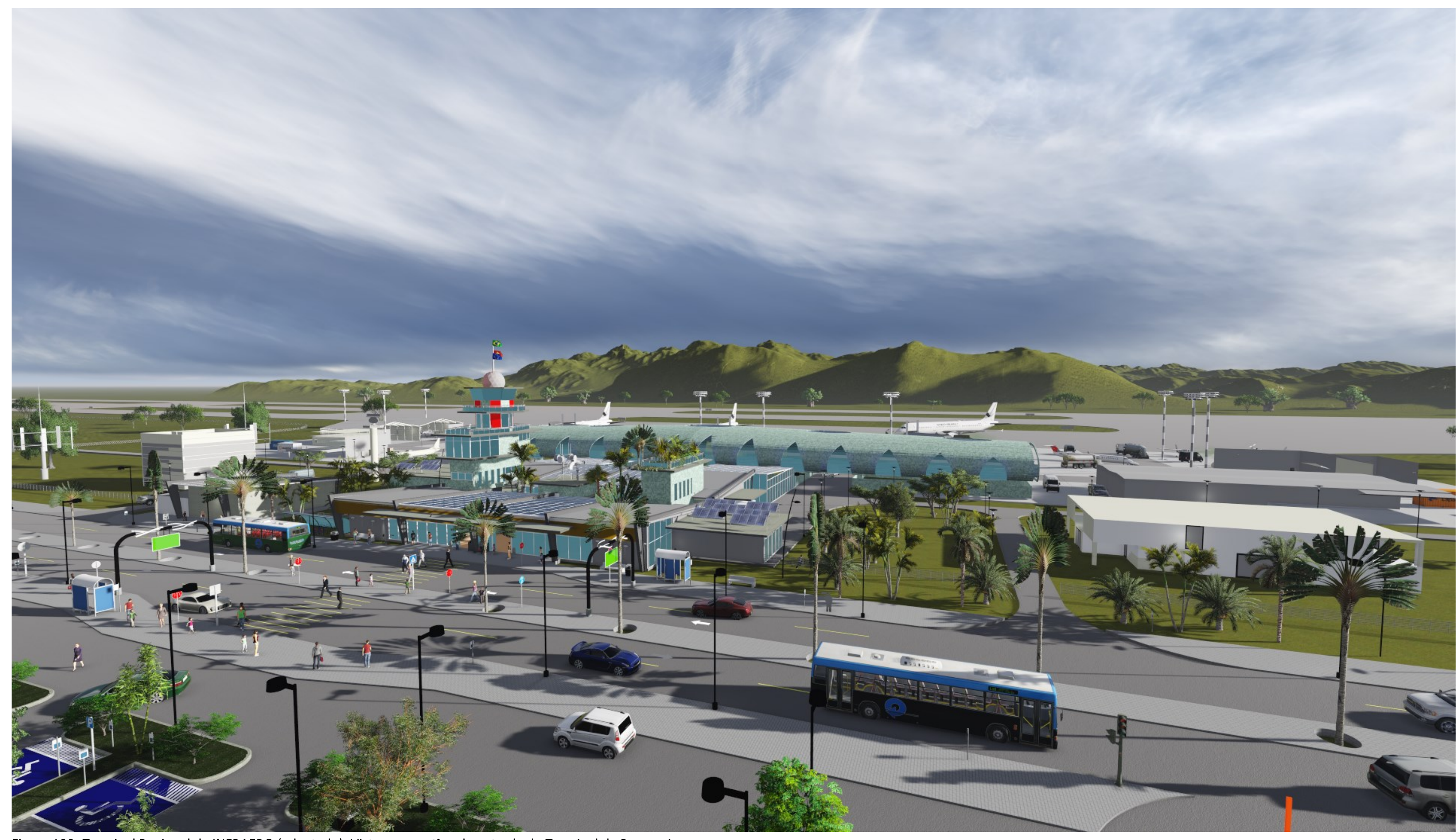

Figura 190- Terminal Regional da INFRAERO (adaptado). Vista perspectiva da entrada do Terminal de Passageiros.

NA FIGURA 190 ACIMA PODE OBSERVAR IMAGEM PERSPECTIVA QUE OFERECE VISÃO GLOBAL DA MODELAGEM DO TERMINAL REGIONAL.

OBSERVA-SE A EXPANSÃO PARA UMA TORRE DE CONTROLE (ALTERNATIVA 3), SENDO POSSIVEL VER AO FUNDO TERRENO IMPORTADO ATRAVÉS DE INFORMAÇÕES DE SATÉLITE. 


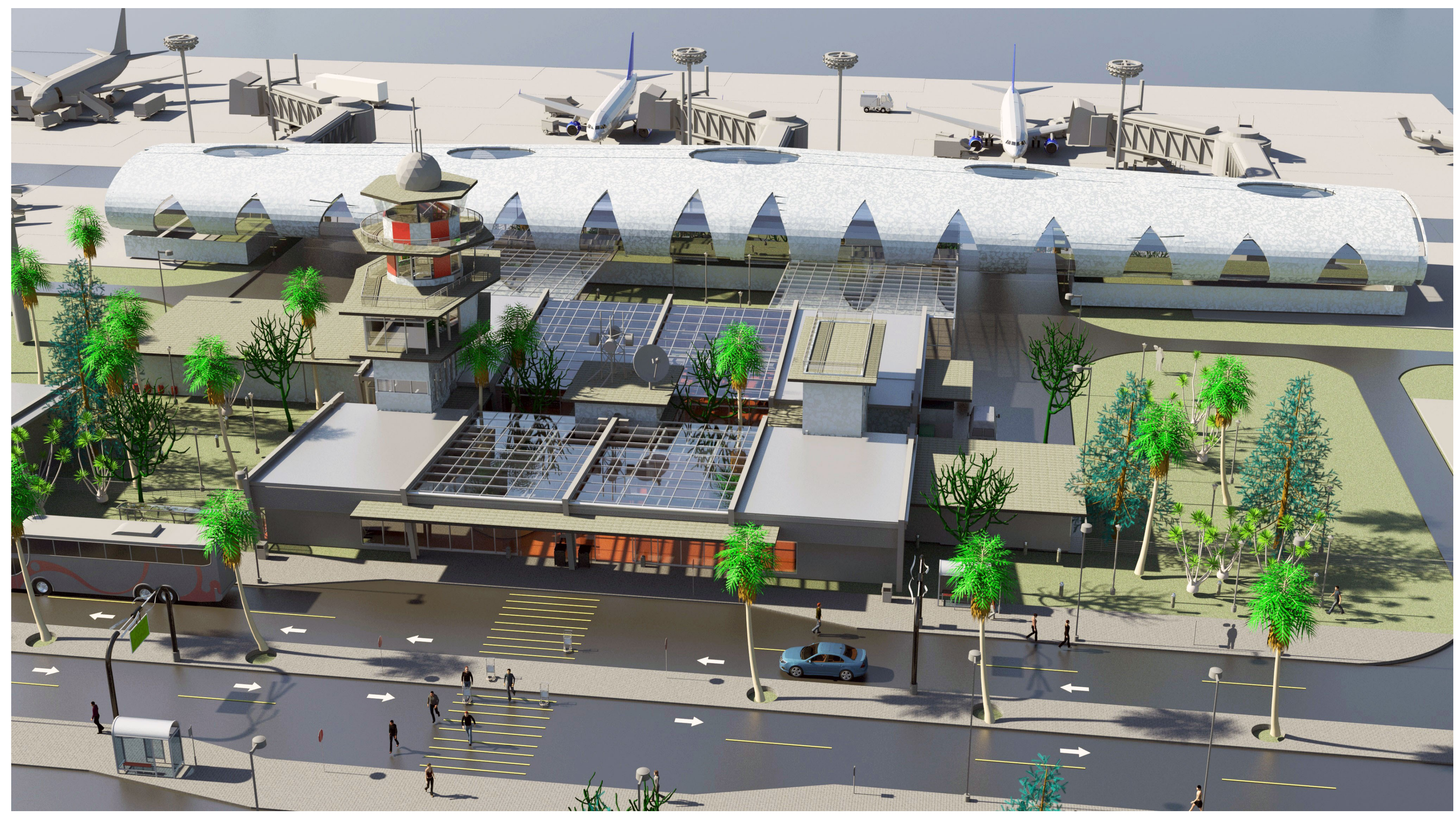

Figura 191- Vista perspectiva superior do Terminal Regional.

NA FIGURA 191 ACIMA PODE-SE OBSERVAR EM DETALHE O TERMINAL MODELADO, ONDE É POSSÍVEL IDENTIFICAR A COMPOSIÇÃO DO TERMINAL REPRODUZIDO POR MEIO DO PROJETO

O "CONCOURSE" REALIZA A CONEXÃO ENTRE O EDIFÍCIO E AS PONTES DE EMBARQUE. PODECEDIDO PELA INFRAERO

SE AINDA OBSERVAR A LIGAÇÃO DO EDIFÍCIO COM O ACESSO VIÁRIO E AINDA A CIRCULAÇÃO DE PEDESTRES. 


\section{5- CONCLUSÕES}

A elaboração de uma matriz semântica, com a proposta de representação de informações referentes ao ambiente organizacional da INFRAERO com o processo de projeto por meio dos sistemas BIM, constitui-se em nossa principal contribuição original ao conhecimento. Nesta matriz semântica, a representação da informação foi limitada à ótica do arquiteto de aeroportos, com ênfase na sua dimensão e nas atividades complementares à sua especialidade. Por isto, recomendamos que os profissionais das diferentes áreas da INFRAERO completem a matriz com informações de suas respectivas especialidades e, assim contribuir para alcançar de forma plena o seu potencial.

A simulação do processo de projeto do Terminal Regional de Passageiros, das três diferentes alternativas de uma torre de controle e de novos componentes paramétricos nos sistemas BIM, possibilitou ao autor ilustrar a utilização da matriz semântica como guia no processo de projetação aeroportuária. A associação dos sistemas BIM com o SIG com o objetivo de permitir a representação em vários níveis de detalhe, permitindo ambiguidade de interpretação, frustrou nossas expectativas. Contudo, a utilização associada de ambos os sistemas foi importante enquanto experimento de teste da utilidade da matriz semântica no processo de projetação.

A criação de componentes paramétricos customizados no contexto da INFRAERO juntamente com seus aspectos semânticos, por meio de uma matriz que expresse a estrutura organizacional da empresa, pode representar um diferencial competitivo para o Brasil. O conhecimento da produção de componentes aeroportuários nos sistemas BIM e SIG e a associação dos mesmos com as responsabilidades existentes nos processos de aprovação de projetos da INFRAERO podem constituir uma ferramenta útil de consulta sobre os impactos dos processos de projeto de aeroportos no Brasil. Tais informações podem ser valiosas para dimensionar as tarefas e as responsabilidades dos profissionais de projeto face aos requisitos e condicionantes, fornecendo uma "leitura" de procedimentos associados aos mesmos.

A informação da matriz sobre o processo de projeto é também semântica e inclui a forma de desenvolvê-lo. O nível de abstração das fases iniciais, exigido nos processos de concepção e análise, tende a ser elevado. No entanto, os sistemas BIM exigem especificação dos atributos e comportamentos dos objetos por meio da parametrização de seus elementos construtivos, definida antecipadamente em relação aos modeladores tridimensionais genéricos. 
A inserção de projetos organizados em conjuntos funcionais, do edifício, como o modulo de "check-in" detalhado nesta pesquisa, é consistente com a natureza e a dinâmica dos projetos aeroportuários.

Podemos citar três benefícios principais da utilização da matriz semântica no ambiente de projeto, tais como:

1- Gerar uma linguagem para a comunicação entre as pessoas ou interoperabilidade entre os sistemas envolvidos;

2- Atuar como uma descrição formal dos elementos e relações entre os mesmos, em uma área de conhecimento específico, de projetos de funções complexas, na área da $\mathrm{AEC}$, sob a égide das normas e requisitos dos sistemas de aviação comercial civil;

3- Ajudar na aquisição de conhecimentos, técnicas e metodologias, tanto do ponto de vista acadêmico, em termos de ensino, como do ponto de vista profissional, pelos profissionais de arquitetura e de engenharia aeroportuária no Brasil, facilitando a construção de modelos de domínio e de reutilização de conhecimento entre domínios.

A utilização de uma ferramenta como esta pode ser útil em todas as fases de um processo de projeto, servindo como um repositório de informação e fonte de consulta, podendo conectar diferentes partes do aeroporto a seus processos e projeto. Outra vantagem da matriz é que ao invés de definir regras rígidas, as quais podem facilmente se desatualizar, em relação ao ambiente organizacional da INFRAERO, foi elaborado um sistema que pode ser constantemente atualizado ao longo de sua utilização.

Por detrás dos benefícios não estão explícitos inúmeros pequenos processos para realização das tarefas de projeto. Estes deveriam ser objeto de futuras pesquisas, propiciando melhor definição desse novo processo de projeto representado pelos sistemas BIM. A possibilidade de visualização e modificações interativas de modelos virtuais tem revolucionado o processo de projetação, pois permitem a compreensão e análise de grandes quantidades de informação de natureza espacial, com eficiência sem precedentes.

Os aeroportos representam uma área de aplicação ideal para a simulação de ambientes complexos. Os processos estão em contínua mudança, requerendo metodologias que possam ser avaliadas por meio de indicadores de desempenho. 
Dentro dos aeroportos, processos semelhantes de projeto são repetidos inúmeras vezes em dimensão nacional pela INFRAERO. Porém, frequentemente são construídos modelos de simulação novos para cada projeto, possivelmente copiando algumas partes de modelos prévios. A reutilização de componentes de simulação raramente é vista. Neste sentido, a associação dos sistemas BIM e SIG representa um recurso valioso para gestão de projetos aeroportuários.

Particularmente, na INFRAERO, permitem integrar a participação dos profissionais de projeto e reunir informação, tanto geométrica, comportamental e relacional, quanto dos processos de projeto na estrutura organizacional.

As lacunas existentes em relação aos estágios iniciais de projeto em virtude da limitação dos sistemas BIM de representar componentes e sistemas abstratos poderiam ser respondidas em parte, pela associação com os SIG. No entanto, não o foram, muito mais por uma questão de abordagem, em relação a testes efetivos do caminho que se utiliza do "CityGML". Os testes de variação de informação (SLOD) e detalhe (GLOD) mostraram isto conforme mencionado anteriormente.

A criação de componentes paramétricos customizados, por sua vez, demonstrou a importância de se personalizar o ambiente BIM de trabalho de acordo com o contexto de projeto. Aliado a isto, soma-se a criação de novos parâmetros nos componentes modelados e sua conexão com a gestão da informação no processo de projeto. Foram verificadas vantagens na adoção dos sistemas BIM associado ao SIG na projetação aeroportuária, bem como em parte dos experimentos realizados nesta pesquisa, enfocando a INFRAERO. Contudo, ainda não foram realizados quaisquer estudos que simulassem de fato todo processo de modelagem da construção associado ao fluxo organizacional dos processos de projeto da empresa.

O uso dos sistemas BIM associado ao SIG traz impactos, positivos e negativos, nos processos de projeto de uma empresa administradora de aeroportos como a INFRAERO. Em razão da necessidade de revisão dos processos em vigor na INFRAERO, no tocante a produção de projetos de arquitetura e de engenharia, foi proposto um trabalho inicial nesse sentido, desenvolvido pelo autor, para o redesenho futuro do processo de aprovação de projetos da empresa, conforme consta do Anexo I desta tese. Tendo em vista as deficiências observadas para integração efetiva dos sistemas BIM e GIS, no tocante à representação de diferentes LOD`s, o autor devera em breve realizar continuação da presente pesquisa em um possível "Post-Doc". A matriz semântica desenvolvida nesta pesquisa pode ser relevante para aplicações especificas de projetos de aeroportos. 
A eventual adoção dos sistemas BIM na INFRAERO deverá enfrentar dificuldades e limitações em função de fatores como a mudança cultural e das práticas da $A E C$, que envolvem a revisão dos atuais processos de aprovação e de projeto na empresa, além de necessidade de treinamento das equipes de projeto, utilização efetiva da área de "Tecnologia da Informação - Tl" nos processos de obras e serviços de engenharia. Os sistemas BIM necessitam unificar a troca de informação e dados em torno de modelos únicos de informação, que devem ser gerenciados em servidores BIM. A logica projetual, não apenas no desenvolvimento de soluções mais vantajosas, como em relação à formação de requisitos e aos processos de aprovação dos mesmos, encontra-se atualmente defasada tecnologicamente. A informação referente aos processos de arquitetura e de engenharia apresenta-se pulverizada em função do uso predominante de documentação bidimensional e baseada em papel.

No entanto, as barreiras culturais devem ser destacadas em uma eventual adoção dos sistemas BIM na INFRAERO, pois o BIM representa um processo ativo de participação efetiva dos profissionais de projeto e de construção de forma colaborativa. Em relação aos estágios iniciais de projeto, esta pesquisa indica limitações dos sistemas BIM para representar a informação sob diferentes formas de abstração justamente para permitir que as associações das propostas de projeto em relação ao contexto possam ocorrer livremente. Esta limitação atua como fator de impedimento da colaboração efetiva, para a busca de soluções de projeto, sobretudo nos estágios iniciais, o que certamente poderá impactar na dimensão cultural das equipes da INFRAERO sobre como proceder em suas práticas de trabalho e cultura organizacional para comunicação efetiva de ideias e propostas de projeto de forma integrada.Neste sentido, a matriz desenvolvida nesta pesquisa visa contribuir na diminuição das barreiras citadas por meio do estabelecimento de bases semânticas associadas aos módulos funcionais de um aeroporto da INFRAERO. As bases semânticas permitem que os profissionais possam embasar a troca de informações de projeto para representar informações projetuais e, responder as lacunas relativas aos estágios iniciais, utilizando de forma conjunta os sistemas BIM e SIG para o provimento de infraestrutura aeroportuária.

O autor, enquanto servidor público da INFRAERO e pesquisador brasileiro, acredita que a matriz pode responder de forma positiva aos desafios citados, se complementada e utilizada pela INFRAERO, em uma eventual adoção dos sistemas BIM na empresa, por meio da colaboração efetiva dos profissionais das diversas áreas e disciplinas de projeto concorrentes para os projetos de aeroportos. Poderia ainda incentivar o desenvolvimento do modelo Bryan Lawson que relaciona clientes, projetistas e tecnologia. 


\section{REFERÊNCIAS BIBLIOGRÁFICAS}

ABNT - Associação brasileira de normas técnicas. NBR ISSO 12006-2:2010. Recuperado em 17 de agosto de 2012, de http://www.abntcatalogo. com.br/norma.aspx?ID=57992;

ACHTEN, H. Experimental design methods: a review. International Journal of Architectural Computing, v.7, n.4, 2009;

ACHTEN, H.; BEETZ, J. What Happened to Collaborative Design? In: CONFERENCE ON EDUCATION AND RESEARCH IN COMPUTER AIDED ARCHITECTURAL DESIGN IN EUROPE. 27., 2009, Istanbul. Proceedings ... Istanbul: eCAADe \& ITL/YTU: 358-365 p. 2009;

ALEXANDER, C. "A City is Not a Tree". Architectural Forum, Vol. 122, New York: Time Inc., 1965, p. 58-62;

ALMEIDA, M. B; Interoperabilidade entre fontes heterogêneas, Dissertação apresentada ao Curso de Mestrado da Escola de Ciência da Informação da Universidade Federal de Minas Gerais, Belo Horizonte, 2002, P.42;

ALMEIDA, G. Georreferenciamento de imóveis rurais e urbanos, FAIPE, 2012, p.3);

ANDRADE, B., AMORIM, S., em "Alterações metodológicas na gestão de processo de projeto aplicada com a utilização de Software tipo BIM" $2^{\circ}$. Simpósio Brasileiro de Qualidade do Projeto no Ambiente Construído, X Workshop Brasileiro de Gestão do Processo de Projeto na Construção de Edifícios, 03 e 04 de Novembro de 2011 - Rio de Janeiro, RJ - Brasil, p.795-796);

ANDRADE, M. e RUSCHEL, R; Interoperabilidade de aplicativos BIM usados em arquitetura por meio do formato IFC, 2009, p. 92;

ARNDT, L. T; SCHEER, S; PHILIPS, J. W. em "Desenvolvimento de estudos para sistemas CAD nd em projetos integrados de edificações - construção civil, sustentabilidade e sistemas de informação geográfica", IV Simpósio Brasileiro de Ciências Geodésicas e Tecnologias da Geoinformação, 
Universidade Federal do Paraná - UFPR, Departamento de Construção Civil - DCC, Curitiba, PR, 2012, p. 1-5;

ASHFORD, N., STANTON, M. H. P. e MOORE, C. A. (1997) Airport Operations. New York: McGraw-Hill;

“AUTODESK”. "REVIT®” Architecture 2010: Families Guide - Metric Tutorials. 2009. 812p. Disponível em: <http://www." AutoDesk".com/ "REVIT®" architecturedocumentation>. Acesso em: 15 set. 2012;

“AUTODESK". Building Information Modeling: The Power of BIM. 2008a. Disponível em: <http://www."AutoDesk".com/BIM>. Acesso em: 25 ago. 2012;

“AUTODESK". Melhores práticas para a criação de componentes paramétricos (famílias) com o "AutoDesk" "REVIT®". 2008c. 15p. Disponível em: <http://www." AutoDesk".com/BIM>. Acesso em: 15 set. 2012;

AYRES F', C. e SCHEER, S. (2008) "DIFERENTES ABORDAGENS DO USO DO CAD NO PROCESSO DE PROJETO ARQUITETÔNICO";

AZUMA, F.; FREITAS, M.; MACHADO, C.; SCHEER, S.; SCHIMID, A. Revista produção Online - Inovação Tecnológica: Técnicas e Ferramentas aplicadas ao Projeto de Edificações. Vol. 7, Num. 3. 2007, Florianopolis;

BAEYENS, T. (2004) "The State Of Workflow". "DIGITAL FABRICATION OF ARCHITECTURAL MODELS: AN EXPLORATORY STUDY". Disponível em: http://www.jboss.com/products/jbpm/stateofworkflow;

BALL, M. Denver's airport expansion - primes a push toward BIM for facility management. Autodesk. Acessado em 30/03/2015 aas 19:57 http://bimontherocks.typepad.com/Files/dia bim for facility mgmt.pdf;

BARISON, M. B., e SANTOS, E. T. (2010a). "BIM Teaching Strategies: an Overview of Current Approaches." Proc., ICCCBE 2010 International Conference on Computing in Civil and Building Engineering. University of Nottingham, Nottingham, UK, http://www.engineering.nottingham.ac.uk/ icccbe/proceedings/pdf/pf289.pdf (Feb. 10, 2011); 
BARISON, M. B., and SANTOS, E. T. (2010b). "Review and Analysis of Current Strategies for Planning a BIM Curriculum." Proc., CIB W78 $201027^{\text {th }}$ International Conference, Virginia Tech, Cairo, Egypt, 1--- 10, < http://itc.scix.net/data/works/att/w78---2010---83.pdf> (Feb. 10, 2011);

BARROS, N.; Mapas de GANTT e Redes de PERT, Escola Secundária de Emídio Navarro, Estruturas, Tratamento e Organização de Dados, 2003, p.3;

BATISTA, L. O processo de projeto na era digital. Um novo deslocamento da prática profissional. Belo Horizonte, Escola de Arquitetura da UFMG, 2010, p.17;

BAZJANAC, V. Virtual Building Environments (VBE) - Applying Information Modeling to Buildings. Lawrence Berkeley National Laboratory, University of California. Berkeley, CA, U.S.A., 2004;

BELL, H.; BJǿRKHAUG, L. "A building SMART Ontology e Work and Business in Architecture, Engineering and Construction”. ECPPM, 2006, 185p;

BERLO, L. VAN, LAAT, R., 2011. Integration of BIM and GIS: the Development of CityGML GeoBIM extension. In: Proceedings of 3D Geo-Information Conference, Berlin, Germany;

BIRX, Glenn W. Getting started with Building Information Modeling. The American Institute of Architects - Best Practices, 2006b. Disponível em: < http://www.aia.org/bestpratctices index > Acessado em: 03.12.2012;

BODDY, S., REZGUL, Y., COOPER, G., \& WETHERILL, M. (2007). Computer integrated construction: A review and proposals for future direction. Advances in Engineering Software, 38(10), 677-687;

BOGADO, W. H. Customização de Sistemas Comerciais de CAD. 1997, Dissertação (Mestrado em Métodos Numéricos), Universidade Federal do Paraná, Curitiba, 1997;

BONGIOLO, R., Uso de Sistemas de Informação Geográfica na Saúde Pública, Faculdades Associadas de Ariquemes - FAAr, 2008, p.186-188; 
BITTENCOURT, G. em Inteligência artificial: ferramentas e teorias. Editora UFSC, 2001;

BORST, W. N. Construction of engineering ontologies. 1997. Tese de Doutorado. $\quad \leq H \mathrm{Htp}: / / w w w . u b . u t w e n t e . n 1 / w e b d o c s / i n f / 1 / t 0000004 . \mathrm{pdf}>$. Acesso em: 08/032015;

BRAHA, D., and REICH, Y., Topological structures for modeling engineering design processes, Research in Engineering Design, Vol. 14, (2003), pp. 185-199;

BREITMAN, K. Web Semântica: a Internet do futuro. Rio de Janeiro: LTC, 2005, p.5;

BRIDGES, A. H. (1991) The challenge of constraints, A discussion of Computer Applications in Architectural Design, University of Strathclyde, Reino Unido;

BRIDGES, A. H. A Critical Review of Problem Based Learning in Architectural Education, 24th eCAADe Conference, 2006, p.6-8;

BRITISH Airways PLC Baggage Handling Project Management Manual, Prepared by Vector Management Limited December 1999;

BURROUGH, P.A. (1986), Principles of Geographic Information Systems for Land Resources Assessment. Clarendon Press, Oxford, P.299;

CALLEAM Consulting Ltd - Why Technology Projects Fail, em Denver Airport Baggage Handling System Case Study;

CÂMARA, G. e DAVIS, C. Introdução: por que geoprocessamento? INPE-8562PRE/4306, São José dos Campos, 2001, p.3;

CARBASHO, T. "Integrated Project Delivery Improves Efficiency, Streamlines Construction. Lean Management Approach Eliminates Waste and Enhances Project Outcome". Acessado em 10/6/2014, em http://www.tradelineinc.com/reports/0A03D1C0-2B3B-B525 85702BCEDF900F61 2008;

CECCATO, C. (2001). "EVOLUTIONARY DESIGN TOOLS FOR MASSCUSTOMISATION". "Hong Kong: The Hong Kong Polytechnic University, Hong Kong", China; 
CELANI, G; GODOI, G; RODRIGUES, G. em "O processo de projeto arquitetônico mediado por computador: um estudo de caso com o "Architectural Desktop". UNICAMP - Universidade Estadual de Campinas, Faculdade de Engenharia Civil, Arquitetura e Urbanismo (FEC), 2007, p.5;

CHENG, J; DENG, Y; \& DU, Q. em: "Mapping between BIM models and 3d GIS city models of different levels of detail". Proceedings of the 13th International Conference on Construction Applications of Virtual Reality, 30- 31 October 2013, London, UK;

CLAYTON, M. J., JOHNSON, R. E., VANEGAS, J., NOME, C. A., OZENER, O. O., \& CULP, C. E. (2008). Downstream of Design: Lifespan Costs and Benefits of Building Information Modeling. College Station: Texas A\&M University;

COELHO, S; NOVAES, C. Modelagem de Informações para Construção (BIM) e ambientes colaborativos para gestão de projetos na construção civil, 2008;

COPPOCK, J. T; RHIND, D. W. The History of GIS. In: MAGUIRE, D. J. (Edi.), GOODCHILD, M. F. (Edi.); RHIND, D. W. (Edi.). Geographical Information Systems: Principles and Applications. London: Longmans Publishers, 1991. p. 21-43. Cap. II. Disponível em: < http://www.wiley.com/legacy/ wileychi/gis/Volume1/BB1v1 ch2.pdf > Acesso em: 04/08/2014;

CORREA, F. R.; SANTOS, E. T. Ontologias na construção civil: Uma alternativa para o problema de interoperabilidade com o uso do IFC. Gestão e Tecnologia de Projetos, São Paulo, v. 9, n. 2, jul./dez, 2014, p. 7-22;

CREIGHTON, V. T. Le, D., S. NAHAVANDI, "Simulation-based Input Loading Condition Optimization of Airport Baggage Handling Systems", Proceedings of the IEEE Intelligent Transportation Systems Conference, USA, 2007, pp. 574-579;

CRESPO, C. C., \& RUSCHEL, R. C. (2007). Ferramentas BIM: um desafio para a melhoria no ciclo de vida do projeto. Campinas: Programa de PósGraduação em Engenharia Civil - FEC - UNICAMP; 
CROSS, A., "Towards an understanding of intrinsic values of design education. Design Studies 5(1), 1984, p.31-39);

CROSS, N., Engineering Design Methods. Strategies for product Design, ed. Wiley, Segunda Edição, Londres, 1994;

DANTAS, D., Autonomia projetual: um novo olhar sobre as estratégias de ensino de metodologia de projetos em design Revista Design em Foco, Vol. III, Núm. 2, julho -dezembro, 2006, pp. 129-141 Universidade do Estado da Bahia Brasil. Disponível em: http://redalyc.uaemex.mx/src/inicio/ArtPdfRed.jsp?iCve=66111515010;

DAVIES, A., DODGSON, M., GANN, D. "From iconic design to lost luggage: innovation at Heathrow Terminal 5", Paper presented at the Summer Conference 2009 on CBS - Copenhagen Business School, Solbjerg Plads 3, DK2000 Frederiksberg, DENMARK, Imperial College Business School, Imperial College London, June 17 - 19, 2009;

DAWOOD, N; SRIPRASERT, E.; MALLASI, Z; HONNS, B. 4D visualization development: Real Life Case Studies. International Council for Research and Innovation in Building and Construction. Aarhus School of Architecture, 2002;

DAWSON, R. (2000), "Knowledge capabilities as the focus of organizational development and strategy", Journal of Knowledge Management, 4 (4), p. 320-327;

DENIS, R. Design cultura material e o fetichismo dos objetos. Arcos volume 1 número único, $1998 . \quad$ Disponível em: http://www.esdi.uerj.br/arcos/imagens/artigo rafael(14a39).pdf. Acesso em: 22 set. 2012 ;

DENZIN, N. K. (1978). The research act: A theoretical introduction to sociological methods. New York: McGraw-Hill;

DENZIN, N. K., \& LINCOLN, Y. S. (1998) (Eds). Collecting and interpreting qualitative materials. Thousand Oaks: Sage Publication;

DENZIN, N. K., \& LINCOLN, Y. S. Eds. (1998). The landscape of qualitative research: Theories and issues. Thousand Oaks: Sage Publications; 
DILLON, M. Breaking down the walls: An online resource for users of Autodesk Building Solutions products. San Antonio, Texas, Estados Unidos da América, 2005;

DZIEKANIAK, G. V.; KIRINUS, J. B. Web Semântica. Florianópolis, n. 18, p. 20-39, 2004;

EASTMAN, C.; TEICHOLZ, P.; SACKS, R.; LISTON, K. BIM Handbook: A guide to Building Information Modeling for owners, managers, designers, engineers, and contractors. Hoboken, New Jersey: John Wiley \& Sons, 2008. $490 \mathrm{p}$;

EISNER, E. W. (1991). The enlightened eye: Qualitative inquiry and the enhancement of educational practice. New York, NY: Macmillan Publishing Company;

ESPINDOLA, E., A importância do Modelagem de Objetos no Desenvolvimento de Sistemas, disponível em: http://www.linhadecodigo.com.br lartigo/1293/a-importancia-do-modelagem-de-objetos-no-desenvolvimento-de-sistemas.aspx\#ixzz3Twof7RJJ, acessado em 09/03/2015 as 23:55 horas, 2001, p.1-2;

FABRícIO, M. M. Projeto simultâneo na construção de edifícios. 2002. Tese (Doutorado em Engenharia) - Escola Politécnica da Universidade de São Paulo, São Paulo, 2002;

FARIA, R. Construção Integrada. REVISTA TÉCHNE. São Paulo, Outubro de 2007. Edição 127, p.46-51;

FERREIRA, R. e SANTOS, E. T. em "Uso do CAD 3D na compatibilização espacial em projetos de produção de vedações verticais em edifícios". Boletim Técnico da Escola Politécnica da USP, Departamento de Engenharia de Construção Civil, ISSN 0103-9830 BT/PCC/493, Santos, São Paulo - 2008, p.3;

FILHO, CERVANTES, A. Acesso ao modelo integrado do edifício. Dissertação apresentada pelo Programa de Pós- Graduação em Construção Civil do Setor de Tecnologia da Universidade Federal do Paraná. Curitiba, 2009, p. 13-14); 
FITZ, P. R. Geoprocessamento sem Complicação. São Paulo: Oficina de textos, 2008. Cap. 2, p. 19-30;

FLORIO, W. (JULHO de 2007). CONTRIBUIÇÕES DO BUILDING INFORMATION MODELING NO PROCESSO DE PROJETO EM ARQUITETURA. TIC - INTEGRAÇÃO DE SISTEMAS EM ARQUITETURA, ENGENHARIA E CONSTRUÇÃO;

FOGGIATTO, J; VOLPATO, N; BONTORIN, A. em "Recomendações para modelagem em sistemas CAD-3D, Universidade Tecnológica Federal do Paraná (UTFPR), Departamento Acadêmico de Mecânica (DAMEC), Centro de Inovação Tecnológica da UTFPR (CITEC), Núcleo de Prototipagem e Ferramental (NUFER), 2007, p.2;

FORMOSO, C. T., CESARE, C. M., LANTELME, E. M., \& SOIBELMAN, L. As perdas na construção civil: conceitos, classificações e seu papel na melhoria do setor. Porto Alegre, RS: Universidade Federal do Rio Grande do Sul (UFRGS) 1996;

GERO, J.S. e E. TYUGU (Eds.) Formal Design Methods for CAD: Proceedings of the IFIP TC5/WG5.2. Amsterdam: Elsevier, 1994 apud CELANI, G. Beyond analysis and representation in CAD. Ph.D. theses. Cambridge, MA: MIT, 2002, p.30);

GUIRALD, P. A semântica. São Paulo: DIFEL, 1980;

GLENN, H. The program In Contract (Washington) vol.49, 2006 n 5 p.192;

GOEL, V.: Sketches of Thought, MIT Press, Cambridge, MA, 1995, p. 193-194;

GOLAFSHANI, N., "Understanding Reliability and Validity in Qualitative Research";

HACKETT, J; "Beyond Knowledge Management - New Ways to Work", em BONTIS, N. e CHOO, W. C. (2002), The Strategic Management of Intellectual Capital and Organizational Knowledge, Nova lorque, Oxford University Press, p. 725-738; 
HÄKKINEN, T. M. Sustainable building related new demands for product information and product model based design. Disponível em http://itcon.org/2007/2. Acessado em: 14.11.2013;

HAMID, B. Mapping Design Process into Process Design: Implementing Collaborative Design from Social Psychological Approaches. In: CONFERENCE ON EDUCATION IN COMPUTER AIDED ARCHITECTURAL DESIGN IN EUROPE, 24, Frankfurt. Procedings, Frankfurt: eCAADe, p. 711-716. 2007;

HEALY, M., \& PERRY, C. (2000). Comprehensive criteria to judge validity and reliability of qualitative research within the realism paradigm. Qualitative Market Research, 3(3), 118-126;

HEESOM, D.; MAHDJOUBI, L. Technology Opportunities and Potential for the Virtual Construction Site - Volume 1: Emerging Research Initiatives. Universidade de Wolverhampton, 2003;

HERNANDEZ, C. "Thinking parametric design: introducing parametric Gaudi. In: Design Studio", 27 (2006) 309-324: ELSEVIER. 2006. Disponível em < www.elsevier.com/locate/destud $>$;

HIPPS, J. A. (1993). Trustworthiness and authenticity: Alternate ways to judge authentic assessments. Paper presented at the annual meeting of the American Educational Research Association. Atlanta, GA;

HUDSON, R. Frameworks for Practical Parametric Design in Architecture. IN; eCAADe 26, 2008;

HUOVILA, P.; KOSKELA, L.; LAUTANALA, M. Fast or concurrent: the art of getting construction improved. Lean Construction, Santiago, p.143 60, 1994;

I. A. T. A. - Baggage improvement programme, simplifying the business, International Air Transport Association, Tech. Rep., 2008. www.iata.org;

IBRAHIM, M.; KRAWCZYK, R. e SCHIPPOREIT, G. "Two Approaches to BIM: A Comparative Study. In: eCAADe Conference", 22, 2004, Copenhagen. 610-616. Disponível em http://cumincad.scix.net/cgi-bin/works/ Show?2004 610. Acessado em: 12.2008; 
ISIKDAG, U.; UNDERWOOD, J. Two design patterns for facilitating Building Information Model-based synchronous collaboration. Automation in Construction, v. 19 , n. 5, p. 544-553, ISSN 09265805. Disponível em: < http://dx.doi.org/10.1016/j.autcon.2009.11.006;

JACOSKI, C. A. (2003). A interoperabilidade em projetos digitais como condicionante à integração e virtualização da indústria da construção. Chapecó: Centro Tecnológico da Unichapecó;

JIM, H.K.; CHANG, Z.Y; An airport passenger terminal simulator: A planning and design tool, Simulation Practice and Theory, Vol. 6, (1998), pp. 387396;

JONES, JC. A method of systematic design. In Conference on Design Methods (ed. Jones and Thorneley). London: Pergamon Press (1963).

KALAY, Y.E. The impact of information technology on design methods, products and practices. Design Studies, v. 27, n. 3, p. 357-380, May 2006;

KALISPERIS, L. Quadro Conceitual para a computação no Projeto Arquitetônico, Tese de Doutorado, da PennState University, University Park, em 1988;

KALISPERIS, L. (1996) CAD in Education at Penn State University, em ACADIA Quarterly, summer;

KHEMLANI, L. Top criteria for BIM solutions: AECbytes Survey Results. AECbytes, 10 de outubro de 2007. Disponível em: <http://www.aecbytes.com/feature/2007/BIMSurvey Report.html>. Acesso em: 29 de outubro de 2013;

KIVINIEMI, A.; TARANDI, V.; KARLSHØJ, J.; BELL, H.; KARUD, O. "Review of the Development and Implementation of IFC Compatible BIM. ERABUILD FUNDING ORGANIZATIONS", 2008;

KOLAREVIC, B. "Architecture in the digital age: design and manufacturing". Nova York, Spon Press, 2003;

KOWALTOWSKI, D. C. C. K. et al. Reflexão sobre metodologias de projeto arquitetônico. 24/01/06, p.8; 
KVAN, T. Collaborative design: what is it? Automation in Construction, v. 9, n. 4, p. 409-415, July 2000. KYMMEL, W. Building Information Modeling. Planning and managing construction project with $4 \mathrm{D}$ and simulations. McGraw-Hill 2008;

LANG, J.T. Designing for human behavior: Architecture and the Behavioral Sciences. Stroudsburg: Dowden, Hutchinson and Ross, 1987;

LAWSON, B. (2004), "WHAT DESIGNERS KNOW", Elsevier/Architectural Press, 08/11/2004;

LAWSON, B. (1994) Design in Mind, Architectural Press, ButterworthHeinemann Publishers, Oxford, Reino Unido;

LAWSON, B. How designers think: the design process demystified. $3^{\text {a }}$ Edição, Architectural press, 1997;

LOGAN, B. (1987) The Structure of Design Problems, Tese de Doutorado, University of Strathclyde, Department of Architecture and Building Science, Reino Unido;

LIMA JR., O. F. Análise e Avaliação do Desempenho dos Serviços de Transporte de Carga (2001), In: Caixeta-Filho, J.V. e Martins, R.S. (eds.) Gestão Logística do Transporte de Cargas. Ed. Atlas, São Paulo;

LÖBACH, B. Design industrial: bases para a configuração dos produtos industriais. São Paulo: Edgard Blücher, 2001;

MCPHEE, A. "Practical BIM" - Acessado em 10/03/2015 e disponível em: http://practicalbim.blogspot.com.br/2013/03/what-is-this-thing-calledlod.html, 2013;

MAGUIRE, D. J (Edi.). An Overview and Definition of GIS. In:; GOODCHILD, M. F. (Edi.); RHIND, D. W (Edi.). Geographical Information Systems: Principles and Applications. London: Longmans Publishers, 1991, cap.I. Disponível em: < http://www.wiley.com/legacy/wileychi/gis/ Volume1/BB1v1 ch1.pdf > Acesso em: 29/03/2010, p.11; 
MALARD, M.L. O processo de projeto: problemas a resolver. CD-ROM do Seminário Arquitetura e Conceito, Universidade Federal de Minas Gerais, Escola de Arquitetura, NPGAU, agosto de 2003;

MARSHALL-PONTING, A. J.; AOUAD, G. An nD modeling approach to improve communication processes for construction. Automation in Construction, v.14, p. 311-321, 2005;

MITCHELL W J, "The theoretical foundation of computer-aided architectural design" Environment and Planning B 2(2) 1975, p. 131;

MITCHEL, W. J. 2005. Constructing Complexity. In: Martens, Bob and Brown André (eds), Computer Aided Architectural Design Futures 2005, Vienna, Austria;

MITCHELL, W. J. "The logic of architecture: design, computation and cognition. Cambridge, MA: The MIT Press", 1990. p. 304;

MITCHELL, W. J.; MCCULLOUGH, M. "Digital design media. 2 ed.": Wiley, 1994. $512 \mathrm{p}$;

MUSTOE, J. "Artificial intelligence and its application in architectural design", Tese de doutorado, University of Strathclyde, Glasgow, Reino Unido, Capitulo 1, 1990, p.9;

NARDELLI, E. em "Tecnologia digital avançada na produção de Habitações de Interesse Social - HIS no Brasil (HIS in Brazil: Advanced Digital Technology for the Production of Social Housing)", 2010, p.404;

NASCIMENTO, L. A.; SANTOS, E. T. A indústria da construção na era da informação. Ambiente Construído, Porto Alegre, v. 3, n. 1, p. 69-81, jan./mar. 2003;

NEUFVILLE, R; The Baggage System at Denver: Prospects and Lessons, paper on Technology and Policy Program Massachusetts Institute of Technology Cambridge, MA 02139 (U.S.A.);

NEVES, A. P. H. C. S; 2008, Tecnologias para a Gestão Multimodal de Bagagens, Tese de Mestrado no Instituto Superior Técnico de Lisboa; 
NONAKA, I. A empresa criadora de conhecimento. Aprendizagem organizacional: os melhores artigos da Harvard Business Review. Rio de Janeiro: Elsevier, 2006;

NONAKA, I; RYOKO, T. The knowledge-creating theory revisited: knowledge creation as a synthesizing process. Knowledge Management Research \& Practice, n. 1, p. 2-10, 2003;

OLIVEIRA, L. C. C. F. "Características e particularidades das ferramentas BIM: reflexos da implantação recente em escritórios de arquitetura." Universidade Federal de Santa Catarina Programa de Pós-graduação em Arquitetura e Urbanismo | Pós-arq;

OMNICLASS. Omniclass Construction Classification System. Recuperado em 20 de setembro de 2012, de: http://www.omniclass. org/ - 20/09/2012;

ONUMA, K. G. Twenty First Century Architect: Transformed by Process not Software. In: ONUMA White Papers, 2007. Disponível em < http://onuma.com/services/onuma V4c.pdf > Acesso em 24 de novembro de 2008;

OPUS HONG KONG - http://www.opushongkong.com/en/SalesInfo.php

OXMAN, R. "Prior knowledge in design: a dynamic knowledge-based model of design and creativity. Design Studies", v. 11, n 1, p.17-27, 1990;

PASQUIRE, C.L.; CONNOLLY, G.E., "Design for Manufacture and Assembly", "In: 11th ANNUAL CONFERENCE OF THE INTERNATIONAL GROUP FOR LEAN CONSTRUCTION, Proceedings... Blacksburg, USA, July 2003", pp 184 - 194, ISBN 0- 9721257-4-4;

PATTON, M. Q. (2002). Qualitative evaluation and research methods (3rd ed.). Thousand Oaks, CA: Sage Publications, Inc;

PAUWELS, P., em: "Reconsidering information system support in architectural design thinking - PhD Dissertation", Universidade de Gent, Gent Bélgica, 2012;

PERES, O., POLIDORI, M., Modelagem urbana e cidades visuais: fundamentos e convergências, XIII Encontro da Associação Nacional de Pós-Graduação 
e Pesquisa em Planejamento Urbano e Regional, 25 a 29 de maio de 2009, Florianópolis - Santa Catarina - Brasil, 2009, p.3;

PICKLER, M. "Web Semântica: ontologias como ferramentas de representação do conhecimento", Perspectivas em Ciência da Informação, versão impressa ISSN 1413-9936 - Perspect. ciênc. inf. v.12 n.1 Belo Horizonte, Universidade Estadual de Londrina; Bolsista de IC/PROIC, 2007, p.2;

PINHEIRO, E; Mestre em Engenharia Civil, Departamento de Arquitetura e Construção, UNICAMP, Campinas, SP, Brasil, e CELANI, Gabriela, Ph.D., Universidade Estadual de Campinas, Campinas, Brasil;

PREZOTO, L. Introdução a Sistemas Especialistas. Universidade Estadual de Campinas - UNICAMP, Faculdade de Tecnologia - FT, Limeira - SP, 2010, p.2;

PUPO, R; apud KALISPERIS, L. Arquitextos ISSN 1809-6298, I "International Workshop Digital Design for Architecture" - concepção arquitetônica em ambiente computacional, 2007, p. 3;

QUEIROZ, G. E FERREIRA, K., Tutorial sobre Bancos de Dados Geográficos, GeoBrasil,2007, p.5;

QUEIROZ, S. R. S. L, Uso de Servidores BIM em Ambientes de Projeto Colaborativo. Faculdade de Engenharia Civil, Arquitetura e Urbanismo, Unicamp, Campinas, $1^{\circ}$ Semestre de 2012, Programa de Pós-graduação em Arquitetura e Construção;

RENGIFO, A. RAEDER, M. MARKUSSEN, B. JAKOBSEN, A. WHITE, B. em "Case Study: Gardermoen Airport, Oslo, Norway", 2008;

RIBEIRO, J, SILVA, N; LIMA, E. "Building Information Modeling" como instrumento de projetos aeroportuários, em artigo publicado no SIIGRADI2009, p. 1 a 6. Faculdade de Arquitetura e Urbanismo, Universidade de Brasília, Brasil;

RITTEL, H.W.J. "On the planning crisis: systems, analysis of the 'first and second' generation" Berdiftsokonomen, n.8, 1972, p.390 a 396;

ROSSO, T. Racionalização da construção. São Paulo: FAUUSP, 1980; 
SANTOS, E; BIM e a Gestão de Projetos. In: VIII Workshop Brasileiro do Processo de Projetos na Construção de Edifícios, 2008;

SASS, L. "Synthesis of design production with integrated digital fabrication. Automation in construction", 2006, v.16, n.3, p. 298-310;

SEBASTIAN, R., BÖHMS, H.M., BONSMA, P., VAN DEN HELM, P.W., em: "Semantic BIM and GIS modelling for energy - efficient buildings integrated in a healthcare district". ISPRS Annals of the Photogrammetry, Remote Sensing and Spatial Information Sciences, Volume II-2NW1, ISPRS 8th 3DGeolnfo Conference \& WG II/2 Workshop, 27 - 29 November, Istanbul, Turkia, 2013;

SCHEER et al, Impacto do uso do sistema CAD Geométrico e do uso do CADBIM no processo de projeto em escritórios de arquitetura. Em: VII Workshop Brasileiro de gestão do processo de projetos na construção civil, 2007, Curitiba. Disponível em: < http://www.cesec.ufpr.br/workshop2007> Acesso em 15/9/2008;

SCHEER, S, AYRES FILHO, G. Abordando a BIM em níveis de modelagem SBQP 2009, Simpósio Brasileiro de Qualidade do Projeto no Ambiente Construído IX Workshop Brasileiro de Gestão do Processo de Projeto na Construção de Edifícios 18 a 20 de Novembro de 2009 - São Carlos, SP - Brasil Universidade de São Paulo;

SCHEER, S. e AZUMA, F. em "Processos de projeto, sistemas CAD e modelagem de produto para edificações", Ed. №. 29 - Agosto/09, p. 2-3;

SCHÖN, D. Educando o Profissional Reflexivo: um novo design para o ensino e a aprendizagem. Porto Alegre: Artes Médicas, 2000;

SIDAWI B. and Hamza, N. (2012). Intelligent knowledge - based repository to support informed design decision making. ITCON special issue: CAAD and innovation. pg. $308-318$;

SIDAWI, B; RABEE M., Elmarsafawy, Hesham, El - Wageeh, Sherif, Bennadji Amar (Ed.). (2012) - $6^{\text {th }}$ ASCAAD Conference 2012: CAAD| INNOVATION | PRACTICE proceedings. 21 - 23 February 2012, College of Architectural Engineering and Design, the Kingdom University. Manama, Bahrain; 
SILVA, N. F. (1996) Design Computing, Previous Knowledge and Innovation, estratos de tese de doutorado, University of Strathclyde, Reino Unido;

SIMOFF, S, J; MARY, L. M. Analysing participation in collaborative design environments. Design Studies, v 21 p. 119-144, 2000 www.elsevier.com/locate/destud;

SIMON, H. The Sciences of the Artificial. 3rd. Edition. Massachusetts: MIT Press, 1996, p.108 e 109;

SCHÖN, D. Educando o Profissional Reflexivo: um novo design para o ensino e a aprendizagem. Porto Alegre: Artes Médicas, 2000;

SCHÖN, D.; WIGGINS, G. Kinds of seeing and their functions in designing. Design Studies, v. 13, n² 2, p.135-156, 1992;

SITA GROUP 2nd. Airport IT Trends Survey. Executive Overview (2005). Disponível em: www.sita.aero/NR/rdonlyres/5A3CCC1A-F6FE-40D6-A628 B!DEB289584 3/0/SITA Airport IT Trends report Nov 05. PDF. Acesso em: 10 Jul 13;

STEELE, J. (2001). "Arquitectura y revolución digital". México: Gustavo Gili, as;

TSE, T. K., \& WONG, K. A. (2005). The utilization of building information models in "Nd" modelling: a study of data interfacing and adoption barriers. Hong Kong: ITCOM, v. 10, p. 85-102, abr. 2005;

ULLMAN, D.G; The mechanical design process (1997). New York: McGraw Hill;

VAN BERLO, L. \& DE LAAT, R. Integration of BIM and GIS: The development of the CityGML GeoBIM extension. In: KOLBE, T. H., KÖNIG, G. \& NAGEL, C. (eds.) Advances in 3D Geo-Information Sciences. Berlin, 2011;

VANDERLANDE, System Book, Part 2 Baggage handling, 2001, Vanderlande Industries, Veghel, the Netherlands;

VASCONCELOS, M. A. F; Mestrando em Design - Design Gráfico e Experimentalismo, Universidade Anhembi Morumbi; 
VOGEL, T; Technical system specification to RFID-enable the baggage sorting system at Zurich Airport,ll Master's thesis, Swiss Federal Institute of Technology Zurich, 2007;

WEYGANDT J.J., D.E. KIESO, P.D. KIMMEL. Managerial Accounting Tools for Business Decision Making. John Wiley \& Sons, United States, 2005, p. 495-499;

WEISBERG, D. E., The Engineering Design Revolution - The People, Companies and Computer Systems That Changed Forever the Practice of Engineering, 2008;

WILLEY, J. \& S; Modeling for Owners, Managers, Designers, Engineers and Contractors. Hoboken (NJ): 2008;

ZEVI, B. Saber Ver a Arquitetura, Trad. Maria Izabel Gaspar, Gaetan Martins de Oliveira. 5. ed. São Paulo: Martins Fontes, 1996.

\section{IULIO TOLLENDAL GOMES RIBEIRO}

M.Sc. Gestão do Processo de Projetos de Aeroportos - BIM (FAU/ Pós- UnB)

Especialista em Gestão da Aviação Civil (Lato Sensu/ CEFTRU/ UnB)

Espec. em Proj. Arquitetura Assistido por Computador (Lato Sensu/ FAU/ Pós- UnB)

http://www.linkedin.com/profile/view? id $=69827693 \&$ trk $=h$ b tab_pro top http://dgp.cnpq.br/buscaoperacional/detalheest.jsp?est=6828962696337252

http://lecomp.fau.unb. 


\section{ANEXO I}

\section{REDESENHO DO PROCESSO DE APROVAÇÃO DE PROJETOS DA INFRAERO}




\section{ANÁLISE E PROPOSTA DE REDESENHO DO FLUXOGRAMA DO PROCESSO DE APROVAÇÃO DE PROJETOS NA INFRAERO (BIM)}

Imagina-se que um ambiente organizacional estruturado na utilização dos sistemas BIM criaria uma estrutura conectada, onde cada área da empresa representaria uma área de conhecimento ou de responsabilidade, sendo que no centro estariam núcleos de trabalho compostos pela representação de cada área específica, e gerenciados de forma compartilhada. Essa estrutura organizacional propiciaria trocas entre o núcleo e as partes, equilibrando as polarizações de conhecimento e de informação.

Este é um princípio simbiótico de criação e manipulação de dados, que deve estar espelhado nas responsabilidades e nas atribuições da empresa. Na prática, estamos falando da responsabilidade compartilhada, da maturidade dos processos e da qualidade do ambiente organizacional, em termos humanos, de conhecimento e de cooperação. Em última instancia, estamos falando de se "materializar" o conhecimento presente, pulverizado presente no corpo técnico da organização ou no somatório do conhecimento técnico dos profissionais de uma equipe de projeto ou de obra em unidades funcionais de conhecimentos aplicados.

Vale ressaltar que uma possível contribuição desta pesquisa para um futuro ambiente BIM e SIG na INFRAERO reside na reunião, classificação e sistematização de informações sobre a forma como o processo de projeto acontece dentro da organização e a relação com as áreas complementares à de Engenharia, que atuam como clientes internos, como as áreas Comercial, Operações, Gestão, entre outras. Para isso, ao pensar e fazer arquitetura e engenharia, é preciso conhecer não apenas os processos relativos mas ainda conhecer como os mesmos acontecem na estrutura da empresa, que no caso da INFRAERO, por ser público, exige transparência no uso dos recursos do Tesouro Nacional. A intenção final do autor residiu no redesenho do fluxograma do processo de aprovação de projeto da INFRAERO, sendo que o projetopiloto atuou como um recorte para que tal análise se torne possível, permitindo ainda uma maior clareza na definição das diferenças entre as duas ferramentas de projeto e das potencialidades de cada uma delas.

Foi realizado um recorte na questão dos relacionamentos entre os agentes intervenientes num processo de projeto da INFRAERO, de forma a retratar sob a forma de uma matriz semântica as conexões existentes entre os componentes do aeroporto e suas partes, bem como em relação à extensão de atribuições especificas, tarefas e processo de projeto e responsabilidades de cada um. 
A discussão da formatação e das soluções propostas com todos os integrantes da equipe de projeto, e a possibilidade de cada um inferir e modificar o modelo tridimensional, que sofre contínuo processo de análise e discussão pelos demais projetistas e agentes intervenientes, gerando maior qualidade ao produto final, apresentando maior aproveitamento dos recursos e do conhecimento das diversas áreas de projeto, além de maior rapidez no processo de projetação como um todo, o que tem representado um grande diferencial competitivo de mercado.

No processo utilizando a tecnologia BIM, ocorre uma inversão: ao invés de uma série de desenhos bidimensionais, o projetista "constrói" virtualmente um modelo da edificação, utilizando objetos que simulam em forma e comportamento, os elementos construtivos a serem empregados na construção.

Os modelos virtuais podem ser entendidos como bases de dados onde são armazenados tanto os dados geométricos, como os textuais de cada elemento construtivo utilizado no projeto. A Figura I, na próxima página, representa o fluxograma de utilização figurativo dos sistemas BIM como ambiente de trabalho na INFRAERO, envolvendo seus principais atores, enquanto clientes internos e externos (ANAC), bem como os requisitos e caminhos formais de aprovação de projetos pela empresa.

Tem por objetivo mostrar que a parte nuclear do processo reside nas atividades de processos de análise, diagramas de fluxos, avaliação e "layout". O processo de projeto representa a evolução e o amadurecimento da informação associada a esses campos e desemboca em uma representação gráfica na busca por soluções mais vantajosas de atendimento aos requisitos impostos no início do processo. Os processos de análise são efetuados de forma contínua, a cada nova solução proposta, de forma a validar constantemente os requisitos impostos a cada projeto.

Na Figura I, a seguir, encontram-se expressas as atividades de regulação, formação de requisitos, projetação e melhoria, validação de requisitos, construção, instalação e operação da edificação.

Do ponto de vista de projeto, as ontologias funcionariam como as palavras ou vocábulos, e a semântica como dicionário ou significado agregando sentido aos conceitos e atributos. Intentam contribuir para que o processo de projeto, envolvendo elementos de infraestrutura aeroportuária possa se desenvolver no Brasil, por meio da constituição de uma base de dados atual e alinhada com os padrões empregados pelo mercado na especificação, em projeto, destes equipamentos. 


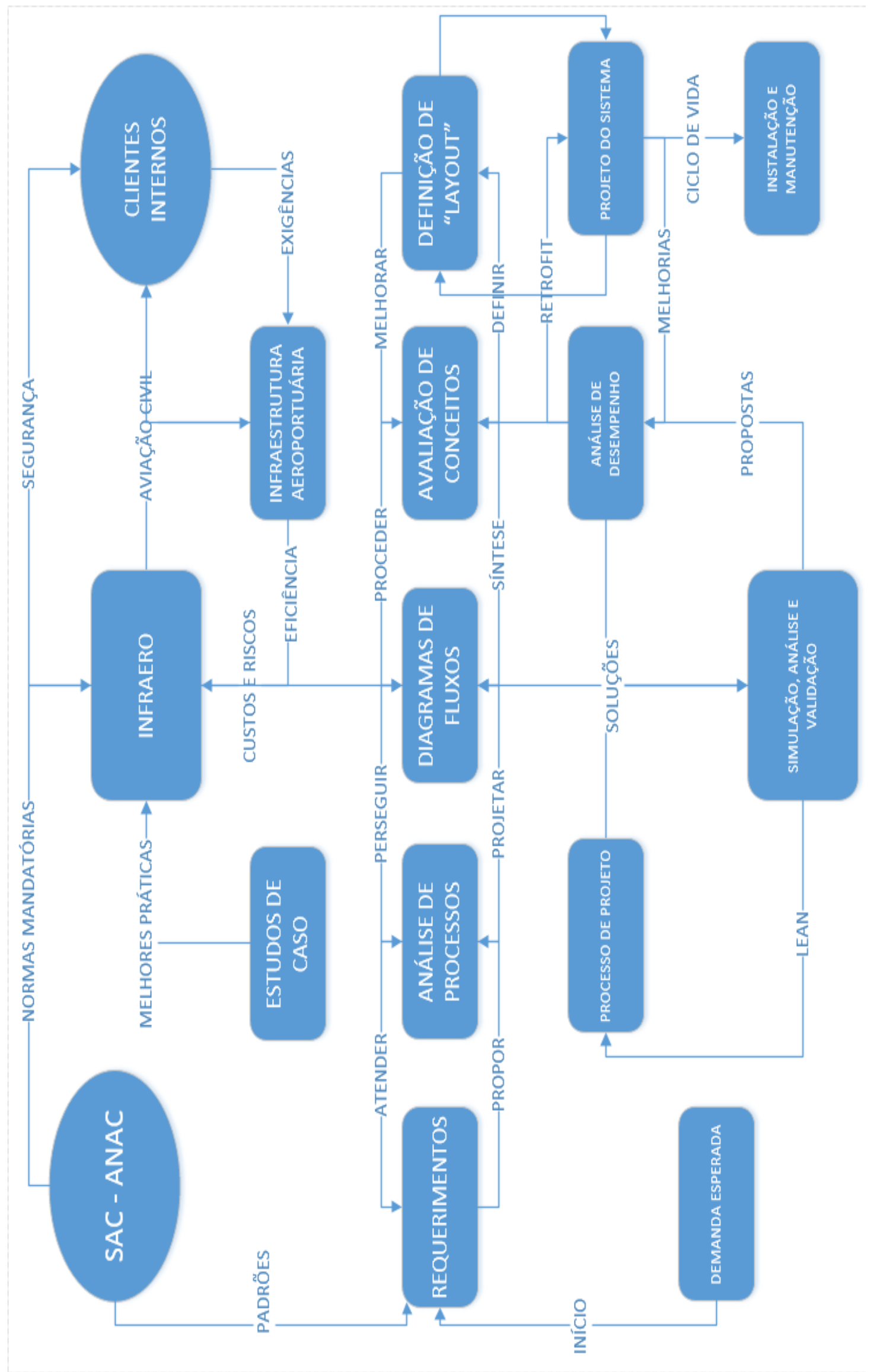

Figura I- Fluxograma de utilização figurativo dos sistemas BIM como ambiente de trabalho na INFRAERO. 
Diversos mapeamentos de processos já ocorreram na empresa e atualmente uma grande reestruturação está em curso, porem muita mais no aspecto administrativo e financeiro, visando talvez uma futura abertura de capital, do que numa real atualização dos processos de aprovação e projetos na empresa. Do ponto de vista técnico, a INFRAERO está eliminando estruturas intermediarias, chamadas de "Regionais", para ligar as responsabilidades das Superintendências dos Aeroportos diretamente com a Sede.

Analisando esta reorganização do ponto de vista de projeto de arquitetura, concluímos que a normatização e unificação da produção de obras e serviços de engenharia da empresa ficaria muito mais complicada, uma vez que as práticas entre cada localidade são muito diferentes. Acreditamos que a restruturação da informação na INFRAERO, através da transição do ambiente papel para o ambiente digital e a atualização dos processos de aprovação e projetos são fundamentais e requisitos importantes para a transformação em curso.

A Figura I na página anterior expressa atividades regulatórias, exigências de formação, projetando e melhoria, validação de requisitos, construção, instalação e operação do edifício. Ao observarmos a inter-relação que se estabelece neste processo, podemos ver que a estrutura proposta baseia-se nos conceitos da metodologia que utiliza sistemas BIM, sobre a centralidade das atividades de análise, avaliação e projeto. As posições centrais tendem a estabelecer ligações com os processos associados (radiais) de cada fase fazendo com que o modo de cooperação recomendado pelos sistemas BIM possa ser concebido nesta estrutura (diagrama de fluxo de processo), mostrado na Figura I (INFRAERO x PROCESSOS): Os processos de analise são efetuados de forma continua, a cada nova solução proposta, de forma a se validar constantemente os requisitos impostos a cada projeto.

O diagrama de fluxo apresentado representa uma novidade em relação ao processo de aprovação de projetos atualmente em vigor na INFRAERO, uma vez que tais fluxos servem para acompanhar e guiar as informações entre o modelo único de informações e as atividades de análise e de tomada de decisão ao longo do processo de projeto. A figura I, anterior, ilustra a organização por processos na empresa, levando em consideração as dimensões social, tecnológica e econômicas, que são representadas pela ANAC, "reguladora", INFRAERO, "provedora" e Clientes, "usuários internos e finais". No centro desta figura encontram-se as atividades principais de projeto, como analise e tomada de decisão. Podemos observar a influência da ANAC nos requerimentos e dos usuários no escopo da INFRAERO (Figura I) 
Destacamos ainda as atividades de simulação e analise, que amparam as tomadas de decisão e a busca por soluções vantajosas. Só após a avaliação dos conceitos e da definição do "Layout", ou projeto, pois estão intimamente associados, inicia-se a construção e a operação do aeroporto. Imagina-se que os sistemas BIM e SIG estariam atuando de forma conjunta nas atividades centrais da figura, cuja informação circula de forma a propiciar momentos de síntese e momentos de abstração.

Uma nova reestruturação da INFRAERO pode ser necessária, desta vez do ponto de vista dos processos e práticas de projeto e do domínio da informação e de sua manipulação pelos profissionais envolvidos. Essas mudanças deslocariam as atividades de análise e de tomada de decisão para o centro do processo, onde atualmente encontram-se as atividades de aprovação de projetos.

Uma vez que no processo BIM a participação dos agentes intervenientes ocorre de forma integrada, a aprovação de projetos ocorre simultaneamente a tomada de decisão, pois as áreas da INFRAERO responsáveis pelas mesmas participam ativamente do processo de projeto. Nesta pesquisa, foi desenvolvida uma Matriz de Dados que fornece informações sobre os módulos funcionais de um aeroporto ligados à estrutura organizacional da INFRAERO.

As relações entre as partes de um aeroporto relacionado com os processos de aprovação correspondentes, as tarefas do projeto e os requisitos previstos fazem parte dessa matriz. A utilização dos sistemas BIM em conjunto com o SIG pode auxiliar na manipulação da informação de projeto. No SIG e possível testar diversas possibilidades formais, conectivas e contextuais, bem como realizar analises topográficas, de interferências e contextualização em relação ao entorno imediato, entre outras. Ao mesmo tempo, nos sistemas BIM a informação pode ser consolidada e automatizada, ou seja, enquanto no SIG procede-se a uma busca por diferentes alternativas, no BIM formaliza-se as decisões tomadas sob a forma de soluções de projeto.

O SIG pode agregar informações importantes para os processos e analises como por exemplo sistemas urbanos de transporte, infraestrutura existente, redes pluviais, de gás e de energia subterrânea e aérea, sistemas de telecomunicações, relevo e vegetação e muitas outras dimensões que podem complementar os processos de análise dos sistemas BIM. Como podemos observar, existe uma especialização entre os principais sistemas de uma edificação, cujos próprios fabricantes de "softwares" reproduzem em suas plataformas de trabalho. A partir de uma visão crítica, que não apenas "importa" soluções prontas e geralmente de teor comercial, reconhecemos a existência destes quatro núcleos principais de informação no processo de projeto. 


\section{D CAD EM VOGA - PROCESSOS DE APROVACÃO E PROJETOS}

A partir de uma demanda especifica, as áreas da INFRAERO são acionadas, para que se realizem estudos e projetos que se atenda a essa nova demanda. Isto pode ser feito através da ampliação da infraestrutura existente ou através da criação de novas edificações e sistemas (Figura II abaixo). Após a previsão de uma estimativa de tempo, elabora-se um diagnóstico preciso do escopo e de suas características, restrições e limites para os projetos nas diferentes áreas. A formalização dessas informações constitui-se nos requerimentos para o desenvolvimento do projeto e ainda em critérios de aprovação de projetos.

\section{FORMACAO DO PROCESSO DE APROVACAO DE PROJETOS NA INFRAERO}

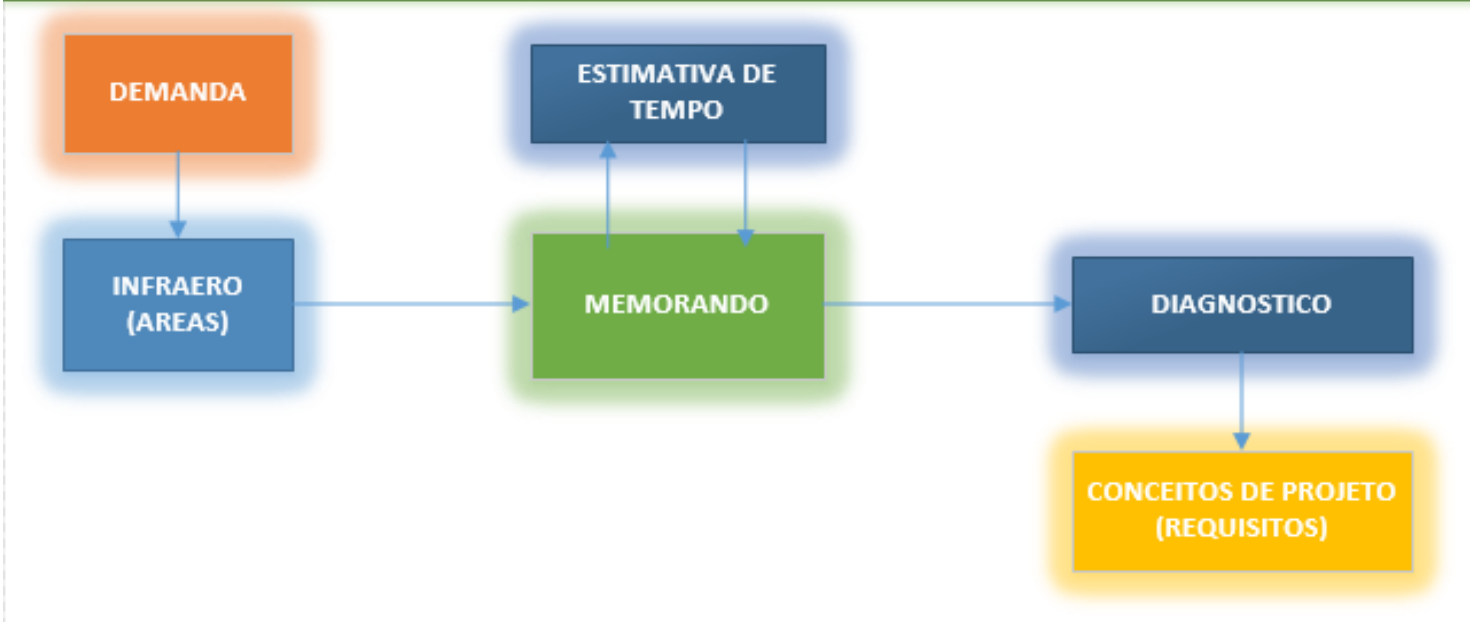

Figura II- Processo de Aprovação de Projetos em voga na INFRAERO.

A Figura III a seguir mostra as etapas de aprovação e os "loopings" que devem ser percorridos na eventualidade de ocorrer a reprovação de alguma solução de projeto. Como esse processo é essencialmente linear, o compartilhamento de informação entre as áreas é pequeno e geralmente através de papel. A implantação de um sistema BIM resulta em alteração do método de trabalho convencional, uma vez que estabelece um novo fluxo de trabalho e de gerenciamento da informação. Essa mudança ocorre no encadeamento da informação, que nos sistemas BIM não caminha de forma linear e sequencial. Ao contrário, ocorre simultaneamente entre as equipes de projeto. Na Figura III podemos observar que na eventual reprovação do Estudo Conceitual, do Anteprojeto ou do Projeto Básico, deve-se retroceder uma etapa, para que ajustes possam ser feitos. O retrabalho projetual recai sobre a consulta aos Conceitos de Projeto e sobre o "Termo de Referência" do projeto (requisitos), como Especificações Técnicas, Memoriais Descritivos, Manuais de Critérios e Condicionantes, entre outros. Devemos observar que inexiste a integração de todas as disciplinas na readequação de soluções que não foram aprovadas. Apenas a(s) áreas(s) e disciplina(s) envolvida(s) participam das discussões e reprojeto das soluções, cuja aprovação encontra-se pendente. 


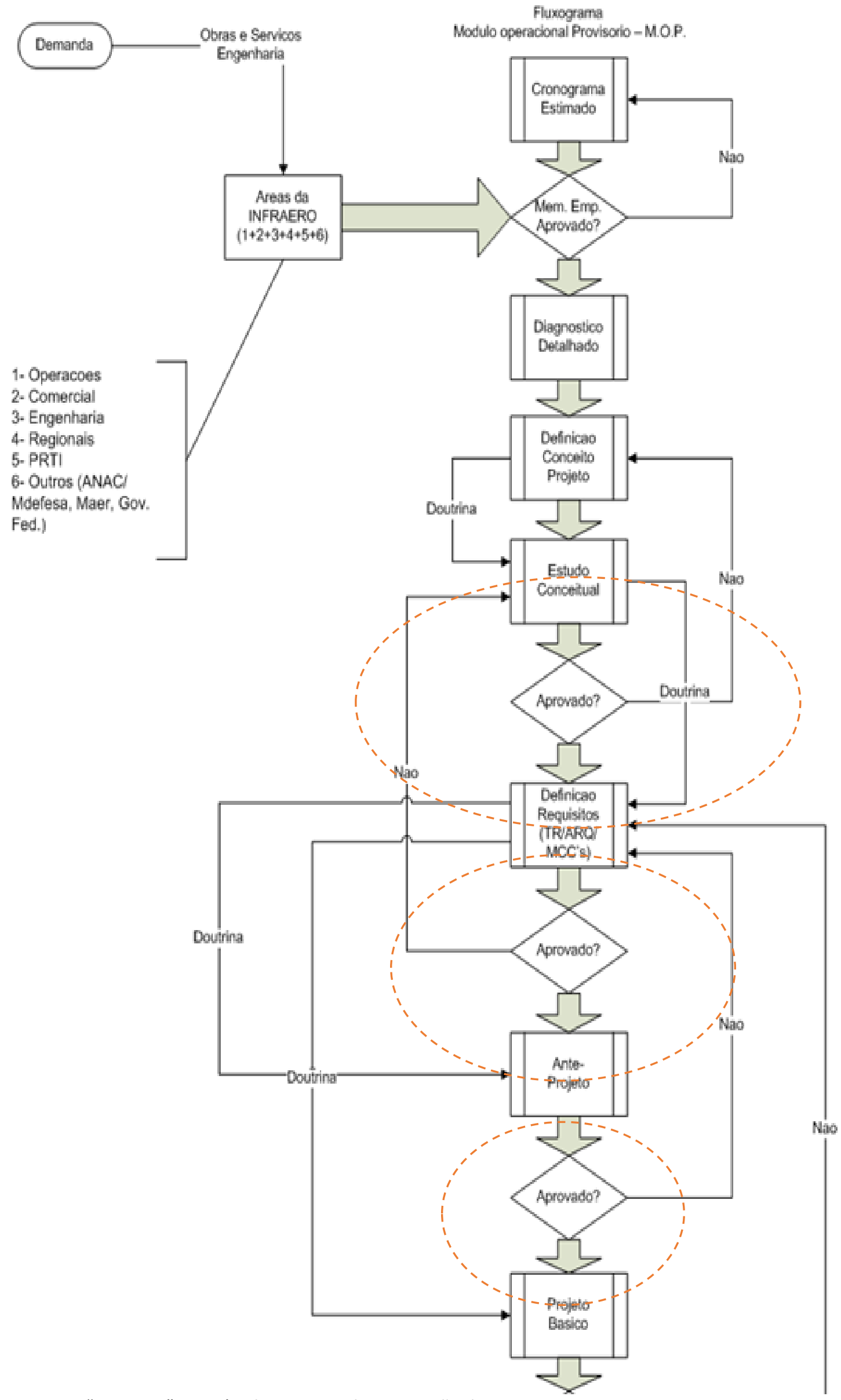

Figura III- "Loopings" no método em voga de Aprovação de Projetos. Fonte: INFRAERO. 
Portanto, eventuais impactos negativos em outros sistemas do aeroporto, ou outras soluções espaciais e funcionais não podem ser mitigados. Uma outra questão relevante diz respeito a contribuição especifica do saber envolvido em cada profissional, ou CAT - Certidão de Acervo Técnico. A bem dizer, uma empresa não possui qualificação técnica em si própria, mas no corpo de funcionários habilitados nas diversas áreas de engenharia e arquitetura que compõem o seu acervo humano. Na forma como atualmente está organizado o processo de aprovação de projetos na INFRAERO o somatório dos conhecimentos das áreas e especialidades da empresa não e levado em consideração, sendo que as soluções e os ajustes realizados nos "loopings" de aprovação ocorrem de forma pontual (Figura III na página anterior).

Pode-se dizer que estas características do processo em vigor impedem a integração das equipes de projeto e consequentemente a amplificação das capacidades de análise e tomada de decisão e a qualidade das soluções de projetos geradas pela empresa. (Figura IV)

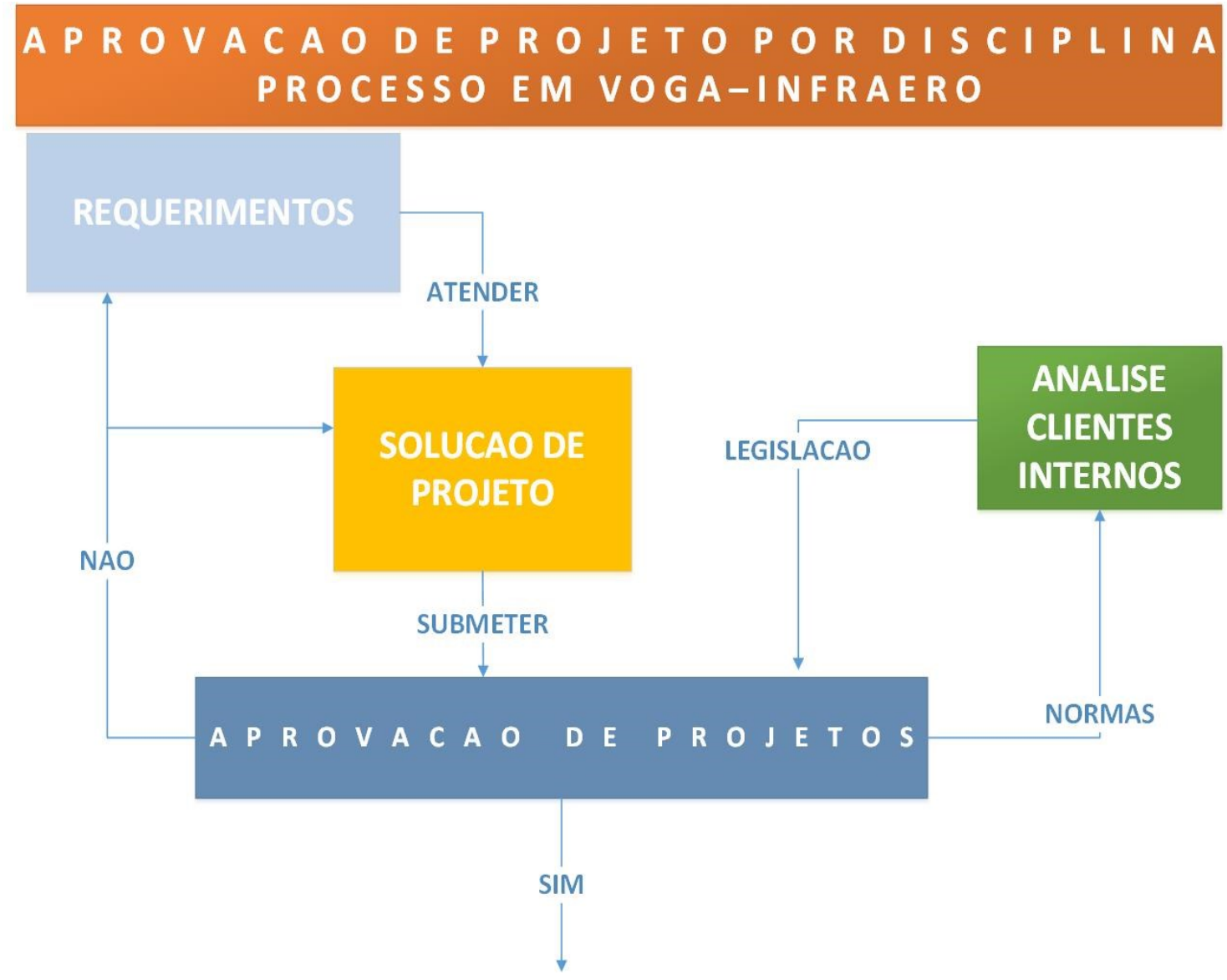

Figura IV- Aprovação por disciplina de Projeto.

A Figura IV demonstra como o processo de aprovação está estruturado individualmente, por disciplina. Não existe um processo que integre e conjugue a busca de soluções com o saber e a contribuição especifica de todas as disciplinas de projeto. 


\section{SISTEMAS BIM NO PROCESSO DE PROJETO- INFRAERO}

Este estudo demostrou que a associação entre os sistemas BIM e SIG visando a flexibilizar o nível de detalhe, ao longo do processo de projeto, pode facilitar significativamente a adoção dos sistemas BIM em projetos aeroportuários no Brasil.

As condições necessárias para que se possa estabelecer um ambiente de transição entre o atual processo de projeto empregado pela INFRAERO (linear e fragmentado) e o processo integrado dos sistemas BIM, que represente ativamente o conjunto de especialidades de projeto (engenharia e arquitetura), através da participação efetiva e antecipada das mesmas no processo de projeto, só pode ser possível a partir do comprometimento da alta direção da empresa e de uma tomada de decisão em favor da revisão dos atuais processos da INFRAERO.

Restariam apenas três fases no eventual processo de projeto com uso dos sistemas BIM pela INFRAERO: viabilidade, concepção do modelo e desenvolvimento do projeto final. Essa estrutura organizacional ocorreria em trocas entre o núcleo e as partes, equilibrando as polarizações de conhecimento e de informação.

$\mathrm{Na}$ prática, isso significa responsabilidade compartilhada, maturidade nos processos e qualidade do ambiente organizacional, em termos humanos, de conhecimento e de cooperação. Para que isto seja possível, estas aplicações devem "conversar" entre si, permitindo a transposição de informações de um projeto ao outro (Estrutural, Elétrico, Hidrossanitários, Eletromecânico, etc.).

Esta capacidade de troca de informações - chamada de interoperabilidade - é capaz de identificar os dados necessários para serem passados entre as aplicações informáticas (EASTMAN et al., 2008), possibilitando a criação de um único protocolo. Este corresponde a uma convenção ou um padrão, que controla e possibilita uma conexão, comunicação ou transferência de dados entre os sistemas computacionais dos intervenientes e o sistema computacional central onde reside o modelo partilhado do empreendimento.

Através da capacidade de comunicação de dados assegurada entre os diversos "softwares", a busca por soluções mais vantajosas de projeto. Face aos requisitos impostos pelo programa de necessidades, torna-se viável ao pensarmos a utilização das ferramentas de projeto em conjunto, no que chamamos de trabalho colaborativo, se realizado de forma simultânea. 


\section{PROPOSTA DE REDESENHO DO PROCESSO DE APROVAÇÃO DE PROJETOS NA INFRAERO COM O USO DOS SISTEMAS BIM}

Através da construção de uma base conceitual, orquestrada por uma ontologia comum, diferentes áreas da INFRAERO poderão interagir com as dimensões cultural, social, econômica e tecnológica. Existe duas situações distintas na INFRAERO. A primeira diz respeito a contratação dos projetos de arquitetura e de engenharia através de licitação pública, que são desenvolvidos por uma Contratada que possui CAT Certificado de Anotação Técnica compatível com o objeto contratual.

Tal situação gera processos de análise e de fiscalização por parte da INFRAERO para balizar e aceitar as soluções de projeto. A segunda situação envolve o corpo técnico da empresa para realizar de forma orgânica os projetos. Ainda que o saber técnico - cientifico envolvido nas duas situações seja o mesmo, os processos de análise e de projeto são distintos.

Na primeira situação a empresa possui pouca capacidade de interferência no processos e projeto em curso, mas tem total influência nas soluções empregadas. $\mathrm{Na}$ segunda situação a empresa possui a missão não só de realizar o projeto, mas de se auto analisar e aprovar as soluções que vão surgindo.

A comparação dessas duas situações demonstra que a INFRAERO necessita de flexibilidade de processos de análise e projeto, mas com estrutura ontológica comum a ambos os casos. Atualmente a estrutura, baseada em papel, fragmentada, e a cadeia sequencial de desenvolvimento de projetos e análise de soluções acarreta processos decisórios cujos significados semânticos e complexidade ficam limitados ao domínio especifico de cada área da empresa.

Na Figura $\mathrm{V}$ a seguir encontra-se descrita uma possível estrutura do processo de aprovação de projetos que se utiliza dos Sistemas BIM. A grande diferença em relação ao processo em voga reside no estabelecimento de núcleos de desenvolvimento e aprovação de projetos, centralizados numa estrutura nuclear, em cujo centro encontram-se as áreas da empresa.

Imagina-se que, dessa forma, a participação de cada especialidade de projeto ocorra integrada ao processo de análise, e consequente tomada de decisão. Ou seja, o desenvolvimento do projeto e sua aprovação tornam-se um processo único, cujos estágios variam entre alternativas de projeto, análise e melhorias e, finalmente, a formalização das soluções escolhidas. 
SISTEMAS BIM APLICADOS AO PROCESSO DE PROJETO- INFRAERO

PROCESSO BIM DE APROVACAO DE PROJETOS NA INFRAERO
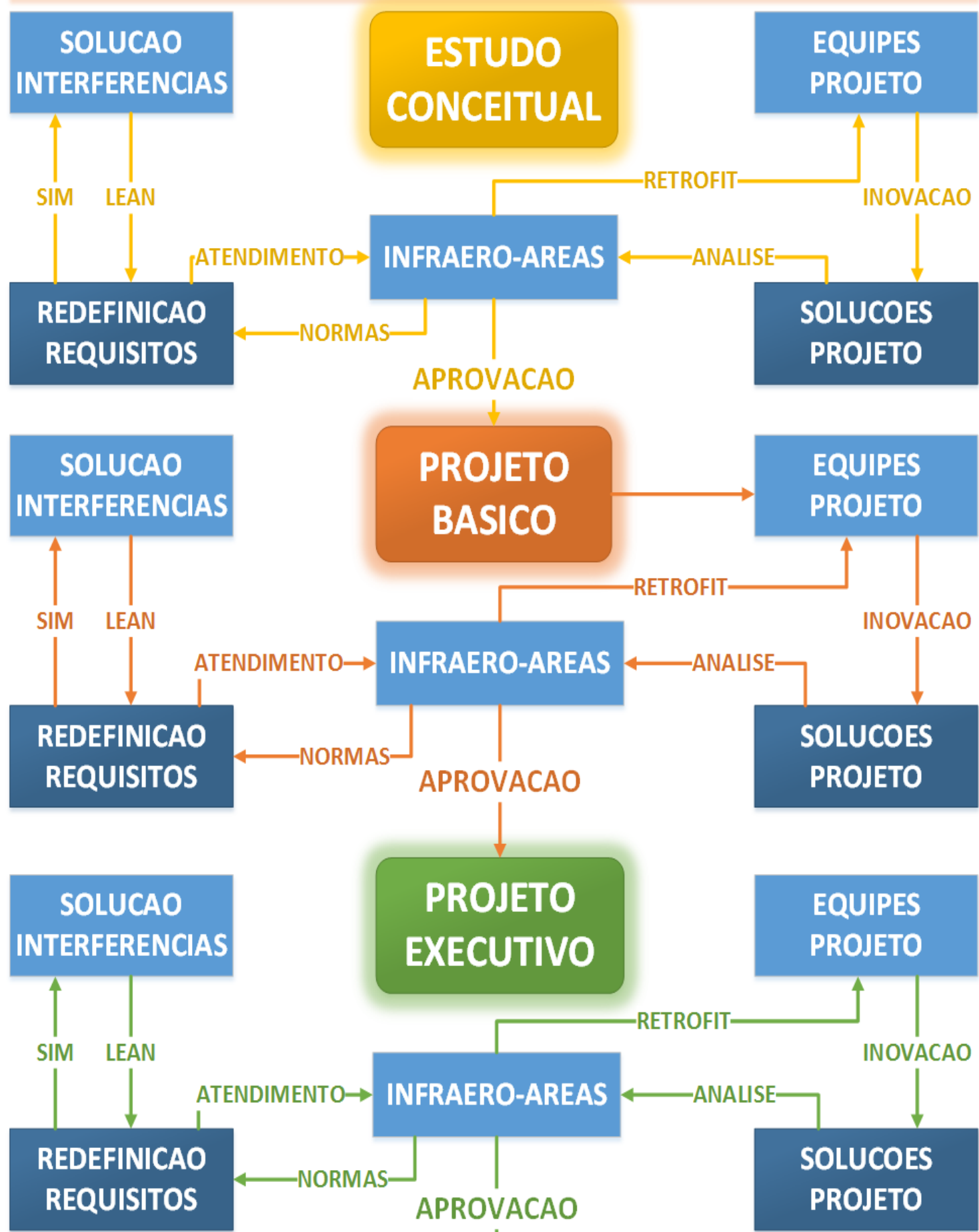

LICITACAO

Figura V- Processo BIM de Aprovação Projetos na INFRAERO. 
Como é possível observar na Figura $V$, na página anterior, não existem "loopings" nos processos de aprovação de projetos. As responsabilidades envolvidas nas tarefas de projeto, análise, tomadas de decisão e de aprovação são unificadas nas tomadas de decisão compartilhadas no modelo único de informação. A partir do momento em que o processo de projeto na INFRAERO for implementado, teremos necessariamente arquivos únicos de informação compartilhados pelos profissionais responsáveis por projetar, fiscalizar e aprovar uma solução de projeto. Se pensarmos nos "softwares" desenvolvidos pela AutoDesk, uma vez que atualmente este fabricante é o escolhido para os projetos de arquitetura e engenharia, (como AutoCAD, Revit ${ }^{\circledR}$, entre outros), teremos quatro núcleos trabalhando em paralelo, mas que devem ser integralizados pelos "Coordenadores" e "Gerentes BIM". Imaginando-se o processo BIM na INFRAERO, o primeiro núcleo, baseado no modelo de arquitetura, utilizaria o Revit ${ }^{\circledR}$ "Architecture", onde a configuração espacial, a inserção no terreno e de, forma geral, toda a informação sistêmica é depositada.

O segundo núcleo responderia pelos sistemas estruturais, utilizando o Revit ${ }^{\circledR}$ "Structure", para desenvolver, calcular e representar as estruturas de uma edificação, em conjunto com outras ferramentas de engenharia. $O$ terceiro núcleo reúne as disciplinas chamadas MEP - "Mechanical, Electrical and Plumbing", para Sistemas Eletromecânicos, Hidrossanitários e Elétricos, utilizando o Revit ${ }^{\circledR}$ MEP. O quarto e último núcleo diz respeito à parte da infraestrutura, topografia e geotecnia (Figura V). Nesta visão de projeto orientado ao produto, cada disciplina atua independentemente das demais, sendo que eventuais interferências são dirimidas de forma local, em detrimento de uma solução global. Ao derivarmos essas premissas para a estrutura organizacional da INFRAERO - Sede, poderíamos imaginar que as áreas de planejamento, operações e meio ambiente seriam as "proprietárias" das bases SIG e responsáveis por desenvolver, pesquisar e atualizar as mesmas em relação às variações na rede de aeroportos da empresa, legislação cabível, impactos e planos de manejo ambientais, planos diretores aeroportuários, operação e certificação do aeródromo, entre outras. Já as áreas de Engenharia, Administração e Comercial, seriam as "proprietárias" das bases $\mathrm{BIM}$, atuando no provimento de infraestrutura aeroportuária. Claro que a consulta e a manipulação da informação entre as bases BIM e SIG, deve ocorrer, porém através da participação efetiva das diversas áreas e especialidades da empresa. Desta forma é possível agregar o conjunto de conhecimento das diferentes equipes de projeto e áreas reguladoras, para que as soluções de projeto e sua gestão sejam unificadas. Isto garante o balizamento de normas e requisitos, como também fomenta a inovação e a criatividade no processo. 
ANEXO II

MATRIZ SEMÂNTICA 


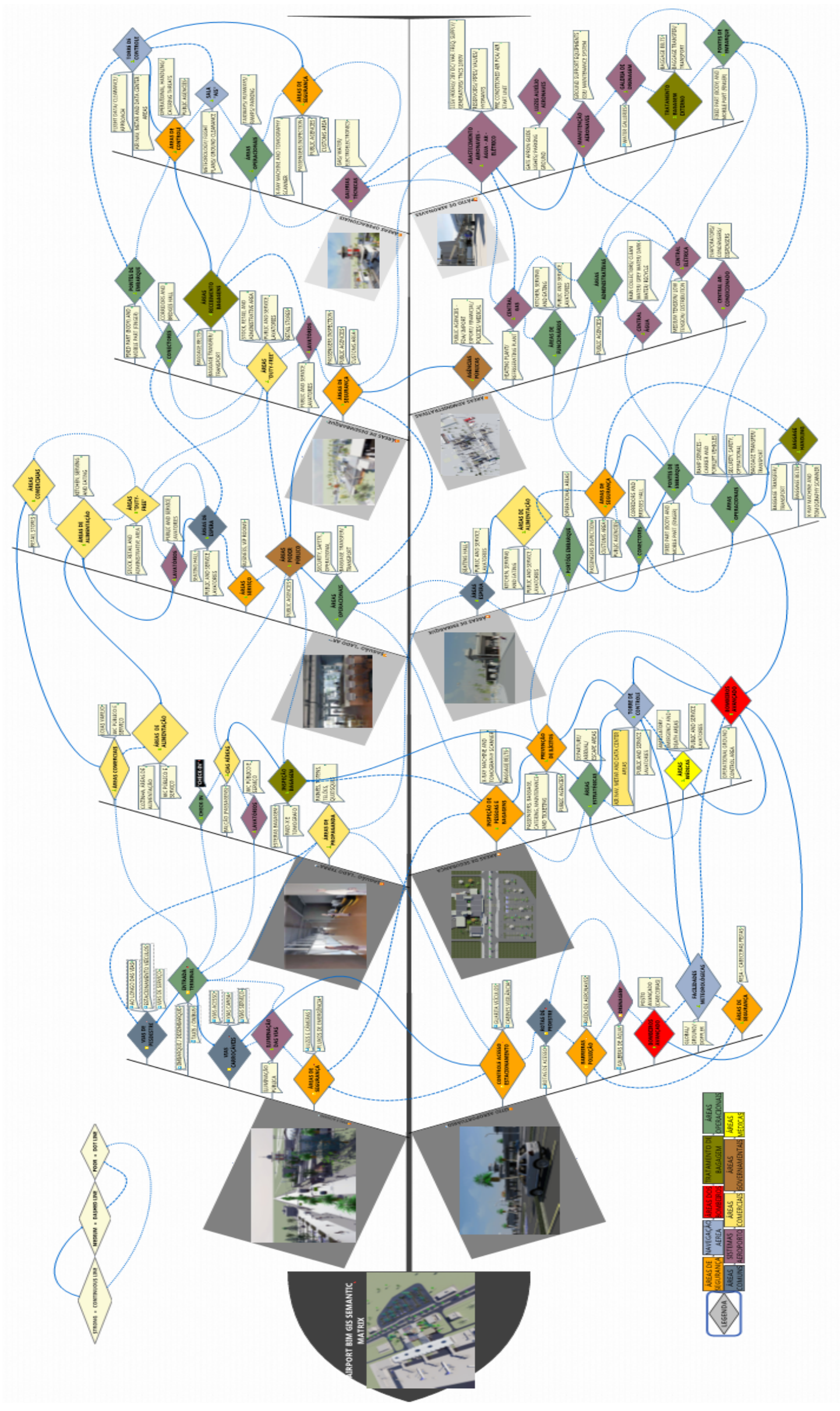




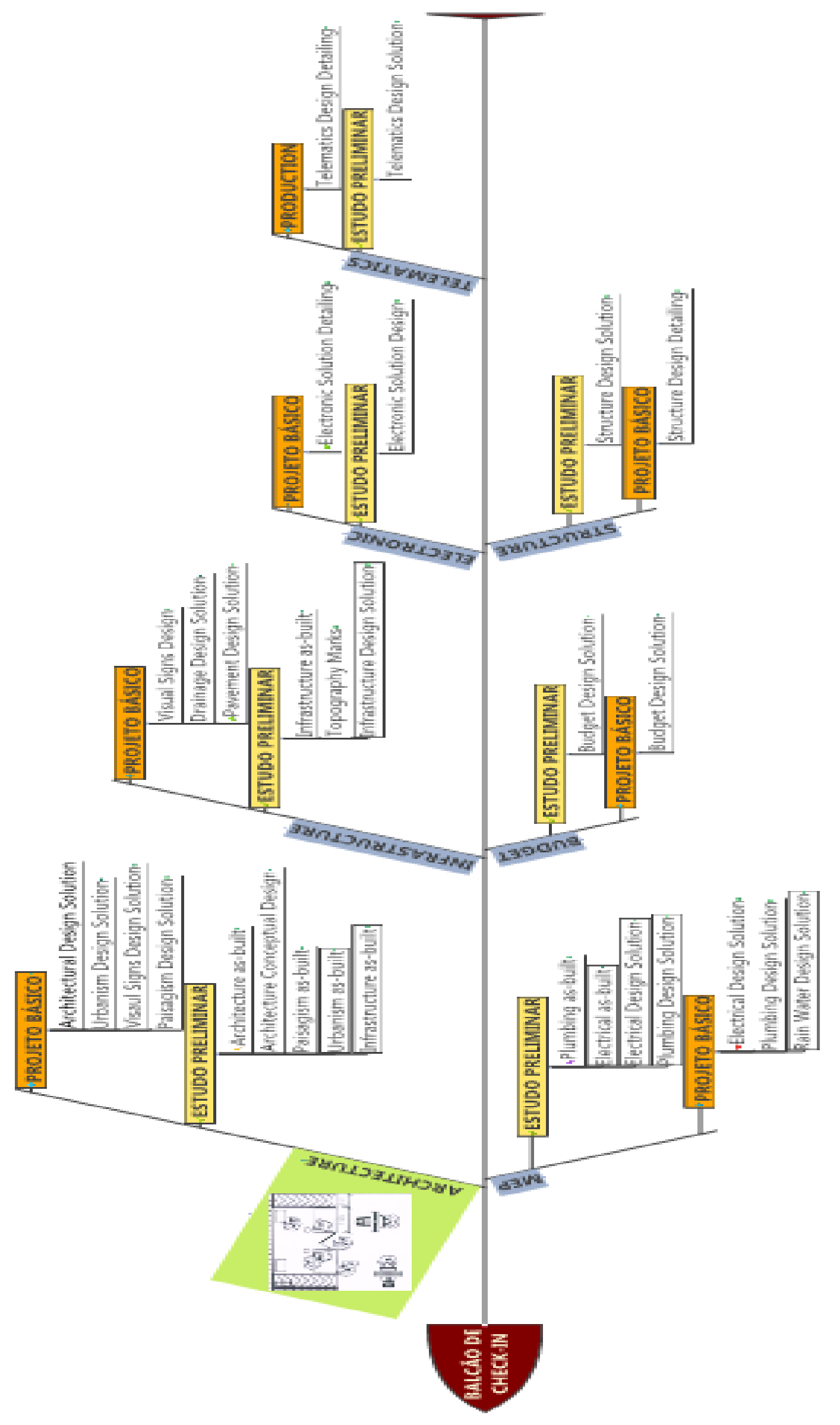




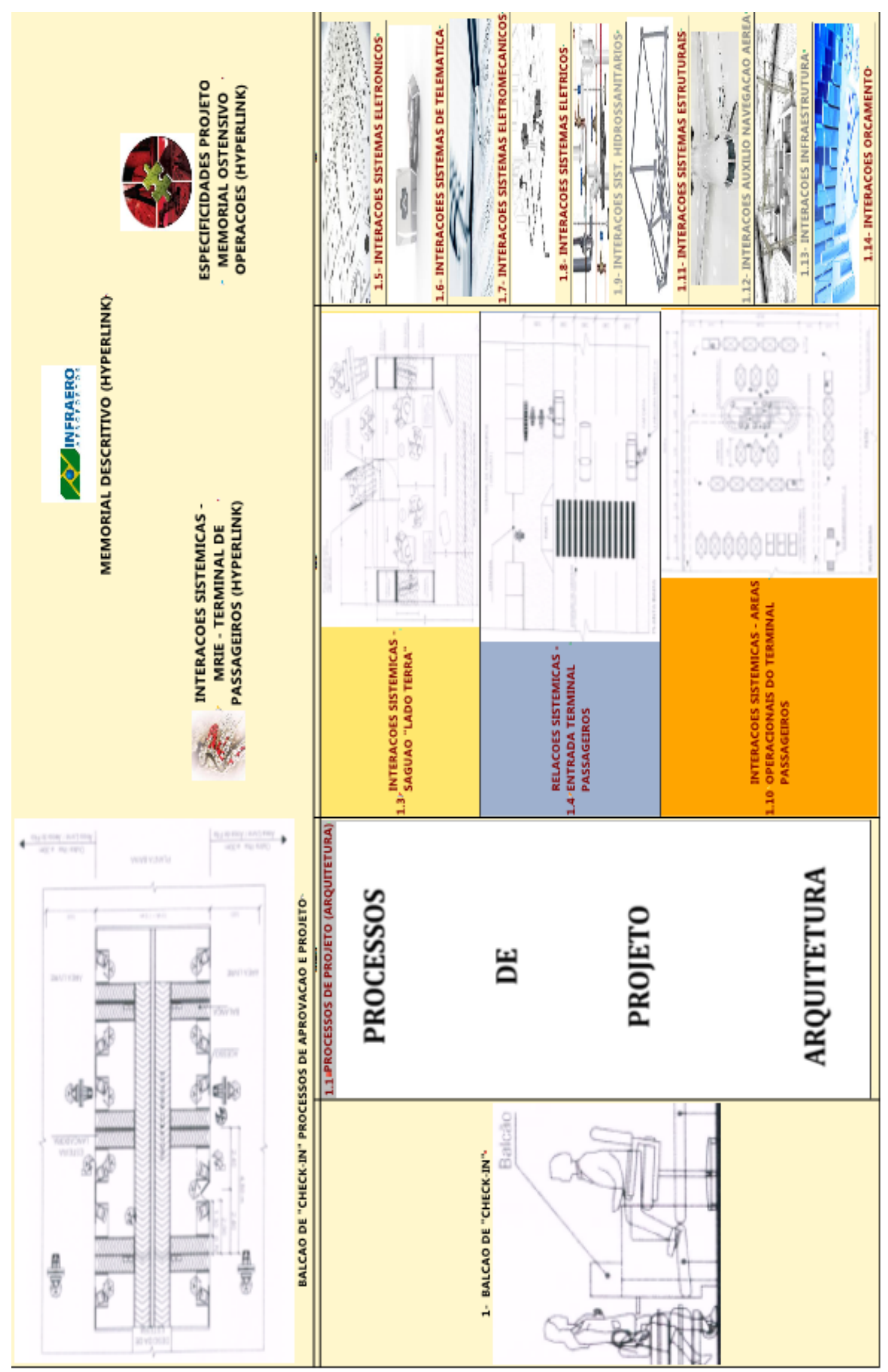




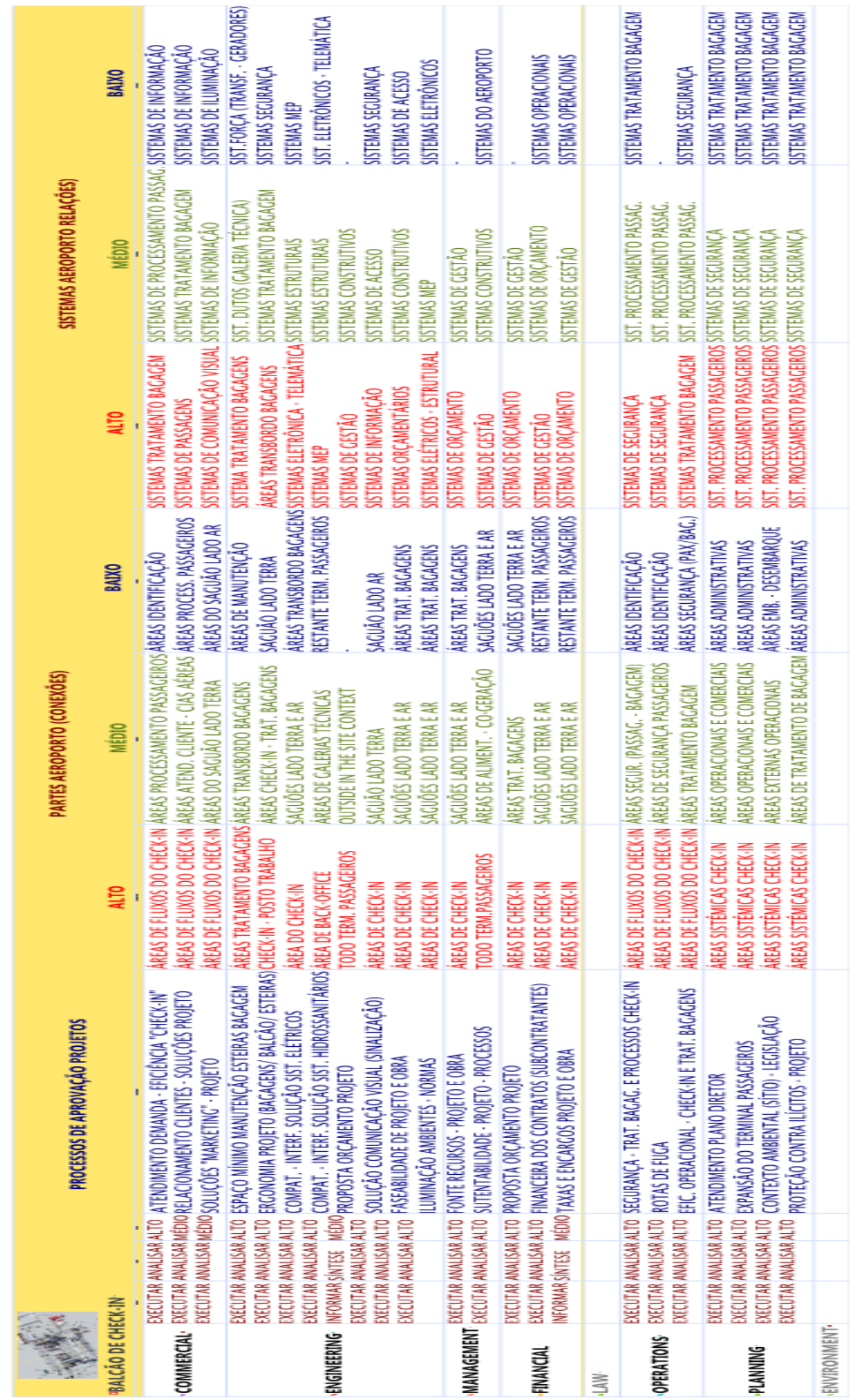




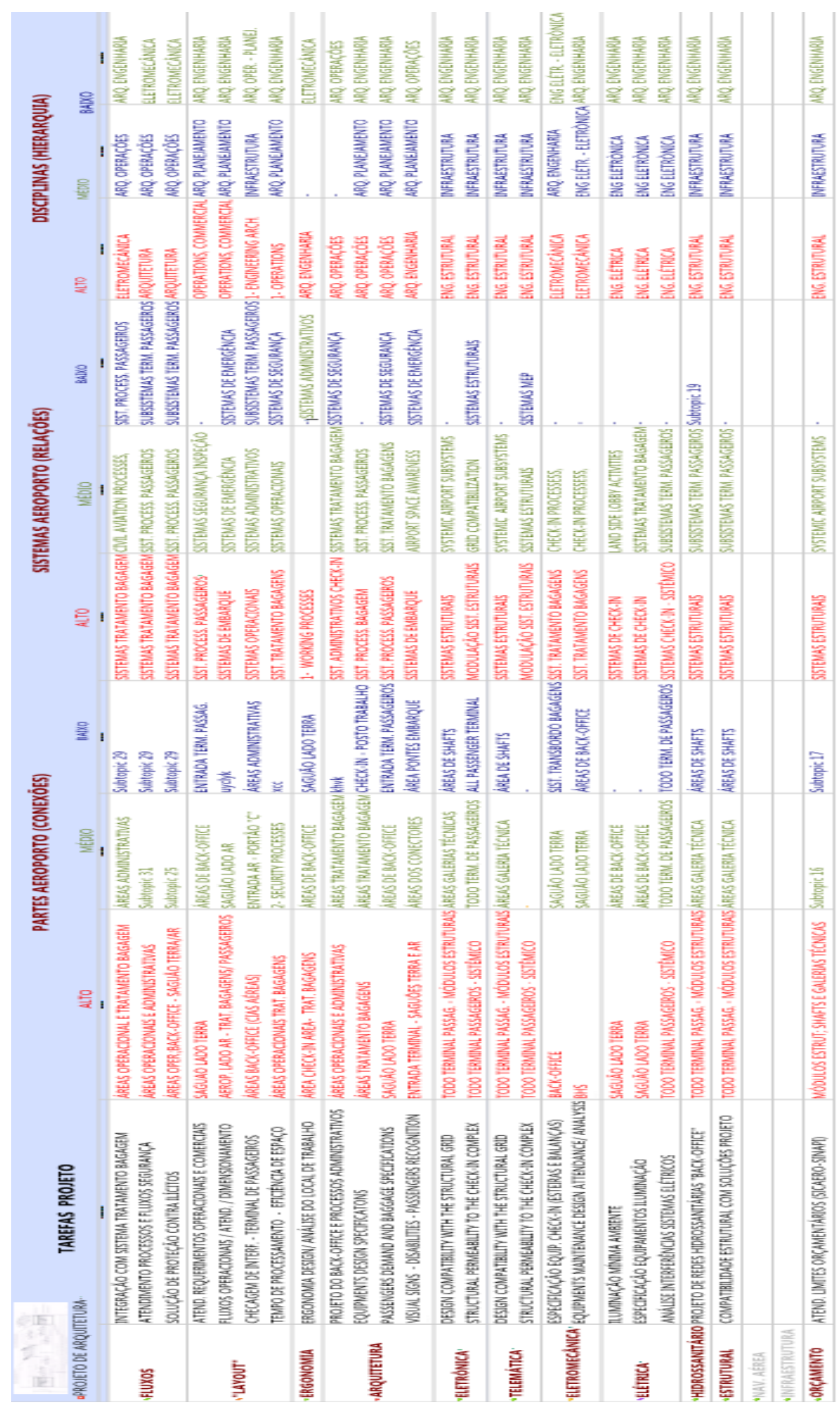




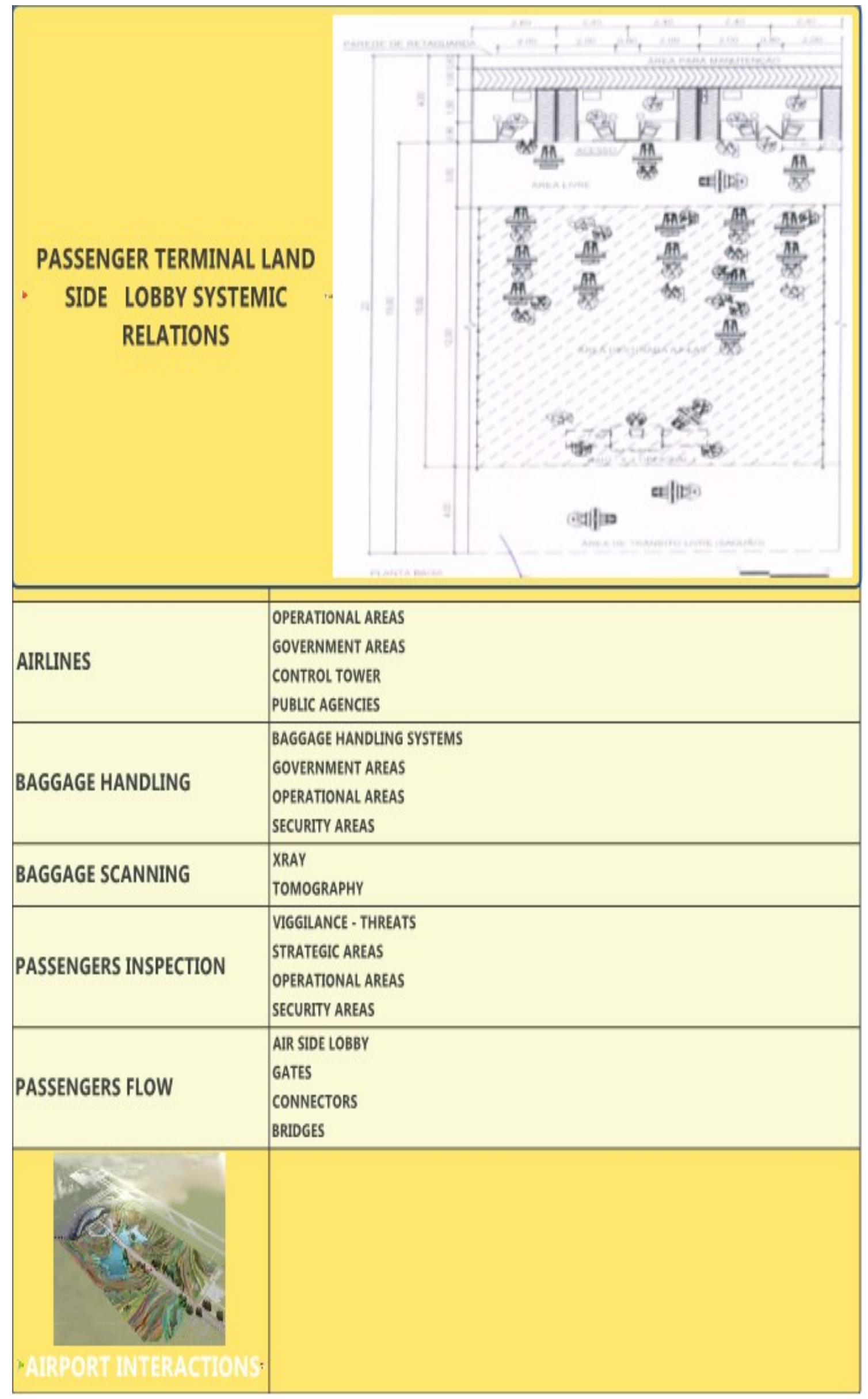




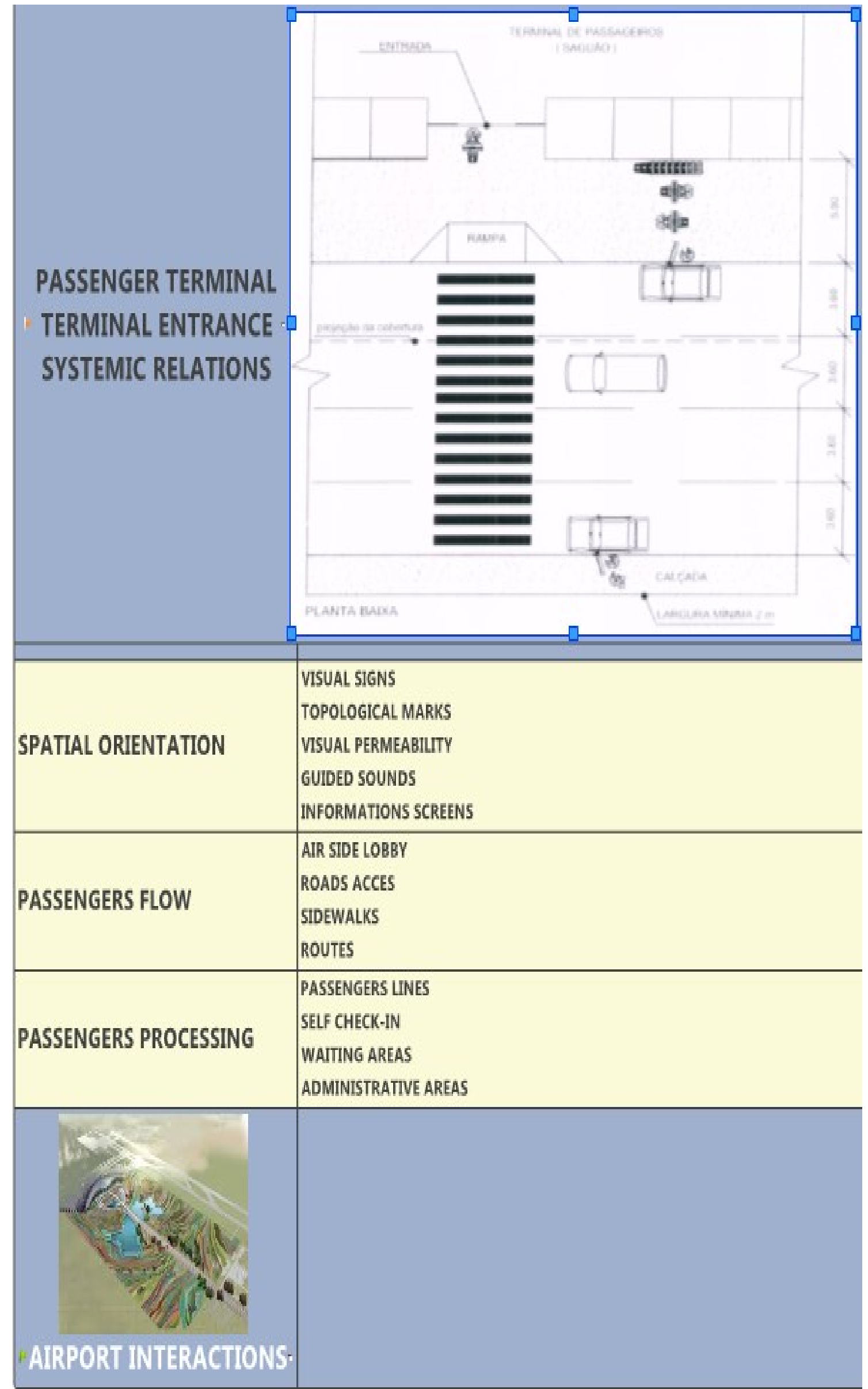




\begin{tabular}{|l|l|} 
PASSENGER TERMINAL \\
OPERATIONAL AREAS SYSTEMIC \\
RELATIONS
\end{tabular}



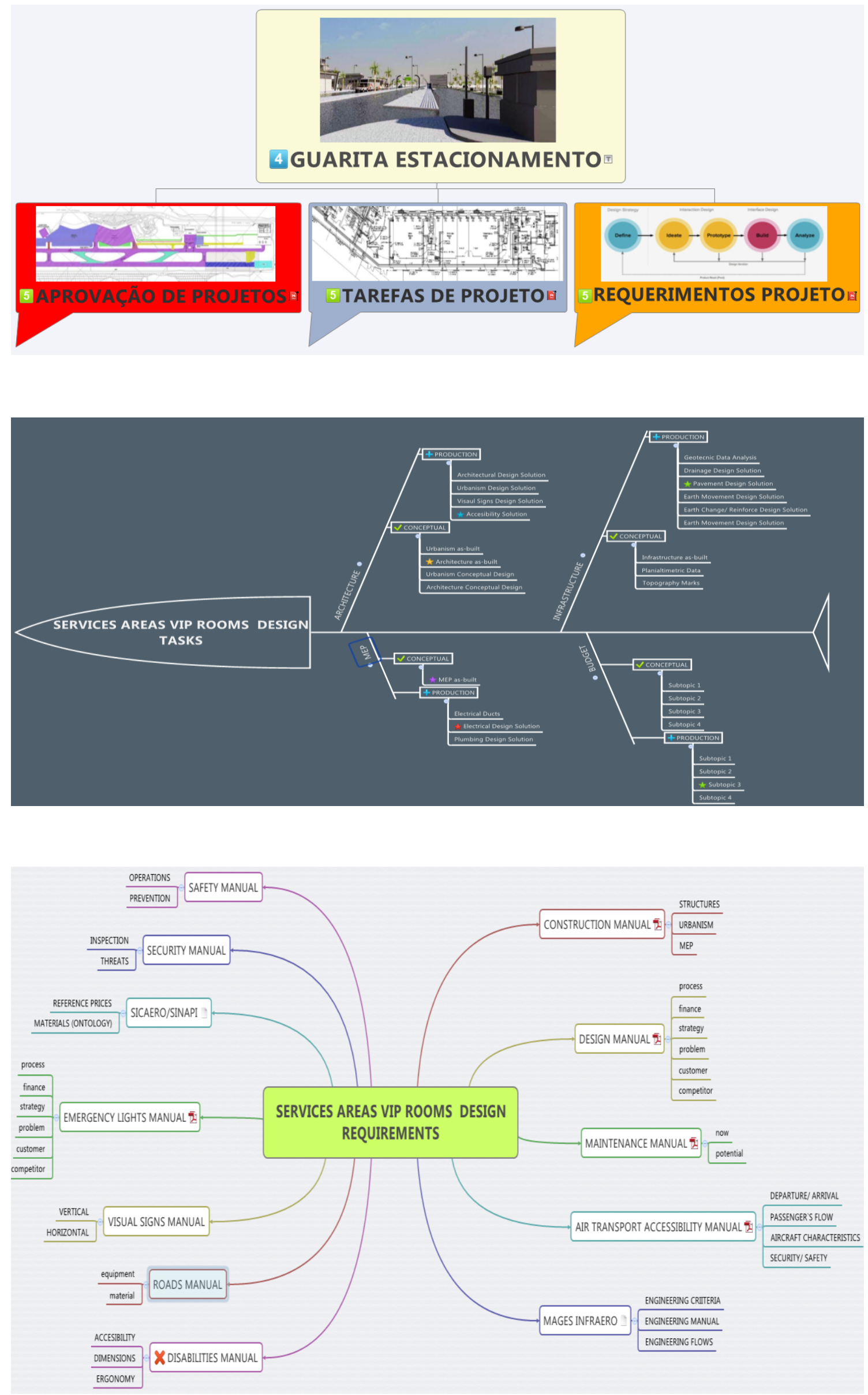


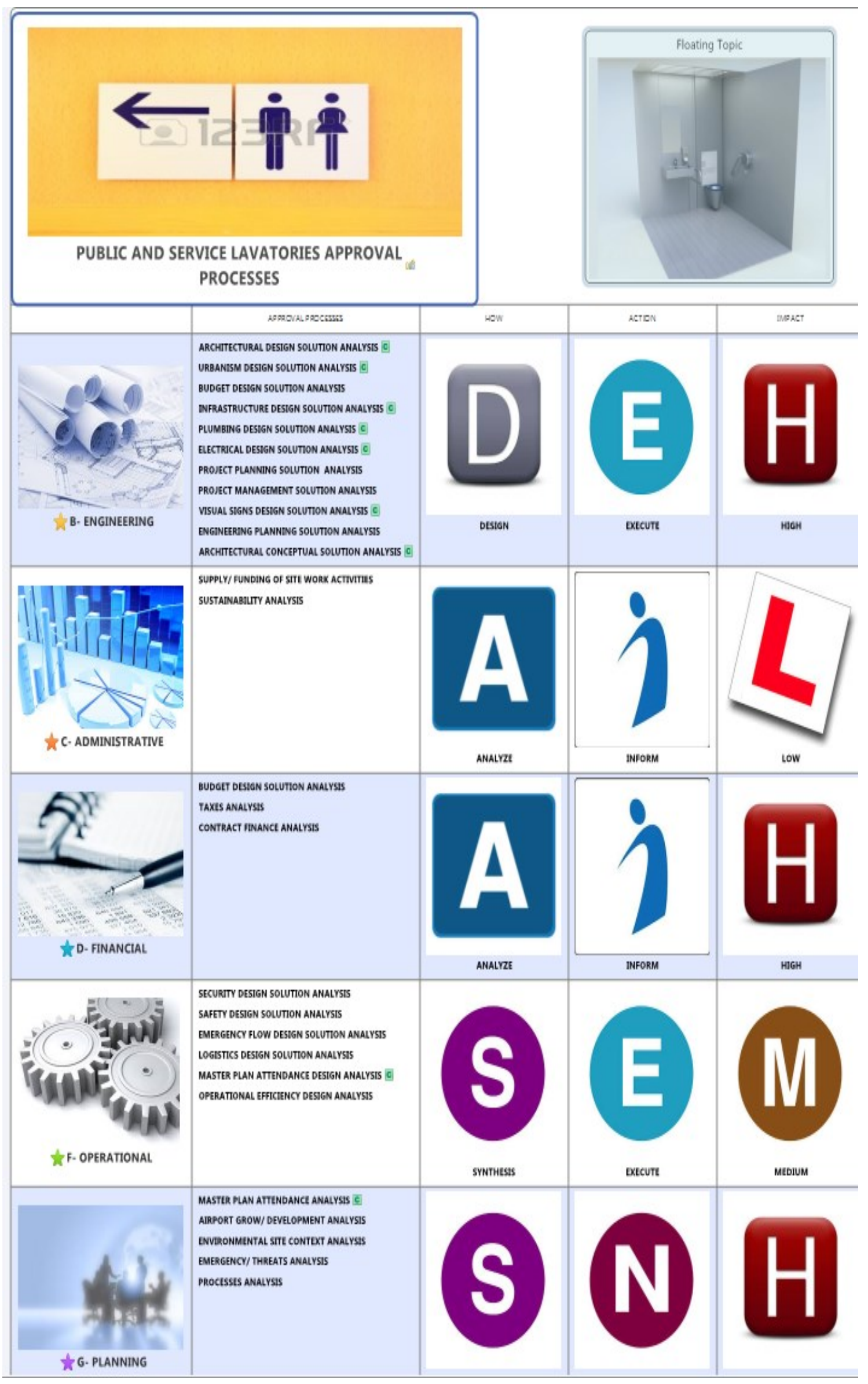




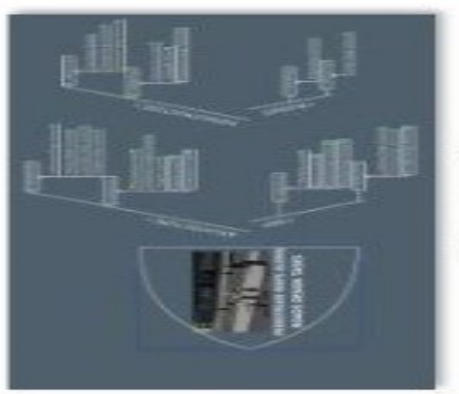

홈

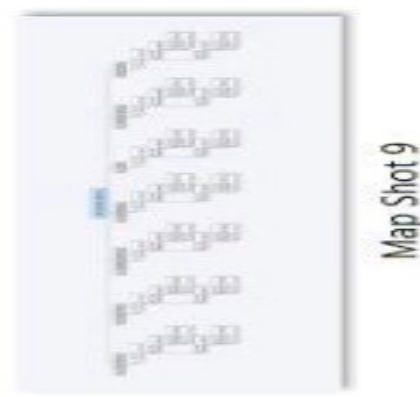

흔

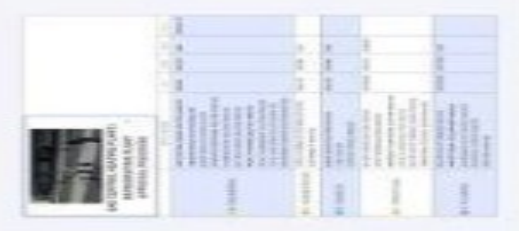

음
율
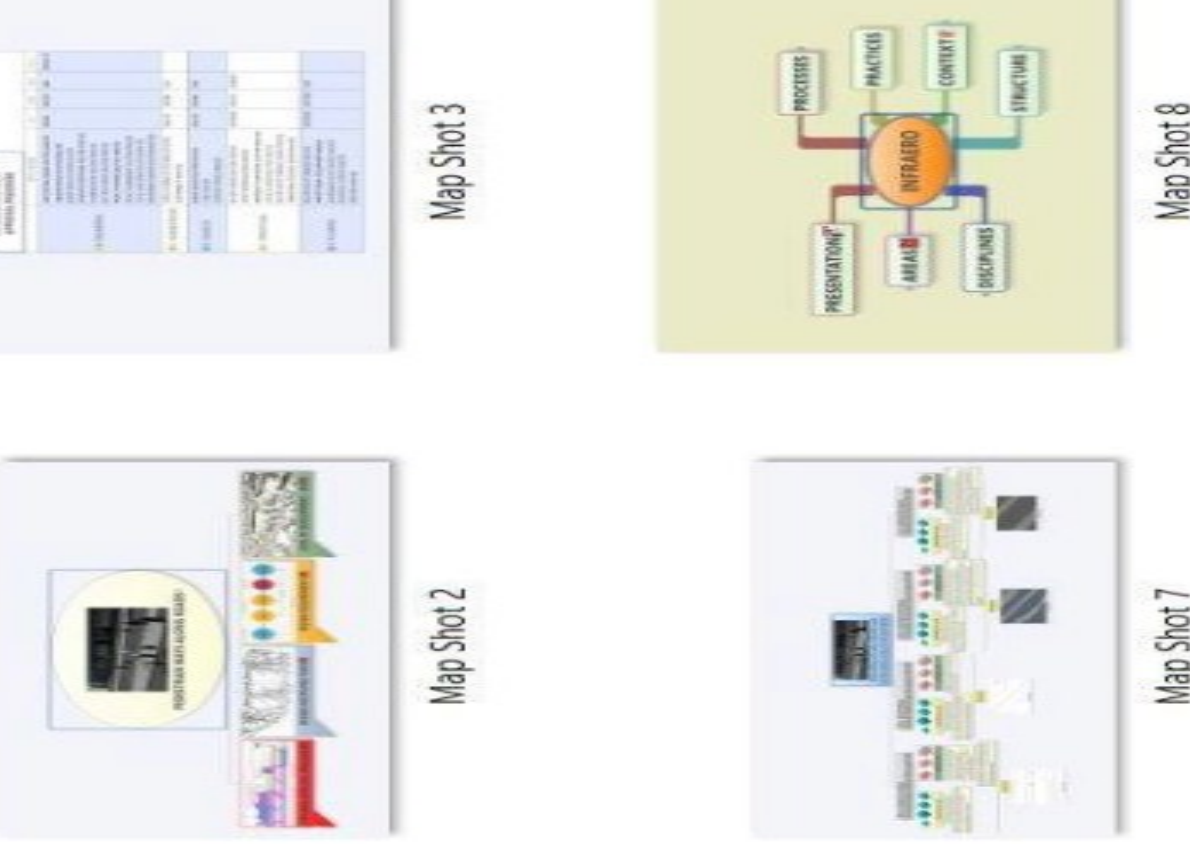

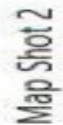
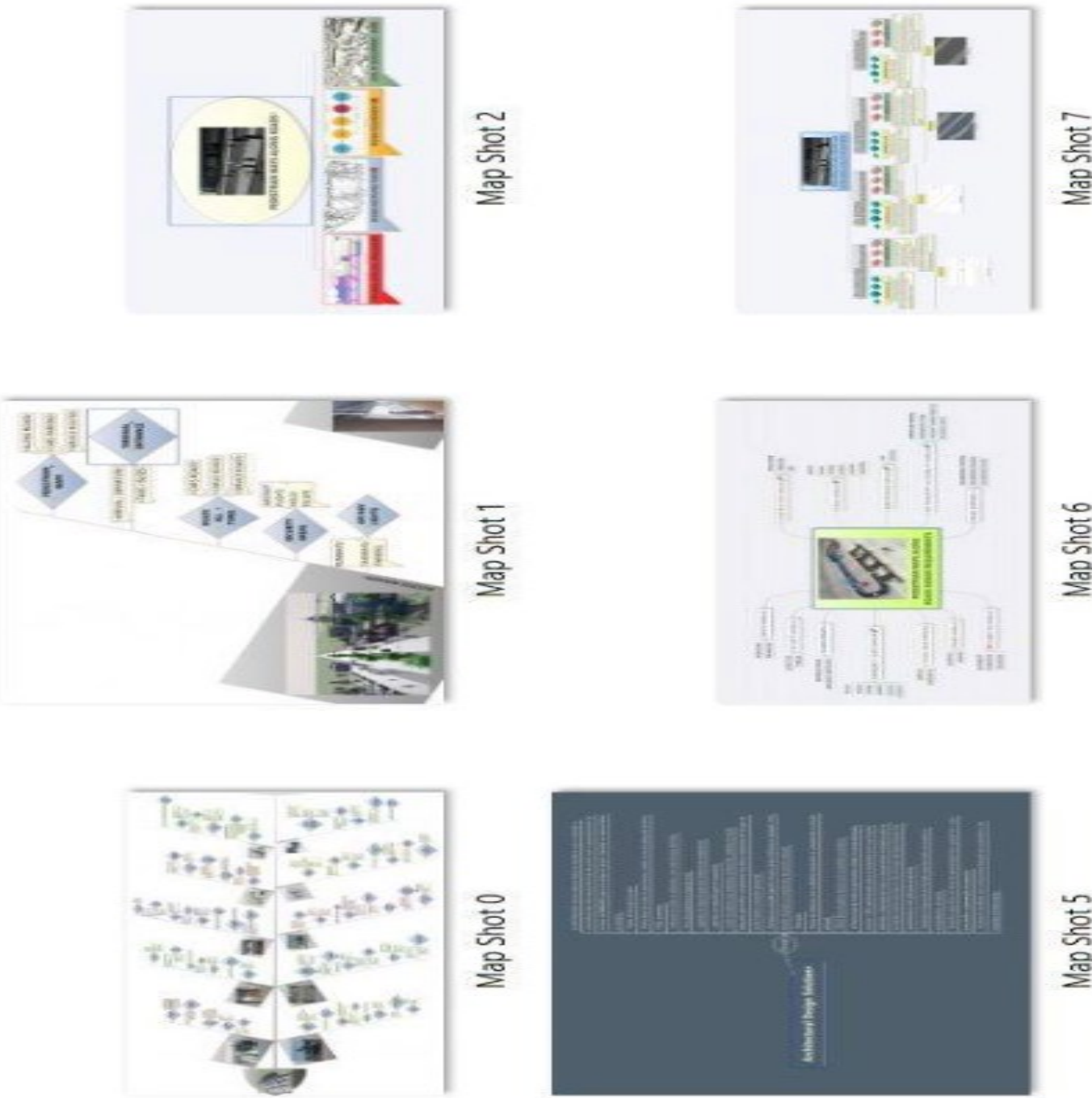

흘 


\section{CONFIGURAÇÃO DE RESPONSABILIDADES E TAREFAS}

As responsabilidades e tarefas nos processos de projeto da INFRAERO dividemse entre as atividades de projetação e de aprovação. Dois tipos de aprovação são possíveis: um no qual a própria área de engenharia analisa e realiza a tomada de decisão sobre alternativas (soluções propostas) de projeto. Outro no qual a área cliente a de engenharia atesta que as soluções de projeto escolhidas atendem aos requisitos de projeto.

Da mesma forma, engenheiros e arquitetos das diferentes especialidades podem atuar tanto nos processos de projetação como de aprovação, representando diferentes áreas da empresa e interagindo entre si. Imaginamos que pela natureza sistêmica e de planejamento operacional, as áreas de Operações e de Planejamento devam assumir a gestão do ambiente SIG na INFRAERO, estabelecendo uma base compartilhada de informações espaciais, podendo informar sobre relevo, recursos hídricos e geológicos, infraestrutura, vegetação, vias de acesso e toda sorte de informação que vai da escala local até a escala regional.

Esta base de dados pode servir para suporte aos processos de cadastramento, inserção do aeroporto na malha urbana, conexão e/ou inversão de fluxos, gestão do "Plano Diretor do Aeroporto", entre outros. As áreas de Engenharia e de Gestão da INFRAERO apresentam forte vocação para gerir os Sistemas BIM, de forma a distribuir as informações e conhecimento das equipes de projeto em torno dos empreendimentos e projetos da empresa.

O encontro entre os dois sistemas, BIM e SIG, ocorreria de forma concatenada, através de processos de aprovação e projetos compartilhados e simultâneos, em oposição aos atuais processos, lineares e redundantes. As conexões possíveis entre os profissionais da INFRAERO, amparadas por uma base de conhecimento comum, podem ser suficientemente fortes para transformar o grau de maturidade da empresa.

O somatório de conhecimento entre os profissionais poderia alimentar de forma constante, dicionários ontológicos e bases semânticas. Isto permitiria a organização da informação de forma modular e ainda o reuso da mesma. As possíveis utilizações da matriz no ambiente de trabalho da INFRAERO dizem respeito à coordenação e compatibilização de projetos, bem como a gestão do processo de projeto. Esta matriz foi desenvolvida no nível de informação referente aos conjuntos funcionais de um aeroporto e apresenta, portanto, toda a informação relevante para cada parte do aeroporto, trazendo "significado" do ponto de vista do processo de projeto. 
Sua utilidade reside na identificação precisa dos níveis de abstração envolvidos na informação atrelada ao modelo e ainda nas características do detalhamento geométrico dos componentes. Permite ainda comparar informações simultâneas entre diversas partes e associar sua realização numa linha de tempo, através de gráficos de "Gantt".

A INFRAERO necessita fomentar um ambiente colaborativo de projeto, através do uso da tecnologia associado ao potencial humano de suas equipes de trabalho. As experiências adquiridas nestes processos ditarão as normas e os padrões, protocolos e práticas profissionais que poderão ser internamente criadas, testadas e avaliadas, para então serem formalizadas na documentação contratual de contratação de projetos pela empresa. A investigação de diferentes soluções de projeto e a representação de contextos e conexões com diferentes variáveis torna os estágios iniciais de projeto processos multidisciplinares por natureza.

Lembrando BREITMAN (2005, p. 44), as ontologias "[...] servem para estruturar e compartilhar conhecimento, não para representar inteligência." Neste sentido o papel da ontologia num ambiente de projeto de aeroportos, é fornecer um padrão para o compartilhamento da informação, fornecendo um modelo comum que permita aos participantes trocar informações de modo significativo. Os esforços para a realização de uma matriz de informação buscam aprimorar a definição semântica, ou de significado, organizando os módulos funcionais do aeroporto em uma linguagem padronizada.

A futura definição de ontologias no ambiente INFRAERO podem servir de vocabulário controlado, porém flexível, a fim de que os conceitos de projeto sejam perfeitamente definidos e compartilhados entre as equipes de projeto, permitindo a adição de semântica aos requisitos e condicionantes previamente estabelecidos.

Duas questões necessitam de atenção, para permitir não apenas digitalizar o ambiente de projeto da INFRAERO, mas organizar a informação dispersa entre as diversas áreas e profissionais das diferentes disciplinas de projeto em um conjunto semântico de conhecimento: a caracterização dos modelos paramétricos para o ambiente organizacional e de gestão e ainda uma ferramenta de auxílio ao processo de projeto (matriz semântica) que forneça regras de abstração para os mesmos.

Esta caracterização da estrutura de dados da empresa parte do princípio de que o significado e a importância contextual de cada componente construtivo, ou modulo funcional de um aeroporto possa variar de importância e de significado relativo ao andamento do projeto e as soluções e prioridades envolvidas. 


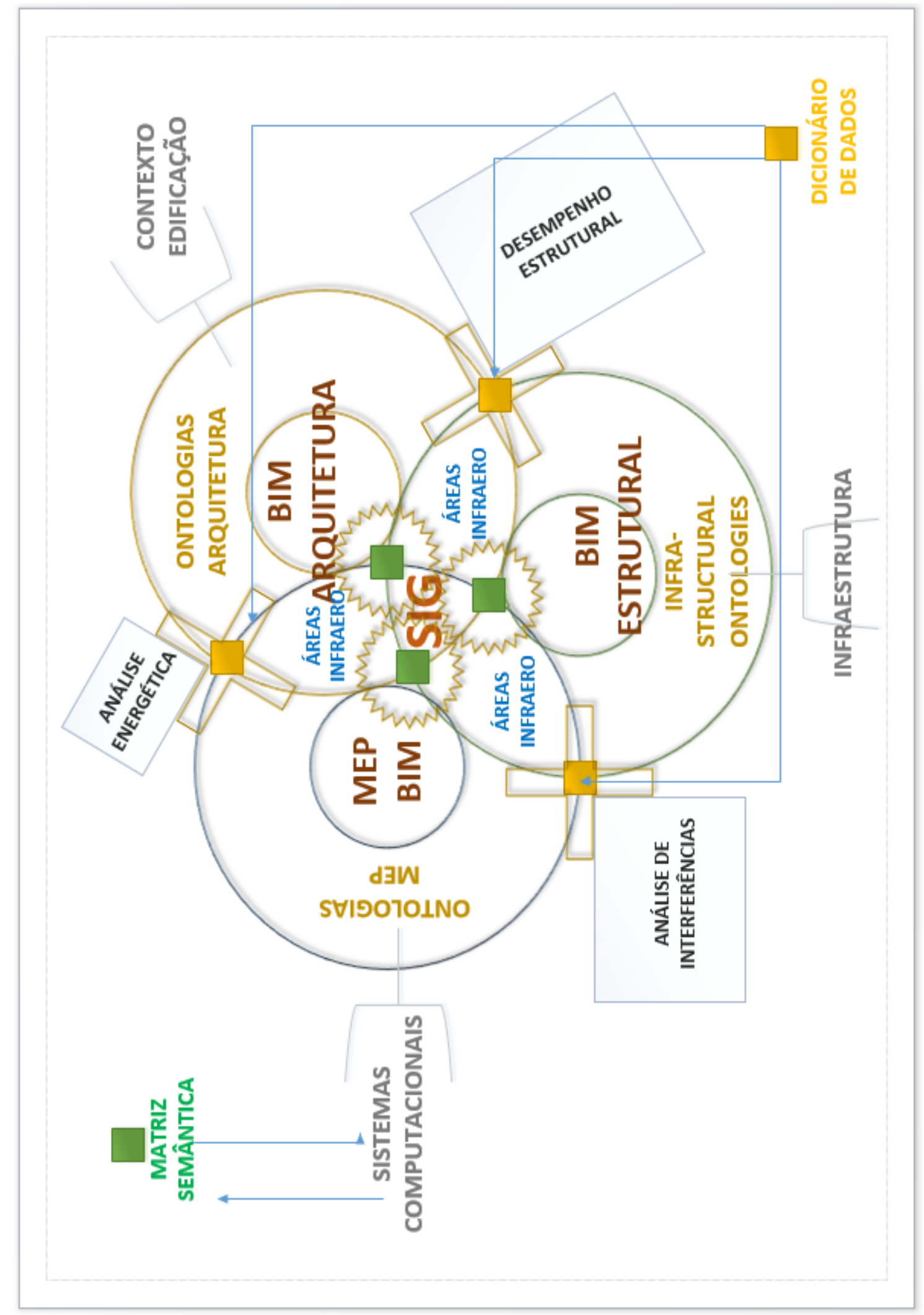

Figura VI- Processo de Projeto BIM - SIG na INFRAERO.

A Figura VI acima detalha a organização do processo de projeto que se utiliza dos Sistemas BIM e SIG para o provimento de infraestrutura aeroportuária na INFRAERO. 
No centro do processo encontram-se as atividades relacionadas com o ambiente SIG, pois dali surgem as alternativas e os estudos conceituais sobre a infraestrutura que cerca a edificação e o entorno imediato face às diferentes alternativas ou soluções de projeto. As diferentes especialidades de projeto ("MEP", Arquitetura, Infraestrutura, entre outras) atuam em conjunto com as áreas da INFRAERO, integrando os processos de projetação e aprovação, através da análise conjunta das alternativas e possíveis soluções de projeto. A interface entre o ambiente SIG e as equipes de projeto ocorre através do sistema de suporte ao processo de projeto, chamado de matriz semântica, provendo informações precisas sobre o nível de detalhamento dos componentes construtivos, escopos e tarefas nas diferentes fases de projeto e ainda a conexão entre as responsabilidades e os módulos funcionais de um aeroporto. Representando os campos de conhecimento de cada área de projeto (como sistemas, infraestrutura e o contexto do edifício) estão os domínios ontológicos definidos segundo parâmetros e regras mínimas e relevantes para a comunicação eficiente da informação associada. $A$ matriz atua como um tradutor e filtros, de informação, que podem variar em nível de detalhe e abstração para um mesmo componente construtivo. Devido ao porte da INFRAERO, não apenas em relação à complexidade dos projetos que a empresa executa, mas sobretudo em função de sua estrutura organizacional, o uso da tecnologia representa a solução e o desafio dos tempos atuais. A revisão e melhoria dos processos em voga na empresa são pré-requisitos para que seja possível extrair os melhores benefícios em sua utilização. Portanto, a investigação prévia sobre os impactos que o uso dos sistemas BIM e SIG trará à estrutura organizacional da INFRAERO pode facilitar a eventual adoção desses sistemas e ainda indicar os melhores caminhos para a transformação interna da empresa.

Ao investigar o processo de projeto de um aeroporto da INFRAERO com uso dos sistemas BIM e SIG foi possível identificar áreas sensíveis, que poderiam evidenciar os resultados positivos em sua utilização, como por exemplo a melhoria dos estudos conceituais e dos processos decisórios, amparados pela qualidade de análise em diferentes níveis de abstração, representados em contextos variáveis (entorno imediato). Essa diferença entre os objetos (entre seus significados semânticos) e as representações geométricas é bastante relevante, pois em ambos os sistemas - BIM e SIG - a linguagem deve ser a mesma em todos os níveis de abstração (a linguagem não deve distinguir o que ele descreve). A figura 41 demonstra que em todas as fases do processo de projeto existem atividades recorrentes de análise e de tomada de decisão, reunindo os campos cognitivo, intuitivo e semântico nestes processos. O nível de abstração é elevado nos estágios que antecedem os processos decisórios, pois requerem que múltiplas conexões e diferentes contextos sejam confrontados com o projeto. 


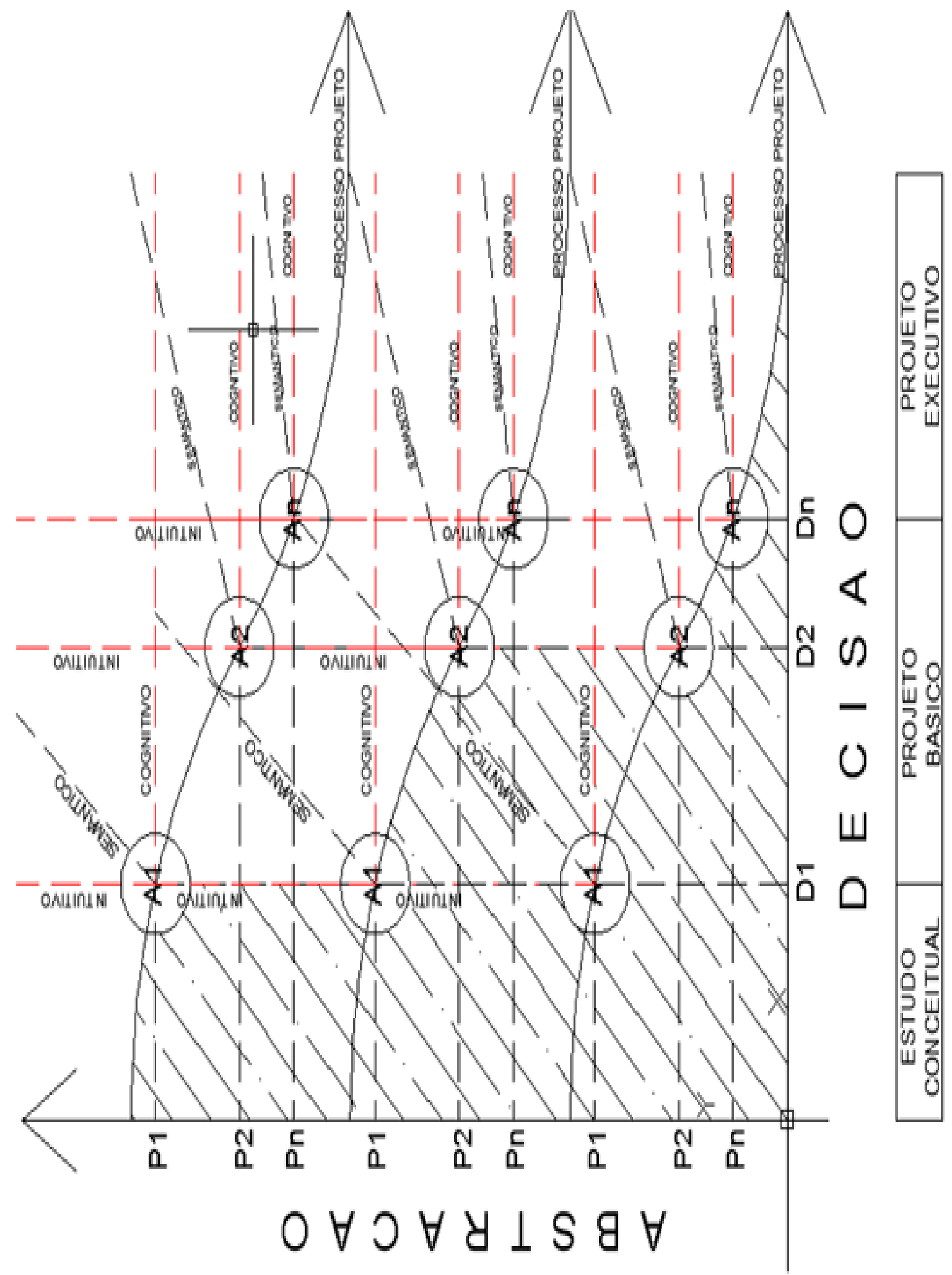

\begin{tabular}{|c|c|c|}
\hline 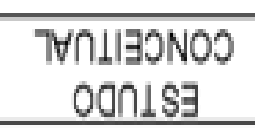 & $\begin{array}{c}\text { OOISVG } \\
\text { Olyroyd }\end{array}$ & 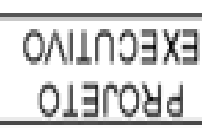 \\
\hline
\end{tabular}

Figura VII- Abstração e decisão nos processos de análise. 
A Figura VII, na página anterior, demonstra que, em todas as fases do processo de projeto, existem atividades de análise que se amparam nos aspectos cognitivos, ao relacionar as variáveis de projeto com seus aspectos semânticos, que traduzem o significado entre o mundo digital e o mundo real. Ao mesmo tempo, a experiência de cada profissional e dos componentes relativos ao julgamento pessoal encontram nos processos de intuição uma interface de proposição criativa. Ao relacionar abstração com decisão, a Figura VII estabelece uma associação entre a qualidade e o conteúdo da informação (abstração) manipulada e acessada em um projeto com a capacidade de tomada de decisão ao longo do processo de projeto. Os benefícios da utilização desta matriz vão além dos processos de projeto na INFRAERO, pois a mesma contribuiu para o processo de criação de componentes paramétricos, por meio de informação sobre os sistemas a que um determinado módulo funcional deverá se conectar, sobre quais partes do aeroporto estão implicadas e a identificação de requisitos referentes às disciplinas de projeto. A matriz também foi importante para nortear o processo de simulação de variação no nível de detalhe de tais componentes construtivos nos SIG, mais especificamente no "software" InfraWorks ${ }^{\circledR}$, da AutoDesk, mais especificamente, através da consulta aos requerimentos de projeto, de forma a ter informações sobre as descrições e escopos das fases de estudo preliminar e de projeto básico, servindo para embasar o grau de variação de detalhe exigido em cada uma delas.

Através da consulta à matriz, foi possível ainda identificar as possíveis conexões com sistemas e partes do aeroporto que os componentes exportados para o SIG apresentam, como por exemplo, um balcão de "check-in" possui forte ligação com o sistema de tratamento de bagagem e com os sistemas de inspeção e de segurança. Além de fornecer informações desse tipo, a matriz permite que se consulte sobre quais as áreas e quais processos estão envolvidos, bem como quais disciplinas e quais são as tarefas de cada uma delas, ajudando nos processos de análise, decorrentes da simulação entre o componente e seu contexto. A constituição de uma matriz de dados relacional e hierárquica permitiu a consulta sobre os componentes aeroportuários em termos de tarefas de projeto, requisitos, diferentes níveis de detalhe e sua implicação geométrica e semântica. Assim, a matriz poderá facilitar a adoção dos sistemas BIM na INFRAERO e auxiliar em sua conexão com os SIG. Nesse sentido, com foco nos estágios iniciais de projeto, a investigação das interfaces com o ambiente SIG pode favorecer as discussões entre as áreas e disciplinas sobre alternativas de projeto e os processos de tomada de decisão e de aprovação dos mesmos. Sugere-se que a utilização da matriz associada a uma planilha de controle de dados (como o Microsoft Project $\left.{ }^{\circledR}\right)$, por meio de gráficos de gráficos de "Gantt", de forma a oferecer maior controle sobre os processos envolvidos em cada uma das metas, além da realização $x$ tempo, atribuindo o impacto, o relacionamento e as responsabilidades nas atividades de gestão. 


\section{AVALIAR A CONTRIBUIÇÃO DA MATRIZ SEMÂNTICA DE REGRAS DE ABSTRAÇÃO NO PROCESSO DE PROJETO DO TERMINAL DE PASSAGEIROS REGIONAL, POR MEIO DE SIMULAÇÃO DE EXPANSÃO DO TERMINAL EXISTENTE (TWR)}

Existe uma correlação entre as áreas da INFRAERO e as disciplinas de projeto, assim como entre as normas e os requerimentos e os processos de aprovação de projetos. Cada área da empresa possui uma atribuição especifica dentro do sistema aeroporto. A área de operações responde pela segurança da aviação civil e de carga, além da integridade física dos passageiros, realizando ainda a fiscalização e o suporte à navegação aérea. A área de Engenharia responde pelo escopo de projetos e serviços de engenharia, incluindo as obras.

Obviamente, quando da realização de um projeto, cada área é responsável pela adequação do projeto a suas metas e objetivos. As disciplinas de projeto dividem-se entre as especialidades de projeto de arquitetura e de engenharias, perfazendo 0 somatório intelectual e de conhecimento técnico da empresa. A matriz integrou os dados, de forma a triangular as normas técnicas (requerimentos), tarefas de projeto e processo de aprovação de soluções técnicas, representando uma ferramenta que pode auxiliar na capacidade da INFRAERO de processar informações de projeto, elaborar soluções e aprová-las formalmente, frente aos requisitos necessários à futura certificação do aeroporto.

Os sistemas BIM oferecem uma interface digital entre as diferentes áreas da INFRAERO envolvidas no ambiente de projeto. A integração da informação entre as áreas, disciplinas e normas precisa acontecer em diferentes níveis semânticos. Por esta razão a matriz de dados foi configurada adotando essas dimensões como as características dos módulos funcionais descritos. A matriz semântica recebe este nome exatamente porque traz significado a cada parte funcional do aeroporto em relação às responsabilidades e aos impactos que isso traz ao ambiente de projeto.

A capacidade de diálogo entre as diversas áreas e disciplinas de projeto deve ocorrer em bases unificadas de conhecimento. Ou seja, precisa possuir uma sintaxe bem definida (ontologia) e uma gramática de conceitos (semântica) suficientemente especializada para abranger o escopo de todas essas áreas e disciplinas. A inserção na matriz de dados de informações sobre os módulos funcionais de um aeroporto proporciona uma fonte de consulta sobre como os parâmetros dos componentes se relacionam com os sistemas a que os mesmos devem se conectar e ainda sobre como esses parâmetros influenciam os próprios processos de projeto, dentro da empresa. Tais possibilidades podem ampliar ainda a percepção do domínio da arquitetura e de sua interação com as demais especialidades de projeto. 


\section{ANEXO III}

\section{COMPONENTES PARAMÉTRICOS AEROPORTUÁRIOS - BIM}




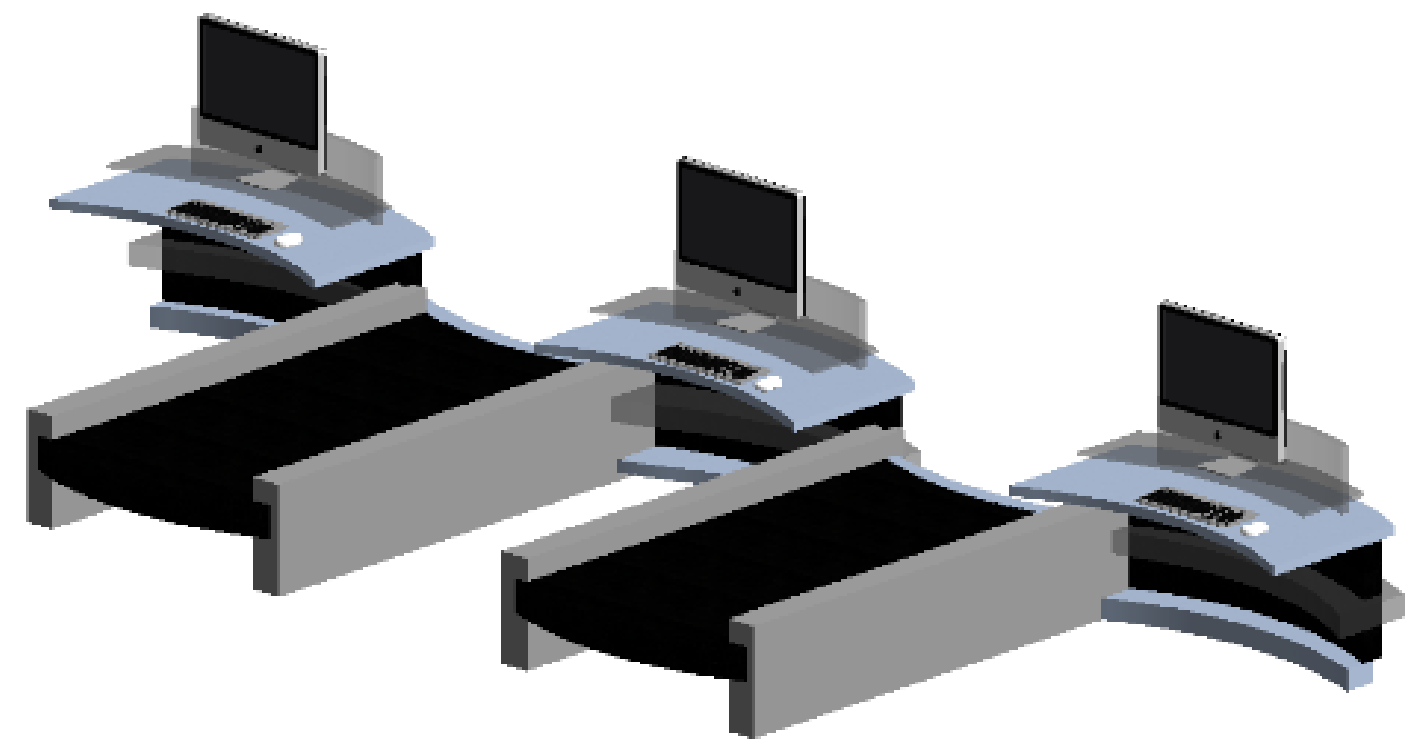

Balcão de Check-in de aeroporto. Fonte: autoria própria.

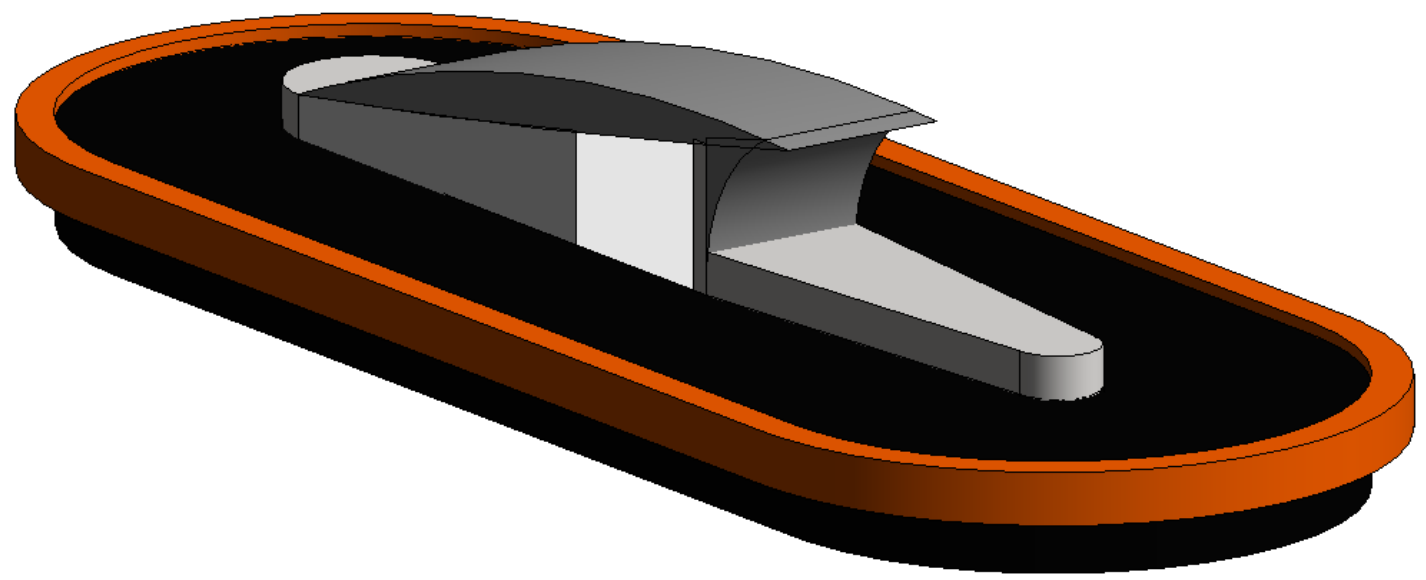

Esteira de Bagagem Desembarcada de aeroporto. Fonte: autoria própria

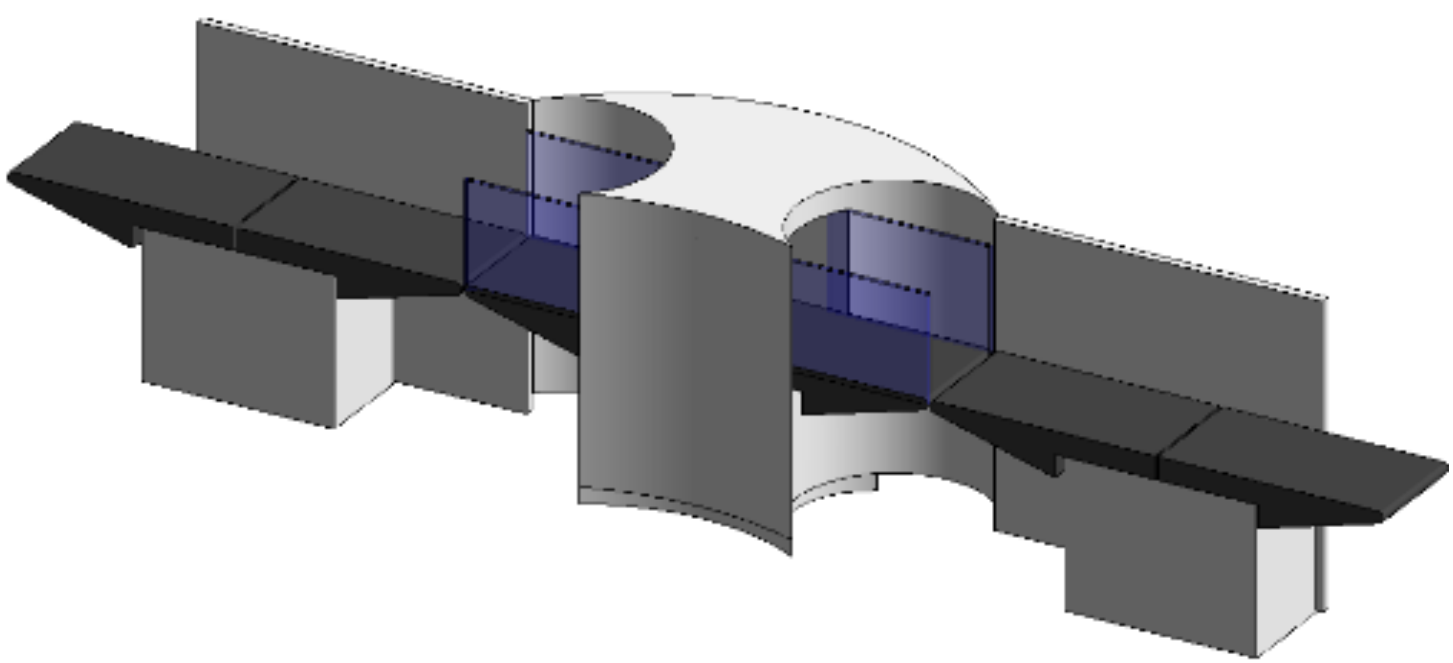

Raio-X de Bagagem Passageiro de aeroporto. Fonte: autoria própria. 


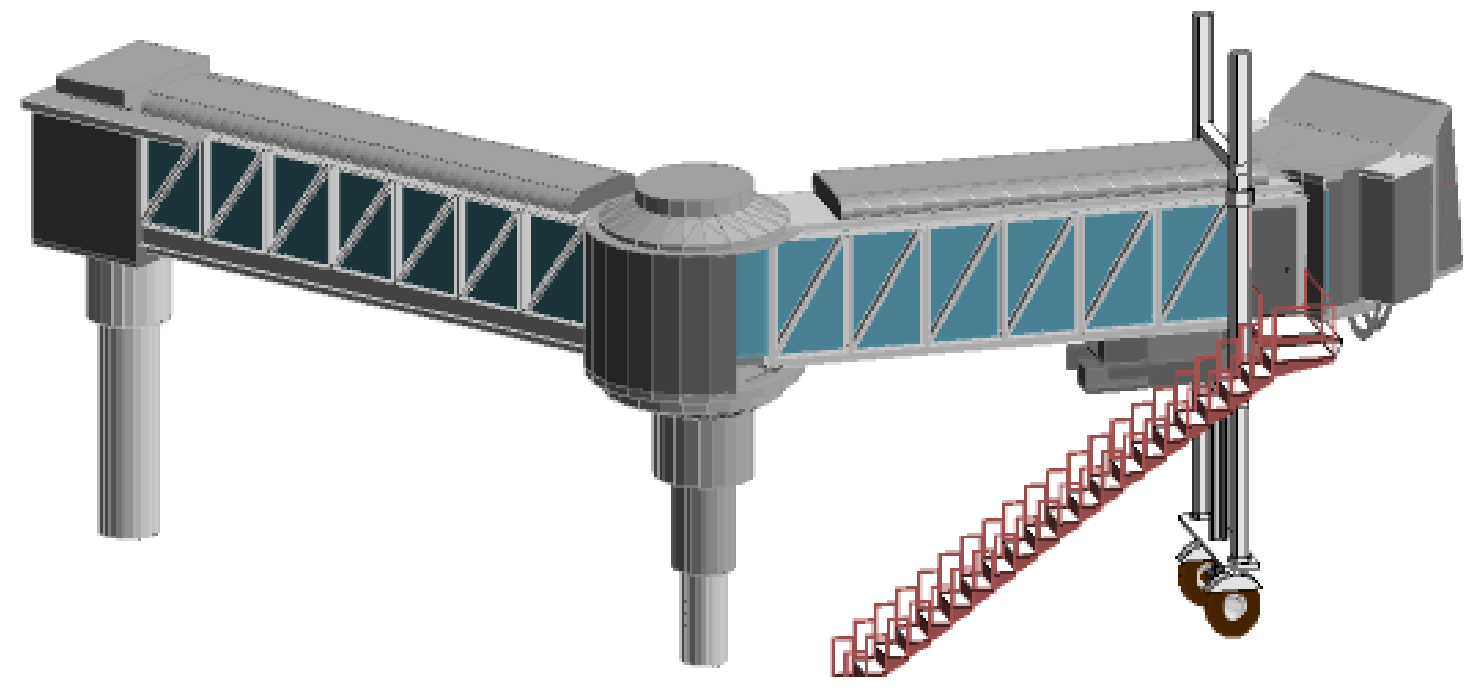

Ponte de Embarque de aeroporto. Fonte: autoria própria.

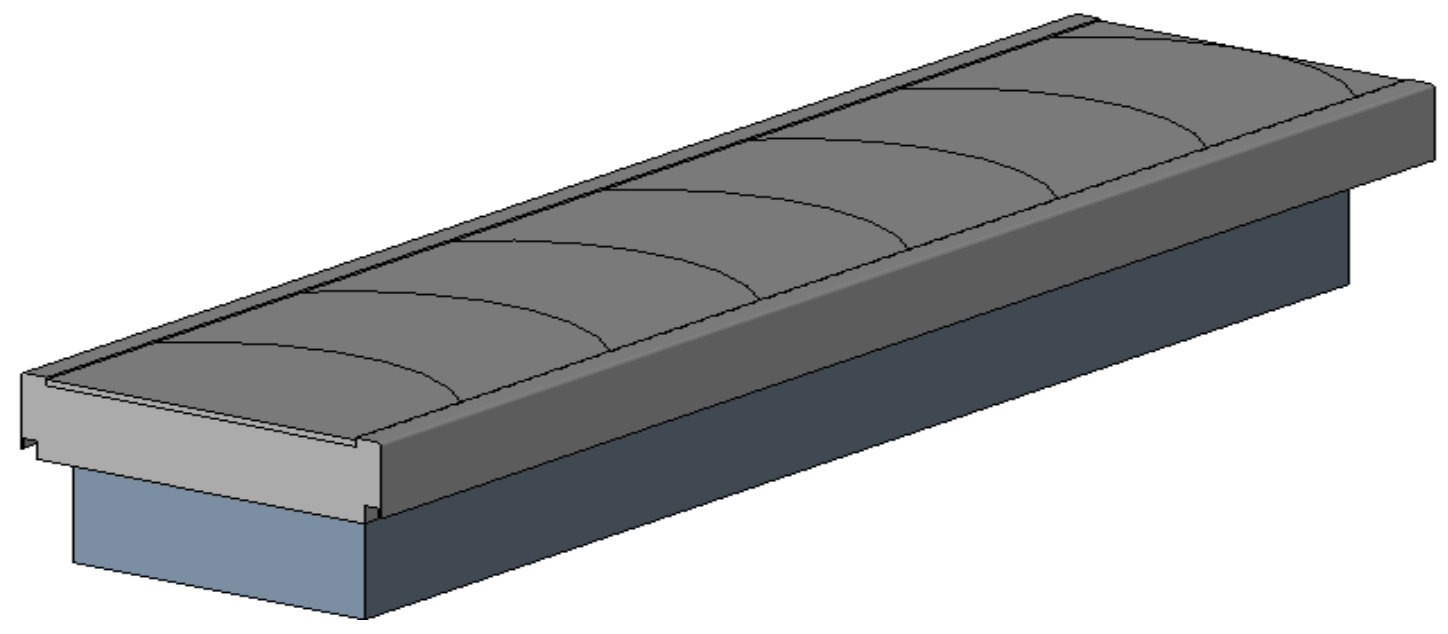

Esteira de Bagagem Geral de aeroporto. Fonte: autoria própria.
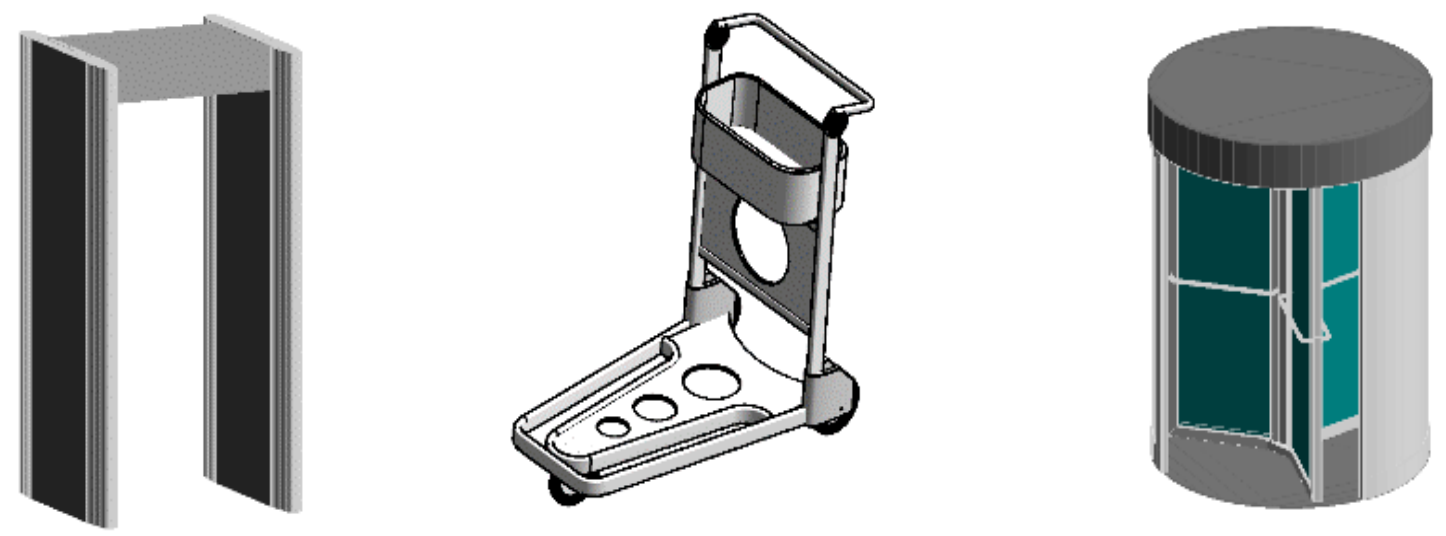

Pórtico, Carrinho e Porta Acesso de aeroporto. Fonte: autoria própria. 

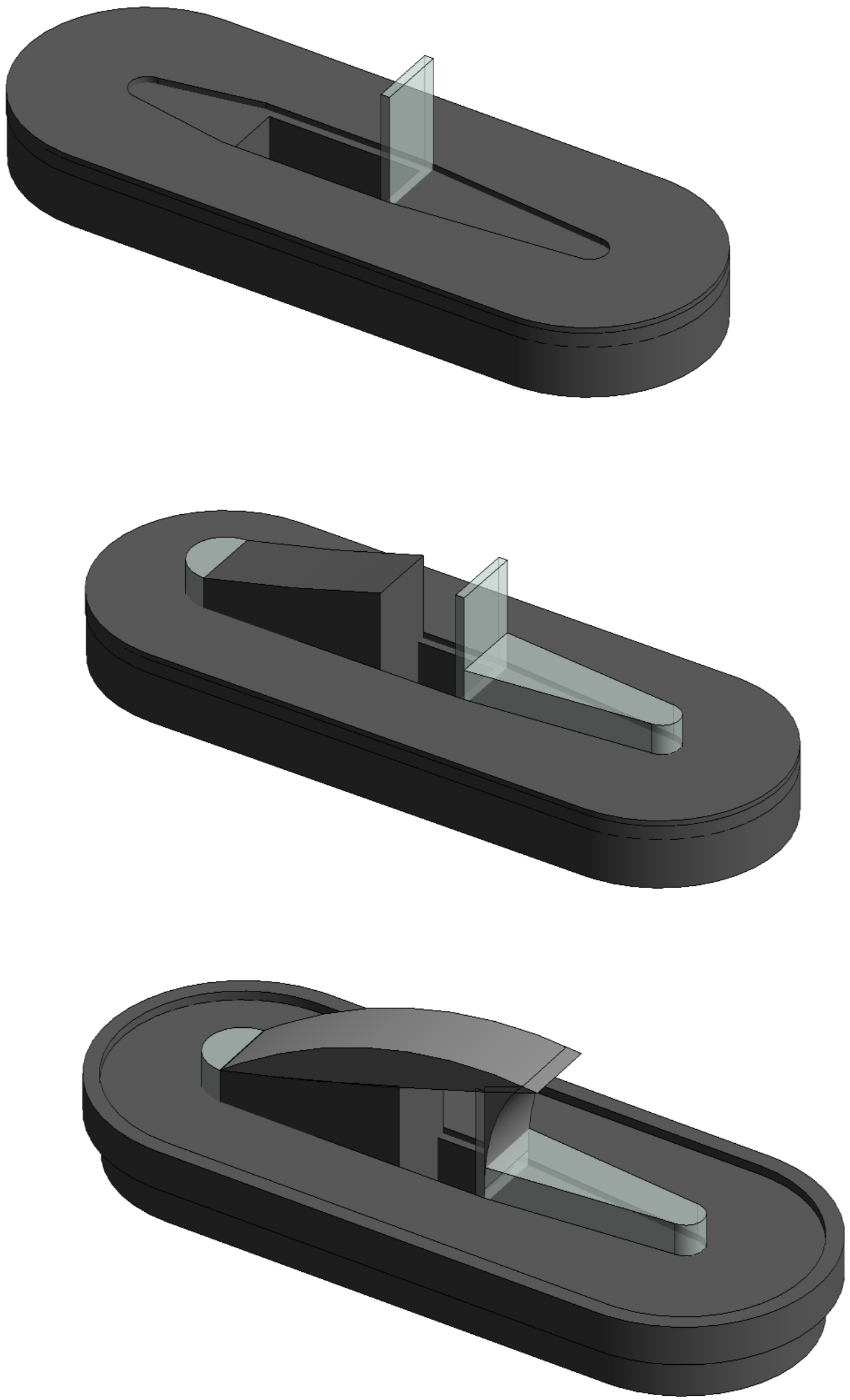

Diferentes graus de LOD nos sistemas BIM. Fonte: autoria própria. 


\section{ANEXO IV}

\section{COMPONENTES PARAMÉTRICOS AEROPORTUÁRIOS - GIS}



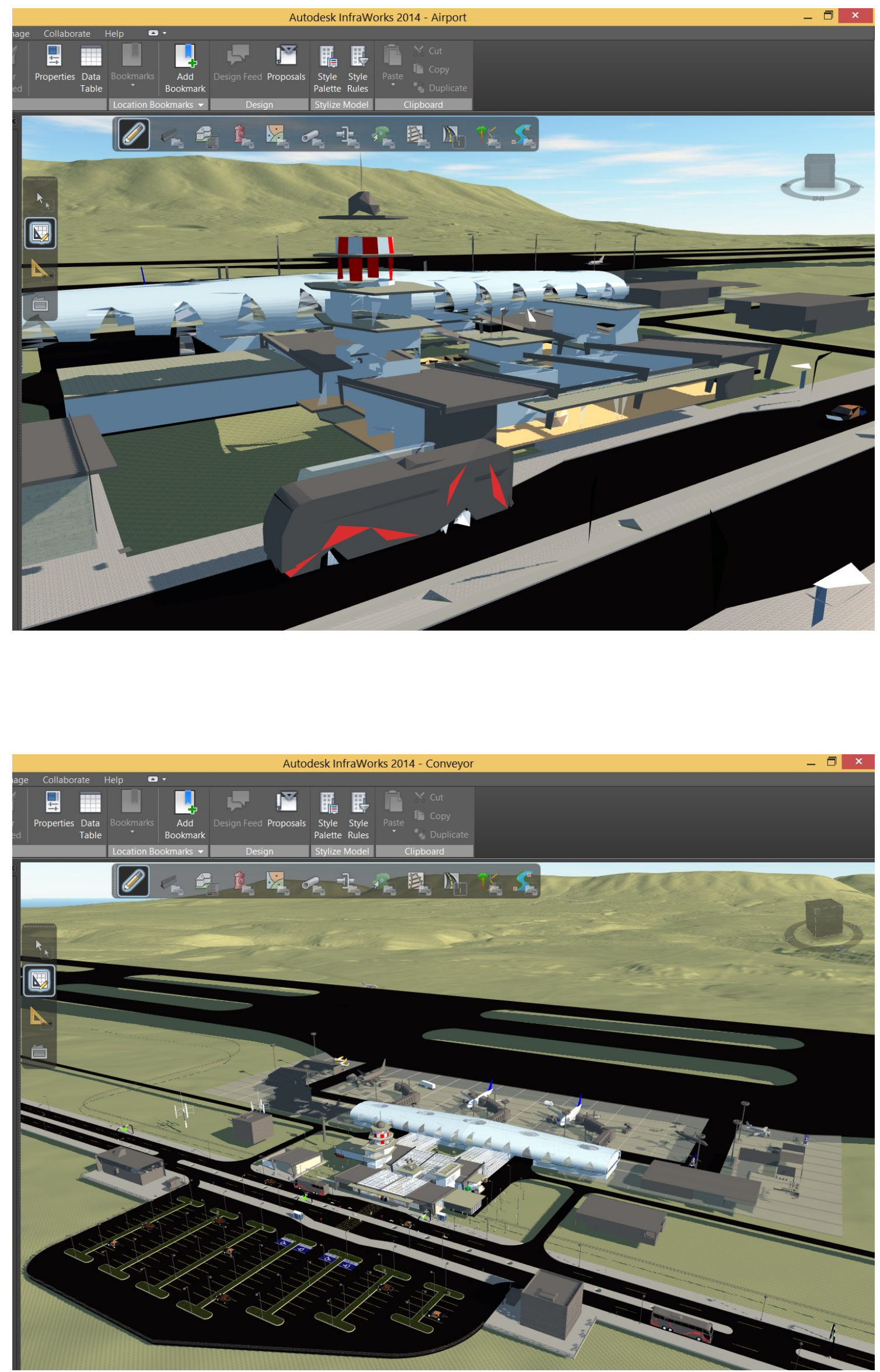

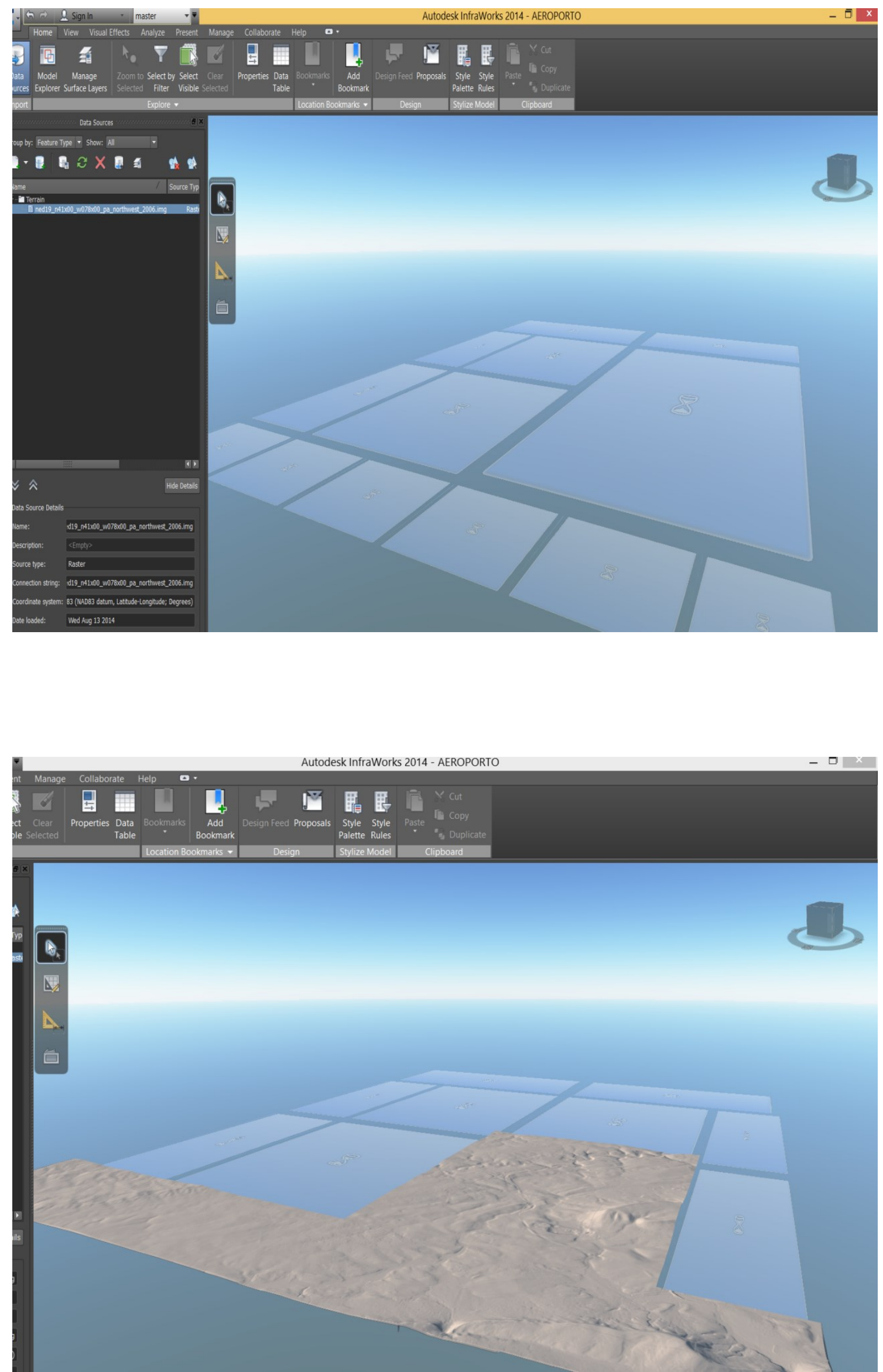

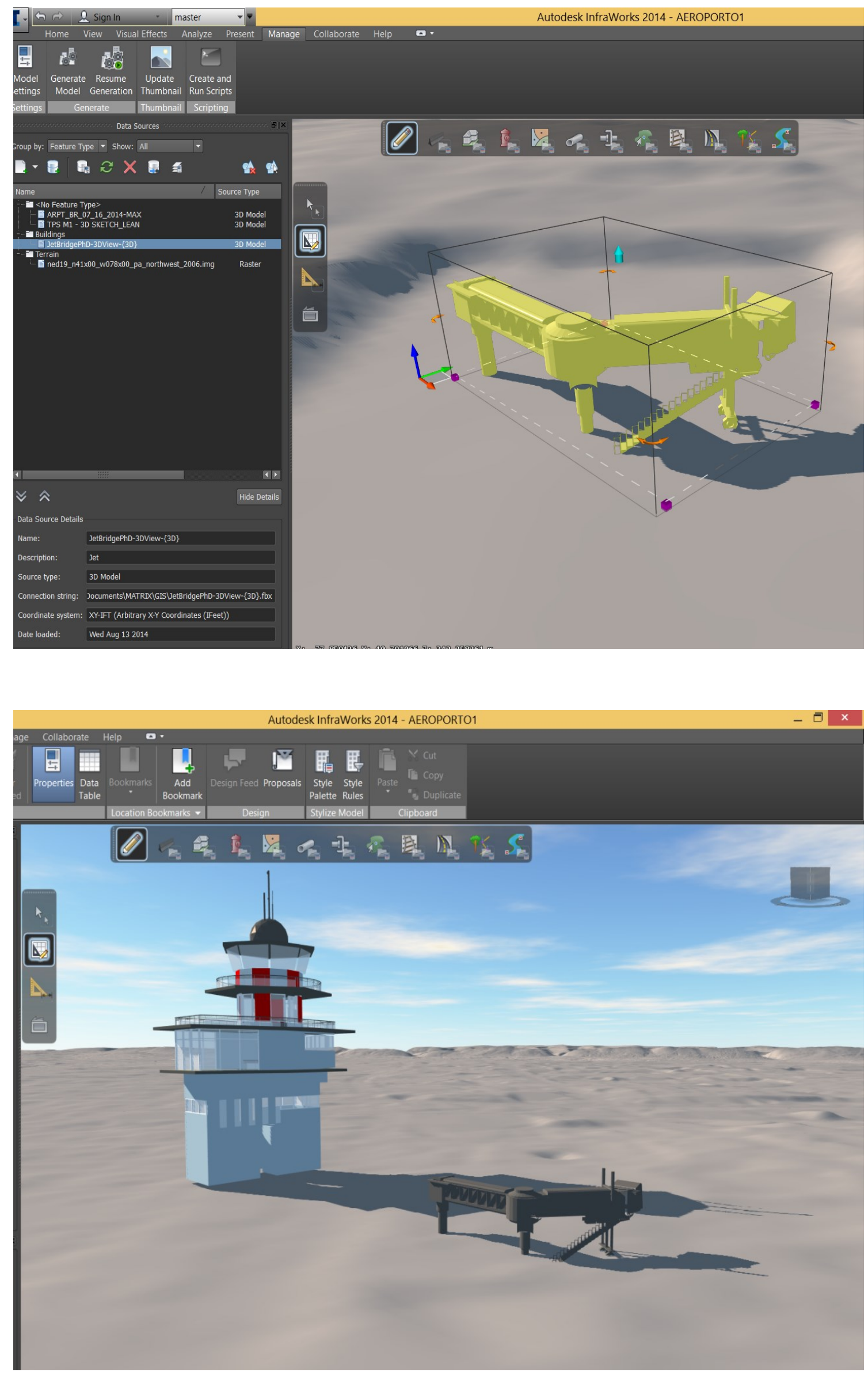

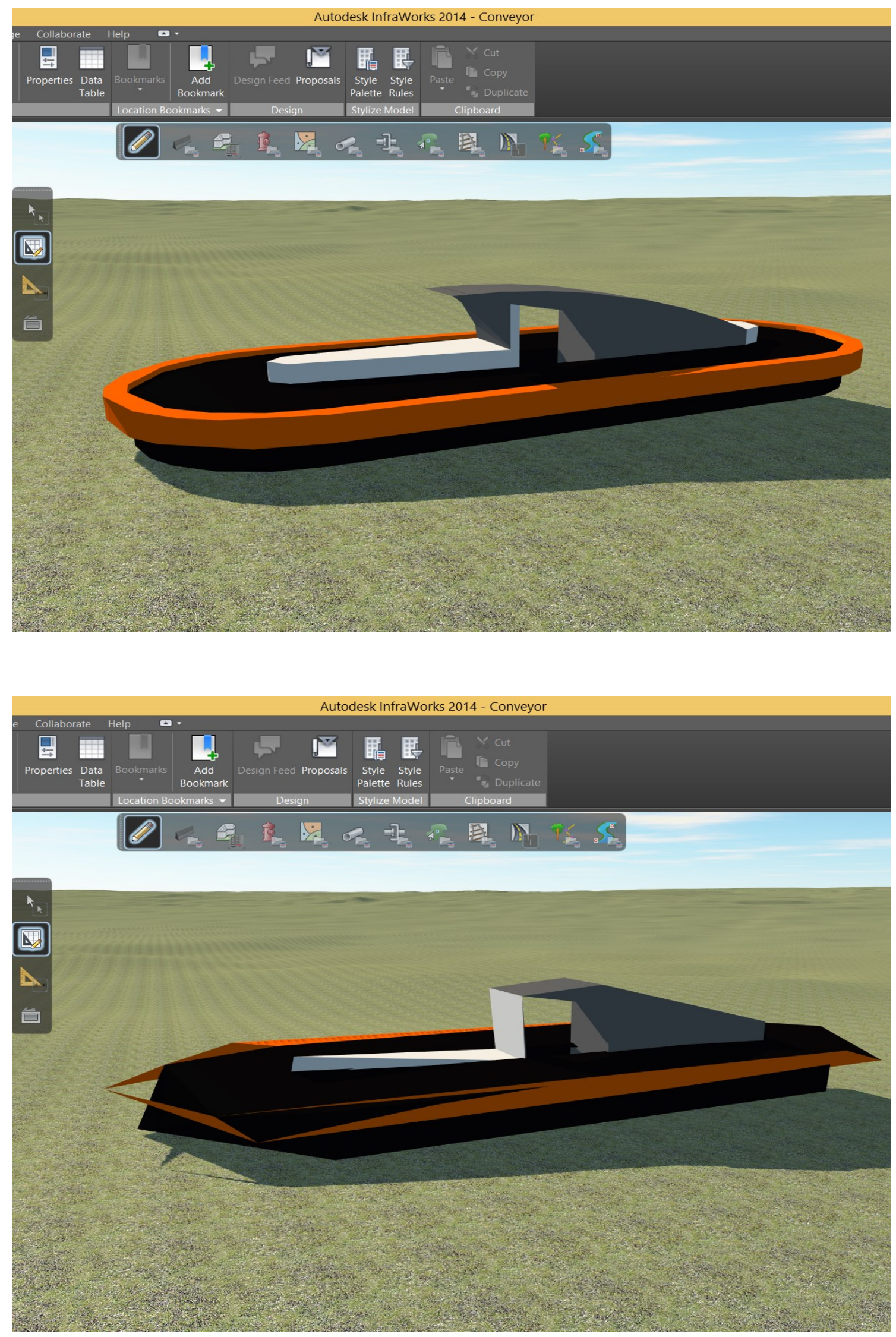

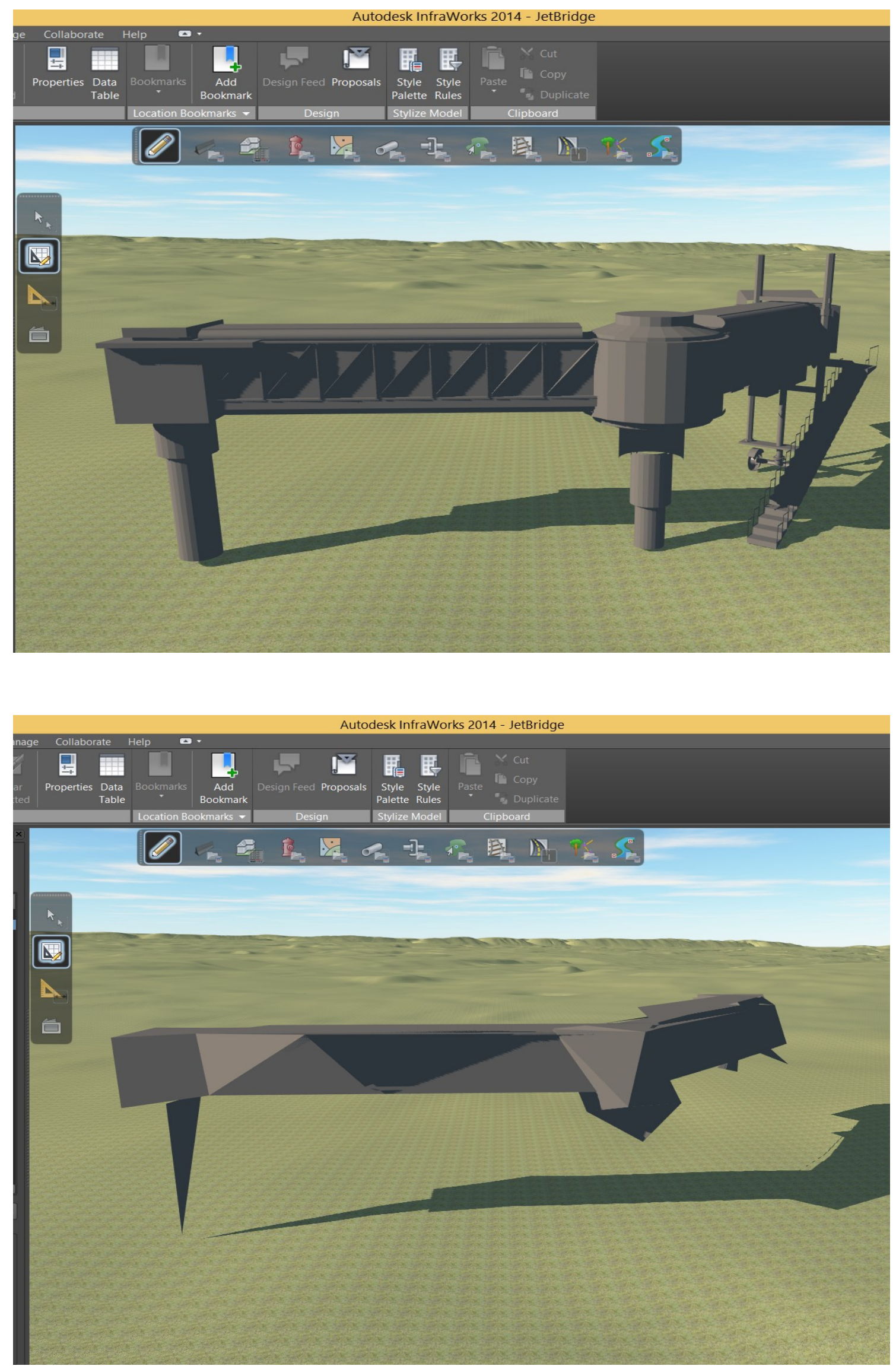
ANEXO V

\section{MODELAGEM DO \\ TERMINAL DE PASSAGEIROS REGIONAL DO BRASIL}



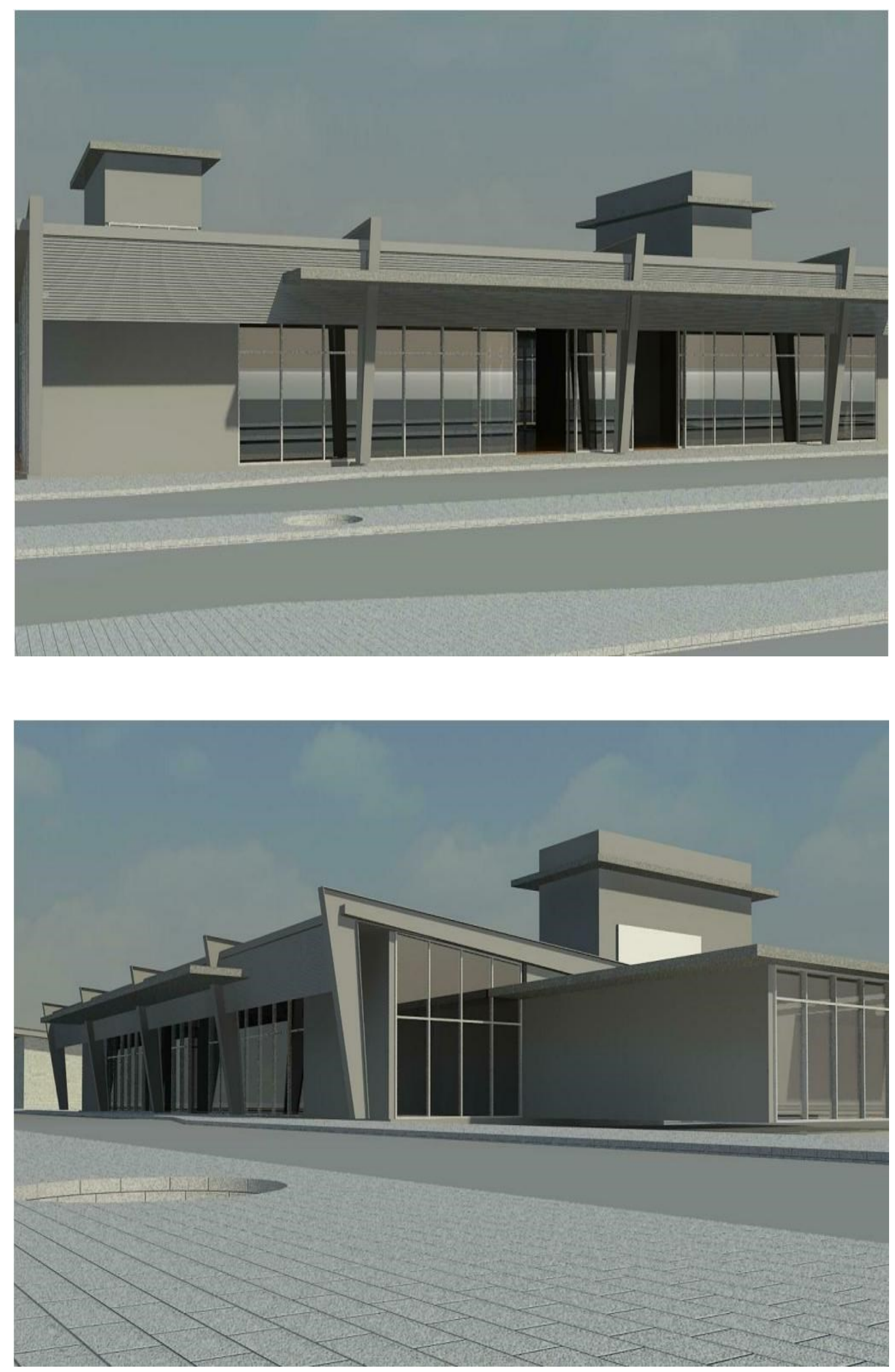

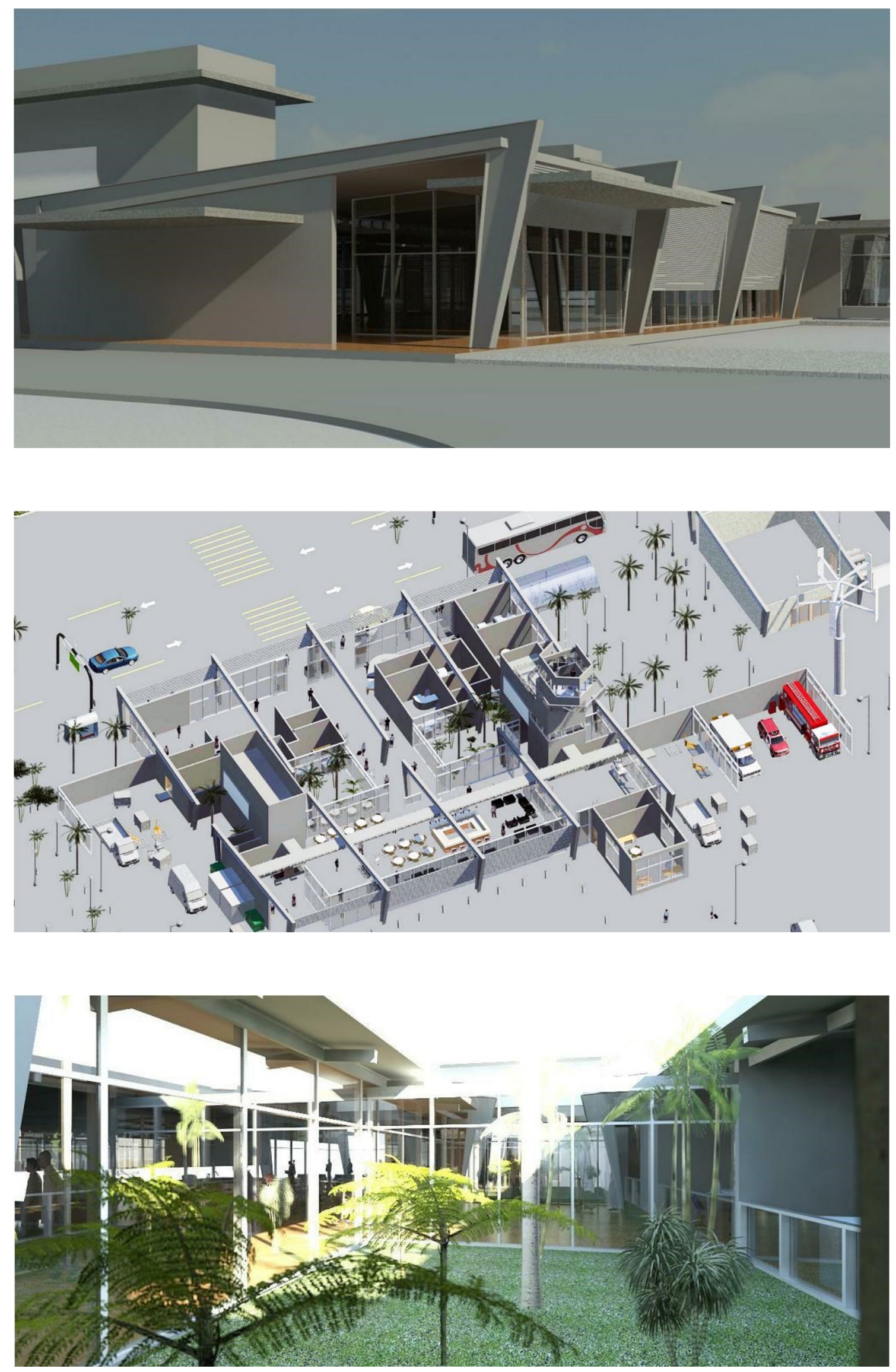

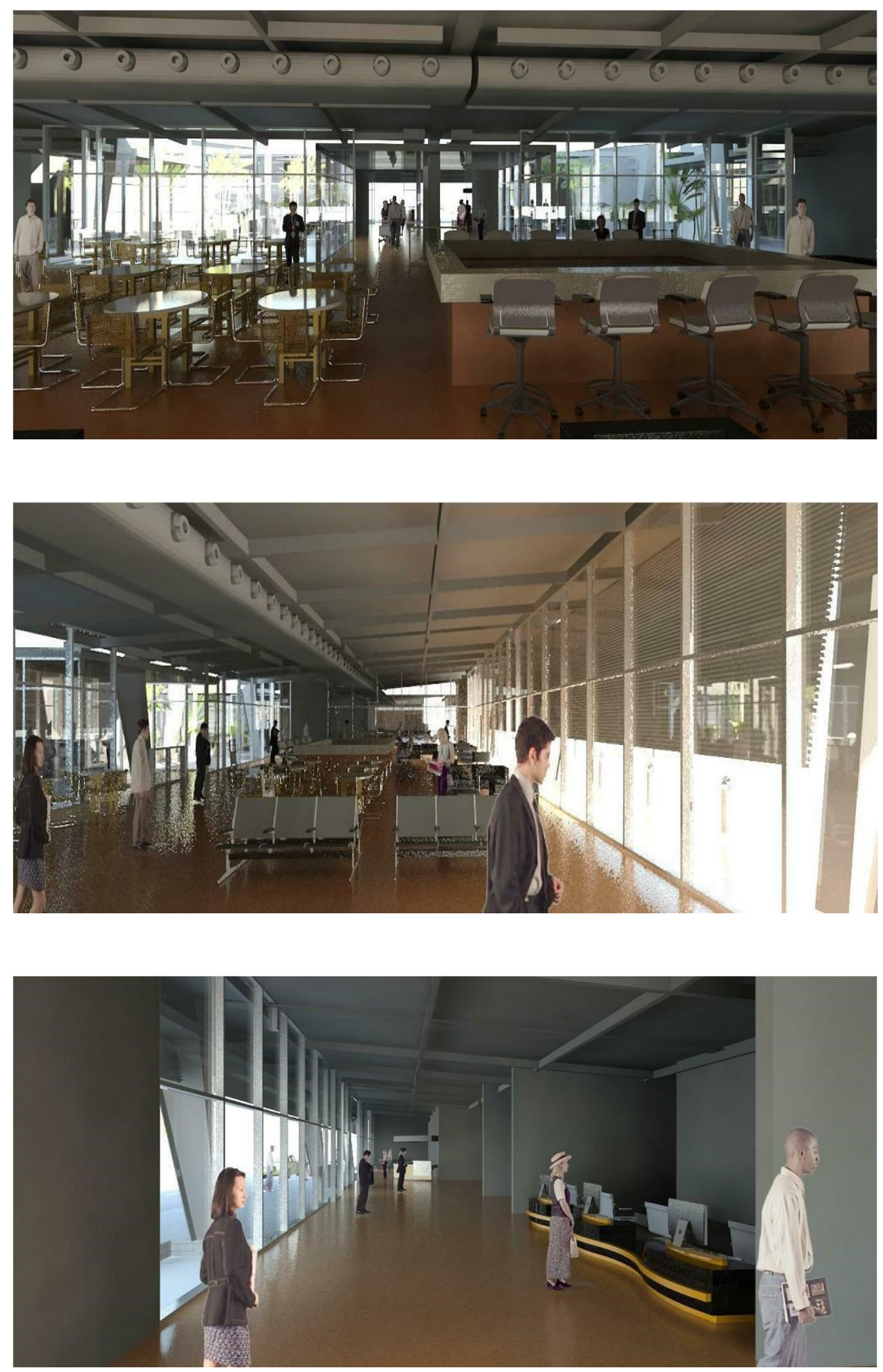

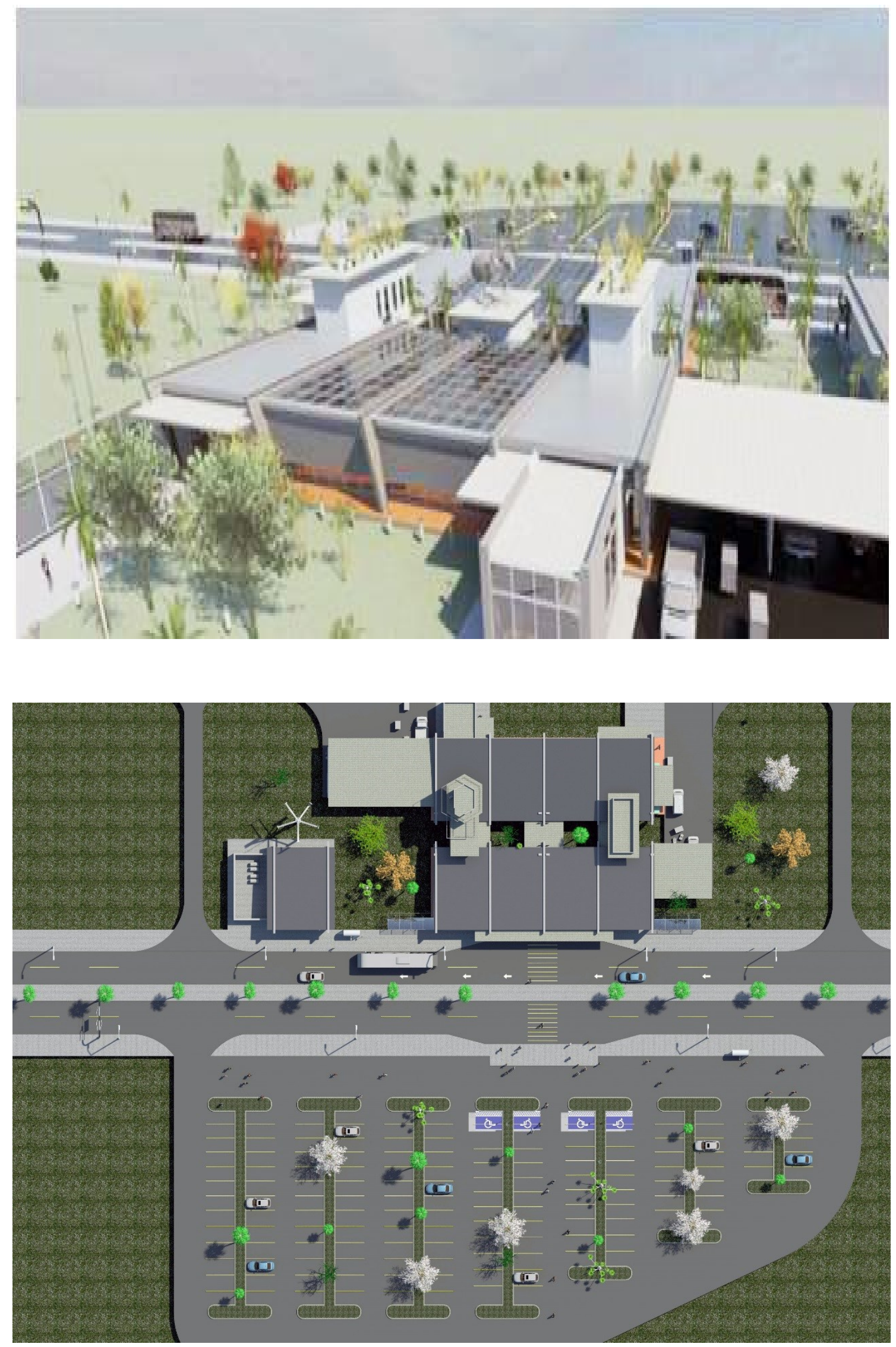


\section{RESULTADOS MODELAGEM (SISTEMAS BIM - REVIT®)}

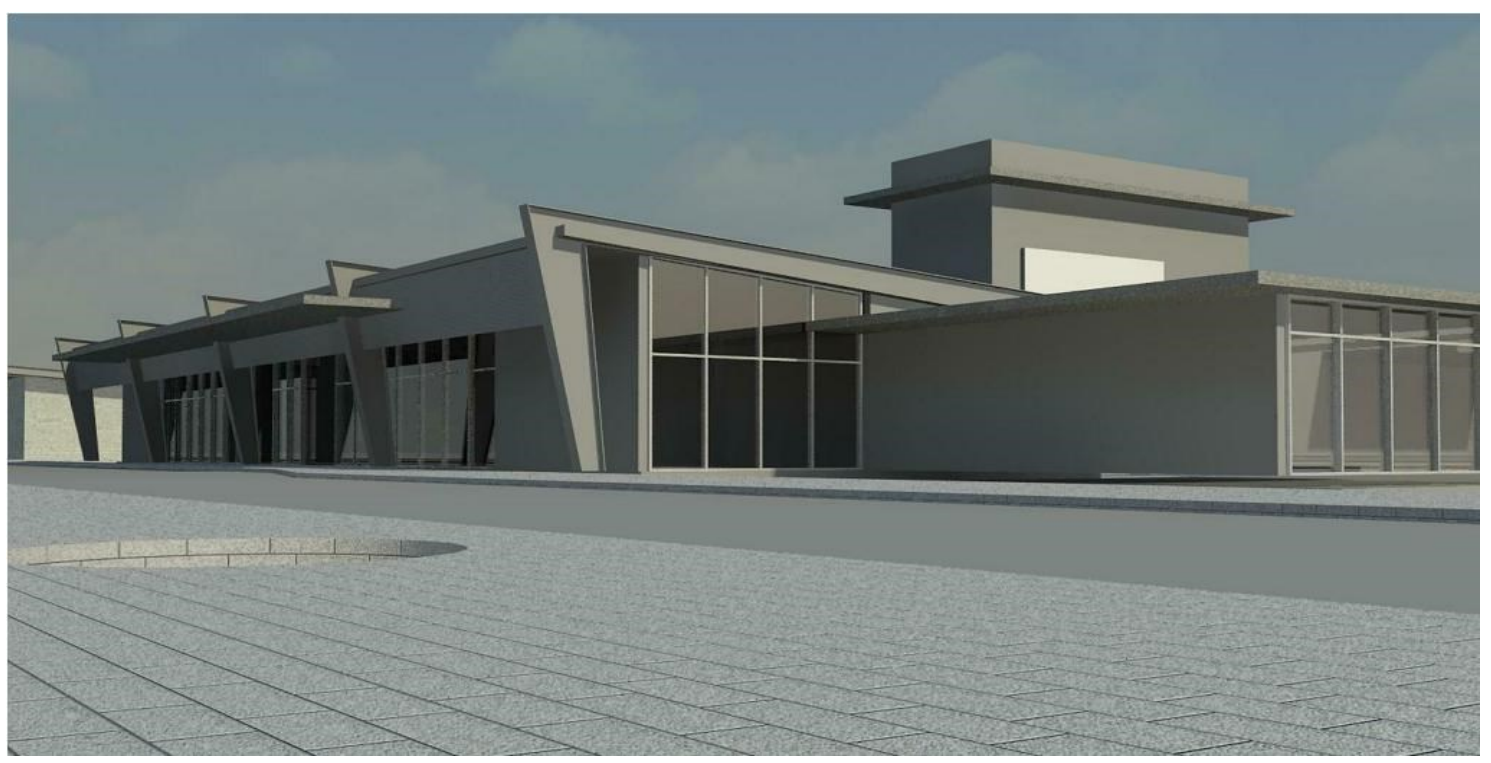

Figura A- Projetação do TPS REGIONAL no REVIT ${ }^{\circledR}$ 2014. Fonte: autoria própria.

O Revit ${ }^{\circledR}$ pode ser definido como uma ferramenta de automatização do processo de projeto, Também associa informações não apenas geométricas, mas regras de relacionamento entre os componentes da edificação e parâmetros relativos ao processo de projeto e de construção e manutenção. Esta diferença torna-se visível quando analisamos as diferenças de potencialidade e de recursos entre o processo atualmente em vigor na INFRAERO, baseado em AutoCAD ${ }^{\circledR}$ e o que se utiliza dos sistemas BIM $\left(\right.$ Revit $\left.^{\circledR}\right)$ e aponta para a obsolescência de padrões tecnológicos e de gestão da informação de projeto associada aos processos e a estrutura organizacional da empresa (Figura A).

O que acontece em nosso país atualmente é que todo um modelo de processo de projeto, e mesmo de negócios na AEC encontra-se baseado em geração fragmentada de informação, e na simples utilização do CAD nos processos de desenho tridimensional. Essa característica constitui-se em grandes defasagens tecnológicas, se compararmos o Brasil com os EUA, onde os sistemas BIM encontram-se atualmente sendo utilizados por $70 \%$ dos escritórios e empresas de arquitetura, engenharia e de construção naquele país. Os resultados obtidos nesta pesquisa apontam para a necessidade de revisão das atuais práticas de processo de projeto empregadas na projetação de terminais de passageiros aeroportuários, bem como sobre as possíveis formas do emprego da tecnologia para as práticas de trabalho desenvolvidas no setor. O objetivo é saber como as mesmas poderiam obter novas competências em projetos na medida em que se aprende com experiências em projetos anteriores e com o capital intelectual presente em cada agente interveniente. 


\section{MÉTRICA DE TEMPOS OPERACIONAIS E INTELECTUAIS}

Tempos totais, tempos operacionais e intelectuais absolutos/ relativos da modelagem global - aeroporto e das três alternativas para a torre de controle

Esta métrica de análise foi desenvolvida tendo como principal objetivo diferenciar os tempos de projeto (relativos e absolutos) entre as atividades que o projetista gasta operando o "software" no computador e o tempo em que efetivamente se ocupa de atividades intelectuais voltadas para o processo de projeto.

Obviamente a métrica proposta não indica a qualidade ou profundidade das soluções frente ao programa e aos requisitos de projeto. Tão somente fornece um indicativo provisório sobre o grau de diferenciação entre as atividades intelectuais que envolvem operar as ferramentas computacionais e aquelas destinadas a resolução do problema arquitetônico. Nestes casos, quando se inicia um processo de exteriorização do processo de projeto, inicia-se paralelamente a utilização de materiais que afetarão a forma de se projetar. O que é relevante nas razões de tempo (relativo) é que o tempo, de forma implícita ou explícita, é um componente essencial e intrínseco no comportamento do tempo total. Conforme os conceitos descritos acima, apresentamos a metodologia de medição adotada nesta pesquisa.

Definiremos para uso geral que o Fator de Tempo - $\mathbf{T}(\mathbf{r})$ refere-se aos tempos relativos de cada tarefa, "T(t)" é o Tempo Total gasto para realizar a tarefa e "T(o)" representa o Tempo Operacional, ou seja, aquele gasto operando o computador para realizar a tarefa. O tempo residual, chamado de Tempo Intelectual "T(i)" representa o tempo que o arquiteto ou projetista demanda nos processos criativos e decisórios para realizar o projeto de arquitetura.

A relação entre o tempo total e o tempo operacional portanto está ligada não apenas ao desempenho operacional das ferramentas computacionais de projeto, e ainda às suas capacidades e aderências para integrar-se no processo criativo e decisório do arquiteto na busca de melhores soluções de projeto.

Pensando na possibilidade de medição do processo de projeto realizado com o uso dos sistemas BIM - Revit $^{\circledR}$ e visando quantificar o desempenho e a flexibilidade dos mesmos em diferentes momentos do processo de projeto, adotamos a métrica:

\section{O Fator de Tempo (T) calculado pela seguinte equação:}

$$
T(r)=T(o) / T(t)
$$


A métrica de tempos operacionais e intelectuais foi a forma encontrada para avaliar a contribuição que os sistemas computacionais poderiam trazer ao processo de projeto, uma vez que separa as atividades "pensantes", intelectuais, das atividades de entrada, configuração, processamento e acesso de dados pelo computador.

Esta metodologia foi aplicada tanto na reprodução pura e simples do terminal de passageiros regional, a partir da documentação fornecida pela INFRAERO, como, num segundo momento, através da simulação de diferentes alternativas de projeto para a criação de uma torre de controle - TWR no terminal modelado.

As diferenças entre as duas situações projetuais descritas podem representar os estágios iniciais de projeto, no caso da criação de uma nova infraestrutura associada ao modelo existente, como de modelagem e documentação de algo previamente concebido, como é o caso da reprodução do aeroporto, que se assemelha às fases de projeto básico ou executivo, em termos dos processos de criação e tomada de decisão.

A separação entre o tempo demandado pela inserção e operação de funcionalidades nos "softwares" dos computadores pode ser entendido como atividade agregada ao processo de projeto, porém não intelectual do ponto de vista criativo. A métrica proposta nesta pesquisa pretende estabelecer a razão entre o tempo puramente operacional e o tempo que o projetista gasta solucionando as questões e problemas de projeto.

A análise do AutoDesk Revit ${ }^{\circledR}$, através da métrica de desempenho, procurou avaliar qual a participação efetiva da máquina no processo de projeto e qual a participação intelectual do projetista. Para tanto, dividimos o tempo total de projeto pelo tempo operacional, ou tempo gasto pelo computador para processar as informações que são inseridas pelo usuário.

\section{EQUIPAMENTOS UTILIZADOS PARA EXECUÇÃO DAS TAREFAS}

1- Notebook Dell Alienware ${ }^{\circledR}$ M-18X com processador Intel 3920XM. HD SSD 500GB, 16Gb de memória RAM, monitor de WLED com 18.4" com 2 placas de vídeo AMD RADEON ${ }^{\circledR} 7970 M$ e sistema operacional Windows 7 "Ultimate" 64bits (Abertura de plantas 2D do AutoCAD).

2- RenderPro ${ }^{\circledR}$ da $B O X X^{\circledR}$ Technologies (Renderizacão de Imagens);

3- Digital Storm ${ }^{\circledR}$ P570WM3 "Desktop Replacement" Intel 3820K SBE (modelagem 3D paramétrica nos sistemas BIM) 


\section{REPRODUÇÃO POR MEIO DE MODELAGEM DO TERMINAL DE PASSAGEIROS REGIONAL - ARQUIVOS 2D CEDIDOS PELA INFRAERO}

\section{PASSO A PASSO}

5- Preparação e customização do ambiente de trabalho - Foi realizada a Configuração da interface Revit ${ }^{\circledR}$, através das unidades de medida correta, no caso em metros e das definições de grid e ainda dos níveis customizados de projeto; Os níveis conduzem a modelagem dos diversos pisos e cobertura, informando as alturas corretas dos componentes construtivos.

6- Inserção de planta referencial do projeto existente - Foi realizada a inserção de uma planta de referência que correspondeu ao projeto adotado, servindo de "guia" para o desenvolvimento do projeto nos sistemas BIM. Funcionou como uma marca d'água orientando a modelagem das paredes, fechamentos e permitindo uma compreensão clara das funções na edificação, auxiliando o arquiteto ou projetista a organizar e racionalizar seu ambiente de trabalho, pois muitos componentes devem ser inseridos e/ou modelados.

7- Preparação do Terreno e entorno imediato - Foi realizada a modelagem do terreno, vias de acesso e demais infraestruturas urbanas que cercam o terminal de passageiros.

Foram realizados desenhos e/ou inserção de elementos construtivos (utilização de elementos construtivos nativos “.RVT”) como descritos a seguir.

1- Criação de níveis referentes às alturas da edificação;

2- Construção de terrenos;

3- Construção de pilares;

4- Construção de paredes interiores;

5- Construção do modelo: cortes, fachadas;

6- Adicionar portas / janelas;

7- Adicionar objetos;

8- Construção de coberturas.

O processo de modelagem envolveu tanto a modelagem, utilizando-se das ferramentas e potencialidades nativas do $\operatorname{Revit}^{\circledR}$, como a importação de geometria, que posteriormente foi incorporada como componente paramétrico. 


\subsection{2- Parametrização dos elementos construtivos}

A essência do processo de projeto paramétrico, desenvolvido nesta pesquisa, residiu nas relações de dependência entre os componentes construtivos e a função que desempenham na edificação, de forma a serem incorporados ao modelo BIM. A criação e a manipulação de tais relações permitiram coordenar alterações feitas em qualquer lugar, como por exemplo, ao selecionar e mover uma parede todos os elementos relacionados ajustam-se automaticamente.

O teto se move junto com a parede, que preserva qualquer relacionamento previamente configurado. A parametrização dos objetos no Revit ${ }^{\circledR}$ variou de acordo com o componente construtivo e situações específicas de projeto.

Destaca-se o campo referente à Planilha SINAPI, que pode referenciar o componente construtivo a uma planilha que oferece informações referentes aos custos atualizados, mês a mês. Pode-se ainda criar novos parâmetros de forma a incluir, por exemplo, campos para outras planilhas orçamentárias como o SINAPI Aeroportuário ou planilha SICAERO.

Componentes como paredes, pisos, pilares, vigas e coberturas são chamados "nativos" do sistema, e devem ser configurados quanto às relações de dependência em relação a outros componentes de sistema.

Por exemplo, foi necessário configurar as paredes para que estivessem conectadas nas lajes e que fossem limitadas pelos níveis corretos, para que pudessem obedecer às alturas indicadas. Vigas e pilares foram configurados quanto ao piso de referência a que pertenciam (hospedeiros) e ainda quanto às suas características internas, que puderam ser personalizadas. Para isto rotineiramente foi duplicado o componente construtivo por meio da aba "Propriedades", ao clicar em "Editar tipo". Depois deve-se clicar em "Duplicar", inserindo um novo nome para o pilar (no exemplo, $19 \times 100 \mathrm{~cm})$, mudando os valores em b $(=0,19)$ e em $\mathrm{h}(=1)$ e confirmando em "OK". Procedemos então à configuração da "Altura": para determinar a altura da base e ainda vincular a parte superior do pilar à altura da laje ou cobertura superior.

Após isso, para que o pilar seja considerado área de contorno de paredes, usase a ferramenta "Ambiente". Inserimos então o pilar na área de trabalho racionando conforme necessidade, além de utilizar a ferramenta "Mover" para colocar o pilar no local indicado na planta baixa de referência que importamos do AutoCAD ${ }^{\circledR}$. 
A determinação do nível de detalhe de cada componente ocorreu através da configuração do $\operatorname{Revit}^{\circledR}$ em três possíveis níveis de detalhe, baixo (LOD-100), médio(LOD-200) e alto (LOD-300). Isto corresponderia às fases de estudos preliminares, projeto básico e executivo.

A parametrização dos demais componentes nativos do sistema ocorreu da mesma forma descrita acima, sendo que ainda podemos configurar outros relacionamentos no modelo, como a fase construtiva de cada componente, que irá estabelecer quando o componente deve ser construído.

Isso foi bastante relevante para a compatibilização das informações de arquitetura com as demais especialidades e pode servir para a retirada de interferências em programas como o NavisWorks ${ }^{\circledR}$, que irá simular o processo construtivo com base nos parâmetros estabelecidos no Revit ${ }^{\circledR}$.

\subsection{3- Documentação de projeto (automática para cortes, vistas e fachadas)}

5.1 - Zonas - extração de informação;

5.1.1 - Listagens integradas, áreas, componentes;

5.2 - Mapas interativos;

5.2.1 - Mapa de vãos;

5.2.2 - Listagem de paredes e objetos;

5.3 - Documentação tridimensional;

5.3.1 - Colocação de cotas;

5.3.2 - Detalhes;

5.4.1 - Documento tridimensional, colocação de cotas tridimensionais;

5.4.2 - Imagens renderizadas;

5.5 - Representação do modelo: cortes, fachadas;

5.5.1 - Guardar vistas; 
1.0- Abrir arquivos originais do projeto do TPS REGIONAL:

1.1- Tempo de operação: $15 \mathrm{~min}$;

1.2- Tempo de visualização: 15 min;

1.3- Tempo de compreensão: $30 \mathrm{~min}$;

1.4- Métrica de tempo (To / Tt); $25 \%$ Operacional e $75 \%$ Intelectual;

1.5- Tempo intelectual (atividades residuais): $45 \mathrm{~min}$.

2.0- Salvar arquivo: renomear e salvar o arquivo para que possa ser editado:

2.1- Renomear e salvar o arquivo: $1 \mathrm{~min}$;

2.2- Tempo de operação: 10s;

2.3- Métrica de tempo (To / Tt); $90 \%$ Operacional e 10\% Intelectual;

2.4- Tempo intelectual (atividades residuais): $1 \mathrm{~min}$;

3.0- Modelar os pisos do TPS REGIONAL a partir dos dados do projeto:

3.1- Criar pisos do pavimento térreo: $180 \mathrm{~min}$;

3.2- Tempo de operação: $160 \mathrm{~min}$;

3.3- Métrica de tempo (To / Tt); $88,8 \%$ Operacional e 16,7\% intelectual;

3.4- Tempo intelectual (atividades residuais): $20 \mathrm{~min}$.

4.0- Modelar os pilares do TPS REGIONAL a partir dos dados do projeto:

4.1- Criar os pilares do pavimento térreo: $120 \mathrm{~min}$;

4.2- Tempo de operação: $100 \mathrm{~min}$;

4.3- Métrica de tempo (To / Tt); 83,3\% Operacional e 33,3\% Intelectual;

4.4- Tempo intelectual (atividades residuais): $20 \mathrm{~min}$;

5.0- Modelar as vigas do TPS REGIONAL a partir dos dados do projeto:

5.1- Criar as vigas do pavimento térreo: $180 \mathrm{~min}$;

5.2- Tempo de operação: $155 \mathrm{~min}$;

5.3- Métrica de tempo (To / Tt); 86,1\% Operacional e 13,9\% Intelectual;

5.4- Tempo intelectual (atividades residuais): $25 \mathrm{~min}$. 
6.0- Modelar as paredes do TPS REGIONAL a partir dos dados do projeto:

6.1- Criar as paredes do pavimento térreo: $240 \mathrm{~min}$;

6.2- $\quad$ Tempo de operação: $210 \mathrm{~min}$;

6.3- Métrica de tempo (To / Tt); 87,5\% Operacional e 12,5\% Intelectual;

6.4- Tempo intelectual (atividades residuais): $30 \mathrm{~min}$.

7.0- Modelar os elementos de fechamento:

7.1- Inserção de bloco de porta e/ou janela: $180 \mathrm{~min}$;

7.2- $\quad$ Tempo de operação $150 \mathrm{~min}$;

7.3- Métrica de tempo (To / Tt); 83,3\% Operacional e 16,7\% Intelectual;

7.4- Tempo intelectual (atividades residuais): $\mathbf{3 0} \mathrm{min}$.

8.0- Modelar os elementos acessórios à edificação:

8.1- Inserção de blocos de elementos acessórios: 480min;

1.1- Tempo de operação: 390 min;

1.2- Métrica de tempo (To / Tt); 81,2\% Operacional e 18,8\% Intelectual;

1.3- Tempo intelectual (atividades residuais): $90 \mathrm{~min}$.

9.0- Modelar a cobertura do TPS REGIONAL a partir dos dados do projeto:

9.1- Criar cobertura no primeiro pavimento $180 \mathrm{~min}$;

9.2- $\quad$ Tempo de operação; $145 \mathrm{~min}$;

9.3- Métrica de tempo (Tto/ Tt); $80,5 \%$ Operacional e 19,5\% Intelectual;

9.4- Tempo intelectual (atividades residuais): $35 \mathrm{~min}$.

Tempo Global para modelagem do TPS REGIONAL (nos sistemas BIM/ REVIT $^{\circledR}$ ): 1.620 minutos ou 27 horas.

Métrica de TEMPO MÉDIO para modelagem do TPS REGIONAL: (T(0)=81,79\% e $\mathrm{T}(\mathrm{i})=\mathbf{1 8 , 2 1 \%}$

Equipamento utilizado para medição: Cronômetro digital Ultrachron Lite Fonte: Google Play Store ${ }^{\circledR}$. 


\section{INFORMAÇÕES GERADAS (REVIT ${ }^{\circledR}$ 2014) - MODELAGEM 3D}

Na utilização do BIM pode-se dizer que apesar da possibilidade de separar as tarefas por blocos de trabalho e de quantificar o volume de tempo gasto para cada um deles, a grande vantagem é que a qualquer momento pode-se voltar e alterar alguma etapa ou informação previamente configurada. Portanto, fica evidenciada a natureza holística do processo, pois acontece simultaneamente à análise que perdura por todo o processo de projeto. É possível separar as atividades de configuração inicial do ambiente de trabalho, modelagem, documentação, análise e, por fim, de apresentação do projeto.

Estes cinco blocos principais acontecem com certa ordem e cadência, porém a grande vantagem neste modelo de processo de projeto é que a todo momento é possível a realização de "loopings" de análise, de modificações e de retomadas de decisão, sem prejuízo do fluxo de trabalho, da documentação gerada e da comunicação dessas mudanças a todos os parceiros e agentes intervenientes no projeto.

Com isto pode-se trazer o processo de concepção para praticamente todo o ciclo de projeto, e em sentido inverso, trazer aos estágios iniciais a simulação e o processo da análise dos vários aspectos e dimensões do edifício como um todo. Esta dualidade entre se proceder a uma análise com base em algo que se tem em mente (concebido) e alterar este mesmo elemento em seu estágio de concepção inicial para, novamente, ser simulado e testado em seu desempenho, constitui-se na alavanca de melhoria contínua que pode ser implementada em um processo de projeto de arquitetura.

\section{SEPARAÇÃO EM CINCO BLOCOS POR TEMPO}

1- Preparação do ambiente de trabalho: inclui a configuração das unidades e variáveis do ambiente de trabalho de projeto, o geo-referenciamento do terreno de implementação e atributos diversos. O tempo gasto foi de 1 hora.

2- Modelagem de todos os elementos construtivos e acessórios (como vegetação, mobiliário, pessoas, veículos, etc.) da edificação, perfazendo um tempo aproximado de 22,5 horas.

3- Documentação de projeto, que requer cerca de 1 hora.

4- Análise e discussão do projeto: necessitou de aproximadamente 1,5 horas.

5- Apresentação e comunicação do projeto, requerendo cerca de 1 hora de trabalho, aqui incluídas as animações e renderizações. 
Tabela I - TEMPO GASTO EM CADA UM DOS CINCO BLOCOS:

\begin{tabular}{|l|c|}
\hline DESCRIÇÃO & TEMPO GASTO (HORAS) \\
\hline 1- Preparação do ambiente de trabalho & 22,5 \\
\hline 2- Modelagem elem. construtivos e acessórios & 1 \\
\hline 3- Documentação de projeto & 1,5 \\
\hline 4- Análise e discussão do projeto & 1 \\
\hline 5- Apresentação e comunicação do projeto & 27 \\
\hline TOTAL & \\
\hline
\end{tabular}

O tempo total aproximado gasto neste projeto com a utilização da ferramenta BIM foi de 27 horas de trabalho. A análise deste processo nos mostra que a maior parte do tempo despendido foi na etapa de modelagem de informações de projeto. A parte de configuração inicial deve ser realizada com muita atenção por parte do arquiteto, uma vez que estabelece as bases do ambiente de trabalho, onde são configuradas as unidades métricas, os "grid's" que variam de projeto para projeto e ajudam o arquiteto na abordagem de projeto, estando arraigada na própria forma como o processo de projeto se estrutura. A etapa de documentação, apesar de automatizada, envolve a seleção da informação de projeto na colocação de textos e cotas (que também podem ser automatizados), na definição de vistas e câmeras (que representam diversos pontos de vista selecionados pelo arquiteto, para melhor demonstrar o projeto e suas particularidades. Cada elemento é independente, não possuindo qualquer conexão inteligente entre si.

TABELA II- MÉTRICA DE TEMPOS RELATIVOS PARA MODELAGEM BIM.

MÉTRICA DE TEMPOS RELATIVOS (REVIT)

PARA A MODELAGEM 3D DO TERMINAL DE PASSAGEIROS REGIONAL

\section{OPERACIONAL}

TEMPO

\subsection{HORAS}

INTELECTUAL 
A análise de desempenho dos sistemas BIM - projeto global, demonstra que:

1- Configuração do ambiente de trabalho: ocorreu de forma mais ou menos previsível, uma vez que o processo é semelhante ao de outros aplicativos computacionais. Porém, no Revit ${ }^{\circledR}$ este processo foi mais complexo, uma vez que nesta etapa ocorre a configuração dos níveis de trabalho, onde posteriormente serão inseridos os pisos da edificação;

2- Modelagem de informação da edificação: é feita por meio de procedimentos de parametrização complexos no Revit ${ }^{\circledR}$, uma vez que formam o cerne do processo de desenvolvimento do projeto. Não basta simplesmente desenhar ou modelar os objetos e elementos constituintes da edificação, mas é preciso configurar os parâmetros de cada objeto para que fiquem em consonância com as características que se deseja imprimir a eles e com os demais elementos e objetos que fazem parte do projeto;

3- Documentação de projeto: ocorre de forma automática em termos da incorporação da informação contida nos parâmetros dos objetos que compõem a edificação. Porém para esta tarefa deve ser realizada a colocação de cotas e dos textos e demais informações referentes ao projeto, o que é realizado de forma manual pela maior parte dos arquitetos;

4- Análise e discussão da relação forma $x$ função da edificação: caracteriza-se pela reflexão sobre a relação entre a forma da edificação e sua função (que deve estar em consonância com os parâmetros realizados no projeto), possibilitando ao arquiteto avaliar se os parâmetros que foram configurados até o presente momento atendem aos requisitos e condicionantes de projeto e se esteticamente as soluções propostas atendem aos objetivos e ao partido arquitetônico;

5- Readequação do projeto (parâmetros): incluindo a readequação dos parâmetros do modelo virtual como um todo, ocorre em função de qualquer alteração oriunda do processo de análise. Esta tarefa permite que todos os elementos de projeto estejam atualizados e em sintonia com o processo decisório de projeto, espelhando as alterações realizadas;

6- Apresentação e comunicação de projeto: $O$ Revit ${ }^{\circledR}$ mostrou-se bastante eficiente nas atividades de apresentação e de comunicação do projeto, onde foram geradas diversas imagens renderizadas e animações para possibilitar maior entendimento do projeto. 


\section{ANÁLISE DE TEMPO E MÉTRICA DE DESEMPENHO - MODELAGEM BIM}

O tempo intelectual no processo de modelagem do terminal de passageiros regional foi de $18,21 \%$. Isto indica que apesar de ser uma reprodução, onde inexiste atividade criativa, o fato de se ter de consultar as informações em diferentes documentos e plantas faz com que o tempo de se "pensar" no projeto tenha levado quase $20 \%$ do tempo total de projetação. Este resultado é comparado com os índices de simulação de alterações de projeto mais adiante. O estabelecimento de uma métrica de projeto pode ajudar a INFRAERO, em uma eventual adoção dos sistemas BIM, a avaliar o rendimento que um usuário pode atingir, bem como dimensionar especificações otimizadas de "hardware", se utilizar métrica semelhante e comparar com os índices obtidos na modelagem global do terminal de passageiros regional e os índices referentes às alternativas de projeto para o desenvolvimento da torre de controle - TWR. O interesse em saber quais são as formas de se integrar as equipes de projeto da INFRAERO em torno de um modelo único de informações BIM, moveu o autor a incluir na metodologia de pesquisa o ambiente organizacional da empresa

Por meio desta tecnologia, observam-se duas vantagens primordiais: a primeira é a elaboração dos projetos tridimensionalmente, incrementando sutileza espacial à visualização geométrica dos edifícios. A grande novidade, porém, reside na atribuição de informações aos elementos do desenho. Mais: essas informações, muito além do que simples legendas seguem referenciadas àquele elemento durante todas as fases do projeto - até o material chegar à fase de execução (construção). Com o uso dos sistemas BIM qualquer ajuste feito nessa informação, nesse atributo do elemento, é imediatamente processado, repercutindo de maneira instantânea ao longo de todo o projeto. Em segundo lugar, tal atitude permite que se estabeleça um fluxo de informação radial, que nos leva a um processo de contínuas melhorias ao longo do tempo.

O "software" ou ferramenta computacional, seja ele o Revit ${ }^{\circledR}$ ou qualquer outro, por si só não representa o que podemos chamar como processo BIM. A separação do tempo intelectual pode indica o tempo em que o projetista se ateve a atividades e raciocínios de projetação, tanto imaginando como deverá operar a máquina como também qual a lógica empregada na busca de soluções que possam melhor se adequar aos requisitos e condicionantes de projeto. O uso dos sistemas BIM tende a integrar esses dois tipos de raciocínio, estando porem ambos separados do tempo gasto com a entrada de dados e a realização de operações nos "softwares". Como os componentes paramétricos apresentam campos de informação dos processos de projetação e de construção, o tempo requerido para pensar como realizar as tarefas nas ferramentas BIM confunde-se com o próprio raciocínio projetual. 
ANEXO VI

MODELAGEM TWR-1 

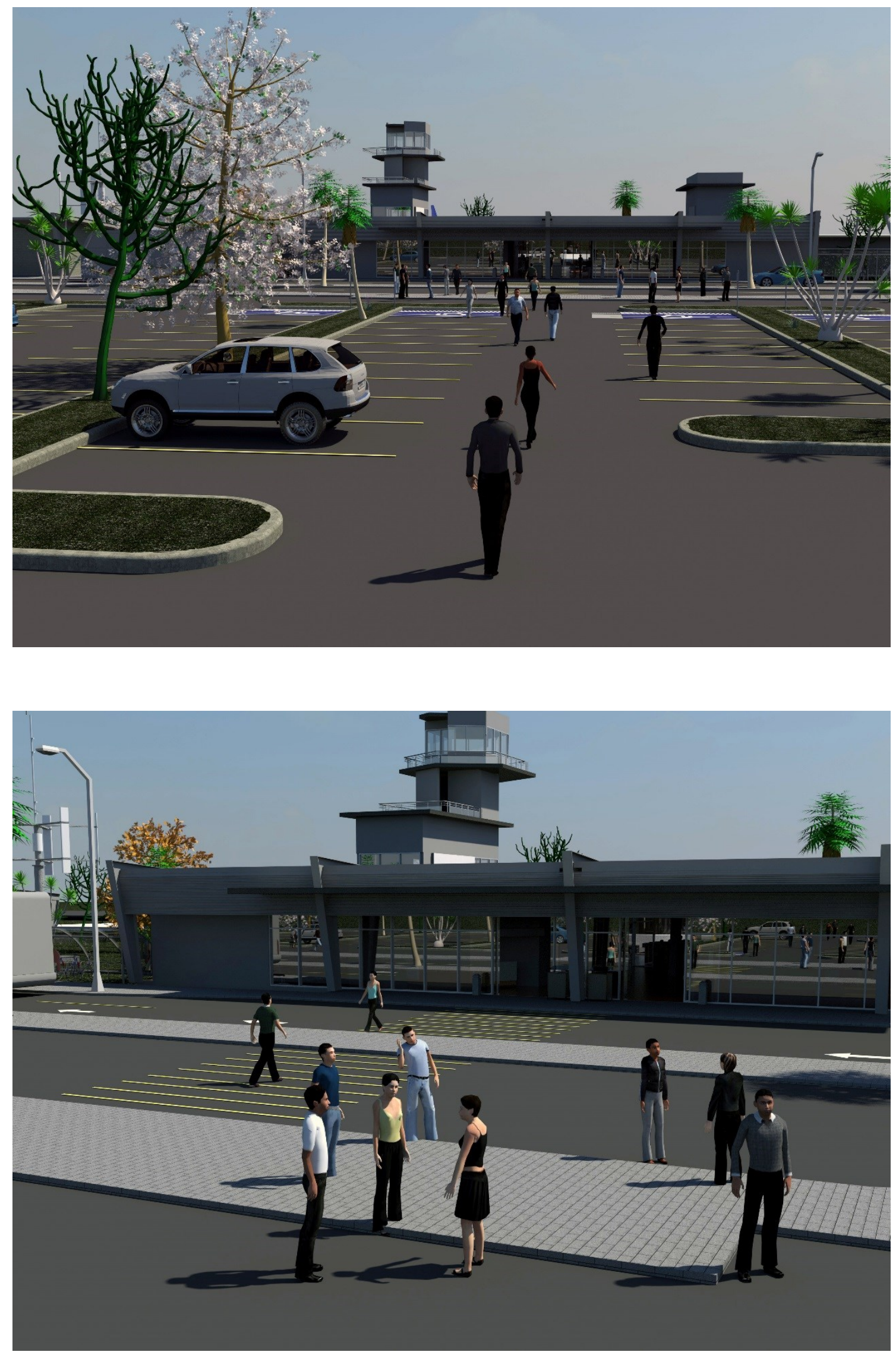

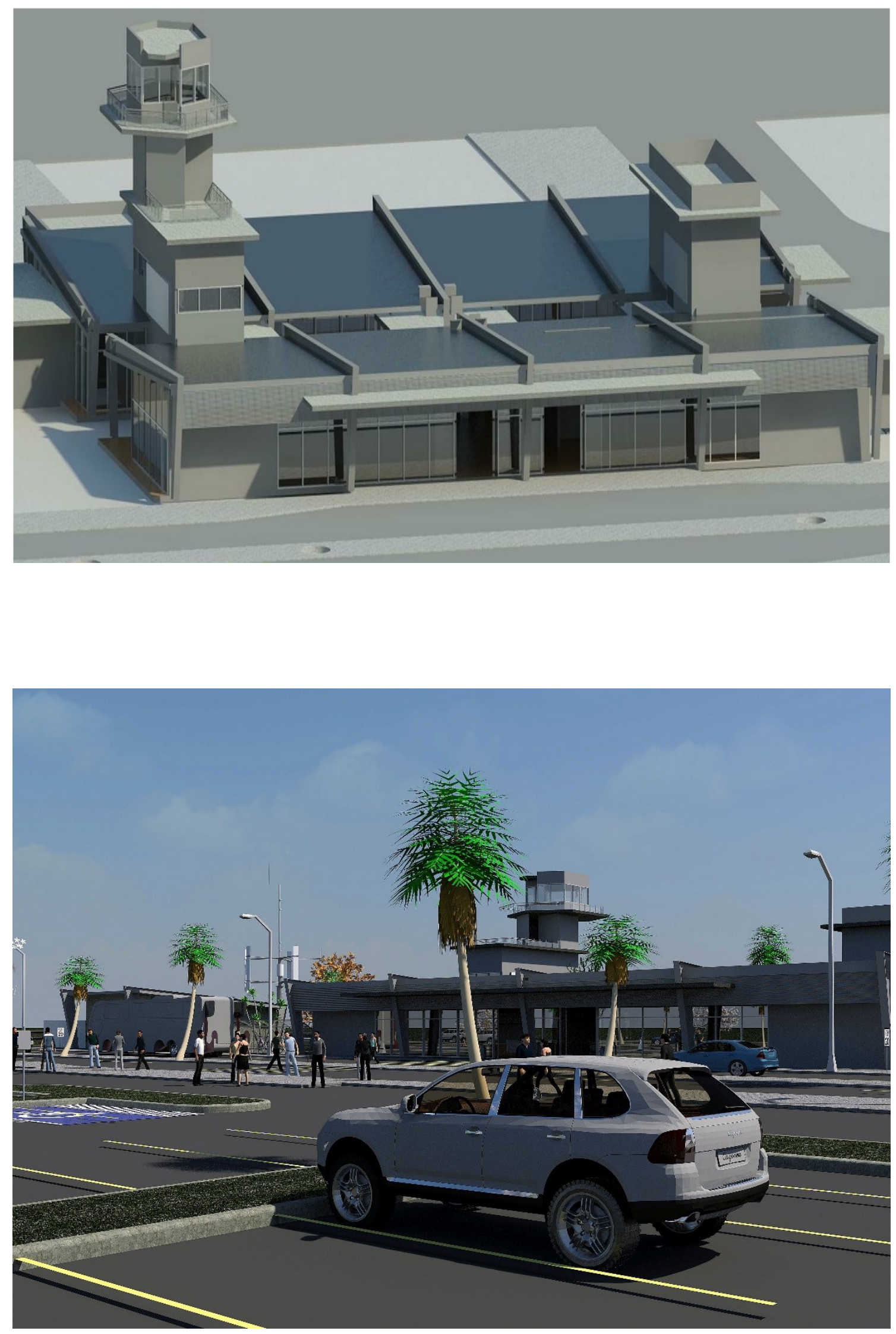

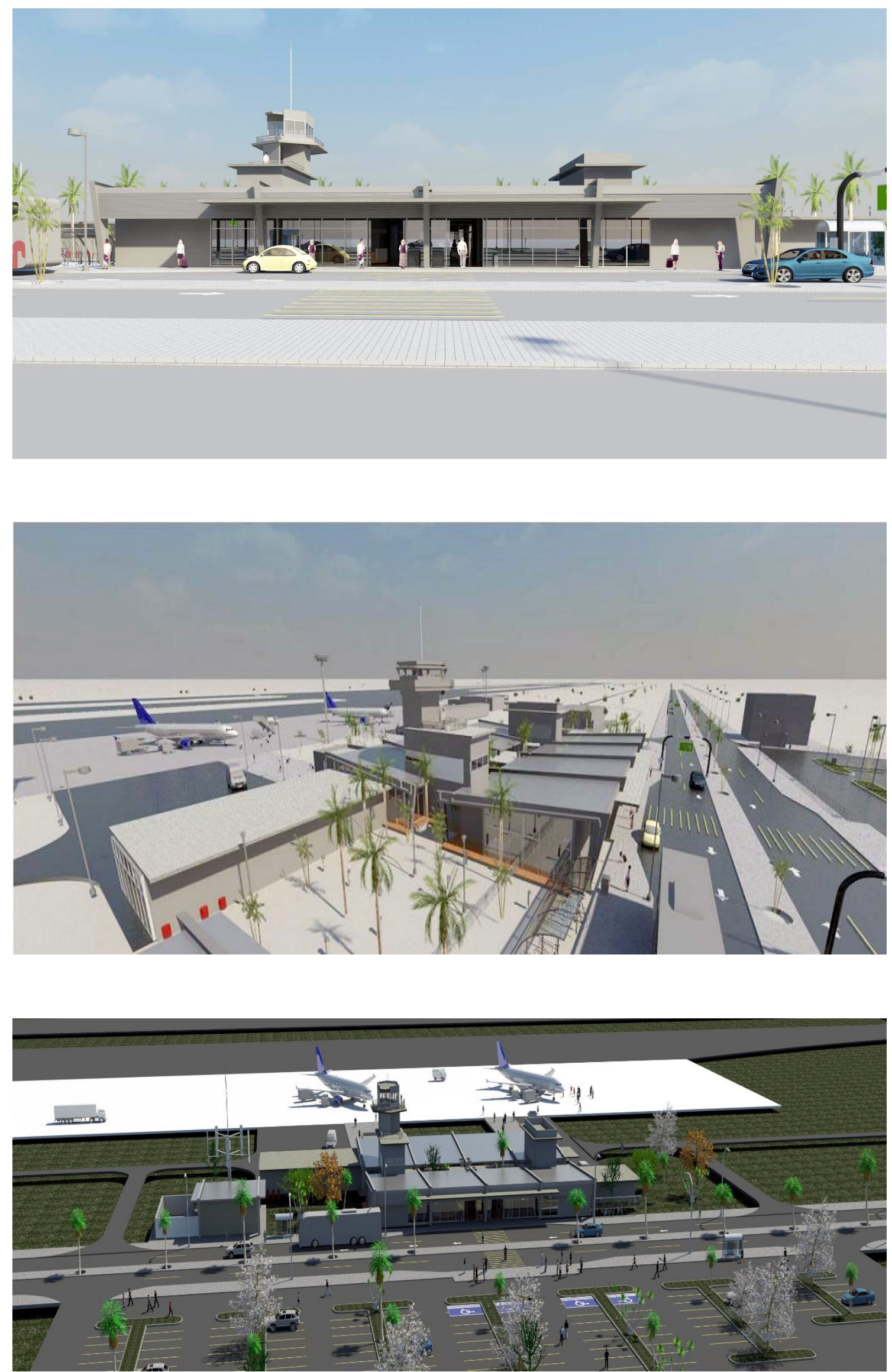
ANEXO VII

MODELAGEM TWR-2 

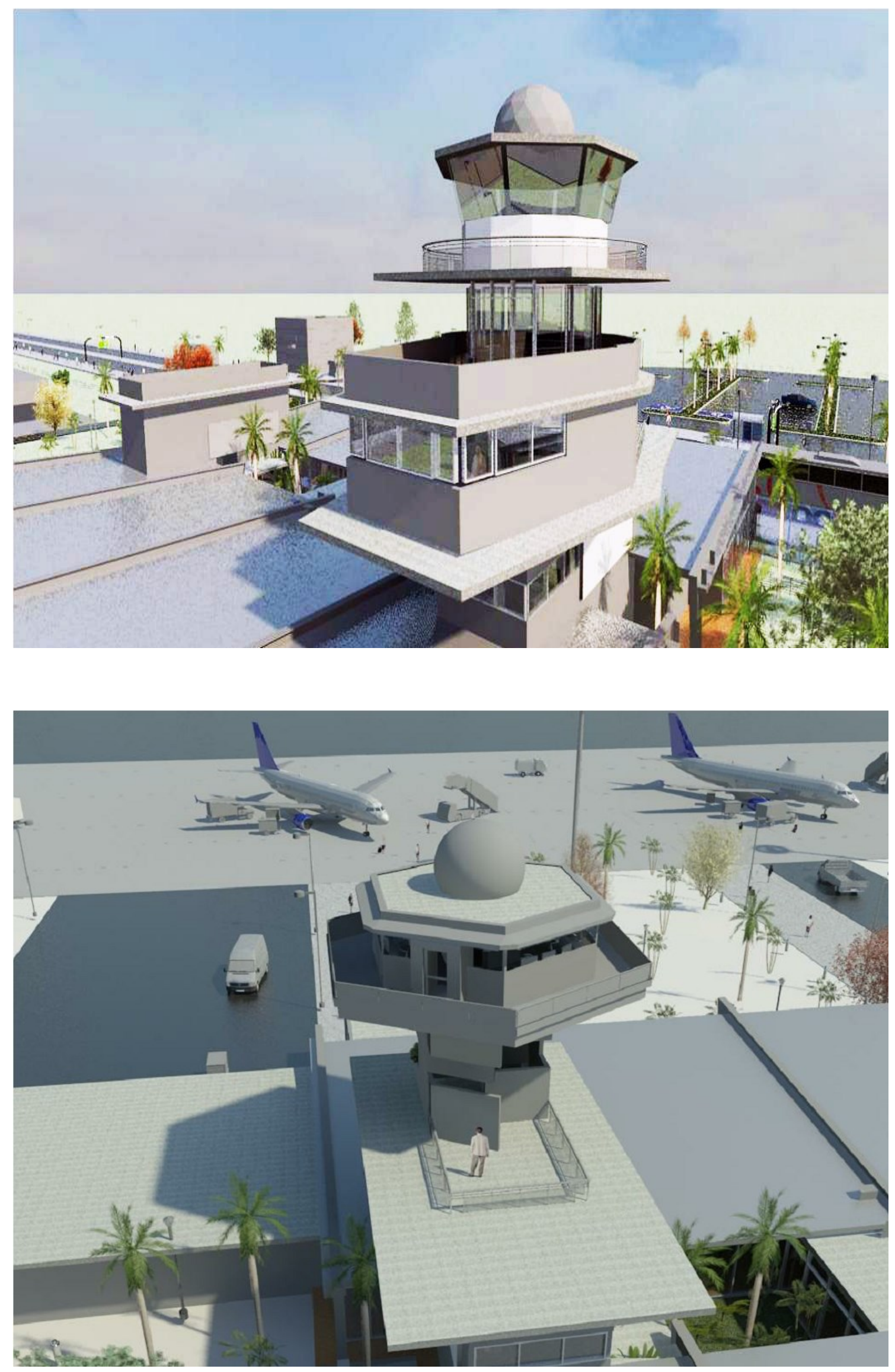

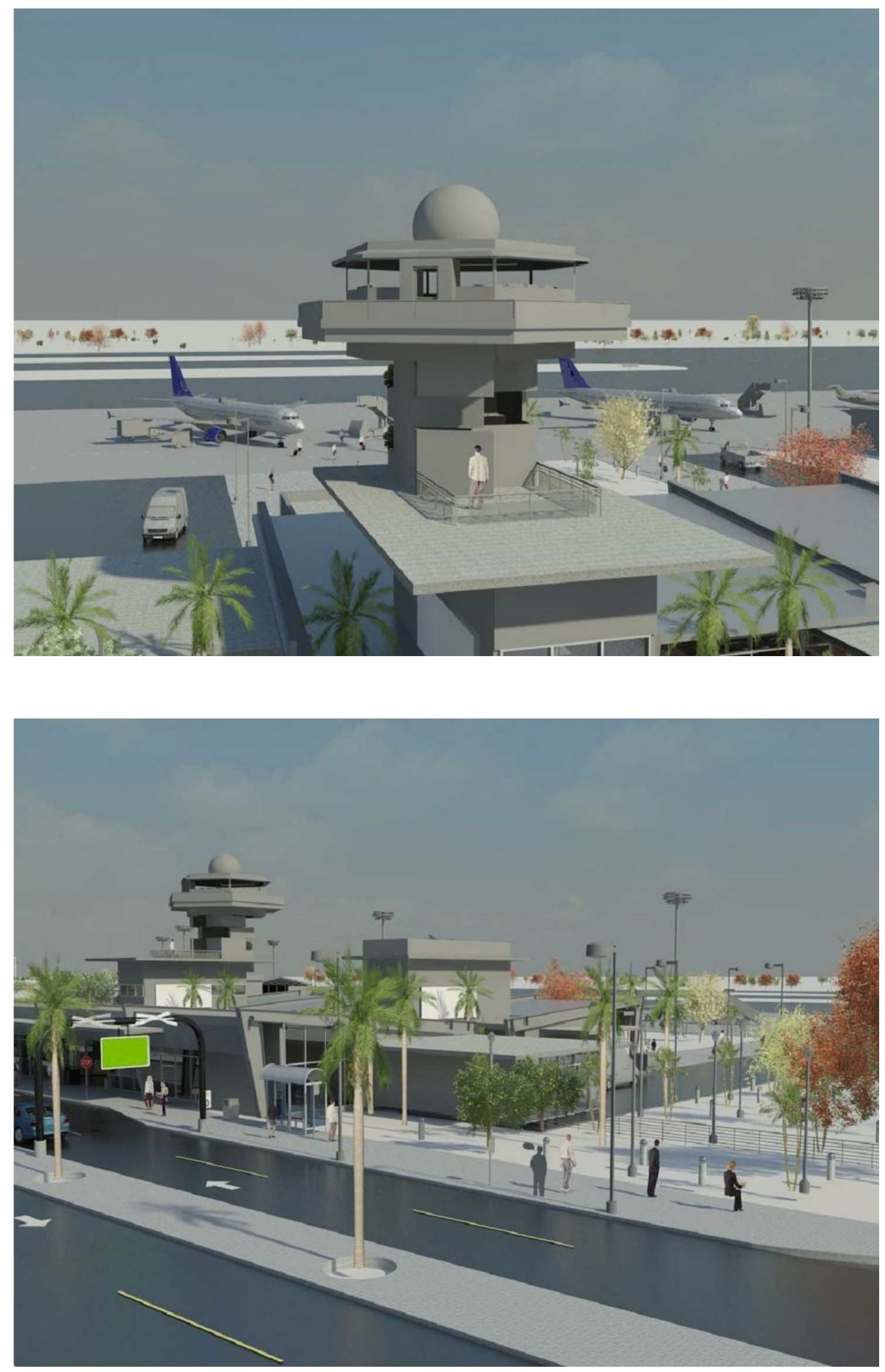
ANEXO VIII

MODELAGEM TWR-3 

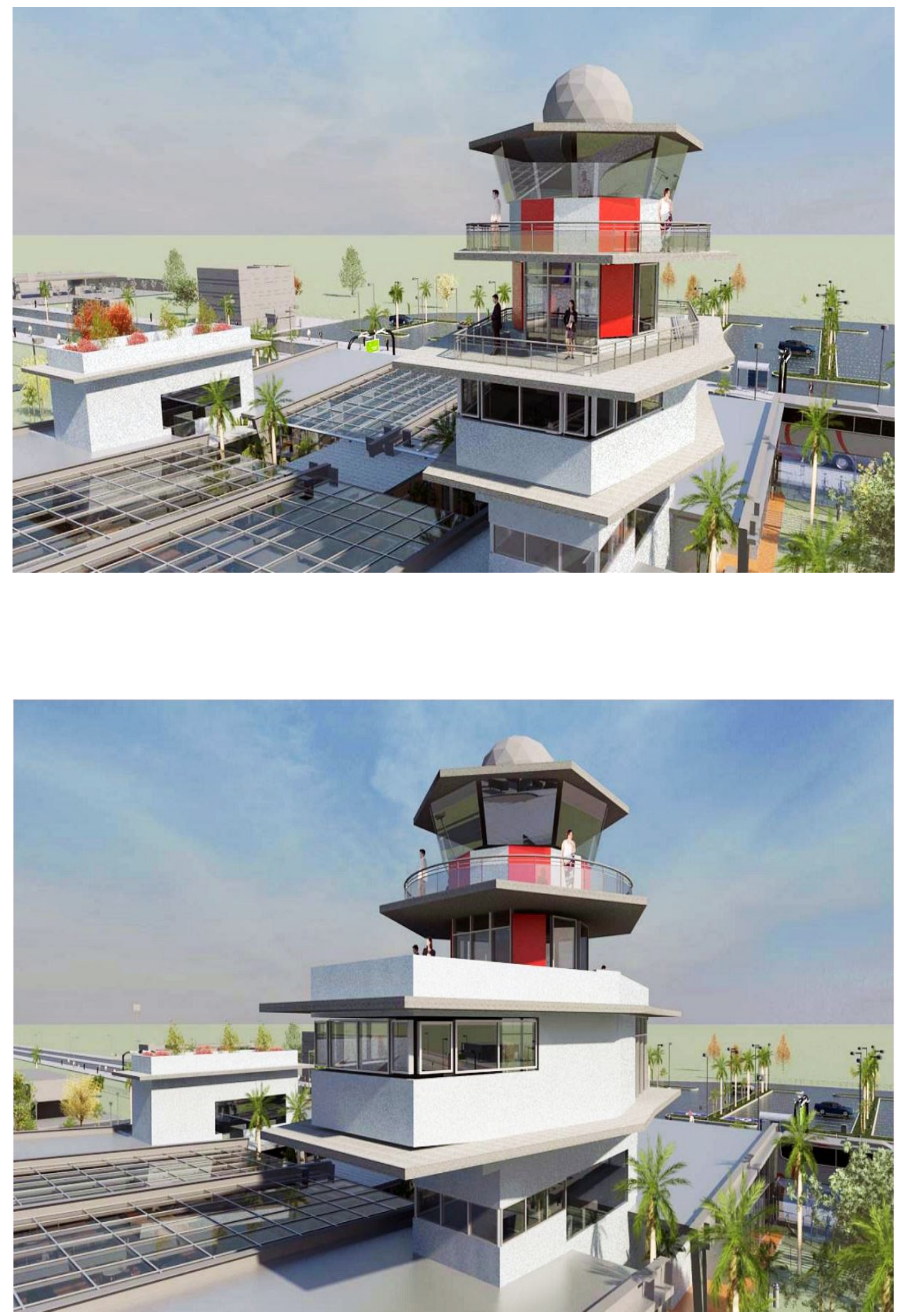

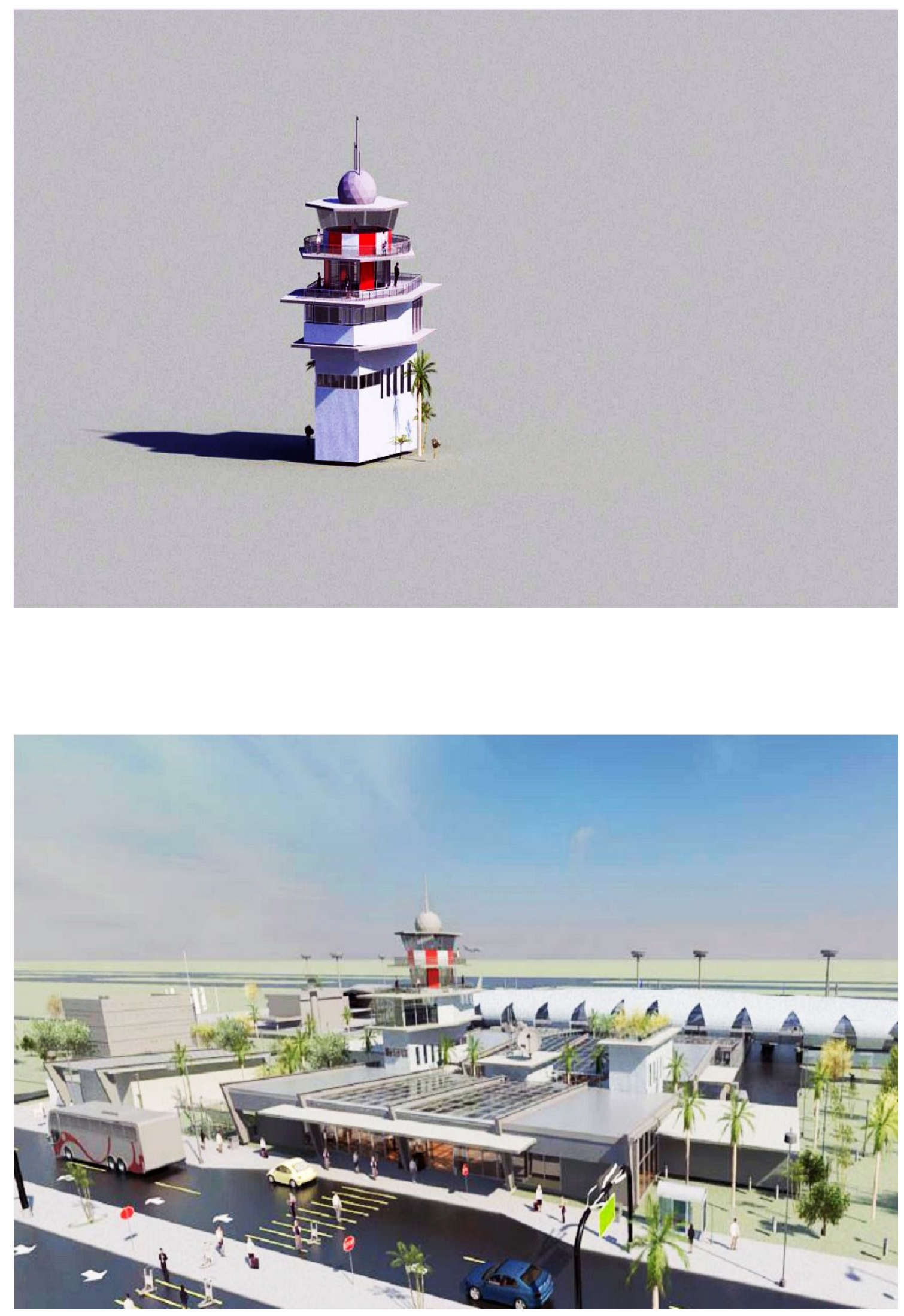
DESEMPENHO E FLEXIBILIDADE EM REALIZAR A EXPANSÃO (TWR) DO TERMINAL DE PASSAGEIROS REGIONAL- AUTODESK REVIT®

TABELA III- MÉTRICA DE DESEMPENHO - ALTERNATIVA 01.

MÉTRICA DE TEMPOS RELATIVOS (REVIT)

PARA A MODELAGEM BIM DA ALTERNATIVA 1 DA TWR

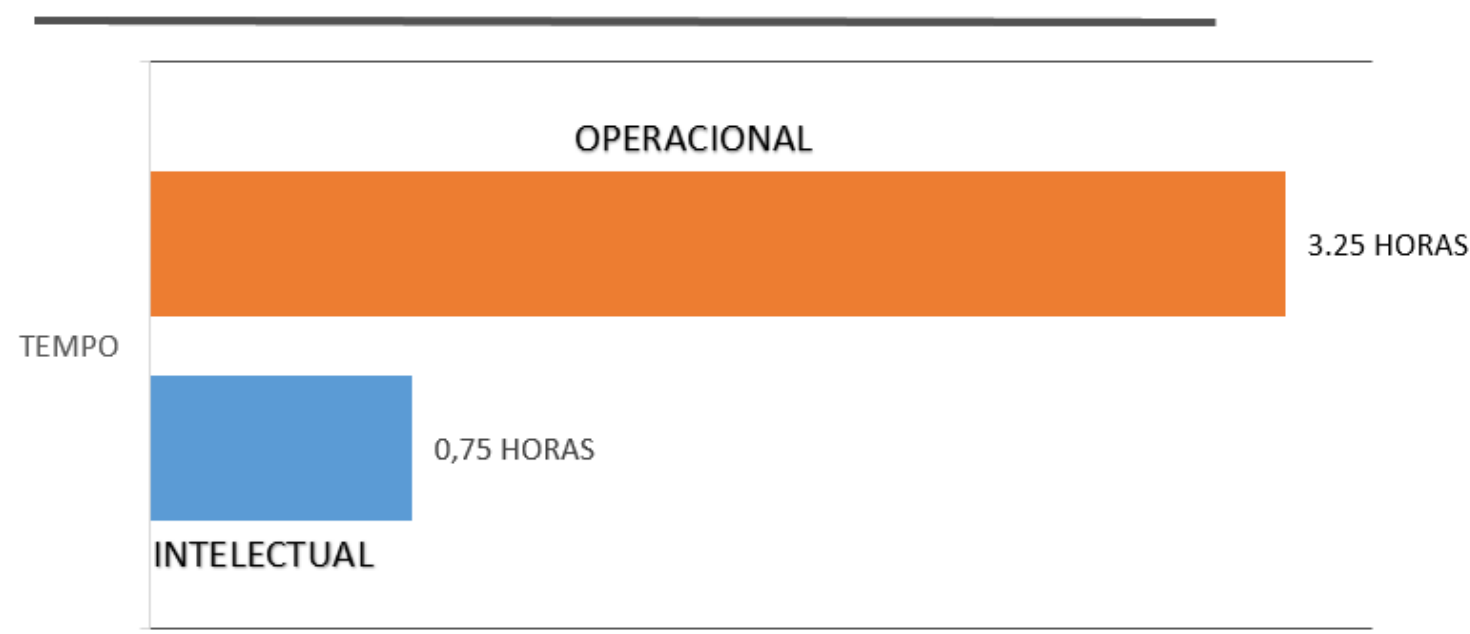

A métrica de tempos relativos obtida com a modelagem das alternativas demonstra que em projetos de menor complexidade, como a alternativa 1 de projeto, $\mathrm{o}$ Revit $^{\circledR}$, a participação intelectual do projetista no processo de projeto representa aproximadamente $20 \%$ do tempo total, em razão de permitir que o projetista gaste menos tempo com tarefas de análise e de reflexão projetual. Ao mesmo tempo, existe um número menor de tomadas de decisão ao longo deste processo. (Tabelas III a $\mathrm{VI})$

TABELA IV - MÉTRICA DE DESEMPENHO - ALTERNATIVA 02.

MÉTRICA DE TEMPOS RELATIVOS (REVIT)

PARA A MODELAGEM BIM DA ALTERNATIVA 2 DA TWR

OPERACIONAL

$76,92 \%$

5 HORAS

TEMPO

$23,08 \%$ 1,5 HORAS

INTELECTUAL 
As alternativas 2 e 3 apresentam índices crescentes de participação intelectual no processo de projeto. Existe sim um número maior de componentes modelados nas alternativas de maior complexidade, porém a maior diferença de participação de tempo intelectual se deveu ao fato de que as atividades de análise e os processos de tomada de decisão precisam realizar conexões cognitivas e semânticas com um maior número de contextos e variáveis. Como a alternativa 3 é a mais complexa das três, exigiu maior tempo de análise e de projetação, sendo que a razão entre os tempos total e de analise indica um desempenho parecido com a alternativa intermediaria. (Tabelas III a VI)

TABELA V - MÉTRICA DE DESEMPENHO - ALTERNATIVA 03.

MÉTRICA DE TEMPOS RELATIVOS (REVIT)

PARA A MODELAGEM BIM DA ALTERNATIVA 3 DA TWR

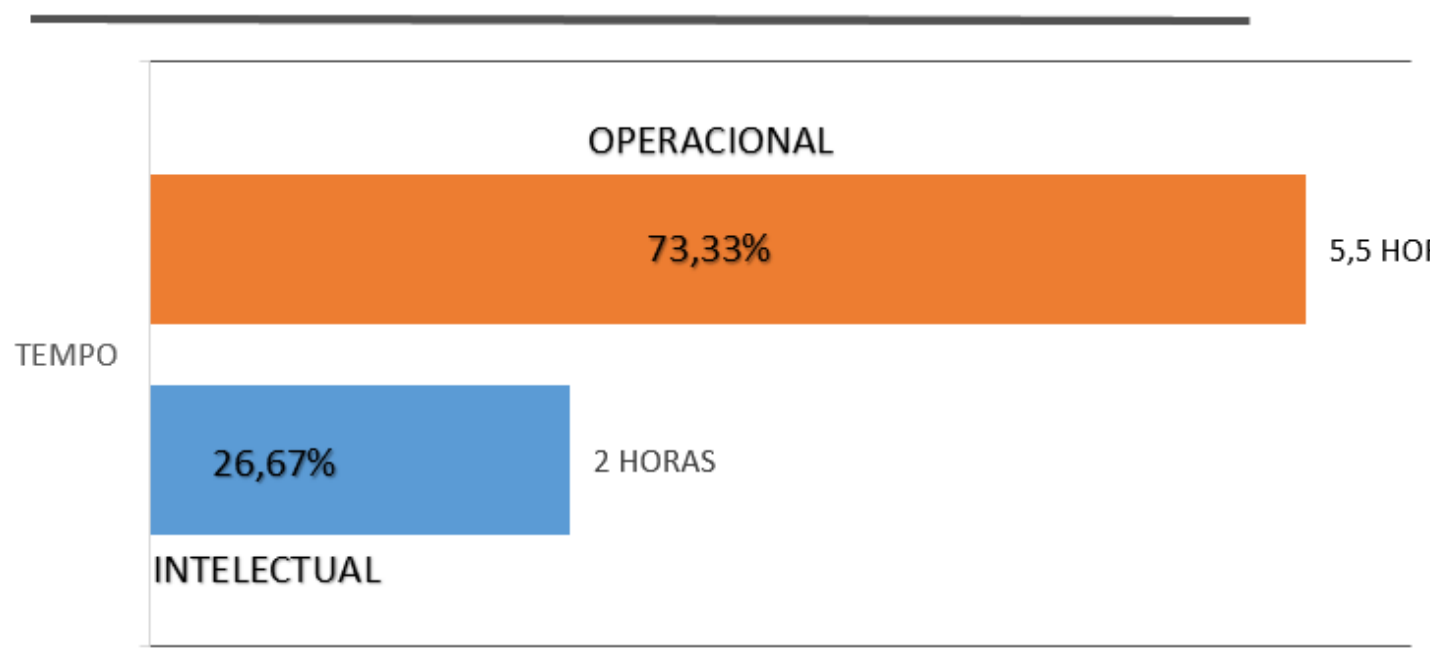

Obviamente, num projeto de menor complexidade, como a alternativa 1, teremos uma pontuação maior do desempenho, obtido em função de tempos menores de uso do computador e do tempo que o projetista passa pensando. Mas o que pudemos perceber é que quando aumentamos a complexidade a ser interpretada e representada graficamente, ao mesmo tempo que elaboramos um raciocínio projetual de maior complexidade, foi possível aumentar a razão de participação de tempo intelectual com o uso dos sistemas BIM - Revit ${ }^{\circledR}$.

A busca por soluções cabíveis culmina com o processo de tomada de decisões, e o desempenho dos sistemas BIM cai em função da parametrização obrigatória, mas também em função da dificuldade de representar diferentes níveis de detalhe e de informação. Já a análise de desempenho das três alternativas de projeto demonstrou que os sistemas BIM são ferramentas altamente eficientes e rápidas para formalização de ideias pré-concebidas. A realização das alternativas variou entre 4 a 7,5 horas de trabalho para cada uma delas, o que é um tempo relativamente pequeno dado à complexidade crescente das tarefas e dos resultados obtidos. (Tabelas III a VI) 
TABELA VI - TEMPOS TOTAIS, OPERACIONAIS E INTELECTUAIS, ABSOLUTOS E RELATIVOS, DA MODELAGEM GLOBAL E DAS TRÊS ALTERNATIVAS PARA A TORRE DE CONTROLE DO TERMINAL REGIONAL DA INFRAERO. OS TEMPOS TOTAIS ESTÃO À DIREITA DAS BARRAS, EM NEGRITO; OS TEMPOS RELATIVOS ESTÃO ACIMA DAS BARRAS E OS TEMPOS ABSOLUTOS ABAIXO DAS BARRAS.

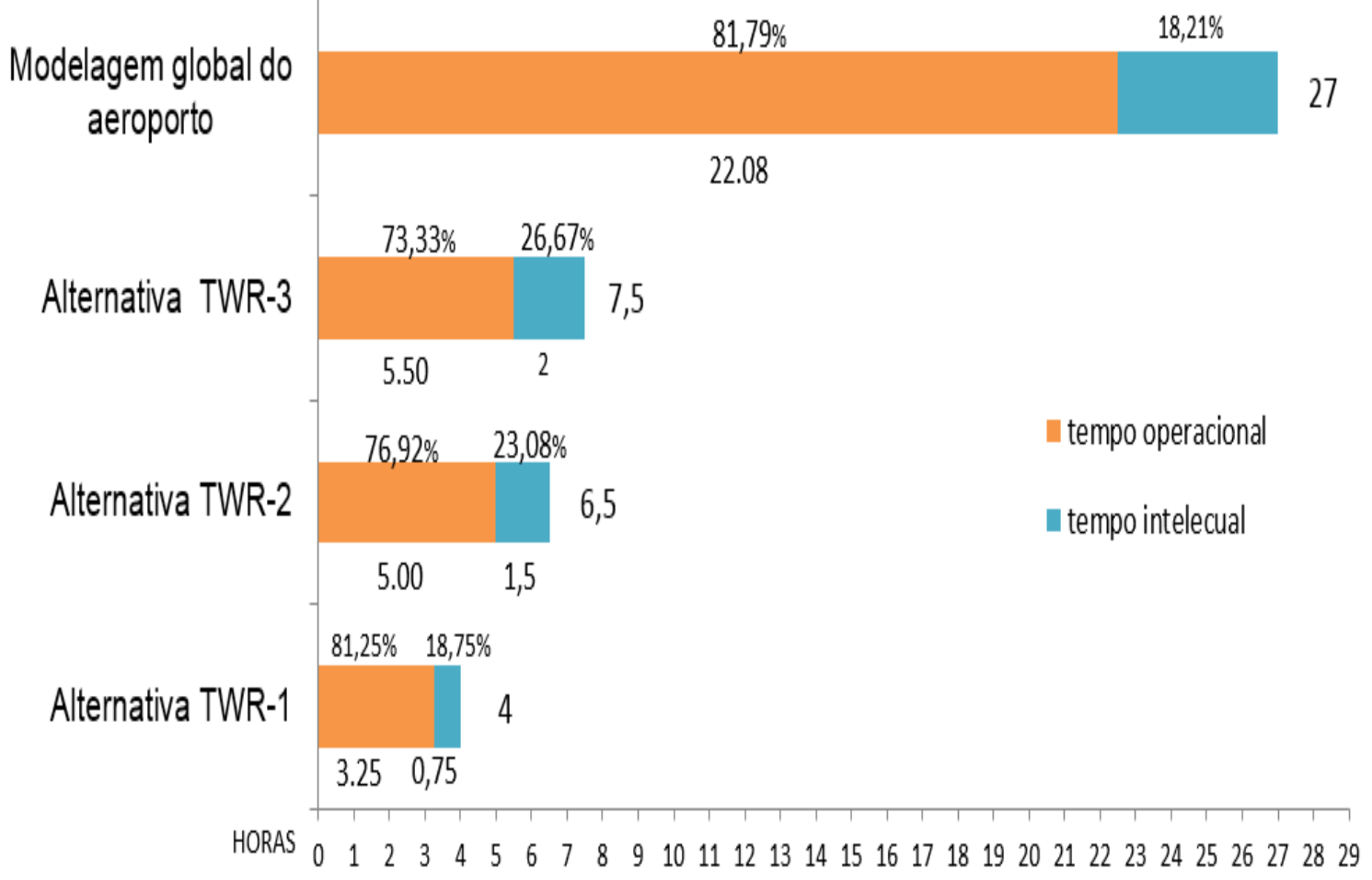

Se considerarmos os benefícios que um único profissional pode trazer a uma empresa como a INFRAERO, operando os sistemas BIM, para reproduzir projetos realizados em bases bidimensionais, e de documentação fragmentada, em bases tridimensionais paramétricas, em tempos relativamente curtos, se considerarmos os resultados desta pesquisa, indicando que a eventual adoção dos sistemas BIM pode representar um grande impacto na estrutura organizacional e nos processos de projeto desenvolvidos na empresa. Um projeto reproduzido nos sistemas BIM pode ser objeto de análises para retirada de interferências, de faseabilidade dos processos construtivos (obra), retirada de redundâncias, identificação de omissões de projeto e ainda orçamentação automatizada.

Pudemos então concluir que os sistemas BIM são ferramentas com alto grau de desempenho (eficiência) e baixo grau de flexibilidade, dados a complexidade e escopo dos projetos desenvolvidos. Os estudos realizados nesta pesquisa apontam índices que justificam o uso dos SIG como apoio aos estágios iniciais de projeto e ainda aos processos de tomada de decisão. Pelo baixo grau de flexibilidade dos sistemas BIM em lidar com a representação e a informação em diferentes níveis de detalhe, acreditamos que a criação de uma ontologia que permita a integração dessas plataformas no ambiente organizacional da INFRAERO possa auxiliar o emprego dessas ferramentas e a obtenção das vantagens ao longo de todo o processo de projeto. 


\section{COMPARACAO DOS INDICES DE DESEMPENHO ENTRE OS DOIS MOMENTOS DO PROCESSO DE PROJETO (REPRODUCAO DO TERMINAL DE PASSAGEIROS REGIONAL E ALTERNATIVAS DE EXPANSAO - TWR)}

No intuito de realizar a comparação entre a simples reprodução do terminal de passageiros regional no $\operatorname{Revit}^{\circledR}$ e a simulação de alternativas diferentes para a expansão do mesmo, através da Torre de Controle - TWR, inexistente originalmente, comparamos os tempos absolutos e relativos, índice que representa a relação entre o tempo gasto operando o computador (Operacional) e o tempo em que efetivamente o projetista realiza atividades intelectuais (formulação, síntese, análise e decisões).

As métricas de tempos relativos e absolutos referentes à reprodução do terminal de passageiros regional indicam que a participação intelectual do usuário em um sistema BIM - REVIT ${ }^{\circledR}$ aumenta proporcionalmente à utilização operacional, dado um aumento de complexidade no objeto ou modelo de projeto. Indicam ainda que o "software" BIM obteve desempenho razoável, se considerarmos os tempos absolutos (finais) para resultados como os obtidos. A expansão do terminal de passageiros regional certamente exigiu maior tempo de análise (intelectual) se comparada com a simples reprodução de um projeto pré existente, como a etapa de reprodução (modelagem global).

Uma vez que o índice de desempenho corresponde ao tempo total / tempo operacional, quanto maior o índice, maior o tempo em que o projetista desenvolveu as atividades intelectuais, e menor o tempo gasto com tarefas mecânicas ou pouco relevantes, do ponto de vista intelectual, para o processo de projeto. A análise dos índices mostra que a associação entre os sistemas BIM e SIG na realização de diferentes alternativas de projeto comprova uma maior atividade intelectual comparada à simples utilização do "software" Revit ${ }^{\circledR}$ para a reprodução do terminal de passageiros regional. Isto indica que a metodologia empregada nos sistemas BIM, associada ao poder de analise presente no SIG, permite gerar projetos cujos processos de concepção e analise representam uma parcela significativa do processo de projeto como um todo. Indica ainda capacidade significativa de gestão para a mudança de requisitos e a inserção de novos parâmetros de projeto (como foi o caso da simulação de expansão realizada) e expressos na medição dos índices levantados.

A grande diferença entre os dois momentos do processo de projeto reside no fato de que na primeira etapa de modelagem, estávamos apenas reproduzindo o projeto elaborado pela INFRAERO, ao passo que, na segunda etapa de modelagem, foi simulado o desenvolvimento de alternativas de projeto para uma torre de controle (TWR). 
A criação de diferentes propostas de projeto assemelha-se muito aos estágios iniciais de um projeto, do ponto de vista do processo criativo e da elaboração conceitual de possíveis "soluções" num determinado problema arquitetônico. Para a realização dessa tarefa, a matriz semântica foi utilizada como fonte de consulta sobre qual a relação que a TWR teria com as demais partes do aeroporto e quais os sistemas que deveria possuir. Obtivemos ainda informações sobre o nível de desenvolvimento previsto (GLOD e SLOD) para os estágios preliminares de projeto, e desta forma pudemos inserir sua elaboração esquemática em um ambiente SIG (AutoDesk InfraWorks ${ }^{\circledR}$ ). Isto permitiu avaliar a relação do objeto de projeto com seu entorno imediato, bem como sua relação com as demais partes da edificação.

Para testar as diferentes alternativas, inserimos todo o terminal de passageiros regional nessa plataforma, de modo que ao acionarmos diferentes níveis de detalhe, pudéssemos visualizar os diferentes aspectos do conjunto como um todo, seus módulos funcionais e, finalmente, os componentes construtivos. O desenvolvimento de um projeto pré-existente nos sistemas BIM (como foi o caso) em que não se precisa realizar processos de tomada de decisão, nem elaborar processos de análise e de síntese na busca de soluções de projeto, ocorre através da modelagem e parametrização correta dos componentes construtivos.

A inserção na base SIG possibilitou testar sua relação com o terreno imediato, que no caso de uma torre de controle, deve-se ater a eventuais obstruções do relevo e sua relação com a edificação. Obviamente, ao escolher como objeto de pesquisa um aeroporto projetado pela INFRAERO e desenvolver uma matriz de dados referente aos processos e à estrutura organizacional da empresa, objetiva-se promover transformações e atualizações nos processos de provimento de obras e serviços de engenharia.

Isto representa dois níveis diferentes de informação. A interligação com as informações de projeto acarreta um volume grande de informação, que deve ser processada. O grande perigo envolvido nessa situação ocorre quando as equipes de projeto gastam boa parte de sua energia tentando entender e manipular corretamente os dados, que nos processos em vigor na INFRAERO encontra-se boa parte em papel. Isto acarreta uma subordinação dos profissionais a informação, e não o contrário. Existem relativamente poucos estudos para quantificar os benefícios obtidos com o uso de sistemas BIM e SIG em empresas públicas brasileiras, porém pesquisas na área de tecnologia da informação concordam em relação à sua influência positiva sobre o desempenho do processo de projeto e sobre a irreversibilidade da transição do CAD geométrico para uma prática integrada de projeto. 


\section{ANÁLISE DO PROCESSO DE PROJETO PARA A EXPANSÃO \\ DO TERMINAL DE PASSAGEIROS REGIONAL- SISTEMAS BIM E SIG}

A melhoria dos processos garante que as tarefas necessárias para realização de um determinado produto, serviço ou conceito intelectual racionalizem os recursos demandados da empresa ou organização. Porém, não asseguram que a qualidade do produto final seja melhorada. A compleição de processos eficientes - e que ao mesmo tempo gerem produtos de qualidade - representa a meta desta pesquisa, de forma a se implantarem mudanças visando à melhoria do trabalho e à melhoria do produto. $\mathrm{A}$ composição de um arcabouço de projeto e o saber envolvido no seu emprego prático são temas centrais desta pesquisa.

O sucesso no uso dos sistemas BIM possui algo subjetivo, ou seja, seus benefícios dependem muito mais da transformação das práticas empregadas como mudanças internas de processos e de responsabilidades, associadas ao processo de projeto nas organizações, do que apenas do simples treinamento e emprego de ferramentas avançadas de computação. Envolve mudanças também culturais e de trabalho colaborativo em equipe. Exige maturidade profissional e organizacional, dentro de uma profunda visão sistêmica na definição de um conjunto de normas e de boas práticas, que consigam extrair da tecnologia e do emprego das ferramentas computacionais a informação necessária para a correta tomada de decisão ao longo do processo. Através de um estudo de caso (projeto-piloto) pesquisamos as melhores formas de utilização da tecnologia envolvida nos sistemas BIM, no processo de projeto de aeroportos brasileiros, e verificamos quais são os impactos, as barreiras e os benefícios. Detivemo-nos ainda às questões referentes à tomada de decisão e suas relações com as fases existentes no processo de projeto-nos sistemas BIM.

Obviamente, no início do projeto foi necessário um nível menor de detalhe, que foi crescendo ao longo do projeto. Apesar de muito útil, a variação de LOD disponível nos sistemas BIM não foi suficiente para representar os diferentes níveis de abstração e detalhe empregados para a elaboração de diferentes alternativas de projeto (torre de controle), configurações e ligações semânticas destas alternativas com os diferentes contextos que puderam ser testados nos SIG. A complexidade que os estágios iniciais de projeto representam para a representação da informação de um componente construtivo não está ainda disponível nos sistemas BIM. Essa complexidade pode ser definida como uma forma e um conteúdo maleáveis, ou seja, forma e informação variáveis, mutantes, de acordo com o pensamento criativo do projetista. Neste sentido, a associação dos sistemas BIM e SIG traz uma maior possibilidade de manipulação do LOD geométrico e semântico, sendo atualmente a melhor solução disponível para oferecer suporte aos sistemas BIM no início de um projeto. 


\section{ANEXO IX}

ARTE FINAL 

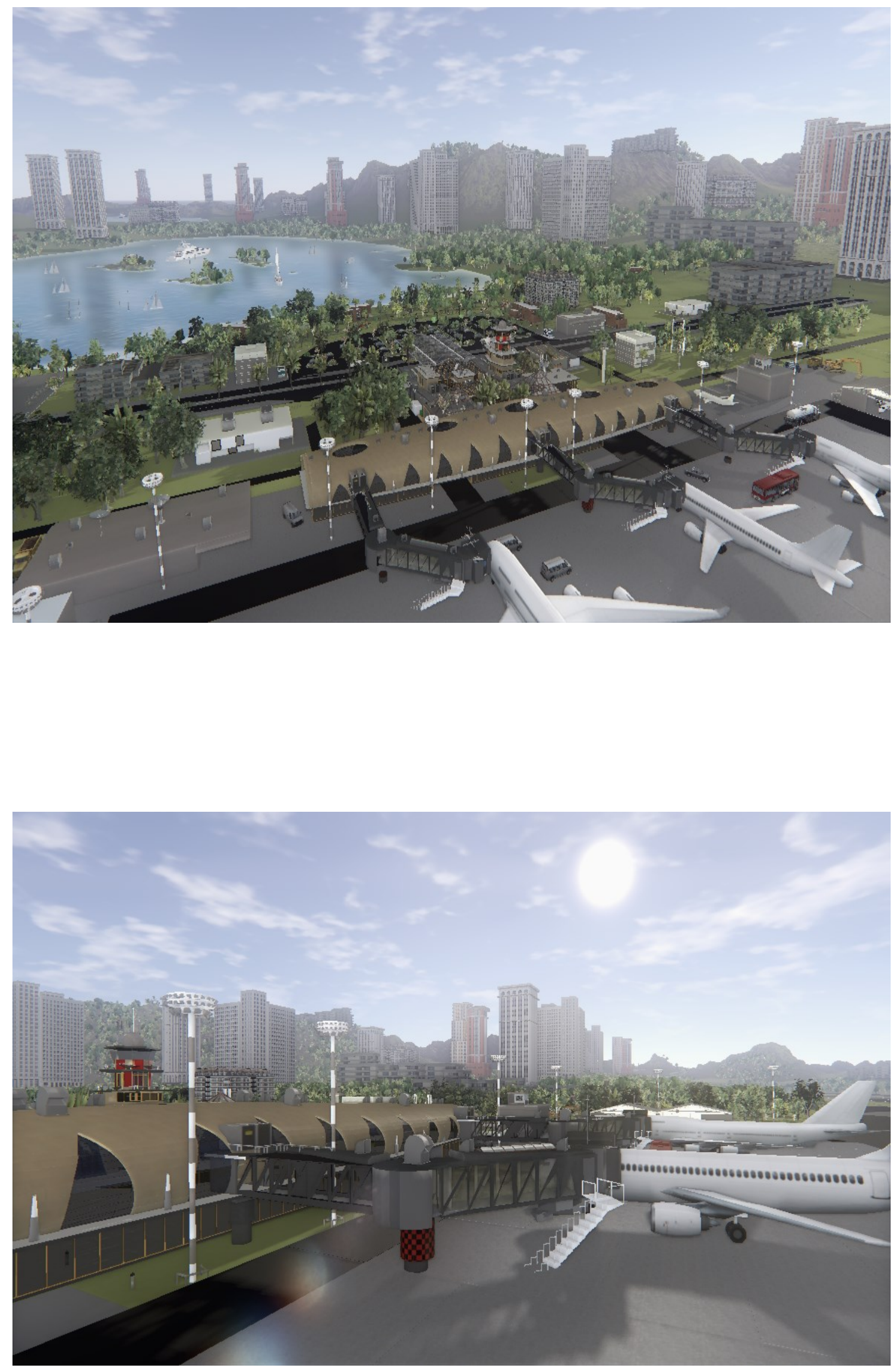

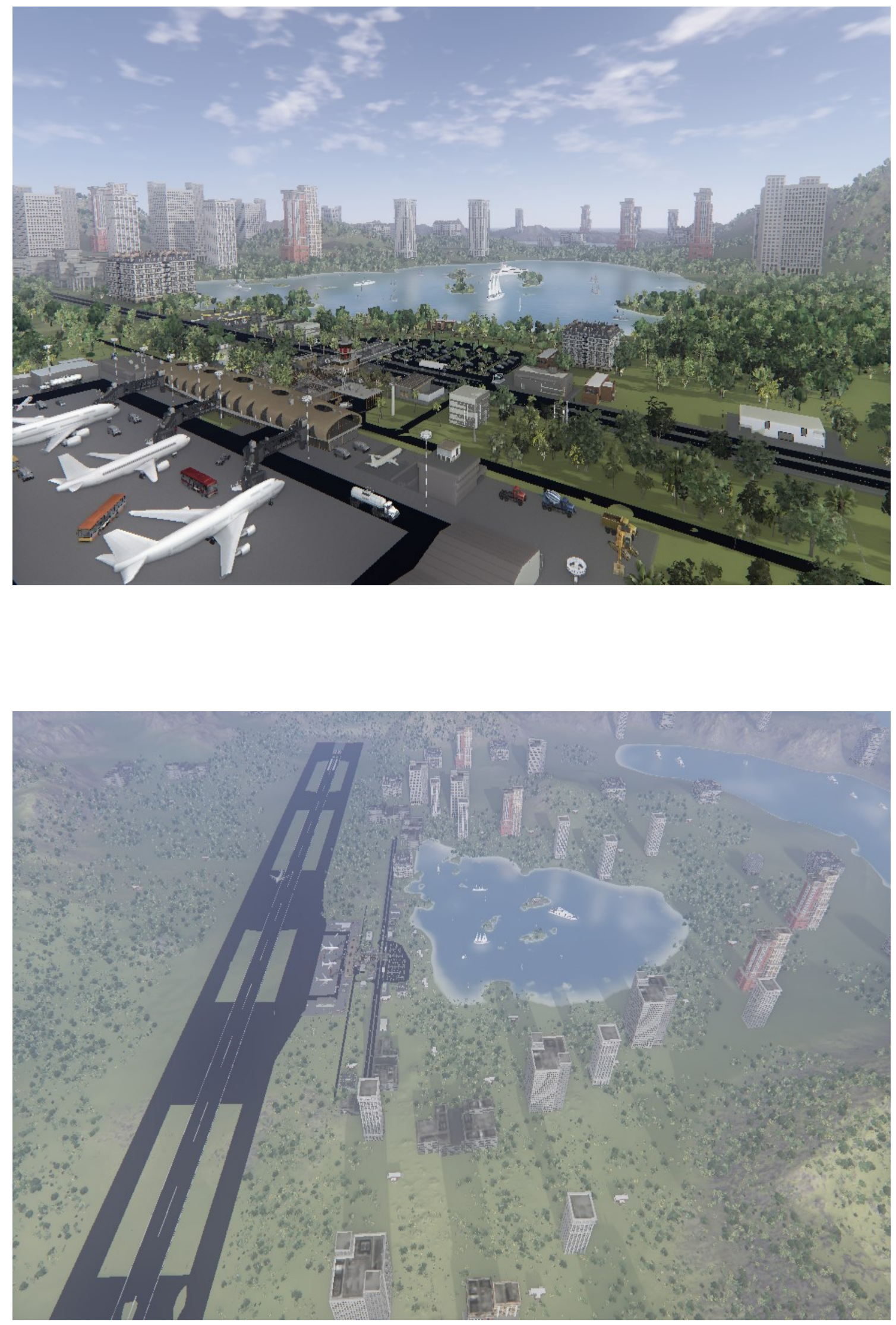

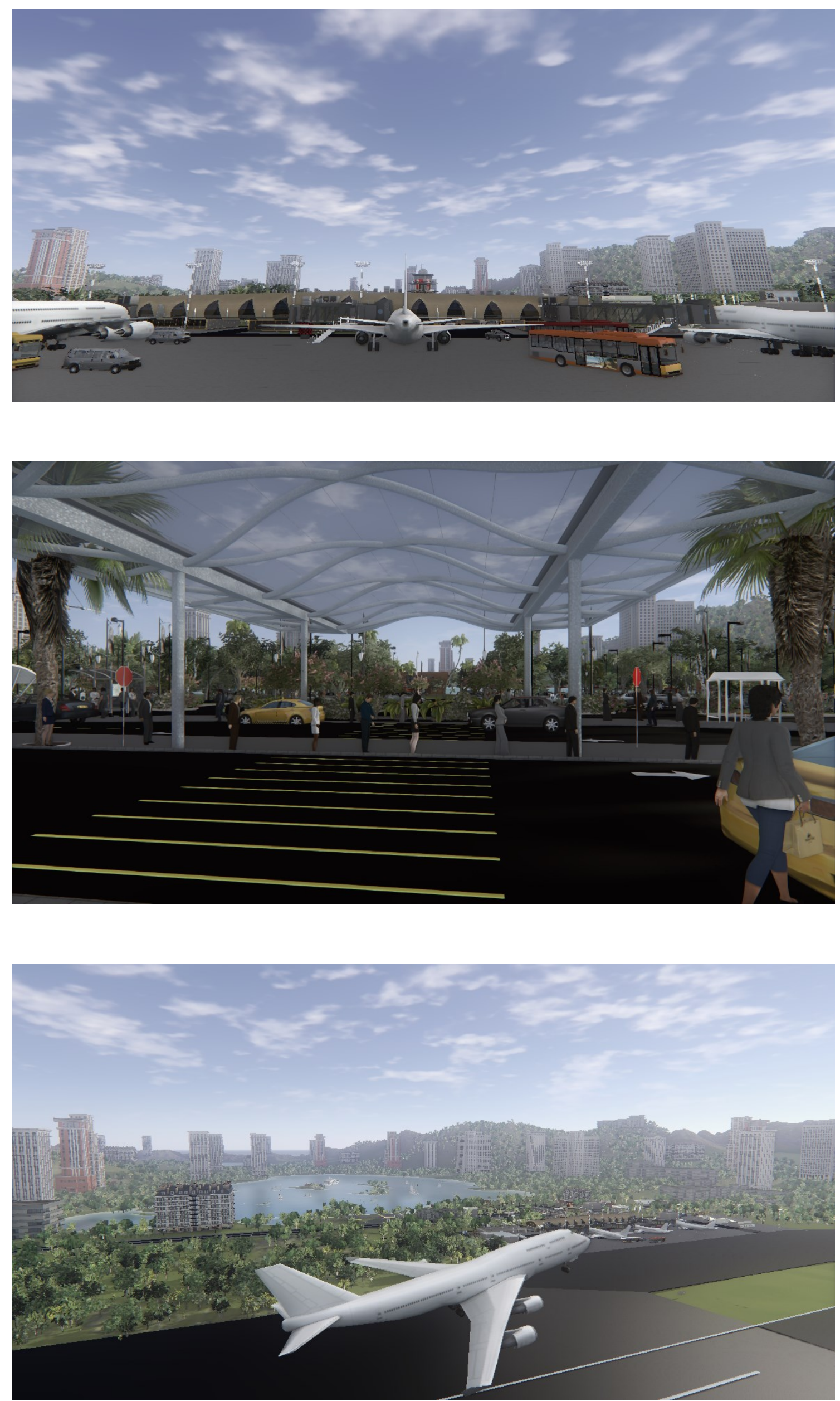
ANEXO X

TERMO DE REFERÊNCIA 
EMPRESA BRASILEIRA DE INFRA-ESTRUTURA AEROPORTUÁRIA

\section{SUPERINTENDÊNCIA DE NAVEGAÇÃO AÉREA}

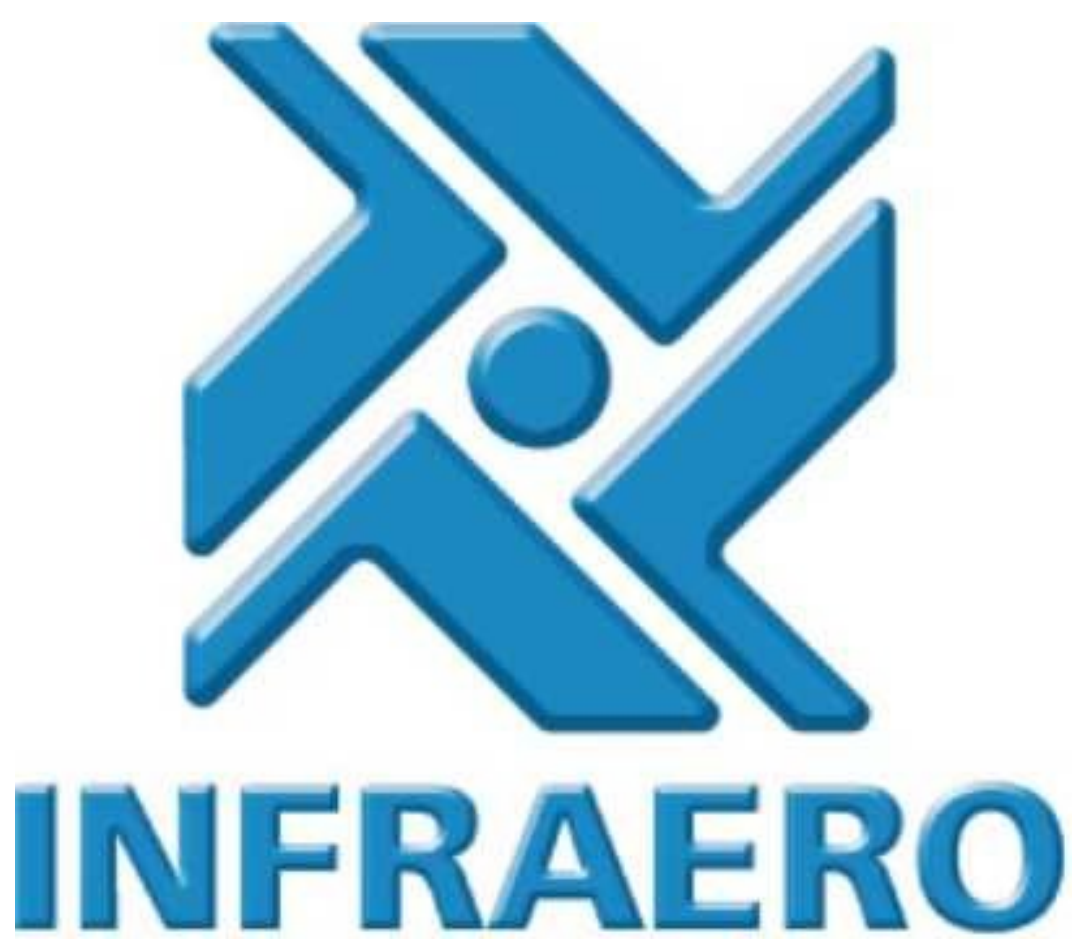

REQUISITOS DE NAVEGAÇÃO AÉREA PARA A ELABORAÇÃO DO PROJETO DE CONSTRUÇÃO DA TORRE DE CONTROLE DE ARACAJU (TWR-AR) 


\section{1- Disposições Preliminares}

\section{1- Finalidade}

O presente documento tem por objetivo estabelecer as necessidades, diretrizes e critérios para a elaboração do projeto de construção das instalações da Torre de Controle (TWR) de SBAR, permitindo a operação conjunta da referida TWR com o Controle de Aproximação (APP) de SBAR, utilizando o mesmo espaço físico, de maneira a assegurar que a execução de suas atividades ocorra segundo padrões de desempenho compatíveis com o Aeroporto e a Área Terminal de Aracaju.

\section{2- Âmbito}

O disposto no presente documento deverá ser observado por todos os órgãos envolvidos, direta ou indiretamente, na elaboração do projeto de construção da Torre de Controle e do Controle de Aproximação do Aeroporto de Aracaju.

\section{3- Grau de sigilo}

Fica o presente documento classificado como OSTENSIVO. 


\section{2- Generalidades}

\section{1- Abreviaturas}

ACC Centro de Controle de Área

AFTN Rede de telecomunicações Fixas Aeronáuticas

AIS Serviço de Informação Aeronáutica

AFIS Serviço de Informação de Vôo de Aeródromo

APP Controle de Aproximação

ATC Controle de Tráfego Aéreo

ATIS Serviço Automático de Informação em terminal

ATS Serviços de Tráfego Aéreo

ATCO Controlador de Tráfego Aéreo

CCAM Centro de Comutação Automática de Mensagens

CLRD Autorização de Tráfego

CMA Centro Meteorológico de Aeródromo

DDD Discagem Direta à Distância

EMS Estação Meteorológica de Superfície

FPV Ficha de Progressão de Vôo

GNDC Controle de Solo

H-24 Serviço contínuo de dia e noite

NASV Gerência de Navegação Aérea da Superint. Regional do Centro-Leste

ONA Órgãos de Navegação Aérea

PC Computador pessoal padrão IBM

SAC Secretaria de Aviação Civil

SBAR Aeroporto de Aracaju

SCl Serviço Contra-Incêndio

SGTAI Sistema Gerenciador de Telecomunicações Aeronáuticas da INFRAERO

SISCEAB Sistema de Controle do Espaço Aéreo Brasileiro

SGTC Sistema de Gerenciamento de Torre de Controle

SUP Supervisor de Torre de Controle

UTC Tempo Universal Coordenado

TF-2 Enlace Telefônico Operacional

TMA Área de Controle Terminal

TWR-AR Torre de Controle do Aeroporto de Aracaju

UHF Freqüência Ultra Alta

VHF Freqüência Muito Alta 


\section{2 - Definições}

Assistente - Controlador de Tráfego Aéreo habilitado para exercer as atribuições específicas da posição assistente de um setor operacional de controle de um órgão ATC.

Cabine - Espaço físico da Torre de Controle destinado a acomodar a equipe operacional, equipamentos e mobiliário específico, necessários ao funcionamento do órgão.

Controle de Aproximação - Órgão estabelecido para prestar Serviço de Controle de Tráfego Aéreo aos vôos controlados nas Áreas de Controle Terminal e nas Zonas de Controle.

Coordenador - Controlador de tráfego aéreo, designado para coordenar as atividades ATC entre as posições operacionais de um órgão ATC e entre este e órgãos ATS.

Efetivo Operacional - Total de ATCO habilitados e necessários ao desempenho dos serviços operacionais inerentes ao órgão ATC.

Equipe Operacional - Conjunto de operadores designados para a execução das atividades de um órgão operacional, em um turno de serviço.

Hot-line - Enlace telefônico que permite ligações instantâneas.

Incidente de Tráfego Aéreo - Ocorrência envolvendo Tráfego Aéreo que constitua risco para as aeronaves, relacionadas com facilidades, procedimentos e proximidade de aeronaves.

Módulo SGTC - Microcomputador do SGTC instalado nas posições operacionais.

Posição Assistente de Torre - Posição operacional de uma TWR, ativada para auxiliar a posição Torre nas tarefas inerentes ao controle de aeródromo.

Posição Autorização de Tráfego - Posição operacional de uma TWR, responsável pela expedição de autorizações de tráfego aéreo.

Posição Operacional - Posição, em um Órgão ATC, caracterizada por um conjunto de encargos atribuídos a um Controlador de Tráfego Aéreo, no desempenho de um serviço operacional

Posição Solo - Posição operacional de uma TWR responsável pelo controle dos movimentos de aeronaves, veículos e pessoas na área de manobras, exclusive a pista.

Posição Supervisor - Posição operacional responsável por supervisionar as atribuições e o desempenho dos ATCO de uma equipe operacional, bem como os aspectos relacionados ao trabalho em equipe.

Posição Torre - Posição Operacional de uma TWR, responsável pela prestação dos Serviços de Tráfego Aéreo na Zona de Tráfego de Aeródromo.

Serviço de Alerta - Serviço prestado para notificar os órgãos apropriados a respeito das aeronaves que necessitem de ajuda de busca e salvamento e para auxiliar tais órgãos no que for necessário.

Serviço de Controle de Tráfego Aéreo - Serviço prestado com a finalidade de prevenir colisões, acelerar e manter ordenado o fluxo de tráfego aéreo.

Serviço de Informação de Vôo - Serviço prestado com a finalidade de proporcionar avisos e informações úteis para a realização segura e eficiente dos vôos.

Serviço de Tráfego Aéreo - Expressão genérica que se aplica aos Serviços de Controle de Tráfego Aéreo, de Assessoramento, de Informação de Vôo e de Alerta.

Torre de Controle de Aeródromo - Órgão estabelecido para prestar o Serviço de Controle de Tráfego Aéreo ao tráfego de aeródromo. 


\section{3 - Análise da Situação}

\section{1 - Cenário Atual}

3.1.1- O Aeroporto de Aracaju dispõe, atualmente, de um Controle de Aproximação (APP-AR) que é responsável pela prestação dos Serviços de Controle de Tráfego Aéreo, de Informação de Voo e de Alerta a todas as aeronaves em evolução na TMA e na CTR Aracaju.

3.1.2- Os espaços aéreos da TMA e da CTR Aracaju abrangem os seguintes aeródromos, identificados nas publicações aeronáuticas:

- Aracaju;

- Aeroclube de Aracaju;

- Laranjeiras/Fazenda Boa Luz;

- Estância/Praia do Saco;

- Propriá; e

- Penedo (Alagoas).

3.1.3- Face à inexistência de uma Torre de Controle, o APP-AR, cumulativamente com suas atividades específicas, proporciona, também, o Serviço de Informação de Vôo de Aeródromo (AFIS), na mesma frequência do APP, no espaço aéreo correspondente ao Circuito de Tráfego do aeródromo de Aracaju, bem como na área de movimento do mesmo.

3.1.4- Dentro da rotina de suas atividades, o APP-AR tem, ainda, a seu encargo a coordenação dos voos de instrução e dos demais pousos e decolagens, realizados no Aeroclube de Aracaju, além de ser responsável pelo acompanhamento e gerenciamento do movimento de helicópteros no litoral, com destino ou procedentes das plataformas de exploração de petróleo.

3.1.5- O controle de tráfego aéreo na região emprega o "sistema passo-a-passo", no qual as coordenações de tráfego aéreo são efetuadas diretamente entre os APP.

3.1.6- Tendo em vista a situação de aeródromo não controlado, compete aos pilotos das aeronaves operando no aeródromo de Aracaju a escolha da pista a ser utilizada para pousos e decolagens, acarretando inconvenientes ao planejamento efetuado pelo APP-AR e, muitas vezes, ocasionando irregularidades de tráfego aéreo e colocando em risco as operações aéreas naquele aeroporto. 
3.1.7- O aeródromo de SBAR possui somente uma pista de táxi central para acesso do pátio de estacionamento à pista de pouso/decolagens e vice-versa, necessitando de atenção redobrada e coordenação bastante rígida por parte do APP, haja vista que não existe visão da Área de Manobras.

3.1.8- A inexistência de pistas de táxi para acesso às cabeceiras faz com que as aeronaves que estão por decolar efetuem uma longa espera no pátio, até que se complete o pouso das aeronaves chegando. O APP, não podendo emitir autorizações e não tendo os tráfegos à vista, fica exposto a uma situação que seria facilmente solucionada por uma TWR.

\subsection{9- Movimento do Aeroporto de Aracaju}

A quantidade de operações aéreas no aeroporto de Aracaju, nos últimos anos, vem aumentando gradativamente, conforme demonstram os dados constantes da tabela abaixo, o que aponta para a necessidade de implantação de uma Torre de Controle de Aeródromo naquele aeroporto.

\begin{tabular}{|l|l|l|l|}
\hline ANO & COMERCIAL & IFR & TOTAL ARR/DEP \\
\hline 2004 & 7.728 & 8.943 & 14.272 \\
\hline 2005 & 8.141 & 9.604 & 15.598 \\
\hline 2006 & 10.169 & 10.484 & 18.458 \\
\hline 2007 & 9.459 & 10.747 & 19.980 \\
\hline
\end{tabular}

\section{2- Cenário Desejado}

3.2.1- Devido ao elevado número de aeronaves que operam no aeroporto de Aracaju as operações aéreas que se desenvolvem naquele aeródromo devem ser controladas.

3.2.2- O Aeroporto de Aracaju deve dispor de uma Torre de Controle de Aeródromo suficientemente ampla para abrigar e suportar, de forma ergonômica, todas as posições operacionais necessárias para atender a demanda de tráfego aéreo existente naquele aeroporto e permitir possibilidades de expansões futuras.

3.2.3- A TWR-AR deve dispor de recursos técnicos com padrão de sofisticação compatível com os níveis de desempenho operacional que dela se espera, no âmbito do SISCEAB. 
3.2.4- A implantação de uma Torre de Controle em Aracaju permitirá um efetivo Serviço de Controle de Tráfego Aéreo no aeródromo, proporcionando maior segurança às operações que se desenvolvem naquele aeroporto, diminuindo os conflitos e os riscos à segurança de voo, e permitindo maior fluidez ao fluxo de tráfego aéreo naquela localidade.

3.2.5- As dimensões da cabine da Torre de Controle deverão possibilitar acomodação suficiente e adequada para as posições operacionais da TWR e do APP, uma vez que ambos compartilharão o mesmo ambiente.

3.2.6- Com a implantação de uma TWR, o APP-AR deixará de prestar o AFIS no Aeródromo de Aracaju o que, consequentemente propiciará uma diminuição da carga de trabalho do controlador do APP e aumentará o seu fator de disponibilidade, obtendo, com isto, maior tempo para o planejamento e prestação do Serviço de Controle de Tráfego Aéreo na TMA SBXA.

\section{3- Situação Específica}

3.3.1- A implantação da TWR-AR propiciará a instalação de uma estrutura adequada de órgãos de navegação aérea em Aracaju, compatível com as necessidades locais, incluindo o controle de aeródromo, atualmente inexistente, proporcionando maior disponibilidade de tempo para o APP-AR para a prestação de controle de tráfego aéreo na TMA SBXA.

3.3.2- O trabalho de coordenação, planejamento e controle do tráfego aéreo na TMA e na CTR Aracaju ficará facilitado, evitando o congestionamento da frequência do APP, nos horários de maior movimento na área de manobras e no circuito de tráfego, tendo em vista que as aeronaves passarão a chamar a TWR para as instruções de saídas e chegadas.

3.3.3- As aeronaves, que evoluem no Circuito de Tráfego e Área de Manobras do aeródromo de Aracaju, passarão a ter um controle de tráfego aéreo efetivo, por parte da TWR-AR, proporcionando maior índice de segurança para as operações aéreas.

3.3.4- As instalações da Torre de Controle de Aeródromo do Aeroporto de Aracaju trarão, como benefício, a possibilidade de implantação de novas posições operacionais e instalação de novos equipamentos e, consequentemente, elevação dos padrões de eficiência na prestação dos Serviços de Tráfego Aéreo naquele aeródromo. 


\section{4 - Descrição}

4.1- O prédio da Torre de Controle será edificado entre o TPS atual e o novo TPS e abrigará no mesmo espaço físico de sua cabine operacional a TWR e o APP-AR.

4.2- A TWR-AR terá sob sua jurisdição o circuito de tráfego e a Área de Manobras do aeródromo, estando adequada para atender a expectativa de incremento do tráfego aéreo naquela localidade.

4.3- A TWR-AR será subordinada operacionalmente ao APP-AR e ao ACC-RE e, portanto, estará sujeita aos procedimentos de ordem operacional por eles impostos, além dos previamente estabelecidos na regulamentação vigente.

4.4- A TWR e o APP Aracaju, abrigados no mesmo espaço físico, operarão em frequências distintas e estabelecerão os contatos necessários às coordenações à viva voz.

4.5- A fim de atender à atual demanda de tráfego aéreo, a Torre de Controle de Aracaju (TWR-AR) terá as seguintes posições operacionais:

\section{a) TORRE}

Posição operacional, caracterizada por um conjunto de encargos atribuídos a um ATCO, para a prestação dos Serviços de Controle de Aeródromo, de Informação de Vôo e de Alerta.

\section{b) ASSISTENTE DE TORRE}

Posição operacional, caracterizada por um conjunto de encargos atribuídos a um ATCO, com o objetivo de auxiliar o titular da posição TORRE na prestação dos Serviços de Controle de Aeródromo, de Informação de Vôo e de Alerta, bem como promover o intercâmbio de informações com as demais posições operacionais da TWR e com os órgãos ATS adjacentes, com a finalidade de assegurar a continuidade da prestação dos serviços de tráfego aéreo a um determinado tráfego.

4.6- Objetivando adequar a construção da torre às necessidades operacionais, o projeto deverá, a fim de possibilitar expansões futuras, prever as seguintes posições operacionais:

a) Torre 

b) Assistente de Torre
c) Solo
d) Autorização de Tráfego
e) Coordenador; e

f) Supervisor.

4.7- O APP-AR funcionará no mesmo ambiente físico da TWR e deverá possuir as seguintes posições operacionais:

\section{a) CONTROLE}

Posição operacional, caracterizada por um conjunto de encargos atribuídos a um ATCO, para a prestação dos Serviços de Controle de Aproximação, de Informação de Voo e de Alerta em um APP não setorizado.

\section{b) POSIÇÃO ASSISTENTE}

Posição operacional, caracterizada por um conjunto de encargos atribuídos a um ATCO, com o objetivo de auxiliar o titular da posição controle na prestação de Serviços de Tráfego Aéreo, de Informação de Voo e de Alerta, bem como promover o intercâmbio de informações com as demais posições operacionais do mesmo APP ou de órgãos ATS adjacentes, com a finalidade de assegurar a continuidade da prestação dos serviços de tráfego aéreo a um determinado tráfego.

4.8- O plano de operação e a estrutura funcional e organizacional do APP e da TWRAR deverão constar do Modelo Operacional e do Manual dos referidos órgãos ATC que serão elaborados pela Gerência ou Coordenação de Navegação Aérea de Aracaju, sob supervisão da Gerência de Navegação Aérea da NASV.

4.9- O horário de funcionamento do APP e da TWR-AR será H-24, dividido em 4 (quatro) turnos de 6 (seis) horas.

4.10-. O efetivo operacional necessário para operar a TWR-AR e o APP-AR, no mesmo ambiente, atendendo à legislação do DECEA e à legislação trabalhista, é de 29 (vinte e nove) controladores, devidamente habilitados.

4.11- A configuração (limites vertical e horizontal) da TMA SBXA não sofrerá alteração. 


\subsection{2- Enlaces}

Os enlaces dos serviços fixo e móvel se darão de conformidade com a figura abaixo:

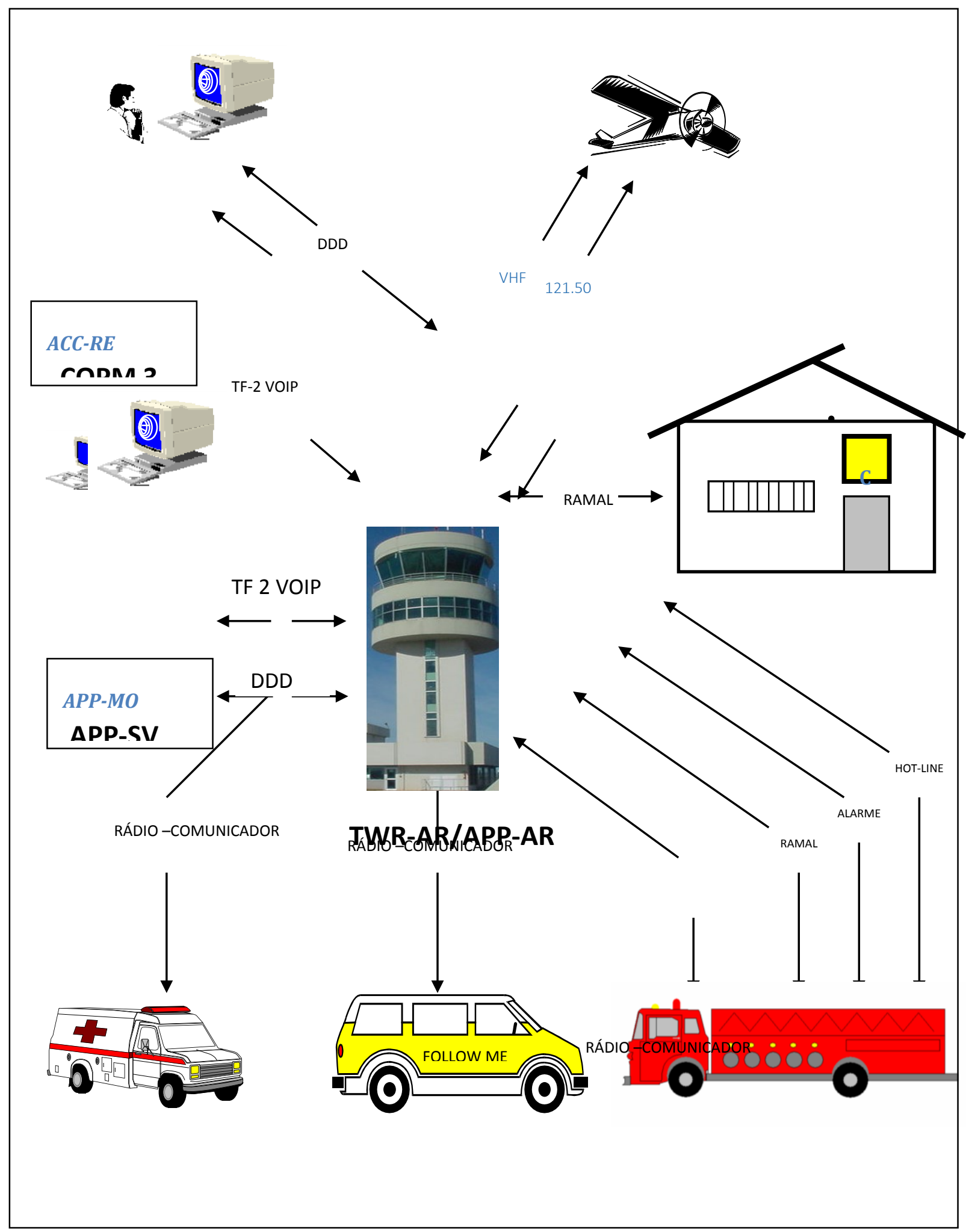




\section{5- Requisitos e Critérios Operacionais}

\section{1- Requisitos Operacionais}

A TWR e o APP-AR deverão possuir os recursos abaixo discriminados, visando à provisão efetiva e eficiente dos serviços a serem prestados:

1. Enlaces telefônicos que proporcionem comunicações de alta confiabilidade com os seguintes órgãos e serviços:

- ACC-RE;

- COPM 3;

- APP-MO;

- APP-SV;

- Sala AIS SBAR;

- EMS-2 SBAR;

- Administração do aeroporto (Operações);

- Serviço Contra Incêndio do Aeroporto;

- Serviço de Manutenção de Aeronavegação.

2. Sistema de energia secundária para suprir eventuais quedas de energia comercial. Sistema que garanta o funcionamento ininterrupto dos VHF's.

\subsection{1 - Consoles Operacionais}

A torre deverá dispor de consoles para atender às seguintes posições operacionais:

a) Torre, com o seu respectivo assistente (2 módulos);

b) Consoles Reservas (3).

Os 3 (três) módulos reservas deverão atender a um possível aumento de tráfego, redundando na necessidade de ativação das posições Solo, Autorização de Tráfego e Supervisor, em conformidade com os critérios estabelecidos na ICA 100-30.

\subsubsection{1 - Console de Torre}

Os módulos da posição Torre e da posição Assistente de Torre comporão um único console de comprimento duplicado, de forma que os equipamentos abaixo sejam distribuídos ergonomicamente entre ambos: 
a) relógio digital;

b) indicador digital de direção e velocidade do vento;

c) indicador digital de ajuste de altímetro;

d) indicador digital de temperatura;

e) indicador analógico de direção e velocidade do vento (reserva);

f) indicador analógico de ajuste de altímetro (reserva);

g) postos-operadores radiotelefônicos, um para cada console (com microfone, "head-set" e controle de volume individual para os sinais sonoros de chamada telefônica), disponibilizando as seguintes ligações:

- frequências em VHF da Torre, do Controle e mais a frequência $121.5 \mathrm{Mhz}$;

- 2 ramais TF-2, via VOIP (extensão do APP);

- linha telefônica externa, liberada para ligações DDD;

- linha telefônica externa, independente da central, a ser utilizada caso haja degradação desta;

- ramais internos;

- hot-line com SCl;

h) transceptor VHF variável de emergência (a bateria);

i) transceptor rádio UHF para contato com $\mathrm{SCl}$, viaturas, serviço médico e operações de pátio;

j) painel alfanumérico demonstrativo das frequências em operação do APP-AR;

k) módulo torre do SGTC, com monitor LCD 17';

l) terminal do SGTAl;

m) monitor de visualização da EMS-2;

n) botão de alarme para acionamento do $\mathrm{SCl}$.

o) painéis de controle dos sistemas de balizamento e auxílios visuais; e

p) um computador para os serviços gerais da TWR/APP. 


\subsubsection{2- Console do APP}

O APP deverá dispor de consoles para atender às seguintes posições operacionais:

a) Controle, com o seu respectivo assistente (2 módulos);

b) Console Reserva (1).

Os módulos da posição Controle e da posição Assistente comporão um único console de comprimento duplicado, de forma que os equipamentos abaixo sejam distribuídos ergonomicamente entre ambos

a) relógio digital;

b) indicador digital de direção e velocidade do vento;

c) indicador digital de ajuste de altímetro;

d) indicador digital de temperatura;

e) indicador analógico de direção e velocidade do vento (reserva);

f) indicador analógico de ajuste de altímetro (reserva);

g) postos-operadores radiotelefônicos, um para cada console (com microfone e "head-set" e controle de volume individual para os sinais sonoros de chamada telefônica), disponibilizando as seguintes ligações:

- frequências em VHF do APP, da TWR e mais a frequência 121.5 Mhz;

- 2 ramais TF-2, via VOIP;

- linha telefônica externa, independente da central, a ser utilizada caso haja degradação desta;

- ramais internos;

- hot-line com SCI (extensão da TWR);

h) transceptor VHF variável de emergência (a bateria);

i) frequências em VHF capazes de proporcionar cobertura de comunicações nos limites da TMA, no FL mínimo das aerovias, de forma a suportar todos os procedimentos de saída e de descida.

j) módulo do SGTC, com monitor LCD 17';

k) módulos Supervisor e Servidor do SGTC;

I) impressora para o SGTC;

m) painel alfanumérico demonstrativo das frequências em operação da TWR-AR, do APP-SV, do APP-MO e do ACC-RE;

n) painéis de controle dos sistemas de balizamento e auxílios visuais;

o) Sistema de monitoramento dos auxílios à navegação aérea (VOR/DME e NDB); e

p) TARIS, monitor LCD de 17 polegadas, para visualização de dados radar de rota de Maceió e Salvador. 


\subsection{2- Equipamentos e Recursos Adicionais}

A torre deverá dispor, ainda, dos seguintes equipamentos e/ou recursos adicionais:

a) terminal CCAM/SGTAI, composto de PC padrão INFRAERO e impressora matricial;

b) pistola de sinalização, afixada no teto, de forma a permitir o acesso, do controlador da posição Torre;

c) iluminação indireta e articulada em todos os consoles, com acionamento individual, para permitir anotações e consultas, durante a noite, com luzes apagadas, sem ofuscar a visão dos controladores;

d) spots de iluminação embutidos no teto, com facho de luz na vertical, acionados por potenciômetro regulador de intensidade de luz, um para cada fileira de pontos;

e) cobertura de vidro ou acrílico em todos os consoles, para permitir a exposição e o acesso imediato de informações úteis à operação;

f) persianas corta-luz (*) em todas as janelas, para regular o acesso da luz do sol, nos diversos horários do dia.

g) isolamento acústico e térmico externo e interno( $\left.{ }^{* *}\right)$, através da utilização de vidros especiais e de revestimento do forro e teto com material acústico apropriado, em toda a navegação aérea, devido à proximidade do pátio, pistas e oficinas;

q) climatização com máquinas no exterior (para evitar ruído) e insufladores adequadamente distribuídos no forro, de forma a evitar fluxo excessivo de ar para cada uma das saídas e controle remoto de temperatura junto aos operadores; e

i) binóculos 12 - 60x70, "field" $0.95^{\circ}$ a 60 vezes.

(*) Evita o ofuscamento da visão do controlador, além de reduzir a dificuldade na consulta de instrumentos luminosos e de monitores de vídeo.

${ }^{\left({ }^{* *}\right)}$ O ruído produzido pelas aeronaves em operação, notadamente aquelas que taxiam ou acionam motores próximas à torre, interfere nas comunicações terra-avião, além de elevar o nível de stress nos controladores, sendo ambos fatores contribuintes, em potencial, para a ocorrência de incidentes de Tráfego Aéreo.

\subsection{3- Espaço Físico e Dependências}

\subsubsection{1 - Instalações do Piso da Cabine da TWR}

As seguintes dependências e/ou detalhes deverão ser previstos, de forma a atender às necessidades operacionais e técnicas do órgão: 


\section{A- Cabine}
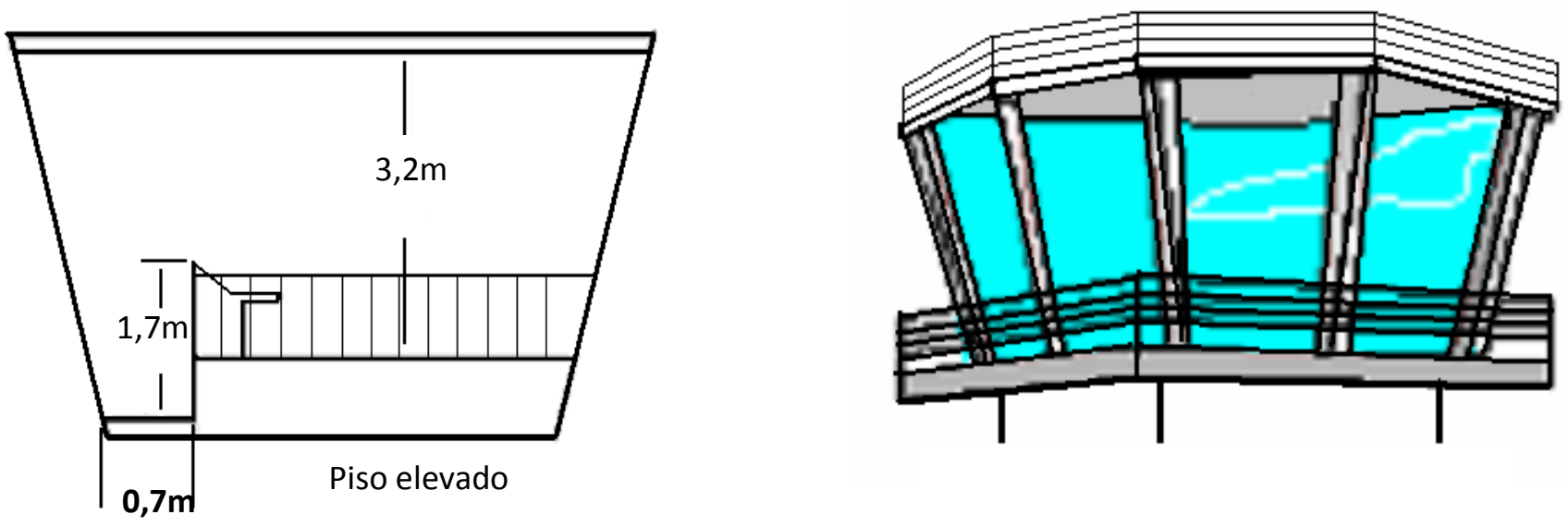

Fig 1 - fosso de manutenção e pé direito

Fig 2- área externa

É o espaço operacional propriamente dito, destinado a acomodar todos os equipamentos, mobiliário e efetivo operacional, por turno de serviço.

Deve dispor de uma área de circulação interna compatível com as necessidades operacionais e com o conforto e bem estar dos controladores em serviço.

Deverá ser prevista uma saída de acesso à área externa, e saída de emergência, nos termos da legislação em vigor.

Para efeito do presente documento, considera-se satisfatória uma cabine, preferencialmente, octogonal irregular, com área útil interna (piso operacional) não inferior a $32 \mathrm{~m}^{2}$.

Para fins deste projeto, foi considerado que a área útil interna (piso operacional) relatada no item 116 do MP - 16.04 (NAE) engloba a área destinada para as consoles operacional. 


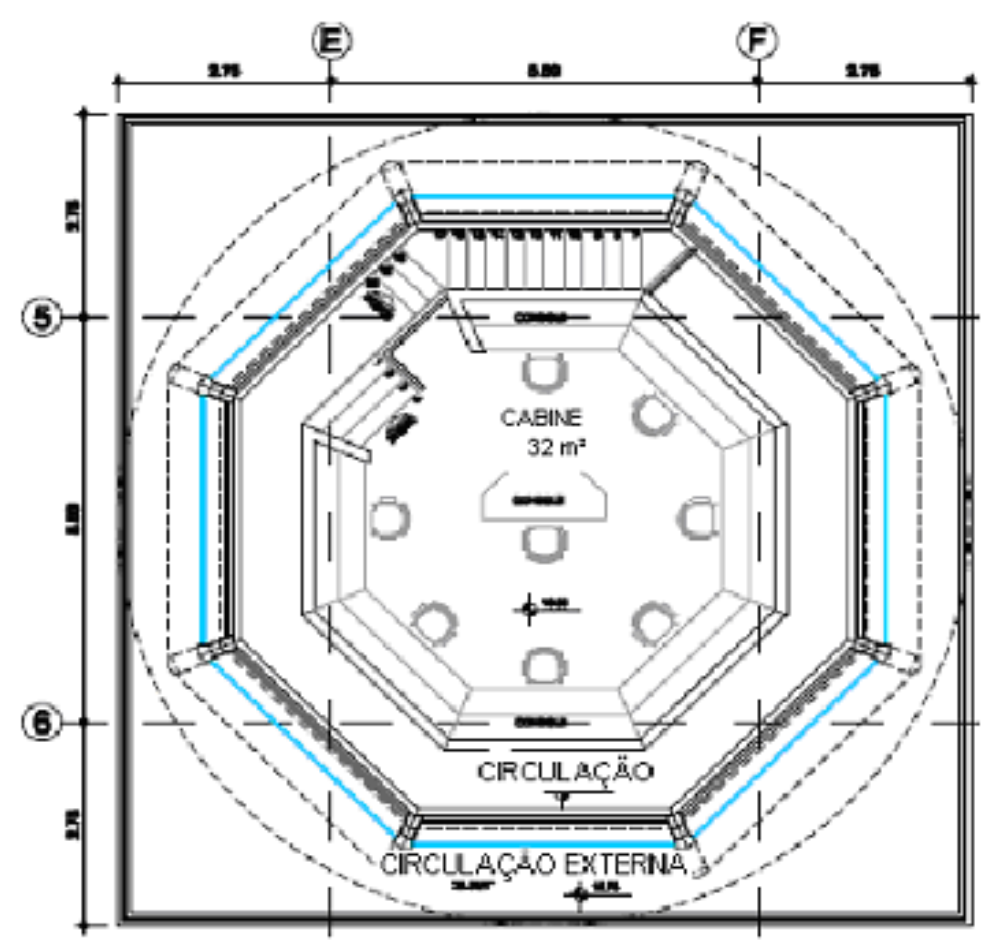

Fig 3- CABINE

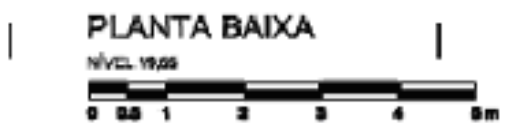

A cabine deverá ser envidraçada, do chão ao teto (sem paredes de tijolo ou concreto sendo permitido, no entanto, uma base de alvenaria que se eleve até $30 \mathrm{~cm}$ acima do piso elevado, para proteção contra impacto), conforme a figura 2. Cada seção de vidro não poderá possuir qualquer tipo de emenda, devendo ter uma inclinação de $15^{\circ} \mathrm{em}$ relação ao plano vertical. Deverá ser considerada, ainda, a necessidade de pequenos basculantes próximos ao piso elevado, para permitir a circulação controlada de ar natural.

Objetivando assegurar a boa visualização das aeronaves, tanto no circuito de tráfego como sobre o aeródromo, recomenda-se um pé direito de 3,2 metros, a partir de um piso elevado, o qual deverá empregar placas removíveis.

Deverá, ainda, ser previsto um fosso de manutenção (com largura de aproximadamente $0,80 \mathrm{~m}$ ), de forma a garantir-se um corredor destinado à circulação de técnicos e à execução da manutenção dos equipamentos instalados no console.

A localização e altura da torre deverá ser tal que permita a plena visualização, nos 360 graus, e, principalmente, da pista de pouso com suas cabeceiras, setores de aproximação e decolagem, pistas de táxi e pátio de estacionamento (sugere-se levantamento topográfico prévio). 
A inclinação dos vidros da cabine deverá ser adequada, conforme especificado no MP - 16.4 (NAE), Padrão INFRAERO para Órgãos de Navegação Aérea, para evitar reflexos.

Os caixilhos de junção vertical dos vidros deverão ter a mínima largura possível, para não dificultar a visibilidade para o exterior da cabine.

Deverão ser evitadas junções dos vidros da cabine no sentido horizontal. Se inevitável, a sua colocação deverá ocorrer acima do terço superior do vão, ou seja, acima da altura da visão normal do Controlador de Tráfego Aéreo.

O número de pilares de sustentação do teto da cabine deverá ser limitado ao mínimo necessário, evitando-se a sua colocação à frente das posições operacionais Torre e Solo.

O acesso até o piso imediatamente inferior ao da cabine será efetuado através de elevador.

A escada de acesso à cabine da Torre deverá ser de alvenaria e deverá terminar, preferencialmente, na lateral oposta à face de trabalho da TWR.

\section{B - Laje Externa}

O projeto deverá considerar a necessidade de uma laje externa às paredes da cabine, em prolongamento ao piso da torre, de forma a proporcionar uma passarela protegida com grades, ao longo da qual pode-se circular livremente, para a execução da limpeza e manutenção dos vidros e canaletas, pelo lado externo, sem a necessidade de andaimes ou outro dispositivo similar. O acesso ao exterior deverá ser feito por uma porta discretamente construída, de forma a permitir a passagem de uma pessoa abaixada.

\section{C - Laje de Cobertura}

Essa laje com alçapão corrediço de acesso deverá ser reforçada, para suportar o peso de, pelo menos, dois homens, além de permitir a futura instalação de equipamentos destinados a atender à operação, tais como antenas, farol de aeródromo, etc. Deverá ser circundada por um gradil de proteção e acessada a partir de uma escada escamoteável com $60 \mathrm{~cm}$ de largura, instalada junto a uma das colunas opostas à face de trabalho da torre.

\subsubsection{2 - Instalações do Piso inferior ao da Cabine}

O piso imediatamente abaixo da cabine da TWR deverá ter espaço suficiente para abrigar a sala de operação da EMS-2, a sala de equipamentos, a climatização, o ambiente para descanso dos operadores, a copa e os sanitários masculino e feminino. 
O projeto deverá considerar a necessidade de uma laje externa às paredes do piso inferior ao da cabine, em prolongamento, de forma a proporcionar uma passarela protegida com grades, ao longo da qual se pode circular livremente, para a realização das observações meteorológicas, execução da limpeza e manutenção dos vidros, pelo lado externo, sem a necessidade de andaimes ou outro dispositivo similar. O acesso deste piso ao piso da cabine será feito por escada de alvenaria, com final situado no extremo da cabine, oposto aos consoles, o mais próximo possível da parede envidraçada.

\section{A - Sala de Observação da EMS-2}

Deve possuir uma área mínima de $25 \mathrm{~m}^{2}(5 \times 5)$ e devem estar posicionadas de maneira a permitir uma visão desobstruída das condições de tempo, tanto no aeródromo como em suas vizinhanças, a partir do campo de visão do observador meteorológico.

\section{B - Ponto de Observação da Estação Meteorológica de Superfície}

Esta posição operacional tem por finalidade permitir a execução das tarefas inerentes a uma EMS.

A sala do observador da EMS deverá estar localizada no pavimento imediatamente inferior ao da cabine da TWR. O ambiente disponibilizado para a EMS deverá permitir uma visão desobstruída das condições de tempo, tanto no aeródromo como em suas vizinhanças, a partir do campo de visão do observador meteorológico. Deve ser feito o possível para que o observador, no mínimo, possa manter a vigilância das áreas que envolvem o conjunto de pistas e as de aproximação para pouso e decolagem das aeronaves. É recomendável que a área a ser observada esteja livre de outros tipos de interferência, tais como luzes de pátio, superfícies refletoras ou incidência direta de luz solar

C - Copa - Área mínima de 6,27 $\mathrm{m}^{2}$.

\section{D - Sala de Repouso}

A sala de repouso é o local destinado ao descanso do controlador, durante o turno de serviço. É recomendável que esta dependência possua uma área total de, no mínimo, $13,25 \mathrm{~m}^{2}$.

\section{E - Sala de Briefing}

Esta dependência, com área total recomendada de $20 \mathrm{~m}^{2}$, localizada no piso inferior da cabine da TWR, destina-se à reunião de controladores (e demais profissionais de outras 
áreas, se for o caso), para a divulgação da realidade operacional referente ao turno de serviço que se inicia.

Reuniões periódicas, testes operacionais, etc, com todo o efetivo, serão realizados em Auditório / Sala de reuniões localizada no térreo do prédio do ONA.

\section{F - Banheiros}

O piso inferior à cabine da Torre deve dispor de um banheiro masculino e outro feminino, cada um com uma área total de $3,45 \mathrm{~m}^{2}$, e guarda volumes individuais.

\subsubsection{3- Instalações para Sala IFR}

O projeto das edificações deverá contemplar a existência de uma área de, no mínimo, $30 \mathrm{~m}^{2}$, com piso falso, para a implantação de um futuro APP radar. Esta sala poderá estar situada em qualquer piso operacional das edificações destinadas à navegação aérea.

\subsubsection{4 - Instalações do Piso Térreo}

No andar térreo, deverão ser previstas dependências destinadas às demais áreas operacionais e a atender às tarefas de gerenciamento local das atividades de navegação aérea, conforme se segue:

\section{A - Instalações da Sala AIS, CMA/EMS e ECM}

As instalações da Sala AIS, CMA/EMS e ECM deverão possuir no total, uma área mínima de $204 \mathrm{~m}^{2}$, incluindo a sala de pilotos e hall de entrada, ficando estes órgãos no mesmo ambiente.

A Sala AIS deverá ter acesso direto e facilitado ao TPS.

\section{B - Sala Técnica}

É o espaço destinado à instalação dos equipamentos que, pelo seu porte ou natureza, não podem permanecer no ambiente operacional (transceptores VHF, gravador/reprodutor, etc.), além de um espaço para escuta de gravação de comunicações, com proteção acústica.

A sala técnica será constituída dos seguintes ambientes:

- Sala de equipamentos de telecomunicações - 22,50 m²

- Sala OLE (Oficina Local Especializada) - 11,73 m²

- Sala de equipamentos de gravação/reprodução RACAL - 11,73 m².

\section{C - SICAD}


É o espaço destinado a realização de treinamentos simulados para os ATCO - Área mínima: $12,92 \mathrm{~m}^{2}$.

\section{D - Sala de Reuniões / Auditório}

Sala para reuniões, testes operacionais, instrução, palestras, etc. com todo efetivo, com capacidade para 50 assentos, com área mínima de $65,50 \mathrm{~m}^{2}$.

E - Tarifas - área mínima de 20,00 $\mathrm{m}^{2}$.

F - SAC/ANAC - área mínima de $15,00 \mathrm{~m}^{2}$.

\section{G - Sala de Espera para pilotos / banheiro:}

Sala de espera para os pilotos com banheiro privativo, fins de evitar acesso destes na área interna do prédio do ONA, com área mínima de $18,00 \mathrm{~m}^{2}$.

\section{H - Chefia}

Sala de, no mínimo, $22,00 \mathrm{~m}^{2}$, com banheiro privativo de $3,50 \mathrm{~m}^{2}$.

\section{I - Secretaria}

Sala de, no mínimo, 18,00 $\mathrm{m}^{2}$, a ser utilizada como sala de espera de acesso à chefia, conjugada ao ambiente do PSA ADMINISTRATIVO.

\section{J - Sala de Encarregados}

Sala de, no mínimo $24,00 \mathrm{~m}^{2}$, a ser utilizada pelos encarregados de apoio operacional.

\section{K- Banheiros / Vestiários}

Os banheiros / vestiários masculino e feminino, distribuídos da seguinte forma:

Banheiro / vestiário masculino com 25,00 $\mathrm{m}^{2}$

Banheiro / vestiário feminino com 21,00 $\mathrm{m}^{2}$

Banheiro $\mathrm{p} /$ portadores de necessidades especiais com $4,50 \mathrm{~m}^{2}$

\section{L - Depósitol Arquivol Almoxarifado}

Espaço destinado para o armazenamento de objetos diversos, equipamentos, arquivomorto, etc. Tal dependência será subdividida em três ambientes diferentes destinados a:

Depósito com 8,50 m²;

Arquivo com 9,50 $\mathrm{m}^{2} \mathrm{e}$

Almoxarifado com 10,00 m². 


\section{M - Copa}

Área mínima de $16,00 \mathrm{~m}^{2}$, para atender a todo o efetivo da AIS, CMA/EMS, ECM, Administrativo do ONA, SAC e TARIFAS, localizado no piso térreo do ONA.

\section{N - Sala de Repouso}

A sala para repouso dos operadores, com $30,00 \mathrm{~m}^{2}$, deverá estar próxima às instalações da Sala AIS, CMA/EMS e ECM.

\section{O - Jardim de Inverno}

Área destina a circulação interna administrativa com espaço para jardim de inverno com espelho d'água com iluminação natural, área mínima de 40,00 m².

\section{2 - Estacionamento}

Será disponibilizado espaço para estacionamento dos empregados do ONA e usuários, sendo necessário posto de vigilância para controle de acesso às dependências da Infraero.

\section{3- Mobiliário e Eletroeletrônicos}

Os itens descritos a seguir destinam-se a atender às diversas dependências relacionadas direta ou indiretamente com o funcionamento da nova torre.

\begin{tabular}{|c|c|c|c|c|}
\hline ITEM & DISCRIMINAÇÃO & QUANT & OBS & LOCAL \\
\hline 1 & Módulo de Console & 06 & Incluindo EMS & \multirow{5}{*}{ CABINE } \\
\hline 2 & Poltronas Giratórias & 06 & 01 deve ser alta & \\
\hline 3 & $\begin{array}{l}\text { Estação de trabalho para } \\
\text { supervisor }\end{array}$ & 1 & $\begin{array}{l}\text { SGTAI/ATIS/SGT } \\
\text { C/ADM. }\end{array}$ & \\
\hline 4 & Armário & 2 & $\begin{array}{l}\text { Publicações e } \\
\text { pequenos objetos }\end{array}$ & \\
\hline 5 & $\begin{array}{l}\text { Persianas Insulfilm em todas } \\
\text { as vidraças }\end{array}$ & & $\begin{array}{ll}\text { Com controle } \\
\text { remoto }\end{array}$ & \\
\hline 6 & Geladeira frost free & 1 & & \multirow{5}{*}{$\begin{array}{l}\text { Copa / Cozinha } \\
\text { - Piso inferior da } \\
\text { Cabine }\end{array}$} \\
\hline 7 & $\begin{array}{l}\text { Purificador de água } \\
\text { natural/gelada }\end{array}$ & 1 & & \\
\hline 8 & Mesa de fórmica & 1 & & \\
\hline 9 & Cadeira & 2 & & \\
\hline 10 & Armário & 1 & & \\
\hline
\end{tabular}




\begin{tabular}{|c|c|c|c|c|}
\hline 11 & Cafeteira Automática & 1 & & \\
\hline 12 & Liquidificador & 1 & & \\
\hline 13 & Forno de Micro-ondas & 1 & & \\
\hline 14 & TV LCD 26' & 1 & & \multirow{4}{*}{$\begin{array}{l}\text { Sala de } \\
\text { Repouso PTA - } \\
\text { Piso inferior da } \\
\text { Cabine }\end{array}$} \\
\hline 15 & $\begin{array}{llll}\begin{array}{l}\text { Conjunto estofado de } \\
\text { lugares }\end{array} & & & \\
\end{array}$ & 1 & & \\
\hline 16 & Mesa de centro & 1 & & \\
\hline 17 & Aparelho de som/CD & 1 & & \\
\hline 18 & $\begin{array}{l}\text { Poltrona em longarina } \\
\text { c/prancheta escamoteavel }\end{array}$ & 12 & & \multirow{4}{*}{$\begin{array}{l}\text { Sala de briefing } \\
\text { PTA }\end{array}$} \\
\hline 19 & Quadro branco & 1 & & \\
\hline 20 & Mesa & 1 & & \\
\hline 21 & Cadeira & 1 & & \\
\hline 22 & Geladeira 450It Frost free & 1 & & \multirow{11}{*}{$\begin{array}{l}\text { Copa-cozinha } \\
\text { piso térreo do } \\
\text { ONA }\end{array}$} \\
\hline 23 & Forno micro-ondas & 1 & & \\
\hline 24 & Ozonizador para água & 1 & & \\
\hline 25 & Talha para água & 2 & & \\
\hline 26 & Fogão elétrico & 1 & & \\
\hline 27 & Mesa de fórmica & 2 & & \\
\hline 28 & Cadeira & 8 & & \\
\hline 29 & Armário de aço & 1 & 6 portas & \\
\hline 30 & Liquidificador & 1 & & \\
\hline 31 & Cafeteira automática & 2 & \multirow{2}{*}{$\begin{array}{l}\text { Sendo } 1 \text { para sala } \\
\text { de espera de } \\
\text { pilotos }\end{array}$} & \\
\hline 32 & $\begin{array}{lll}\text { Purificador de água } \\
\text { natural/gelada }\end{array}$ & 2 & & \\
\hline 33 & Estação de trabalho & 2 & $\begin{array}{l}\text { Treinamento } \\
\text { SICAD }\end{array}$ & \multirow[t]{3}{*}{ Sala SICAD } \\
\hline 34 & $\begin{array}{l}\text { Poltrona giratória com } \\
\text { espaldar baixo }\end{array}$ & 3 & & \\
\hline 35 & Mesa secretária & 1 & Instrutor SICAD & \\
\hline 36 & Mesa secretária & 1 & 2 gavetas & \multirow{5}{*}{$\begin{array}{l}\text { Sala } \\
\text { Reunião/auditór } \\
\text { io }\end{array}$} \\
\hline 37 & Cadeira estofada & 1 & & \\
\hline 38 & $\begin{array}{l}\text { Poltrona em longarina } \\
\text { c/prancheta escamoteável }\end{array}$ & 50 & & \\
\hline 39 & Quadro branco com pincel & 1 & & \\
\hline 40 & Aparelho DVD & 1 & & \\
\hline
\end{tabular}




\begin{tabular}{|c|c|c|c|c|}
\hline 41 & $\begin{array}{l}\text { Projetor multi mídia mínimo } \\
2000 \text { lumens }\end{array}$ & 1 & & \\
\hline 42 & $\begin{array}{l}\text { Lousa Interativa } \\
\text { SMART BOARD }\end{array}$ & 1 & $\begin{array}{|lr|}\text { Utilização } & \text { em } \\
\text { instrução } & \text { e } \\
\text { reuniões } & \end{array}$ & \\
\hline 43 & Sistema de som & 1 & & \\
\hline 44 & Banco estofado & 2 & 3 lugares & \multirow{3}{*}{ Vestiários } \\
\hline 45 & $\begin{array}{l}\text { Armários individuais para } \\
\text { vestiário em MDF com chave }\end{array}$ & 25 & $\begin{array}{l}2 \text { portas e dois } \\
\text { pavimentos }\end{array}$ & \\
\hline 46 & Espelho grande & 4 & & \\
\hline 47 & TV LCD 26' & 1 & & \multirow{5}{*}{$\begin{array}{lr}\text { Sala } & \text { de } \\
\text { repouso dos } & \text { do } \\
\text { operadores } & \end{array}$} \\
\hline 48 & $\begin{array}{l}\text { Conjunto estofado de } \\
3 \text { e } 2 \text { lugares }\end{array}$ & 1 & & \\
\hline 49 & Aparelho de som/CD & 1 & & \\
\hline 50 & Estante & 1 & & \\
\hline 51 & Mesa de centro & 1 & & \\
\hline 52 & Estação de trabalho & 3 & AIS, EMS e ECM & \multirow{5}{*}{$\begin{array}{l}\text { Ambiente Sala } \\
\text { AIS para } \\
\text { atendimento } \\
\text { aos usuários }\end{array}$} \\
\hline 53 & Armário & 3 & AIS, EMS e ECM & \\
\hline 54 & $\begin{array}{l}\text { Poltronas giratórias com } \\
\text { espaldar baixo }\end{array}$ & 6 & AIS, EMS e ECM & \\
\hline 55 & Mesa de reunião & 1 & $\begin{array}{l}\text { Planejamento de } \\
\text { vôo }\end{array}$ & \\
\hline 56 & $\begin{array}{l}\text { Poltrona fixa com espaldar } \\
\text { baixo }\end{array}$ & 6 & $\begin{array}{l}\text { Planejamento de } \\
\text { vôo e balcão } \\
\text { AIS/EMS }\end{array}$ & \\
\hline 57 & Estação de trabalho individual & 3 & \begin{tabular}{|l|}
$|l|$ \\
Encarregados \\
para apoio \\
operacional
\end{tabular} & \multirow{4}{*}{$\begin{array}{l}\text { Sala de Apoic } \\
\text { operacional }\end{array}$} \\
\hline 58 & $\begin{array}{l}\text { Poltrona giratória com } \\
\text { espaldar alto }\end{array}$ & 3 & & \\
\hline 59 & Armário & 2 & & \\
\hline 60 & $\begin{array}{l}\text { Poltrona fixa com espaldar } \\
\text { baixo }\end{array}$ & 3 & & \\
\hline 61 & Estação de trabalho individual & 1 & & \multirow[b]{2}{*}{$\begin{array}{l}\text { Sala de Apoio } \\
\text { PSA }\end{array}$} \\
\hline 62 & $\begin{array}{l}\text { Poltrona giratória com } \\
\text { espaldar baixo }\end{array}$ & 1 & & \\
\hline
\end{tabular}




\begin{tabular}{|c|c|c|c|c|}
\hline 63 & Armário & 1 & & \multirow[t]{2}{*}{ Administrativo } \\
\hline 64 & $\begin{array}{llll}\begin{array}{l}\text { Conjunto } \\
\text { lugares }\end{array} & & & \\
\end{array}$ & 1 & & \\
\hline 65 & Estação de trabalho individual & 1 & & \multirow{6}{*}{ Sala Chefia } \\
\hline 66 & $\begin{array}{l}\text { Poltrona giratória com } \\
\text { espaldar alto }\end{array}$ & 1 & & \\
\hline 67 & Mesa reunião & 1 & Para 6 pessoas & \\
\hline 68 & Poltrona fixa espaldar baixo & 8 & & \\
\hline 69 & Armário & 1 & & \\
\hline 70 & Geladeira frigobar & 1 & & \\
\hline 71 & Armário arquivo deslizante & 1 & & Sala Arquivo \\
\hline 72 & $\begin{array}{l}\text { Conjunto estofado de } 3 \text { e } 2 \\
\text { lugares }\end{array}$ & 1 & & \multirow[t]{3}{*}{$\begin{array}{l}\text { Sala de espera } \\
\text { de pilotos }\end{array}$} \\
\hline 73 & TV LCD 26' & 1 & & \\
\hline 74 & Mesa de centro & 1 & & \\
\hline
\end{tabular}

Obs.: Os itens listados na planilha acima são uma perspectiva preliminar inicial que estará sujeita à alteração conforme o projeto finalizado.

\section{6- Disposições Finais}

6.1- Este documento entra em vigor a partir da presente data, revogando-se as disposições anteriormente publicadas.

6.2- Os casos omissos serão resolvidos pela Superintendência de Navegação Aérea (DONA).

Brasília, maio de 2008.

WILL WILSON FURTADO

Superintendente de Navegação Aérea 
ANEXO XI

\author{
"WORKSHOP" \\ UNIVERSIDADE \\ DE GENT
}




\section{USO DA TECNOLOGIA DA INFORMACAO E COMUNICACAO NO PROJETO DE AEROPORTOS}

\author{
1- JULIO TOLLENDAL GOMES RIBEIRO \\ Universidade de Brasilia - UnB \\ juliotolendal@hotmail.com \\ http: // lecomp.fau.unb.br
}

\author{
2- NEANDER FURTADO SILVA \\ Universidade de Brasilia - UnB \\ neander.furtado@gmail.com \\ http: // lecomp.fau.unb.br
}

\section{RESUMO}

Em associação com a Universidade de Gent, "Department of Architecture and Urban Planning, Faculty of Engineering and Architecture" e o LFDC - Laboratório de Fabricação Digital e Customização em Massa, da Universidade de Brasília, os arquitetos JULIO RIBEIRO e PIETER PAUWELS, supervisionados pelo professor Ronald de Meyer, compartilharam conhecimentos, experiências e boas práticas no uso das tecnologias da informação durante a concepção e construção de aeroportos ou outras construções complexas em uma Oficina de Projeto. Foram abordados aspectos de tecnologia de informação e comunicação ao longo do processo de projeto, gestão da informação paramétrica e criação de novos parâmetros, saída de informação "on-demand" através de relatórios personalizados, produtividade, através da programação em linguagem "C\#" para confecção de "plug-ins" para os softwares "Microsoft/ AutoDesk" e ainda simulação de "Timeline" de Obra no "AutoDesk NavisWorks ${ }^{\circledR}$ ", gerenciando fases, parâmetros e geometria advinda do "AutoDesk Revit ${ }^{\circledR ”}$ e demais ferramentas de projeto (Estruturas, MEP, Energia, Sustentabilidade, Meio-ambiente). Os objetivos envolvidos nesta Oficina de Projeto com o uso das tecnologias da informação durante a concepção e construção de aeroportos ou de outros edifícios complexos (com utilização dos Sistemas BIM) é principalmente estabelecer uma interface entre os pesquisadores das Universidades do Brasil, Bélgica e Estados Unidos da América. Informações valiosas sobre "Building Information Modeling", trabalho colaborativo, extração de dados e de troca de informação, Ontologia e Questões Semânticas do Processo podem ser compartilhadas neste sentido. Estamos ainda procurando a fronteira dos conhecimentos relacionados na utilização dos Sistemas BIM na área da AEC. Objetivou ainda a transferência de tecnologia da equipe de professores e pesquisadores da Universidade de Gent que gentilmente se dispuseram a tratar especificamente do assunto e do contexto sugerido para indicar boas práticas no provimento de infraestrutura aeroportuária, possíveis caminhos e ainda estabelecer um ambiente pratico de teste e de validação de conceitos em um modelo paramétrico BIM de um pequeno Terminal de Passageiros Aeroportuário, T3 - SBCF, MG.

Keywords: Tecnologia da Informação e Comunicação, Gestão Paramétrica, Linguagem "C\#” e Simulação de "Time-line" de Obra.

\section{INTRODUÇÃO}

Como forma de orientação e apoio para as atividades da Oficina de Projeto, bem como uma maneira de contextualizar o objeto de estudo, foi caracterizado um Termo de Referência que consiste em uma série de documentos que compõem o projeto de expansão do Aeroporto Internacional de Confins, MG. Informações relativas ao Plano de Implantação, os edifícios existentes, as normas para a aviação civil e engenharia INFRAERO, padrões e modelos a serem utilizados são neste Termo de Referência.

O balizamento das ações de pesquisa através da utilização dos Sistemas BIM para o provimento de infraestrutura aeroportuária com as normas e padrões de engenharia vigentes na INFRAERO é fundamental para que num possível panorama de implantação as boas práticas, fatores críticos de sucesso e possíveis gargalos sejam conhecidos e estudados, para que a troca de informação envolvida no processo de aprovação de projetos da empresa seja fluida.

Isto só e possível a partir da formatação de "templates" e padrões definidos, praticas integradas e semelhantes entre a equipe multidisciplinar e ainda através da definição de uma ontologia especifica para o domínio de informação na INFRAERO. Realizamos uma análise entre as principais diferenças entre os métodos de projeção bidimensional, amplamente utilizado em projetos de terminais de passageiros, em comparação com aqueles que usam o sistema como ambiente de trabalho BIM modelando TPSR / SBCF global.
Esta pesquisa, através desta Oficina de Projeto pretendeu identificar quais são as melhores formas de implantação e utilização de sistemas inteligentes para gerenciamento de projetos e obras em organizações como a INFRAERO. Talvez o fator mais importante neste processo é a dificuldade de gerir esta informação atualmente em empresas desta natureza, (fragmentado em vários arquivos) na coordenação entre os projetos complementares e estágio de execução própria (trabalho). Os desenhos e informações específicas e precisas tornaram-se muito importante, inclusive no que diz respeito a fatores indesejáveis, tais como inconsistência de dados e duplicidade de informações, ligue para a interferência entre os projetos complementares, tais como arquitetura, estrutura, infraestrutura, sistemas hidro sanitárias, sistemas eletromecânicos, telemática, navegação, etc.

$O$ processo de projeto em uma ferramenta de CAD do tipo genérico, como o AutoCAD, caracterizado pela escassez e má qualidade dos dados do projeto e da documentação específica (em seus arquivos), precisamente porque não é definível (aceitar parâmetros ou informações incorporadas aos elementos de construção e acessórios de projeto). Isto leva à necessidade de criar novos arquivos no "software" diferente, como o uso de uma planilha de texto (como "Microsoft Word", por exemplo) para criar um memorial descritivo ou um programa como "Microsoft Excel" para gerir tabelas e gráficos de gestão de materiais quantitativa do trabalho e orçamento. 


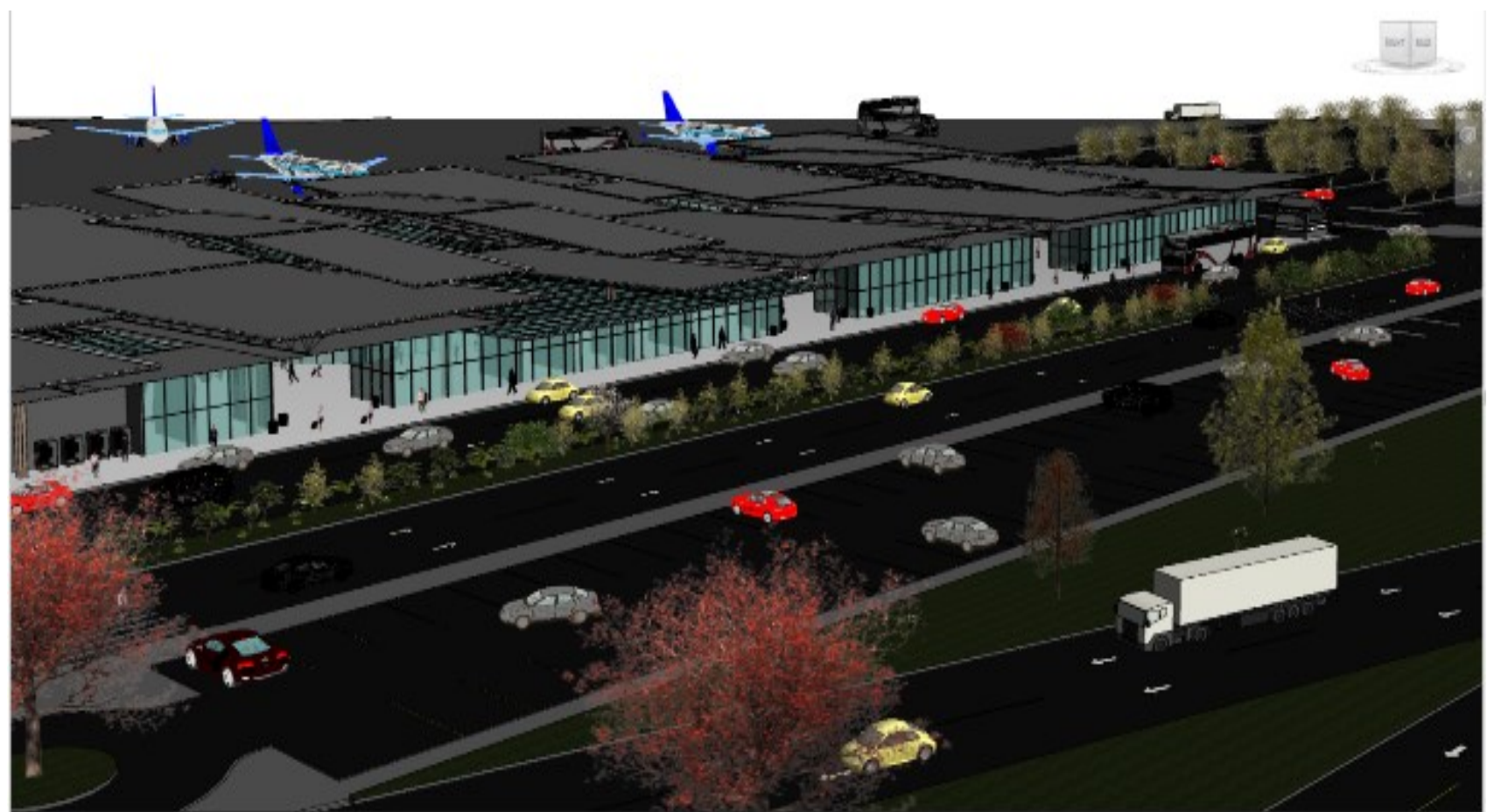

Figura A- Modelagem do TPS SBCF/ BIM. (Perspectiva)

No processo que se utiliza dos Sistemas BIM, ocorre uma inversão em vez de uma série de desenhos bidimensionais, o projetista deve "desenvolver" um modelo virtual do edifício, utilizando objetos que simulam o comportamento de forma e os elementos construtivos a serem utilizados na construção. Os modelos virtuais podem ser entendidos como os bancos de dados que armazenam os dados de ambos os geométricos, tais como texto de cada elemento de construção usado no projeto.

A combinação destes dados permite a extração automática de documentos, tais como plantas, cortes, perspectivas ou quantitativos. A atenção do projetista é, portanto, direcionado principalmente para soluções de projeto e não para desenhos técnicos, que são em grande parte geradas automaticamente pelo computador (BIRX, 2006).

$\mathrm{Na}$ Oficina de Projeto abordamos a utilização do "software" BIM existente na INFRAERO (Revit ${ }^{\circledR}$ ) de forma a testar suas capacidades frente aos requisitos $e$ condicionantes da empresa, no tocante não só ao seu emprego, como na abrangência das diversas especialidades de engenharia, que necessitam trocar informações entre os aplicativos utilizados, ainda que da mesma plataforma (AutoDesk).

O processo de projeto que se utiliza dos Sistemas BIM caracteriza-se por grande quantidade de informações disponíveis e configuráveis ainda nos estágios iniciais, como no início da etapa de projeto, estudo preliminar, porque oferta informação precisa acerca das características e composição de cada elemento de construção. Seus parâmetros, o que no caso desta Oficina de Projeto, facilitou o desenvolvimento de proposições acerca do fluxo da informação ao longo do processo de projeto, por ter maior clareza de interferência entre os diferentes elementos de construção e suas especialidades complementares e o método de construção propriamente dito.
Inferências nos parâmetros de configuração de objetos construtivos permitem o estudo de várias soluções formais, estéticas e funcionais que podem ser simuladas na concepção do projeto.

Tais variáveis são indicativos das maiores vantagens e desvantagens do uso de cada um desses sistemas.

Outro aspecto é a dificuldade de adaptação do projeto gerado em relação a possíveis mudanças, uma vez que todo o trabalho, com o uso do AutoCAD, só pode ser feito manualmente $e$, portanto sujeito a erros $e$ inconsistências nos dados e informações possivelmente duplicadas. Na segunda etapa, foi realizado o processo de concepção, através da utilização do BIM utilizando o programa REVIT da AutoDesk.

\section{OFICINA DE PROJETO - CAMPOS DE PESQUISA}

1- Desenvolvimento de objetos paramétricos;

2- Gestão de Bibliotecas e extração de dados;

3- Ontologia e Web Semântica;

4- Trabalho Colaborativo;

5- Interoperabilidade;

6- Troca de informações (dados);

7- Processo de projeto de edifícios complexos.

A sequência lógica obedece ao ganho de complexidade que o fluxo de informação apresenta ao longo do processo de projeto. Para realizar tarefas que vão desde a modelagem paramétrica, que abrange as especialidades da AEC e apresentam um desafio em termos de interoperabilidade de dados uma vez que são utilizados diferentes aplicativos ao longo do processo. Finalmente temos a integração, quando toda a informação de projeto condensa-se em servidor (interno a organização) ou em rede externa (internet). 
OFICINA de PROJETO - METODOLOGIA

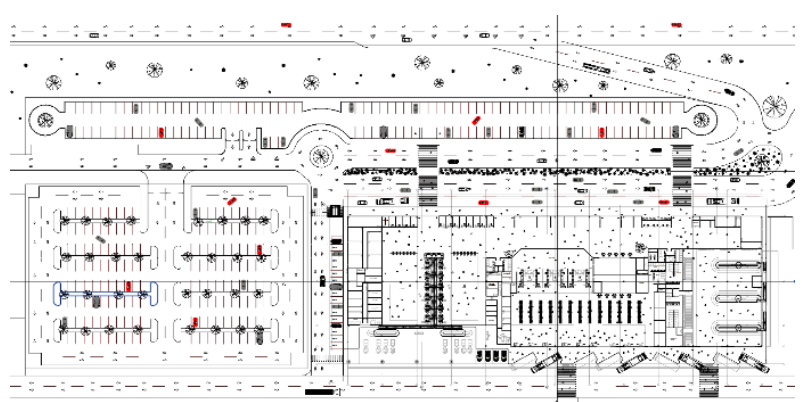

Figura B- Modelagem do TPS SBCF/ BIM. (Perspectiva)

A infraestrutura de pesquisa proposta nesta Oficina de Projeto BIM tem como ponto de partida um modelo único de informação representada pelo arquivo do Terminal Remoto - MG, totalmente modelado, mas não parametrizado.

A estratégia para o desenvolvimento de atividades de pesquisa é a parametrização do modelo pelos participantes da Oficina (trabalho em equipe) e na preparação de pelo menos um componente aeroportuário paramétrico de acordo com as normas e padrões fornecidos e que contenha parâmetros personalizados (criação de novos parâmetros). Esta atividade representa a primeira parte da oficina, ou seja, a sistematização de informações do modelo BIM, e gerando componentes paramétricos que se adequam a construção e os requisitos e restrições do projeto.

O segundo objetivo dessa primeira etapa consistiu na proposta de colaboração de cada membro da equipe de trabalho com o seu campo de conhecimento específico dentro do conhecimento sobre os sistemas BIM. A ideia foi realizar não só o intercâmbio de conhecimentos entre pesquisadores e instituições, mas visando ainda a transferência de tecnologia entre as melhores práticas na concepção e fornecimento de infraestrutura aeroportuária, com o uso dos sistemas BIM.

Para ser capaz de alcançar esses objetivos, propusemos a metodologia colaborativa de pesquisa e a prática do trabalho integrado. Cabe ainda ressaltar a importância das listagens de parâmetros ("Schedules") que devem conter toda a semântica adotada no projeto, de forma sistematizada, abrangendo as fases de construção, parâmetros existentes e novos, bem como relacionadas a ferramentas de análise e de orçamentação, se for o caso.

Ocorre que as formas nativas do Revit ${ }^{\circledR}$ para exportação de geometria 3D paramétrica nos formatos "DXF", FBX ou "DWG" não atendem aos requisitos da maioria dos aplicativos utilizados pelos profissionais das demais especialidades.

A segunda opção nativa, baseada no formato neutro "IFC" que permite a leitura por outro aplicativo de projeto (software). O formato "IFC" possui limitações relacionadas a quantidade de informação que pode transferir e anda divergências de representação da geometria entre as plataformas.

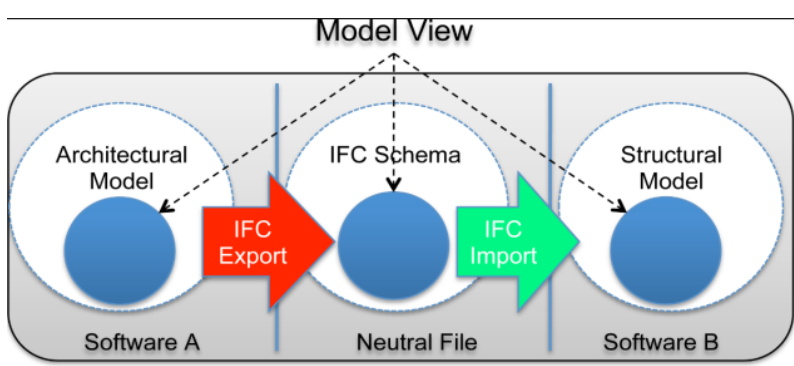

Figura C- Exportação de dados "IFC"

No entanto encontra-se em desenvolvimento e versões aprimoradas vem sendo lançadas de tempos em tempos. Finalmente, exploramos as potencialidades da programação C\# para adição de "plug-ins" personalizados aos softwares da AutoDesk e simulação no NavisWorks ${ }^{\circledR}$, parte da plataforma desta empresa, do "timeline" de obra do Terminal de Passageiros Remoto (T3) do SBCF - MG bem como dos parâmetros criados (teste).

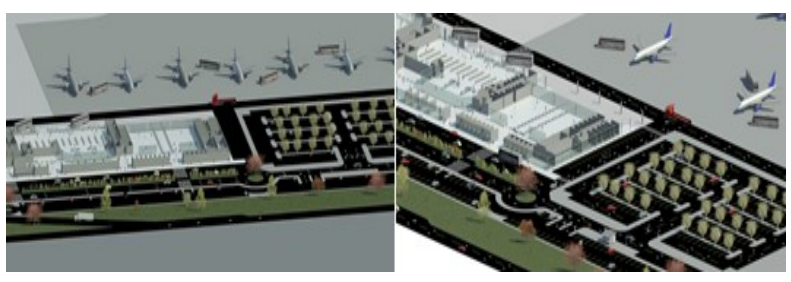

Figura D- Modelo utilizado T3/SBCF- "Revit ${ }^{\circledR}$ "

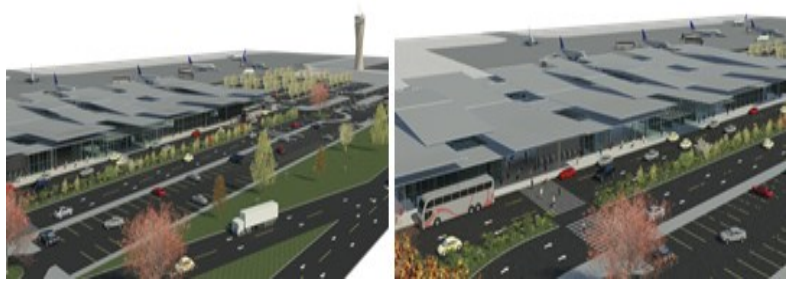

Figura E- Modelo utilizado T3/SBCF- "Revit ${ }^{\circledR}$ "

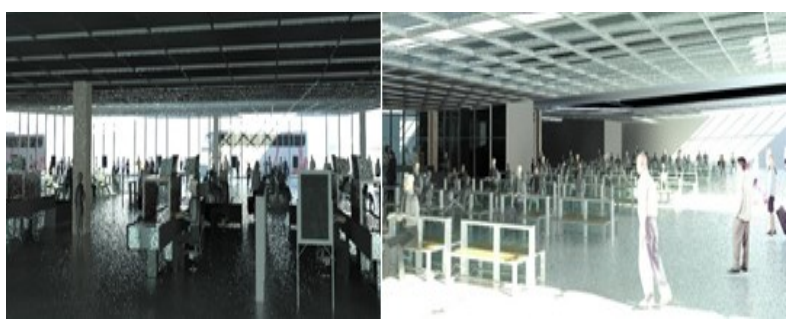

Figura F- Modelo utilizado T3/SBCF- "Revit ${ }^{\circledR}$ "

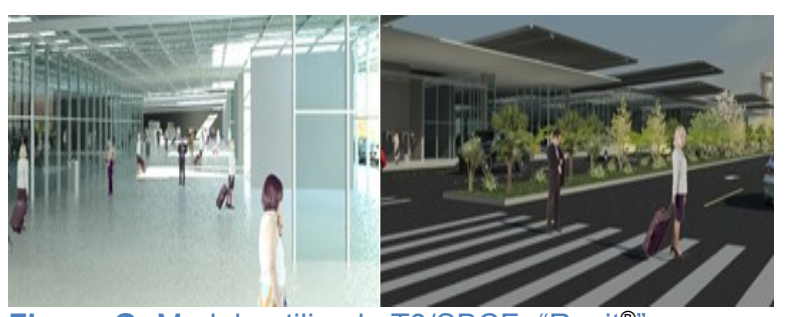

Figura G- Modelo utilizado T3/SBCF- "Revit ${ }^{\circledR}$ " 
O trabalho da Oficina de Projeto, através do desenvolvimento do projeto TPSR/ SBCF, foi dividido em sete fases distintas, em quatro etapas, durante a Oficina Pratica BIM: Estas etapas foram pensadas para desvelar informações importantes acerca da utilização pratica dos Sistemas BIM $\left(\right.$ Revit $\left.^{\circledR}\right)$ para o provimento de infraestrutura aeroportuária no contexto da INFRAERO. A primeira etapa abrange questões relativas a modelagem e parametrização de dados BIM. A segunda aborda a produtividade no processo de projeto. A terceira etapa realiza de forma pratica a simulação de Obra no NavisWorks ${ }^{\circledR}$ de um terminal de passageiros aeroportuário da INFRAERO. A quarta e última etapa relaciona-se com os fluxos de informação e os processos de aprovação de projetos da INFRAERO.

\section{ETAPA “A” Modelagem e Parametrização}

1- Modelagem do Terminal de Passageiros Remoto TPS - SBCF, em sua totalidade, (já concluído);

2- Simulação de Aplicação da Biblioteca de Componentes Paramétricos Aeroportuários com uma equipe multidisciplinar em TPSR SBCF, analisando as questões de interoperabilidade envolvidas no processo, bem como apontando quais seriam os possíveis caminhos para cada utilização especifica (MEP, Estruturas, Analises de Desempenho energético, etc.)

\section{ETAPA “B” Produtividade no Processo de Projeto}

3- Inferência pratica sobre a produtividade das ferramentas da AutoDesk, através da Programação em linguagem "C\#" para criação de plug-ins específicos a estes softwares;

ETAPA “C” Simulação de Obra - BIM

4- Exportação do Modelo Único de Informação BIM do TPS - SBCF para o AutoDesk NavisWorks ${ }^{\circledR}$ de forma a simular o "timeline" de obra de um aeroporto, com fases definidas, parâmetros personalizados e possibilidade de checagem de interferências através da propriedade nativa do software de "Clashdetection" entre os projetos das diversas especialidades:

\section{ETAPA “D” Fluxos de Informação e Processos}

5- Desenho dos diagramas de fluxos de informação (possíveis) através da utilização dos sistemas BIM (Oficina de Projeto);

6- Comparação com o fluxo de informação do Processo em voga na INFRAERO;

7- Inferência e adaptações de metodologia de pesquisa em sistemas BIM.
1- Modelagem do Terminal de Passageiros Remoto TPS - SBCF, em sua totalidade, (já concluído);

2- Simulação de Aplicação da Biblioteca de Componentes Paramétricos Aeroportuários com uma equipe multidisciplinar em TPSR SBCF, analisando as questões de interoperabilidade envolvidas no processo, bem como apontando quais seriam os possiveis caminhos para cada utilização especifica (MEP, Estruturas, Analises de Desempenho energético, etc.)

A realização desta Oficina de Projeto BIM teve como ponto de partida um modelo único de informação representada pelo arquivo do Terminal Remoto - MG, totalmente modelado, mas não parametrizado. A estratégia para o desenvolvimento de atividades de pesquisa é a parametrização do modelo pelos participantes da Oficina (trabalho em equipe) e na preparação de pelo menos um componente aeroportuário paramétrico de acordo com as normas e padrões fornecidos e que contenha parâmetros personalizados (criação de novos parâmetros). Esta atividade representa a primeira parte da oficina, ou seja, a sistematização de informações do modelo BIM, e gerando componentes paramétricos que se adequam a construção e os requisitos e restrições do projeto. $O$ segundo objetivo dessa primeira etapa consistiu na proposta de colaboração de cada membro da equipe de trabalho com o seu campo de conhecimento específico dentro do conhecimento sobre os sistemas BIM.

A ideia foi realizar não só o intercâmbio de conhecimentos entre pesquisadores e instituições, mas visando ainda a transferência de tecnologia entre as melhores práticas na concepção e fornecimento de infraestrutura aeroportuária, com o uso dos sistemas BIM. Para ser capaz de alcançar esses objetivos, propusemos a metodologia colaborativa de pesquisa e a prática do trabalho integrado. Cabe ainda ressaltar a importância das listagens de parâmetros ("Schedules") que devem conter toda a semântica adotada no projeto, de forma sistematizada, abrangendo as fases de construção, parâmetros existentes e novos, bem como relacionadas a ferramentas de análise e de orçamentação, se for o caso.

Ocorre que as formas nativas do Revit ${ }^{\circledR}$ para exportação de geometria 3D paramétrica nos formatos "Dxf", Fbx ou "Dwg" não atendem aos requisitos da maioria dos aplicativos utilizados pelos profissionais das demais especialidades. A segunda opção nativa, baseada no formato neutro "IFC" que permite a leitura por outro aplicativo de projeto (software). O formato "IFC" possui limitações relacionadas a quantidade de informação que pode transferir e anda divergências de representação da geometria entre as plataformas. No entanto, encontra-se em desenvolvimento e versões aprimoradas vem sendo lançadas de tempos em tempos. Finalmente, exploramos as potencialidades da programação $\mathrm{C \#}$ para adição de "plug-ins" personalizados aos softwares da AutoDesk e simulação no Navisworks ${ }^{\circledR}$, parte da plataforma desta empresa, do "timeline" de obra do Terminal de Passageiros Remoto (T3) do SBCF - MG bem como dos parâmetros criados (teste). 


\section{ETAPA “B” Produtividade no Processo de Projeto}

3- Inferência pratica sobre a produtividade das ferramentas da AutoDesk, através da Programação em linguagem C\# para criação de plug-ins específicos a estes softwares;

A segunda parte da Oficina Prática consistiu na elaboração de "plug-ins" para a interface do sistema BIM utilizado, Autodesk Revit ${ }^{\circledR}$, através do Microsoft Visual Studio e da programação em C\#, que possibilita adicionar funcionalidades específicas, aumentar a produtividade e ainda alterar protocolos e criar interfaces customizadas para interoperabilidade de dados entre outros aplicativos de análise e de produção na cadeia da AEC

A criação de dois novos parâmetros de teste programados durante a Oficina Prática serviu de base para o exercício de listagem automática de valores através de "plug-in" especialmente criado para tal fim.

Este exemplo fornece compreensão da facilidade de sua criação, uma vez dominadas as linguagens e os aplicativos de programação, como também permitem visualizar as potencialidades de se poder alterar e personalizar quaisquer aplicativos da Autodesk ou da Microsoft com tal metodologia.

Tais capacidades ganham ainda maior importância dentro de uma organização como a INFRAERO, em função da complexidade do escopo de seus projetos e ainda pela dinâmica de aprovação dos requisitos e do desenvolvimento das soluções entre as diversas especialidades de projeto, com atenção para as áreas de estruturas, orçamento e de infraestrutura, que demandam larga utilização de softwares específicos de projetação.

Esta segunda parte representa a utilização dos sistemas BIM de forma avançada para que possa responder de forma satisfatória a ambientes agressivos de negócios, carregados de especificidades e heterogêneos em suas equipes, práticas e trocas de informação ao longo do processo de projetação.

Isto é possível para a plataforma BIM da AutoDesk com aplicações especializadas que usam uma API, "Application Programming Interface" (ou Interface de Programação de Aplicativos) que é um conjunto de rotinas e padrões estabelecidos por um software para a utilização das suas funcionalidades por aplicativos que não pretendem envolver-se em detalhes da implementação do software, mas apenas usar seus serviços.

De modo geral, a API é composta por uma série de funções acessíveis somente por programação, e que permitem utilizar características do software menos evidentes ao utilizador tradicional para operar diretamente sobre os dados construtivos.

Por exemplo, muitos aplicativos de "software" contam com formatos abertos, como "STEP, IFC, ou CIS / 2", para intercambiar os dados de construção entre os diversos programas de engenharia.

Outras integrações são baseadas em um driver de banco de dados neutro, como "ODBC", que atua como um tradutor entre os programas de "software".
Segundo TSE e WONG (2005), existem pelo menos três possíveis caminhos para a melhor integração na implantação dos sistemas BIM:

1- Implantar módulos adicionais dos projetos complementares ao projeto arquitetônico na mesma plataforma;

2- Exportação do módulo arquitetônico como arquivo de dados em um padrão aberto, o qual pode ser importado pelos colaboradores do projeto e utilizado em suas aplicações específicas.

3- Desenvolver aplicações específicas por meio de "Application Programming Interface" - (API) que depende da permissão dada pelo representante BIM e da acessibilidade das propriedades dos objetos.

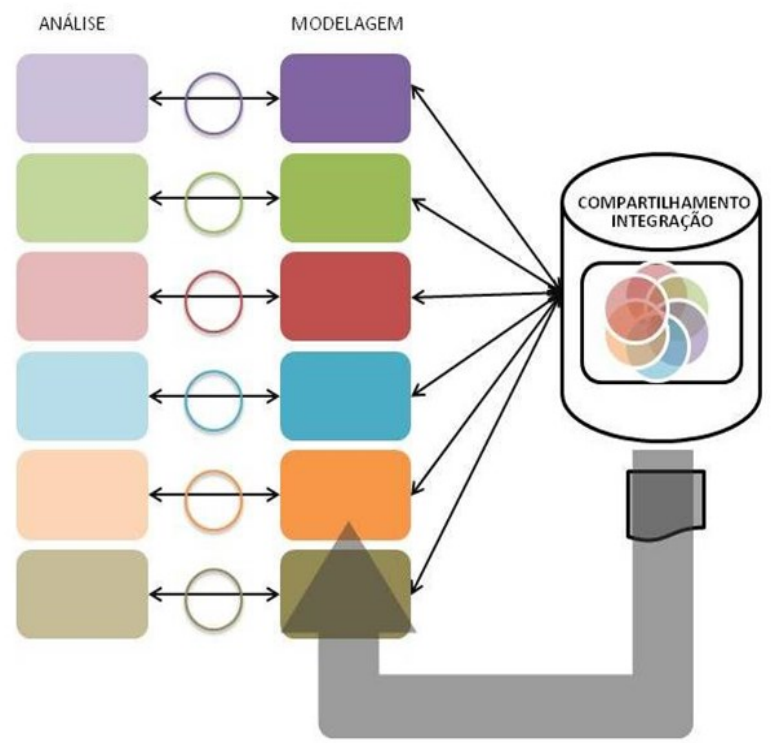

Figura $\mathrm{H}$ - O repositório de modelos incorpora funções de integração entre modelos. Fonte: (QUEIROZ, S. 2012, p. 6).

A coordenação das informações do modelo BIM é assegurada por um repositório de informações padronizadas de desenhos da construção que contém informações embutidas que vão sendo acrescentadas pelos diversos participantes do desenvolvimento do produto da construção, garantindo a qualidade e a integridade do modelo.

Todas as mudanças são guardadas e as visões dos projetos complementares em implantação são atualizadas automaticamente. Contudo para suportar todas as informações embutidas ao objeto CAD em um único modelo, exige que seu banco de dados seja tão grande quanto ao volume de dados. Portanto, requer avançados recursos de Tecnologia da Informação para o seu bom desempenho (CYON, 2003).

Nesta configuração, a coordenação da informação do edifício fica nas mãos do arquiteto, pois é ele que inicia o processo. E requer que todos os especialistas trabalhem em uma plataforma comum. O potencial de utilização das ferramentas BIM é bastante significativo na fase de produção de um projeto (ao longo do processo). 

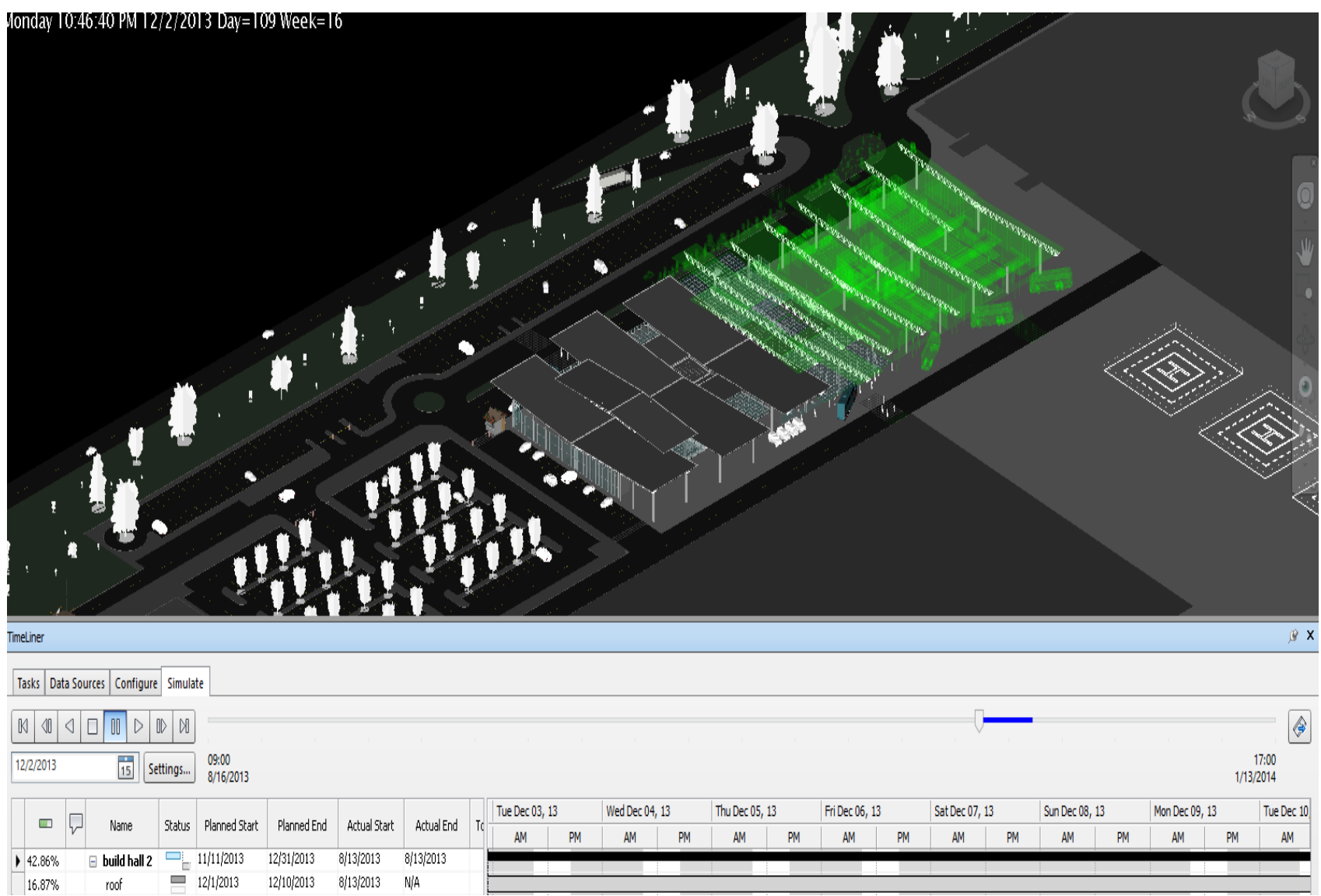

Figura I- Simulação NavisWorks ${ }^{\circledR}$ TPS/ SBCF

1- Exportação do Modelo Único de Informação BIM do TPS - SBCF para o AutoDesk NavisWorks ${ }^{\circledR}$ de forma a simular o "timeline" de obra de um aeroporto, com fases definidas, parâmetros personalizados e possibilidade de checagem de interferências através da propriedade nativa do software de "Clashdetection" entre os projetos das diversas especialidades;

A terceira parte deste Workshop centrou-se na utilização do "Autodesk NavisWorks ${ }^{\circledR}$ " para realização de um "timeline" de planejamento de projeto associado as atividades de obra usuais em um terminal de passageiros da INFRAERO. O NavisWorks ${ }^{\circledR}$ e um aplicativo altamente poderoso que permite a checagem de interferências entre os projetos das diversas especialidades bem como realizar a simulação do "timeline" de obra segundo as fases previamente estabelecidas no Revit ${ }^{\circledR}$.

A Oficina de Projeto realizou a criação de dois novos parâmetros não existentes de forma nativa no Revit $^{\circledR}$, e gerenciou a informação destes parâmetros desde sua exportação até o NavisWorks ${ }^{\circledR}$ bem como sua edição já dentro do novo aplicativo.

A partir de um modelo paramétrico de um aeroporto, no aplicativo Revit ${ }^{\circledR}$, foi realizada a configuração de etapas (faseamento) de obra, a partir das funções operacionais principais presentes em edificações desta natureza, embarque, administração e desembarque. O delineamento do faseamento criado no Revit ${ }^{\circledR}$ foi lido pelo NavisWorks ${ }^{\circledR}$ e expresso em forma de um fluxograma de atividades e de tempo, segundo as fases pré-estabelecidas.

Foi então realizada a simulação do processo construtivo de forma a atestar a capacidade do aplicativo em gerenciar o fluxo de informações, bem como da eficiência de troca de dados. O bom desempenho não surpreende, já que estamos falando de uma solução "fechada", do tipo plataforma, que necessariamente possui funcionalidade pratica, até mesmo por uma questão de sobrevivência comercial, ou seja, perfaz uma gama de produtos "softwares" de mesma natureza, do mesmo fabricante.

O NavisWorks ${ }^{\circledR}$ e a ferramenta indicada, dentro da plataforma AutoDesk, para realizar a integração de projetos complementares visando a checagem de interferência e futuro planejamento de obra.

ETAPA “D” Fluxos de Informação e Processos 
4- Desenho dos diagramas de fluxos de informação (possíveis) através da utilização dos sistemas BIM em solução do tipo "Plataforma" (Oficina de Projeto);

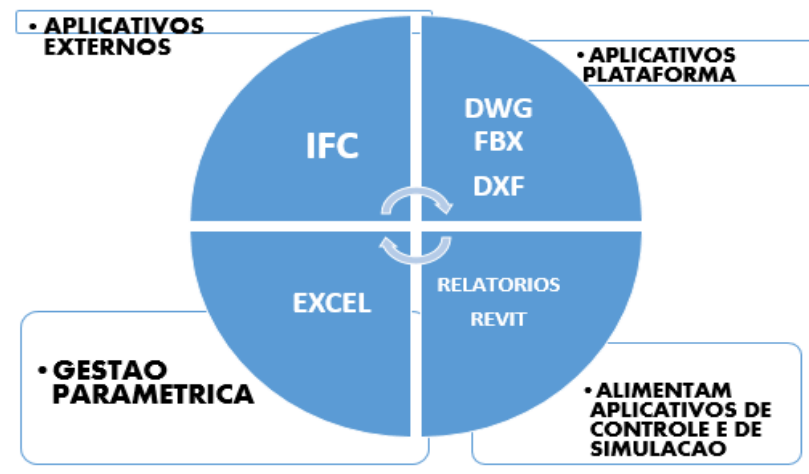

Figura J- Exportação de dados - AutoDesk Revit ${ }^{\circledR}$

Como podemos observar na figura acima, a opção de exportação de dados a partir do software Revit ${ }^{\circledR}$ dividese em quatro grupos básicos:

1- Formatos nativos (Dwg, Dxf e Fbx), que permitem a exportação para "softwares" da mesma plataforma ou que possuam a capacidade de importa-los;

2- Microsoft Excel, que pode ser conectado sob a forma de "link" de forma a permitir a gestão paramétrica do modelo 3D Revit ${ }^{\circledR}$ através da alteração de seus parâmetros no Excel;

3- IFC, padrão universal de troca de dados via arquivo neutro.

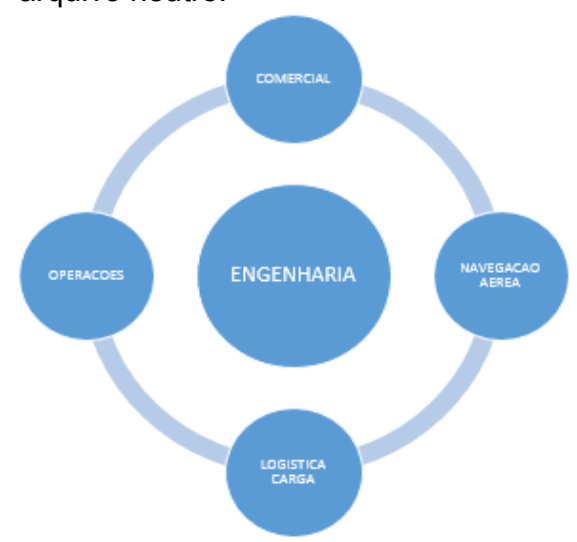

Figura K- Áreas clientes a de Engenharia - INFRAERO

No âmbito da INFRAERO, as atribuições da Área de Engenharia são geradas pelas demandas e necessidades das áreas cliente, como as de Operações, Comercial, Navegação Aérea e Logística de Carga. Obviamente o atendimento de eventuais soluções de projeto deve passar pela análise e aprovação destas áreas afins. Portanto ao se pensar na aplicação de um Sistema BIM para a empresa necessariamente deve-se incluir no fluxograma de dados os "loopings" necessários.

Ao pensarmos em uma metodologia BIM de projeto para a INFRAERO devemos nos ater a necessidade de que a informação percorra as necessidades e configurações de cada especialidade, expressas em soluções de projeto que não devem possuir interferências entre si. Além disso, devem ser capazes de comprovar que atendem a solução mais vantajosa face aos critérios, requisitos e condicionantes de cada Área Cliente do Departamento de Engenharia, de forma que se torna necessário que exista conexão não apenas de dados, mas uma metodologia colaborativa entre os agentes intervenientes neste processo. Em face do exposto, acreditamos que as fases de projeto devam estar interconectadas em relação ao ganho de complexidade que a informação de projeto adquire ao longo das mesmas.

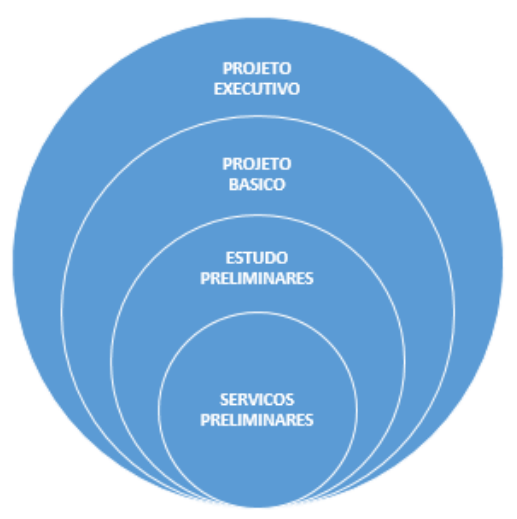

Figura L- Fases de Projeto na INFRAERO

Porém para que seja possível a conexão devida entre as áreas clientes e as fases de projeto dentro de um processo de projeto que se utilize dos Sistemas BIM torna-se fundamental que as atividades de modelagem e a busca de soluções de projeto e de análise de dados sejam integradas. A capacidade organizacional de uma empresa como a INFRAERO para integrar seus processos, seus fluxos de informações e suas metodologias de análise e de projeto, ou seja, sua pratica profissional exige-se que se desenvolva lentamente um senso crítico expresso em maturidade empresarial.

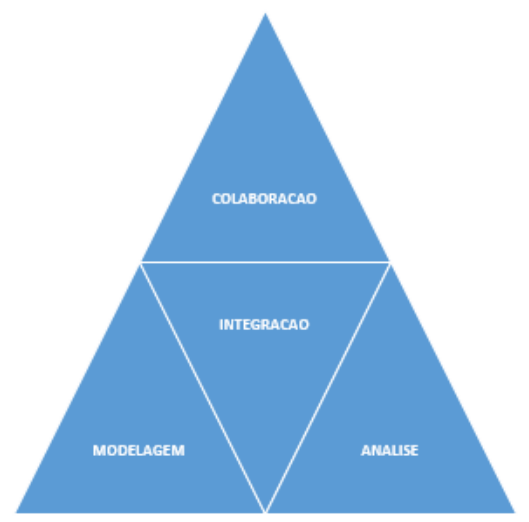

Figura M- Estágios de Maturidade BIM

6- Comparação com o fluxo de informação do Processo em voga na INFRAERO (bidimensional não paramétrico);

A inferência a partir das diferenças e divergências entre os dois processos investigados projeto permite que seja 
possível supor quais seriam os fatores críticos de sucesso na implantação de um Sistema BIM para o fornecimento de infraestrutura aeroportuária no Brasil e possivelmente indicar as melhores formas para a sua implantação. Os benefícios e os impactos da utilização de um sistema BIM para esses fins serão de grande valia por ser capaz de quantificar os impactos sobre a estrutura organizacional INFRAERO e a extensão e complexidade das mudanças em sua eventual implantação na empresa.

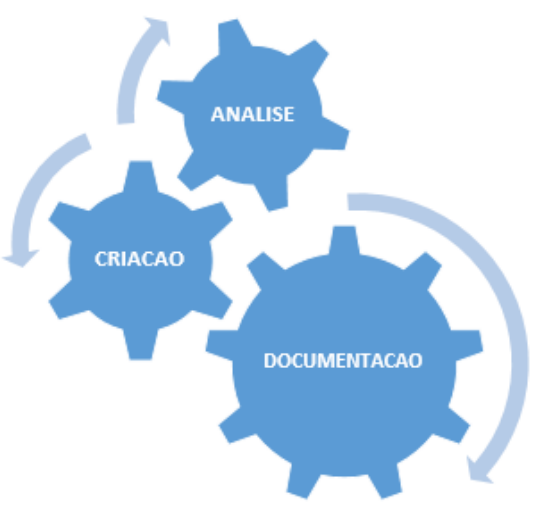

Figura N- Processos de projeto

Os processos de Criação (concepção), analise e de documentação devem estar interligados quando se utiliza um "software" paramétrico, de forma a que se estabeleça uma metodologia colaborativa a que chamamos BIM. Ao envolvermos os diversos agentes intervenientes da INFRAERO ao longo de um processo de projeto que obedeça as fases definidas de Serviços e Estudos Preliminares, Projeto Básico e Executivo, representados pelas diversas áreas da empresa, de forma colaborativa e integrada, poderemos observar que as interfaces tradicionais de entrega de informação de projeto irão se transformar de simples campos de sobreposição a algo totalmente permeado pelas informações inerentes de cada área (vide Fig. 11). A figura abaixo representa o fluxo de informação no processo tradicional em voga na INFRAERO, onde os campos que se sobrepõem não perfazem a totalidade da informação existente em cada fase de projeto. O restante de cada conjunto perde disponibilidade de entrega de informação ao longo do processo de projeto.

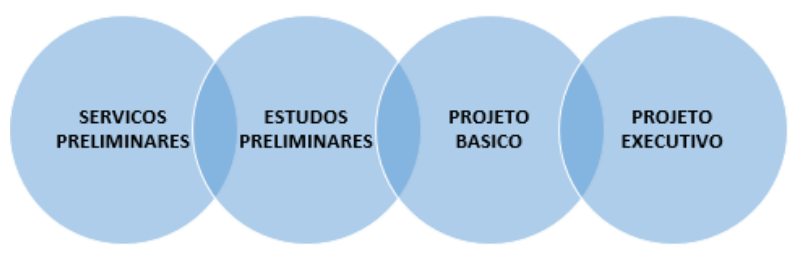

Figura O- Fluxo de Informação bidimensional não paramétrico ao longo das fases de projeto

Como podemos observar na figura abaixo, que representa o processo de aprovação de projetos atualmente utilizado pela INFRAERO, caracteriza-se por um processo linear que invariavelmente depende da finalização da etapa anterior para que aja andamento na aprovação das soluções propostas por cada área cliente. No entanto, o fluxo de informações fica retido nas interfaces de aprovação, uma vez que caso ocorra um descompasso ou discrepância nas soluções apresentadas, deve-se retornar ao início da etapa sem que aja uma interação de dados e de analise entre os profissionais das diversas especialidades de projeto.

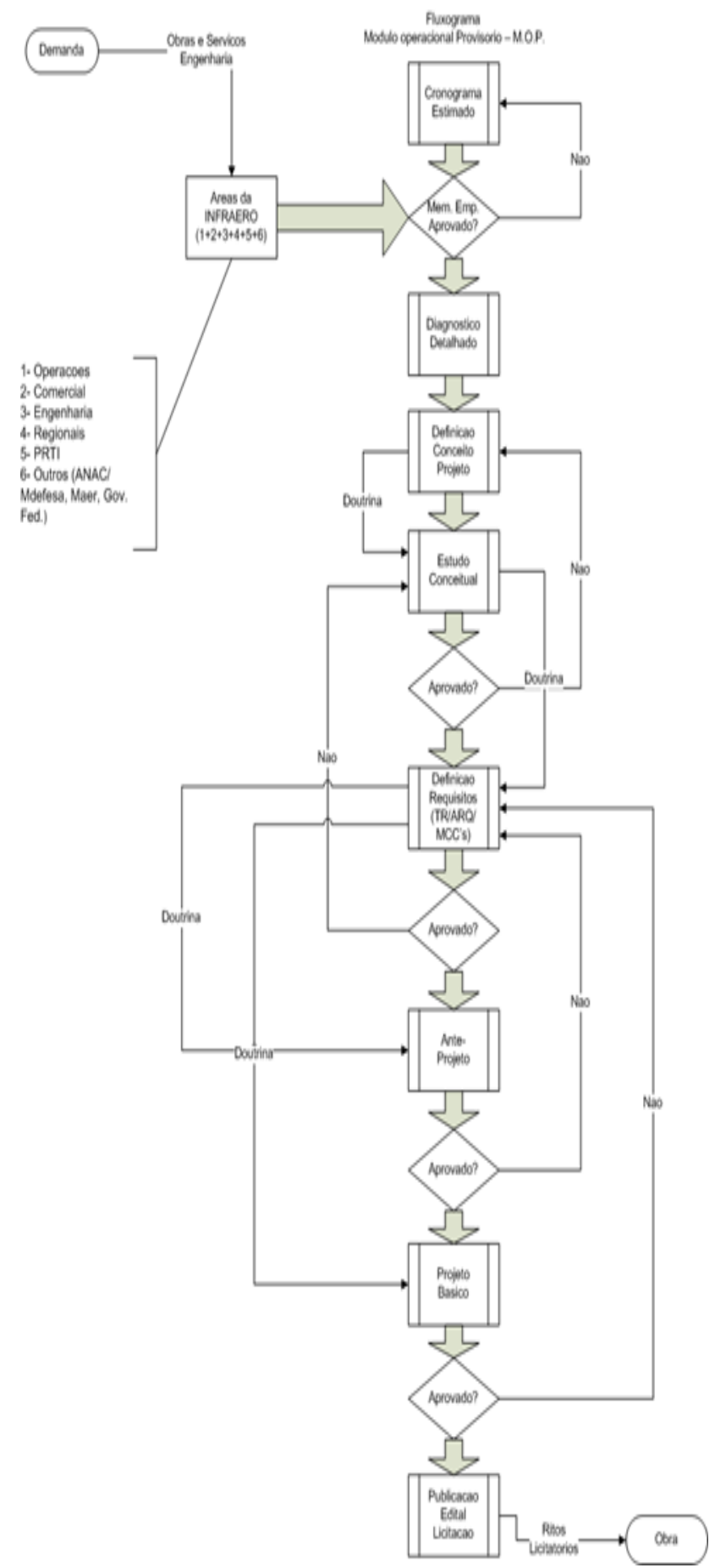

Figura P- PROCESSO APROVACAO PROJETOS INFRAERO SEDE. Fonte: INFRAERO.

\section{METODOLOGIA DETALHADA (OFICINA DE PROJETO)}

1- Configuração de Parâmetros (TPS-SBCF); 
Esta etapa é a parametrização de partes do Terminal Remoto de cada participante da Oficina, a fim de retratar o uso do modelo de informação único para o trabalho colaborativo entre os vários projetos de especialidade.

O processo de mapeamento de informações de parâmetros do modelo único de informações e os protocolos de compatibilidade com as interfaces de aplicativos, em interação com outras ferramentas de projeto e / ou análise (software) aumenta a complexidade e o nível de maturidade exigida para tais fins.

Aspectos semânticos e ontológicos a respeito da complexidade do projeto e os requisitos de nível e as informações associadas a esta, bem como em relação aos aspectos de interoperabilidade de troca de dados e extração de informações são contribuições significativas que a equipe da Universidade de Gent, representados pelos professores RONALD MEYER e PIETER PAUWELS, pode trazer.

\section{2- Ontologia aplicada em Ciência da Computação}

Em Ciência da Computação, Sistemas de Informação e Ciência da Informação, uma ontologia é um modelo de dados que representa um conjunto de conceitos dentro de um domínio e os relacionamentos entre estes. Uma ontologia é utilizada para realizar inferência sobre os objetos do domínio. Ontologias são utilizadas em inteligência artificial, web semântica, engenharia de software e arquitetura da informação, como uma forma de representação de conhecimento sobre o mundo ou alguma parte deste.

\section{3- Ontologia "Conceitual" BIM:}

Desenvolvida para reduzir a complexidade e possibilitar a aquisição do conhecimento e validação dos tópicos do Framework. É uma linguagem para representar o BIM Framework. Existem muitos tipos de ontologias que variam em sua formalidade, estrutura e uso pretendido.

\section{Três principais usos:}

1- Gerar uma linguagem para a comunicação entre as pessoas ou interoperabilidade entre sistemas:

2- Atuar como uma "descrição formal dos elementos e relações entre os elementos" dentro do domínio.

3- Ajudar na aplicação de aquisição de ferramentas de conhecimentos, técnicas e metodologias, facilitando a construção de modelos de domínio e de reutilização de conhecimento entre domínios.

As soluções encontradas durante o desenvolvimento de um projeto (processo de projeto) devem servir para melhorar a metodologia em relação aos processos de BIM e estruturas organizacionais, sejam públicas ou privadas, de modo que as mudanças necessárias em sua estrutura ser possível.

\section{Ontologias geralmente descrevem:}

A) Indivíduos: os objetos básicos;

B) Classes: conjuntos, coleções ou tipos de objetos;
C) Atributos: propriedades, características ou parâmetros que os objetos podem ter e compartilhar;

D) Relacionamentos: as formas como os objetos podem se relacionar com outros objetos.

\section{4- Modelagem paramétrica no projeto aeroportos}

A modelagem de componentes de informação do aeroporto é importante na pesquisa desenvolvida nesta oficina para a realização especifica aplicabilidade para o fornecimento de sistemas de infraestrutura aeroportuária BIM, bem como permitir o processo de projeto envolvidos na sua criação é determinado.

Além disso, o uso desses componentes permitirá a extração aeroporto paramétrico simulação e troca de informações em todo o processo, bem como a inferência sobre o mapeamento adequado das informações do projeto e a metodologia envolvida na sua preparação e utilização (aspectos semânticos e ontológicos).

O fluxograma de utilização dos Sistemas BIM como ambiente de trabalho na INFRAERO, deve cobrir seus atores principais, enquanto clientes internos e externos (ANAC), bem como os requisitos e formas de aprovação formal dos projetos pela empresa. A parte principal do processo está nas atividades de análise de processos, diagramas de fluxo e avaliação "layout".

O processo de projeto é a evolução e maturidade de informações associadas a estes campos, que flui em uma representação gráfica e na busca de soluções mais vantajosas para cumprir os requisitos no início do processo.

Entre estes, vários campos de prestação de profissional de infraestrutura aeroportuária através da estação INFRAERO todas as atividades de análise, melhoria, qualidade e gestão, permeando todo o processo.

Os processos de análise são realizados de forma contínua em cada nova solução proposta, a fim de validar constantemente os requisitos de cada projeto.

Os diagramas de fluxo de representar uma novidade em relação ao processo de aprovação de projetos atualmente em voga na INFRAERO, uma vez que esses fluxos são usados para monitorar e orientar as informações entre o modelo de informações exclusivas e ferramentas de análise e produtividade de cada projeto de especialidade.

A adoção de um sistema do tipo BIM, permite a integração dos dados de diferentes especialidades complementares de forma a se aprimorar o processo de concepção e consequente tomada de decisão ao longo do processo de projeto.

O domínio da metodologia BIM como ferramenta de gestão da informação de projeto e de obra no Brasil, além de significar a apropriação da tecnologia no âmbito brasileiro, perfaz um diferencial competitivo.

A síntese da forma é a atividade onde o arquiteto ou projetista deve partir de um conjunto de requisitos do programa de necessidades e condicionantes e propor uma configuração espacial que não só atenda a esses requisitos, mas que também seja viável dos pontos de vista estrutural, econômico e ambiental. 
Aqui está o cerne da atividade profissional e criativa do arquiteto no processo de projeto.

As características que se esperam de uma ferramenta CAD para esta etapa são a facilidade na manipulação de objetos, criação e visualização virtual.

O passo seguinte consiste basicamente em se agregar à configuração inicial toda a informação de projeto e detalhamento necessário para que este possa ser executado e/ou licitado.

Nesta etapa, espera-se que as ferramentas CAD apoiem o desenvolvimento do projeto tanto no que se refere à incorporação de novas informações e geometria ao modelo, quanto na comunicação e compartilhamento do projeto, da informação e dos dados gerados para que profissionais de diversas áreas possam realizar os projetos complementares.

O aspecto mais importante a se ressaltar neste método de projeto é que uma vez que se ultrapasse a fase de síntese, não existe volta para que uma nova solução ou proposta sejam incorporadas ao projeto.

O desenvolvimento do projeto e o enorme volume de documentação gerado neste processo constituem-se em uma barreira devido à enorme tarefa de retrabalho envolvida nesta situação.

Resta ainda a análise de pequenas alterações de projeto, que passam pelo incômodo óbvio de terem que ser atualizadas individualmente em todas as pranchas ou arquivos do projeto, o que pode ser uma fonte de erros e de omissões.

Portanto, o processo de aprovação de projeto atualmente estruturado na INFRAERO deverá passar por revisões ao adotarmos os sistemas BIM como ambiente de trabalho na empresa.

Ao pensarmos a utilização de um modelo único de informações de projeto para que seja desenvolvido e complementado por todas as especialidades de projeto, necessariamente sairemos de uma estrutura linear para alguma forma radial que represente as conexões e interfaces entre o núcleo (modelo único de informação BIM) e as partes (especialidades de projeto).

A parte subjetiva neste processo, que extrapola as variáveis desta pesquisa reside nos "loopings" representados pelas atividades de submissão de soluções desenvolvidas para aprovação junto aos clientes internos da área de engenharia.

Citando os principais, Comercial, Operações, Segurança, Manutenção, Navegação Aérea, meio ambiente, entre outros que deverão também utilizar ferramentas BIM para tais fins, mas que não perfazem objeto de investigação ou recorte nesta Oficina de Projeto.

A INFRAERO atualmente passa por reestruturação significativa de processos e financeira.

Inferência e adaptações de pesquisa em sistemas BIM.
O uso persistente do sistema CAD tradicional para a maioria das empresas hoje em dia, no Brasil, pode ser devido à falta de informações lá sobre o potencial dos sistemas BIM- CAD, mas que a sua implantação, em geral, mudanças na demanda do processo de projeto próprio. Apesar das diferenças entre os dois sistemas CAD examinados, verificou-se que em ambos os casos, a informação de importância para a gestão da qualidade projetiva bem como documentação da qualidade do edifício concluído.

Enquanto uma informação CAD tradicional pode ser compartimentada em ficheiros diferentes, a representação tridimensional de um edifício só faz sentido se todos os elementos que a constituem estejam presentes no mesmo ficheiro, ocupando as posições relativas, que vai ocupar o edifício construído. Apesar de uma vantagem sobre CAD tradicional, a presença de todos os elementos geométricos em uma localização não garante a possibilidade de estruturação e de extração de informação, principalmente sob a forma de documentação de projeto.

Embora ainda poucos estudos quantificar os benefícios obtidos com o uso de BIM do CAD, a pesquisa na área de tecnologia da informação concorda em relação à sua influência positiva sobre o desempenho do processo de projeto e sobre a irreversibilidade da transição do CAD geometria para sistemas BIM. No entanto, não só a ferramenta utilizada para gerar a documentação de projeto deve ser modificada, mas também o processo de criação, que não deve permanecer inalterado face às novas possibilidades proporcionadas pela tecnologia.

Os diagramas de fluxo representam uma novidade em relação ao processo de aprovação de projetos atualmente em voga na INFRAERO, uma vez que tais fluxos servem para acompanhar e guiar as informações entre o modelo único de informações e as ferramentas de análise e de produtividade de cada especialidade de projeto.

Como exemplo, a especialidade de conforto térmico, luminoso e acústico muito provavelmente irá se utilizar de ferramentas como o Ecotect ${ }^{\circledR}$ Analysis, ou similar. Aspectos de interoperabilidade, a definição precisa das interfaces necessárias para a troca de informação entre os sistemas BIM e as ferramentas de análise e os protocolos envolvidos em tais processos são escopo da etapa de diagrama de fluxos proposta.

A etapa de definição de "layout" constitui-se uma parte importante do macro processo por ser uma etapa preparatória para o desenvolvimento do projeto, onde o autor propõe que se proceda a investigações da forma e da função propostas para a edificação. No caso do Revit $^{\circledR}$, estes estudos se dão através da ferramenta de massas disponível no "software".

A proposta de investigação metodológica (figura abaixo) define as conexões e inter-relaciona os diversos estágios de pesquisa que o autor acredita que melhor responda como teste da hipótese face ao processo de utilização dos sistemas BIM na INFRAERO detalhado acima. Por detrás dos benefícios estão ocultos inúmeros pequenos processos para realização das tarefas de projeto, que deveriam ser objeto de pesquisa para melhor definição deste novo processo de projeto que os sistemas BIM representam. 
Como componentes paramétricos são projetados em uma reutilização lógica construtiva e organização sistemática de recursos e funcionalidades, diferentes espaços de um terminal de passageiros em um aeroporto podem ser pensados como define paramétrico funcional dentro de uma metodologia de projeto que faz uso do sistema BIM.

O uso de conjuntos inteiros que representam partes dos elementos de construção como a inserção de projetos, organizados em bibliotecas de conjuntos funcionais do edifício é consistente com a natureza e a dinâmica dos projetos aeroportuários.

A Oficina de Projeto teve como objetivo investigar os aspectos semânticos e ontológicos no uso de componentes paramétricos neste intervalo.

A possibilidade de visualização e manipulação interativa de modelos virtuais com auxílio do computador tem revolucionado o processo de projetação, pois permite a compreensão e análise de enormes quantidades de informação de natureza espacial com eficiência sem precedentes.

A visualização e a manipulação interativa de modelos virtuais é uma ferramenta valiosa para a área da AEC, sobretudo quando se deseja checar interferências e simular o processo construtivo a ser utilizado na Obra.

A capacidade de simular projetos futuros, verificar se correspondem ou não ao empreendimento, além da possibilidade de fundir aspectos da realidade atual com a realidade virtual oferece novos patamares de análise e compreensão em ambientes complexos de trabalho.

Essas capacidades geram um detalhamento preciso da edificação, de forma a permitir uma análise mais cuidadosa dos requisitos funcionais, estruturais $e$ ambientais.

Aeroportos representam uma área de aplicação ideal para simulação de ambientes complexos.

Os processos estão em continua mudança, requerendo um desempenho que possa ser medido em vários indicadores de desempenho diferentes.

Dentro dos aeroportos, mas também entre aeroportos, o mesmo tipo de perguntas é respondido inúmeras vezes.

Porém, frequentemente são construídos modelos de simulação novos para cada pergunta, se possível copiando algumas partes de modelos prévios.

A reutilização de componentes de simulação raramente é vista.

Este papel mostra uma aproximação entre os requisitos de provimento de infraestrutura aeroportuária e os benefícios que um sistema BIM pode proporcionar.

Partindo da suposição de que a construção de componentes paramétricos (blocos) pode formar 0 núcleo de um sistema de gestão para infraestrutura de um aeroporto, pode-se responder aos desafios deste setor de forma mais rápida que nos modelos tradicionais.

Os sistemas BIM agregam o conjunto de informação (capacidade técnica) de cada profissional da equipe de projeto, possibilitando somar este conjunto de conhecimento em uma composição palpável das variáveis de informação presentes neste universo.

5 - Demonstrações de práticas inovadoras no processo de projeto que se utiliza dos Sistemas BIM, como extração de informação, estratégias de modelagem, a troca de informações (dados de interoperabilidade), orçamento, etc.

Aqui reside a contribuição específica de cada pesquisador em seu campo de estudo e/ ou ensino, com foco no conhecimento público representado por pesquisas anteriores e no desenvolvimento da pesquisa atual de cada pesquisador. A ideia é trazer as diferentes vertentes de investigação em todos os domínios do conhecimento associadas aos Sistemas BIM.

Aspectos como a interoperabilidade de dados, orçamento automático (quantificação, extração), e formação de componentes paramétricos, entre outros podem se beneficiar desta pesquisa, bem como o desenho das melhores práticas associadas ao uso dos Sistemas BIM, caminhos de implantação e definição de interfaces, protocolos e padrões apropriados para tais fins.

Neste momento ficou clara a defasagem entre o saber adquirido através da experiência teórica e o domínio pratico da metodologia e da tecnologia que envolve os Sistemas BIM. Além disso, a Universidade de Gent possui registros próprios em relação ao fluxo de informação associado à utilização dos Sistemas BIM, abordando aspectos como ontologia aplicada para tipologias de projeto e de concepções semânticas específicas para integração das disciplinas de projeto e de obra em um ambiente colaborativo "Web".

A implantação de um Sistema BIM em uma estrutura organizacional com a INFRAERO apresenta uma disposição em camadas que vão se sobrepondo em função da complexidade envolvida no uso das ferramentas BIM por toda a equipe de projeto e de obra. Em cada camada existem novos níveis de informação associada (parâmetros) bem como informações adicionais relacionadas ao comportamento e a interrelação (conectividade) entre estes componentes construtivos. A integração em servidor interno à organização (INFRAERO) de um projeto de funções complexas como um aeroporto exige que se estabeleçam regras, critérios e atributos dos componentes construtivos de forma a gerar uma linguagem comum e interoperava entre os diversos aplicativos ("softwares") utilizados no processo de projeto.

A isto se dá o nome de ontologia aplicada aos processos de engenharia. Sem a organização ontológica das tipologias aeroportuárias inserida nos processos internos da organização, no caso a INFRAERO, a extração dos benefícios de um Sistema BIM fica comprometida em função do caos que se ira estabelecer na troca de informação e na subsequente tomada de decisão e na imperfeição inerentemente associada aos processos de análise. A integração maior, em rede externa, via internet, exige uma maturidade ainda maior, representada pelos aspectos semânticos destas tipologias. 


\section{METODOLOGIA DETALHADA (OFICINA DE PROJETO)}

BIM Framework é uma metodologia para gerenciar o projeto de construção e dados do projeto em formato digital ao longo do ciclo de vida do edifício.

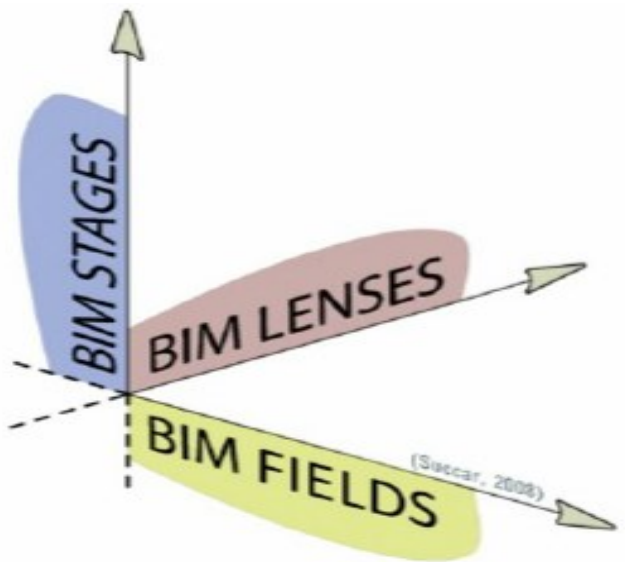

Figura Q- Quadro BIM: campos, estágios e lentes modelo tri-axial. Extraído de "Building Information Modeling: "A research and delivery foundation for industry stakeholders" B. SUCCAR, 2009, "Automation in Construction", Elsevier B.V."

SUCCAR (2009, p. 358) desenvolveu um quadro de pesquisa para: sistematizar o conhecimento, referente aos Sistemas BIM como uma solução integrada e dessa forma conectar as lacunas que existem entre os teoricos academicos acadêmico e seus colegas no mundo prático (mercado).

Os campos - "fields" (participantes e resultados), os estágios - "stages" (maturidade de implementação) e as lentes - "lenses" (conhecimento atraves de diferentes pontos de vista)

SUCCAR (2009) argumenta que o IPD deve ser o ponto final de implantacao, declarando que "... a visão a longo prazo dos Sistemas BIM [é o de] uma amálgama de domínio de tecnologias, processos e políticas "( $p$. 365).

\section{Construção de uma Ontologia}

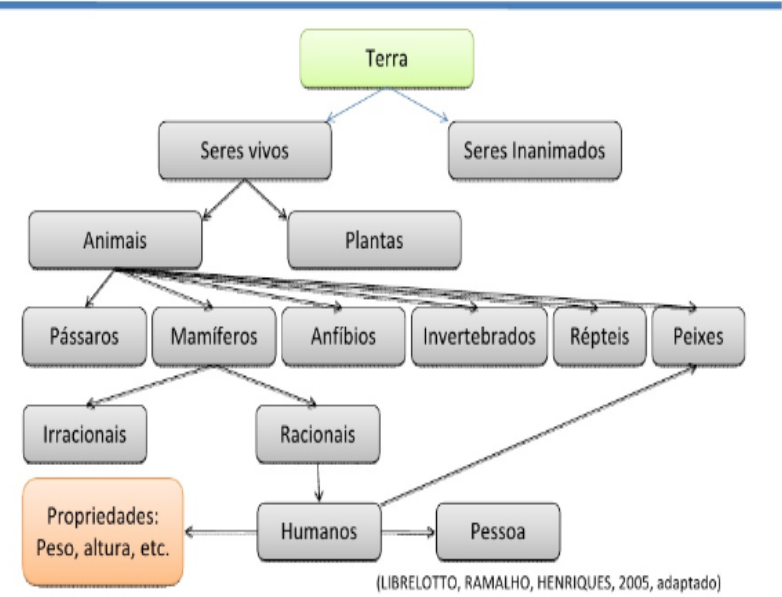

Figura R- Construção de uma Ontologia. Fonte: LIBRELOTTO et. Al, 2005).

\section{Diferenças entre Lentes e Filtros BIM}

São ferramentas de investigação da pesquisa e análise de domínio, permitindo a descoberta de conceitos e relações:

1- Lentes: aditivos implantados a partir de "lado do investigador" no campo de informação do BIM destacam observações que satisfazem os critérios de pesquisa e identificam as suas relações (Ex. detecção de calor infravermelho);

2- Filtros: subtrativos implantados a partir do "lado dos dados", removendo observações que não atendem os critérios de pesquisa (esconder dados não condizentes dentro de uma planilha).

Existem três tipos de lentes e filtros que podem ser aplicados individualmente ou coletivamente para gerar uma visão do conhecimento:

\section{1- Lentes e Filtros Disciplinares}

Geram vistas BIM através da aplicação de campos do conhecimento.

Geram visões distintas do domínio BIM

"Lente de gerenciamento de dados": destacam os dados que fluem e controlam

"Filtro de fluxo de dados": isola os tipos de arquivos trocados

"Lente de gestão de processo": destaca os papéis, procedimentos e tarefas.

"Filtro de tarefas": isola reuniões específicas e chamadas de telefone

\section{2- Lentes e Filtros de Escopo}

Altera a abstração horizontal e vertical do ponto de vista pretendido. Resume a visão do conhecimento mudando sua granularidade e filtrando as informações indesejadas através de "unidades de arredondamento de medição"

- Lente Macroscópica: possui ampla cobertura tópica, mas baixa em detalhe.

- Lente Mesoscópica: cobertura média para focos e detalhes

- Lente Microscópica: pobre de foco, mas rico em detalhes

\section{3- Lentes e Filtros Conceituais}

Gera vistas de conhecimento através da aplicação conceitual de filtros derivados da Ontologia BIM

Incluem: Agentes, Restrições, Entregas, Equipamentos, Tarefas e Desencadeamentos.

Em resumo, lentes e filtros BIM (disciplinar, escopo ou conceitual) podem ser aplicados individualmente ou coletivamente para gerar uma série de pontos de vista. Estas capacidades de extrair vistas e conhecimento, através da abstração e representação, proporcionam ao Quadro BIM flexibilidade e granularidade investigativa. 


\section{Lentes BIM - Terceira dimensão do Framework}

Geram uma profundidade de investigação

"São camadas distintas ("layers") de análise aplicada a Campos e Estágios para gerar "Vistas Conhecimento"

Resumem o Domínio BIM e controlam a sua complexidade removendo detalhes desnecessários
Permitem que o investigador foque qualquer aspecto da indústria $A E C$ e elabore vistas de conhecimento que destaquem observações que satisfaçam os critérios de pesquisa ou filtrem observações que não satisfaçam.

Todas as vistas sobre o conhecimento são abstrações derivadas a partir da aplicação de uma ou mais lentes e/ou filtros.

\section{abstract introduction to BIM Framework}

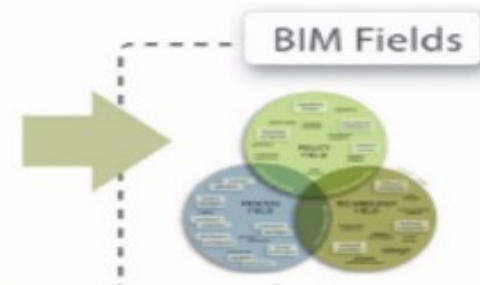

clusters

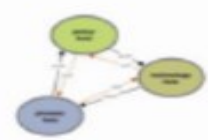

interactions

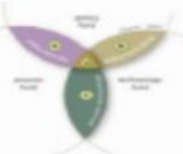

overlaps

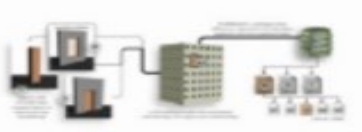

data flows

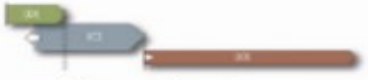

lifecycle phases

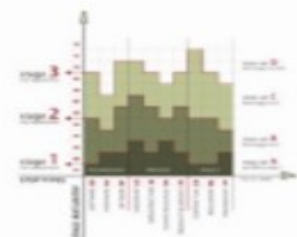
steps steps

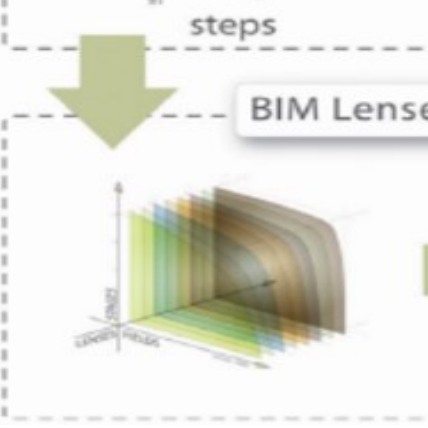

Figura S- BIM Framework

O "Sistema de Competências BIM" é uma coleção hierárquica de competências individuais identificadas para fins de implementação BIM e avaliação da equipe..

O termo competência - neste artigo, não reflete necessariamente as habilidades humanas, mas um conjunto genérico de habilidades adequadas para a implantação visando avaliar a capacidade BIM em face do prazo.

Possivelmente um "Sistema de Competência BIM" que seja utilizado em um processo de implantação, ele seria uma parte integrante das etapas de implantação BIM. No entanto, se for utilizado para avaliar implantações existentes, eles representam áreas de avaliação do domínio BIM.
O diagrama acima reflete como o "BIM Framework" (Succar, 2009) gera um Sistema de Competência BIM para Conjuntos de Multiplos Campos, Estágios e Lentes Os Campos BIM são aglomerados conceituais de participantes no domínio de interação e sobreposição dentro da indústria (SUCCAR, 2009). Existem três tipos de campos BIM (Tecnologia, Processos e Política) e três componentes dentro dos campos (Participantes Requerimentos e Entregas). Os Sistemas de Competências BIM são um reflexo direto dos Requisitos e Entregas do dominio BIM e pode ser groupedinto três conjuntos - Tecnologia, Processos e Política: conjuntos de tecnologia em software, hardware e redes. Por exemplo, a disponibilidade de um BIM toolallows a migração desde a elaboração de base para o fluxo de trabalho baseado em objeto (uma exigência do BIM Fase 1) conjuntos de processos em liderança, infraestrutura, recursos humanos, produtos e serviços. 


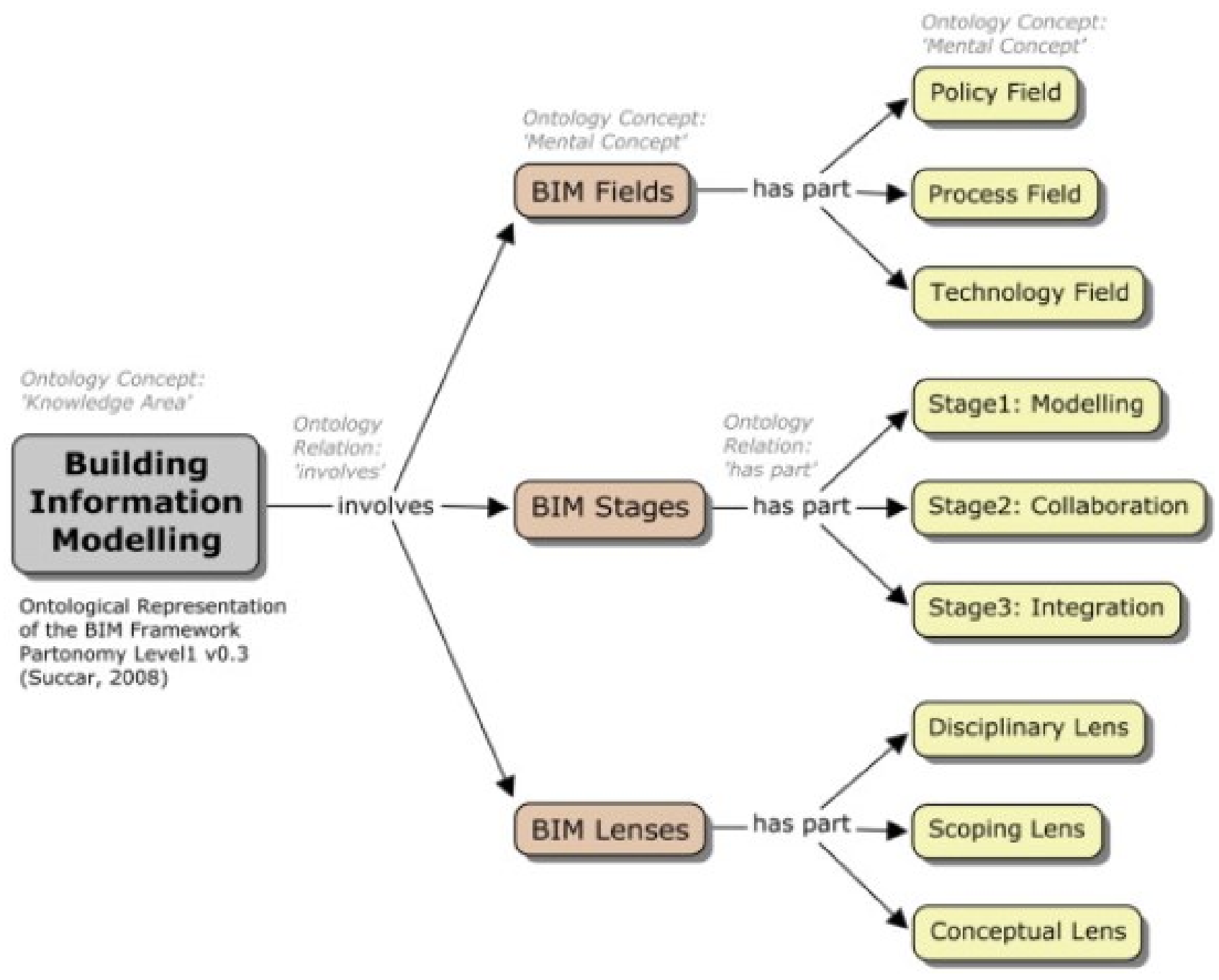

Figura T- Representações ontológicas BIM Framework

Os processos de colaboração e as habilidades de compartilhamento do banco de dados são necessários para permitir a colaboração baseado em modelo um BIM (Estagio 2).

Conjuntos de políticas em contratos, regulamentos e pesquisa em novas práticas e processos para a que seja possível a integração baseada em rede (BIM Fase 3) dentro de uma organização especifica.

As lentes BIM são camadas distintas de análise que permitem aos pesquisadores de domínio se concentrar seletivamente sobre qualquer aspecto ou conjunto de parâmetros desejado, podendo gerar vistas de conhecimento (recortes) que possibilitam acesso a campos de conhecimento específicos dentro de um vasto domínio. (SUCCAR, 2009).

A caracterização de um domínio e seus componentes, com regras e parâmetros definidos constitui-se tarefa fundamental para não só estabelecer uma ontologia pertinente ao contexto da empresa útil para eventual implantação de um sistema BIM, no caso a INFRAERO, como permite que se possa aumentar a eficiência do processo de projeto e garantir o cumprimento de metas.
"Building Information Modeling" (BIM) é uma coleção em expansão de conceitos e ferramentas com capacidades transformadoras dentro da AEC - indústria de Arquitetura, Engenharia e Construção. Discussões acerca dos Sistemas BIM tem crescido face as crescentes capacidades dos "softwares", utilizações infinitamente variadas e padrões concorrentes provenientes de sobreposições de definições que tentam delinear o termo BIM.

Os Sistemas BIM podem ser entendidos como um catalisador para a mudança (BERNSTEIN, 2005) prestes a reduzir a fragmentação do setor (CWIC, 2004), melhorar a sua eficiência (HAMPSON \& BRANDON, 2004) e reduzir seus custos elevados de interoperabilidade inadequada (NIST, 2004).

Em essência, os Sistemas BIM representam um leque de possibilidades e desafios que precisam ser compreendidos e atendidos, respectivamente, através de uma abordagem mensurável e repetível. Cabe aos interessados explorar a natureza multidimensional do domínio BIM na busca de uma utilização segura, inteligente e eficiente para a gestão do conhecimento da AEC de forma a auxiliar indivíduos, organizações e equipes de projeto BIM, ampliar sua capacidade, maturidade e melhorar o seu desempenho. 


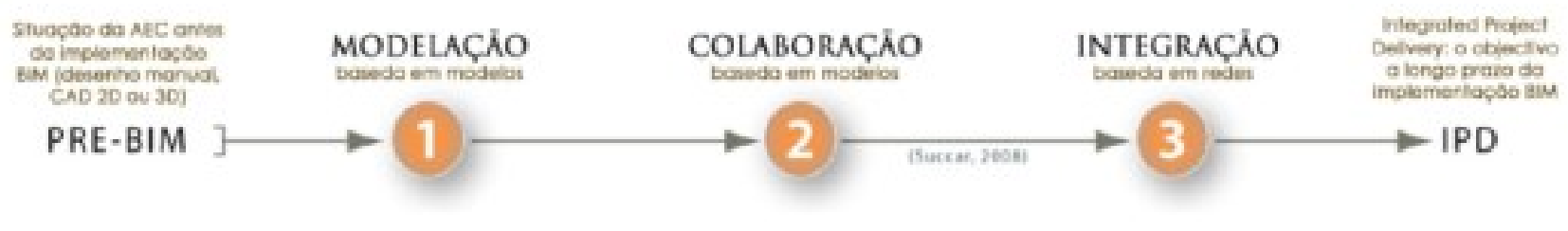

Figura U- Fases de maturidade BIM

\section{INTEGRAÇÃO PRODUTO/ PROCESSO DE MODELAGEM}

Existe a necessidade de se estabelecer e estreitar a relação entre o ponto de vista acadêmico e o industrial para o entendimento e utilização do BIM.

O frame é com uma rede de trabalho composta por relações e nós. Implantações de BIM e discussões continuam a aumentar à medida que mais organizações e entidades reconhecem seu valor agregado, evidenciado pelo aparecimento de diretrizes e relatórios definindo requisitos e demonstrando resultados.

A adoção de um Sistema BIM pela INFRAERO exige que se obedeça aos níveis de maturidade que vão dos estágios iniciais de modelagem pura de componentes e projetos aeroportuários pela empresa, passando pelo estagio colaborativo da equipe de projeto (que exige interoperabilidade de dados entre os aplicativos das diversas especialidades) até a fase de integração (em servidor e em rede), que prescindem de domínio dos aspectos ontológicos para a integração radial em torno de um servidor na empresa e de aspectos semânticos quando esta integração ocorre na rede (Web).

Existe a necessidade de se estabelecer e estreitar a relação entre o ponto de vista acadêmico e o industrial para o entendimento e utilização do BIM.

Podemos pensar em frame com uma rede de trabalho composta por relações e nós. Implementações de BIM e discussões continuam a aumentar a medida que mais organizações e entidades reconhecem seu valor agregado, evidenciado pelo aparecimento de diretrizes e relatórios definindo requisitos e demonstrando seus resultados.

\section{Pré/ BIM -}

Modelagem iconográfica: modelagem bi ou tridimensional que apenas representa os componentes construtivos sem conter parâmetros e informações relacionais entre os mesmos.

Ocorre em uma base de dados fragmentada e independente entre as diversas especialidades de projeto.

Documentação 2D para uma realidade 3D. Comumente um modelo $3 D$ é gerado com uma informação desconexa, dependente de documentação e detalhamento bidimensional.

Quantidades, estimativas de custo e especificações, não derivadas de visualização, nem documentação. Práticas de colaboração entre envolvidas não priorizadas, fluxo de trabalho linear e assíncrono.

No Pré-BIM destaca-se a falta de investimento em tecnologia e a falta de interoperabilidade.
BIM Fase 1 - modelagem baseada em objetos (BIM):

Representa a capacidade paramétrica dos softwares aplicada a objetos construtivos, de forma a que se estabeleçam relações além dos parâmetros nativos dos mesmos. Inicia-se com a utilização de um software de ferramentas paramétricas baseado no objeto 3D. Semelhante ao estado Pré-BIM, onde não há trocas baseadas em modelos entre as diferentes disciplinas, as trocas de dados entre os envolvidos são unidirecionais, comunicação assíncrona e desconexa. Nesta fase ocorrem apenas mudanças nos processos menores, sendo que os usos de modelos baseados em objetos acabam estimulando a resolução antecipada e detalhada do projeto durante as fases de seu ciclo de vida.

BIM Fase 2 - colaboração baseada em modelos (BIM):

A colaboração no projeto avança por uma nova era, através de dados mais complexos e consistentes do modelo de informação do edifício. A utilização dos Sistemas BIM tende a gerar uma procura crescente por uma verdadeira colaboração de projeto baseada em modelos. Um modelo baseado na colaboração pode ocorrer dentro de uma ou mais fases do ciclo de vida do projeto. A comunicação ainda é assíncrona, porém os papéis de disciplinas sequenciais e fases do ciclo de vida começam a desaparecer. O estágio 02 oferece aos profissionais um aumento considerável de informações aos seus modelos. Duas abordagens fundamentalmente diferentes surgiram: uma conhecida como a abordagem da "plataforma", onde a colaboração acontece com os diferentes ramos da mesma solução de software, e a outra conhecida como a abordagem "aberta", onde diferentes soluções de software formam o suporte da colaboração baseada em modelos.

Ambas, com ênfase na criação compartilhada e colaborativa do modelo da edificação, em todo o processo do empreendimento, envolvendo as fases de concepção, construção e operação, e as múltiplas disciplinas da área da AEC.

IPD - "Integrated Project Delivery Synopsis" (IPD) tem como missão Integrar pessoas, sistemas, estruturas de negócio e práticas em um ambiente colaborativo.

Otimização dos resultados, redução de desperdícios em todas as fases (processo de projeto). Modelo nD. No caso desta Oficina de Projeto, como a concepção do projeto foi realizada previamente pela INFRAERO - UnB, nos atemos ao caminho necessário (fluxo) que a informação de projeto e de obra deve percorrer ao longo do processo de projeto, bem como quais seriam as melhores práticas para manipulação e análise de dados dentro da plataforma AutoDesk em voga na INFRAERO.

A implantação dos Sistemas BIM na INFRAERO certamente trará consigo, a reboque, os meandros da gestão e comunicação da informação de projeto entre as diversas especialidades de projeto e de obra (AEC). 


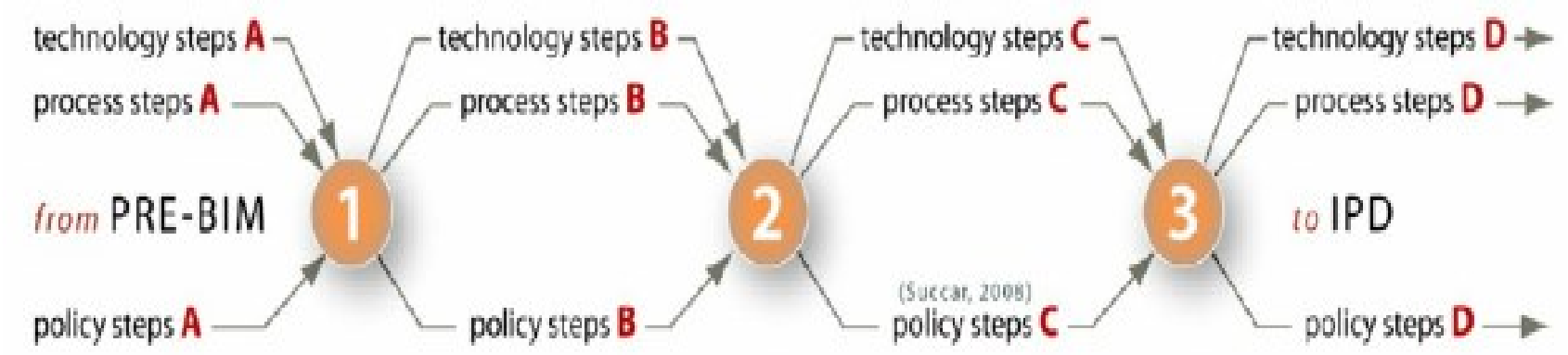

Figura V- Caminho de maturidade BIM.

\section{MACRO FRAMEWORK INFRAERO}

O método proposto é extensivamente conhecido no acadêmico, uma vez que a utilização de sistemas de BIM e suas particularidades não é novidade. No entanto, a sua aplicação em uma empresa pública como a INFRAERO, que apresenta nuances específicas relativas às restrições impostas pela Lei 8.666 e os seus juízos específicos para políticas de controle, internas e externas, na figura do tribunal de Contas da União TCU.

A lentidão e burocracia inerentes em empresas públicas brasileiras faz com que o uso da metodologia de Sistemas BIM nestas organizações possua especificidades que merecem ser investigadas, para futura implantação. Os processos e os principais atores para o processo de projeto de preencher aeroporto INFRAERO.

$\mathrm{Na}$ figura abaixo são expressas atividades regulatórias, exigências de formação, projetando e melhoria, validação de requisitos, construção, instalação e operação do edifício.

Ao observarmos a inter-relação que se estabelece neste processo, podemos ver que a estrutura proposta baseiase nos conceitos da metodologia que utiliza sistemas BIM, sobre a centralidade das atividades de análise, avaliação e projeto.

As posições centrais tendem a estabelecer ligações com os processos associados (radiais) de cada fase fazendo com que o modo de cooperação recomendado pelos sistemas BIM possa ser concebido nesta estrutura (diagrama de fluxo de processo), mostrado na figura abaixo (INFRAERO x PROCESSOS):

Os processos de analise são efetuados de forma continua, a cada nova solução proposta, de forma a se validar constantemente os requisitos impostos a cada projeto.

Os diagramas de fluxo representam uma novidade em relação ao processo de aprovação de projetos atualmente em voga na INFRAERO, uma vez que tais fluxos servem para acompanhar e guiar as informações entre o modelo único de informações e as

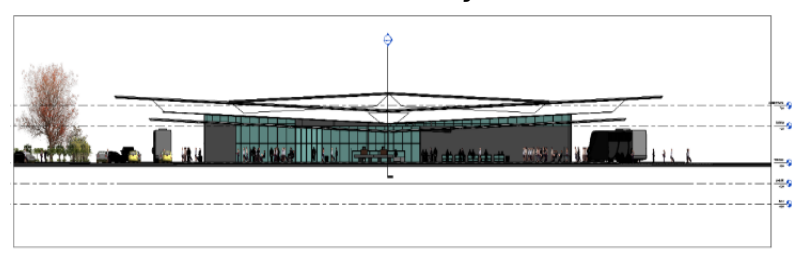

Figura W- Corte Esquemático TPS 3 - SBCF (Revit ${ }^{\circledR}$ ).
Ferramentas de análise e de produtividade de cada especialidade de projeto.

Como exemplo, a especialidade de conforto térmico, luminoso e acústico muito provavelmente irá se utilizar de ferramentas como o Ecotect ${ }^{\circledR}$ Analysis, ou similar.

Aspectos de interoperabilidade, a definição precisa das interfaces necessárias para a troca de informação entre os sistemas BIM e as ferramentas de análise e os protocolos envolvidos em tais processos são escopo da etapa de diagrama de fluxos proposta.

A etapa de definição de "layout" constitui-se uma parte importante do macro processo por ser uma etapa preparatória para o desenvolvimento do projeto, onde o autor propõe que se procedam investigações da forma e da função propostas para a edificação.

No caso do Revit ${ }^{\circledR}$, estes estudos se dão através da ferramenta de massas disponivel no "software".

A proposta de investigação metodológica (figura abaixo) define as conexões e inter-relaciona os diversos estágios de pesquisa que o autor acredita que melhor responda como teste da hipótese face ao processo de utilização dos sistemas BIM na INFRAERO detalhado acima. Por detrás dos benefícios estão ocultos inúmeros pequenos processos para realização das tarefas de projeto, que deveriam ser objeto de pesquisa para melhor definição deste novo processo de projeto que os sistemas BIM representam.

Estes pequenos processos podem ser delimitados como a prática profissional do arquiteto e a tecnologia, por ser um componente cada vez maior deste processo, passam a influir diretamente na definição do próprio processo de projetação.

Acreditamos que o fato da informação de projeto estar associada de forma automática ao processo de projeto, e do trabalho ocorrer em torno de um modelo único, faz dos sistemas BIM um ambiente favorável para a realização de projetos de funções complexas, como os aeroportuários, uma vez que os sistemas BIM facilitam as atividades de análise, o que contribui para a tomada de decisões e a busca por soluções e melhorias ao longo do processo.

Tais considerações são valiosas para que seja possível a inferência de onde estariam os "gargalos" na implantação de uma ferramenta BIM na empresa, bem como onde estariam os benefícios mais evidentes. 


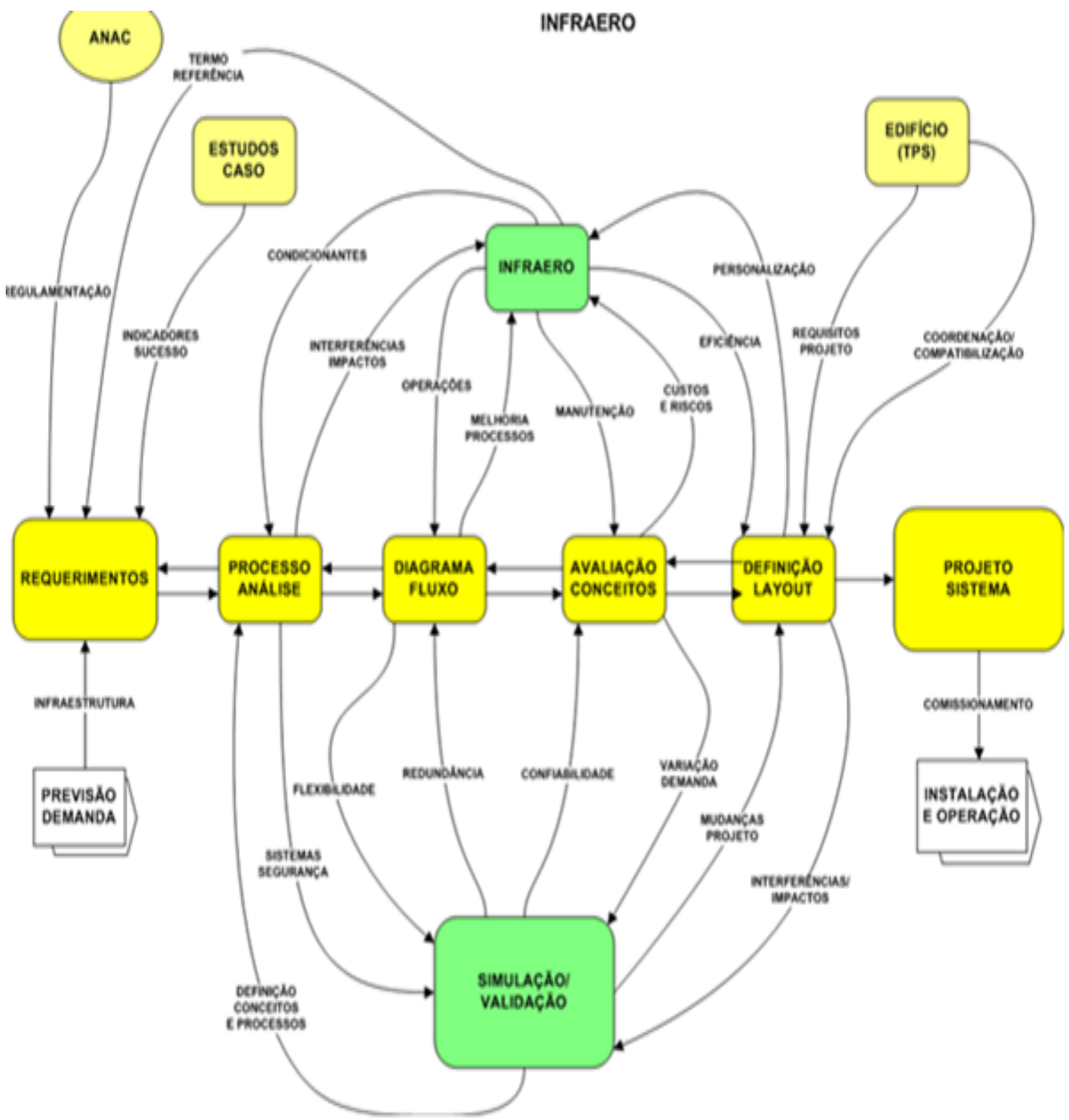

Figura X- Macroprocessos INFRAERO.

A figura acima relaciona os processos e os atores principais referentes ao processo de projeto de provimento aeroportuário na INFRAERO. Nesta figura encontram-se expressas as atividades de regulação, formação de requisitos, projetação e melhoria, validação de requisitos, construção, instalação e operação da edificação.

Se observarmos atentamente a inter-relação estabelecida neste processo, podemos perceber que a estrutura proposta tem como base os conceitos da metodologia que se utiliza dos sistemas BIM, no tocante à natureza nuclear das atividades de análise, avaliação e projeto.

Estabelecer posições centrais e com conexões radiais aos processos inerentes de cada fase faz com que a metodologia de colaboração preconizada pelos sistemas BIM possa ser projetada nesta estrutura (fluxograma de processo) demonstrada na figura acima.

Representa o fluxograma de utilização dos sistemas BIM como ambiente de trabalho na
INFRAERO, abarcando seus principais atores, enquanto clientes internos e externos (ANAC), bem como os requisitos e caminhos formais de aprovação de projetos pela empresa. Se prestarmos atenção na figura acima, veremos que a parte nuclear do processo reside nas atividades de processos de analise, diagramas de fluxos, avaliação e "layout".

O processo de projeto representa a evolução e a maturidade de informação associada a estes campos, que desemboca em uma representação gráfica e na busca por soluções mais vantajosas em atendimento aos requisitos impostos no início do processo.

Entre estes diversos campos de atuação profissional de provimento de infraestrutura aeroportuária através da INFRAERO estão todas as atividades de analise, melhoria, qualidade $\mathrm{e}$ gestão, permeando todo o processo. 
ACHTEN, H.; BEETZ, J. What Happened to Collaborative Project? In: CONFERENCE ON EDUCATION AND RESEARCH IN COMPUTER AIDED ARCHITECTURAL PROJETO IN EUROPE. 27., 2009, Istanbul. Proceedings ... Istanbul: eCAADe \& ITL/YTU: 358-365 p. 2009.

ASHFORD, N., STANTON, M. H. P. e MOORE, C. A. (1997) Airport Operations. New York: McGraw-Hill;

"AUTODESK". "Revit" Architecture 2010: Families Guide - Metric Tutorials. 2009c. 812p. Disponível em:

<http://www."AutoDesk".com/"Revit"architecture documentation>. Acesso em: 15 set. 2012.

AYRES $F^{\circ}, \quad$ C. e SCHEER, S. (2008) "DIFERENTES ABORDAGENS DO USO DO CAD NO PROCESSO DE PROJETO ARQUITETÔNICO"

AZUMA, F.; FREITAS, M.; MACHADO, C.; SCHEER, S.; SCHIMID, A. Revista produção Online - Inovação Tecnológica: Técnicas e Ferramentas aplicadas ao Projeto de Edificações. Vol. 7, Num. 3. 2007, Florianópolis.

BAEYENS, T. (2004) "The State Of Workflow". "DIGITAL FABRICATION OF ARCHITECTURAL MODELS: AN EXPLORATORY STUDY". Disponível em: http://www.jboss.com/products/jbpm/stateofwork flow

BARISON, M. B., e SANTOS, E. T. (2010a). "BIM Teaching Strategies: an Overview of Current Approaches." Proc., ICCCBE 2010 International Conference on Computing in Civil and Building Engineering. University of Nottingham, Nottingham, UK, http://www.engineering.nottingham.ac.uk/icccbe/ proceedings/pdf/pf289.pdf (Feb. 10, 2011).

BARISON, M. B., and SANTOS, E. T. (2010b). "Review and Analysis of Current Strategies for Planning a BIM Curriculum." Proc., CIB W78 2010 27th International Conference, Virginia Tech, Cairo, Egypt, 1--- 10, < http://itc.scix.net/data/works/att/w78---2010--83.pdf> (Feb. 10, 2011).

BAZJANAC, V. Virtual Building Environments (VBE) - Applying Information Modeling to Buildings. Lawrence Berkeley National Laboratory, University of California. Berkeley, CA, U.S.A., 2004.

BELL, H.; BJǾRKHAUG, L. "A building SMART Ontology e Work and Business in Architecture, Engineering and Construction". ECPPM, 2006, $185 p$.

BIRX, Glenn W. Getting started with Building Information Modeling. The American Institute of Architects - Best Practices, 2006b. Disponível em: < http://www.aia.org/bestpratctices index > Acessado em: 03.12.2012.

BODDY, S., REZGUL, Y., COOPER, G., \& WETHERILL, M. (2007). Computer integrated construction: A review and proposals for future direction. Advances in Engineering Software, 38(10), 677-687.

BRAHA, D., and REICH, Y., Topological structures for modeling engineering project processes, Research in Engineering Projects, Vol. 14, (2003), pp. 185-199;

CALLEAM Consulting Ltd - Why Technology Projects Fail, em Denver Airport Baggage Handling System Case Study;

CECCATO, C. (2001). "EVOLUTIONARY CUSTOMISATION". "Hong Kong: The Hong Kong Polytechnic University, Hong Kong", China.

CLAYTON, M. J., JOHNSON, R. E., VANEGAS, J., NOME, C. A., OZENER, O. O., \& CULP, C. E. (2008). Downstream of Project: Lifespan Costs and Benefits of Building Information Modeling. College Station: Texas A\&M University.

COELHO, S; NOVAES, C. Modelagem de Informações para Construção (BIM) e ambientes colaborativos para gestão de projetos na construção civil, 2008.

CREIGHTON, V. T. Le, D., S. NAHAVANDI, "Simulation-based Input Loading Condition Optimisation of Airport Baggage Handling Systems", Proceedings of the IEEE Intelligent Transportation Systems Conference, USA, 2007, pp. 574-579.

DAWOOD, N; SRIPRASERT, E.; MALLASI, Z; HONNS, B. 4D visualization development: Real Life Case Studies. International Council for Research and Innovation in Building and Construction. CIB W78 Conferência. Aarhus School of Architecture, 2002.

DAWSON, R. (2000), "Knowledge capabilities as the focus of organizational development and strategy", Journal of Knowledge Management, 4 (4), p. $320-327$

DENIS, R. Projeto cultura material e o fetichismo dos objetos. Arcos volume 1 número único, 1998. Disponível em: http://www.esdi.ueri.br/arcos/imagens/artigo raf ael(14a39).pdf. Acesso em: 22 set. 2008.

DENZIN, N. K., \& LINCOLN, Y. S. (1998) (Eds). Collecting and interpreting qualitative materials. Thousand Oaks: Sage Publication.

EISNER, E. W. (1991). The enlightened eye: Qualitative inquiry and the enhancement of educational practice. New York, NY: Macmillan Publishing Company.

EASTMAN, C.; TEICHOLZ, P.; SACKS, R.; LISTON, K. BIM Handbook: A guide to Building 
Information Modeling for owners, managers, designers, engineers, and contractors. Hoboken, New Jersey: John Wiley \& Sons, 2008. 490 p.

HACKETT, J; "Beyond Knowledge Management - New Ways to Work", em BONTIS, N. e Choo, W. C. (2002), The Strategic Management of Intellectual Capital and Organizational Knowledge, Nova Iorque, Oxford University Press, p. 725-738.

HÄKKINEN, T. M. Sustainable building related new demands for product information and product model based projeto. Disponível em http://itcon.org/2007/2. Acessado em: 14.11.2012.

HAMID, B. Mapping Projeto Process into Process Projects: Implementing Collaborative Project from Social Psychological Approaches. In: CONFERENCE ON EDUCATION IN COMPUTER AIDED ARCHITECTURAL PROJETO IN EUROPE, 24, Frankfurt. Procedings ..., Frankfurt: eCAADe, , p. 711-716. 2007.

HEESOM, D.; MAHDJOUBI, L. Technology Opportunities and Potential for the Virtual Construction Site - Volume 1: Emerging Research Initiatives. Universidade de Wolverhampton, 2003.

HERNANDEZ, C. "Thinking parametric project: introducing parametric Gaudi. In: Project Studio", 27 (2006) 309-324: ELSEVIER. 2006. Disponível em < www.elsevier.com/locate/destud>

HUDSON, R. Frameworks for Practical Parametric Project in Architecture. IN; eCAADe 26, 2008.

I. A. T. A. - Baggage improvement programme, simplifying the business, II International Air Transport Association, Tech. Rep., 2008. www.iata.org;

ISIKDAG, U.; UNDERWOOD, J. Two project patterns for facilitating Building Information Model-based synchronous collaboration. Automation in Construction, v. 19 , n. 5, p. 544553, ISSN 09265805. Disponível em: < http://dx.doi.org/10.1016/j.autcon.2009.11.006 >.

KALAY, Y.E. The impact of information technology on project methods, products and practices. Project Studies, v. 27, n. 3, p. 357-380, May 2006. doi:10.1016/j.destud.2005.11.001.

KIVINIEMI, A.; TARANDI, V.; KARLSHØJ, J.; BELL, H.; KARUD, O. "Review of the Development and Implementation of IFC Compatible BIM. ERABUILD FUNDING ORGANIZATIONS", 2008.

KVAN, T. Collaborative project: what is it? Automation in Construction, v. 9, n. 4, p. 409-415, July 2000.
KYMMEL, W. Building Information Modeling. Planning and managing construction project with 4D and simulations. McGraw-Hill 2008.

LAWSON, B. (2004), "WHAT PROJETOERS KNOW", Elsevier/Architectural Press, 08/11/2004

MITCHELL, W. J. "The logic of architecture: projects, computation and cognition. Cambridge, MA: The MIT Press", 1996. 304p.

MITCHEL, William J. 2005. Constructing Complexity. In: Martens, Bob and Brown André (eds), Computer Aided Architectural Project Futures 2005, Vienna, Austria.

NARDELLI, E; Tecnologia digital avançada na produção de Habitações de Interesse Social HIS no Brasil - Universidade Presbiteriana Mackenzie, Brasil.

NASCIMENTO, L. A.; SANTOS, E. T. A indústria da construção na era da informação. Ambiente Construído, Porto Alegre, v. 3, n. 1, p. 69-81, jan./mar. 2003.

NEVES, A. P. H. C. S; 2008, Tecnologias para a Gestão Multimodal de Bagagens, Tese de Mestrado no Instituto Superior Técnico de Lisboa;

OLIVEIRA, L. C. C. F. "Características e particularidades das ferramentas BIM: reflexos da implantação recente em escritórios de arquitetura." Universidade Federal de Santa Catarina Programa de Pós-graduação em Arquitetura e Urbanismo | Pós-arq.

OXMAN, R. "Prior knowledge in project: a dynamic knowledge-based model of project and creativity. Project Studies", v. 11, no 1, p.17-27, 1990.

PASQUIRE, C.L.; CONNOLLY, G.E., "Project for Manufacture and Assembly", "In: 11th ANNUAL CONFERENCE OF THE INTERNATIONAL GROUP FOR LEAN CONSTRUCTION, Proceedings... Blacksburg, USA, July 2003", pp 184 - 194, ISBN 0- 9721257-4-4

SASS, L. "Synthesis of project production with integrated digital fabrication. Automation in construction", 2006, v.16, n.3, p. 298-310.

SCHÖN, D. Educando o Profissional Reflexivo: um novo projeto para o ensino e a aprendizagem. Porto Alegre: Artes Médicas, 2000.

SCHEER, S, AYRES FILHO, G. Abordando a BIM em níveis de modelagem SBQP 2009, Simpósio Brasileiro de Qualidade do Projeto no Ambiente Construído IX Workshop Brasileiro de Gestão do Processo de Projeto na Construção de Edifícios 18 a 20 de Novembro de 2009 - São Carlos, SP - Brasil Universidade de São Paulo

SIMOFF ,S, J; MARY,L. M. Analysing participation in collaborative project environments. Project Studies, v 21 p. 119-144, $2000<w w w . e l s e v i e r . c o m / l o c a t e / d e s t u d>$ 
ANEXO XII

MÍDIA DIGITAL 
UTILIZAÇÃO DA VERSÃO DIGITAL DA MATRIZ SEMÂNTICA, DISPONÍVEL PARA 0 “SOFTWARE OPEN-SOURCE” XMIND ${ }^{\circledR}$

\section{OS SEGUINTES PASSOS DEVEM SER OBSERVADOS:}

1- Criar pasta na raiz do sistema, usualmente $C: I$ com o endereço "C:IUsers/Julio RibeirolDocumentsIMATRIX; A pasta chamada MATRIX disponível no DVD deve ser copiada de forma a sobrescrever a existente.

2- Instalar o "software" $\mathrm{Xmind}^{\circledR}$ no disco rígido local;

3- Abrir o arquivo de nome "Matriz INFRAERO".

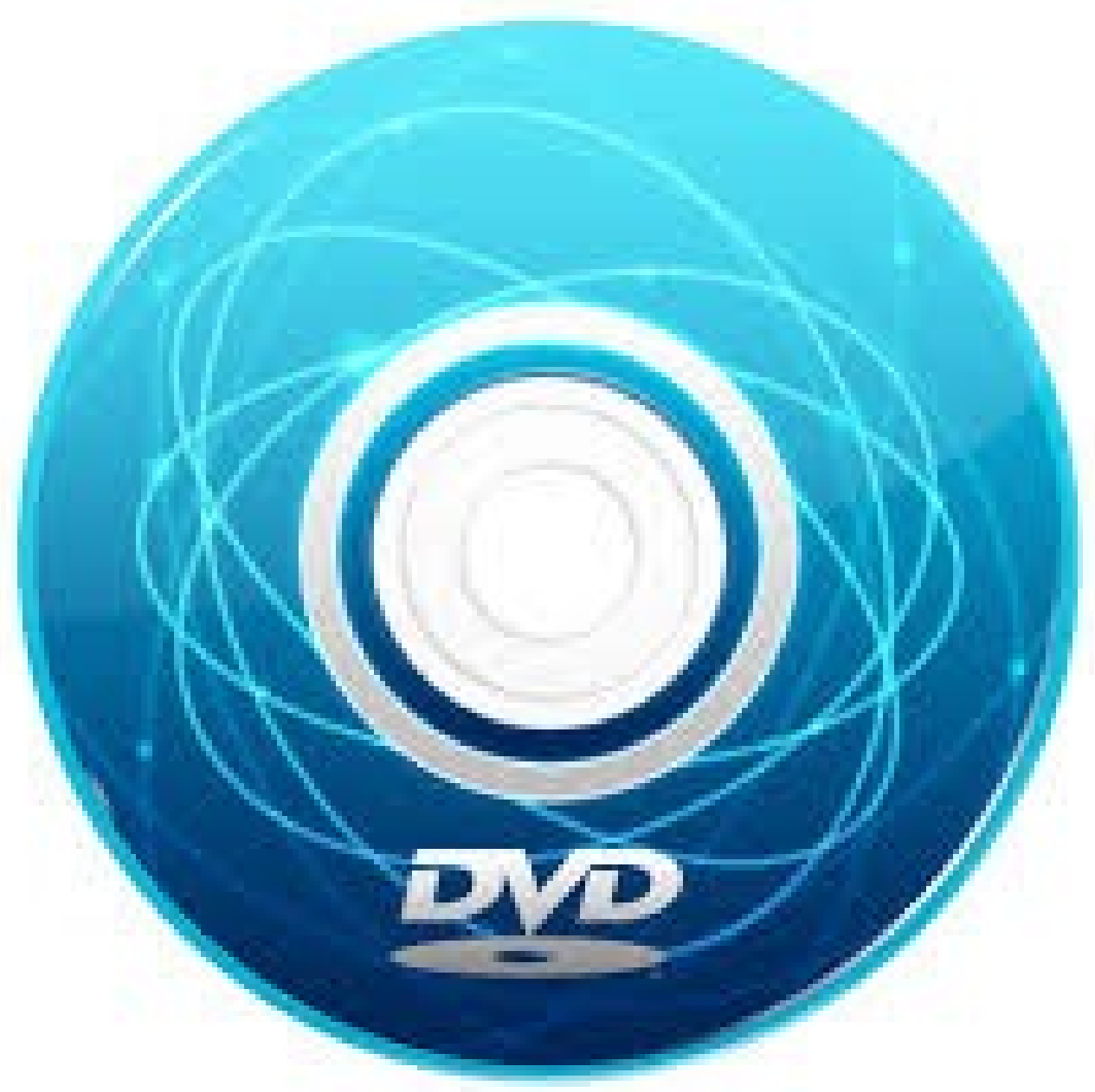

